\title{
PREPARING FOR LIFE IN A DIGITAL WORLD
}

IEA International Computer and Information Literacy Study 2018 International Report
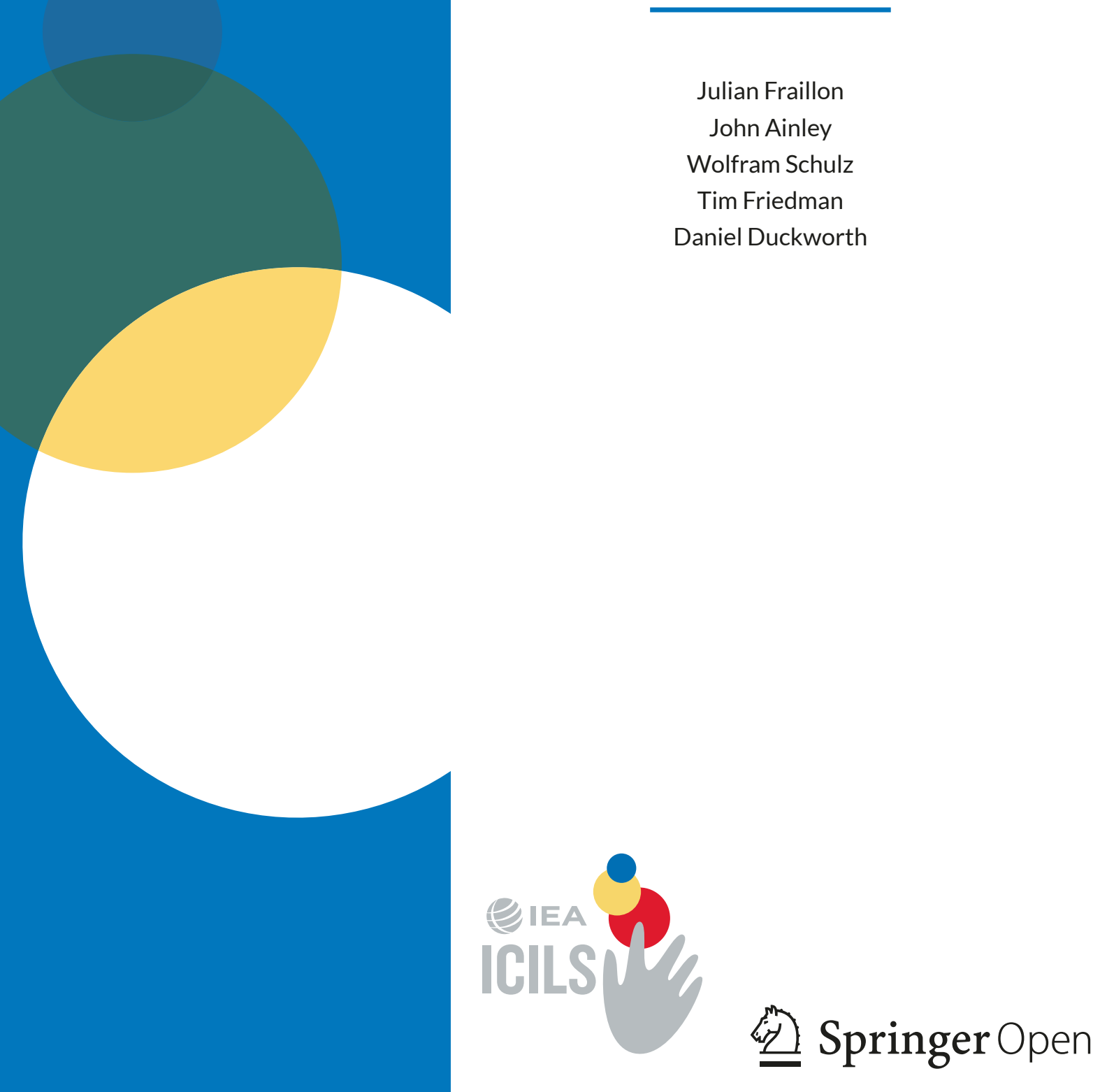
Preparing for Life in a Digital World 
Julian Fraillon · John Ainley · Wolfram Schulz · Tim Friedman • Daniel Duckworth

\section{Preparing for Life in a Digital World}

IEA International Computer and Information Literacy Study 2018 International Report 
Julian Fraillon

The Australian Council for Educational Research

Camberwell, VIC, Australia

Wolfram Schulz

The Australian Council for Educational Research

Camberwell, VIC, Australia

Daniel Duckworth

The Australian Council for Educational Research

Camberwell, VIC, Australia
John Ainley

The Australian Council for Educational Research

Camberwell, VIC, Australia

Tim Friedman

The Australian Council for Educational Research

Camberwell, VIC, Australia

The International Association for the Evaluation of Educational Achievement (IEA), with headquarters in Amsterdam, is an independent, international cooperative of national research institutions and governmental research agencies. It conducts large-scale comparative studies of educational achievement and other aspects of education, with the aim of gaining in-depth understanding of the effects of policies and practices within and across systems of education.

\section{IEA}

Keizersgracht 311

1016 EE Amsterdam

The Netherlands

Telephone: +31206253625

Fax: + 31204207136

Email: secretariat@iea.nl

Website: www.iea.nl

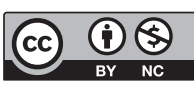

ISBN 978-3-030-38780-8

ISBN 978-3-030-38781-5 (eBook)

https://doi.org/10.1007/978-3-030-38781-5

(c) IEA International Association for the Evaluation of Educational Achievement 2020. This book is an open access publication.

Open Access This book is licensed under the terms of the Creative Commons Attribution-NonCommercial 4.0 International License (http://creativecommons.org/licenses/by-nc/4.0/), which permits any noncommercial use, sharing, adaptation, distribution and reproduction in any medium or format, as long as you give appropriate credit to the original author(s) and the source, provide a link to the Creative Commons license and indicate if changes were made. The images or other third party material in this book are included in the book's Creative Commons license, unless indicated otherwise in a credit line to the material. If material is not included in the book's Creative Commons license and your intended use is not permitted by statutory regulation or exceeds the permitted use, you will need to obtain permission directly from the copyright holder.

This work is subject to copyright. All commercial rights are reserved by the author(s), whether the whole or part of the material is concerned, specifically the rights of translation, reprinting, reuse of illustrations, recitation, broadcasting, reproduction on microfilms or in any other physical way, and transmission or information storage and retrieval, electronic adaptation, computer software, or by similar or dissimilar methodology now known or hereafter developed. Regarding these commercial rights a non-exclusive license has been granted to the publisher.

The use of general descriptive names, registered names, trademarks, service marks, etc. in this publication does not imply, even in the absence of a specific statement, that such names are exempt from the relevant protective laws and regulations and therefore free for general use.

The publisher, the authors and the editors are safe to assume that the advice and information in this book are believed to be true and accurate at the date of publication. Neither the publisher nor the authors or the editors give a warranty, expressed or implied, with respect to the material contained herein or for any errors or omissions that may have been made. The publisher remains neutral with regard to jurisdictional claims in published maps and institutional affiliations.

Design by Becky Bliss Design and Production, Wellington, New Zealand Cover design by Studio Lakmoes, Arnhem, The Netherlands.

This Springer imprint is published by the registered company Springer Nature Switzerland AG

The registered company address is: Gewerbestrasse 11, 6330 Cham, Switzerland 


\section{Foreword}

IEA (International Association for the Evaluation of Educational Achievement) is an international cooperative of national research institutions, governmental research agencies, scholars, and analysts working to research, understand, and improve education worldwide. More than 60 countries are actively involved in the IEA network and over 100 education systems participate in IEA studies. Founded in 1958, IEA is a pioneer in the field of large-scale assessments in education. Our studies are based on diverse topics, including mathematics, science, reading, civic and citizenship education, and early childhood and teacher education. By linking research, policy, and practice, we support countries to understand effective practices in their education systems and to develop evidence-based policies to improve education.

Over the past four decades, information and communications technology (ICT) has had a profound impact on our daily lives, work, and social interactions. In a digital world, knowing how to use ICT and having access to such technologies are proving increasingly important for participating effectively in society. IEA's International Computer and Information Literacy Study (ICILS) was designed to respond to a question of critical interest today: How well are students prepared for study, work, and life in a digital world?

ICILS 2018 deals with the core knowledge, skills, and understanding students need to succeed in a dynamic information society, collecting valuable data, which can be used by educators, researchers, and policymakers. ICILS 2018 follows on from the first cycle of the study, ICILS 2013, which was successfully administered in 21 education systems around the world. In-depth results were presented in the ICILS 2013 international report, Preparing for life in a digital age.

ICILS 2013 focused on students' computer and information literacy (CIL) skills: their abilities to use computers to investigate, create, and communicate in order to participate effectively at home, at school, in the workplace, and in the community. ICILS 2018 reports on changes in students' CIL since 2013 and also introduces an innovative assessment of students' computational thinking (CT) skills, namely their abilities to recognize, analyze, and describe real-world problems so that their solutions can be operationalized with a computer. This approach to problem solving is a fundamental skill that is attracting increased interest from a range of education, professional, and policy stakeholders.

ICILS 2018 and ICILS 2013 are the outcome of a rich history of IEA studies on ICT in education. The first was the Computers in Education Study (COMPED), conducted in both 1989 and 1992. This was followed by IEA's Second Information Technology in Education Study (SITES) in 1998-1999 (Module 1), 2001 (Module 2), and 2006, which examined how teachers and students from 26 countries used ICT in education. IEA remains proud of our continued role as leaders in the field of international large-scale assessments focused on ICT in education. Details of all IEA studies can be found on our website.

This report on ICILS 2018 presents the outcomes of student CIL and CT at the international level and provides valuable information on the contexts in which they are taught and learned. The study also yields insights into how students and teachers use ICT in their daily lives and their views on the impact of ICT in society.

These findings contribute to a deeper understanding of not only the ways in which students develop ICT skills but also their learning environment. The findings provide valuable insights for researchers, policymakers, and practitioners interested in understanding and improving the use of ICT in an education context. The insights are based on a rich sample of over 46,000 grade 8 students and over 26,000 teachers from more than 2200 schools in a total of 14 education systems ( 12 countries and two benchmarking entities). 
This international report is accompanied by the ICILS 2018 assessment framework publication. The ICILS 2018 international database and technical report will be released in 2020.

As an independent research cooperative, IEA relies on an extended network of partner organizations and collaborators to conduct our studies. Delivering ICILS 2018 has been a collaborative effort and I am grateful to all of the people involved.

In partnership with IEA, ICILS 2018 was developed and implemented by the international study center at the Australian Council for Educational Research (ACER). I sincerely thank research director, Julian Fraillon, project coordinator, John Ainley, assessment coordinator, Wolfram Schulz, and operations coordinator, Tim Friedman, for their expert leadership and guidance. I am grateful to the staff at SoNET Systems in Melbourne (Australia) for their part in developing the software for the computer-based student assessment, especially Mike Janic and Stephen Birchall. My thanks go also to colleagues at both IEA Amsterdam and IEA Hamburg for their dedicated work and commitment throughout. I also gratefully acknowledge the work of sampling referee, Marc Jonas, and the IEA Publications and Editorial Committee for their contributions to the review of this report.

As with all IEA studies, ICILS 2018 would not have succeeded without the dedication, enthusiasm, and commitment of the national research coordinators from participating countries. Their expertise and diverse perspectives played crucial roles in the development and implementation of the study.

Finally, I wish to thank the students, teachers, and school administrators who participated in the study and without whom this research would not have been possible. Together we are researching education to improve learning.

Dirk Hastedt

IEA EXECUTIVE DIRECTOR 


\section{Contents}

Foreword $\quad v$

List of tables and figures $\quad$ ix

Executive summary xvii

About the study xvii

Data collection xviii

Assessing CIL and CT xviii

Collecting data on students' personal and educational contexts for developing xix

CIL and CT

Findings $\quad$ xix

References xxii

Chapter 1: Introduction to the IEA International Computer and Information Literacy 1

Study 2018

Background

Purposes of ICILS 2018

Research questions 3

The ICILS assessment framework $\quad 4$

ICILS instruments 8

Participating countries, population, sample design, and achieved samples 10

$\begin{array}{ll}\text { Structure of this report } & 12\end{array}$

References 13

Chapter 2: The contexts for education on computer and information literacy and 15 computational thinking

Chapter highlights $\quad 15$

Introduction 17

Collecting data on contexts for CIL/CT education 17

Education systems and national contexts 19

ICT infrastructure and economic characteristics of countries 28

Approaches to CIL/CT education in ICILS countries 30

Schools' access to ICT resources

School policies and practices for using ICT 46

References $\quad 50$

Chapter 3: Students' computer and information literacy $\quad 51$

Chapter highlights $\quad 51$

Introduction $\quad 53$

Assessing CIL $\quad 53$

The CIL described achievement scale $\quad 55$

Describing CIL learning progress 59

Example CIL items $\quad 60$

Comparison of CIL across countries $\quad 74$

Achievement across countries with respect to proficiency levels $\quad 77$

Trends in CIL achievement $\quad 77$

Variation in CIL across countries with respect to student background characteristics 77

Home background indicators and CIL 79

$\begin{array}{ll}\text { References } & 87\end{array}$

Chapter 4: Students' computational thinking $\quad 89$

Chapter highlights $\quad 89$

Introduction $\quad 91$

Assessing CT 91

The CT achievement scale $\quad 92$ 
Example CT tasks 94

Comparison of CT across countries 102

Variation in CT across countries with respect to student background characteristics 105

The association between CT and CIL 110

References 112

Chapter 5: Students' engagement with information and communications technologies 113

Chapter highlights 113

Introduction 115

Student general engagement with ICT 117

Student engagement with ICT for school-related purposes 136

Learning about ICT at school $\quad 150$

Student perceptions of ICT 157

References 172

Chapter 6: Teaching with and about information and communications technologies 175

Chapter highlights $\quad 175$

$\begin{array}{ll}\text { Introduction } & 177\end{array}$

Teachers' familiarity with and views of ICT 178

Perceptions of schools' ICT learning environments 189

Teacher emphasis on learning CIL and CT 200

Teachers' use of ICT for teaching and learning 207

References $\quad 213$

Chapter 7: Investigating variations in computer and information literacy and 215 computational thinking

Chapter highlights $\quad 215$

$\begin{array}{ll}\text { Background } & 217\end{array}$

Data and methods $\quad 218$

Explaining variation in CIL $\quad 222$

Explaining variation in CT 227

References 237

Chapter 8: Reflections on the IEA International Computer and Information Literacy 239

Study 2018

ICILS as a pioneering study $\quad 239$

The nature of CIL and CT 239

CIL and CT achievements vary greatly within countries 241

CIL, CT, digital literacy, and student gender $\quad 243$

Evidence of the digital divide 244

Supporting teachers to use ICT in their teaching 246

$\begin{array}{ll}\text { Future directions for research } & 248\end{array}$

References $\quad 249$

$\begin{array}{ll}\text { Appendices } & 251\end{array}$

Appendix A: Sampling information and participation rates 251

Appendix B: Percentage correct by country for example large task scoring criteria 254

Appendix C: Percentiles, means, and standard deviations of computer and 261 information literacy and computational thinking

Appendix D: Pair-wise comparisons of average achievement data 265

Appendix E: Student percentages for dichotomous variables 267

Appendix F: Item maps 269

Appendix G: Organizations and individuals involved in ICILS 2018 


\section{List of tables and figures}

\section{Tables}

Table 1.1: Mapping of variables to the contextual framework related to CIL and CT 7 outcomes (examples)

Table 2.1: Characteristics of education systems participating in ICILS 2018: compulsory schooling, years of education by levels, and percentage of lower-secondary students in private/public schools

Table 2.2: Degree of school autonomy regarding different aspects of school policies by school type

Table 2.3: ICT infrastructure and economic characteristics of the ICILS countries

Table 2.4: Emphases in national curricula of teaching aspects related to CIL

Table 2.5: Emphases in the national curricula of teaching aspects related to CT 34

Table 2.6: CIL-related subjects at different levels of schooling and ICT assessment 36 policies

Table 2.7: Requirements for developing teachers' capacity to use ICT

Table 2.8: Level of support for teacher access to and participation in ICT-based 39 professional development

Table 2.9: School reports on technology-related resources for both teaching and learning

Table 2.10: School reports on software-related resources for both teaching and learning

Table 2.11: Schools' reports on available technology facilities for teaching and learning of target grade students

Table 2.12: National ratios for number of students to number of ICT devices in school by school location

Table 2.13: School reports of school ICT devices at different locations and student access to portable devices at school

Table 2.14: School reports of procedures regarding different aspects of ICT use at school

Table 2.15: School reports of priority given to different ways of facilitating ICT use in teaching and learning

Table 3.1: Summary of ICILS CIL test modules and large tasks 54

Table 3.2: CIL described achievement scale $\quad 57$

Table 3.3 Example large-task scoring criteria with framework references and overall 72 percent correct

Table 3.4: Country averages for CIL, average age, CIL score, ICT development index score, and percentile graph

Table 3.5: Percent of students at each proficiency level across countries

Table 3.6: Changes in average CIL achievement scores between 2013 and 2018 and in the percentage of students achieving at Level 2 or above on the CIL scale

Table 3.7: Gender differences in CIL

Table 3.8: Average CIL by category of parental occupation, parental education, and number of books in the home

Table 3.9: Percentages by category of immigrant background and language spoken at home, and comparison of average CIL between categories

Table 3.10: Average CIL by category of computer availability at home and years' experience of ICT use

Table 4.1: Country averages for CT, average age, CT score, ICT development index score, and percentile graph 
Table 4.2: $\quad$ Gender differences in CT 104

Table 4.3: Average CT by category of parental occupation, parental education, and 106 number of books in the home

Table 4.4: $\quad$ Average CT by category of immigrant background and language spoken at 108 home

Table 4.5: Percentages by category of computer availability at home and years' experience of ICT use, and comparison of average CT between categories

Table 4.6: Correlations between CT and CIL and average CT performance for students at each CIL proficiency level across countries

Table 5.1: $\quad$ Percentages of students with at least five years' experience with ICT devices and the association of ICT experience with $\mathrm{CIL}$

Table 5.2: Percentages of students reporting daily use of ICT in and outside school for school-related and other purposes

Table 5.3: Percentages of students using ICT on a weekly basis, in or outside school, to create or edit information products

Table 5.4: National averages for students' use of general applications and students' use of specialist applications for activities

Table 5.5: National average scale scores indicating students' use of general applications for activities by experience with computers, study of ICT-related subject, and level of CIL

Table 5.6: National average scale scores indicating students' use of specialist applications for activities by experience with computers, study of ICT-related subject, and level of CIL

Table 5.7: National averages for students' use of ICT for social communication and students' use of ICT for exchanging information

Table 5.8: National average scale scores indicating students' use of ICT for social communication by experience with computers, study of ICT-related subject, and level of CIL

Table 5.9: National average scale scores indicating students' use of ICT for exchanging information by experience with computers, study of ICT-related subject, and level of CIL

Table 5.10: Percentages of students' using ICT on a weekly basis for specified leisure activities

Table 5.11: National average scale scores indicating students' use of ICT for accessing content from the internet by gender group

Table 5.12: National average scale scores indicating students' use of ICT for accessing content from the internet by experience with computers, computer resources at home, and level of $\mathrm{CIL}$

Table 5.13: Percentages of students using ICT on a weekly basis for specified school-related purposes

Table 5.14: National average scale scores indicating students' use of ICT for school-related purposes by gender group

Table 5.15: National average scale scores indicating students' use of ICT for school-related purposes by experience with computers, study of ICT-related subject, and level of CIL

Table 5.16: Percentages of students using computers during most lessons in specified subject areas 
Table 5.17: Percentages of students using general and specialist ICT applications 145 during most or all lessons

Table 5.18: National averages for scales reflecting the extent of students' use of general and specialist ICT applications in class

Table 5.19: National average scale scores indicating students' use of general ICT applications in class by gender group, study of ICT-related subject, and level of CIL

Table 5.20: National average scale scores indicating students' use of specialist ICT applications in class by gender group, study of ICT-related subject, and level of $\mathrm{CIL}$

Table 5.21: Percentages of students who reported having learned to a large or moderate extent about CIL at school

Table 5.22: National average scale scores indicating students' learning of CIL tasks at school by country and gender group

Table 5.23: National average scale scores indicating students' learning of CIL tasks at school by experience with computers, study of ICT-related subject, and level of CIL

Table 5.24: Percentages of students reporting having learned to a large or moderate extent about aspects of CT at school

Table 5.25: National average scale scores indicating students' learning of CT-related tasks at school by country and gender group

Table 5.26: National average scale scores indicating students' learning of CT-related tasks at school by experience with computers, study of ICT-related subject, and level of CT

Table 5.27: Percentages of students who indicated that they knew how to use ICT for specified tasks

Table 5.28: National average scale scores for students' ICT self-efficacy regarding the use of general applications and the use of specialist applications

Table 5.29: National average scale scores indicating students' ICT self-efficacy regarding the use of general applications by gender group, experience with computers, and level of CIL

Table 5.30: National average scale scores indicating students' ICT self-efficacy regarding the use of specialist applications by gender group, experience with computers, and students' level of CIL

Table 5.31: Percentages of students who strongly agreed or agreed with statements about ICT in society

Table 5.32: National average scale scores for students' perceptions of positive outcomes of ICT for society and students' perceptions of negative outcomes of ICT for society

Table 5.33: National average scale scores indicating students' perceptions of positive outcomes of ICT for society by gender group, experience with computers, and level of CIL

Table 5.34: National average scale scores indicating students' perceptions of negative outcomes of ICT for society by gender group, experience with computers, and level of CIL

Table 5.35: National average scale scores indicating students' expectations of future ICT use for work and study by gender group

Table 5.36: Correlation coefficients of students' ICT self-efficacy for both general applications and specialist applications with CIL and CT 
Table 6.1: Teachers' experience with and use of ICT

Table 6.2: National percentages of teachers who reported to know how to do different ICT tasks

Table 6.3: National average scores of teachers' confidence in doing ICT tasks, overall and by age group

Table 6.4: National percentages of teachers agreeing with statements about positive outcomes of the use of ICT for teaching and learning

Table 6.5: National percentages of teachers agreeing with statements about negative outcomes of the use of ICT for teaching and learning

Table 6.6: National averages for teachers' perceptions of positive outcomes when using ICT in teaching and learning, and teachers' perceptions of negative outcomes when using ICT in teaching and learning

Table 6.7: National averages of scales reflecting teachers' ICT self-efficacy and perceptions of positive and negative outcomes of ICT use by teachers' frequency of using ICT in class

Table 6.8: National percentages of students enrolled at schools where ICT coordinators reported that the use of ICT for teaching and learning was hindered a lot or to some extent by insufficient computer resources

Table 6.9: National percentages of students enrolled at schools where ICT coordinators reported that the use of ICT for teaching and learning was hindered a lot or to some extent by insufficient pedagogical resources

Table 6.10: National percentages of teachers agreeing with statements about the availability of ICT for teaching at school

Table 6.11: National percentages of teachers agreeing with statements about the collaborative use of ICT in teaching and learning

Table 6.12: National averages for teachers' reports on availability of ICT resources at school and teachers' reports on collaboration between teachers in using ICT

Table 6.13: National averages of scales reflecting teachers' reports on the environment for teachers' use of ICT in class

Table 6.14: National percentages of students at schools where principals reported expected and required teacher knowledge regarding ICT-based activities

Table 6.15: National percentages of teachers who reported to have participated in professional learning activities related to ICT use

Table 6.16: National averages of teacher emphasis on developing ICT-based capabilities overall and within subject areas

Table 6.17: Multiple regression analyses of predictors of teacher emphasis on developing CIL

Table 6.18: National averages of teacher emphasis on teaching CT-related tasks overall and within subject areas

Table 6.19: Multiple regression analyses of predictors of teacher emphasis on teaching CT-related skills in class

Table 6.20: National percentages of teachers who reported using general utility ICT tools in most lessons, almost every, or every lesson

Table 6.21: National percentages of teachers who reported using digital learning ICT tools in most lessons, almost every, or every lesson

Table 6.22: National percentages of teachers who reported that students used ICT often or always when engaging in different class activities 
Table 6.23: National percentages of teachers who reported use of ICT for different teaching practices in most lessons, almost every, or every lesson

Table 7.1: Total and explained variance in CIL

Table 7.2: Student-level and school-level regression coefficients for background predictors of $\mathrm{CIL}$

Table 7.3: Student-level regression coefficients for ICT-related predictors of CIL

Table 7.4: School-level regression coefficients for ICT-related predictors of CIL

Table 7.5: Summary of statistically significant effects on CIL across 10 countries

Table 7.6: Total and explained variance in CT scores

Table 7.7: Student-level and school-level regression coefficient for background

Table 7.8: Student-level regression coefficients for ICT-related predictors of CT

Table 7.9: School-level regression coefficients for ICT-related predictors of CT

Table 7.10: Summary of statistically significant effects on CT across six countries

Table A.1: Coverage of ICILS 2018 target population

Table A.2: Participation rates and sample sizes for student survey

Table A.3: Participation rates and sample sizes for teacher survey

Table B.1: Percent correct in large task by country for Criterion 1

Table B.2: Percent correct in large task by country for Criterion 2

Table B.3: Percent correct in large task by country for Criterion 3

Table B.4: Percent correct in large task by country for Criterion 4

Table B.5: Percent correct in large task by country for Criterion 5

Table C.1: Percentiles of computer and information literacy

Table C.2: Means and standard deviations of computer and information literacy

Table C.3: Percentiles of computational thinking

Table C.4: Means and standard deviations of computational thinking

Table D.1: Pair-wise comparisons of average computer and information literacy scores 


\section{Figures}

Figure 1.1: ICILS 2018 CIL framework 5

Figure 1.2: ICILS 2018 CT framework 6

Figure 1.3: Contexts for ICILS 2018 CIL/CT outcomes 7

Figure 3.1: Example Item 1 with framework references and overall percent correct $\quad 61$

Figure 3.2: Example Item 2 with framework references and overall percent correct $\quad 62$

Figure 3.3: Example Item 3 with framework references and overall percent correct $\quad 64$

Figure 3.4: Example Item 4 with framework references and overall percent correct $\quad 66$

Figure 3.5: Band competition: large task details 69

Figure 3.6: Band competition: assessment criteria review 69

Figure 3.7: Band competition: large task webpage editor software 70

Figure 3.8: Band competition: large task instruction email 70

Figure 4.1: Example CT Task 1 with framework references and overall percent correct 95

Figure 4.2: Example CT Task 2 with framework references and overall percent correct 97

Figure 4.3: Example CT Task 3 with framework references and overall percent correct 99

Figure 4.4: Example CT Task 4 with framework references and overall percent correct 101

Figure F.1: Example of questionnaire item map 270

Figure F.2: Item map for the scale reflecting students' use of general applications for 271 activities

Figure F.3: Item map for the scale reflecting students' use of specialist applications for activities

Figure F.4: Item map for the scale reflecting students' use of ICT for social communication

Figure F.5: Item map for the scale reflecting students' use of ICT for exchanging information

Figure F.6: Item map for the scale reflecting students' use of ICT for accessing content from the internet

Figure F.7: Item map for the scale reflecting students' use of ICT for study purposes

Figure F.8: Item map for the scale reflecting students' use of general applications in class

Figure F.9: Item map for the scale reflecting students' use of specialist applications in class

Figure F.10: Item map for the scale reflecting students' learning of ICT tasks at school

Figure F.11: Item map for the scale reflecting students' learning of ICT coding tasks at school

Figure F.12: Item map for the scale reflecting students' self-efficacy regarding the use of general applications

Figure F.13: Item map for the scale reflecting students' ICT self-efficacy regarding the use of specialist applications

Figure F.14: Item map for the scale reflecting students' perceptions of positive outcomes of ICT for society

Figure F.15: Item map for the scale reflecting students' perceptions of negative outcomes of ICT for society 
Figure F.16: Item map for the scale reflecting students' expectations of future ICT use for work and study

Figure F.17: Item map for the scale reflecting teachers' ICT self-efficacy

Figure F.18: Item map for the scale reflecting teachers' perceptions of positive outcomes when using ICT in teaching and learning

Figure F.19: Item map for the scale reflecting teachers' perceptions of negative outcomes when using ICT in teaching and learning

Figure F.20: Item map for the scale reflecting teachers' perceptions of the availability of ICT resources at school

Figure F.21: Item map for the scale reflecting teachers' perceptions of collaboration between teachers when using ICT

Figure F.22: Item map for the scale reflecting teachers' emphasis on developing ICT capabilities in class

Figure F.23: Item map for the scale reflecting teachers' emphasis of teaching CT-related tasks in class 


\title{
Executive summary
}

\begin{abstract}
About the study
The International Computer and Information Literacy Study 2018 (ICILS 2018) studied the extent to which young people are able to use information and communication technology (ICT) productively in school, home, society, and their future workplaces. ICILS 2018 builds on methods and findings from the first cycle of ICILS, conducted in 2013 (ICILS 2013).

ICILS 2013 focused on student's computer and information literacy (CIL) which was defined as "an individual's ability to use computers to investigate, create, and communicate in order to participate effectively at home, at school, in the workplace, and in society" (Fraillon et al. 2013, p. 17). Put simply, CIL refers to a student's ability to use computer technologies to collect and manage information, and to produce and exchange information. The structure of the CIL construct references four strands that frame the skills and knowledge addressed by the CIL assessment: understanding computer use, gathering information, producing information, and digital communication.
\end{abstract}

ICILS 2018 continued to investigate CIL and added an investigation of students' computational thinking (CT) as an option for participating countries.* $\mathrm{CT}$ is the type of thinking used when programming on a computer or digital device. In ICILS 2018, CT is defined as "an individual's ability to recognize aspects of real-world problems which are appropriate for computational formulation and to evaluate and develop algorithmic solutions to those problems so that the solutions could be operationalized with a computer" (Fraillon et al. 2019, p. 27). CT comprises two strands: conceptualizing problems (through algorithmic or systems thinking) and operationalizing solutions (creating, implementing, and evaluating computer-based solutions to problems).

ICILS 2018 used a customized assessment software platform that delivered the assessment content and a questionnaire about ICT use to students offline. In the majority of schools the assessment was delivered from a USB drive. Although the software could have been delivered via the internet, USB delivery ensured a uniform assessment environment for students regardless of the quality of internet connections in participating schools. Data were either uploaded to a server or delivered to the ICILS research center in that country.

The ICILS 2018 instrument used purpose-built applications that followed standard interface conventions. Students completed a range of tasks, including skills-based tasks using software tools (such as text editors or presentation applications) and web content. The purpose-built applications were designed to be consistent with the applications that could reasonably be expected to be within the realm of students' typical experience of computer use.

ICILS 2018 was based around research questions that focused on the following for CIL (in all countries) and CT (in countries where CT was also assessed):

- Variations in CIL and CT within and across countries;

- Aspects of schools and education systems that are related to student achievement in CIL and $\mathrm{CT}$;

- Relationships of CIL and CT with students' levels of access to, familiarity with, and self-reported proficiency in using computers;

- Aspects of students' personal and social backgrounds (such as gender and socioeconomic background) that are related to students' $\mathrm{CIL}$ and $\mathrm{CT}$; and

- The relationship between CIL and CT.

* In this report, education systems are usually referred to as "countries." This is for ease of reading, but it should be noted that there are systems that are not countries but are units with a degree of educational autonomy that have participated following the same standards for sampling and testing. 
Four countries participated in both ICILS 2013 and ICILS 2018. It is possible to compare student CIL between 2013 and 2018 in the three of those countries that met the ICILS technical requirements for both cycles.

\section{Data collection}

ICILS 2018 gathered data from 46,561 grade 8 (or equivalent) students in more than 2226 schools from 12 countries and two benchmarking participants. These student data were augmented by data from 26,530 teachers in those schools and by contextual data collected from school ICT coordinators, principals, and national research centers. Eight of the countries and one benchmarking participant participated in the optional CT assessment.

The ICILS 2018 main survey data collection took place in the first half of 2018 for participants in the Northern Hemisphere and the second half of 2018 for participants in the Southern Hemisphere.

ICILS collected data using six instruments (seven in countries that participated in the CT assessment). Students completed the test of CIL, a questionnaire, and (where applicable) the test of CT. Separate questionnaires were completed by teachers, school ICT coordinators, school principals, and staff in national research centers.

\section{Assessing CIL and CT}

ICILS 2018 measured students' ability to use computers to collect and manage information, and to produce and exchange information $(\mathrm{CIL})$, as well as formulate solutions to problems so that those solutions could be operationalized with a computer (CT). In ICILS 2018 the two domains are regarded as complementary aspects of a broader notion of digital competence. ICILS 2018 assessed these domains through computer-based assessments based on real-world scenarios and problems. It investigated variations in CIL and CT across and within countries, and the relationships between each construct and student attributes (background characteristics and developed attributes), including their use and experience of computer technologies and the contexts in which CIL and CT are developed. ICILS 2018 also investigated the associations between $\mathrm{CIL}$ and $\mathrm{CT}$.

The ICILS 2018 test instrument tasks were embedded within modules. In total, there were five 30-minute CIL modules and two 25-minute CT modules. Each student completed two of the five available CIL modules and (where applicable) the two CT modules. The CIL modules were allocated to students in a balanced randomized design. The order in which CT modules were presented was randomly allocated to students. In countries participating in the CT option, students completed the CT modules after having finished both the CIL assessment and the student questionnaire.

CIL modules consisted of a sequence of tasks contextualized by a real-world theme. Each module was a series of five to eight smaller tasks, each of which typically took students less than one minute to complete, and a single large task which typically took 15 to 20 minutes to complete and involved the development of an information product. The large tasks were specified for students in terms of the software tool and format to be used, the communicative purpose, and the target audience of the information product. Three of the CIL modules had been used in ICILS 2013 and kept secure. Two new modules were developed for the ICILS 2018 CIL test instrument. Data collected from all five CIL modules were used as the basis for reporting ICILS 2018 CIL results on the ICILS CIL achievement scale.

Two 25-minute CT modules were developed for the ICILS 2018 CT assessment. Each had a unifying theme, and a sequence of tasks that related to the theme (but not a large task). The tasks in the CT module focusing on conceptualizing problems related to planning aspects of a program to operate a driverless bus. This included the visual representation of real-world situations in ways 
that could support the development of computer programs to execute automated solutions (e.g., path diagrams, flow charts, and decision trees). Further tasks related to the use of simulations to collect data and draw conclusions about real-world situations that could inform the development of a computer program. In the CT module focusing on operationalizing solutions, students worked within a simple visual coding environment to create, test, and debug code that controlled the actions of a drone used in a farming context. In this module, the tasks were incrementally more complex as the students progressed through the module. The complexity of the tasks related to the variety of available code functions and the sequence of actions required by the drone for completion of the task.

\section{Collecting data on students' personal and educational contexts for developing $\mathrm{CIL}$ and $\mathrm{CT}$}

As had been the case for ICILS 2013, a secondary purpose of ICILS 2018 was to investigate the use of computers and other digital devices by students and teachers, as well as students' and teachers' attitudes toward the use of digital technologies. Some of these aspects of ICT use are potentially related to student outcomes, while others may not be directly associated with them but may inform understanding of the broader context in which digital technologies are used, including contexts both inside and outside of school in which CIL and CT are learned.

ICILS 2018 investigated student engagement with ICT through a 30-minute student questionnaire completed on computer by students following the CIL assessment. It included questions relating to students' experience and use of ICT to complete a range of different tasks in school and out of school, their attitudes towards the use of computers and ICT, and background characteristics.

ICILS also included a teacher questionnaire that was completed by a random sample of 15 teachers of grade 8 students in each school. The questionnaire asked teachers about their familiarity with ICT, their use of ICT in educational activities in teaching focused on a randomlyselected reference class, teachers' perceptions of ICT in schools, learning to use ICT in teaching, and their background.

A 15-minute questionnaire completed by ICT coordinators asked about ICT resources in the school, ICT use in the school, ICT technical support, and provisions for professional development in ICT. A 15-minute questionnaire completed by school principals provided information about school characteristics and policies, procedures, and priorities for ICT. National research coordinators collated information provided by experts about contextual factors concerned with the structure of the education system and other aspects of education policy concerning ICTrelated learning.

\section{Findings}

\section{National contexts for CIL and CT education}

The plans and policies of countries for improving student learning and ICT resources, methods to support student learning, and the priorities for the use of ICT were similar. Although many countries recognized aspects of CIL in curricula (in nine of the 14 participants as part of a designated subject) aspects of CT were less commonly included. There were large differences across countries in terms of the availability of ICT devices for students.

\section{Student CIL}

CIL achievement was described across four levels of increasing sophistication. However, 18 percent of students on average across all countries were working below the lowest proficiency level, which meant that they did not have a functional working knowledge of computers as tools and are unlikely to be able to create digital information products unless they have support and guidance. 
On average across all countries:

- Twenty-five percent of students were working at Level 1, which meant they demonstrated a functional working knowledge of computers as tools.

- Thirty-six percent of students were working at Level 2, and could use computers, under direct instruction, to complete basic and explicit information gathering and management tasks.

- Nineteen percent of students were working at Level 3, and demonstrated the capacity to work independently when using computers as information gathering and management tools.

- Two percent of students were working at Level 4, and could execute control and evaluative judgment when searching for information and creating information products.

Access to computers at home and experience of using computers were positively associated with student CIL. Student use of productivity software was positively associated with student CIL, as was students' confidence in using general ICT applications.

Aspects of student background were also associated with CIL. Female students demonstrated higher CIL achievement than male students. Socioeconomic status was significantly positively associated with student CIL achievement. Students from non-immigrant families had higher CIL scores than students from immigrant families. Students' CIL varied more within countries than across countries.

\section{Student CT}

CT can be described as increasing according to a progression:

- At the lower region of the scale, students demonstrate a functional working knowledge of computation as input and output. They record data from observed outputs and implement complete solutions to simple coding problems.

- In the middle region of the scale, students demonstrate an understanding of computation as enabling practical solutions to real-world problems. They systematically associate inputs with outputs when planning solutions, and implement complete solutions to complex coding using non-linear logic.

- At the upper region of the scale, students demonstrate an understanding of computation as a generalizable problem-solving framework. They infer the relationship between observed inputs and outputs to evaluate solutions. They implement elegant and efficient solutions to complex coding problems using non-linear and conditional logic.

Students' CT varied more within countries than across countries. Across countries, the distance between the lowest five percent and the highest five percent of CT scores ranged from 266 to 371 scale points (with a median of 320 scale points); the average scores across all countries varied within a range of 76 scale points.

Access to computers at home and experience using computers were associated with student CT. Students' confidence in using general ICT applications was positively associated with student CT.

CT achievement tended to be higher among male than female students, but statistically significant differences between female and male students in average CT were found in only two countries and one benchmarking participant. Socioeconomic status was significantly positively associated with student CT. Students from non-immigrant families had significantly higher CT scale scores than students from immigrant families.

Student CT achievement was strongly associated with student CIL achievement. On average across all countries, the correlation between students' CIL and CT scale scores was 0.82. 


\section{Students' engagement with ICT}

Slightly fewer than half of the students in grade 8 had been using computers for five or more years. We called these students experienced computer users. Seven out of 10 students used ICT on a daily basis outside school for general purposes (including school-related and other purposes) but only one student in five reported using ICT daily for school-related purposes.

Student use of general applications (such as word processing, presentation, or internet search tools) was more frequent among experienced computer users, those currently studying a computer subject at school, and those with higher levels of CIL.

Student use of ICT for leisure activities was common. Most used ICT at least once each week to download music or watch videos. Approximately two thirds of students used ICT to access information of interest from the internet at least once each week.

The most frequent school-related use of ICT was using the internet to do research. Approximately three students in five did this at least once per week. About a quarter of the students used ICT on a weekly basis to work with other students, organize their time and work, or prepare reports and essays. The most commonly-used ICT tools were computer-based information resources, word processing software, and presentation software.

Four out of five students were confident about their ability to use ICT to search for information, insert an image into a document, and write or edit text for a school assignment. Most students acknowledged positive outcomes of ICT for society, but around half of the students also agreed that ICT had some negative consequences for society.

\section{Teaching with and about ICT}

On average across countries, most teachers tended to have experience and familiarity with ICT. More than two thirds of teachers on average had at least five years of experience with the use of ICT during lessons or with their preparation. However, fewer than half of the teachers reported frequent use of ICT when teaching (though there was considerable variation in the frequency of pedagogical ICT use across participating countries).

Most teachers tended to recognize the value of ICT use for teaching and were confident about using this technology. Majorities of teachers expressed confidence when undertaking a large number of ICT-related tasks, however teachers were less confident regarding their use of online discussions, online collaboration, and the use of learning management systems. Teachers who used ICT frequently for teaching were more confident about using ICT and older teachers felt less confident about using ICT.

Most teachers endorsed the advantages of ICT use for student learning but there were also considerable proportions of teachers mindful of negative effects. Teachers who reported daily ICT use for teaching tended to be less concerned about its potential negative effects.

There were considerable differences across countries in the availability of ICT at schools, the extent of teacher collaboration, and conditions for professional learning. Teachers who used ICT more frequently in class were also more positive about teacher collaboration and the quality of ICT resources at school.

Most teachers emphasized developing skills related to CIL and CT. However, there was considerable variation in teacher emphasis across different subject areas. Teachers' confidence in using ICT, positive perceptions of pedagogical ICT use, and positive perceptions of teacher collaboration were positively associated with teacher emphasis on student learning of CIL and CT.

Teachers' use of ICT in classrooms was still limited and depended on the complexity of tasks and applications. Teachers reported higher levels of use of general ICT tools than digital learning tools. 


\section{Explaining variations in CIL and CT}

ICILS 2018 reports the outcomes of multivariate and multilevel models used to explain variations in CIL and CT within countries. Student-level and school-level influences were incorporated in separate models explaining variation in CIL and CT outcomes.

There were considerable differences in the variance for both CIL and CT as well as the proportion of variance found between schools across participating countries. Most of the variance in CIL and CT scores was explained at the school level, with less variance being accounted for within schools.

Personal and social background had consistent net effects on CIL and CT. Female gender tended to be positively related to CIL scores, but negatively related to CT scores. Home use of test language was a positive predictor of CIL and CT in some countries, in particular in those with larger proportions of students speaking another language at home. Expected university education and socioeconomic background were consistent positive predictors of both CIL and CT ability.

Several student-level variables related to experience and use of ICT had consistent net effects on CIL and CT. Students' daily use of ICT and experience with computers were consistent positive predictors of both CIL and CT. The availability of computers at home was a positive predictor in most countries, but after controlling for personal and social background the effect was weaker. Student reports on having learned about CIL-related tasks at school and student reports on the use of general ICT applications in class tended to be positive predictors of student CIL in several countries. However, students who reported having been taught CT-related tasks had lower CT scores than other students.

There were mostly inconsistent net effects on CIL and CT by school-level ICT-related variables. Schools' socioeconomic context was a consistent positive predictor in almost all countries. In the few countries where school-level factors had significant associations, these were often no longer significant after controlling for social context variables.

\section{References}

Fraillon, J., Ainley, J., Schulz, W., Duckworth, D., \& Friedman, T. (2019). IEA International Computer and Information Literacy Study 2018 assessment framework. Cham, Switzerland: Springer. Retrieved from https:// www.springer.com/gp/book/9783030193881.

Fraillon, J., Schulz, W., \& Ainley, J. (2013). International Computer and Information Literacy Study assessment framework. Amsterdam, The Netherlands: International Association for the Evaluation of Educational Achievement (IEA). Retrieved from https://www.iea.nl/publications/assessment-framework/internationalcomputer-and-information-literacy-study-2013. 
CHAPTER 1:

\section{Introduction to the IEA International Computer and Information Literacy Study 2018}

\section{Background}

The International Association for the Evaluation of Educational Achievement (IEA) has been researching the impact of information and communications technologies (ICT) on educational processes, and factors supporting or impeding the pedagogical use of ICT, since the late-1980s. More recently it has turned its attention to investigating ICT-related educational outcomes. IEA's International Computer and Information Literacy Study (ICILS) was developed in response to the increasing use of ICT in modern society and the need for people to have the capabilities necessary to participate effectively in a digital world.

The first cycle of ICILS in 2013 (ICILS 2013) assessed students' computer and information literacy (CIL) which brings together technical competence with computer applications and the capacity to manage information (Fraillon et al. 2014). This places an emphasis on the use of computers as information seeking, management, and communication tools which are key to participation in the digital age (see, for example, Chalkiadaki 2018; van Laar et al. 2017).

This second cycle of ICILS in 2018 (ICILS 2018) continued to investigate students' CIL but also investigated students' computational thinking (CT). This dimension involves conceptualizing problems (through algorithmic or systems thinking) and operationalizing solutions (creating, implementing, and evaluating computer-based responses to problems). The inclusion of CT as an option in ICILS 2018 reflects recent interest by educators, researchers, and policymakers in the value of CT in schooling. ICILS 2018 studied how these components of digital competence related to each other and to the school and out-of-school contexts that support learning with and about computer technology.

This report presents the outcomes at the international level of analyses of data collected in the ICILS main survey in 2018. The report aims to provide an international perspective on the ICILS data relating to CIL collected across countries. Twelve countries participated in ICILS 2018: Chile, Denmark, Finland, France, Germany, Italy, Kazakhstan, the Republic of Korea (hereafter referred to as Korea, for ease of reading), Luxembourg, Portugal, the United States, and Uruguay. The city of Moscow (Russian Federation) and the state of North Rhine-Westphalia (Germany) participated as benchmarking participants. ${ }^{1}$ Eight countries completed the CT assessment: Denmark, Finland, France, Germany, Korea, Luxembourg, Portugal, and the United States. The CT option was also completed by the state of North Rhine-Westphalia (Germany) as a benchmarking participant. This report responds to the ICILS research questions and provides observations and interpretations that may stimulate further investigation within and across countries.

\section{Purposes of ICILS 2018}

The primary purpose of ICILS 2018 was to assess the capacities of students to use ICT productively for a range of purposes, including those that go beyond a basic use of computers such as producing information products and managing digital information. Authentic computerbased assessments administered to students in their eighth year of schooling generated data that provided measures of two domains of digital competence: CIL and CT.

1 Benchmarking participants are education systems within countries. 
ICILS 2018 measured students' ability to use computers to collect and manage information and to produce and exchange information (CIL) as well as formulate solutions to problems so that those solutions could be operationalized with a computer (CT). In ICILS 2018 the two domains are regarded to be complementary aspects of a broader notion of digital competence. ICILS 2018 assessed these domains through computer-based assessments based on real-world scenarios and problems. It investigated variations in CIL and CT across and within countries, and the relationships between each construct and student attributes (background characteristics and developed attributes), including their use and experience of computer technologies and the contexts in which CIL and CT are developed. Furthermore, using data collected from the countries that participated in the CT assessment, ICILS 2018 investigated the associations between CIL and CT.

As had been the case for ICILS 2013, ICILS 2018 also investigated the use of computers and other digital devices by students and teachers, as well as students' and teachers' attitudes toward the use of digital technologies. Some of these aspects of ICT use are potentially related to student outcomes, while others may not be directly associated with student outcomes but may inform understanding of the broad context in which digital technologies are used, including contexts both inside and outside of school in which CIL and CT are learned.

ICILS 2018 was also intended to describe variations in ICT use in order to contribute to a broader understanding of the roles of information technologies in school education. Secondary analyses of ICILS 2013 data suggested that teacher attitudes were associated with the extent to which, and the ways that, teachers used ICT in their teaching (Drossel et al. 2017a; Eickelmann and Vennemann 2017). There was also evidence that school factors, including teachers' collaborative use of ICT, contribute to shape the pedagogical use of ICT (Drossel et al. 2017b; Gerick et al. 2017).

\section{Computer and information literacy}

CIL was first measured in ICILS 2013, where it was defined as "an individual's ability to use computers to investigate, create, and communicate in order to participate effectively at home, at school, in the workplace, and in society" (Fraillon et al. 2013, p. 17). Put simply, CIL refers to a student's ability to use computer technologies to collect and manage information, and to produce and exchange information.

People's capacity to use applications on computers and other digital devices has been encompassed by various terms such as computer literacy, digital literacy, ICT literacy, and digital competence. The Organisation for Economic Co-operation and Development (OECD) framework for ICT literacy stressed the application of digital technologies to "access, manage, integrate, evaluate, and create information" (ETS [Educational Testing Service] 2002, p. 2). A review by Binkley et al. (2012) of definitions of ICT literacy concluded that they referred to abilities to access, evaluate, manage, and use information, as well as to the efficient application of technology (e.g., the effective use of applications and devices). The European Commission, as part of its DigComp project (Kluzer and Pujol Priego 2018), identified key components of digital competence. DigComp 2.0 resulted in five competence areas: information and data literacy, communication and collaboration, digital content creation, safety, and problem solving (Vuorikari et al. 2016) and DigComp 2.1 described eight proficiency levels (Carretero et al. 2017).

In the United States, the ICT sub-area measured in the Technology and Engineering Literacy assessment as part of the National Assessment of Educational Progress included proficiency with computers and software learning tools, networking systems and protocols, hand-held digital devices, and other technologies for accessing, creating, and communicating information and for facilitating creative expression. It also identified five sub-areas of competence: construction and exchange of ideas and solutions, information research, investigation of problems, acknowledgment of ideas and information, and selection and use of digital tools (US Department of Education, 
National Center for Education Statistics 2016). ICILS 2013 invoked the term CIL to emphasize that having the capacity to use the internet to search for and evaluate information was an important part of the broad capability to use modern technology (Fraillon et al. 2013).

\section{Computational thinking}

CT is the type of thinking used when programming on a computer or developing an application for another type of digital device. Fraillon et al. (2019, p. 27) defined CT as "an individual's ability to recognize aspects of real-world problems which are appropriate for computational formulation and to evaluate and develop algorithmic solutions to those problems so that the solutions could be operationalized with a computer."

CT focuses on learning foundational principles of computing. Wing (2006) regarded CT as a concept that embraces problem solving and system design, based on principles central to computer science. CT has also been described as the ways of thinking when programming a computer (Grover and Pea 2013) and can be seen as "applying tools and techniques from computer science to understand and reason about both natural and artificial systems and processes" (Royal Society 2012, p. 29). Shute et al. (2017) argued that CT is required to solve problems algorithmically (with or without the assistance of computers) by applying solutions that are reusable in different contexts. They suggested that CT involves six elements: decomposition, abstraction, algorithm design, debugging, iteration, and generalization. CT does not necessarily involve developing or implementing a formal computer code (Barr et al. 2011). However, assessments of CT are typically set in computer environments because those facilitate the capturing of the data that reflect the steps in problem solving. These steps usually involve developing or assembling instructions (often including blocks of code) that are necessary to accomplish a task (Brennan and Resnick 2012). Yadav et al. (2018, pp. 91-92) articulated the nature of CT as being focused on the processes of "abstraction, algorithms and automation."

The early stages of the introduction of computers in schools and classrooms included a focus on programming (Lockheed and Mandinach 1986). It can be argued that the links between programming and problem solving are important for educational development (Papert 1980). A key element of this in the 1980s was the educational programming language Logo, in which commands resulted in movement of a cursor or robot (termed a "turtle") on a screen, producing line graphics. Recently there has been a resurgence of interest from researchers, educators, and policymakers in the importance of CT in education (Voogt et al. 2015). Visual programming languages (where programs are created by manipulating program elements, or blocks, graphically) for children have emerged in addition to text-based programming languages (e.g., Scratch and Python) (Ortiz-Colon and Marato Romo 2016). These languages focus on the algorithmic logic underpinning coding across tasks and are considered to be accessible to novice users.

\section{Research questions}

ICILS aimed to investigate the extent of CIL and CT among grade 8 students, and the associations of these learning outcomes with student background, developed attributes, experience with using computer technologies, and learning about computer technologies. It also investigated relations between $\mathrm{CIL}$ and $\mathrm{CT}$.

\section{Computer and information literacy}

The research questions concerned with CIL remain similar to those used in ICILS 2013. The questions are framed around variations in CIL, the relationship of CIL to the characteristics of students, and the contexts in which CIL is developed. These have been articulated more fully in the ICILS 2018 assessment framework (Fraillon et al. 2019). In summary, the four research questions were the following: 
RQ CIL 1 What variations exist across and within countries in students' CIL?

RQ CIL 2 What aspects of schools and countries are related to students' CIL?

RQ CIL 3 What are the relationships between students' levels of access to, familiarity with, and self-reported proficiency in using computers and their CIL?

RQ CIL 4 What aspects of students' personal and social backgrounds (such as gender and socioeconomic background) are related to students' CIL?

Four countries participated in each of ICILS 2013 and ICILS 2018. It is possible to compare student CIL between 2013 and 2018 in the three of those counties that met the ICILS technical requirements for both cycles.

\section{Computational thinking}

The research questions relating to CT closely reflected those proposed for CIL, but excluded reference to changes from ICILS 2013 and included reference to the relationship between CT and CIL. Analyses were limited to those countries participating in the optional assessment of students' CT achievement. The five CT related research questions were the following:

RQ CT 1 What variations exist across and within countries in students' CT?

RQ CT 2 What aspects of schools and education systems are related to students' CT?

RQ CT 3 What are the relationships between students' levels of access to, familiarity with, and self-reported proficiency in using computers and their CT?

RQ CT 4 What aspects of students' personal and social backgrounds (such as gender and socioeconomic background) are related to students' CT?

RQ CT 5 What is the association between students' CIL and CT?

\section{The ICILS assessment framework}

The ICILS 2018 assessment framework provides a conceptual underpinning for the international instrumentation for ICILS (Fraillon et al. 2019). The assessment framework consists of three parts:

- The CIL framework outlines the outcome measures addressed through the CIL test.

- The CT framework outlines the outcome measures addressed through the CT test.

- The contextual framework maps the context factors expected to influence and explain variation in CIL and CT.

\section{The CIL framework}

The structure of the CIL construct references four strands that frame the skills and knowledge addressed by the CIL assessment: understanding computer use, gathering information, producing information, and digital communication. These strands define the CIL construct but are not intended to represent empirically distinct components. Each strand is further defined in terms of two aspects (Figure 1.1).

- Understanding computer use refers to the fundamental technical knowledge and skills that underpin the operational use of computers as tools for working with information. This includes a person's knowledge and understanding of the generic characteristics and functions of computers. Understanding computer use comprises two aspects: foundations of computer use and computer use conventions.

- Gathering information embraces the receptive and organizational elements of information processing and management. This subsumes two aspects: accessing and evaluating information, and managing information. 
- Producing information focuses on using computers as tools for thinking and creating. It involves two aspects: transforming information and creating information.

- Digital communication focuses on information sharing in social networking (and broader webbased information sharing spaces) together with the social, legal, and ethical responsibilities associated with information sharing and using information safely and securely.

Figure 1.1: ICILS 2018 CIL framework

Computer and information literacy refers to an individual's ability to use computers to investigate, create, and communicate in order to participate effectively at home, at school, in the workplace, and in the community.

$\begin{array}{llll} & & & \\ \text { Strand 1 } & \text { Strand 2 } & \text { Strand 3 } & \text { Strand 4 } \\ \text { Understanding } & \text { Gathering information } & \text { Producing information } & \text { Digital communication } \\ \text { computer use } & \text { Aspect 2.1 } & \text { Aspect 3.1 } & \text { Aspect 4.1 } \\ \text { Aspect 1.1 } & \text { Accessing and } & \text { Transforming } & \text { Sharing information } \\ \text { Foundations of } & \text { evaluating information } & \text { information } & \text { Aspect 4.2 } \\ \text { computer use } & \text { Aspect 2.2 } & \text { Aspect 3.2 } & \text { Using information } \\ \begin{array}{l}\text { Aspect } 1.2 \\ \text { Computer use } \\ \text { conventions }\end{array} & \text { Managing information } & \text { Creating information } & \text { responsibly and safely } \\ & & & \\ & & & \end{array}$

Source: Fraillon et al. (2019)

\section{The CT framework}

The CT construct comprises two strands: conceptualizing problems and operationalizing solutions (Figure 1.2). One strand contains three aspects and the other comprises two aspects. The aspects encompass the knowledge, skills, and understandings held in common across the range of definitions of CT.

- Conceptualizing problems acknowledges that before solutions can be developed, problems must first be understood and framed in a way that allows algorithmic or systems thinking to assist in the process of developing solutions. This strand comprises three aspects: knowing about and understanding digital systems, formulating and analyzing problems, and collecting and representing relevant data.

- Operationalizing solutions comprises the processes associated with creating, implementing, and evaluating computer-based system responses to real-world problems. It includes the iterative processes of planning for, implementing, testing, and evaluating algorithmic solutions (as the potential bases for programming) to real-world problems. The strand includes an understanding of the needs of users and their likely interaction with the system under development. This strand comprises two aspects: planning and evaluating solutions, and developing algorithms, programs, and interfaces. 
Figure 1.2: ICILS 2018 CT framework

Computational thinking refers to an individual's ability to recognize aspects of real-world problems which are appropriate for computational formulation and to evaluate and develop algorithmic solutions to those problems so that the solutions could be operationalized with a computer.

$\begin{array}{ll} & \\ \text { Strand } 1 & \text { Strand } 2 \\ \text { Conceptualizing problems } & \text { Operationalizing solutions } \\ \text { Aspect } 1.1 & \text { Aspect } 2.1 \\ \text { Knowing about and understanding digital } & \text { Planning and evaluating solutions } \\ \text { systems } & \text { Aspect } 2.2 \\ \text { Aspect } 1.2 & \text { Developing algorithms, programs, and } \\ \text { Formulating and analyzing problems } & \text { interfaces } \\ \text { Aspect } 1.3 & \\ \text { Collecting and representing relevant data } & \\ & \end{array}$

Source: Fraillon et al. (2019)

\section{The contextual framework}

ICILS 2018 collected contextual information so as to provide bases for understanding variations in CIL and CT (from here on we use CIL/CT to refer to these outcomes when common contextual information is being considered) as well as to collect data about the pedagogical use of ICT at schools. We classified the contextual factors in a framework that was consistent with the multilevel structure inherent in student CIL/CT learning and also considered these factors as antecedents or processes (Figure 1.3).

Conceptual frameworks for analyzing educational outcomes are frequently based on a multilevel structure that is inherent in student learning (Goldstein 2010; Raudenbush and Bryk 2002; Schulz 2018). Learning is set in the overlapping contexts of in-school and out-of-school learning. Out-of-school activities and experiences are important for CIL/CT learning (ACARA [Australian Curriculum, Assessment and Reporting Authority] 2015). The contextual framework of ICILS therefore embraces out-of-school learning through experience and frequency of ICT use by students outside of school (Fraillon et al. 2019).

The temporal status of contextual factors within the learning process is also important. Factors may be considered either as antecedents or processes. Antecedents are exogenous factors that condition the ways in which CIL/CT learning takes place. They are contextual factors that are not directly influenced by learning-process variables or outcomes. It is important to recognize that antecedent variables are level-specific and may be influenced by antecedents and processes found at higher levels, for example, the extent to which schools' ICT resources are likely to be influenced by ICT education policies at the level of the education system. Processes are those factors that directly influence CIL/CT learning. They are constrained by antecedent factors and factors found at higher levels. These antecedent factors could include variables such as opportunities for CIL/CT learning during class, teacher attitudes toward using ICT for study tasks, and students' use of computers at home. 
Figure 1.3: Contexts for ICILS 2018 CIL/CT outcomes

\section{Antecedents}

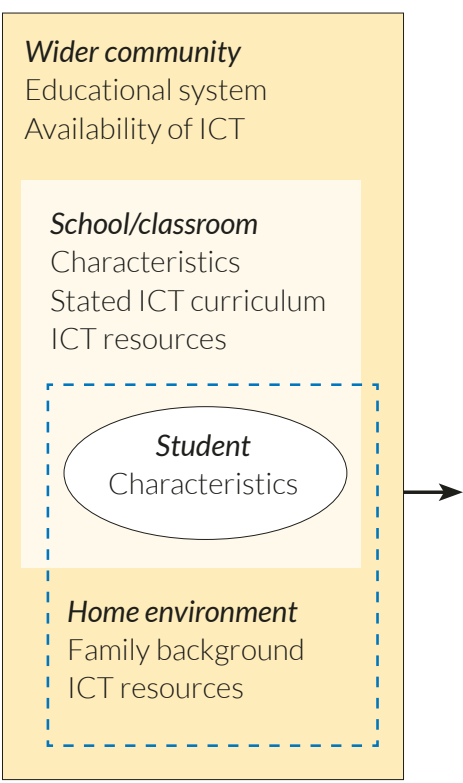

Processes

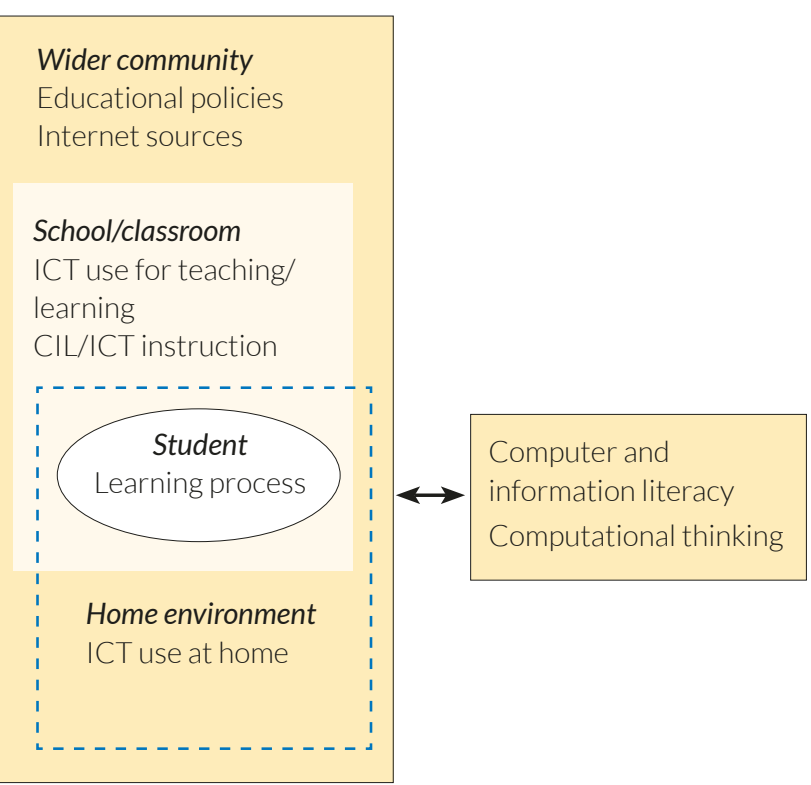

Notes: The double arrow between process-related factors and outcomes emphasizes the possibility of a reciprocal association between learning processes and learning outcomes. The single-headed arrow between antecedents and processes indicates the assumption within the ICILS contextual framework of a unidirectional influence between these two types of contextual factors.

Source: Fraillon et al. (2019).

Reference to this general conceptual framework enabled us to locate potential contextual factors on a two-by-four grid where antecedents and processes constitute the columns and the four levels the rows (Table 1.1 provides examples of the contextual variables collected by the ICILS instruments).

Table 1.1: Mapping of variables to the contextual framework related to CIL and CT outcomes (examples)

\begin{tabular}{|c|c|c|c|}
\hline Level of ... & Analysis level & Antecedents & Processes \\
\hline Wider community & $\begin{array}{l}\text { Not used in } \\
\text { within-country } \\
\text { multilevel analyses }\end{array}$ & $\begin{array}{l}\text { NCS \& other sources: } \\
\text { Structure of education } \\
\text { Accessibility of ICT }\end{array}$ & $\begin{array}{l}\text { NCS \& other sources: } \\
\text { Role of ICT in curriculum }\end{array}$ \\
\hline School/classroom & School level & $\begin{array}{l}\text { PrQ, ICQ, \& TQ: } \\
\text { School characteristics } \\
\text { ICT resources }\end{array}$ & $\begin{array}{l}\text { PrQ, ICQ, TQ, \& StQ: } \\
\text { ICT use in teaching } \\
\text { and learning } \\
\text { CIL/CT instruction }\end{array}$ \\
\hline Student & Student level & $\begin{array}{l}\text { StQ: } \\
\text { Gender } \\
\text { Age } \\
\text { ICT experience }\end{array}$ & $\begin{array}{l}\text { StQ: } \\
\text { ICT activities } \\
\text { Use of ICT } \\
\text { CIL/CT }\end{array}$ \\
\hline Home environment & & $\begin{array}{l}\text { StQ: } \\
\text { Parent socioeconomic } \\
\text { status } \\
\text { Home ICT resources }\end{array}$ & $\begin{array}{l}\text { StQ: } \\
\text { Learning about ICT } \\
\text { at home }\end{array}$ \\
\hline
\end{tabular}

Note: NCS = national contexts survey; $\mathrm{PrQ}$ = principal questionnaire; ICQ = ICT coordinator questionnaire; TQ = teacher questionnaire; $\mathrm{StQ}=$ student questionnaire. 
The student questionnaire collected data on contextual factors pertaining to the level of the individual student and their home context. The teacher, school principal, and ICT coordinator questionnaires were designed to gather information about contextual factors associated with the school/classroom level. In addition, and separate from the multilevel analyses, the national contexts survey (NCS) and other available sources (e.g., published statistics), provided national contextual data that facilitated interpretation.

\section{ICILS instruments}

In total, ICILS collected data using six instruments (seven in countries that participated in the CT assessment). Students completed the test of CIL, a questionnaire, and (where applicable) the test of CT. Separate questionnaires were completed by teachers, school ICT coordinators, school principals, and staff in national research centers.

The ICILS 2018 assessments of students' CIL and CT were designed to provide students with an authentic computer-based assessment experience in a uniform way. ICILS 2018 used a customized assessment platform that delivered the assessment content to students offline. In the majority of schools the assessments were delivered from a USB drive. A few schools installed the materials on a computer that functioned as a server for a network of school computers. The instrument used purpose-built applications that followed standard interface conventions. Students completed a range of tasks including skills-based tasks using productivity software tools (such as text editors or presentation applications) and web-content. The purpose-built applications were designed to be consistent with the applications that could reasonably be expected to be within the realm of students' typical experience of computer use.

\section{CIL test design}

The CIL assessment tasks were embedded within modules. In total, there were five 30-minute CIL modules. Each student completed two of the five CIL modules. The CIL modules were allocated to students in a balanced randomized design.

Each CIL module comprised a sequence of tasks contextualized by a real-world theme and driven by a plausible narrative. Each module included a series of five to eight smaller tasks, each of which typically took students less than one minute to complete, and each of which contributed to the development of contextual knowledge that underpinned work on a single large task. The large tasks typically took 15 to 20 minutes to complete and involved the development of an information product (such as a presentation, poster, website, or social media post) that made use of information and resources managed by students in the lead-up tasks. The large tasks were specified for students in terms of the software tools and format to be used (and consequently the format of the product), the communicative purpose, and the target audience of the information product.

Three of the CIL modules had been developed and used in ICILS 2013 and kept secure. Two new modules were developed for the ICILS 2018 CIL test instrument to address contemporary thematic content and software environments. Data collected from all five CIL modules in ICILS 2018 were used as the basis for reporting ICILS 2018 CIL results on the ICILS CIL achievement scale established in 2013. The rotated module design enabled the instrument to contain, and consequently report on achievement against, a larger amount of content (covering the breadth of the CIL framework and a range of difficulties) than any single student could reasonably complete in 60 minutes. 


\section{CT test design}

Two 25-minute CT modules were developed for the ICILS 2018 CT assessment: one on conceptualizing problems and the other on operationalizing solutions. Each had a unifying theme and a sequence of tasks that related to the theme (but not a large task).

The tasks in the CT module focusing on conceptualizing problems related to planning aspects of a program to operate a driverless bus. This included visual representation of real-world situations in ways that could support the development of computer programs to execute automated solutions (e.g., path diagrams, flow charts, and decision trees). Further tasks related to the use of simulations to collect data and draw conclusions about real-world situations that could inform planning the development of a computer program.

In the CT module focusing on operationalizing solutions, students worked within a simple visual coding environment to create, test, and debug code (blocks of code that have some specified and some configurable functions) that controlled the actions of a drone used in a farming context. In this module, the tasks were incrementally more complex as the students advanced through the module. The complexity of the tasks related to the variety of code functions that were available and the sequence of actions required by the drone for completion of the task.

In countries participating in the ICILS 2018 CT option, students completed both CT modules after having finished both the CIL assessment and the student questionnaire.

\section{International student questionnaire}

A 30-minute international student questionnaire was completed on computer by students following completion of the CIL assessment. It included questions relating to students' background characteristics, their experience and use of computers and ICT to complete a range of different tasks in school and out of school, and their attitudes towards the use of computers and ICT.

\section{Teacher and school questionnaires}

Three instruments were designed to gather information from and about teachers and schools. These instruments could be completed on computer (over the internet) or on paper depending on the availability of resources in schools and countries. These instruments were:

- A 30-minute teacher questionnaire: A teacher questionnaire was designed to be completed by a random sample of 15 teachers of grade 8 students. A consequence of this approach to sampling was that the data could be used to generate school and system-level aggregates but that they could not be linked to individual students. The questionnaire asked about teacher background including familiarity with ICT, their use of ICT in educational activities in teaching focused on a randomly-selected reference class, teachers' perceptions of ICT in schools, and learning to use ICT in teaching.

- A 15-minute ICT coordinator questionnaire: A questionnaire to be completed by ICT coordinators asked about ICT resources in the school (computers, other devices, digital learning resources, networking and internet connectivity), ICT use in the school (provision for specialist teaching of ICT, emphasis in curriculum areas, learning management systems, school administration), ICT technical support (maintenance provision, support for managing resources), and provisions for professional development in ICT at school.

- A 15-minute principal questionnaire: A questionnaire completed by school principals provided information about school characteristics and policies, procedures, and priorities for ICT at the sampled school. 


\section{National coordinator questionnaires}

ICILS 2018 national research coordinators provided information, based on the input of national experts, in response to an online NCS. Data from the NCS were used for comparing profiles of $\mathrm{CIL}$ and CT education in participating countries. The NCS provided data on contextual factors concerned with structure of the education system and systematic descriptions of policy and practice in the use of ICT in school education. The data provided the bases for analyses of the influence of system-level contexts on differences in CIL/CT learning, and for interpreting differences among countries in the patterns of relationships among factors that are related to CIL/CT learning.

\section{Participating countries, population, sample design, and achieved samples}

\section{Countries or education systems}

Twelve countries and two benchmarking participants participated in ICILS 2018.

Countries participating in ICILS 2018

- Chile (CIL)

- Denmark (CIL and CT)

- Finland (CIL and CT)

- France (CIL and CT)

- Germany (CIL and CT)

- Italy (CIL)

Benchmarking participants

- Moscow (Russian Federation) (CIL)
- Kazakhstan (CIL)

- Korea (CIL and CT)

- Luxembourg (CIL and CT)

- Portugal (CIL and CT)

- The United States (CIL and CT)

- Uruguay (CIL)

- North Rhine-Westphalia (Germany) (CIL and CT)

Benchmarking participants are education systems within countries. In ICILS 2018, the city of Moscow in the Russian Federation took part as a benchmarking participant even though the country did not participate. In contrast, the German state of North Rhine-Westphalia took part as a benchmarking participant in addition to the participation of the country of Germany. Additional schools were sampled in North Rhine-Westphalia to enable accurate reporting of data representing that entity. Data collected from North Rhine-Westphalia also contributed to the data reported for Germany as a whole.

Data collected from benchmarking participants were not included in the establishment of reporting scales, nor were they included in the computation of international averages. However, data from a benchmarking participant may be compared to the international data if the benchmarking participant has satisfied the technical requirements of the study. Both the city of Moscow (Russian Federation) and North Rhine-Westphalia (Germany) met the technical requirements of ICILS 2018.

\section{Administration periods}

The ICILS 2018 main survey data collection took place in the first half of 2018 for participants in the Northern Hemisphere ${ }^{2}$ and in the second half of 2018 for participants in the Southern Hemisphere. ${ }^{3}$ In Italy the survey data collection took place in the second half of 2018 (i.e., the beginning of the school year) even though it was a Northern Hemisphere participant.

2 The Northern Hemisphere participants were: Denmark, Finland, France, Germany, Italy, Kazakhstan, Korea, Luxembourg, Portugal, the United States, Moscow (Russian Federation), and North Rhine-Westphalia (Germany).

3 The Southern Hemisphere participants were Chile and Uruguay. 


\section{Population definitions}

The ICILS student population was defined as students in grade 8 (typically around 14 years of age in most countries), provided that the average age of students in this grade was at least 13.5 years at the time of the assessment.

The population for the ICILS teacher survey was defined as consisting of all teachers teaching regular school subjects to the students in the target grade at each sampled school. It included only those teachers who were teaching the target grade during the testing period and who had been employed at the school since the beginning of the school year. ICILS also administered separate questionnaires to principals and nominated ICT coordinators in each school.

\section{Sample design}

\section{Schools}

The samples were designed as two-stage cluster samples. During the first stage of sampling, schools with enrolled students at the target grade were randomly selected with a probability proportional to size as measured by the number of students enrolled in a school. The numbers required in the sample to achieve the necessary precision were estimated on the basis of national characteristics. However, as a guide, each country was instructed to plan for a minimum sample size of 150 schools except in very small education systems where all schools were included in the survey. The schools sampled at the first stage were then used to select both students and teachers. The numbers of schools in the achieved samples in each country or benchmarking participant ranged between 35 (in a very small system, with next smallest sample being 110) and 261.

\section{Students}

Within each participating school, 20 students were randomly sampled from all students enrolled in the target grade. In schools with fewer than 20 students, all students were invited to participate.

\section{Teachers}

Fifteen teachers were selected at random from all teachers teaching the target grade at each sampled school. In schools with 20 or fewer such teachers, all teachers were invited to participate. Because of the intention that teacher information should not be linked to individual students, all teachers of the target grade were eligible to be sampled regardless of the subjects they taught.

\section{Participation requirements and reporting}

The participation rates required for each country were 85 percent of the selected schools and 85 percent of the selected students within the participating schools, or a weighted overall participation rate of 75 percent. The same criteria were applied to the teacher sample, but the coverage was judged independently of those for the student sample.

In the tables in this report, we use annotations to identify those countries that met these response rates only after using replacement schools. Countries that did not meet the response rates, even after replacement, are reported separately below the main section of each table. Results from education systems that took part as benchmarking participants also appear as a further separate section in the tables of this report. (Appendix A documents sampling information and participation rates for each country.)

\section{Achieved samples}

ICILS 2018 gathered data from 46,561 grade 8 (or equivalent) students in 2226 schools from 12 countries and two benchmarking participants. These student data were augmented by data from 26,530 teachers in those schools and by contextual data collected from school ICT coordinators, principals, and national research centers. 
The average student participation rate (after replacement procedures) achieved was 87 percent. Eleven of the 12 participating countries and both benchmarking participants satisfied or nearly satisfied the required participation rate for students and are reported in the main section of the reporting tables. Italy assessed its grade 8 students at the beginning of the school year and therefore the average age of sampled students is lower than 13.5 years at the time of assessment which is below target group population age defined for the survey. As a consequence, CIL results from Italy are reported separately in the tables in Chapter 3 to indicate to readers that results from this country are not entirely comparable with other countries.

The average teacher participation rate (after replacement procedures) was 82 percent. Seven of the 12 participating countries and both benchmarking participants satisfied the required participation rate for teachers.

\section{Structure of this report}

The six chapters following this present and discuss analyses of the ICILS data and serve to address the ICILS research questions. The last chapter (Chapter 8 ) concludes the report with reflections on the themes that are evident across ICILS 2018 and on future directions for research.

Chapter 2 describes the national contexts for CIL and CT education in ICILS 2018 countries. It addresses common patterns as well as policies, curriculum, resources, and practices in specific countries and groups of countries.

Chapter 3 reports on CIL proficiency across countries. It describes how the student test was used to measure CIL and presents the ICILS scale of CIL proficiency. The chapter then documents how student achievement on the CIL scale varied across and within participating countries. It examines gender differences in CIL and variations in CIL related to socioeconomic background, immigrant status, and home ICT resources. For three countries it was possible to report on changes in CIL between 2013 and 2018.

Chapter 4 reports on CT proficiency across countries. It describes the nature of the CT tests and the achievement scale that was derived from the assessment data. It documents how CT achievement varied across and within participating countries and the how variations related to gender, socioeconomic background, immigrant status, and home ICT resources. It also reports on the association between CIL and CT.

Chapter 5 explores students' use of, and engagement with, ICT at home and school. Data reported on in this chapter were collected using the student questionnaire. Standardized scale indices are used to report students' use of ICT for a range of purposes and ICT-related attitudes. The chapter also reports on differences between male and female students as well as differences in use across subject areas, and associations of self-perceptions with CIL/CT achievement.

The focus of Chapter 6 is teaching with and about ICT, specifically on the roles of schools in $\mathrm{CIL/CT}$ education. This chapter is based on data from the teacher, ICT coordinator, and principal questionnaires and describes the variation in approaches to the provision of CIL/CT related education in schools. It reviews teacher familiarity with ICT, teacher confidence in using ICT, teacher views about using ICT in education, and the ICT tools that they use in teaching activities. It reports on the emphasis teachers place on developing CIL/CT, as well as on the pedagogical use of ICT, and associations between these emphases and teacher attributes.

Chapter 7 presents the outcomes of multivariate and multilevel models used to explain variations in CIL/CT within countries. The models incorporate student-level and school-level influences explaining variation in $\mathrm{CIL}$ and $\mathrm{CT}$ outcomes. 
Chapter 8 discusses the themes emerging from the results of ICILS 2018. We reflect on the key findings relating to student achievement in $\mathrm{CIL}$ and $\mathrm{CT}$, the digital divide and student gender, and on the use of ICT in schools and teaching. The chapter includes reflections on implications of the results for policy and practice and suggests some directions for future research on CIL and CT.

\section{References}

ACARA. (2015). National Assessment Program - ICT literacy years 6 \& 102014 report. Sydney, Australia: Australian Curriculum, Assessment and Reporting Authority. Retrieved from http://www.nap.edu. au/_resources/D15_8761_NAP-ICT_2014_Public_Report_Final.pdf.

Barr, D., Harrison, J., \& Conery, L. (2011). Computational thinking: A digital age skill for everyone. Learning \& Leading with Technology, 38(6), 20-23. Retrieved from https://id.iste.org/docs/learning-and-leadingdocs/march-2011-computational-thinking-II386.pdf.

Binkley, M., Erstad, E., Herman, J., Raizen, S., Ripley, M., Miller-Ricci, M., \& Rumble, M. (2012). Defining 21st century skills. In P. Griffin, B. McGaw, \& E. Care (Eds.), Assessment and teaching of 21st century skills (pp. 17-66). Dordrecht, The Netherlands: Springer. Retrieved from https://link.springer.com/chapter/1 0.1007\%2F978-94-007-2324-5_2.

Brennan, K., \& Resnick, M. (2012). New frameworks for studying and assessing the development of computational thinking. Paper presented at the 2012 Annual Meeting of the American Educational Research Association, Vancouver, Canada. Retrieved from https://web.media.mit.edu/ kbrennan/files/ Brennan_Resnick_AERA2012_CT.pdf.

Carretero, S., Vuorikari, R., \& Punie, Y. (2017). DigComp 2.1: The Digital Competence Framework for Citizens with eight proficiency levels and examples of use. Joint Research Centre Report EUR 28558 EN. Luxembourg: Publication Office of the European Union. Retrieved from https://doi.org/10.2760/38842.

Chalkiadaki, A. (2018). A systematic literature review of 21st century skills and competencies in primary education. International Journal of Instruction, 11(3), 1-16. Retrieved from http://www.e-iji.net/dosyalar/ iji_2018_3_1.pdf.

Drossel, K., Eickelmann, B., \& Gerick, J. (2017a). Predictors of teachers' use of ICT in school - the relevance of school characteristics, teachers' attitudes and teacher collaboration. Education and Information Technologies, 22(2), 551-573. Retrieved from https://link.springer.com/article/10.1007\%2Fs10639-0169476-y.

Drossel, K., Eickelmann, B., \& Schulz-Zander, R. (2017b). Determinants of teachers' collaborative use of ICT for teaching and learning: a European perspective. European Educational Research Journal, 16(6), 781-799. Retrieved from https://doi.org/10.1177\%2F1474904116655811.

ETS. (2002). Digital transformation: A framework for ICT literacy. Princeton, NJ: Educational Testing Service. Retrieved from http://www.ets.org/Media/Research/pdf/ICTREPORT.pdf.

Eickelmann, B., \& Vennemann, M. (2017). Teachers' attitudes and beliefs towards ICT in teaching and learning in European countries. European Educational Research Journal, 16(6), 1-29. Retrieved from https:// doi.org/10.1177\%2F1474904117725899.

Fraillon, J., Ainley, J., Schulz, W., Duckworth, D., \& Friedman, T. (2019). IEA International Computer and Information Literacy Study 2018 assessment framework. Cham, Switzerland: Springer. Retrieved from https:// www.springer.com/gp/book/9783030193881.

Fraillon, J., Ainley, J., Schulz, W., Friedman, T., \& Gebhardt, E. (2014). Preparing for life in a digital age: The IEA International Computer and Information Literacy Study international report. Cham, Switzerland: Springer. Retrieved from https://www.springer.com/gp/book/9783319142210.

Fraillon, J., Schulz, W., \& Ainley, J. (2013). International Computer and Information Literacy Study assessment framework. Amsterdam, The Netherlands: International Association for the Evaluation of Educational Achievement (IEA). Retrieved from https://www.iea.nl/publications/assessment-framework/internationalcomputer-and-information-literacy-study-2013.

Gerick, J., Eickelmann, B., \& Bos, W. (2017). School-level predictors for the use of ICT in schools and students' CIL in international comparison. Large-scale Assessments in Education, 5(1), 1-13. Retrieved from https:/doi.org/10.1186/s40536-017-0037-7.

Goldstein, H. (2010). Multilevel statistical models (4th ed.). Hoboken, NJ: John Wiley and Sons. 
Grover, S., \& Pea, R. (2013). Computational thinking in K-12: A review of the state of the field. Educational Researcher, 42(1), 38-43.

Kluzer, S., \& Pujol Priego, L. (2018). DigComp into action: Get inspired, make it happen. In S. Carretero, Y. Punie, R. Vuorikari, M. Cabrera, \& W. O'Keefe (Eds.), JRC Science for Policy Report, EUR 29115 EN. Luxembourg: Publications Office of the European Union. Retrieved from http://publications.jrc.ec.europa. eu/repository/bitstream/JRC110624/dc_guide_may18.pdf.

Lockheed, M., \& Mandinach, E. B. (1986). Trends in educational computing: decreasing interest and the changing focus of instruction. Educational Researcher, 15(5), 21-26.

Ortiz-Colon, A. M., \& Marato Romo, J. L. (2016). Teaching with Scratch in compulsory secondary education. International Journal of Emerging Technologies in Learning, 11(2), 67-70. Retrieved from https://onlinejournals.org/index.php/i-jet/article/view/5094.

Papert, S. (1980). Mindstorms: Children, computers, and powerful ideas. New York, NY: Basic Books.

Raudenbush, S., \& Bryk, A. (2002). Hierarchical linear models: Applications and data analysis methods. Thousand Oaks, CA: Sage.

Royal Society. (2012). Shutdown or restart: The way forward for computing in UK schools. London, UK: Author. Retrieved from https://royalsociety.org/-/media/education/computing-in-schools/2012-01-12computing-in-schools.pdf.

Schulz, W. (2018). The reporting of ICCS 2016 results. In W. Schulz, R. Carstens, B. Losito, \& J. Fraillon (Eds.), ICCS 2016 technical report. Amsterdam, The Netherlands: International Association for the Evaluation of Educational Achievement (IEA).

Shute, V. J., Sun, C., \& Asbell-Clarke, J. (2017). Demystifying computational thinking. Educational Research Review, 22(1), 142-158. Retrieved from https://www.learntechlib.org/p/204418/.

US Department of Education, National Center for Education Statistics. (2016). The nation's report card: 2014 Technology \& Engineering Literacy (TEL) report card at grade 8. Report number NCES2016119. Washington, DC: Author. Retrieved from https://www.nationsreportcard.gov/tel_2014/.

Van Laar, E., van Deursen, A.J.A.M., van Dijk, J.A.G.M., \& de Haan, J. (2017). The relation between 21stcentury skills and digital skills: A systematic literature review. Computers in Human Behavior, 72, 577-588. Retrieved from https://doi.org/10.1016/j.chb.2017.03.010.

Vuorikari, R., Punie, Y., Carretero Gomez, S., \& van den Brande, G. (2016). DigComp 2.0: The digital competence framework for citizens. Update phase 1: The conceptual reference model. Joint Research Centre Report EUR 27948 EN. Luxembourg: Publication Office of the European Union. Retrieved from https:// doi.org/10.2791/11517.

Voogt, J., Fisser, P., Good, J., Mishra, P., \& Yadav, A. (2015). Computational thinking in compulsory education: Towards an agenda for research and practice. Education and Information Technologies, 20(4), 715-728. Retrieved from https://link.springer.com/article/10.1007/s10639-015-9412-6.

Wing, J.M. (2006). Computational thinking. Communications of the ACM, 49(3), 33-35. Retrieved from https://doi.org/10.1145/1118178.1118215.

Yadav, A., Sands, P., Good, J., \& Lishinki, A. (2018). Computer science and computational thinking in the curriculum: Research and practice. In J. Voogt., G. Knezek, R. Christensen, \& K.W. Lai (Eds.), Second handbook of information technology in primary and secondary education. Cham, Switzerland: Springer. Retrieved from https://www.springer.com/gp/book/9783319710532.

Open Access This chapter is licensed under the terms of the Creative Commons Attribution-NonCommercial 4.0 International License (http://creativecommons.org/licenses/by-nc/4.0/), which permits any noncommercial use, sharing, adaptation, distribution and reproduction in any medium or format, as long as you give appropriate credit to the original author(s) and the source, provide a link to the Creative Commons license and indicate if changes were made.

The images or other third party material in this chapter are included in the chapter's Creative Commons license, unless indicated otherwise in a credit line to the material. If material is not included in the chapter's Creative Commons license and your intended use is not permitted by statutory regulation or exceeds the permitted use, you will need to obtain permission directly from the copyright holder. 
CHAPTER 2:

\section{The contexts for education on computer and information literacy and computational thinking}

\section{Chapter highlights}

Characteristics of the educational systems vary considerably across participating ICILS 2018 countries.

- In 11 of the 14 ICILS 2018 educational systems (the exceptions being Germany, the United States, and benchmarking entity, North Rhine-Westphalia, Germany), the national educational ministry leads the primary role of defining the goals and direction for the school education system. The characteristics of these systems in terms of years of schooling at each educational level and school financing type fluctuated across countries. (Table 2.1)

- In almost all countries, schools had at least some autonomy with most aspects of school policies, with private schools typically having a greater degree of autonomy. (Table 2.2)

- A wide range of differences across participating countries exist, both in relation to information and communication technology (ICT) infrastructure availability and economic characteristics. (Table 2.3)

Although the formulation of plans and policies supporting the use of ICT in education differed across countries, there was a high degree of similarity in the content related to improving student learning, ICT resources, methods to support student learning, and the priorities for the use of ICT.

- While many countries had explicit or implicit recognition of different computer and information literacy (CIL) aspects in their national curriculum, ${ }^{4}$ aspects of computational thinking (CT) were less frequently included. (Table 2.4 and Table 2.5)

- CIL was offered to students at lower-secondary level in all 14 participating countries and benchmarking participants. In eight out of 14 this was a separate subject, although it was not always compulsory. (Table 2.6)

- Countries had very different approaches to the development of teachers' capacity to use ICT. In most countries it was either a mandatory component of pre-service education or part of some form of professional development for teachers. Rarely was it a requirement for registration as a teacher. (Table 2.7)

- In general, countries provided a large degree of support for teacher access to ICT-based professional development, mainly by funding teacher participation in programs and/or by providing resources for teachers to access. (Table 2.8)

4 There is no national curriculum for the United States. Data related to the curriculum reported in this chapter are based on selected state curricula. 
Reports from school principals and ICT coordinators provide a contrasting profile of differences across participating ICILS countries in terms of school resourcing, policies, and priorities.

- Most technology-related resources and software-related resources were reported as being available in schools. (Table 2.9 and Table 2.10)

- Considerable variation was evident across countries on whether ICT facilities were available for the teaching and learning of target grade students. (Table 2.11)

- Large differences were evident across countries in terms of the availability of ICT devices per student. The overall influence of school location on this ratio was minimal. (Table 2.12)

- School computers were typically available in computer laboratories. When students were able to bring portable computers to class, these were most commonly provided by the school for school use only. (Table 2.13)

- Schools across countries varied in their implementation of policies towards different aspects of ICT. (Table 2.14)

- School principals had different perspectives on the priority areas for facilitating the use of ICT for teaching and learning (both within and across countries). (Table 2.15) 


\section{Introduction}

This chapter provides information about the national contexts in which computer and information literacy $(\mathrm{CI})$ and computational thinking (CT) are developed for grade 8 students. The chapter is intended to support interpretation of the International Computer and Information Literacy Study (ICILS) 2018 data gathered from students, teachers, and schools. The chapter begins with a discussion of the data sources used in this chapter, primarily the ICILS national contexts survey (NCS) and the information and communication technology (ICT) coordinator and school principal surveys. We then present a series of country profiles, provided by national research coordinators in each participating country. The profiles describe the overarching goals and direction for the educational system in participating countries as well as providing details about how the curriculum relating to the use of ICT in education is developed, implemented, and assessed. We then discuss the approaches to CIL and CT education in participating countries. The chapter concludes with the presentation of results related to schools' access to ICT resources and school policies and practices for using ICT.

The ICILS 2018 assessment framework stresses the importance of setting student outcomes in $\mathrm{CIL}$ and CT in the context of the factors influencing them (Fraillon et al. 2019). Consistent with ICILS 2013, the ICILS 2018 contextual framework identifies four levels that influence student outcomes in this area: contexts of the wider community, contexts of school/classroom, contexts of the student, and contexts of the home environment. The chapter examines data related to the first two of these four contexts to help address Research Question 2 for both CIL and CT: What aspects of schools and countries are related to students' achievement in CIL and CT?

Aspects of schools and education systems potentially related to students' CIL and CT are:

- $\quad$ General approaches and priorities to CIL and CT education at system and school level;

- School coordination and collaboration regarding the use of ICT in teaching;

- School and teaching practices regarding the use of technologies in students' CIL and CT;

- $\quad$ Teacher proficiency in, attitudes towards, and experience with using computers;

- ICT resources in schools; and

- $\quad$ Teacher professional development.

\section{Collecting data on contexts for CIL/CT education}

The results presented in this chapter are gathered from a variety of data sources: national research centers (primarily through responses to the ICILS 2018 NCS); the ICILS 2018 school questionnaires; and external databases including selected statistics from the International Telecommunications Union (ITU 2017) and a United Nations Human Development Programme (UNDP) report (UNDP 2016).

The 2018 version of the ICILS NCS is an extension of the instrument that was first developed for ICILS 2013. That survey in itself was influenced by two previous contextual data collections. The first major influence was the United States (US) Department of Education Technology study on international experiences with ICT in education (US Department of Education, Office of Educational Technology 2011). That particular study collected information from 21 different educational systems on aspects of ICT use for education including the provision of infrastructure, improving student learning through the use of ICT, building capacity through ICT, and using ICT to support school improvement. The report outlined an overview of practice and policy in the area in addition to providing a profile of each of the participating educational systems.

The second major influence on the ICILS 2013 NCS was the IEA Second Information Technology in Education Study (SITES; see IEA 2019). SITES involved 22 educational systems who were asked to provide detailed information on aspects of their national education system, as well as 
information on the use of ICT in education, in particular regarding teacher preparation, changes in the past five years, and system-wide policies and practice on the use of ICT (Anderson and Plomp 2008; Plomp et al. 2009).

The ICILS 2013 NCS incorporated content from both of these sources and consisted of 25 questions and 106 items. National research centers were asked to coordinate responses from experts on key antecedents and processes relevant to CIL education in their country. The questions were grouped into five sections:

(1) Education system;

(2) Plans and policies for using ICT in education;

(3) ICT and student learning at lower-secondary level;

(4) ICT and teacher development; and

(5) ICT-based learning and administrative management systems.

Data from that NCS were used extensively in the ICILS 2013 international report (Fraillon et al. 2014) to provide a context for CIL education in participating countries.

The NCS for ICILS 2018 incorporated many of the aspects included in the previous cycle of the study. We updated some content areas to reflect revised research questions. The response format of some questions was modified to reduce the reliance on subjective information and to capture information that was not clearly identified in the previous cycle. We included some new questions to capture changes to the structure of the countries' education systems or to the way in which countries have conceptualized and delivered CIL education in the years prior to the data collection. Several questions were expanded to include contextual information related specifically to CT in national plans and policies and how it was intended to be taught. The NCS for ICILS 2018 included 25 questions and 174 items allocated to the five sections that were identified in the 2013 version of the NCS.

The NCS was to be completed in 2018 (i.e., at a similar time to when other ICILS data were collected), and responses were intended to reflect policies and structures for that year. We acknowledge that policy regarding the use of technology in education is likely to evolve quite rapidly in future years, and responses to the NCS may not necessarily reflect policies at the time of the publication of this report. It is important to note that while efforts were made to make the questions as objective as possible, much of the content in the questionnaire relies on the subjective judgement of experts within each participating national research center who were encouraged to draw on their own expertise and reference information from their respective countries. Consequently, we advise readers to keep these matters at the forefront when interpreting data from this chapter.

The other main sources of data used in this chapter were the ICILS 2018 ICT coordinator and principal questionnaires. The target audiences for these questionnaires responded to a series of questions related to different types of ICT resourcing and school policies regarding the teaching and learning of ICT. These data provided a complementary perspective on the practice of ICT policies and resourcing at the school level to the information reported from policy documents at the educational system level.

In order to reduce the burden on respondents to the NCS, the chapter also reports on information from external sources including well-established databases. This includes information related to ICT infrastructure and economic characteristics of participating countries. 


\section{Education systems and national contexts}

\section{Country profiles of the responsibility for school education and the design, implementation, and assessment of ICT in education}

The ICILS 2018 NCS included a question asking respondents to indicate who in their country had overall responsibility for establishing the overarching goals and direction for school education. Other questions covered issues related to how the curriculum for the use of ICT in education was developed and implemented for target grade students and how the use of ICT in education was assessed. Each national research center was asked to expand the details from these questions to provide a broad overview of the contexts for CIL (and CT) education in their country. The summary profiles authored by each national research center are presented in this section. ${ }^{5}$ More specific details related to the use of ICT in education for each participating country and benchmarking participant are contained in the sections following this.

\section{Chile}

The Chilean educational system is governed by the National Educational Quality Assurance System. Four institutions make up this system: the Ministry of Education, the Superintendence of Education, the National Council of Education, and the National Agency for Educational Quality. The Ministry of Education is the central institution. It grants official recognition to schools, defines regulations, provides funding, offers support, defines standards of learning, and provides pedagogical training. It is also in charge of defining the national curriculum. Chile's educational system combines public, private, and private subsidized providers in all education levels. Public schools are managed by local governments (municipalities and local public education services) and receive public funding. Private schools have private administration and receive funds from families. Private subsidized schools have private administration and receive public funding.

The national curriculum determines the fundamental objectives and minimum mandatory contents for each grade and subject at a national level. Schools are free to decide how to implement it and may include additional educational objectives, content, and programs. The national curriculum includes digital literacy as an independent subject named Technology. Technology was implemented in 2012 for primary education and 2014 for secondary education. At the target grade, assessment is primarily school-based testing: it includes projects, written assignments and essays, group research, oral presentations, and classroom participation. The National Agency for Educational Quality implements the National System of Learning Assessment to measure student achievement. It is implemented annually in different subjects, although Technology was not evaluated at the time of this report (it was in 2011 and 2013).

\section{Denmark}

The Danish education system is governed by the Ministry of Education and the Ministry of Higher Education and Science. The 98 municipalities are the school owners. Education is compulsory for children from age six. For the target grade of ICILS 2018, 76 percent of the students attended public schools (folkeskoler) and the remaining 24 percent attended other schools (such as private schools or independent residential schools). The Ministry of Education develops national curriculum standards, exams, national tests, and sets regulations, but it is the responsibility of the schools and municipalities to determine how their schools are organized within the state regulations. There is no inspectorate, or similar, in Denmark.

The national curriculum contains no compulsory subjects relating to ICT. Instead, according to the standards, ICT should be integrated into all subjects. National exams, tests, and evaluations of students' learning outcomes only indirectly assess students' ICT competencies.

5 The profiles for each country were contributed by the national research coordinators of the participating countries; the authors of the report undertook only minor language editing. 
Since at least the 1990s, the government and municipalities have continuously provided funding for integration of ICT in teaching and learning. Most recently, in the years 2011-2017, they provided one billion DKK (US\$152 million) as, in part, financial support for digital learning materials. In line with the worldwide interest in CT, and in acknowledgement of students as producers and not only consumers of ICT, the Danish Ministry of Education initiated an experiment in 2018 by introducing Technological Literacy both as a subject and as material integrated in subjects. Forty-six schools are participating. The curriculum includes competencies within CT, digital design, and critical understanding of ICT. Target grade students of ICILS 2018 did not participate in this new curriculum.

\section{Finland}

The republic of Finland has organized the national education administration at two levels: state and local. At state level, the Ministry of Education and Culture is responsible for the education policy and the Finnish National Agency for Education for the implementation of the policy aims (e.g., creating the national core curriculum). At local level, municipalities are responsible for administration, such as allocation of funding and the effectiveness and quality of their education. Some decision-making power is also delegated to the schools (e.g., recruitment of personnel).

The education providers draw up their own curricula within the framework of the national core curriculum, which includes the objectives and core contents of different subjects and learning areas. Schools and teachers can decide how the use of ICT is implemented and assessed. ICT is not a separate subject: ICT competences are assessed as a part of subject based assessments (no separate grades or certificates). However, optional courses of ICT or programming are provided in grades 8 and 9 .

The target grade students in ICILS 2018 followed the old core curriculum, in place from 2004. It included cross-curricular themes called "Media skills and communication" and "Technology and the individual." These mainly covered CIL-related areas including, for example, the use of media and communication tools, information retrieval, and information security. In 2016, Finland started gradually integrating the new core curriculum, which has a strong focus on $\mathrm{CIL}$, across all subjects. For example, the stated objectives of mathematics in grades 7 to 9 explicitly reference issues of CT including logical and algorithmic thinking, and learning good programming practices.

\section{France}

The Ministry of National Education and Youth is responsible for preparing the government's national education policy and national educational curriculum. Implementation is the responsibility of the 30 educational districts (académies). The common base of competences (Socle commun de connaissances, de compétences et de culture) presents what every student must know and master at the end of compulsory schooling. In the digital domain, developing the necessary skills for ICT use is acquired in the context of activities in the various disciplinary fields. ICT is not a separate subject but instead is integrated within all other subjects. The latest curriculum implemented at the start of September 2016 includes learning computer code via algorithms and robotics in mathematics and technology.

Within the ministry, the Directorate of Evaluation, Foresight and Performance assesses and measures performance in the areas of education and training. ICT skills are assessed at the end of primary school, at the end of lower-secondary schooling with the national certificate of ICT standards (Brevet Informatique et Internet), at the end of upper-secondary schooling, and again as pupils enter higher education. 


\section{Germany}

Germany is a federal republic consisting of 16 federal states. Each federal state has supreme legislative and administrative power over all cultural policy issues including its education system. This includes regulation of school curricula and professional requirements, teacher recruitment, and quality development in schools. In lower-secondary schooling, which includes the target grade level of ICILS 2018 (grade 8), there are two to four paths of secondary education in the federal states which vary according to their respective school leaving certificates and qualifications.

Regarding ICT integration into schools, the federal regulations differ between the states. However, in recent years, the topic of digitalization in education has moved clearly into the spotlight of public interest in Germany. In this context, the Standing Conference of the Ministers of Education and Cultural Affairs (Kultusminister Konferenz) published a strategy "Education in the digital world" (Bildung in der digitalen Welt) in the year 2016. In this strategy, a competence model of ICTrelated abilities for students in primary and secondary schools, including explicit reference to the model established with ICILS 2013, is presented. This cross-federal strategy will be carried out from the school year 2018/2019, after the ICILS 2018 data collection. The implementation of these recommendations on federal state level are still in progress in each of the federal states. Furthermore, in 2016 the Federal Ministry of Education and Research announced the provision of a five billion euro budget to equip schools with ICT as part of the Digitalpakt Schule project. For this initiative, the German constitution first needed to be changed, and financing schools with federal money started in 2019.

\section{Italy}

The Ministry of Education, University and Research issues the general guidelines and policies for the public educational system. The main document establishing the objectives of digital education is the National Plan for Digital Education (Piano Nazionale Scuola Digitale), organized into 35 broad actions covering all of the areas connected to the development of ICT in public education. The curriculum is derived from two documents which provide general directives: one relevant to nursery schools and the first cycle of public education (Indicazioni nazionali per il curricolo della scuola dell'infanzia e del primo ciclo di istruzione) and the other relevant to secondary and technical education (Indicazioni nazionali per i licei e Linee guida per il biennio e il triennio). The above mentioned documents contain specific reference to actions, tools, and strategies aimed at acquiring the necessary ICT competence to complete each cycle (e.g., primary, secondary). ICT and its use in education is viewed as a transversal objective, necessary to fulfil the requirements on each subject.

Every school has the autonomy to monitor and assess students' progress in ICT, each using different tools. The Ministry has issued models for certification of competences that each school can use according to their own needs. In those models there is a specific entry for digital competences. In the first cycle of education (primary), moreover, national tests are run digitally since 2018.

\section{Kazakhstan}

Kazakhstan is administratively divided into 14 regions (provinces) and three ${ }^{6}$ cities of republican significance. Each region consists of several smaller districts. The Ministry of Education and Science is responsible for implementation of the unified education and training system with an involvement of regional and district education departments. Education curricula and assessment are standardized across the country and implemented in each region and district. Based on approved curricula, each school prepares its own working curriculum. The national school

6 On December 28, 2018, amendment to the Law of the Republic of Kazakhstan on the administrative and territorial structure took place to include the third city of republican significance. During the ICILS 2018 main survey, there were two cities (April-May 2018). 
system includes primary, lower secondary, and general (upper) secondary education levels. All of these education levels are free and guaranteed for citizens by the Constitution of the Republic of Kazakhstan. Target grade students are enrolled in a lower-secondary education level, which includes grade 5 to grade 9 .

ICT education policy started with the adoption of the State Program for the Informatization of the Secondary Education System for 1997-2002, followed by the State Program for Education Development 2011-2020 and 2016-2019. Thus, ICT is a part of the school curriculum and taught as a separate discipline. Schools administer students' general assessment against all disciplines, including ICT, every school term in accordance with the state compulsory standard. There are also state level external assessments that take place annually. In 2016, a gradual transition to an updated education program started, including the target grade levels of ICILS 2018, with emphasis on the development of students' ICT competencies and increasing teacher use of ICT.

\section{Republic of Korea}

The Korean Ministry of Education has primary responsibility for planning, operation, and management of the national curriculum for primary and secondary schools. The national curriculum standards serve as the basis for educational contents and textbook development. Korean schools follow the national curriculum framework developed by the Ministry of Education, but they can autonomously organize and operate some elective courses.

The Ministry of Education released the 2009 Revised National Curriculum to deal with Korea's continuously evolving national and social needs. Students in the target grade level of ICILS 2018 learned under the 2009 Revised National Curriculum. These students can learn CIL and CT as a separate subject, Informatics, in middle school. The Informatics curriculum focuses on understanding the basic concepts and principles of computer science and fostering the ability to solve various problems in real life with CT. However, because it is an optional subject, there are schools that teach Informatics and schools that do not. Currently, the 2015 Revised Curriculum is being introduced, and Informatics will be changed from an elective to a compulsory subject in middle school. At the target grade, student achievement levels are evaluated in most schools using various assessment tools and methods. Students are evaluated at the end of each semester by a teacher. The Korea Education and Research Information Service assessment of digital literacy monitors ICT literacy of Korean elementary and middle school students at the national level.

\section{Luxembourg}

The Ministry of Education, Children and Youth is responsible for the planning and management of school education, of structures for providing non-formal extracurricular education and care, and of a large part of the adult education provision and support schemes. Within this ministry, the Department of Coordination Service for Educational and Technological Research and Innovation offers support to all public schools in terms of pedagogical and technical innovation, coordination of school projects and initiatives, curriculum development, creation of learning resources, data analysis and evaluation of projects, and support for school development. It is the driving force behind the development of the national education system and is responsible for implementing the educational policies.

The development of ICT is included in the Luxembourg national curriculum from lower-secondary education onwards and as a separate subject for upper-secondary education. Secondary schools are strongly encouraged to use digital media for learning and tablets are used optionally by teachers in all subjects to enhance learning. For upper-secondary education, a new section specializing in ICT was introduced in 2017 addressed to students in grade 11. This initiative emerged in the context of a new label called "Future hub," which serves to highlight innovative high schools in ICT. Learning activities are project-based with a focus on learning autonomy. Emphasis is placed on the learning of sciences and ICT, creative thinking, and communication. Learning is 
placed within a chosen theme, which is cross-curricular. Examples include the construction of a robot, game programming, and the development of a website. The whole teaching and learning approach is based on collaboration between teachers and students; solutions are sought in different subjects as the project is implemented and completed. The use of ICT in education is not assessed in national assessments.

\section{Portugal}

The Portuguese Ministry of Education is responsible for establishing the overarching goals and direction for school education concerning curriculum, national assessment, funding, and schools' resources and organization. In 2017, the document "Student profile at the end of compulsory education," established the benchmark for all schools and curricula within the scope of compulsory education. This included ICT and the development of capacities associated with digital literacy. The ICT core curriculum competences are organized in four domains: digital citizenship; investigate and research; communicate and collaborate; and create and innovate. ICT is also a mandatory subject for students from grade 5 to grade 9 .

The Ministry of Education also promotes and supports several school projects in the area of ICT. The initiative "Introduction to programming in the 1st cycle of basic education" addressed to students from grades 3 and 4, between 2015 and 2018, covered about half of the Portuguese school clusters. The National Network of Programming and Robotics Clubs, launched in 2014/2015, achieved significant coverage in Portuguese schools, with 269 clubs registered in 2018/2019. Assessment for ICILS 2018 target grade students is school-based and includes written assignments and reports, group research and investigation, oral presentations, tests, and classroom participation. There are no national exams in ICT.

\section{United States}

The United States (more fully, the United States of America) consists of 50 states and the District of Columbia. There are three levels of government: federal, state, and local. Education and training are primarily the responsibility of the state and local governments (including school districts), with some decision-making occurring at the school level. Plans and policies to support ICT exist at both the federal and state levels in the United States, with each state's Department of Education responsible for setting policies and standards to guide school instruction within that state. Districts may also set their own academic standards and suggest ICT curricula for schools, such as setting technology skill standards for various grade levels. In addition, principals and teachers usually have a high level of autonomy in curriculum delivery, including selecting instructional materials, teaching techniques, and evaluation methods. There are no required CIL or CT courses at the federal or state levels. Districts and schools have the authority to offer and require ICT courses, or to incorporate ICT into other subjects.

There is no federal requirement for assessing ICT or computing-related skills at the target grade, nor do most states have a compulsory assessment focused solely on ICT at the state level. At the federal level, a sample-based, non-compulsory assessment of technology and engineering literacy has been conducted as part of the National Assessment of Educational Progress. State assessments in other subjects (e.g., engineering and science) may reflect some CIL-related aspects. US districts and schools generally have a high level of autonomy in assessment of ICT skills.

\section{Uruguay}

Uruguay is a South American republic with a population of 3.5 million. There is a national education system. The National Administration of Public Education (ANEP), an autonomous entity, is the state agency responsible for the planning, management, and administration of the public education system (including preschool, primary, secondary, vocational, and teacher education). ANEP is in charge of the public education system and also controls the private system. 
There are two government institutions that aim to ensure quality of education and access to equitable education opportunities. The first is the National Institute for Educational Evaluation, which is a fully autonomous public institution created by the General Law of Education in 2008 to evaluate the quality of national education. Every three years there is a national assessment (Aristas) of representative samples at the primary (primary grades 3 and 6) and secondary level (secondary or vocational schools at secondary grade 3). The assessments are focused on reading and mathematics, but also examine socioemotional abilities and school environment.

Plan Ceibal was created in 2007 to foster inclusion and equal opportunities in schooling and to support the implementation of Uruguayan educational policies related to technology. Since it was implemented, every child in the public education system has been given a computer or tablet device for personal use, with free internet access at school. Plan Ceibal provides programs, educational resources, and teacher training courses to support the use of ICT in teaching and learning. More recently, Plan Ceibal has become an agent for innovation in education. In this new role, it aims to promote new pedagogies for learning and competences for the twenty-first century.

\section{Moscow (Russian Federation)}

The Russian Ministry of Education (Minprosveschenie) is responsible for the development and implementation of educational policy. Regional executive authorities (including the Department of Education of Moscow) are responsible for regulating education within their jurisdiction and exercise state control over educational activities.

Target grade students of ICILS 2018 can be assessed in the subject Informatics, while ICT literacy is represented in the Russian curriculum as a general capability (a capability to be addressed through all the learning areas). The assessment of results in the Informatics subject and in ICT literacy across subjects is carried out at the school, regional, and national levels. School assessments are carried out by teachers and by the administration during the school internal monitoring. Regional assessments include subject-specific diagnostic tests on informatics and diagnostic assessment of general ICT literacy using computer-based testing. National assessments include national Informatics exams taken by students at the end of grade 9 and grade 11.

\section{North Rhine-Westphalia (Germany)}

North Rhine-Westphalia, with 18 million inhabitants, is the most populous of the 16 federal states in Germany. It has supreme legislative and administrative power over all cultural policy issues including its education system. This administrative power includes regulation of curricula and time schedules, professional requirements, teacher recruitment, and quality development in schools. Compulsory education begins at the age of six. In general, there are four paths of secondary education, which vary according to their respective school leaving certificates and qualifications. Compulsory schooling ends after completion of lower-secondary education.

North Rhine-Westphalia follows the cross-federal state strategy of the Standing Conference of the Ministers of Education and Cultural Affairs (Kultusminister Konferenz) developed in 2016, which outlined general ICT competencies. In 2017, North Rhine-Westphalia (NRW) developed the "Media Competence Framework NRW" (Medienkompetenzrahmen NRW) which targets grade 1 to grade 9/10. This was in place from June 2018 (immediately after data collection for ICILS 2018) and as such, the curricula of target grade students for ICILS 2018 did not explicitly cover ICT-related skills. In some schools and school tracks, ICT-related subjects are offered as elective subjects. Additionally, a number of schools have been developing profiles in teaching and learning with ICT in the scope of their pedagogical autonomy. 


\section{Characteristics of the education systems in participating ICILS countries}

The characteristics of school education systems for those countries participating in ICILS 2018 (Table 2.1) show that the starting age of participating countries ranged from four years in Luxembourg and Uruguay, to seven years in Finland, Kazakhstan, and Moscow (Russian Federation). Half of the countries and benchmarking participants had a starting age of six years old. The number of years of compulsory schooling across countries ranged from nine years (in Finland, Germany, and Korea) to 13 years in Chile.

The structure of school-based education also varied considerably across countries (Table 2.1). The number of years typically spent at the three levels of school education provision were classified according to the International Standard Classification of Education (ISCED) (UNESCO Institute for Statistics 2011). The ISCED 1 level loosely corresponds to primary education, the ISCED 2 level to lower-secondary education (and includes the classification of the target grade in ICILS), and the ISCED 3 level to upper-secondary education.

The way in which the first two ISCED levels were implemented varies considerably across the participating countries. Although the number of years these two levels typically apply ranges from eight to 10 years, the proportion at ISCED level 1 varies across countries. For instance, in Germany (including North Rhine-Westphalia), Kazakhstan, and Moscow (Russian Federation) the ISCED 1 programs are of shorter duration (four years) than in other participating countries, but conversely their ISCED 2 programs are longer than in most other countries (being six years for Germany, and five years in Kazakhstan and the Russian Federation). Some countries have longer ISCED 1 programs, and shorter ISCED 2 programs. In Chile, ISCED 2 programs (lower secondary) form the second stage of basic education programs. It is important to note that there is some variation in the number of compulsory years of education at different levels within countries, both across states and provinces, and potentially across educational tracks (e.g., academic or vocational).

The proportion of students who attended the ISCED 2 level (lower secondary) by school type reveals that in 12 of the 13 countries with data available, at least three out of every four students attended a public or government school (instead of a private or other non-government school). The exception is in Chile where less than half (41\%) of students at this level attended public or government schools.

\section{Level of school autonomy for aspects of school policy}

In the NCS, each country respondent was asked to indicate the degree to which schools have autonomy regarding the following aspects of school policy:

- School governance (e.g., whole financial management, setting strategic goals, implementation of the curriculum);

- $\quad$ Selection and purchase of ICT equipment;

- Selection and purchase of software;

- $\quad$ Staff participation in professional learning in the use of ICT;

- ICT curriculum delivery;

- Selection and appointment of teachers;

- Assessment of student achievement in CIL (or its equivalent); and

- $\quad$ Technical support for ICT.

Countries were asked to indicate the level of autonomy for each school type (public/government and private/non-government) (Table 2.2). For each of the eight aspects, respondents could choose between three descriptions that indicated whether schools had full or almost full autonomy, had some autonomy while educational authorities mandated some aspects, or little or no autonomy with education authorities mandated most aspects. 


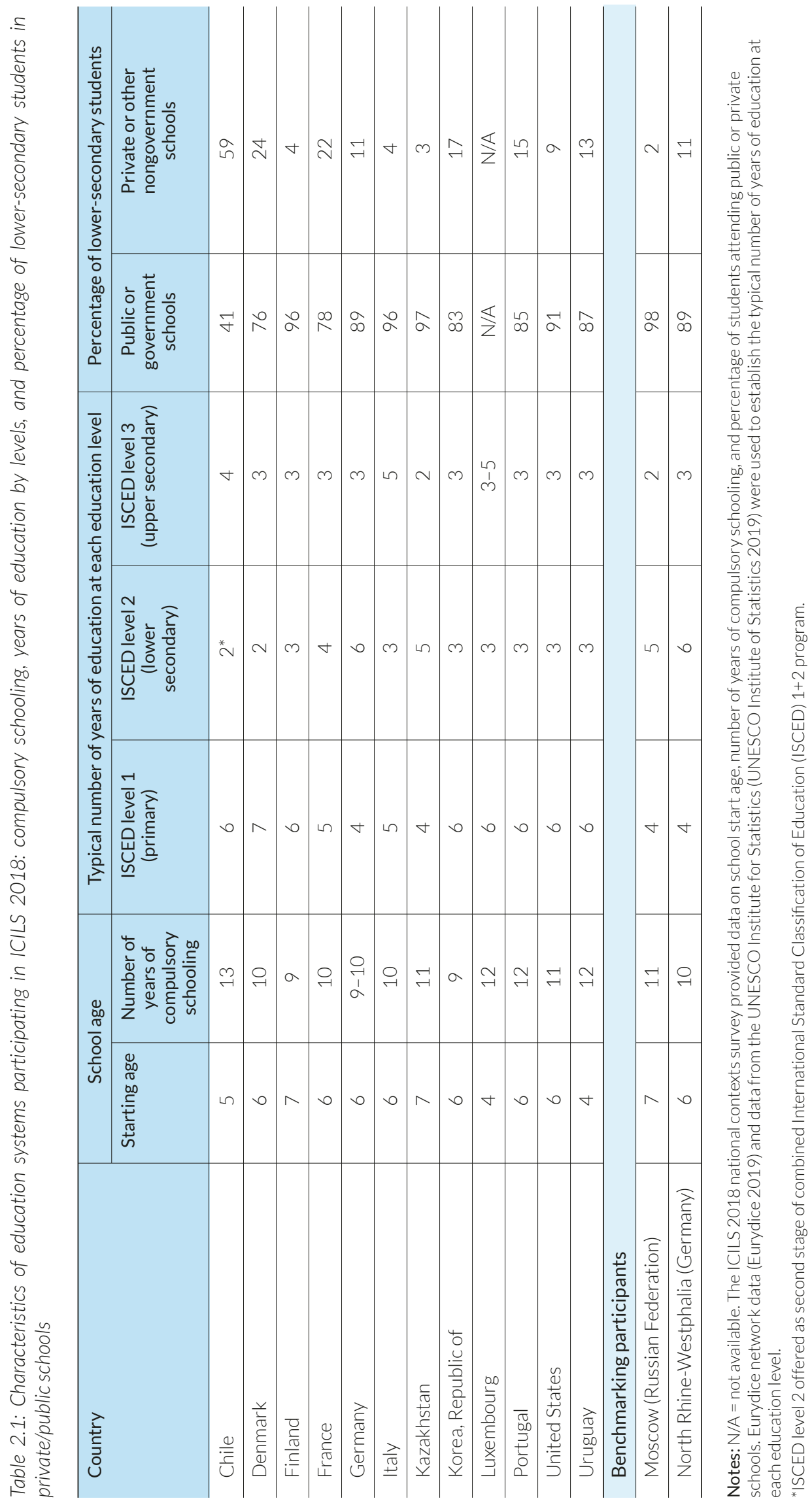



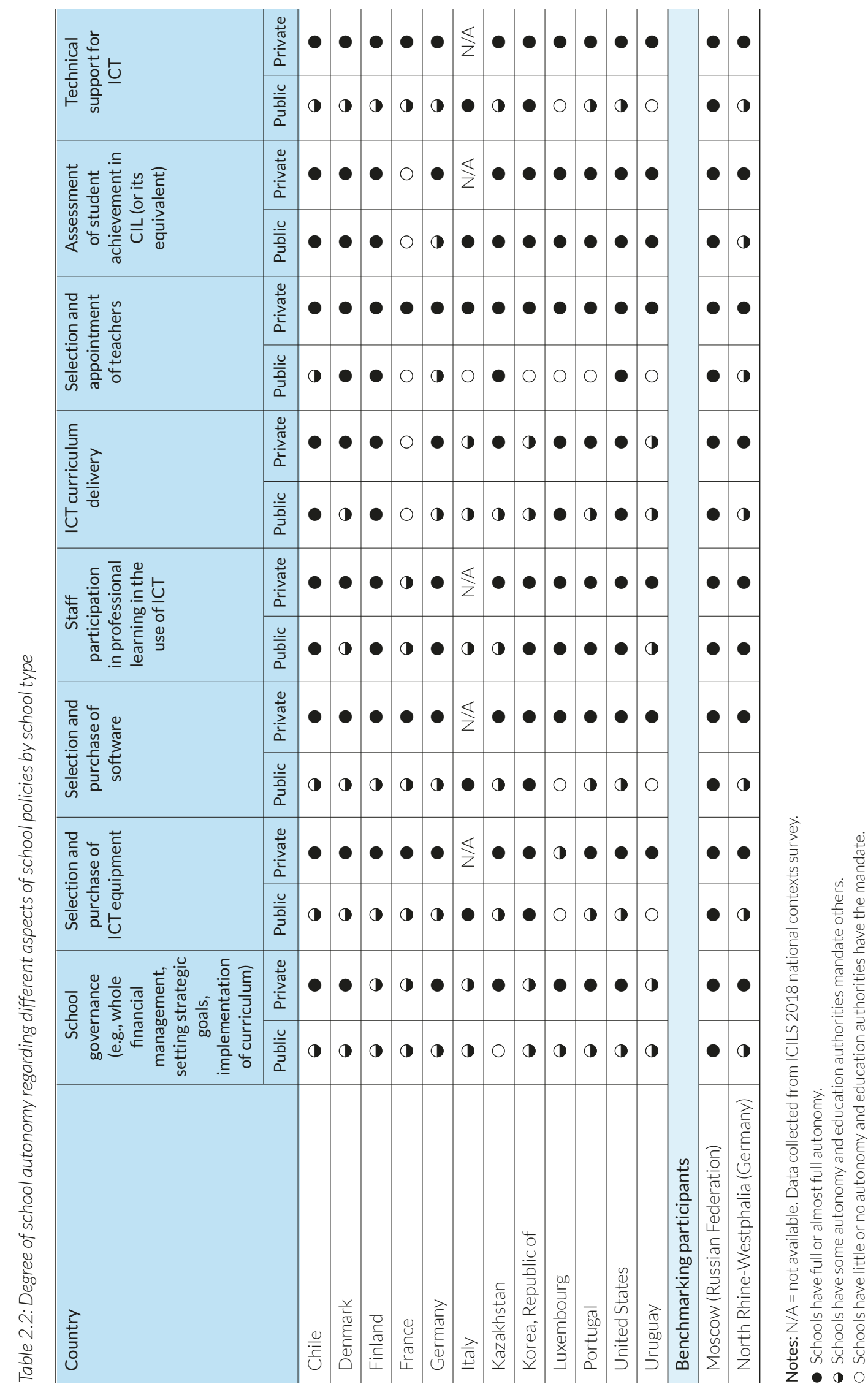
In almost all participating educational systems at the time of the NCS data collection, schools reportedly had at least some autonomy for the eight different aspects. For example, for matters that relate to school governance (including financial management, setting strategic goals, and implementation of the curriculum), public schools in 12 out of 14 educational systems were reported to have some autonomy, whereas these schools in Moscow (Russian Federation) had full autonomy. Only in Kazakhstan were schools reported to have no autonomy for these aspects of governance. As a general pattern, the level of autonomy that public and private schools were reported to have over school policies were not the same, with private schools having a greater degree of autonomy. Schools in Moscow (Russian Federation) reportedly have the greatest degree of autonomy out of all countries. Both public and private schools were reported as having full autonomy for all eight aspects.

An aspect in which schools had a greater degree of autonomy was the assessment of student achievement in CIL (11 countries reported public schools have full autonomy for this aspect). Six out of the 14 countries or benchmarking participants reported that their public schools had no autonomy over the selection and appointment of teachers, whereas all countries reported that private schools had full autonomy for this particular aspect. Similarly, public schools were reported to have no autonomy, or only some autonomy, for technical support for ICT and the selection and purchase of ICT and software in 10 of the countries or benchmarking participants, whereas all countries with data available reported that private schools had full autonomy in these aspects (the exception was Luxembourg where private schools were reported as having only some autonomy for the purchase of ICT equipment). There were relatively higher reported levels of autonomy for staff participation in professional learning in the use of ICT (in all countries the level of autonomy was rated between some and full autonomy for both public and private schools). The level of autonomy for the assessment of student achievement in CIL (or its equivalent) was similarly high, with the exception of France, where it was reported that there was no autonomy in either public or private schools for assessment. The delivery of ICT curriculum had relatively lower levels of reported autonomy in comparison to other aspects of school policies. In France, no autonomy was given to either public or private schools for this aspect.

\section{ICT infrastructure and economic characteristics of countries}

In order to provide information on antecedent aspects of national contexts for the implementation of ICT in education, we collected data relating to ICT infrastructure and economic characteristics in participating countries (Table 2.3). The ICT infrastructure data include the proportion of the population using the internet aged 16-74 in the last three months, and the ICT development index (IDI) score ${ }^{7}$ and country ranking; economic development data include the gross domestic product (GDP), income Gini coefficient, ${ }^{8}$ and the percentage of public expenditure apportioned to education (Table 2.3).

An examination of the information about infrastructure reveals diverse country profiles. The percentage of individuals using the internet provides an indicator of how widespread the ICT infrastructure is in a country. Denmark and Luxembourg had very high levels of access (more than 97\% of people aged 16-74 accessed the internet within three months). The lowest recorded level of access was in Italy (61\%). Denmark, Finland, France, Germany, Korea, Luxembourg, and the

7 The IDI is a composite index that incorporates 11 different indicators relating to ICT readiness (infrastructure, access), ICT usage (individuals using the internet), and proxy indicators of ICT skills (adult literacy, secondary and tertiary enrollment). Each country is given a score out of 10 that can be used to provide a benchmarking measure to compare ICT development levels with other countries and within countries over time. Countries are ranked according to their IDI score.

8 The Gini income coefficient is a measure of the deviation of the distribution of income (or consumption) among individuals or households within a country from a perfectly equal distribution. A value of 0 represents absolute equality. A value of 100 represents absolute inequality (see UNDP 2016). 


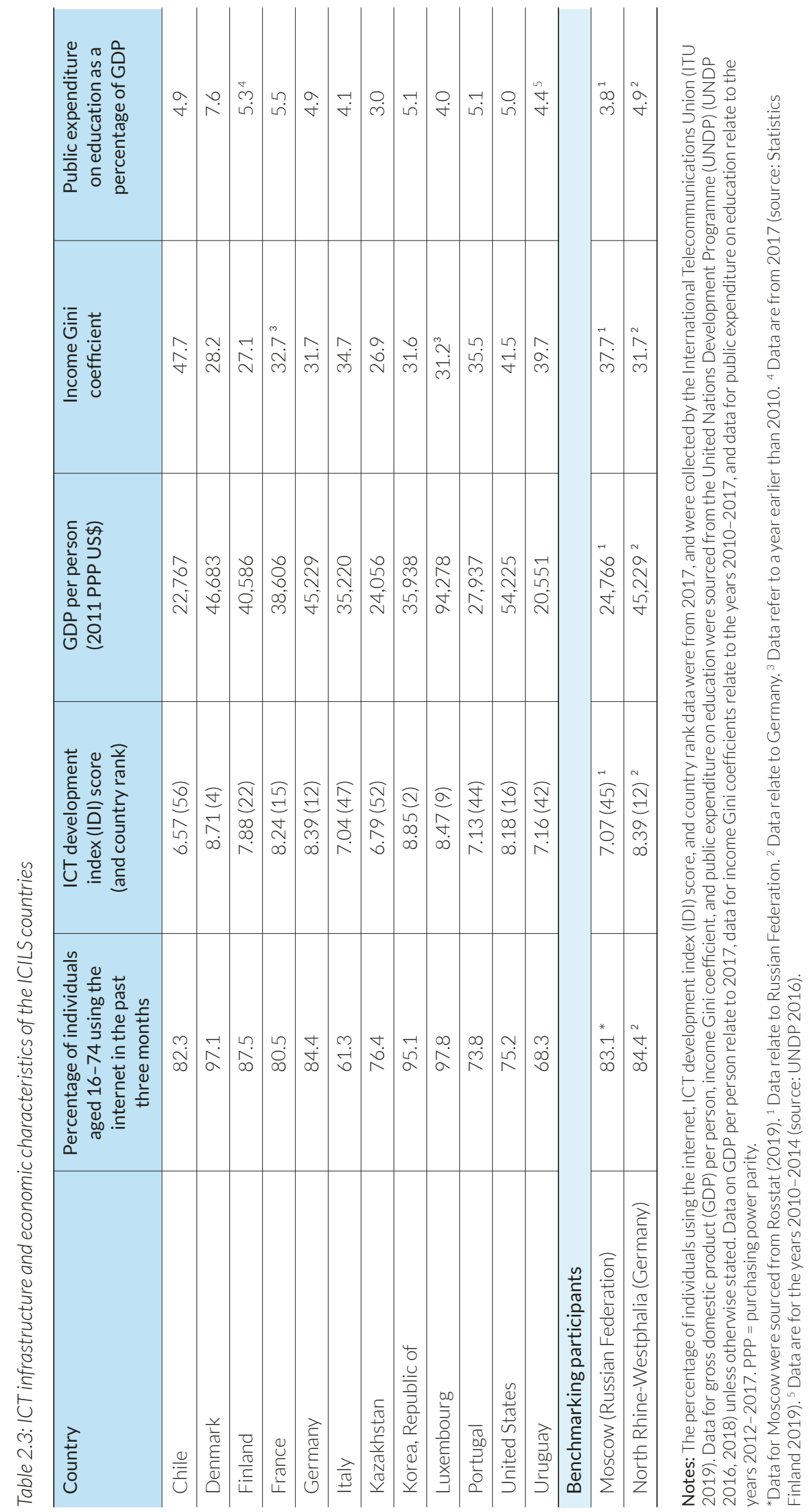


United States were all ranked in the top 22 countries on the IDI. The IDI scores for the remaining countries all ranked lower (country rankings ranged between 42 and 56). Country diversity is also evident when examining the economic characteristics of the participating countries. GDP (expressed in 2011 international dollars using purchasing power parity rates and divided by the total population during the same period) was particularly high for Luxembourg, and relatively high for Denmark, Finland, Germany (including North Rhine-Westphalia), and the United States. GDP was lower for Chile, Kazakhstan, Portugal, Uruguay, and the Russian Federation. The data on the Gini income coefficient (a measure of the variation in income across households within countries) again reinforce the different economic profiles of participating countries. Higher coefficients (representing greater levels of inequality) were found for Chile, the United States, Uruguay, and the Russian Federation. Lower coefficients (representing lower levels of inequality) can be seen in Denmark, Finland, Germany (including North Rhine-Westphalia), Kazakhstan, Korea, and Luxembourg. The level of expenditure on education (relative to the GDP) was found to be higher in Denmark (almost 8\%), and lowest in Kazakhstan (3\%), the Russian Federation (4\%), and Luxembourg (4\%).

\section{Approaches to CIL/CT education in ICILS countries}

\section{Details of plans and policies for the use of ICT in education}

In the NCS, each country was asked a series of questions related to plans or policies that support the use of ICT in education. In general there was little variation across participating countries in their descriptions of their plans and policies.

Support was found for all participating countries either by authorities at the local /district/ municipal level, at the state/provincial level, at the national level, or some combination of the three levels. Countries were asked to indicate whether the plans or policies explicitly or implicitly: emphasize different aspects improving student learning, emphasize the need for different ICT resources, emphasize different methods of supporting student learning, and include different aspects as priorities.

Most of the following seven aspects of ICT in education were largely recognized (either explicitly or implicitly) across the 14 participating countries and benchmarking participants:

- Learning of subject matter content (art, language, mathematics, science, etc.) (except in Kazakhstan and the United States);

- Preparing students for using ICT in their future work;

- Developing information literacy;

- ICT-based skills in critical thinking, collaboration, and communication;

- Increasing access to online courses of study (e.g., for rural students) (except in Denmark and Germany, including North Rhine-Westphalia);

- Computer programming or developing applications for digital devices, 10; and

- Responsible and ethical use of digital devices including cyber-safety.

The importance of all seven of the following ICT resources were recognized (explicitly or implicitly) in plans and policies of most participating countries and benchmarking participants:

- Provision of computer equipment and other ICT resources;

- Maintenance of computer equipment and other ICT resources (except in Chile and Portugal);

- Renewal, updating, and replacement of computer equipment and other ICT resources (except in Chile);

- Support for teachers for using computer equipment and other ICT resources in their work;

9 This aspect applies to a large number of German federal states.

10 The Finnish curriculum at the time of the study did not emphasize this, but this has since been updated to have an emphasis on programming. 
- Access to digital educational resources;

- Internet connectivity; and

- Home access to school-based digital education resources such as through school-hosted online portals (except in Chile, Kazakhstan, and Korea).

The plans and policies of most countries and benchmarking participants emphasized the following methods of supporting student learning (implicitly or explicitly):

- Pre-service teacher education in the use of ICT (except in Portugal);

- In-service teacher education in the use of ICT;

- The use of learning management systems (except in Finland and Germany, including North Rhine-Westphalia);

- Reporting to parents (except in Finland and Germany, including North Rhine-Westphalia); and

- Providing feedback to students (except in Finland, Germany, including North Rhine-Westphalia, and Korea).

When asked about the extent that the plans and policies emphasize priorities for the use of ICT, again there was near full agreement across participating countries that the following were explicitly or implicitly mentioned:

- Professional development for teachers' pedagogical use of ICT;

- Sufficient ICT infrastructure and resources in schools;

- Development of ICT-related competencies in students;

- Development and provision of digital learning materials;

- Reduction of the digital divide between groups of students (except in Finland and Portugal);

- Improvement of administrative and management systems in schools (except in Finland and France); and

- Use of ICT to improve communication with parents (except in Finland and the United States).

A reference to providing one-to-one computing in schools was noted in the plans and policies for Chile, Germany, Luxembourg, and Uruguay. All countries, with the exception of Kazakhstan and Portugal, had coverage of formal support for the development of digital resources in their plans and policies.

\section{Emphasis on aspects of CIL in plans and policies}

All countries were asked to complete a question on the extent to which their plans and policies for the 2018 year emphasized the following aspects of CIL in their national curricula or selected curricula (Table 2.4):

- Searching for information using ICT;

- Evaluating the reliability of information sources accessed using the internet;

- Presenting information for a given audience or purpose using ICT;

- Organizing information obtained from internet sources;

- Issues relating to intellectual property (such as copyright and attribution sources);

- Responsible and respectful publication of information;

- Use of productivity tools (such as word processing, spreadsheet, and presentation software);

- IT security issues (e.g., passwords, malware, phishing); and

- Data security (such as the collection of internet use data by search engines and social media sites). 


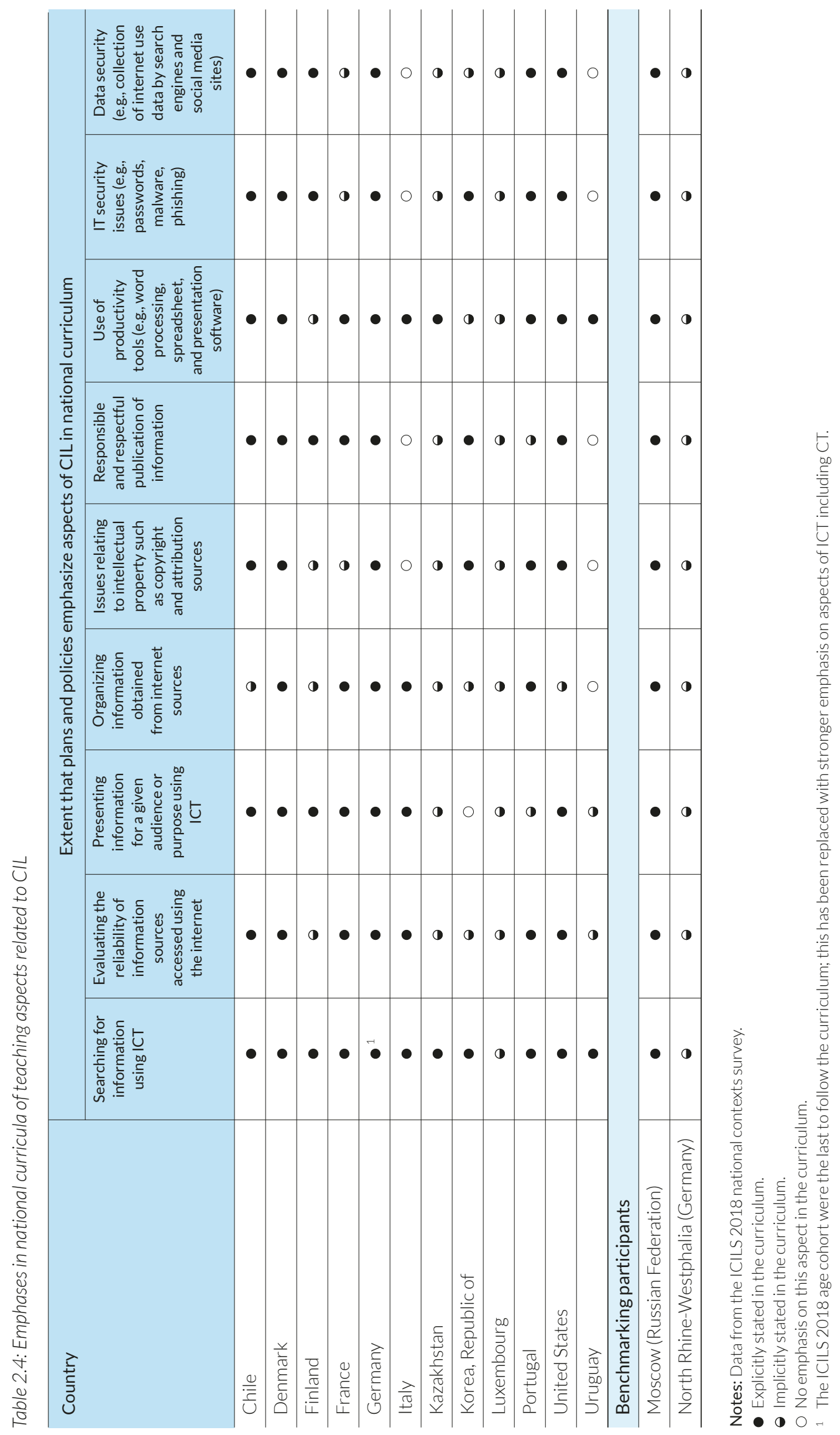


In general, each of these aspects was included in national curriculum documents, either explicitly or implicitly in 12 to 14 of the participating countries and benchmarking participants. In three entities, Denmark, Germany, and Moscow (Russian Federation), all aspects were mentioned explicitly. The aspects that were most often explicitly noted in plans and policies were the use of productivity tools (such as word processing, spreadsheet, and presentation software) (10 countries or benchmarking participants) and searching for information using ICT (12 countries or benchmarking participants). The remaining five aspects were typically included in plans or policies, but often were indicated as being implicitly stated in the curriculum.

\section{Emphasis on aspects of CT in plans and policies}

A feature of ICILS 2018 was the international option for a student test of CT. A new question for the ICILS 2018 NCS was included to assess whether national curriculum emphasized aspects of CT. All ICILS 2018 countries were asked to indicate whether their curriculum documents contained each of the following aspects:

- Planning technology-based products or solutions;

- Developing technology-based products or solutions to meet user requirements;

- Evaluating and refining technology-based products or solutions;

- Creating visual representations (e.g., flow charts and decision trees) of processes;

- Creating visual representations (e.g., flow charts and decision trees) of information/data;

- Designing user interfaces for technology-based products or solutions;

- Revising technology-based products or solutions on the basis of user feedback or other data;

- Creating algorithms;

- Writing code, programs, or macros;

- Evaluating code, programs, or macros;

- Developing digital applications (e.g., programs/apps); and

- Identifying and describing the properties of digital systems.

The extent to which CT aspects were present in curriculum documents varied across the ICILS 2018 countries (Table 2.5). Luxembourg and Uruguay did not contain any details (explicitly or implicitly) of these concepts in their curriculum documents, whereas all were contained in documents for Denmark, Korea, the United States, and Moscow (Russian Federation). The creation of visual representations (e.g., tables, graphs, or charts) of information/data and the creation of algorithms were the only aspects to be explicitly stated by the majority of ICILS 2018 participants (eight countries or benchmarking participants). Amongst the other aspects most likely indicated as being explicit parts of the curriculum were: writing code, programs, or macros (seven countries or benchmarking participants); planning technology-based products or solutions and the creation of visual representations (e.g., flow charts and decision trees) of processes (six countries or benchmarking participants). Revising technology-based products or solutions on the basis of user feedback or other data, identifying and describing the properties of digital systems, and designing user interfaces for technology-based products or solutions were the aspects that were least frequently suggested as being explicitly part of the curriculum. 


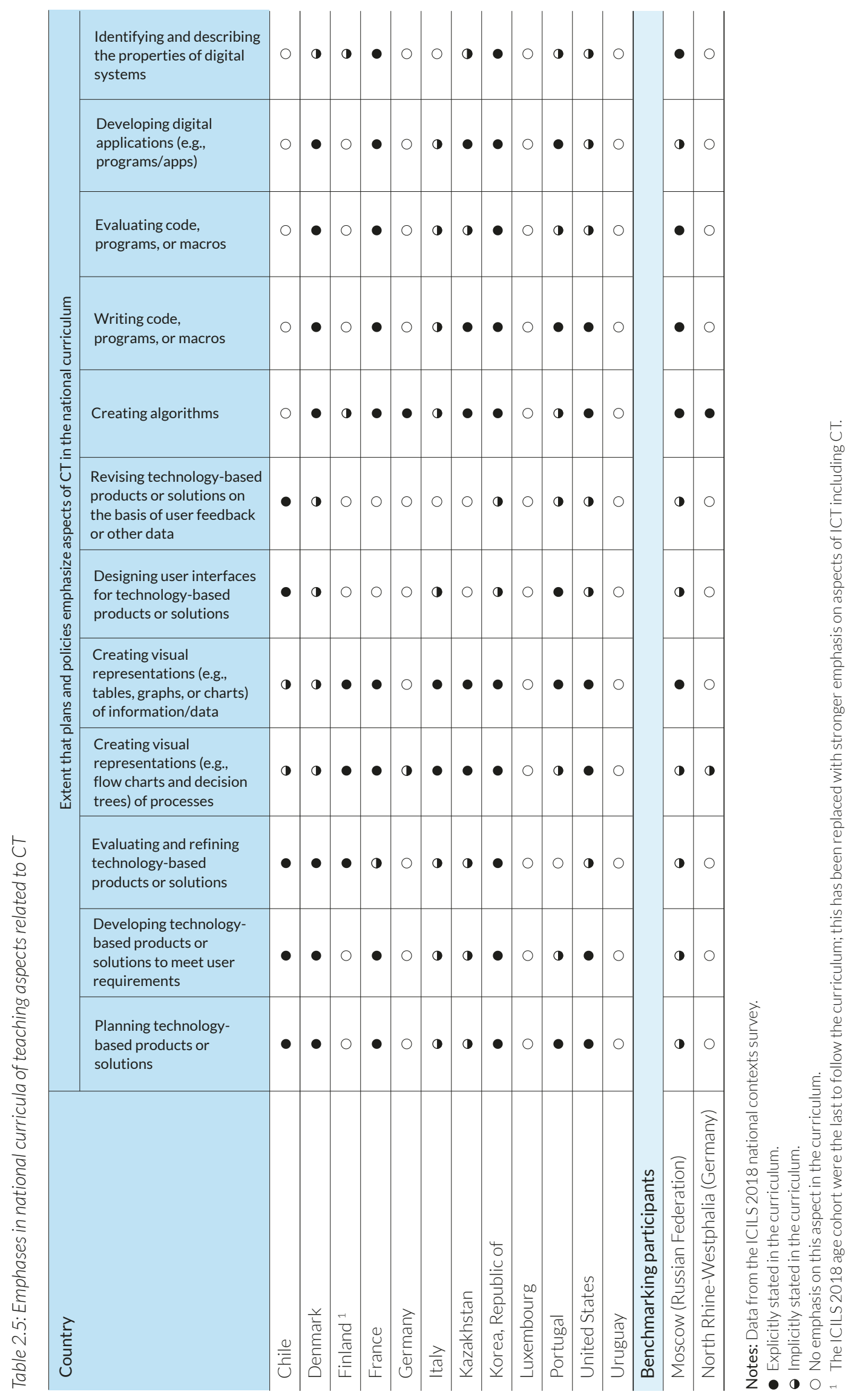




\section{School delivery and assessment of CIL-related skills}

Data from ICILS 2013 show contrasting ways in which CIL was delivered to students across countries (Fraillon et al. 2014). In ICILS 2018, each country was asked a series of questions on how CIL was delivered and assessed in their countries for the year of the data collection (Table 2.6). Firstly, respondents were asked whether CIL was included at each level as either a separate subject, whether it was integrated into science and technology studies, and/or whether it was integrated into other subjects. For each of these options they were asked to indicate whether the subject was compulsory or non-compulsory. At the primary level, it was rare for countries to have a separate subject: in Chile there was a compulsory subject, in Finland schools can choose themselves if they have short compulsory or non-compulsory courses for ICT, whereas the United States had a non-compulsory subject at this level. The remaining educational systems (with the exception of Kazakhstan and North Rhine-Westphalia, Germany), had CIL skills integrated into science and technology studies or integrated into other subjects (noting that in many countries this was a non-compulsory study). In eight countries or benchmarking participants, at the primary level CIL was delivered in two or three different ways (either as a separate subject or as part of another subject).

CIL was delivered as part of a compulsory separate subject in five different countries or benchmarking participants at the ISCED 1 level, and in six at the ISCED 2 level. All countries had some sort of CIL offered at the lower- and upper-secondary levels, via a separate subject or integrated into other studies. The exceptions to this were in North Rhine-Westphalia (Germany) and Uruguay (both at the upper-secondary level). When CIL was integrated into other subjects (e.g., science and technology studies), the subjects tended to be non-compulsory. In nine of the ICILS 2018 countries or benchmarking participants, a separate subject of CIL also included coding and applications data, although this was sometimes defined at the school, district, or state level. In Uruguay the inclusion of coding and applications data is at the discretion of the teachers.

All country respondents were also asked questions about their policies regarding the assessment of ICT. Each country had to indicate whether there was a requirement at school level regarding mandated assessment of ICT and computing skills of target grade students. Only France, Italy, Kazakhstan, Korea, Portugal, and Moscow (Russian Federation) had such policies. Respondents were also asked whether there were different types of ICT student assessments used or supported by ministries or departments of education, including diagnostic assessments, formative assessments, summative assessments, and national or state/provincial monitoring programs. Representatives from Denmark, Finland, the United States, Uruguay, and Moscow (Russian Federation) reported that all four types of assessment/monitoring were implemented in their countries. France, Italy, Kazakhstan, Korea, and Luxembourg all used between one and three of these types of assessments in their countries.

\section{Teacher support and requirements for using ICT}

Using previous research as a guide, the ICILS 2018 assessment framework highlights the importance of collecting process-related information at the system level for the development of teacher expertise in ICT-related teaching and learning (Fraillon et al. 2019; Charalambos and Glass 2007; Law et al. 2008; Scherer and Siddiq 2015). Data from ICILS 2013 confirm that teachers were using ICT extensively for teaching and learning (Fraillon et al. 2014). In the NCS, all participating countries were asked about the support and requirements for developing teachers' capacity in the following aspects of ICT for the year of the data collection (Table 2.7):

- Technical capacity in using ICT;

- Using ICT in pedagogy;

- Collaboration and communication in using ICT; and

- Using ICT for student assessment. 


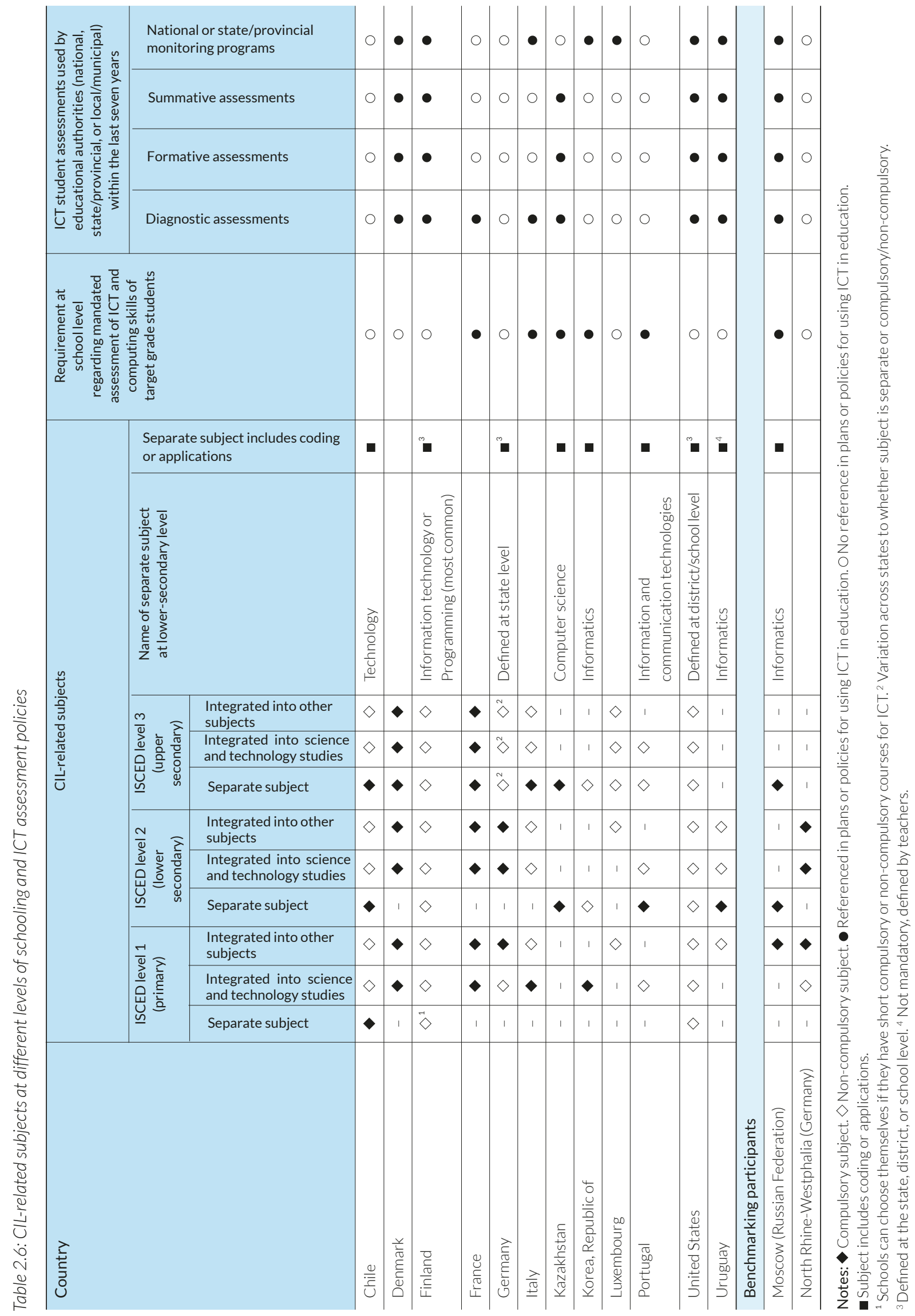


For each aspect, respondents were asked to indicate whether learning is a mandatory component of pre-service education, whether it was a requirement for being a teacher, and also whether participation in some form of professional learning program was required for teachers. The responses present a different profile across participating countries and benchmarking participants in the way in which teachers' capacity to use ICT is mandated. In Finland, Germany (including North Rhine-Westphalia), Kazakhstan, Korea, and Portugal, there are no requirements for any of these aspects to be learned by teachers. In Denmark, France, and Moscow (Russian Federation), those aspects that are required, are a mandatory component of pre-service education. In Chile, Luxembourg, the United States, and Uruguay, there were requirements for participation in some form of professional learning program. Only in Italy and the United States were teachers' capacities in any of these areas a registration requirement. In both the United States and Moscow (Russian Federation), these aspects were all both a mandatory part of pre-service education and teachers were required to obtain some form of professional learning in this area.

\section{Support for ICT-based professional development}

The NCS also asked about the level of support and teacher access to participation in ICT-based professional development. Respondents were asked to judge whether any of the following aspects were supported by funding teacher participation in programs, by providing resources for teachers to access, or by providing relieving teachers to allow regular teachers to attend programs (Table 2.8):

- To improve ICT/technical skills;

- To improve content knowledge with respect to CIL;

- To improve teaching skills with respect to CIL-related content;

- To develop digital teaching and learning resources;

- To integrate ICT in teaching and learning activities; and

- To improve skills in computer programming or developing applications for digital devices.

All aspects were supported in various ways across all countries (the exception is improving skills in computer programming or developing applications for digital devices in Kazakhstan and Portugal). Support was more likely to be provided by funding teacher participation in programs and by providing resources for teachers to access, in comparison to providing relieving teachers to allow regular teachers to attend programs, which occurred less frequently across countries. There was little variation within countries over the types of supports provided across the different aspects. Most countries used a combination of support for each aspect. In Denmark, Finland, Korea, and Luxembourg, all three types of support were provided for each of the six aspects. In Germany, support was offered by providing resources for each of the aspects for teachers to access (support in North Rhine-Westphalia was provided for all except to improve ICT/technical skills), whereas in Kazakhstan this was most likely in the form of funding teacher participation in programs.

\section{Schools' access to ICT resources}

Previous findings from cross-national surveys, including ICILS 2013, show differences in the provision of ICT resources in schools across countries (Anderson and Ainley 2010; Fraillon et al. 2014; Pelgrum and Doornekamp 2009). School ICT coordinators were asked to identify whether a range of specified technology and software resources are available in their school, and whether these were available to only students, only teachers, or both students and teachers. 
Table 2.7: Requirements for developing teachers' capacity to use ICT

\begin{tabular}{|c|c|c|c|c|c|c|c|c|c|}
\hline \multirow{2}{*}{$\begin{array}{l}\text { Country } \\
\text { Chile }\end{array}$} & \multicolumn{3}{|c|}{$\begin{array}{l}\text { Technical capacity } \\
\text { in using ICT }\end{array}$} & \multicolumn{2}{|c|}{$\begin{array}{l}\text { Using ICT in } \\
\text { pedagogy }\end{array}$} & \multirow{2}{*}{\multicolumn{2}{|c|}{$\begin{array}{c}\text { Collaboration and } \\
\text { communication } \\
\text { in using ICT } \\
\diamond\end{array}$}} & \multicolumn{2}{|c|}{$\begin{array}{c}\text { Using ICT for } \\
\text { student } \\
\text { assessment }\end{array}$} \\
\hline & & & $\diamond$ & $\bullet$ & $\diamond$ & & & & $\diamond$ \\
\hline Denmark & \multicolumn{3}{|l|}{ • } & \multicolumn{2}{|l|}{$\bullet$} & \multicolumn{2}{|l|}{$\bullet$} & \multicolumn{2}{|c|}{-} \\
\hline Finland & \multicolumn{3}{|c|}{-} & \multicolumn{2}{|c|}{-} & \multicolumn{2}{|c|}{-} & \multicolumn{2}{|c|}{-} \\
\hline France & \multicolumn{3}{|l|}{$\bullet$} & \multicolumn{2}{|l|}{$\bullet$} & \multicolumn{2}{|l|}{$\bullet$} & \multicolumn{2}{|l|}{$\bullet$} \\
\hline Germany & \multicolumn{3}{|c|}{-} & \multicolumn{2}{|c|}{-} & \multicolumn{2}{|c|}{-} & \multicolumn{2}{|c|}{-} \\
\hline Italy & \multicolumn{3}{|c|}{$\Delta$} & \multicolumn{2}{|r|}{$\diamond$} & \multicolumn{2}{|r|}{$\diamond$} & \multicolumn{2}{|c|}{-} \\
\hline Kazakhstan & \multicolumn{3}{|c|}{-} & \multicolumn{2}{|c|}{-} & \multicolumn{2}{|c|}{-} & \multicolumn{2}{|c|}{-} \\
\hline Korea, Republic of & \multicolumn{3}{|c|}{-} & \multicolumn{2}{|c|}{-} & \multicolumn{2}{|c|}{-} & \multicolumn{2}{|c|}{-} \\
\hline Luxembourg & & & $\diamond$ & & $\diamond$ & & $\diamond$ & & $\diamond$ \\
\hline Portugal & \multicolumn{3}{|c|}{-} & \multicolumn{2}{|c|}{-} & \multicolumn{2}{|c|}{-} & & \\
\hline United States & $\bullet$ & $\boldsymbol{\Delta}$ & $\diamond$ & & $\diamond$ & $\bullet$ & $\diamond$ & $\bullet$ & $\diamond$ \\
\hline Uruguay & & - & & & $\diamond$ & & $\diamond$ & & $\diamond$ \\
\hline Benchmarking participants & & & & & & & & & \\
\hline Moscow (Russian Federation) & $\bullet$ & & $\diamond$ & $\bullet$ & $\diamond$ & $\bullet$ & $\diamond$ & $\bullet$ & $\diamond$ \\
\hline North Rhine-Westphalia (Germany) & & - & & & & & & & \\
\hline
\end{tabular}

Note: Data from the ICILS 2018 national contexts survey.

- Mandatory component of pre-service teacher education.

- Requirement for registration as a teacher.

$\diamond$ Participation in some form of professional learning program in this area required for teachers.

\section{Access to technology-based resources}

ICT coordinator responses on whether different technology resources were available in schools for both teachers and students were recorded (Table 2.9). Access to the internet through the school network was largely available to both groups in all participating countries, on average almost 90 percent across countries (relatively low availability of $66 \%$ was reported for Italy). Digital learning resources that can only be used online were also commonly available to both teachers and students, on average 86 percent of students attended schools with this resource available. On average, approximately two thirds of students across countries attended schools where digital learning resources could be accessed offline and an educational site or network maintained by education authorities was available to both teachers and students. Some country variation was evident for both types of resources, particularly for the latter with a low of 29 percent of students from Italy attending schools with these resources available, compared with a high of 94 percent of students from Moscow (Russian Federation). Email accounts for school-related use was the least common technology resource available for both students and teachers across countries (on average 55\%), although it appears that these are relatively commonplace in some countries (more than 90\% availability in Denmark, Finland, and Luxembourg), but relatively scarce in others (21\% availability in North Rhine-Westphalia, Germany). It is worth noting that in a large proportion of schools cross-nationally, email was made available only for teachers. 


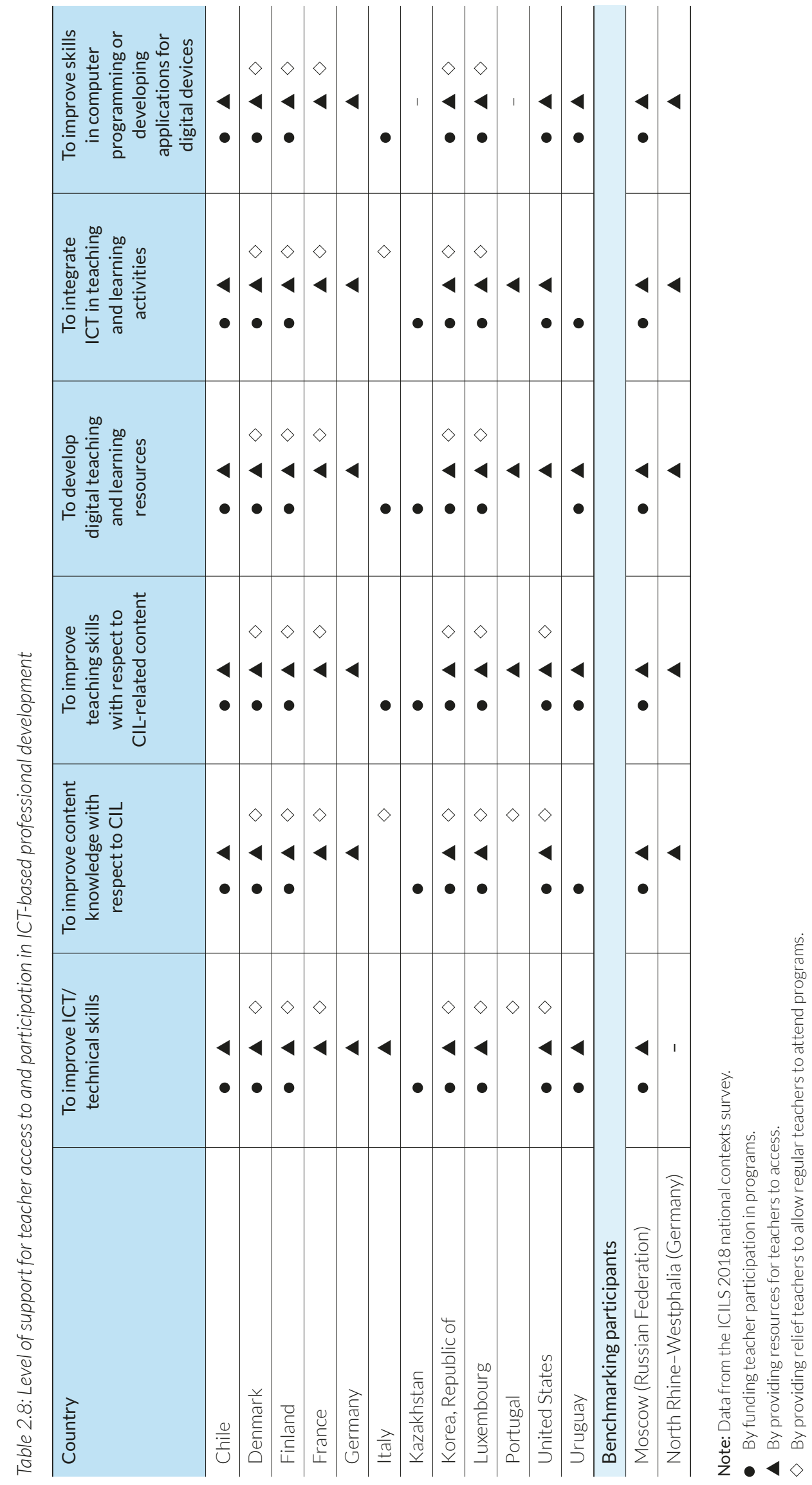


Table 2.9: School reports on technology-related resources for both teaching and learning

\begin{tabular}{|c|c|c|c|c|c|c|c|c|c|c|c|}
\hline \multirow{3}{*}{$\begin{array}{l}\text { Country } \\
\text { Chile }\end{array}$} & \multicolumn{11}{|c|}{ Percentages of students at schools where technology-related resources are available for both teaching and learning } \\
\hline & \multicolumn{2}{|c|}{$\begin{array}{l}\text { Digital learning } \\
\text { resources that } \\
\text { can be } \\
\text { accessed offline }\end{array}$} & \multicolumn{2}{|c|}{$\begin{array}{l}\text { Digital learning } \\
\text { resources that } \\
\text { can only be } \\
\text { used online }\end{array}$} & \multicolumn{3}{|c|}{$\begin{array}{l}\text { Access to the } \\
\text { internet through } \\
\text { the school } \\
\text { network }\end{array}$} & \multicolumn{2}{|c|}{$\begin{array}{l}\text { Access to an education } \\
\text { site or network } \\
\text { maintained by } \\
\text { education authorities }\end{array}$} & \multicolumn{2}{|c|}{$\begin{array}{l}\text { Email accounts } \\
\text { for school- } \\
\text { related use }\end{array}$} \\
\hline & 75 (3.7) & $\triangle$ & $87(3.0)$ & & 85 & (3.9) & & $60(3.2)$ & $\nabla$ & $32(6.2)$ & $\nabla$ \\
\hline Denmark $^{\dagger 1}$ & 68 (4.6) & & $99(0.6)$ & $\Delta$ & 100 & $(0.0)$ & $\Delta$ & 87 (3.3) & $\Delta$ & $91(2.8)$ & $\Delta$ \\
\hline Finland & $46 \quad(4.9)$ & $\nabla$ & $94(2.3)$ & $\triangle$ & 99 & (1.3) & $\triangle$ & $66(4.5)$ & & $93(2.2)$ & $\boldsymbol{\Delta}$ \\
\hline France & 78 (4.1) & $\triangle$ & 85 (3.3) & & 100 & $(0.0)$ & $\Delta$ & $79(3.5)$ & $\Delta$ & $73(4.2)$ & $\Delta$ \\
\hline Germany & 64 (3.9) & & $73(4.3)$ & $\nabla$ & 91 & $(2.6)$ & & $50(4.1)$ & $\nabla$ & $30(4.2)$ & $\nabla$ \\
\hline Italy ${ }^{2}$ & 72 (3.7) & & $75(4.0)$ & $\nabla$ & 66 & $(4.5)$ & $\nabla$ & $29(3.8)$ & $\nabla$ & $38(4.2)$ & $\nabla$ \\
\hline Kazakhstan $^{1}$ & 65 (3.8) & & $77(3.8)$ & $\nabla$ & 80 & (3.5) & $\nabla$ & $63(4.1)$ & & $42(4.6)$ & $\boldsymbol{\nabla}$ \\
\hline Korea, Republic of & $78 \quad(3.4)$ & $\triangle$ & 87 (3.2) & & 82 & (3.8) & $\nabla$ & 77 (4.0) & $\triangle$ & $33(4.1)$ & $\nabla$ \\
\hline Luxembourg & $61(0.0)$ & $\nabla$ & $100(0.0)$ & $\Delta$ & 100 & $(0.0)$ & $\Delta$ & $87 \quad(0.0)$ & $\Delta$ & $99(0.0)$ & $\Delta$ \\
\hline Portugal ${ }^{1+1}$ & 69 (3.4) & & $83(2.7)$ & & 93 & $(2.0)$ & & 67 (3.4) & & $35(3.4)$ & $\boldsymbol{\nabla}$ \\
\hline Uruguay & 74 (4.1) & & $86(3.6)$ & & 86 & (3.9) & & 87 (3.3) & $\Delta$ & $40(5.4)$ & $\boldsymbol{\nabla}$ \\
\hline ICILS 2018 average & $68(1.1)$ & & $86(0.9)$ & & 89 & $(0.9)$ & & $68(1.1)$ & & $55(1.2)$ & \\
\hline \multicolumn{12}{|c|}{ Not meeting sample participation requirements } \\
\hline United States & 74 (3.3) & & $95(1.9)$ & & 99 & $(0.5)$ & & $93(1.6)$ & & $84(2.7)$ & \\
\hline \multicolumn{12}{|c|}{ Benchmarking participants meeting sample participation requirements } \\
\hline Moscow (Russian Federation) & $83(3.1)$ & $\Delta$ & $98(0.9)$ & $\Delta$ & 92 & (2.6) & & $94(2.0)$ & $\boldsymbol{\Delta}$ & $53(4.7)$ & \\
\hline North Rhine-Westphalia (Germany) & $60(4.5)$ & & $69(4.4)$ & $\boldsymbol{\nabla}$ & 86 & (3.7) & & $40(4.4)$ & $\boldsymbol{\nabla}$ & $21(4.5)$ & $\boldsymbol{\nabla}$ \\
\hline
\end{tabular}

Notes: Standard errors appear in parentheses. Because results are rounded to the nearest whole number, some totals may appear inconsistent. Comparisons with ICILS 2018 only reported for countries or benchmarking participants meeting sample participation requirements.

† Met guidelines for sampling participation rates only after replacement schools were included.

t† Nearly met guidelines for sampling participation rates after replacement schools were included.

1 National defined population covers $90 \%$ to $95 \%$ of the national target population.

2 Country surveyed target grade in the first half of the school year.

\section{Access to software resources}

ICT coordinators were also asked about the availability of software resources for both students and teachers (Table 2.10). Word and presentation software were almost universally available to both groups (98\% on average across countries for both types of software). High levels of availability (in terms of students attending schools with resources available to both students and teachers) were also found for:

- Video and photo software for capturing and editing (85\% on average, with national percentages ranging from 66\% in Italy to $96 \%$ in Finland);

- Graphic or drawing software (76\% on average, with national percentages ranging from 48\% in Italy to $97 \%$ in Finland);

- Digital contents linked with textbooks (70\% on average, with national percentages ranging from $37 \%$ in North Rhine-Westphalia, Germany, to $90 \%$ in Italy and Moscow, Russian Federation);

- A learning management system (66\% on average, with national percentages ranging from 25\% in Chile to 97\% in Finland and 90\% in Uruguay);

- Practice programs or apps where teachers decide which questions are asked of students (60\% on average, with national percentages ranging from 23\% in Chile to 98\% in Denmark); 
- Social media (59\% on average, with national percentages ranging from 22\% in France to $84 \%$ in Denmark); and

- Single user digital learning games (54\% on average, with national percentages ranging from $27 \%$ in North Rhine-Westphalia, Germany, to $80 \%$ in Finland).

The following software resources were available to an average of half of ICILS 2018 students or less (in terms of school availability for both teachers and students):

- Concept-mapping software (50\% on average, with national percentages ranging from 25\% in Portugal to $76 \%$ in Denmark);

- Simulations and modeling software (42\% on average, with national percentages ranging from $8 \%$ in Italy to 91\% in Finland and North Rhine-Westphalia, Germany);

- E-portfolios (39\% on average, with national percentages ranging from 3\% in Germany to 85\% in Uruguay):

- Multi-user digital learning games with graphics and enquiry tasks (29\% on average, with national percentages ranging from $4 \%$ in North Rhine-Westphalia, Germany, to $51 \%$ in Finland); and

- Data logging and monitoring tools (22\% on average, with national percentages ranging from $3 \%$ in Italy to $46 \%$ in Denmark).

\section{Access to technology facilities}

ICT coordinators were further asked about technology facilities available in their school for the teaching and learning of the target grade students. Again, they were asked to indicate whether each facility was available either only for students or only for teachers, or for both groups. Summary percentages of the proportion of respondents who indicated that both students and teachers had access to the facilities (Table 2.11) suggest that access to a wireless local area network (LAN or wifi) and the use of a learning management system were relatively common (an average of $65 \%$ of students attended schools where these technologies were reported as being available to both students and teachers). As with the software resources, there was considerable variability: access to wifi was reported as being nearly universally available in Denmark, whereas less than one fifth of students attended schools in North Rhine-Westphalia (Germany) where this was available for both students and teachers. Internet-based applications for collaborative work and space on a school network to store files were also more commonly reported (63\% and $58 \%$ on average respectively across countries). Both resources also had considerably high discrepancies: availability of the former ranged from 97 percent in Finland and Denmark to 13 percent in North Rhine-Westphalia (Germany), while availability of the latter ranged from 97 percent in Luxembourg to 19 percent in Korea. Robots or robotic devices (average 46\%), a school intranet with applications and workplaces (average 46\%), remote access to a school network (39\%), and a 3D printer (27\%), were available to both target grade students and teachers less than half the time. 


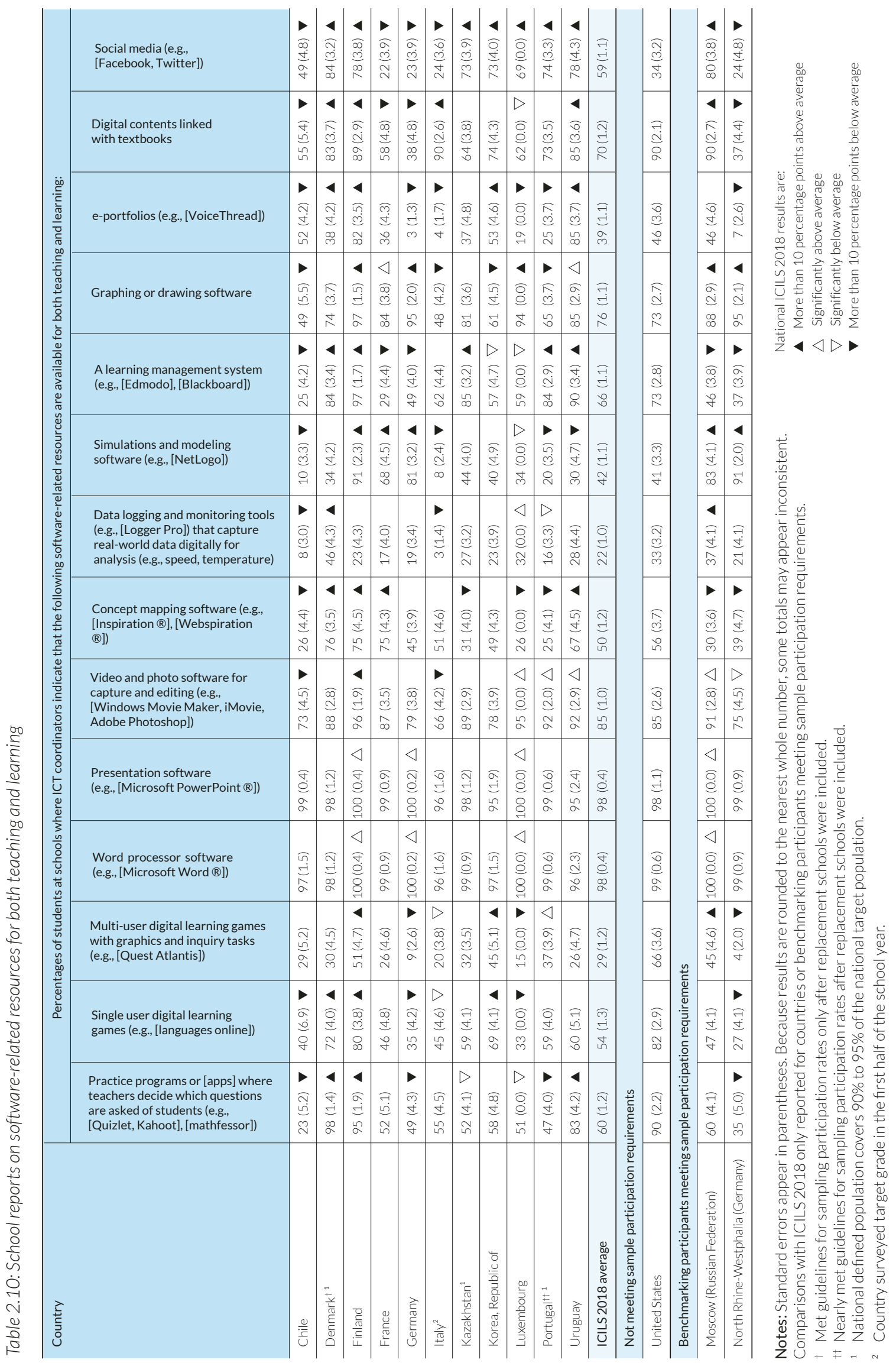




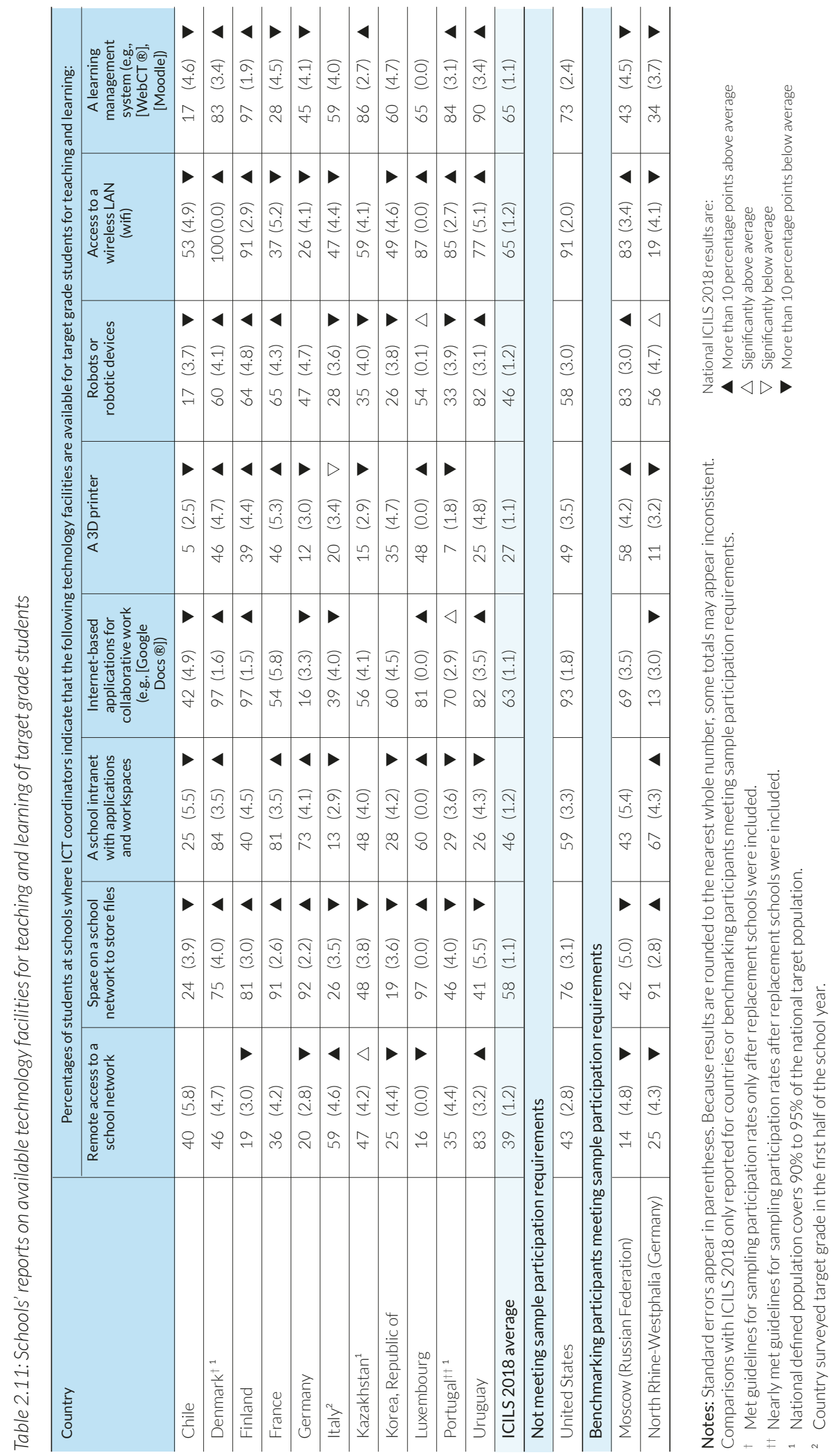




\section{Availability of ICT devices for students}

ICT coordinators at the participating schools were asked to provide information about the number of ICT devices that were available to students, while school principals reported the number of students enrolled at their school. We used these data to compute ratios of the number of students per device (Table 2.12). Lower ratios indicate a better-resourced school whereas higher ratios indicate a school with less access to digital technologies.

Denmark, Finland, France, and Luxembourg were better resourced countries in terms of the ratio of digital devices per student, these countries all had seven students per device or fewer. The remaining countries had ratios ranging between 10 and 22 students per device. In most countries there was a higher ratio in urban areas in comparison to rural areas, although this difference was only significant at the country level for Korea and Luxembourg.

Table 2.12: National ratios for number of students to number of ICT devices in school by school location

\begin{tabular}{|c|c|c|c|c|c|c|c|c|}
\hline \multirow{3}{*}{$\begin{array}{l}\text { Country } \\
\text { Chile }\end{array}$} & \multirow{2}{*}{\multicolumn{2}{|c|}{ All students }} & \multicolumn{4}{|c|}{ By school location } & \multirow{2}{*}{\multicolumn{2}{|c|}{$\begin{array}{c}\text { Difference } \\
\text { (urban - rural) }\end{array}$}} \\
\hline & & & \multicolumn{2}{|c|}{ Urban } & \multicolumn{2}{|c|}{ Rural } & & \\
\hline & 18 & (2.6) & 20 & (3.3) & 14 & (2.4) & 6 & $(3.7)$ \\
\hline Denmark $^{+1}$ & 5 & $(1.2)$ & 7 & $(2.7)$ & 3 & $(0.7)$ & 4 & $(2.8)$ \\
\hline Finland & 3 & $(0.3)$ & 3 & $(0.3)$ & 4 & (1.5) & -1 & $(1.5)$ \\
\hline France & 7 & $(0.9)$ & 8 & (1.9) & 6 & (0.8) & 2 & $(2.0)$ \\
\hline Germany & 10 & $(0.6)$ & 10 & $(0.7)$ & 8 & $(0.9)$ & 2 & $(1.2)$ \\
\hline Italy ${ }^{2}$ & 14 & $(1.7)$ & 14 & $(2.2)$ & 14 & $(2.5)$ & 0 & (3.3) \\
\hline Kazakhstan $^{1}$ & 22 & (1.2) & 24 & (1.9) & 20 & (2.0) & 4 & (3.2) \\
\hline Korea, Republic of & 14 & $(0.8)$ & 14 & $(0.8)$ & 7 & $(0.9)$ & 7 & $(1.2)$ \\
\hline Luxembourg & 5 & $(0.0)$ & 6 & $(0.0)$ & 3 & $(0.0)$ & 3 & $(0.0)$ \\
\hline Portugal ${ }^{+1}$ & 17 & $(1.7)$ & 19 & (3.1) & 15 & (1.5) & 4 & (3.4) \\
\hline ICILS 2018 average & 11 & $(0.4)$ & 13 & $(0.6)$ & 9 & $(0.5)$ & 3 & (0.8) \\
\hline \multicolumn{9}{|c|}{ Not meeting sample participation requirements } \\
\hline United States & 2 & $(0.1)$ & 2 & $(0.1)$ & 1 & $(0.1)$ & 1 & $(0.1)$ \\
\hline \multicolumn{9}{|c|}{ Benchmarking participants meeting sample participation requirements } \\
\hline Moscow (Russian Federation) & 13 & $(0.7)$ & 13 & $(0.7)$ & & & & \\
\hline North Rhine-Westphalia (Germany) & 13 & (1.0) & 13 & $(1.1)$ & 10 & (1.9) & 3 & $(2.2)$ \\
\hline
\end{tabular}

Notes: Data were not available for Uruguay. Standard errors appear in parentheses. Because results are rounded to the nearest whole number, some totals may appear inconsistent. Statistically significant $(p<0.05)$ differences are shown in bold.

† Met guidelines for sampling participation rates only after replacement schools were included.

t+ Nearly met guidelines for sampling participation rates after replacement schools were included.

National defined population covers $90 \%$ to $95 \%$ of the national target population.

Country surveyed target grade in the first half of the school year.

\section{School location of ICT devices and student access to portable devices}

The ICT coordinator questionnaire included questions on where school ICT devices were located at schools for the teaching and learning of target grade students, and on the proportion of students who have portable computers under different policies (Table 2.13). In all countries (except Denmark), the most common location of ICT devices for students of this grade was in computer laboratories (only a quarter of Danish students attended schools where computers were available in such a location). The school library was the only other location that had devices available for more than half of students (on average across countries), although this was much more common in some countries (France, Luxembourg, and Portugal in particular). In Finland (83\%), Luxembourg (65\%), 


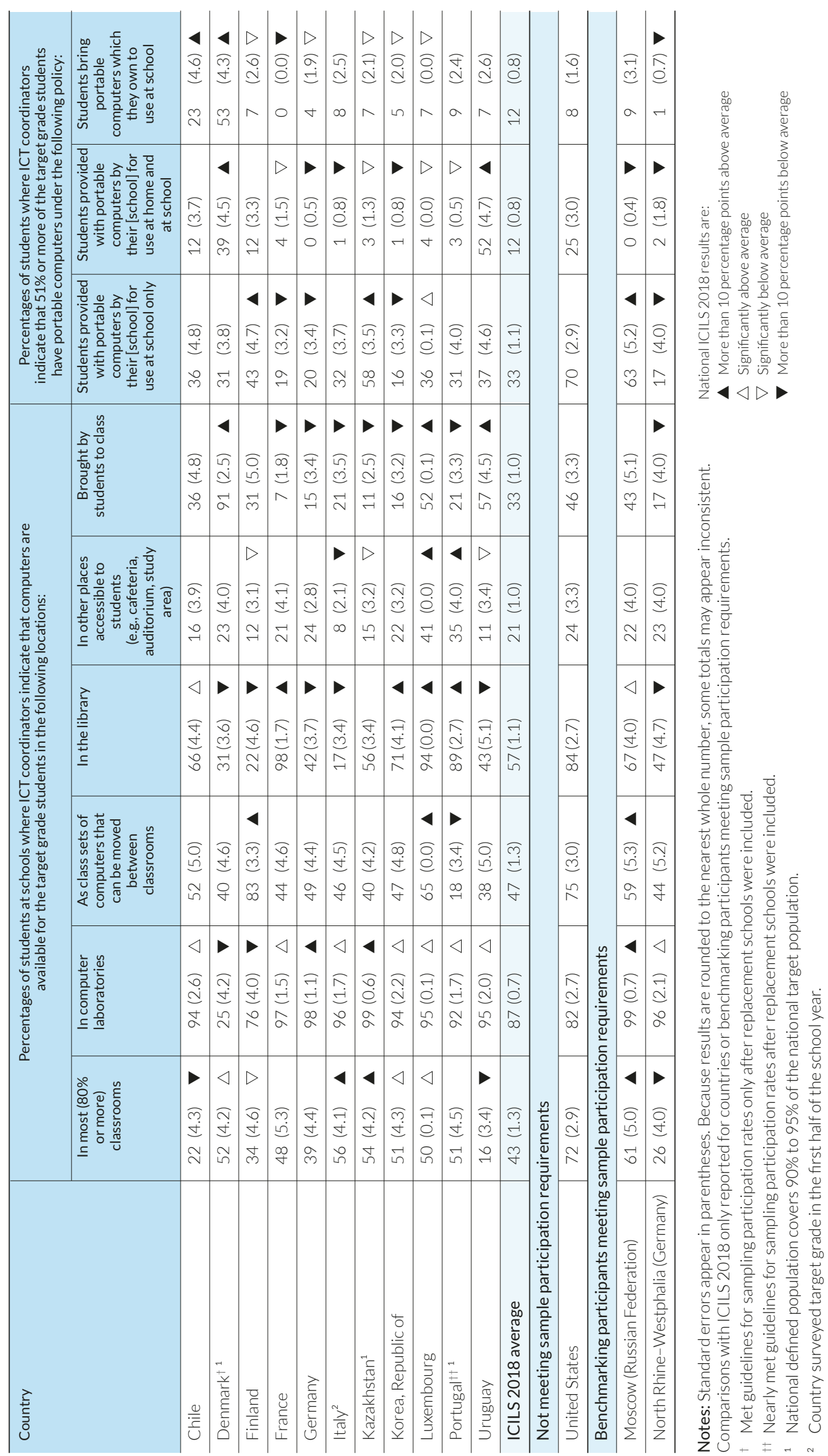


Moscow (Russian Federation) (59\%), and Chile (52\%), class sets of computers that can be moved between classrooms were available to the majority of students. In Denmark, Italy, Kazakhstan, Korea, Luxembourg, Portugal, and Moscow (Russian Federation), just over half of students had access to these in most classrooms (most defined as $80 \%$ or more). In Denmark (91\%) and to a lesser extent in Luxembourg (52\%) and Uruguay (57\%), it is commonplace for target grade students to bring devices to class, but this was less common in other countries and benchmarking participants. In most countries and benchmarking participants there were relatively few devices located in other places accessible to students (e.g., in cafeterias, auditoriums, study areas), although slightly higher percentages were reported for Luxembourg (41\%) and Portugal (35\%).

ICT coordinators indicated the approximate proportion of students who had access to a portable device at school under three policy conditions. The most common of the three conditions was that students were provided with portable computers by their school for use at school only. For approximately one third of students in the study, the majority in their grade brought devices under this condition. This was more common in Moscow (Russian Federation) (63\%) and Kazakhstan (58\%). Students being provided with portable computers by their school for use at home and at school, and students bringing their own portable computers to use at school were much less frequent for the majority of target grade students. Notable exceptions for the former are evident in Uruguay (52\% of students) and for the latter in Denmark (53\% of students).

\section{School policies and practices for using ICT \\ Procedures regarding different aspects of ICT}

NCS data provided evidence of how national and state/provincial plans and policies intend to deliver the teaching and learning of ICT in education. In order to help capture information on the implementation of policies at the school level, principals were asked (yes or no) whether their school or school system had policies regarding different aspects of ICT use (Table 2.14). Aspects that were more commonly identified across countries (in terms of the percentages of students attending schools with these policies) included:

- Prohibitions of access to inappropriate material (e.g., pornography, violence) (92\% on average, with national percentages ranging from 55\% in Denmark to all or nearly all in Germany, including North Rhine-Westphalia, and Moscow, Russian Federation);

- The provision of security measures to prevent unauthorized system access or entry (91\% on average, national percentages ranging from $76 \%$ in Uruguay to $99 \%$ in Portugal and Moscow, Russian Federation);

- Unacceptable behaviors towards other students (e.g., cyberbullying) (87\% on average, national percentages ranging from $41 \%$ in Kazakhstan to $97 \%$ in Finland);

- Support for students with special needs or specific learning difficulties (82\% on average, national percentages ranging from $45 \%$ in Chile to $98 \%$ in Denmark);

- The fulfilment of intellectual property rights (e.g., software copyrights) (80\% on average, national percentages ranging from 66\% in Chile to 98\% in Moscow, Russian Federation);

- Student use of their own ICT at school (70\% on average, national percentages ranging from 35\% in France to $94 \%$ in Moscow, Russian Federation);

- Student access to school computers outside class hours (but during school hours) (70\% on average, national percentages ranging from 37\% in Italy to $92 \%$ in Moscow, Russian Federation);

- Student use of non-school related games on school computers (69\% on average, national percentages ranging from 48\% in Moscow, Russian Federation, to $82 \%$ in Portugal); 


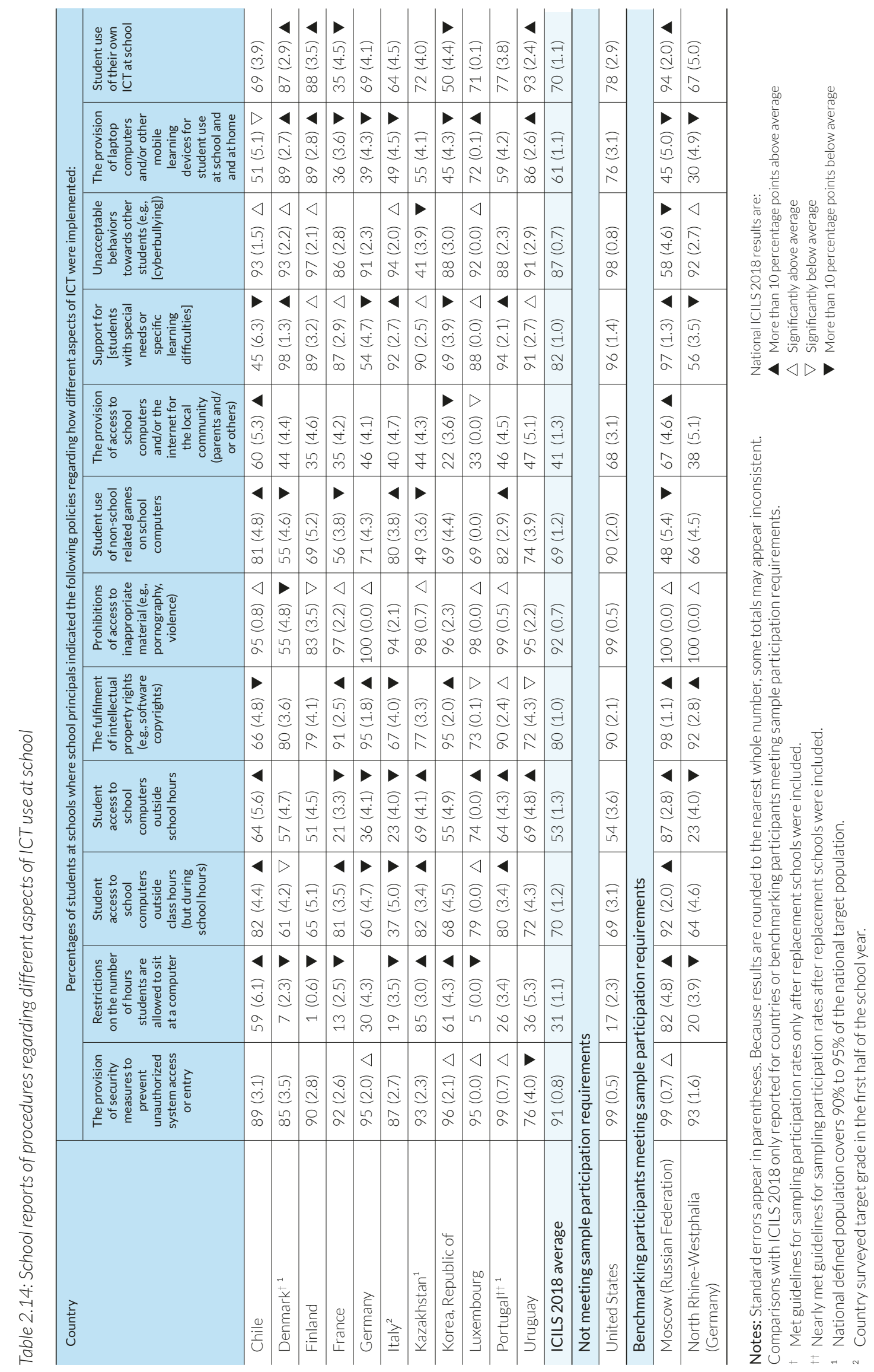


- The provision of laptop computers and/or other mobile learning devices for student use at school and at home (61\% on average, national percentages ranging from 30\% in North RhineWestphalia, Germany, to 89\% in Denmark and Finland); and

- Student access to school computers outside school hours (53\% on average, national percentages ranging from 21\% in France to $87 \%$ in Moscow, Russian Federation).

Aspects that were less commonly identified across countries (less than half of students attended schools with these policies) include:

- The provision of access to school computers and/or the internet for the local community (parents and/or others) (41\% on average, national percentages ranging from 22\% in Korea to 67\% in Moscow, Russian Federation); and

- Restrictions on the number of hours students are allowed to sit at a computer (31\% on average, national percentages ranging from 1\% in Finland to 85\% in Kazakhstan).

\section{Priorities for facilitating ICT in teaching and learning}

Principals were also asked to rate the priority ("high priority," "medium priority," "low priority," "not a priority") in their school for methods of facilitating ICT use in teaching and learning. Methods given a high priority (Table 2.15) by countries included:

- Increasing the bandwidth of internet access for the computers connected to the internet (59\% on average, this typically ranged between $60 \%$ and $78 \%$, with considerably lower proportions for Luxembourg, Korea, and Denmark);

- Increasing the range of digital learning resources available for teaching and learning (55\% on average, all countries ranged between 40\% in Denmark to a high of 78\% in Moscow, Russian Federation); and

- Increasing the number of computers connected to the internet (53\% on average, ranging from a low of 23\% in Luxembourg to a high of 72\% in Moscow, Russian Federation).

Other methods of ICT use that were reported as being a medium or high priority in the schools for less than half of students (on average across countries) included:

- Supporting participation in professional development on pedagogical use of ICT (48\% on average, ranging from a low of $29 \%$ in Denmark to a high of $87 \%$ in Moscow, Russian Federation);

- Increasing the numbers of computers per student in the school (46\% on average, ranging from a low of $24 \%$ in Luxembourg to a high of $69 \%$ in Kazakhstan);

- Increasing the availability of qualified technical personnel to support the use of ICT (45\% on average, ranging from a low of 25\% in Korea to a high of 69\% in Moscow, Russian Federation);

- Providing teachers with incentives to integrate ICT use in their teaching (41\% on average, ranging from a low of 24\% in Finland to a high of 92\% in Moscow, Russian Federation);

- Increasing the professional learning resources for teachers in the use of ICT (40\% on average, ranging from a low of $20 \%$ in Luxembourg to a high of $69 \%$ in Kazakhstan);

- Establishing or enhancing an online learning support platform (37\% on average, ranging from a low of 21\% in France, Germany, and Luxembourg to a high of 64\% in Moscow, Russian Federation); and

- Providing more time for teachers to prepare lessons in which ICT is used (24\% on average, ranging from a low of $6 \%$ in Denmark to a high of 59\% in Kazakhstan). 


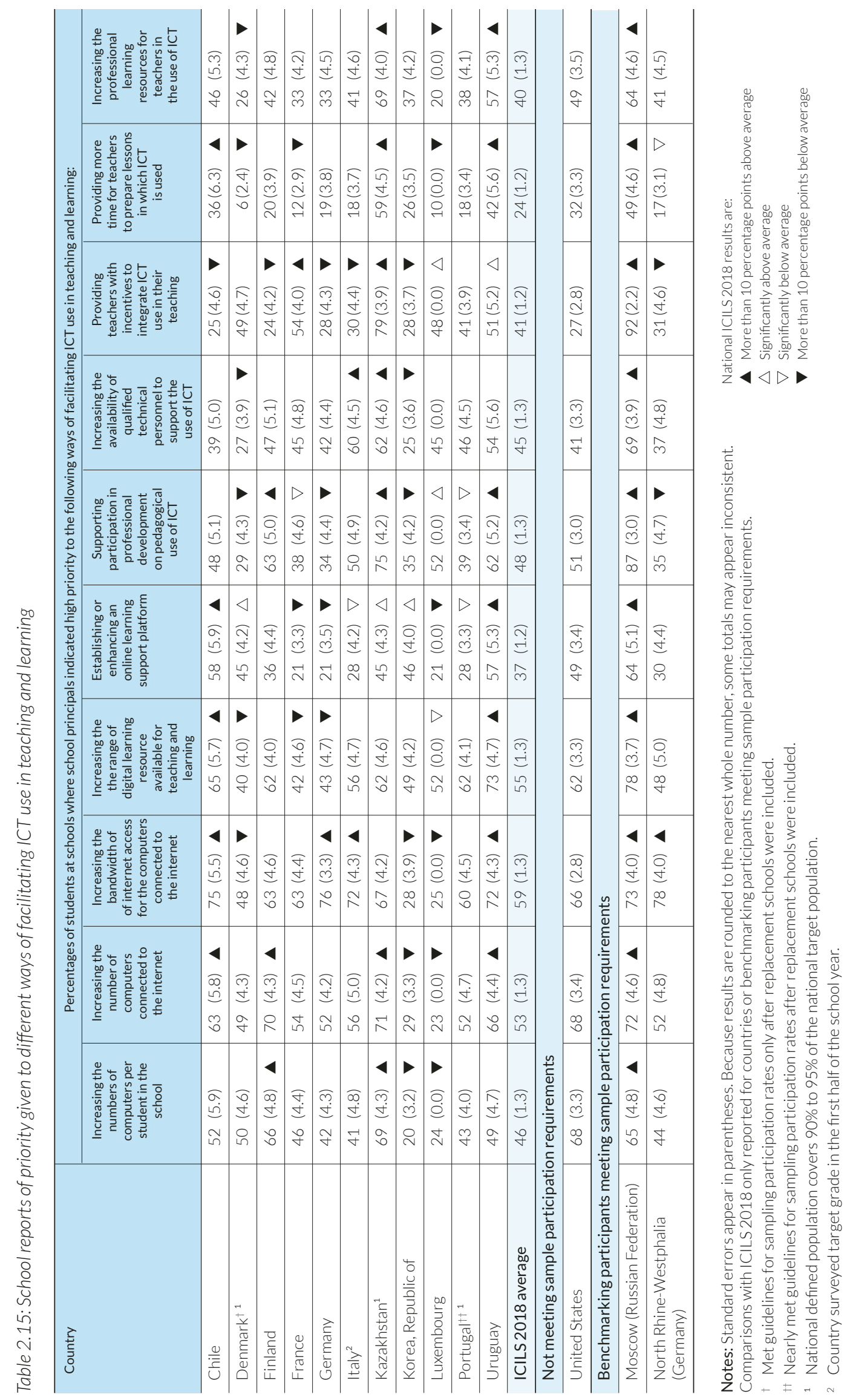




\section{References}

Anderson, R., \& Ainley, J. (2010). Technology and learning: Access in schools around the world. In P. Peterson, R. Tierney, E. Baker, \& B. McGaw (Eds.), International encyclopedia of education (3rd ed., pp. 21-33). Amsterdam, The Netherlands: Elsevier.

Anderson, R. E., \& Plomp, T. (2008). National contexts. In N. Law, W. J. Pelgrum, \& T. Plomp (Eds.), Pedagogy and ICT use in schools around the world: Findings from the IEA SITES 2006 study (pp. 38-66). (CERC studies in comparative education; No. 23.) Hong Kong SAR /The Netherlands: Comparative Education Research Centre, University of Hong Kong/Springer.

Charalambos, V., \& Glass, G. (2007). Teacher professional development and ICT: Strategies and models. National Society for the Study of Education 2007 Yearbook, 106(2), 87-102.

Eurydice. (2019). National education systems [webpage]. Brussels, Belgium: European Commission. Retrieved from https://eacea.ec.europa.eu/national-policies/eurydice/national-description_en.

Fraillon, J., Ainley, J., Schulz, W., Duckworth, D., \& Friedman, T. (2019). International Computer and Information Literacy Study 2018 assessment framework. Cham, Switzerland: Springer. Retrieved from https:// www.springer.com/gp/book/9783030193881.

Fraillon, J., Ainley, J., Schulz, W., Friedman, T., \& Gebhardt, E. (2014). Preparing for life in a digital age: The IEA International Computer and Information Literacy Study international report. Cham, Switzerland: Springer. Retrieved from https://www.springer.com/gp/book/9783319142210.

IEA. (2019). SITES. Second Information Technology in Education Study [webpage]. Amsterdam, The Netherlands: International Association for the Evaluation of Educational Achievement (IEA). Retreived from https://www.iea.nl/studies/iea/sites.

ITU. (2017). ICT development index 2017 [webpage]. Geneva, Switzerland: International Telecommunication Union. Retrieved from https://www.itu.int/net4/ITU-D/idi/2017/.

ITU. (2019). Statistics [webpage]. Geneva, Switzerland: International Telecommunication Union. Retrieved from http://www.itu.int/en/ITU-D/Statistics/Pages/stat/default.aspx.

Law, N., Pelgrum, W., \& Plomp, T. (2008). Pedagogy and ICT use in schools around the world: Findings from the IEA SITES 2006 study. (CERC studies in comparative education; No. 23.) Hong Kong SAR/The Netherlands: Comparative Education Research Centre, University of Hong Kong/Springer. Retrieved from https://www.springer.com/gp/book/9781402089275.

Pelgrum, W. J., \& Doornekamp, B. D. (2009). Indicators on ICT in primary and secondaryeducation (IIPSE). Report commissioned by the Directorate General Education and Culture (IIPSE: EACEA-2007-3278/001-001). Brussels, Belgium: European Commission.

Plomp, T., Anderson, R. E., Law, N., \& Quale, A. (Eds.). (2009). Cross-national information and communication technology policies and practices in education (2nd ed.). Greenwich, CT: Information Age.

Rosstat. (2019). Regions of Russia. Socioeconomic indicators [webpage]. Moscow, Russian Federation: Author. Retrieved from https://www.gks.ru/dbscripts/munst/munst46/DBInet.cgi.

Scherer, R., \& Siddiq, F. (2015). Revisiting teachers' computer self-efficacy: A differentiated view on gender differences. Computers in Human Behavior, 53, 48-57.

Statistics Finland. (2019). Current expenditure on education has decreased in real terms since 2010 [webpage]. Helsinki, Finland: Author. Retrieved from https://www.stat.fi/til/kotal/2017/ kotal_2017_2019-05-09_tie_001_en.html.

UNDP. (2016). Human development report 2016: Human development for everyone. New York, NY: Author. Retrieved from http://hdr.undp.org/en/2016-report.

UNDP. (2018). Human development indices and indicators 2018 statistical update. New York, NY: Author. Retrieved from http://hdr.undp.org/sites/default/files/2018_human_development_statistical_update.pdf.

UNESCO Institute for Statistics. (2011). International Standard Classification of Education: ISCED 2011. Montreal, Canada:Author. Retrieved from http://uis.unesco.org/sites/default/files/documents/internationalstandard-classification-of-education-isced-2011-en.pdf.

UNESCO Institute for Statistics. (2019). ISCED mappings [webpage]. Montreal, Canada: Author. Retrieved from http://uis.unesco.org/en/isced-mappings.

US Department of Education, Office of Educational Technology. (2011). International experiences with educational technology: Final report. Washington, DC: Author. Retrieved from https://tech.ed.gov/ files/2013/10/iete-full-report-1.doc.

Open Access This chapter is licensed under the terms of the Creative Commons Attribution-NonCommercial 4.0 International License (http://creativecommons.org/licenses/by-nc/4.0/), which permits any noncommercial use, sharing, adaptation, distribution and reproduction in any medium or format, as long as you give appropriate credit to the original author(s) and the source, provide a link to the Creative Commons license and indicate if changes were made.

The images or other third party material in this chapter are included in the chapter's Creative Commons license, unless indicated otherwise in a credit line to the material. If material is not included in the chapter's Creative Commons license and your intended use is not permitted by statutory regulation or exceeds the permitted use, you will need to obtain permission directly from the copyright holder. 


\section{CHAPTER 3:}

\section{Students' computer and information literacy}

\section{Chapter highlights}

Computer and information literacy (CIL) achievement can be described across four levels of increasing sophistication.

- Students working at Level 1 demonstrate a functional working knowledge of computers as tools. (Table 3.2)

- Students working at Level 2 use computers, under direct instruction, to complete basic and explicit information gathering and management tasks. (Table 3.2)

- Students working at Level 3 demonstrate the capacity to work independently when using computers as information gathering and management tools. (Table 3.2)

- Students working at Level 4 execute control and evaluative judgment when searching for information and creating information products. (Table 3.2)

Students' CIL varied more within countries than across countries.

- The range between the lowest five percent and the highest 95 percent of students' CIL scores within countries varied between 216 scale points (in Denmark) and 347 scale points (in Kazakhstan). (Table 3.4)

- The difference between the highest and lowest average CIL scores across countries was 157 scale points. (Table 3.4)

CIL achievement was associated with student gender.

- Female students demonstrated higher CIL achievement than male students. (Table 3.7)

- The average CIL scores of female students was statistically significantly higher than that of male students in 10 of 13 countries and benchmarking participants that met the ICILS technical requirements. (Table 3.7)

Socioeconomic status (SES), denoted by parental occupation, parental education, and number of books in the home, was significantly positively associated with student CIL achievement.

- In all countries, students in the high SES groups scored significantly higher than those in the lower SES groups on the CIL achievement scale. (Table 3.8)

Immigrant background and language background were associated with student CIL.

- In nine of 13 countries and benchmarking participants that met the ICILS technical requirements, students from non-immigrant families had statistically significantly higher CIL scores than students from immigrant families. (Table 3.9)

- In 10 of 13 countries and benchmarking participants that met the ICILS technical requirements, students who reported mainly speaking the language of the ICILS test at home had statistically significantly higher CIL scale scores than those who reported speaking another language at home. (Table 3.9) 
Access to computers at home and years' experience using computers were associated with students' CIL.

- In all countries and benchmarking participants that met the ICILS technical requirements, students who reported having two or more computers at home had statistically significantly higher CIL scores than students who reported having fewer than two computers at home. (Table 3.10)

- In 12 of 13 countries and benchmarking participants that met the ICILS technical requirements, students who reported having five years or more experience using computers had statistically significantly higher CIL scale scores than those who reported having less than five years' experience. (Table 3.10) 


\section{Introduction}

The International Computer and Information Literacy Study (ICILS) 2018 assessment framework defines computer and information literacy (CIL) as an "individual's ability to use computers to investigate, create, and communicate in order to participate effectively at home, at school, in the workplace, and in society" (Fraillon et al. 2013, p. 17). In ICILS, there is an operational emphasis on students' abilities to use computer technologies to collect and manage information, and to produce and exchange information. According to the framework, CIL comprises four strands, each of which is specified in terms of a number of aspects. The strands describe CIL in terms of the following: understanding computer use, gathering information, producing information, and digital communication (Fraillon et al. 2019).

In this chapter, we detail the measurement of CIL in ICILS and discuss student achievement across ICILS countries. We begin the chapter by describing the CIL assessment instrument and the proficiency scale derived from the ICILS test instrument and data. We also describe and discuss the student test results relating to CIL. The majority of content in this chapter relates to Research Question CIL 1, which focuses on the extent of variation existing among and within countries with respect to student CIL. In the final sections of the chapter we address aspects of Research Question CIL 3 focusing on the relationships between students' levels of access to, familiarity with, and self-reported proficiency in using computers and their CIL, and Research Question CIL 4 which focuses on aspects of students' personal and social backgrounds (such as gender and socioeconomic background) and their CIL.

\section{Assessing CIL}

The ICILS assessment design was established for the first cycle of ICILS in 2013. The design built on existing work in the assessment of digital literacy (Binkley et al. 2012; Dede 2009) and ICT literacy (ACARA 2012). It also included the following essential features of assessment in this domain:

- Students completing tasks solely on computer;

- The tasks having a real-world, cross-curricular focus;

- The tasks combining technical, receptive, productive, and evaluative skills; and

- The tasks referencing safe and ethical use of computer-based information.

In order to ensure standardization of students' test experiences and comparability of the resultant data, the ICILS instrument operates in a "walled garden," which means students can explore and create in an authentic environment without the comparability of student data being potentially contaminated by differential exposure to digital resources and information from outside the test environment.

The ICILS 2018 test instrument was built to be consistent with the instrument developed for ICILS 2013 and comprised five modules of questions and tasks which took 30 minutes each to complete. Three of the modules were secure modules from ICILS 2013 (trend modules) and were included to enable data collected in ICILS 2018 to be reported on the CIL proficiency scale established as part of ICILS 2013 and to compare CIL achievement over time in countries that participated in both cycles. Two new CIL test modules were developed for ICILS 2018. The new modules were developed to be consistent with the overarching design and conceptual principles established for use in ICILS 2013. They were also developed to represent the content of the ICILS 2018 assessment framework and used contexts that both complemented the existing content of the ICILS trend modules and reflected changes in student use of computer-based applications since 2013. Each student completed two modules randomly allocated from the set of five in a complete balanced rotation. Full details of the ICILS assessment design, including the computerbased test interface, can be found in the ICILS assessment framework (Fraillon et al. 2019). 
Each CIL test module is comprised of a set of questions and tasks based on a real-world theme and following a linear narrative structure. Each module has a series of smaller discrete tasks, ${ }^{11}$ each of which typically takes less than a minute to complete. The narrative of each module positions the smaller discrete tasks as a mix of skill execution and information management tasks that students need to do in preparation for completion of a large task. The large task in each module typically takes 15 to 20 minutes to complete. Students are free to control the time they take to complete each task, however, in each module they are given an indication of how much time is recommended for them to leave available to complete the large task.

When beginning each module, students were presented with an overview of the theme and purpose of the tasks in the module, as well as a basic description of what the large task would comprise. Students were required to complete the tasks in the allocated sequence and could not return to review completed tasks. There were five ICILS assessment modules and large tasks (Table 3.1).

Table 3.1: Summary of ICILS CIL test modules and large tasks

\begin{tabular}{l|l}
\hline Module & Description and large task \\
\hline Band competition & $\begin{array}{l}\text { Students plan a website, edit an image, and use a simple website builder to create a } \\
\text { webpage with information about a school band competition. }\end{array}$ \\
\hline Breathing & $\begin{array}{l}\text { Students manage files and evaluate and collect information to create a presentation } \\
\text { to explain the process of breathing to eight- or nine-year-old students. }\end{array}$ \\
\hline School trip & $\begin{array}{l}\text { Students help plan a school trip using online database tools and select and adapt } \\
\text { information to produce an information sheet about the trip for their peers. The } \\
\text { information sheet includes a map created using an online mapping tool. }\end{array}$ \\
\hline Recycling & $\begin{array}{l}\text { Students use a school-based social network for direct messaging and group posting } \\
\text { to encourage peers to join a board games interest group. }\end{array}$ \\
\hline $\begin{array}{l}\text { Students access and evaluate information from a video sharing website to identify a } \\
\text { suitable information source relating to waste reduction, reuse, and recycling. Students } \\
\text { take research notes from the video and use their notes as the basis for designing an } \\
\text { infographic to raise awareness about waste reduction, reuse, and recycling. }\end{array}$ \\
\hline
\end{tabular}

Data collected from the five test modules were used to measure and describe CIL in this report. In total, the data comprised 102 score points derived from 81 discrete questions and tasks. Just over half of the score points were derived from criteria associated with the five large tasks. Students' responses to these tasks were scored in each country by trained expert scorers. Data were only included where they met or exceeded IEA technical requirements. The ICILS 2018 technical report (Fraillon et al. 2020) provides further information on adjudication of the test data.

As noted previously, the ICILS assessment framework has four strands, each specified in terms of several aspects. The strands refer to the overarching conceptual category for framing the skills and knowledge addressed by the CIL instruments, while the aspects further articulate CIL in terms of the main (but not exclusive) constituent processes that underpin the skills and knowledge. We used this structure primarily as an organizational tool when describing the breadth of content of the CIL construct. The structure was not intended to form the basis of analysis and reporting of achievement by sub-dimensions (such as by strand or aspect).

11 These tasks can be described as discrete because, although connected by the common narrative, students completed each one sequentially without explicit reference to the other tasks. 
The following list sets out the four strands and corresponding aspects of the CIL framework. Also included are the respective percentages (of the 102 total score points) attributed to each strand and to each aspect within the strands.

- Strand 1: Understanding computer use, comprising two aspects, 15 percent:

- Aspect 1.1: Foundations of computer use, 2 percent.

- Aspect 1.2: Computer use conventions, 13 percent.

- Strand 2: Gathering information, comprising two aspects, 24 percent:

- Aspect 2.1: Accessing and evaluating information, 16 percent.

- Aspect 2.2: Managing information, 8 percent.

- Strand 3: Producing information, comprising two aspects, 50 percent:

- Aspect 3.1: Transforming information, 20 percent.

- Aspect 3.2: Creating information, 30 percent.

- Strand 4: Digital communication, comprising two aspects, 12 percent:

- Aspect 4.1: Sharing information, 8 percent.

- Aspect 4.2: Using information safely and securely, 4 percent.

As stated in the ICILS 2018 assessment framework, "[t]he test design of ICILS was not planned to assess equal proportions of all aspects of the CIL construct, but rather to ensure some coverage of all aspects as part of an authentic set of assessment activities in context" (Fraillon et al. 2019, p. 54). Approximately three times as many score points relate to Strands 2 and 3 as to Strands 1 and 4. These proportions correspond to the amount of time the students were expected to spend on the tasks assessing each strand. The aspects of Strand 3 were assessed primarily via the large tasks at the end of each module, with students expected to spend roughly two thirds of their working time on these tasks.

Each student completed two of the five available CIL test modules. These modules were allocated to students in a balanced randomized design. There were 20 possible permutations of the two CIL modules selected from the five available modules. Each student was randomly allocated one module permutation. The rotated module design enabled the assessment and subsequent reporting on achievement of a larger amount of content (covering the breadth of the CIL framework and a range of difficulties) than any single student could reasonably complete in 60 minutes. This design also controlled for the influence of item position on difficulty across the sampled students and provided a variety of contexts for the assessment of CIL.

The ICILS CIL reporting scale was established for ICILS 2013, with a mean of 500 (the average CIL scale score across countries in 2013) and a standard deviation of 100 for the equally weighted national samples. We used combined data from ICILS 2013 and ICILS 2018 and then applied the Rasch item response theory (IRT) model (Rasch 1960) to equate the 2018 data to the ICILS reporting scale. We used plausible value methodology with full conditioning to derive summary student achievement statistics. This approach enables estimation of the uncertainty inherent in a measurement process (e.g., von Davier et al. 2009). The ICILS 2018 technical report provides details on the procedures the study used to scale test items (Fraillon et al. 2020).

\section{The CIL described achievement scale}

When we established the ICILS described scale of CIL achievement in 2013 we considered the content and scaled difficulties of the test items. We described the CIL knowledge, skills, and understanding demonstrated by a student correctly responding to each item and ordered these descriptors, from least to most difficult, according to the scaled difficulties of their corresponding items. We then analyzed the item content and relative difficulty to identify themes of content 
and process that we could use to characterize the different ranges (levels) on the scale. This process was iterative in that we varied the positions of the level boundaries and reviewed the content of each level until each level showed distinctive characteristics and the progression from low to high achievement across the levels was clear.

We established the level boundaries at 407, 492, 576, and 661 scale points. Student scores below 407 scale points indicate CIL proficiency below the lowest level targeted by the assessment instrument. The described CIL scale was established on the basis of a transformation of the original item calibration so that the relative positions of students' scaled scores and the item difficulties would represent a response probability of 0.62 . Thus, a student with ability equal to that of the difficulty of a given item on the scale would have a 62 percent chance of answering that item correctly.

The width of the levels was 85 scale points. We can assume that students achieving a score corresponding to the lower boundary of a level correctly answered about 50 percent of items in that level. We can also expect that students with scores within a bounded level (above the lower boundary) correctly answered more than 50 percent of the items in that level. Thus, once we know where a student's proficiency score is located within a given level, we can expect that they will have correctly answered at least half of the questions for that level, regardless of the location of their score within the level.

We reviewed the content of the described scale using the content and scaled difficulty of the test items used in ICILS 2018. From this review, we concluded that the summary content of the level descriptors should remain unchanged.

The scale description comprises syntheses of the common elements of CIL knowledge, skills, and understanding at each proficiency level (Table 3.2). It also describes the typical ways in which students working at a level demonstrate their proficiency. Each level of the scale references the characteristics of students' use of computers to access and use information and to communicate with others. The scale thus reflects a broad range of development, extending from students' use of software commands under direction, through to their increasing independence in selecting and using information to communicate with others, and on to their ability to independently and purposefully select information and use a range of software resources in a controlled manner in order to communicate with others. Included in this development is students' knowledge and understanding of issues relating to online safety and ethical use of electronic information. This understanding encompasses knowledge of information types and security procedures through to demonstrable awareness of the social, ethical, and legal consequences of a broad range of known and unknown users accessing electronic information.

In summary, the developmental sequence that the CIL scale describes has the following underpinnings: knowledge and understanding of the conventions of electronic information sources and software applications; ability to critically reason about and determine the veracity and usefulness of information from a variety of sources; and the planning and evaluation skills needed to create and refine information products for specified communicative purposes.

The scale is hierarchical in the sense that CIL proficiency becomes more sophisticated as student achievement progresses up the scale. We can therefore assume that a student located at a particular place on the scale because of his or her achievement score will be able to undertake and successfully accomplish tasks up to that level of achievement.

The scale contains four proficiency levels (Table 3.2). A small number of test items had scaled difficulties below Level 1 of the scale. These items represented execution of the most basic skills such as clicking on hyperlinks and interacting with application user interfaces (e.g., adjusting sliders and selectively clicking functional buttons) and therefore did not provide sufficient information to warrant description on the scale. 
Table 3.2: CIL described achievement scale

\begin{tabular}{|c|c|}
\hline Description of the proficiency level & $\begin{array}{l}\text { Examples of tasks achieved by students at this } \\
\text { proficiency level }\end{array}$ \\
\hline \multicolumn{2}{|l|}{ Level 1 (from 407 to 491 scale points) } \\
\hline $\begin{array}{l}\text { Students working at Level } 1 \text { demonstrate a functional } \\
\text { working knowledge of computers as tools and a basic } \\
\text { understanding of the consequences of computers } \\
\text { being accessed by multiple users. They apply } \\
\text { conventional software commands to perform basic } \\
\text { research and communication tasks and add simple } \\
\text { content to information products. They demonstrate } \\
\text { familiarity with the basic layout conventions of } \\
\text { electronic documents. }\end{array}$ & $\begin{array}{l}\text { Students working at Level } 1 \text {, for example: } \\
\text { - Open a link in a new browser tab } \\
\text { - Use an appropriate communication tool for a } \\
\text { particular communicative context } \\
\text { - Identify who receives an email by carbon copy (CC) } \\
\text { - Identify problems that can result from mass } \\
\text { messaging } \\
\text { - Record key points from a video into a text-based } \\
\text { - note taking application } \\
\text { - Use software to crop an image } \\
\text { - Create a title in a prominent position on a webpage } \\
\text { - Demonstrate basic control of color when adding } \\
\text { content to a simple document } \\
\text { - Insert an image into a document } \\
\text { - Suggest one or more risks of failing to log out from } \\
\text { a user account when using a publicly accessible } \\
\text { computer }\end{array}$ \\
\hline
\end{tabular}

Students working at Level 2 use computers to complete basic and explicit information gathering and management tasks. They locate explicit information from within given electronic sources. These students make basic edits and add content to existing information products in response to specific instructions. They create simple information products that show consistency of design and adherence to layout conventions. Students working at Level 2 demonstrate awareness of mechanisms for protecting personal information and some consequences of public access to personal information.
Students working at Level 2, for example:

- Add contacts to a collaborative workspace

- Explain the advantages of using a communication tool for a particular communicative context

- Explain a potential problem if a personal email address is publicly available

- Associate the breadth of a character set with the strength of a password

- Navigate to a URL presented as plain text

- Insert information to a specified cell in a spreadsheet

- Locate explicitly stated simple information within a website with multiple webpages

- Know that search engines can prioritize sponsored content over non-sponsored content

- Differentiate between paid and non-paid search results returned by a search engine

- Explain a benefit of citing sources of information obtained from the internet

- Use formatting and location to denote the role of a title in an information sheet

- Use the full canvas when laying out a poster

- Control the size of elements relative to one another when laying out a poster

- Demonstrate basic control of text layout and color use when creating a slide show

- Use a simple webpage editor to add specified text to a webpage 
Table 3.2: CIL described achievement scale (contd.)

\begin{tabular}{l|l}
\hline Description of the proficiency level & $\begin{array}{l}\text { Examples of tasks achieved by students at this } \\
\text { proficiency level }\end{array}$ \\
\hline Level 3 (from 577 to 661 scale points) &
\end{tabular}

Students working at Level 3 demonstrate the capacity to work independently when using computers as information gathering and management tools. These students select the most appropriate information source to meet a specified purpose, retrieve information questions, and follow instructions to use conventionally recognized software commands to edit, add content to, and reformat information products. They recognize that the credibility of web-based information can be influenced by the identity, expertise, and motives of the creators of the information. from given electronic sources to answer concrete

Students working at Level 3, for example:

- Identify that a generic greeting in an email suggests that the sender does not know the recipient

- Explain the disadvantages of using a communication tool for a particular communicative context

- Evaluate the reliability of information presented on a crowdsourced website

- Identify when content published on the internet may be biased as a result of a publisher's content guidelines or advertising revenue directing content

- Explain the purpose of explicitly labelling sponsored content published on the internet websites

- Select relevant information according to given criteria to include in a website

- Explain the benefit of a common information organization and retrieval system

- Know what information is useful to include when recording a source of information from the internet

- Use generic online mapping software to represent text information as a map route

- Select an appropriate website navigation structure for given content

- Select and adapt some relevant information from given sources when creating a poster

- Demonstrate control of image layout when creating a poster

- Demonstrate control of color and contrast to support readability of a poster

- Demonstrate control of text layout when creating a presentation

Level 4 (Above 661 scale points)

Students working at Level 4 select the most relevant information to use for communicative purposes. They evaluate usefulness of information based on criteria associated with need and evaluate the reliability of information based on its content and probable origin. These students create information products that demonstrate a consideration of audience and communicative purpose. They also use appropriate software features to restructure and present information in a manner that is consistent with presentation conventions. They then adapt that information to suit the needs of an audience. Students working at Level 4 demonstrate awareness of problems that can arise regarding the use of proprietary information on the internet.
Students working at Level 4, for example:

- Evaluate the reliability of information intended to promote a product on a commercial website

- Select and use relevant images to represent a three-stage process in a presentation

- Select and use relevant images to support information presented in a digital poster

- Select from sources and adapt text for a presentation so that it suits a specified audience and purpose

- Demonstrate control of color to support the communicative purpose of a presentation

- Use text layout and formatting features to denote the role of elements in an information poster

- Create a balanced layout of text and images for an information sheet

- Recognize the difference between legal, technical, and social requirements when using images on a website

- Explain that passwords can be encrypted and decrypted 
Table 3.2: CIL described achievement scale (contd.)

\begin{tabular}{|c|c|}
\hline Description of the proficiency level & $\begin{array}{l}\text { Examples of tasks achieved by students at this } \\
\text { proficiency level }\end{array}$ \\
\hline \multicolumn{2}{|l|}{ Level 4 (Above 661 scale points) } \\
\hline & $\begin{array}{l}\text { - Source relevant facts from electronic sources for } \\
\text { use in a social media post to generate support } \\
\text { - Explain how communication tools can be used to } \\
\text { demonstrate inclusive behavior } \\
\text { - Cite the relevant source of information from the } \\
\text { internet when constructing an information product }\end{array}$ \\
\hline
\end{tabular}

\section{Describing CIL learning progress}

In this section we briefly describe the key characteristics of each level on the CIL scale with a focus on the differences between achievements at each level. These differences are discussed with a view to providing ideas for educators about target areas for teaching to support students' learning progress through the levels.

Students working at Level 1 demonstrate familiarity with the basic range of software commands that enable them to access files and complete routine text and layout editing under instruction. They recognize not only some basic conventions used by electronic communications software, including knowing which communication tool to use in a given context, but also the potential for misuse of computers by unauthorized users. A key factor differentiating Level 1 achievement from Below Level 1 achievement is the range of software commands students can use. Students working at Below Level 1 are unlikely to be able to create digital information products unless they have support and guidance. Key factors differentiating Level 1 achievement from achievement at the higher levels are the breadth of students' familiarity with conventional software commands, the degree to which they can search for and locate information, and their capacity to plan how they will use information when creating information products.

Students working at Level 2 demonstrate basic use of computers as information resources. They are able to locate explicit information in simple digital resources, select and add content to information products, and exercise some control over laying out and formatting text and images in information products. They can explain the advantage of using a given communication tool in a given context and demonstrate awareness of the need to protect access to some electronic information and of possible consequences of unwanted access to information. A key factor differentiating Level 2 achievement from achievement at the higher levels is the extent to which students can work autonomously and with a critical perspective when accessing information and using it to create information products.

Students working at Level 3 possess sufficient knowledge, skills, and understanding to independently search for and locate information. They also have ability to edit and create information products. They can select relevant information from within electronic resources, and the information products they create exhibit their capacity to control layout and design. Furthermore, students working at Level 3 demonstrate awareness that the information they access may be biased, inaccurate, or unreliable. They also can evaluate the weaknesses of the use of a given communication tool in a given context. The key factors differentiating achievement at Level 3 from Level 4 are the degree of precision with which students search for and locate information and the level of control they demonstrate when using layout and formatting features to support the communicative purpose of information products. 
Students working at Level 4 execute control and evaluative judgment when searching for information and creating information products. They also demonstrate awareness of audience and purpose when searching for information, selecting information to include in information products, and formatting and laying out the information products they create. Students working at Level 4 additionally demonstrate awareness of the potential for information to be a commercial and malleable commodity and apply the conventions of a given communication tool in a given context to support inclusivity.

\section{Example CIL items}

To provide a clearer understanding of the nature of the scale items, we include in this section of the chapter a set of example items. These indicate the types and range of items that students were required to complete during the ICILS test of CIL. The items also provide examples of responses corresponding to the different proficiency levels of the CIL scale.

The example items are all from the band competition module. This module required students to work on a sequence of tasks associated with planning a website for a school band competition. Students were then asked to create a website page to represent one of the bands in the competition. In this section we present five discrete items followed by a description of the band competition's large task and a discussion of its scoring criteria. The five discrete items and the large task criteria illustrate achievement at different levels of the CIL scale.

\section{Example discrete tasks}

Example Item 1 (Figure 3.1), an open text response item, was the first task in the band competition module. The stimulus presented the login page for a webmail account. The item required students to respond by answering a question relating to browser security. The students' written responses to this item were scored by scorers in each country through an online delivery platform. All scorers had been trained to international standards. ${ }^{12}$ Only data that met the requisite ICILS scoring standards were included in the analysis of this item. ${ }^{13}$

Example Item 1 illustrates achievement at Level 1 on the CIL scale. The item assessed students' understanding of the consequences of allowing a browser or web application to save a password while using a computer that could be accessed by other people. Students who referred to unauthorized access to the webmail account or access to private information stored in the account received credit on this item. On average across all countries, 64 percent of students achieved full credit on Example Item 1. The percentages across countries and benchmarking participants ranged from 50 percent to 84 percent.

Example Item 2 (Figure 3.2) required students to explain how the characteristics of a password can improve the secureness of the password.

Students were presented with two passwords and asked to choose the most secure and explain their choice. Student responses were scored as correct if they selected the password Fky_38\% and included an explanation that related the broader character set used in the second password to password security. A correct response to this item illustrates achievement at Level 2 of the CIL scale. On average across all countries, 62 percent of students achieved full credit on this item. The percentages across countries and benchmarking participants varied from 27 to 80 percent.

12 All scorers across countries were provided the same set of example responses as the basis for training.

13 Three hundred student responses to each constructed response item and large task criterion were independently scored by two scorers in each country in order to assess the reliability of scoring of each item or task within each country. The only data included in the analysis were those with a scoring reliability of at least 70 percent. 
Figure 3.1: Example Item 1 with framework references and overall percent correct

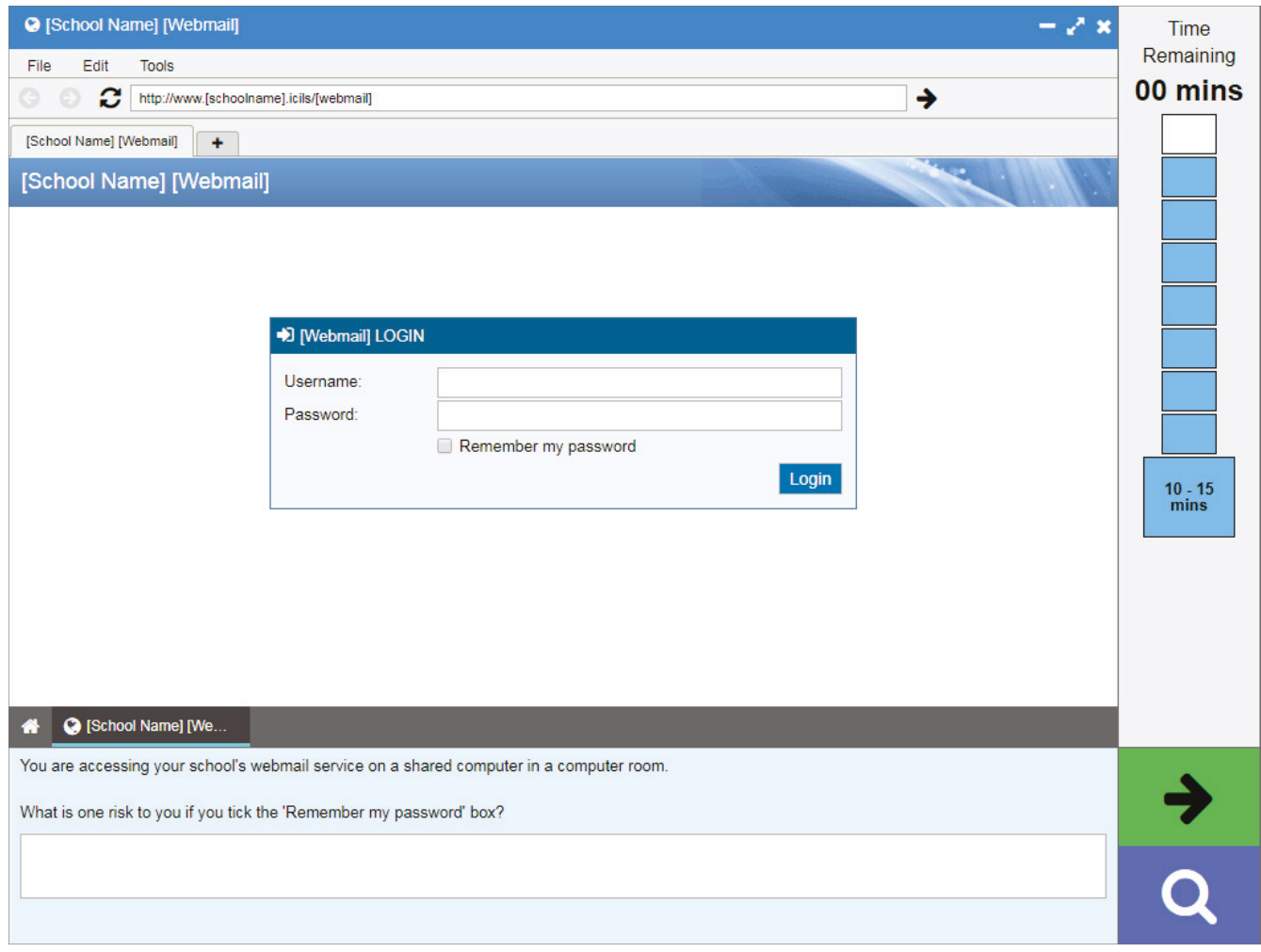

\begin{tabular}{l|c|c}
\hline \multicolumn{1}{c|}{ CIL scale level } & CIL scale difficulty & $\begin{array}{c}\text { ICILS 2018 average percentage correct } \\
\text { responses }\end{array}$ \\
\hline 1 & 489 & $64(0.5)$ \\
\hline Item descriptor & \multicolumn{2}{|c}{} \\
\hline Identify a danger of ticking "Remember your password" on a shared computer \\
\hline ICILS assessment framework reference \\
\hline \multirow{2}{*}{4.2} & Digital communication \\
\cline { 2 - 3 } & Using information responsibly and safely \\
\hline
\end{tabular}


Figure 3.1: Example Item 1 with framework references and overall percent correct (contd.)

\begin{tabular}{l|c}
\hline Country & Percentage of correct responses \\
\hline Chile & $64(1.7)$ \\
\hline Denmark ${ }^{+1}$ & $72(1.3)$ \\
\hline Finland & $70(1.7)$ \\
\hline France & $51(1.5)$ \\
\hline Germany & $56(1.3)$ \\
\hline Kazakhstan ${ }^{1}$ & $50(2.2)$ \\
\hline Korea, Republic of & $77(1.4)$ \\
\hline Luxembourg & $56(0.9)$ \\
\hline Portugal+1 & $84(1.2)$ \\
\hline Uruguay & $59(2.1)$ \\
\hline Testing at the beginning of the school year & $35(1.7)$ \\
\hline Italy & $58(1.1)$ \\
\hline Not meeting sample participation requirements & $71(1.8)$ \\
\hline United States & $57(2.0)$ \\
\hline Benchmarking participants meeting sample participation requirements \\
\hline Moscow (Russian Federation) \\
\hline North Rhine-Westphalia (Germany) \\
\hline
\end{tabular}

Notes: Standard errors appear in parentheses. Because results are rounded to the nearest whole number, some totals may appear inconsistent.

+ Met guidelines for sampling participation rates only after replacement schools were included.

t† Nearly met guidelines for sampling participation rates after replacement schools were included.

1 National defined population covers $90 \%$ to $95 \%$ of national target population.

Figure 3.2: Example Item 2 with framework references and overall percent correct

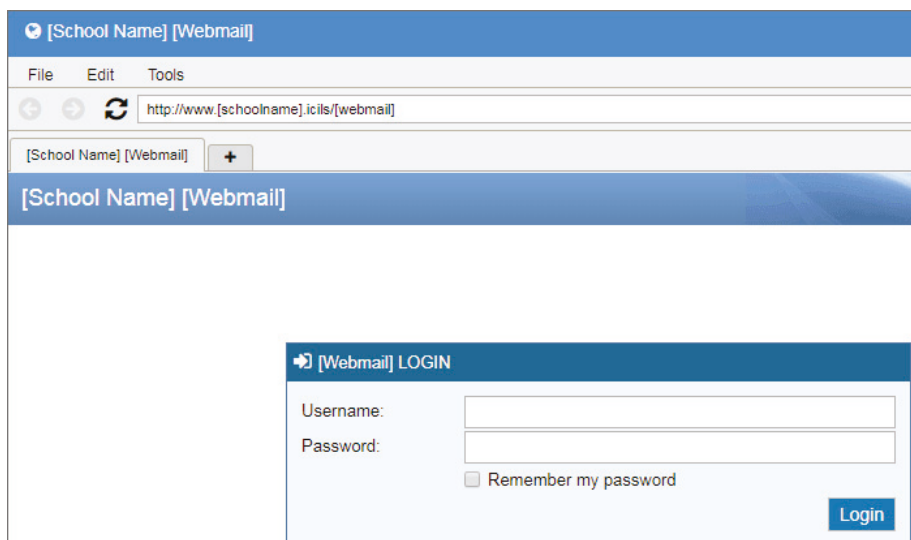

\section{$-x^{x} x$ $\rightarrow$ Remaining 00 mins}

\section{4. [School Name] [We}

Your [webmail] account needs a password to access emails. Which password is more secure?

fky_345 $\bigcirc$ Fky_38\%

Select one password and explain your answer. 
Figure 3.2: Example Item 2 with framework references and overall percent correct (contd.)

\begin{tabular}{l|c|c}
\hline \multicolumn{1}{c|}{ CIL scale level } & CIL scale difficulty & $\begin{array}{c}\text { ICILS 2018 average percentage correct } \\
\text { responses }\end{array}$ \\
\hline \multicolumn{1}{c|}{2} & 493 & $62(0.5)$ \\
\hline Item descriptor & \\
\hline \multicolumn{2}{|c}{ Explain the characteristics that make one of two passwords more secure } \\
\hline ICILS assessment framework reference \\
\hline \multirow{2}{*}{1.1} & Understanding computer use \\
\cline { 2 - 3 } & Foundations of computer use \\
\hline
\end{tabular}

\begin{tabular}{l|c}
\hline Country & Percentage of correct responses \\
\hline Chile & $56(1.7)$ \\
\hline Denmark ${ }^{\dagger 1}$ & $77(1.5)$ \\
\hline Finland & $78(1.4)$ \\
\hline France & $61(1.8)$ \\
\hline Germany & $79(1.5)$ \\
\hline Kazakhstan ${ }^{1}$ & $27(1.8)$ \\
\hline Korea, Republic of & $43(1.7)$ \\
\hline Luxembourg & $74(0.8)$ \\
\hline Portugal+11 & $68(1.6)$ \\
\hline Uruguay & $56(1.9)$ \\
\hline Testing at the beginning of the school year & $49(1.5)$ \\
\hline Italy $^{\mid c}$ & $71(1.1)$ \\
\hline Not meeting sample participation requirements & $65(1.8)$ \\
\hline United States & $80(1.3)$ \\
\hline Benchmarking participants meeting sample participation requirements \\
\hline Moscow (Russian Federation)
\end{tabular}

Notes: Standard errors appear in parentheses. Because results are rounded to the nearest whole number, some totals may appear inconsistent.

† Met guidelines for sampling participation rates only after replacement schools were included.

t† Nearly met guidelines for sampling participation rates after replacement schools were included.

1 National defined population covers $90 \%$ to $95 \%$ of national target population. 
Example Item 3 (Figure 3.3) illustrates student achievement at Level 3 on the CIL scale. It was the fourth task in the narrative sequence of the module and presented the students with four diagrams that represented website structure templates for the band competition website. Each template could be viewed by clicking the template tabs above the diagram.

The page content boxes represented the webpages that comprise the band competition website. Students could arrange the page content onto the templates to evaluate the suitability of each template. Each template page had its own set of content boxes which could be arranged independently.

Students that selected Template 3 received credit for this item. On average across all countries, 30 percent of students achieved full credit on this item. The percentages across countries and benchmarking participants varied from 23 to 44 percent.

Figure 3.3: Example Item 3 with framework references and overall percent correct

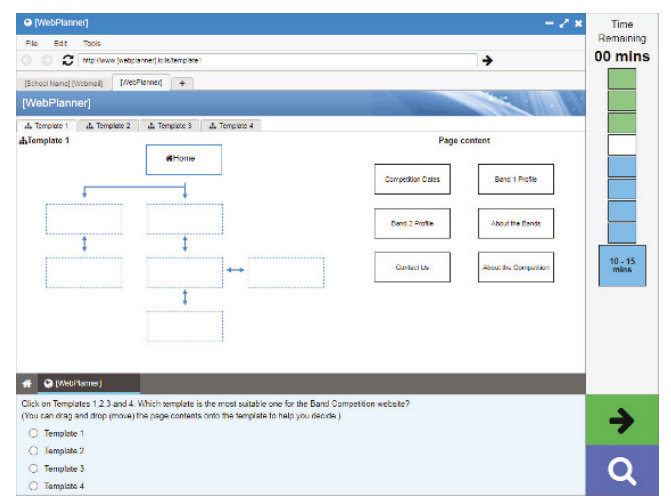

Template 1

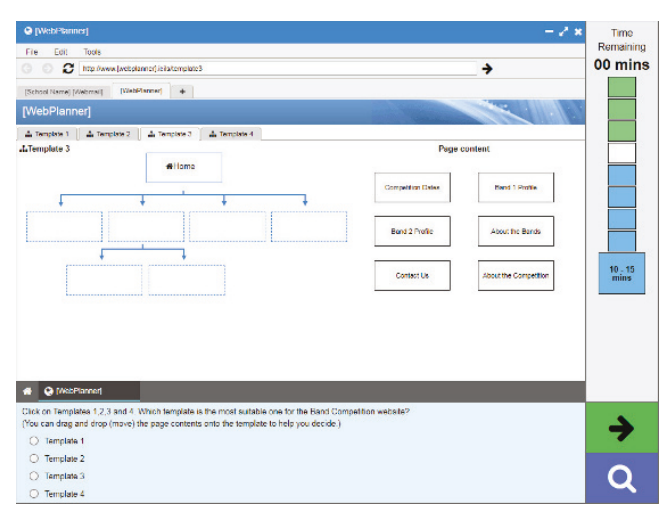

Template 3

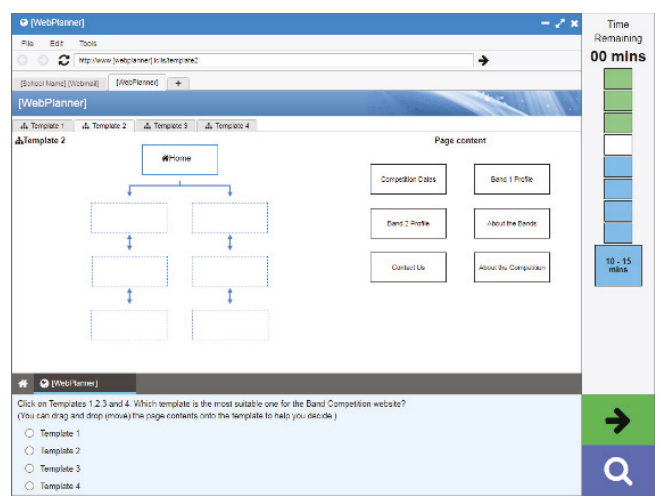

Template 2

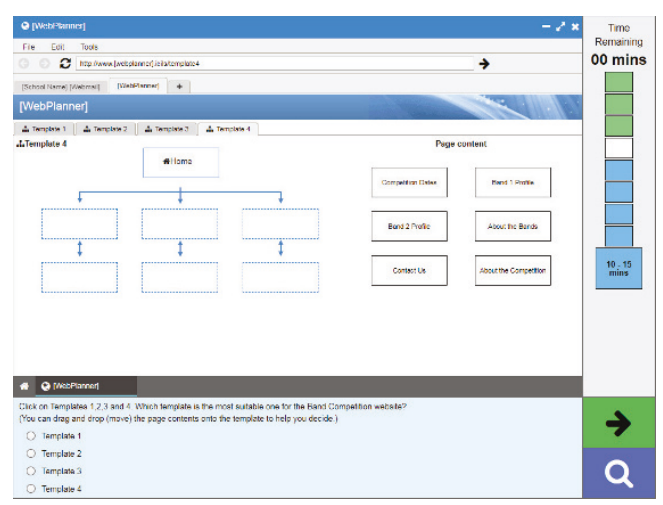

Template 4 
Figure 3.3: Example Item 3 with framework references and overall percent correct (contd.)

\begin{tabular}{|c|c|c|c|}
\hline \multicolumn{2}{|c|}{ CIL scale level } & CIL scale difficulty & $\begin{array}{c}\text { ICILS } 2018 \text { average percentage correct } \\
\text { responses }\end{array}$ \\
\hline \multicolumn{2}{|c|}{3} & 631 & $30(0.5)$ \\
\hline \multicolumn{4}{|c|}{ Item descriptor } \\
\hline \multicolumn{4}{|c|}{ Compare four website navigation structures and select the most appropriate for given webpage content } \\
\hline \multicolumn{4}{|c|}{ ICILS assessment framework reference } \\
\hline \multirow[t]{2}{*}{2.2} & \multicolumn{3}{|c|}{ Gathering information } \\
\hline & \multicolumn{3}{|c|}{ Managing information } \\
\hline \multicolumn{3}{|l|}{ Country } & Percentage of correct responses \\
\hline \multicolumn{3}{|l|}{ Chile } & $28(1.7)$ \\
\hline \multicolumn{3}{|l|}{ Denmark $^{\dagger 1}$} & $34(2.2)$ \\
\hline \multicolumn{3}{|l|}{ Finland } & $32(1.6)$ \\
\hline \multicolumn{3}{|l|}{ France } & $28(1.3)$ \\
\hline \multicolumn{3}{|l|}{ Germany } & $29(1.4)$ \\
\hline \multicolumn{3}{|c|}{ Kazakhstan $^{1}$} & $25(1.8)$ \\
\hline \multicolumn{3}{|c|}{ Korea, Republic of } & $35(1.7)$ \\
\hline \multicolumn{3}{|c|}{ Luxembourg } & $27(0.8)$ \\
\hline \multicolumn{3}{|l|}{ Portugal $\left.\right|^{\dagger+1}$} & $36(1.6)$ \\
\hline \multicolumn{3}{|l|}{ Uruguay } & $24(1.7)$ \\
\hline \multicolumn{4}{|c|}{ Testing at the beginning of the school year } \\
\hline \multicolumn{3}{|l|}{ Italy } & $27(1.5)$ \\
\hline \multicolumn{4}{|c|}{ Not meeting sample participation requirements } \\
\hline \multicolumn{3}{|c|}{ United States } & $29(1.0)$ \\
\hline \multicolumn{4}{|c|}{ Benchmarking participants meeting sample participation requirements } \\
\hline \multicolumn{3}{|c|}{ Moscow (Russian Federation) } & $44(1.8)$ \\
\hline \multicolumn{3}{|c|}{ North Rhine-Westphalia (Germany) } & $23(1.5)$ \\
\hline
\end{tabular}

Notes: Standard errors appear in parentheses. Because results are rounded to the nearest whole number, some totals may appear inconsistent.

+ Met guidelines for sampling participation rates only after replacement schools were included.

it Nearly met guidelines for sampling participation rates after replacement schools were included.

1 National defined population covers $90 \%$ to $95 \%$ of national target population. 
Example Item 4 (Figure 3.4) required students to evaluate different issues relating to the publishing of an image on a website. Each of the five issues presented pertained to one of three aspect of content publishing: legal, technical, and social/personal. Students could drag the issues presented in the boxes into the columns to show their answer.

Students received partial credit (one from a possible two score points) if they correctly classified four of the five issues. This level of credit was located at Level 2 on the CIL scale. Students received full credit (two from a possible two score points) if they correctly classified all five of the issues. This level of credit was located at the boundary between Levels 3 and 4 on the $\mathrm{CIL}$ scale. On average across all countries, 62 percent of students achieved a score of at least one (i.e., partial or full credit) on this item. The percentages of students achieving a score of at least one across countries and benchmarking participants varied from 37 to 83 percent. On average across all countries, 21 percent of students achieved full credit on this item. The percentages across countries and benchmarking participants varied from 10 to 35 percent.

Figure 3.4: Example Item 4 with framework references and overall percent correct

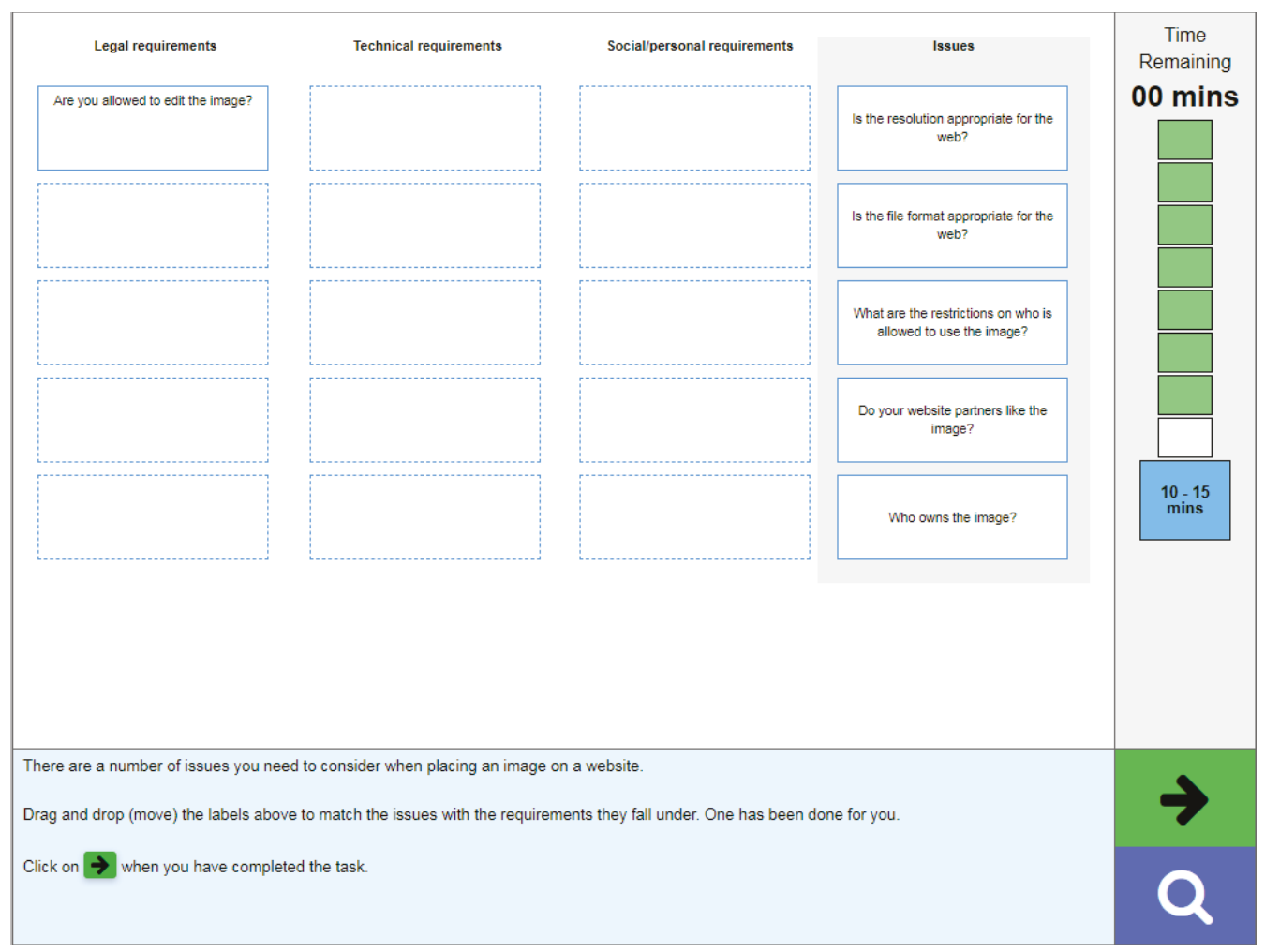


Figure 3.4: Example Item 4 with framework references and overall percent correct (contd.)

\begin{tabular}{|c|c|c|c|c|}
\hline Score & \multicolumn{2}{|c|}{ CIL scale level } & CIL scale difficulty & $\begin{array}{c}\text { ICILS } 2018 \text { average } \\
\text { percentage correct responses }\end{array}$ \\
\hline At least one of two points & & 2 & 502 & $62(1.5)$ \\
\hline Two points & & 4 & 661 & $21(0.4)$ \\
\hline \multicolumn{5}{|c|}{ Item descriptor (one out of two scale points) } \\
\hline \multicolumn{5}{|c|}{ Recognize four of five distinct legal, technical, and social issues associated with image use on a website } \\
\hline \multicolumn{5}{|c|}{ Item descriptor (two out of two scale points) } \\
\hline \multicolumn{5}{|c|}{ Recognize five distinct legal, technical, and social issues associated with image use on a website } \\
\hline \multicolumn{5}{|c|}{ ICILS assessment framework reference } \\
\hline \multirow[t]{2}{*}{4.2} & \multicolumn{4}{|c|}{ Digital communication } \\
\hline & \multicolumn{4}{|c|}{ Using information responsibly and safely } \\
\hline \multicolumn{2}{|l|}{ Country } & \multicolumn{2}{|c|}{$\begin{array}{l}\text { Percentage scoring at least } \\
\text { one out of two points }\end{array}$} & $\begin{array}{l}\text { Percentage scoring } \\
\text { two out of two points }\end{array}$ \\
\hline \multicolumn{2}{|l|}{ Chile } & & $52(2.0)$ & $12(1.4)$ \\
\hline \multicolumn{2}{|l|}{ Denmark $^{\dagger 1}$} & & $80(1.6)$ & $27(1.7)$ \\
\hline \multicolumn{2}{|l|}{ Finland } & & $77(1.7)$ & $35(1.8)$ \\
\hline \multicolumn{2}{|l|}{ France } & & $58(1.5)$ & $21(1.3)$ \\
\hline \multicolumn{2}{|l|}{ Germany } & & $71(1.8)$ & $28(1.6)$ \\
\hline \multicolumn{2}{|l|}{ Kazakhstan ${ }^{1}$} & & $37(1.9)$ & $12(1.1)$ \\
\hline \multicolumn{2}{|l|}{ Korea, Republic of } & & $83(1.4)$ & $25(1.2)$ \\
\hline \multicolumn{2}{|l|}{ Luxembourg } & & $55(1.1)$ & $21(0.6)$ \\
\hline \multicolumn{2}{|l|}{ Portugal $\left.\right|^{\dagger+1}$} & & $62(1.6)$ & $24(1.5)$ \\
\hline \multicolumn{2}{|l|}{ Uruguay } & & $46(2.0)$ & $10(1.1)$ \\
\hline \multicolumn{5}{|c|}{ Testing at the beginning of the school year } \\
\hline \multicolumn{2}{|l|}{ Italy } & & $40(1.6)$ & $16(1.2)$ \\
\hline \multicolumn{5}{|c|}{ Not meeting sample participation requirements } \\
\hline \multicolumn{2}{|l|}{ United States } & & $51(1.1)$ & $20(1.0)$ \\
\hline \multicolumn{5}{|c|}{ Benchmarking participants meeting sample participation requirements } \\
\hline \multicolumn{2}{|c|}{ Moscow (Russian Federation) } & & $70(1.7)$ & $34(1.6)$ \\
\hline \multicolumn{2}{|c|}{ North Rhine-Westphalia (Germany) } & & $71(1.6)$ & $28(1.6)$ \\
\hline
\end{tabular}

Notes: Standard errors appear in parentheses. Because results are rounded to the nearest whole number, some totals may appear inconsistent.

+ Met guidelines for sampling participation rates only after replacement schools were included.

t† Nearly met guidelines for sampling participation rates after replacement schools were included.

1 National defined population covers $90 \%$ to $95 \%$ of national target population. 


\section{Example ICILS large-task item}

The large task in the band competition test module required students to design a webpage for one of the bands competing in the competition. The page was a sub-page within the band competition website. Students were presented with a description of the task details as well as information about how the task was assessed. This information was followed by a short video designed to familiarize students with the task. The video also highlighted the main features of the software students would need to use to complete the task.

Students saw a task details screen (Figure 3.5) before beginning the band competition large task. Students could view the assessment criteria at any time during their work on the task by clicking the button with magnifying glass icon (Figure 3.6). The criteria presented here were a simplified summary of the detailed criteria used by the expert scorers. The task details screen directed students to create a profile page for the band according to instructions presented in an email using a webpage editor (Figures 3.7 and 3.8).

The band competition large task was presented to students as a blank webpage on which they could create a layout using the software functions. The software functions matched the conventions of basic webpage design applications and included the capability to change the background, change the page border style, add text boxes, add images from an image library, and add icons from an icon library. These software functions were presented as dialogue boxes which included a preview window that students could use to preview their selection before committing the selection to the canvas. The buttons to activate the functions included conventional icons to denote the functionality and were used across all national adaptations of the module. The buttons also included tool tips that described each of the functions and were translated into the language(s) of administration in each country.

The following software functions were available for students to use to create the webpage layout:

- Change background: The background dialogue box included a color palette and some styled images suitable for use as a background. Students could style the background as a uniform color from the palette or select one of the images to stretch over the canvas.

- Borders: The borders dialogue box included a color palette and style options such as solid, dashed, and line weight (width in pixels).

- Text: The text dialogue box presented students with a familiar text editor with conventional text formatting functions. Students could enter text and style any part of the text using font, size, color, bold, italics, underline, alignment, bulleted lists, and numbered lists. When the styled text was added to the canvas the text box element could be moved around the page.

- Images: The images dialogue box was a simple gallery of image thumbnails that students could add to the canvas. The images included the band profile photo and band competition logo along with some other generic, primarily decorative images that could likely be found in a typical image library. Images added to the canvas could be moved around the page and resized by dragging the corners or sides of the image's bounding box.

- Icons: The icons dialogue box included some simple icons such as a tick, speech bubble, and love heart that could be added to the canvas and manipulated in the same way as the images.

At the top of the screen (see Figures 3.7 and 3.8) were clickable web-browser tabs that allowed the students to toggle between the web-design application and the email with the instructions for creating the webpage. The content of the email included four instructions: add the band's name; add the band's photo; add the band competition logo; and add the description of the band (Figure 3.8). The description of the band was included at the end of the email and could be copied and pasted into a textbox in the webpage editor. 
Figure 3.5: Band competition: large task details

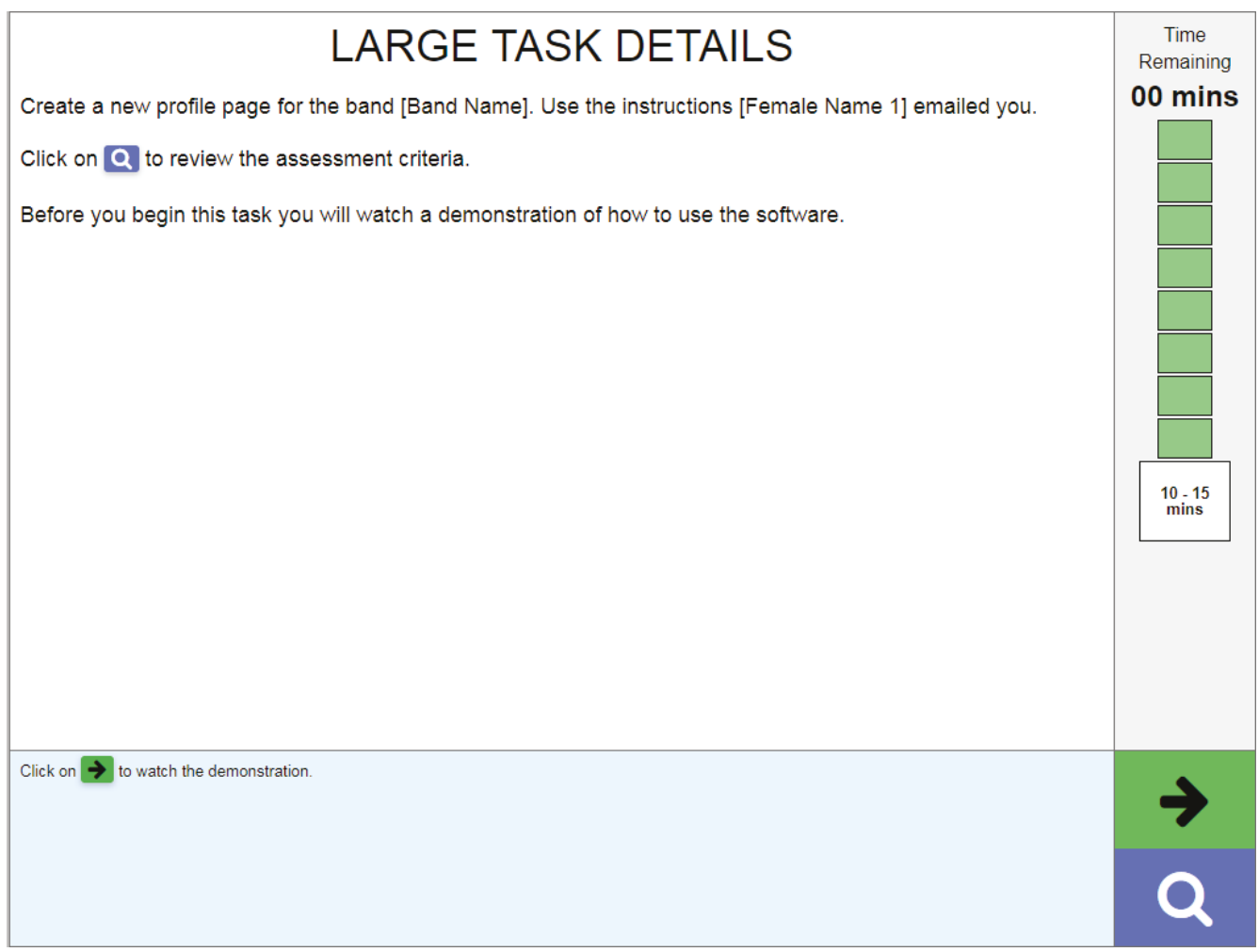

Figure 3.6: Band competition: assessment criteria review

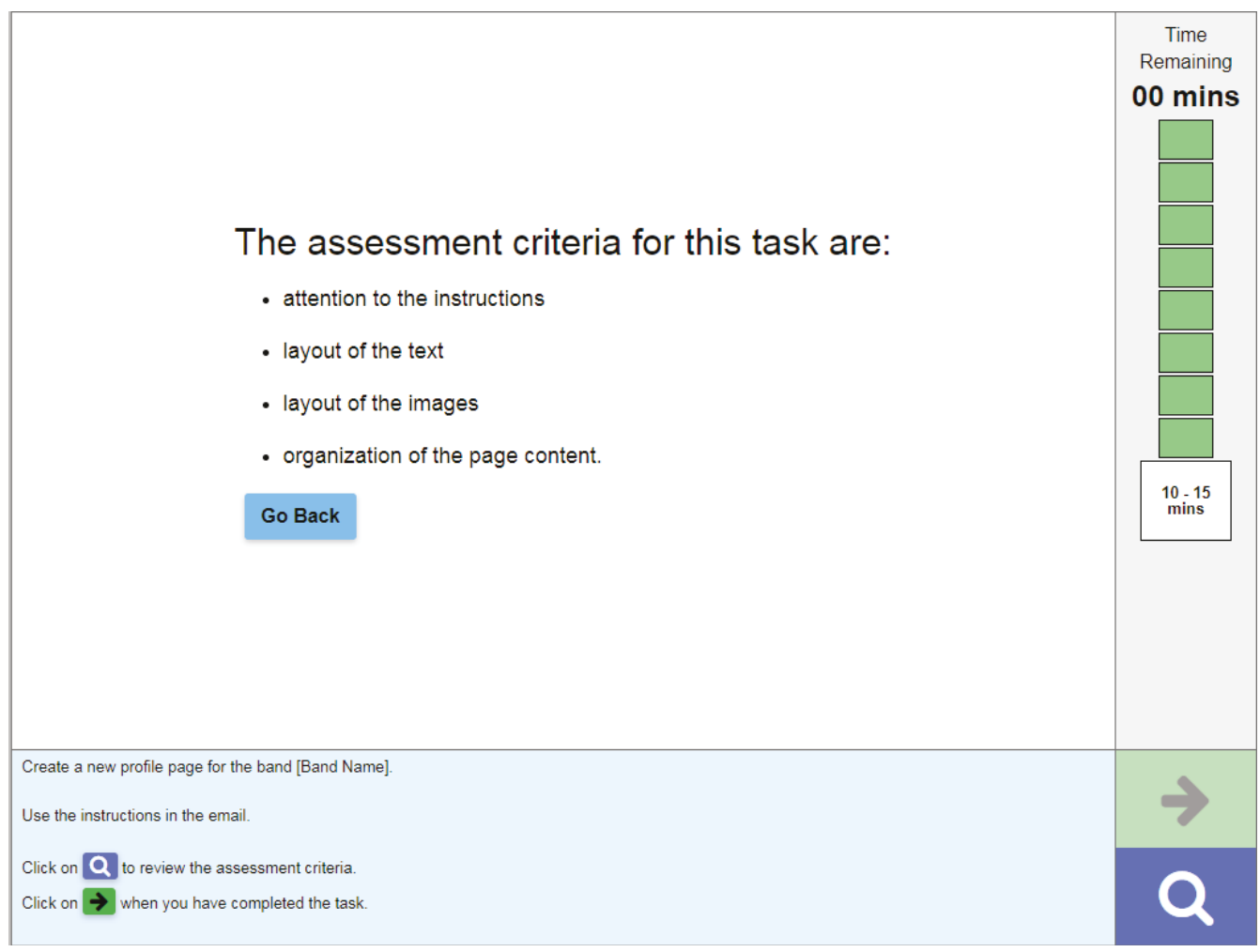


Figure 3.7: Band competition: large task webpage editor software

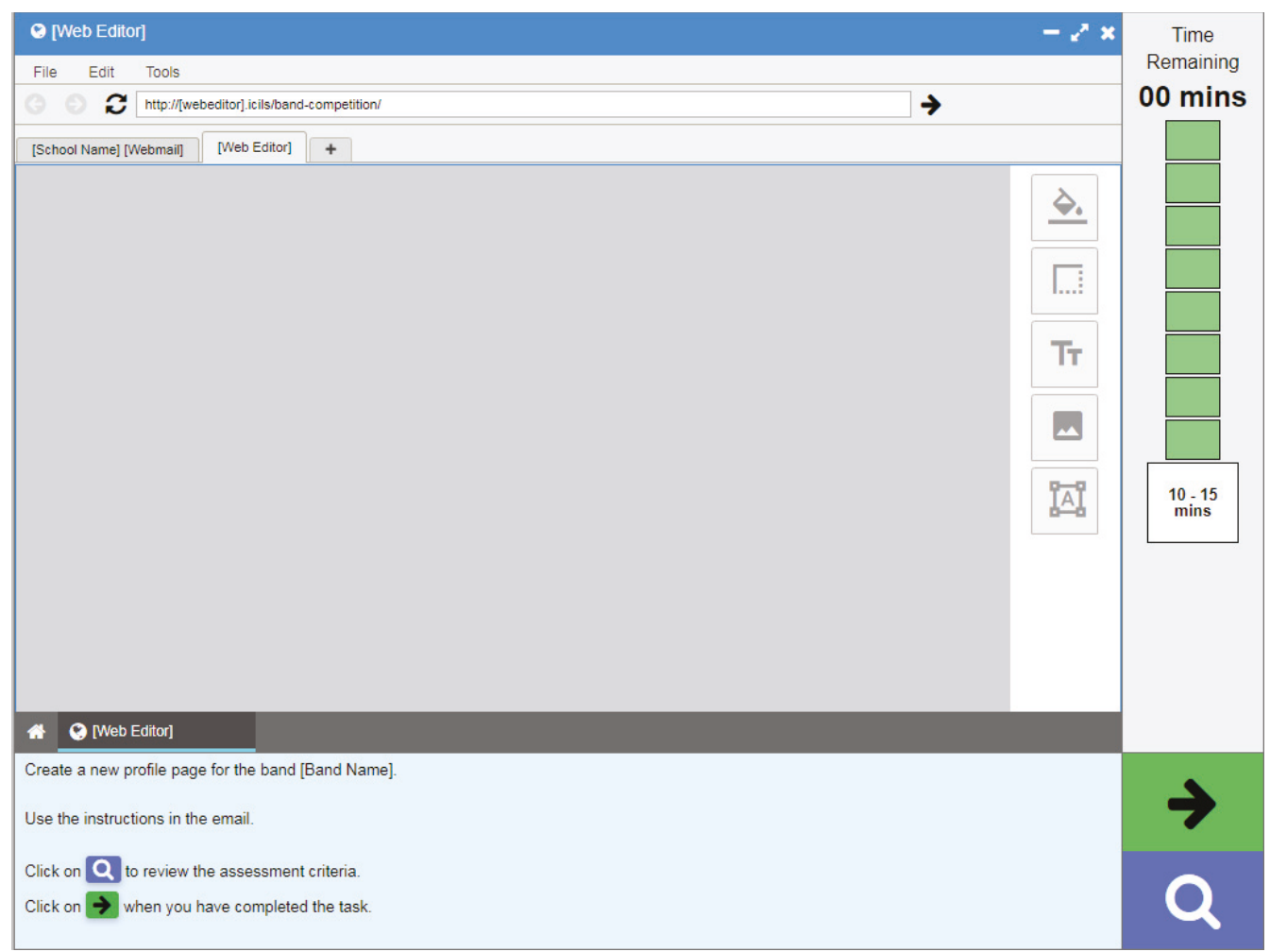

Figure 3.8: Band competition: large task instruction email

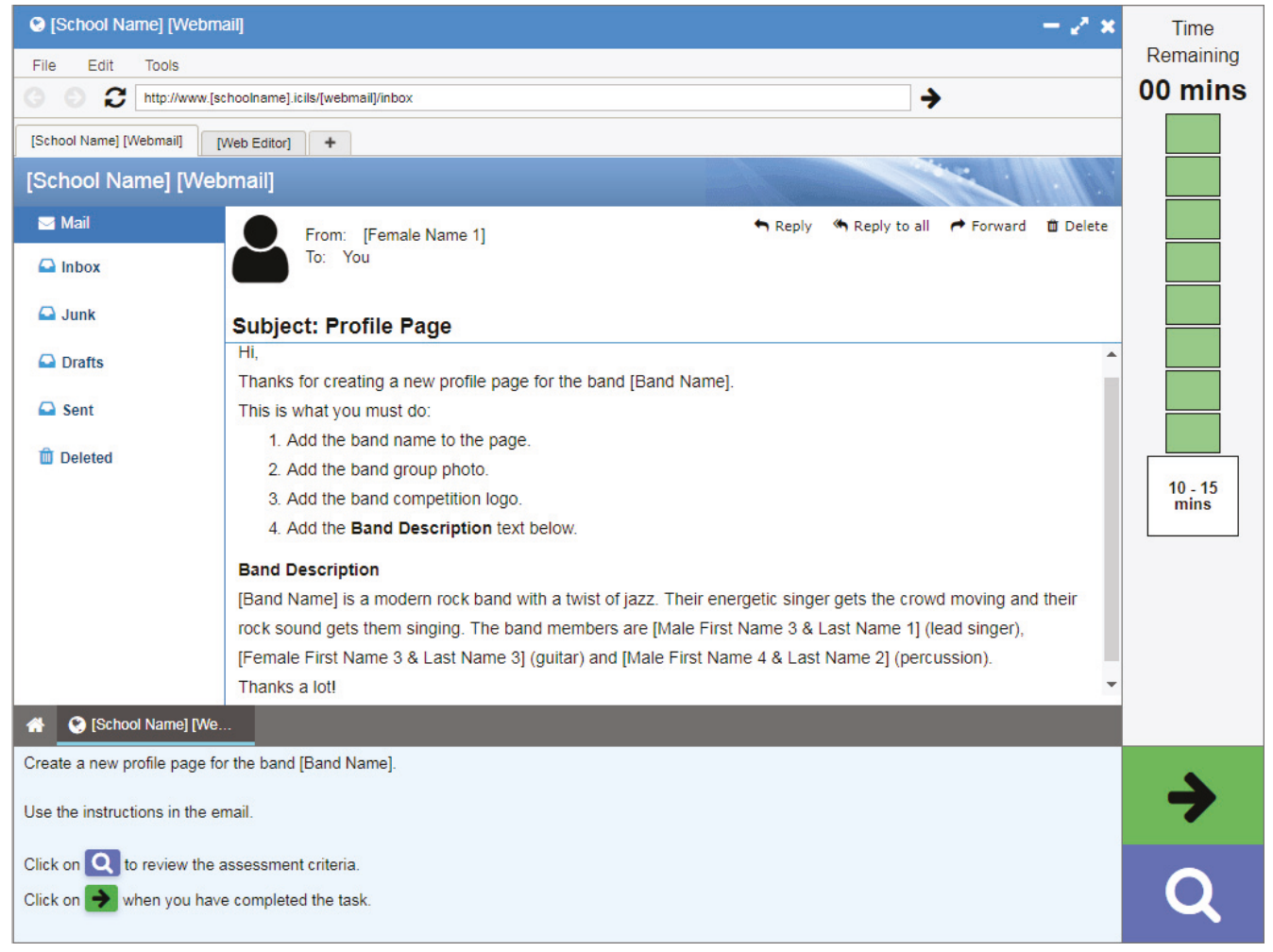


When students had completed their webpage, they clicked on the "I've finished" button, an action which saved their webpage as the "final" version. (The test delivery system also completed periodic automatic saves as a backup while students were working on their tasks.) Students then had the option of exiting the module or returning to the large task to continue working.

Once students had exited the module the final version of the webpage was saved in preparation for later scoring by trained scorers within each country. Each webpage was scored according to a set of seven criteria. As was the case for the open response items described previously, data were only included in analyses if they met IEA standards for scoring reliability.

The large tasks in the ICILS test modules were all scored using task-specific criteria. In general, these fell into two categories: technical proficiency and information management. Criteria relating to technical proficiency usually related to elements such as text and image formatting and use of color across the tasks.

Assessment of technical proficiency typically included a hierarchy from little or no control at the lower end, to the use of the technical features to enhance the communicative impact of the work at the higher end. The criteria thus focused on ability to use the technical features for the purpose of communication rather than on simply an execution of skills. Criteria relating to information management centered on elements such as adapting information to suit audience needs, selecting information relevant to the task (or omitting information irrelevant to it), and structuring the information within the task. Some criteria allowed for dichotomous scoring as either zero (no credit) or one (full credit) score points; others allowed for partial credit scoring as zero (no credit), one (partial credit), or two (full credit) score points.

The manifestation of the assessment criteria across the different tasks depended on the nature of each task. For example, information flow or consistency of formatting to support communication in a presentation with multiple slides requires consideration of the flow within and across the slides. The band competition large task comprised a webpage. As such, the scoring criteria related to the necessary elements and content of a webpage.

The scoring criteria used for the band competition's large task are presented according to their levels on the CIL scale and CIL scale difficulties as well as their ICILS 2018 assessment framework references, relevant score category and maximum score, the percentage of all students achieving each criterion, and the minimum and maximum percentages achieved on each criterion across countries (Table 3.3). (Full details of the percentages that students in each country achieved on each criterion appear in Appendix B.)

The design of the large tasks in the ICILS assessment meant that the tasks could be accessed by students regardless of their level of proficiency. The design also allowed students across this range to demonstrate different levels of achievement against the CIL scale, as evident in the levels shown in the scoring criteria (Table 3.3).

Criteria 4, 5, 6, and 7 each occupy a single row because they are dichotomous criteria (scored as zero or one); the description corresponding to a score of one is included for each of these criteria (Table 3.3). Criteria 1, 2, and 3 are partial-credit criteria (scored as zero, one, or two); descriptions corresponding to a score of one and a score of two are included for each of these criteria (Table 3.3). In most cases, the different creditable levels of quality within the partial-credit criteria correspond to different proficiency levels on the CIL scale. For example, the description of a score of one on Criterion 1 is shown at Level 1 (439 scale points) and the description of a score of two on the same criterion is shown at Level 4 (736 scale points).

The lower category for each of two partial-credit scoring criteria for the webpage corresponded to Level 1 on the CIL scale (Table 3.3). These both related to students' control over the role of page elements and reflected students' familiarity with the basic conventions of using one of size, 


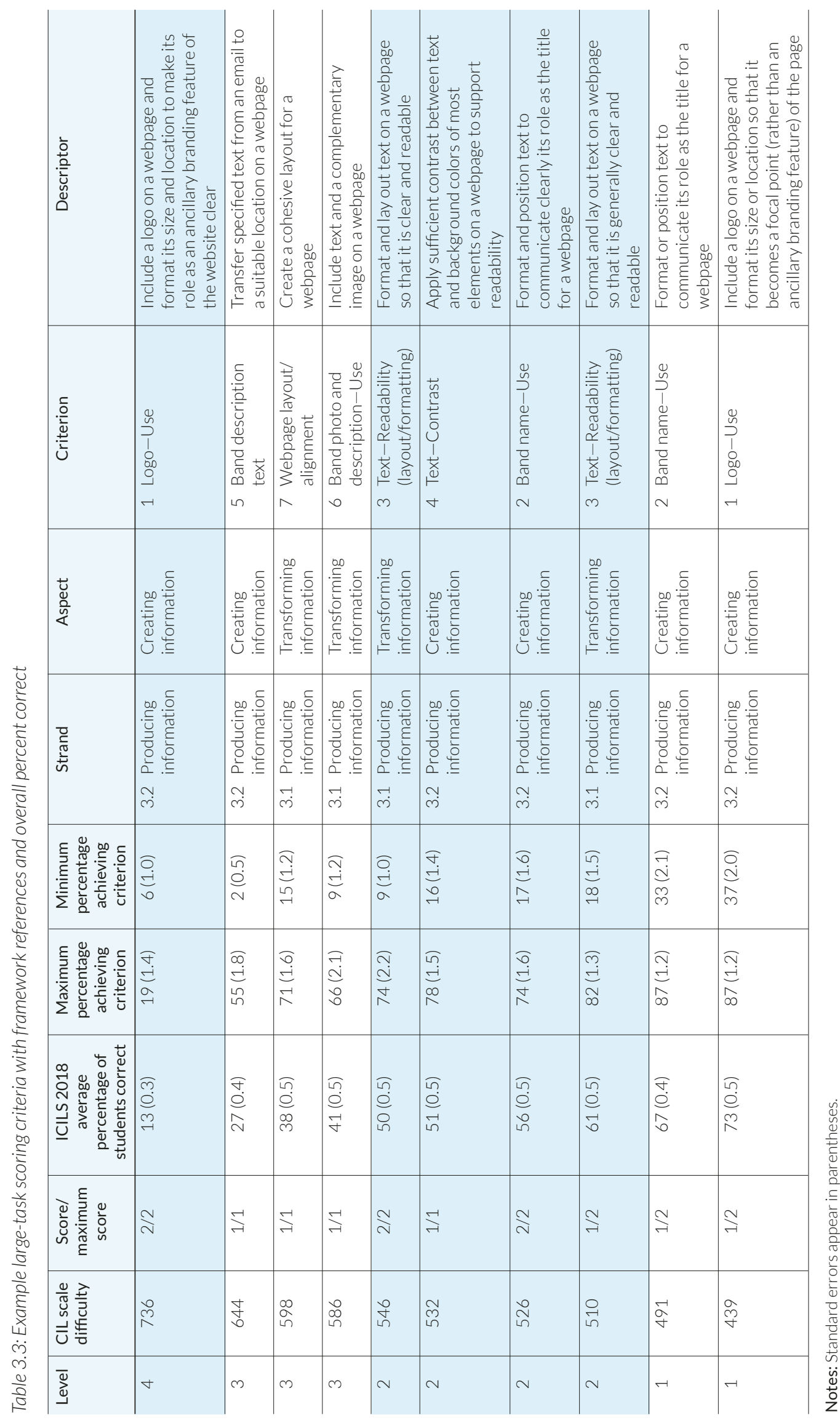


position, or formatting to denote the prominence of information. For Criterion 1, Logo-Use, 73 percent of students on average across all countries could include the logo as a prominent feature of the webpage. For Criterion 2, Band name-Use, 67 percent of students on average across all countries were able to create a textbox containing the band name and demonstrate some control of the textbox to indicate its role as the title for the webpage. Full credit on this criterion (Band name-Use) was achieved by 56 percent of students on average across all countries. To achieve this, students demonstrated control over the textbox by using both position and formatting to more clearly communicate its role as the title of the webpage representing Level 2 of the CILScale.

Three other scoring criteria corresponded to Level 2 achievement on the CIL scale. One of these, Text-Contrast, was dichotomous and appears at Level 2 only. On average across all countries 51 percent of students were able to demonstrate some planning in their use of color and ensure that most text elements in the webpage contrasted sufficiently with the background color to aid readability. The ICILS scoring system automatically generated a suggested score for TextContrast based on an adaptation of relevant criteria in the Web Contents Accessibility Guidelines 2.0 (WCAG 2.0; World Wide Web Consortium 2019). The ICILS technical report provides full details of this process (Fraillon et al. 2020). Human scorers reviewed the automatically generated suggested score for each webpage and could either accept or modify the score. Students whose webpages exhibited sufficient color contrast for most text elements to be read clearly received one score point.

Level 2 achievement on the scale was also exemplified by webpages with evidence of the use of the formatting tools (e.g., text size and bolding) to support the readability of text elements (Criterion 3, Text-Readability). Students who could use the formatting tools to support text readability for some elements received one score point while students who could consistently apply formatting to all text elements received two score points. On average across all countries, 61 percent and 50 percent of students achieved one and two score points respectively on this criterion.

At Level 3, students' execution of webpage design shows greater control and independent planning than at Levels 1 and 2 . The control over webpage elements typically showed evidence of independent planning extending beyond completion of the procedural aspects of the task. In essence, Level 3 webpages could be considered as complete products that were largely fit for purpose.

Three dichotomous scoring criteria exemplify Level 3 achievement. Each of these criteria required students to demonstrate technical proficiency with an emphasis on information management. Criterion 7, Webpage layout/alignment, required students to include at least two of three specified elements on the webpage ${ }^{14}$ : the band competition logo, band description text, and band photo. In addition, students needed to demonstrate control of the overall flow of information by arranging and manipulating the elements to create a harmonious layout. On average across all countries, 38 percent achieved full credit on this criterion.

Criterion 5, Band description text, assessed the accuracy with which students replicated the text describing the band from the email students were provided as part of the task (see Figure 3.8) on to the band webpage. The text could be copied and pasted or (somewhat less efficiently) transcribed from the email to the page. Full credit was awarded on this criterion only when the band description text on the webpage exactly matched that in the email. Students who included the signoff message in the email ("Thanks a lot!") received no credit for this criterion, as the signoff message was deemed to be irrelevant to the webpage. On average across all countries, 27 percent of students achieved full credit on this criterion. Criterion 6, Band photo

14 See Figure 3.8 for the elements described in the email, noting that use of the page title was scored separately. 
and description-Use, assessed the degree to which students communicated a clear relationship between the band description text and the band photo on the webpage. This relationship was typically demonstrated by positioning the text and photo close to each other, relative to the other elements on the page. On average across all countries, 41 percent of students achieved full credit on this criterion.

Full credit on Criterion 1, Logo-Use, is an example of Level 4, the highest level of achievement on the CIL scale. Students achieving full credit (two score points) showed careful and deliberate use of position and size to make the role of the band competition logo an ancillary branding feature, rather than a prominent feature, of the webpage. Achievement at this level is evidence of students' understanding the role of the webpage as a subpage of the band competition website and the importance of directing the viewer's attention to the most relevant information given the role of the webpage in the broader context of the website. On average across all countries, 13 percent of students achieved full credit on this criterion.

\section{Comparison of CIL across countries}

\section{Distribution of student achievement scores}

Across countries, the average student achievement scores on the CIL scale ranged from 395 to 553 scale points, thereby forming a range that spanned a standard of proficiency Below Level 1 to a standard of proficiency within Level 3 . This range was equivalent to approximately 1.5 standard deviations (Table 3.4).

Differences in the within-country student score distributions tended to be larger in countries with lower average achievement than in countries with higher average achievement, and the variation in student CIL scores within countries was greater than that across countries (Table 3.4). The distance between the lowest five percent and the highest five percent of CIL scores across countries ranged from 216 to 347 scale points (with a median of 269 scale points), in comparison to a range of average scores across all countries of 157 scale points.

The differences between the average scores of adjacent countries were between two and 18 scale points with the exception of a difference of 55 scale points between the average scores of students in Uruguay and Kazakhstan.

\section{CIL relative to the ICT development index for each country}

As additional context, we also calculated the average age of students in ICILS countries and then provide ICT development index (IDI) scores for each country ${ }^{15}$ (Table 3.4).

In ICILS 2013, we reported that that higher IDI scores were typically associated with higher CIL scores across countries (Fraillon et al. 2014). In ICILS 2018 the association between CIL achievement and the IDI scores across countries was again strong, with a Pearson's correlation coefficient of 0.72 . As in ICILS 2013 it is important to take into account the relatively small number of countries when interpreting these results.

15 The IDI is a composite index that incorporates 11 different indicators relating to ICT readiness (infrastructure, access), ICT usage (individuals using the internet), and proxy indicators of ICT skills (adult literacy, secondary and tertiary enrollment). Each country is given a score out of 10 that can be used to provide a benchmarking measure with which to compare ICT development levels with other countries and within countries over time. Countries are ranked according to their IDI score. 


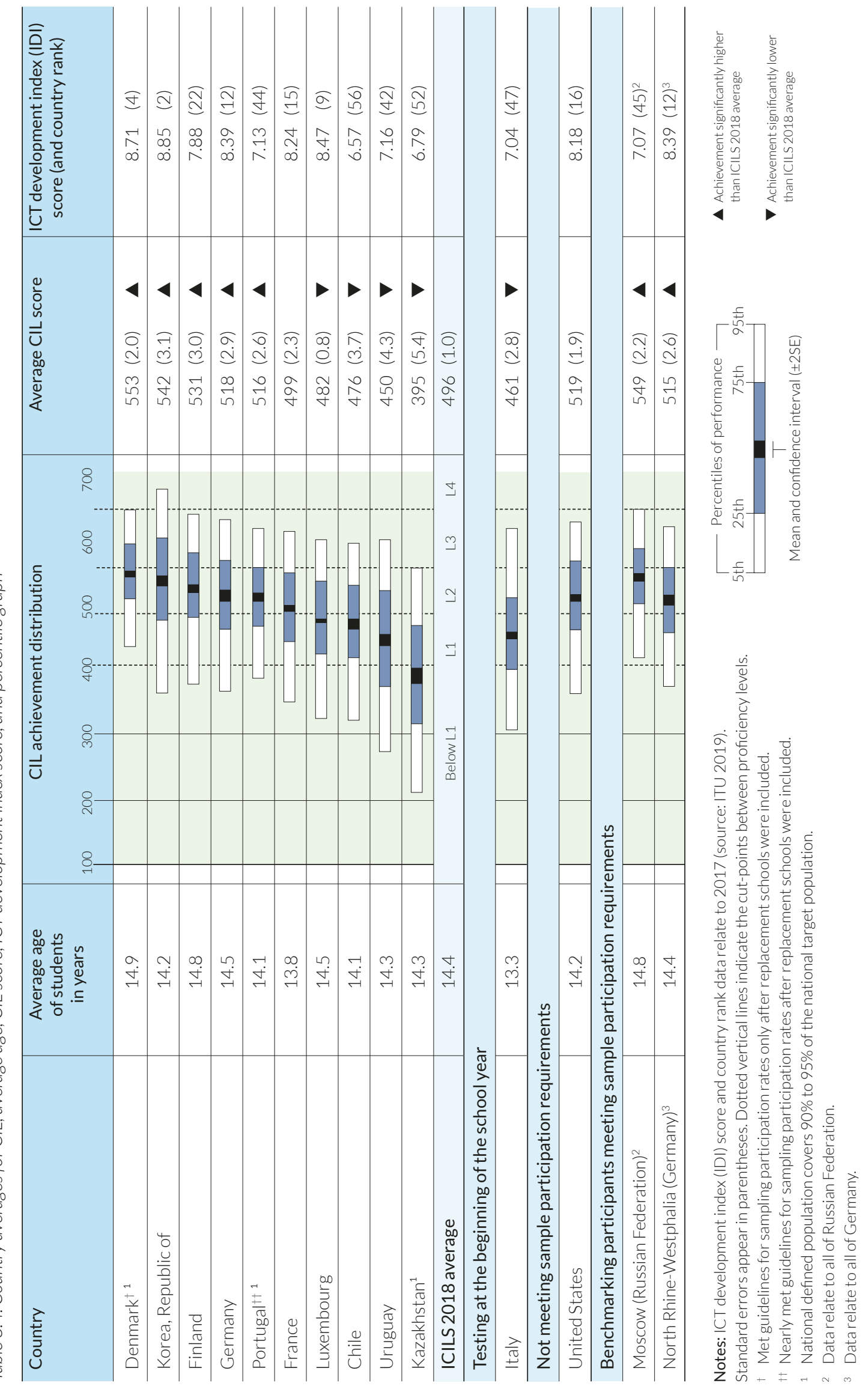




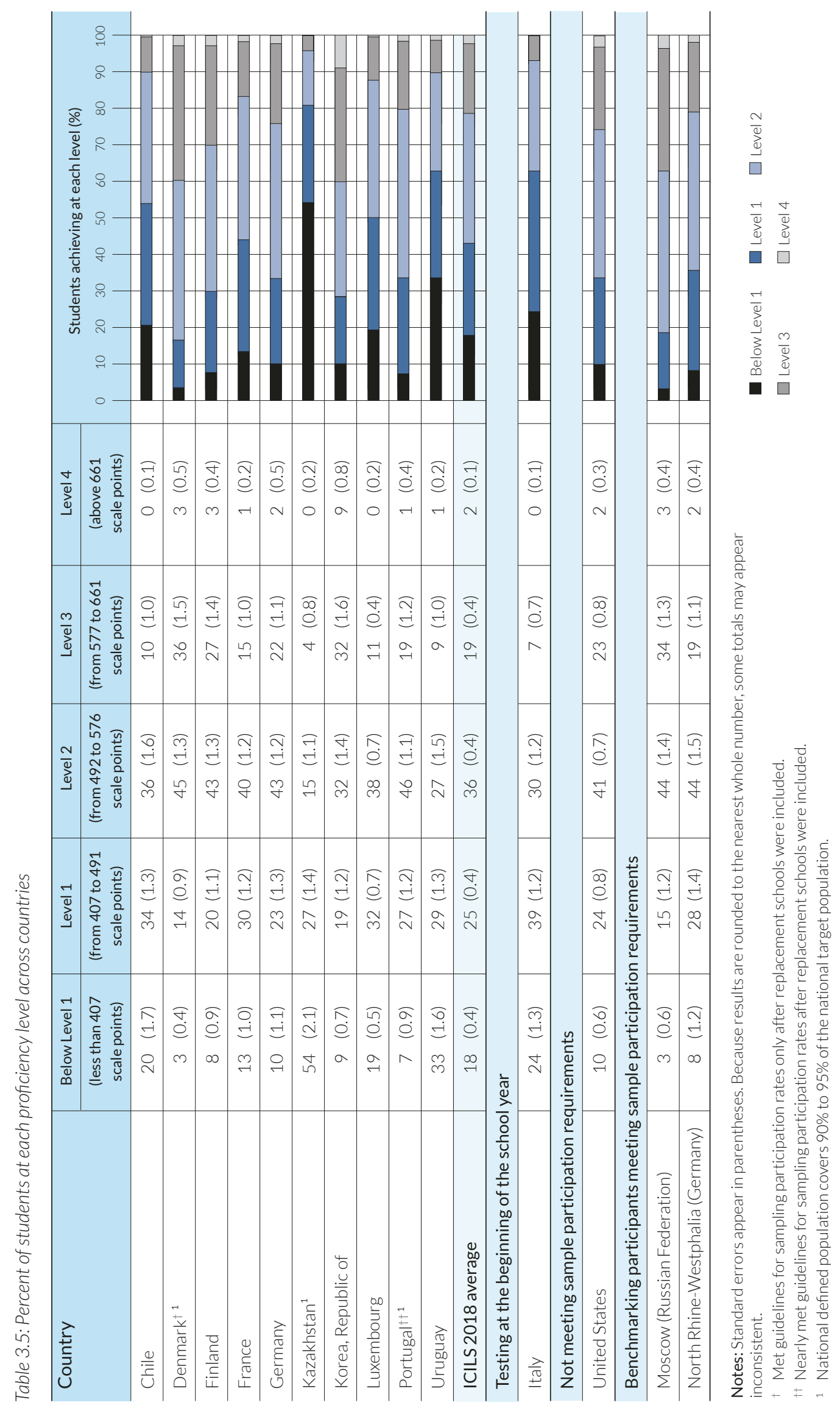




\section{Achievement across countries with respect to proficiency levels}

Across all countries, 80 percent of students achieved scores that placed them within CIL Levels 1, 2, and 3 (Table 3.5). Overall, however, the distribution of student scores across countries and benchmarking participants sits largely within Level 2. The highest percentage of students is in Level 2 in all countries and benchmarking participants except for Uruguay and Kazakhstan.

Although majorities of students in most countries had CIL scores in Level 2, there was some variation in the distribution of percentages across countries. In three countries with the highest percentage of students at Level 4 (Korea, Denmark, and Finland) the proportion of students above Level 2 (i.e., at Levels 3 and 4 combined) is higher than the proportion of students below Level 2 (i.e., at Level 1 or Below Level 1). Across all other countries, the proportion of students above Level 2 is lower than the proportion of students below Level 2.

\section{Trends in CIL achievement}

The ICILS 2018 test included three secure CIL test modules from ICILS 2013 comprising 61 items. This meant that we could report student CIL achievement scores for the current ICILS cycle on the scale established in 2013, and also compare changes in CIL achievement across these first two cycles of ICILS. Four of the countries that participated in ICILS 2013 also participated in ICILS 2018. Three of these countries met the necessary sample participation requirements within each cycle to allow valid comparisons of students' CIL achievement across the two cycles.

The differences in average CIL achievement scores in each of the three countries that met the necessary sample participation requirements in each of ICILS 2013 and 2018 were small (11 scale points or less) and not statistically significant (Table 3.6). However, in Chile, the percentage of students achieving at Level 2 or above decreased by seven percentage points between 2013 and 2018 and this difference was statistically significant. The difference in the percentage of students achieving at Level 2 or above in Germany and Korea did not change significantly between 2013 and 2018 (Table 3.6).

\section{Variation in CIL across countries with respect to student background characteristics}

In this section we address Research Question CIL 4: What aspects of students' personal and social backgrounds (such as gender and socioeconomic background) are related to students' CIL?

Our focus at this point is on student characteristics that are commonly associated with student achievement as reported in large-scale assessments such as ICILS. In this section we report on the associations between students' CIL and student gender, and between students CIL and variables associated with students' socioeconomic status (SES), whether or not students had an immigrant background, and the language students spoke at home. (See Chapter 7 for a further investigation, based on regression analyses, of the relationships between student CIL and student-level and school-level factors.)

\section{Gender and CIL}

Previous surveys of digital literacies have reported that female students outperform male students. The Australian triennial sample assessments of ICT literacy reported that the average achievement of year 6 and year 10 female students was statistically significantly higher than that of year 6 and year 10 male students in each of 2008, 2011, 2014, and 2017 (ACARA 2018). The US National Assessment of Education Progress sample assessment of Technology and Engineering Literacy reported higher achievement scores for female grade 8 students in ICT in both 2014 and 2018 (US Department of Education, National Center for Education Statistics 2018). In ICILS 2013 it was reported that "the average CIL scale scores of female students were statistically significantly higher than those of male students in all countries except Turkey and Thailand" (Fraillon et al. 


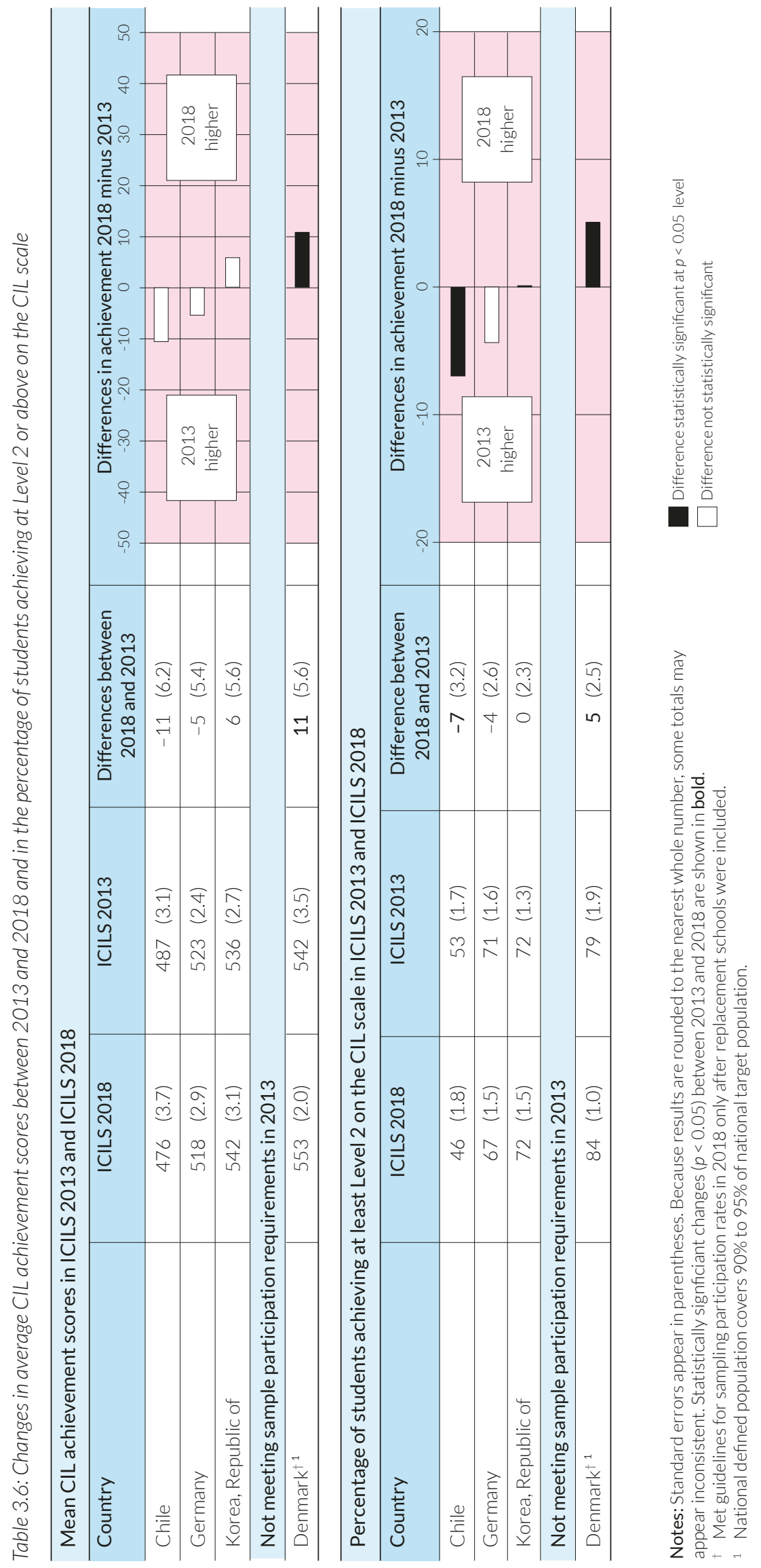


2014, p. 102) and that in those two countries the difference in performance between male and female students was not statistically significant.

In ICILS 2018, the average CIL scale scores of female students were statistically significantly higher than those of male students in all countries and benchmarking participants except Chile, Uruguay, and North Rhine-Westphalia (Germany). In these three participants, there was no statistically significant difference between the average scores of female students and male students (Table 3.7). On average across all countries, the average score for female students was 505 scale points and for male students it was 488 scale points, an average difference of 18 scale points and equivalent to about one fifth of the ICILS standard deviation.

The magnitude of the statistically significant differences in achievement between female and male students within countries and benchmarking participants ranged from six scale points in Moscow (Russian Federation) to 39 scale points in Korea. ${ }^{16}$

\section{Home background indicators and CIL}

\section{Socioeconomic background}

Socioeconomic background is a construct regarded as manifest in occupation, education, and wealth (Hauser 1994). While it is widely regarded internationally as an important correlate of a range of learning outcomes (Sirin 2005; Woessmann 2004), there is no scholarly consensus on which measures should be used for capturing family background (Entwistle and Astone 1994; Hauser 1994) and no agreed standards for creating composite measures of SES (Gottfried 1985; Mueller and Parcel 1981). Furthermore, in the context of international studies, there are caveats relating to the validity and cross-national comparability of socioeconomic background measures (Buchmann 2002). In this chapter, our consideration of the influence of socioeconomic background on CIL focuses on within-country associations between indicators of SES and achievement.

In ICILS 2013, "[c]haracteristics reflecting higher socioeconomic status were associated with higher CIL proficiency both within and across countries" (Fraillon et al. 2014, p. 250). To measure and report on socioeconomic background during ICILS 2018, we used responses from the student questionnaire. These related to parental occupational status, parental education, and the number of books in the home, and were the same three socioeconomic background variables used in ICILS 2013.

The ICILS student questionnaire collected data on parental occupational status through questions that allowed students to give open-ended responses. The students' responses were classified according to the International Standard Classification of Occupations (ISCO-08) framework (International Labour Organization 2007). Research indicates relatively high consistencies between data on parental occupation collected from students and from parents (Schulz 2006; Vereecken and Vandegehuchte 2003).

To generate a continuous measure of occupational status, Ganzeboom et al. (1992) coded the ISCO codes in order to derive their international socioeconomic index (SEI). The SEI provides a cross-nationally comparable framework for organizing occupations in a hierarchical order according to their occupational status. We assigned SEI scores to each parent's occupation and then, for each student with two parents, took the higher of the two SEI scores as the indicator score. For students from single-parent families, the one score served as the indicator.

16 The nonsignificant differences were in Chile (eight scale points), Uruguay (five scale points), and North RhineWestphalia (Germany) (four scale points). 


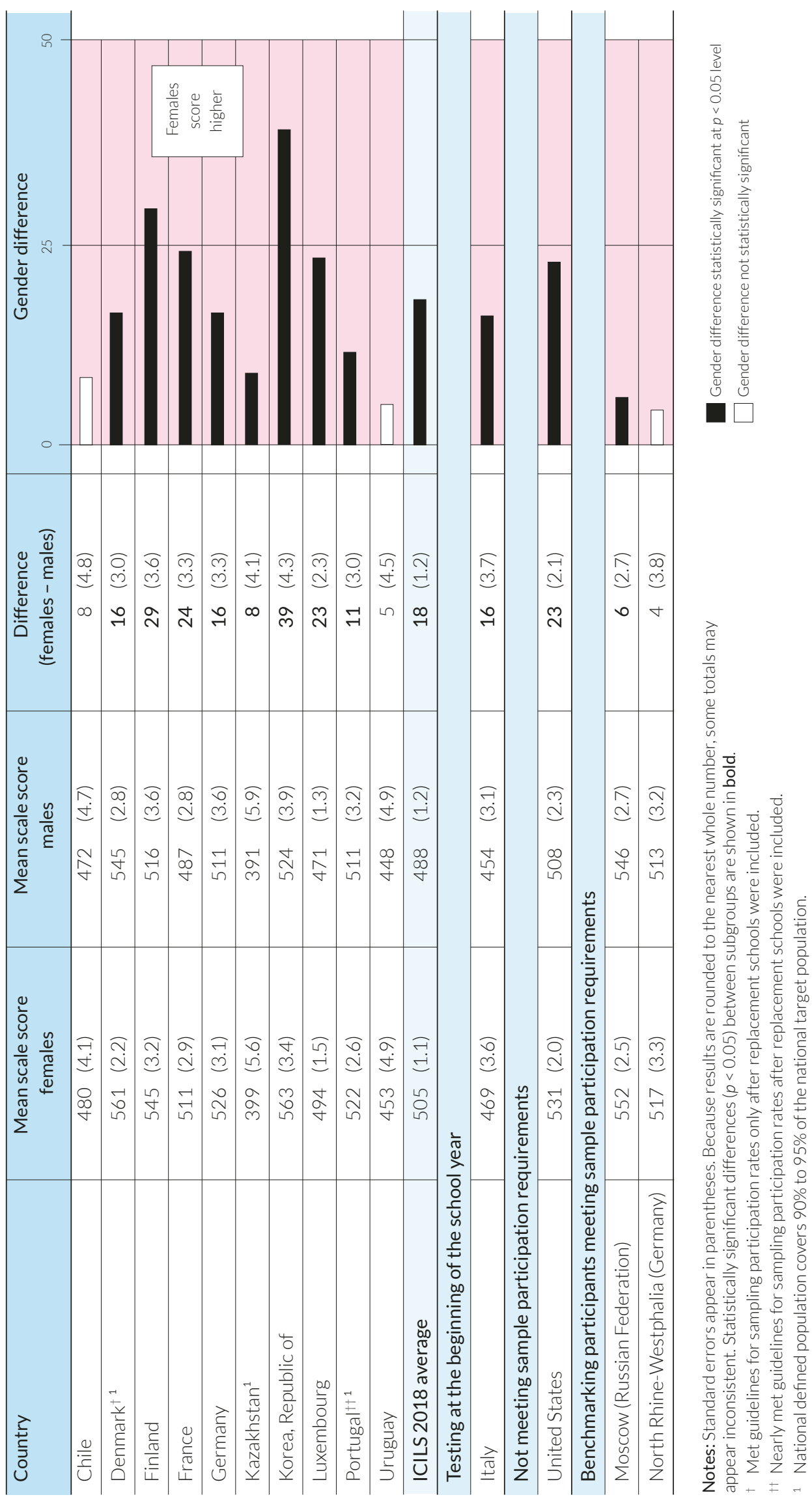


The SEI scale is continuous and ranges from 16 to 90 score points. To describe the parental occupation results in terms of broader categories, we divided the SEI scale into two groups based on international cut-off points. These were "low-medium occupational status" (below 50 score points) and "medium-high occupational status" (50 score points and above).

To measure the educational attainment of each parent (based on the student responses), we used predefined categories denoting educational levels in each country. These categories were constructed with reference to the International Standard Classification of Education (ISCED) and consisted of "ISCED 6, 7, or 8," "ISCED 4 or 5," "ISCED 3," "ISCED 2," and "did not complete ISCED 2" (OECD 1999; UNESCO 2006). When students provided data for both their parents, we used the highest ISCED level as the indicator of parental educational attainment, and when summarizing the association between the highest level of parental education and students' CIL achievement, we used two categories of parental education: "below ISCED 6 (short-cycle tertiary or below)" and "ISCED 6, 7, or 8 (Bachelor's degree or higher)."

As a measure of home literacy resources, we used students' reports of number of books in the home. Number of books was broken down into six categories: "0 to 10 books," "11 to 25 books," "26 to 100 books," "101 to 200 books," and "more than 200 books." When summarizing the relationship between the number of books in the home and students' CIL achievement, we used two categories: "below 26 books" and "26 books and above."

We found statistically significant associations between each of the three socioeconomic background variables and CIL across all countries (Table 3.8). (As a brief explanatory note, the horizontal graphs in these types of tables indicate the magnitude [in CIL scale points], direction, and statistical significance of the differences between the average scores of students in each group. For each of the variables, green bars indicate a statistically significant difference in student $\mathrm{CIL}$ in favor of one group, and red bars indicate a statistically significant difference in favor of another group.)

For each of the three socioeconomic background variables in each country, and overall across countries, the average CIL scores of students in the "higher" groups were statistically significantly higher than that of students in the "lower" groups. However, the magnitude of the differences between groups for all three variables varied across countries.

On average across all countries, the difference between students in the highest and lowest parental occupation categories was $36 \mathrm{CIL}$ scale points, with differences ranging from 18 scale points in Korea to 51 scale points in Luxembourg.

The difference between the average CIL scale scores of students in the lower (short-cycle tertiary or below) and in the higher (Bachelor's degree or higher) parental education groups on average across all countries was 31 scale points, with the minimum difference of 15 scale points in Finland and the maximum of 47 scale points in Chile and Uruguay.

Cross-nationally, the difference between the average CIL scale scores of students who reported having 26 or more books at home and those students who reported fewer than 26 books at home on average was 50 scale points, with a minimum difference of 31 scale points in Portugal and a maximum of 63 scale points in Luxembourg.

All three indicators of students' SES contributed to a composite index of SES (this index is included in the multilevel regression analyses presented in Chapter 7). 


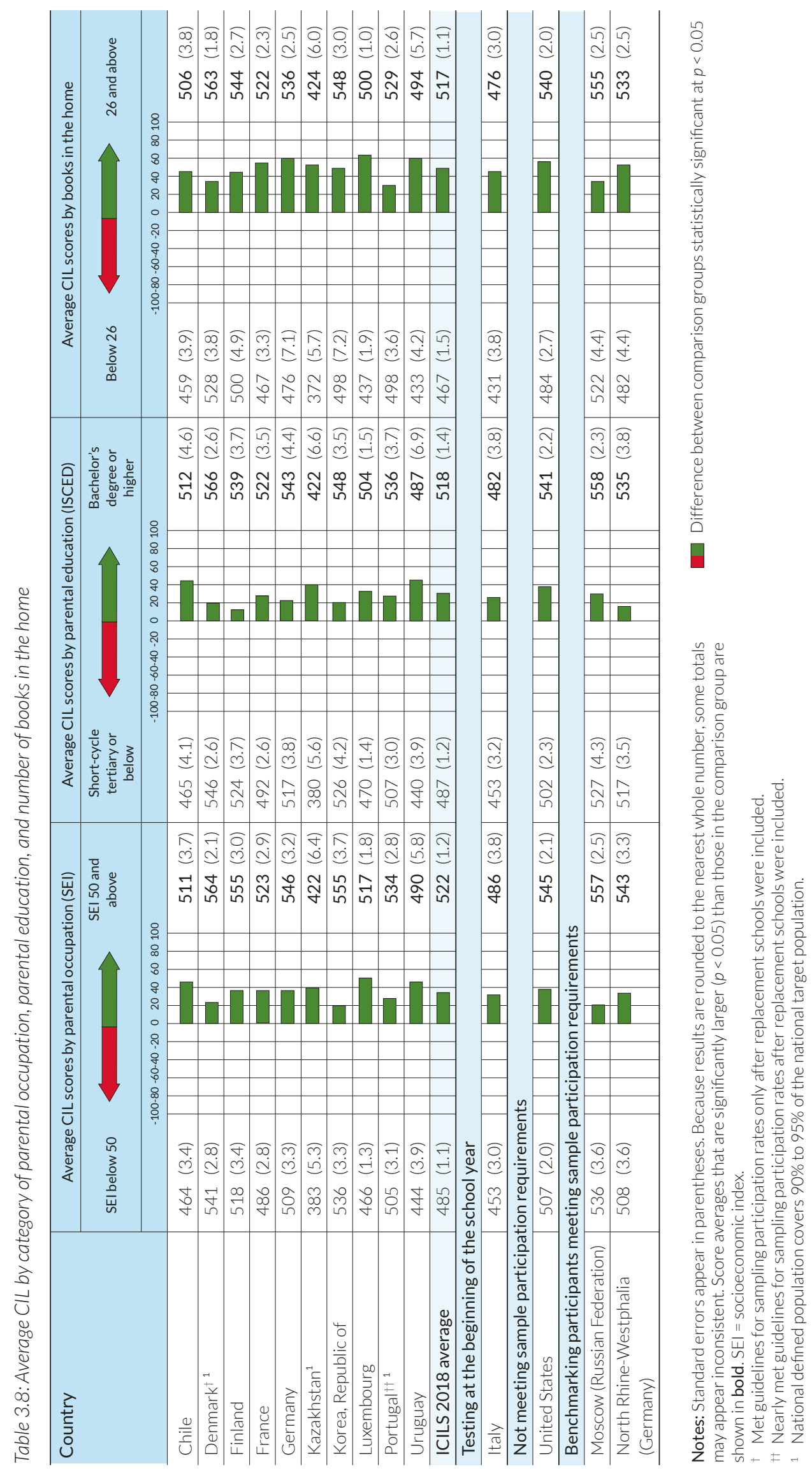




\section{Immigrant status and language use}

Many studies provide evidence of the influence of students' cultural and language background on their educational performance (see, for example, Elley 1992; Kao 2004; Kao and Thompson 2003; Mullis et al. 2007; Stanat and Christensen 2006). Students from immigrant families, especially those families recently arrived in a country, often lack proficiency in the language of instruction and may be unfamiliar with the norms of the dominant culture. Ethnic minorities also tend to have a lower SES, which in turn is often negatively associated with learning and engagement. A number of studies indicate that when socioeconomic background is controlled for, immigrant status and language provide unique predictors of students' literacy achievement (Lehmann 1996).

In ICILS 2013 we reported that the CIL scores in students without immigrant background tended to be higher than those with an immigrant background. Similarly, CIL scores in students who reported speaking the test language at home tended to be higher than those who reported speaking another language at home (Fraillon et al. 2014).

As a means of measuring these aspects of student background, the ICILS student questionnaire asked students about their own and their parents' countries of birth. The questionnaire also asked students to specify which language was spoken most frequently at home.

The question asking where students and their parents were born was first coded to classify each student and any reported parents as "born in country of test" or "not born in country of test." These data were further reduced to form a single variable relating to the student. This variable was coded as "immigrant family" when the student reported all parents ${ }^{17}$ as born abroad (regardless of where the student was born) and "non-immigrant family" when at least one parent was born in the country where the survey was conducted. The second question asked students what language they spoke at home most of the time. This variable was coded as "language of test" or "other" for the purpose of the analyses. Nearly all students across most participating countries provided valid responses to these questions.

Students without immigrant backgrounds tended to have higher CIL average scores than those with an immigrant background (Table 3.9). In nine countries and benchmarking participants that met the ICILS technical requirements, the students from non-immigrant family backgrounds had statistically significantly higher average CIL scores than students from immigrant backgrounds. In Chile, Uruguay, and Portugal the difference between the two groups was not statistically significant. On average across countries and benchmarking participants, the difference between students with immigrant backgrounds and those without was $28 \mathrm{CIL}$ scale points. The differences ranged from 19 scale points in Moscow (Russian Federation) to 51 scale points in Finland.

In most participating countries, majorities of students indicated speaking the test language at home. Across countries and benchmarking participants, CIL scores tended to be higher among students speaking the test language at home; the average difference was 38 scale points. For 10 participating countries and benchmarking participants meeting the technical requirements, we recorded statistically significant differences between students speaking the test language and those speaking other languages at home. The statistically significant positive differences ranged from 31 scale points in Luxembourg to 66 in Uruguay.

17 "All parents" refers to both parents when a student reported on the background of two parents or to one parent if the student reported on the background of only one parent. 


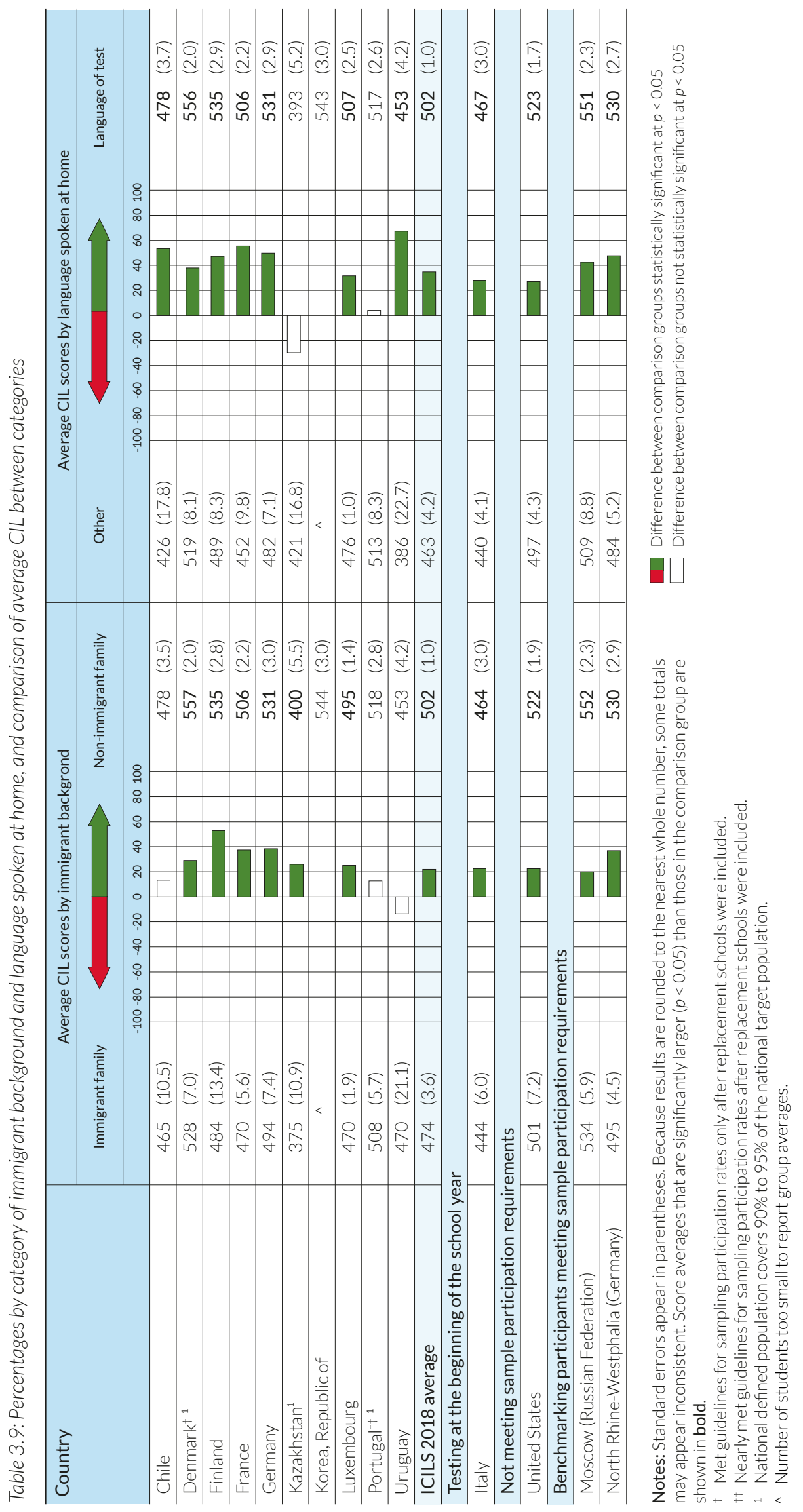




\section{Computers at home and experience using computers}

The ICILS 2018 assessment framework explains that the CIL construct assessed in ICILS 2018 was conceptualized with the notion of a computer having sufficient screen size (including available display space) and a keyboard and mouse to support the development of information products that include manipulation of layout elements and the potential for extended text (Fraillon et al. 2019). In ICILS 2018, students were required to complete the CIL test on a device with a minimum screen size of $29 \mathrm{~cm}$ and an external keyboard and mouse. While the test could be completed on a tablet device, this was only permitted if the device included an external keyboard and mouse. This conceptual and operational definition of a computer was consistent with ICILS 2013.

In ICILS 2013, we reported that "students with more computers at home tended to have higher CIL scores" (Fraillon et al. 2014, p. 116) and that students' experience in using computers (in approximate years) was also positively associated with CIL achievement (Fraillon et al. 2014). In ICILS 2018 students were asked to report separately the number of computers (desktop or laptop) and tablet devices (including e-readers) at home as well as the number of years of experience they had using computers and tablet devices. As CIL was conceptualized with the notion of a computer that most closely resembles that defined as desktop or laptop, we report on the relationship between $\mathrm{CIL}$ achievement and responses to the two questions (number at home and years of experience using) relating only to desktop or laptop computers. (In Chapter 5, we examine the relationships between CIL and home resources and experience of all digital devices in more detail.)

In ICILS 2018, students with more computers at home tended to have higher CIL scores (Table 3.10). On average across countries, the CIL scores of students reporting having two or more computers were 32 scale points higher than those who reported having fewer than two computers at home. This difference ranged from 17 points in Portugal to 48 points in Kazakhstan and was statistically significant in all countries.

Students' years of experience using computers was also positively associated with CIL (Table 3.10). On average, across all countries, the CIL scores of students with five or more years of experience using computers were 32 scale points higher than those with less than five years' experience. The difference was statistically significant in all countries and benchmarking participants except North Rhine-Westphalia (Germany) where the difference was seven scale points. The statistically significant differences ranged from 10 scale points in Germany to 63 scale points in Uruguay. 


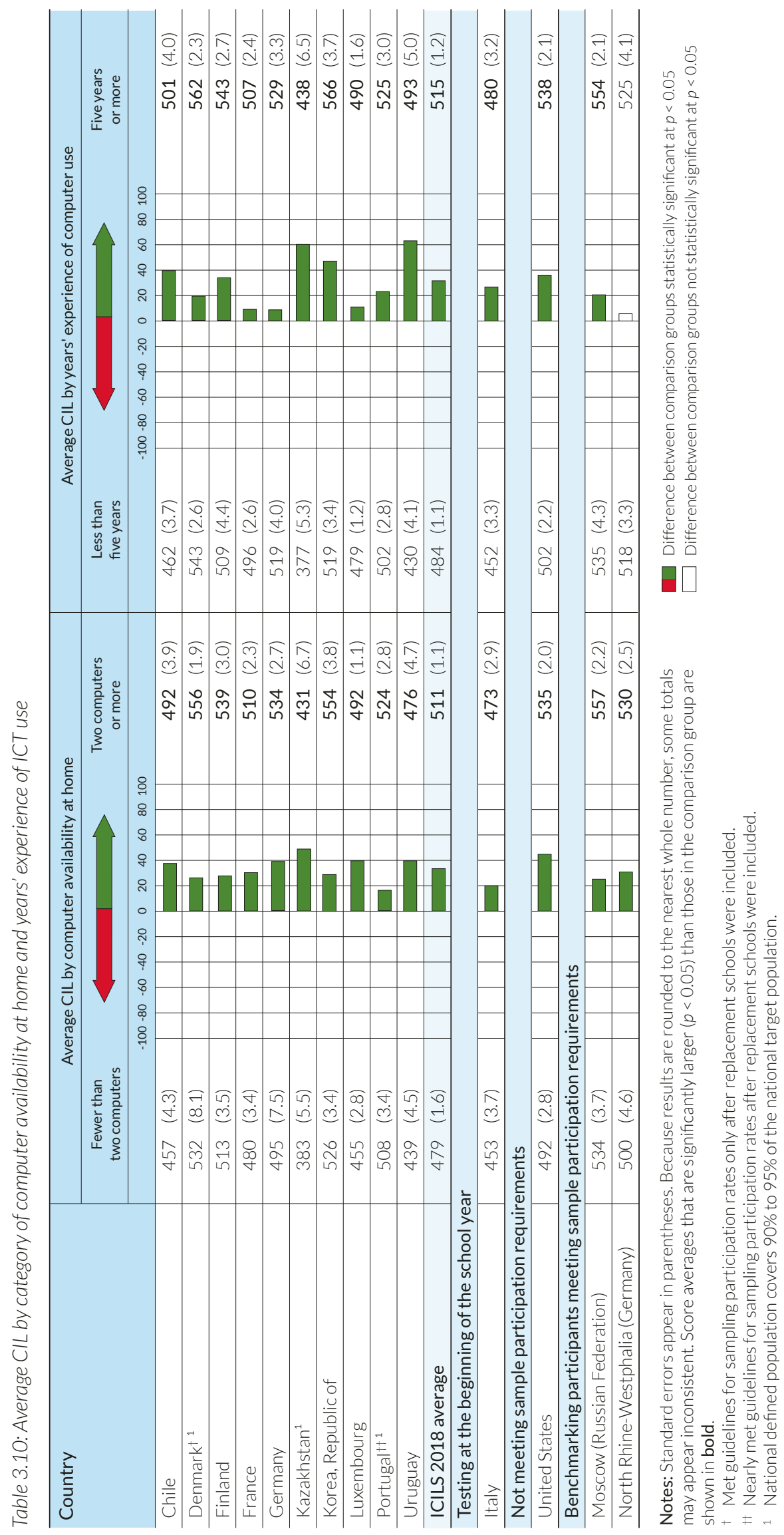




\section{References}

ACARA. (2012). National Assessment Program-ICT literacy years 6 and 10 report 2011. Sydney, Australia: Australian Curriculum, Assessment and Reporting Authority. Retrieved from https://www.nap.edu. au/_resources/NAP_ICTL_2011_Public_Report_Final.pdf.

ACARA. (2018). NAP sample assessment ICT literacy years 6 and 10 November 2018. Sydney, Australia: Australian Curriculum, Assessment and Reporting Authority. Retrieved from https://www.nap.edu.au/docs/ default-source/default-document-library/2017napictlreport_final.pdf?sfvrsn=2

Binkley, M., Erstad, E., Herman, J., Raizen, S., Ripley, M., Miller-Ricci, M., \& Rumble, M. (2012). Defining 21st century skills. In P. Griffin, B. McGaw, \& E. Care (Eds.), Assessment and teaching of 21st century skills (pp. 17-66). Dordrecht, The Netherlands: Springer. Retrieved from http://dx.doi.org/10.1007/978-94007-2324-5_2.

Buchmann, C. (2002). Measuring family background in international studies of education: Conceptual issues and methodological challenges. In A. Porter, \& A. Gamoran (Eds.), Methodological advances in cross-national surveys of educational achievement (pp. 150-197). Washington, DC: National Academy Press. Retrieved from https://www.nap.edu/read/10322/chapter/7\#153.

Dede, C. (2009). Comparing frameworks for 21st century skills. Cambridge, MA: Harvard Graduate School of Education.

Elley, W. B. (1992). How in the world do students read? The Hague, The Netherlands: International Association for the Evaluation of Educational Achievement (IEA). Retrieved from https://www.iea.nl/ publications/study-reports/international-reports-iea-studies/how-world-do-students-read.

Entwistle, D. R., \& Astone, N. M. (1994). Some practical guidelines for measuring youth's race/ethnicity and socioeconomic status. Child Development, 65, 1521-1540.

Fraillon, J., Ainley, J., Schulz, W., Duckworth, D., \& Friedman, T. (2019). International Computer and Information Literacy Study 2018 assessment framework. Cham, Switzerland: Springer. Retrieved from https:// www.springer.com/gp/book/9783030193881.

Fraillon, J., Ainley, J., Schulz, W., Friedman, T., \& Gebhardt, E. (2014). Preparing for life in a digital age: The IEA International Computer and Information Literacy Study international report. Cham, Switzerland: Springer. Retrieved from https://www.springer.com/gp/book/9783319142210.

Fraillon, J., Schulz, W., Friedman, T., \& Meyer, S. (Eds.). (2020). IEA International Computer and Information Literacy Study 2018 technical report. Amsterdam, The Netherlands: International Association for the Evaluation of Educational Achievement (IEA). Manuscript in preparation.

Ganzeboom, H. B. G., de Graaf, P. M., \& Treiman, D. J. (1992). A standard international socioeconomic index of occupational status. Social Science Research, 21(1), 1-56.

Gottfried, A. (1985). Measures of socioeconomic status in child development research: Data and recommendations. Merrill-Palmer Quarterly, 31(1), 85-92.

Hauser, R. M. (1994). Measuring socioeconomic status in studies of child development. Child Development, 65, 1541-1545.

International Labour Organization. (2007). International Standard Classification of Occupations: ISCO-2008. Geneva, Switzerland: Author.

ITU. (2019). IDI 2017 rank [webpage]. Geneva, Switzerland: International Telecommunications Union. Retrieved from https://www.itu.int/net4/ITU-D/idi/2017/index.html.

Kao, G. (2004). Social capital and its relevance to minority and immigrant populations. Sociology of Education, 77, 172-183.

Kao, G., \& Thompson, J. S. (2003). Racial and ethnic stratification in educational achievement and attainment. Annual Review of Sociology, 29, 417-442. Retrieved from https://www.annualreviews.org/ doi/abs/10.1146/annurev.soc.29.010202.100019.

Lehmann, R. (1996). Reading literacy among immigrant students in the United States and former West Germany. In M. Binkley, K. Rust, \& T. Williams (Eds.), Reading literacy in an international perspective: Collected papers from the IEA Reading Literacy Study (pp. 101-114). Washington, DC: National Center for Education Statistics (NCES).

Mueller, C.W., \& Parcel, T. L. (1981). Measures of socioeconomic status: Alternatives and recommendations. Child Development, 52(1), 13-30.

Mullis, I. V. S., Martin, M. O., Kennedy, A., \& Foy, P. (2007). PIRLS 2006 international report: IEA's Progress in International Reading Literacy Study in primary schools in 40 countries. Chestnut Hill, MA: TIMSS \& 
PIRLS International Study Center, Boston College. Retrieved from https://timss.bc.edu/PDF/PIRLS2006_ international_report.pdf.

OECD. (1999). Classifying educational programmes: Manual for ISCED-97 implementation in OECD countries. Paris, France: Author.

Rasch, G. (1960). Probabilistic models for some intelligence and attainment tests. Copenhagen, Denmark: Nielsen \& Lydiche.

Schulz, W. (2006). Measuring the socioeconomic background of students and its effect on achievement in PISA 2000 and PISA 2003. Paper presented at the annual meeting of the American Educational Research Association, San Francisco, CA, April 7-11, 2006. Retrieved from https://files.eric.ed.gov/ fulltext/ED493510.pdf.

Sirin, S. R. (2005). Socioeconomic status and academic achievement: A meta-analytic review of research. Review of Educational Research, 75(3), 417-453.

Stanat, P., \& Christensen, G. (2006). Where immigrant students succeed: A comparative review of performance and engagement in PISA 2003. Paris, France: OECD.

UNESCO. (2006). ISCED 1997: International standard classification of education (Revised ed.). Paris, France: UNESCO Institute of Statistics.

US Department of Education, National Center for Education Statistics. (2018). NAEP Report Card: Technology \& Engineering Literacy (TEL): Highlights from the 2018 assessment [webpage]. Washington, DC: Author. Retrieved from https://www.nationsreportcard.gov/tel_2018_highlights/.

Vereecken, C., \& Vandegehuchte, A. (2003). Measurement of parental occupation: Agreement between parents and their children. Archives of Public Health, 61, 141-149.

Von Davier, M., Gonzalez, E., \& Mislevy, R. (2009). What are plausible values and why are they useful? In M. von Davier, \& D. Hastedt (Eds.), IERI Monograph Series: Issues and Methodologies in Large-Scale Assessments, Volume 2 (pp. 9-36). Hamburg, Germany/Princeton, NJ: International Association for the Evaluation of Educational Achievement (IEA)/Educational Testing Service (ETS). Retrieved from http://www. ierinstitute.org/fileadmin/Documents/IERI_Monograph/IERI_Monograph_Volume_02_Chapter_01.pdf.

Woessmann, L. (2004). How equal are educational opportunities? Family background and student achievement in Europe and the United States (IZA Discussion Paper 1284). Bonn, Germany: Institute for the Study of Labor (IZA). Retrieved from http://ftp.iza.org/dp1284.pdf.

World Wide Web Consortium. (2019). Web content accessibility guidelines 2.0, W3C World Wide Web Consortium recommendation March, 2016 [webpage]. World Wide Web Consortium. Retrieved from http://www.w3.org/TR/WCAG20/.

Open Access This chapter is licensed under the terms of the Creative Commons Attribution-NonCommercial 4.0 International License (http://creativecommons.org/licenses/by-nc/4.0/), which permits any noncommercial use, sharing, adaptation, distribution and reproduction in any medium or format, as long as you give appropriate credit to the original author(s) and the source, provide a link to the Creative Commons license and indicate if changes were made.

The images or other third party material in this chapter are included in the chapter's Creative Commons license, unless indicated otherwise in a credit line to the material. If material is not included in the chapter's Creative Commons license and your intended use is not permitted by statutory regulation or exceeds the permitted use, you will need to obtain permission directly from the copyright holder. 


\section{CHAPTER 4:}

\section{Students' computational thinking}

\section{Chapter highlights}

Computational thinking (CT) achievement can be described as increasing according to the following progression:

- At the lower region of the scale, students demonstrate a functional working knowledge of computation as input and output. They record data from observed outputs and implement complete solutions to simple coding problems.

- At the middle region of the scale, students demonstrate an understanding of computation as enabling practical solutions to real-world problems. They systematically associate inputs with outputs when planning solutions, and implement complete solutions to complex coding using non-linear logic.

- At the upper region of the scale, students demonstrate an understanding of computation as a generalizable problem-solving framework. They infer the relationship between observed inputs and outputs to evaluate solutions. They implement elegant and efficient solutions to complex coding problems using repeat and conditional statements.

Eight countries and one benchmarking participant completed the ICILS CT option. Students' CT varied more within countries than across countries.

- The range between the lowest five percent and the highest 95 percent of students' CT scores within countries varied between 266 scale points (in Portugal) and 371 scale points (in Korea). (Table 4.1)

- The difference between the highest and lowest average CT scores across countries was 76 scale points. (Table 4.1)

CT achievement tended to be higher among male students.

- Across all countries the average CT scale scores of male students was statistically significantly higher than that of female students. (Table 4.2)

- However, statistically significant differences in the average CT scale scores between female and male students were found in only two countries. In one of those countries the difference was in favor of female students and in the other it was in favor of male students. (Table 4.2)

Socioeconomic status (SES), denoted by parental occupation, parental education, and number of books in the home, was significantly positively associated with student CT.

- In all countries, students in the high SES groups scored significantly higher on the CT scale than those in the lower SES groups. (Table 4.3)

Immigrant background and language background were associated with student CT achievement.

- In six of seven countries, students from non-immigrant families had statistically significantly higher CT scale scores than students from immigrant families. (Table 4.4)

- In five of seven countries, students who reported mainly speaking the language of the ICILS test at home had statistically significantly higher CT scale scores than those who reported speaking another language at home. (Table 4.4) 
Access to computers at home and years' experience using computers were associated with student CT.

- In all countries, students who reported having two or more computers at home had statistically significantly higher CT scores than students who reported having fewer than two computers at home. (Table 4.5)

- In all countries, students who reported having five years or more experience using computers had statistically significantly higher CT scale scores than those who reported having less than five years' experience. (Table 4.5)

Student CT achievement was strongly associated with student computer and information literacy (CIL) achievement.

- On average across all countries, the correlation between students' CIL and CT scale scores was 0.82. (Table 4.6)

- The correlation between students' CIL and CT scale scores varied between 0.74 and 0.89 across countries. (Table 4.6) 


\section{Introduction}

The International Computer and Information Literacy Study (ICILS) 2018 assessment framework defines computational thinking (CT) as "an individual's ability to recognize aspects of real-world problems which are appropriate for computational formulation and to evaluate and develop algorithmic solutions to those problems so that the solutions could be operationalized with a computer" (Fraillon et al. 2019, p. 27).

According to the ICILS 2018 framework, CT comprises two strands, each of which is specified in terms of a number of aspects. The strands are: conceptualizing problems and operationalizing solutions. The aspects further articulate CT in terms of the main processes applied within each strand. The three aspects that make up the conceptualizing problems strand are: knowing about and understanding digital systems, formulating and analyzing problems, and collecting and representing relevant data. The two aspects that make up the operationalizing solutions strand are: planning and evaluating solutions, and developing algorithms, programs, and interfaces.

The ICILS 2018 CT assessment was an option for countries participating in ICILS. Eight countries and one benchmarking participant participated in the optional CT assessment. In this chapter, we detail the measurement of CT in ICILS 2018 and discuss student achievement across the countries that participated in the ICILS CT option. We begin the chapter by describing the CT assessment instrument and the proficiency scale derived from the ICILS 2018 test instrument and data. We also describe and discuss the international student results relating to CT. The majority of content in this chapter relates to Research Question CT 1, which focuses on the extent of variation existing among and within countries with respect to student $\mathrm{CT}$. In the final sections of the chapter we address aspects of Research Questions CT 3 (the relationships between students' levels of access to, familiarity with, and self-reported proficiency in using computers and their CT), CT 4 (aspects of students' personal and social backgrounds, such as gender and socioeconomic background, related to students' CT), and CT 5 (the association between students computer and information literacy [CIL] and CT).

\section{Assessing CT}

The CT test instrument comprised two 25-minute test modules. In countries participating in the CT option, students completed the two CT test modules in randomized order after they had completed the CIL test and the student questionnaire.

One of the CT test modules (automated bus) focused on CT Strand 1: Conceptualizing problems, and the second (farm drone) focused on CT Strand 2: Operationalizing solutions. The automated bus module comprised a set of discrete, thematically related tasks relating to the configuration of the navigation and braking systems in a driverless bus. The farm drone module provided a visual coding interface that students were required to use to complete discrete coding tasks. The code in each task controlled the behavior of a programmable drone that could complete a set of actions on a farm. Students were presented with a work space, draggable commands, and a visual output that showed the outcomes of the executed commands. The complexity of each task related to the number of targets and actions required to solve the problem instance.

Data collected from the two CT test modules were used to measure and describe CT proficiency. In total, the data comprised 39 score points derived from 18 discrete tasks and questions. Student responses to most tasks were automatically scored. The exceptions were some open-response questions that were scored by trained expert scorers in each country. Data were only included where they met or exceeded the International Association for the Evaluation of Educational Achievement (IEA) sample participation requirements. The ICILS 2018 technical report (Fraillon et al. 2020) provides further information on adjudication of the test data. 
The two strands of the ICILS CT framework are each specified in terms of several aspects. The strands describe $\mathrm{CT}$ in terms of conceptualizing problems and operationalizing solutions. The aspects further articulate $\mathrm{CT}$ in terms of the main (but not exclusive) constituent processes. We used this structure primarily as an organizational tool when describing the breadth of content of the CT construct. The structure was not intended to form the basis of analysis and reporting of achievement by sub-dimensions (such as by strand or aspect).

The following list sets out the two strands and corresponding aspects of the CT framework together with the percentages of score points (of the 39 total score points) attributed to each strand and to each aspect within the strands.

- Strand 1: Conceptualizing problems, comprising three aspects, 41 percent:

- Aspect 1.1: Knowing about and understanding digital systems, 18 percent.

- Aspect 1.2: Formulating and analyzing problems, 10 percent.

- Aspect 1.3: Collecting and representing relevant data, 13 percent.

- Strand 2: Operationalizing solutions, comprising two aspects, 59 percent:

- Aspect 2.1: Planning and evaluating solutions, 31 percent.

- Aspect 2.2: Developing algorithms, programs, and interfaces, 28 percent.

\section{The CT achievement scale}

The structure described for the CT construct (two strands comprising two and three respective aspects) was established to "allow readers to clearly see the different related aspects of CT and to support the auditing of the CT instruments against the full breadth of content in the CT construct" (Fraillon et al. 2019, p. 28). As mentioned, this described structure did not presuppose a sub-dimensional structure for the analysis and reporting of the CT construct. For ICILS 2018 a single scale of $\mathrm{CT}$ achievement has been established and described. Further exploration of the potential of sub-dimensions of CT to be reported are planned for future cycles of ICILS.

We used the Rasch item response theory (IRT) model (Rasch 1960) to derive the CT achievement from the 39 score points obtained from the 18 CT tasks. We set the final reporting scale to a metric that had an international mean of 500 (the ICILS average score) and standard deviation of 100 for the equally weighted national samples. We used plausible value methodology with full conditioning to derive summary student achievement statistics. This approach enables estimation of the uncertainty inherent in a measurement process (e.g., von Davier et al. 2009). The ICILS technical report provides details on the procedures the study used to scale test items (Fraillon et al. 2020).

Description of the ICILS CT scale is based on the content and scaled difficulties of the assessment items. As part of the test development process, the ICILS research team wrote descriptors for each item in the assessment instrument. These item descriptors, which also reference the ICILS assessment framework, describe the CT knowledge, skills, and understandings demonstrated by a student correctly responding to each item. An item map similar to the item map for CIL was produced for $\mathrm{CT}$.

In order to describe the underlying characteristics of achievement across the breadth of the scale we divided the items that were ordered in the item map into thirds with equal numbers of items in each third. For ICILS 2018 we refer to these as the lower, middle, and upper regions of the scale. The descriptions of each region are syntheses of the common elements of CT knowledge, skills, and understanding described by the items within each region. ${ }^{18}$ The regions

18 The lower and upper regions are unbounded. The descriptions for these regions are based on items with a scaled difficulty that are within a range of 130 scale points below 459 scale points (for the lower region) or above 589 scale points (for the upper region). 
of the CT scale should not be directly compared to the levels in the CIL scale, as they have been developed using a different process and the scale metrics are not comparable.

The lower region of the $\mathrm{CT}$ scale was defined as the region below 459 scale points, the middle region is that between 459 and 589 scale points (inclusive), and the upper region is above 589 scale points.

The scale is hierarchical in the sense that CT proficiency becomes more sophisticated as student achievement progresses up the scale. We can therefore assume that a student located at a particular place on the scale because of their achievement score will be able to undertake and successfully accomplish tasks up to that level of achievement. Following is a description of the characteristics of each region on the $\mathrm{CT}$ scale.

\section{Lower region (below 459 scale points)}

Students showing achievement corresponding to the lower region of the scale demonstrate familiarity with the basic conventions of digital systems to configure inputs, observe events, and record observations when planning computational solutions to given problems. When developing problem solutions in the form of algorithms, they can use a linear (step by step) sequence of instructions to meet task objectives.

Students working at the lower region of the scale can, for example:

- Create a complete but suboptimal route from one location to another on a network diagram;

- Partially debug an algorithm that uses a repeat statement by correcting the logic of connected statements;

- Create an efficient algorithm that meets all of the given task objectives for a low-complexity problem (i.e., a problem with a limited set of available commands and objectives); and

- Create an inefficient algorithm that meets all of the given task objectives for a mediumcomplexity problem (e.g., a problem with multiple objectives best solved using a repeat statement).

\section{Middle region (459 to 589 scale points)}

Students showing achievement corresponding to the middle region of the scale demonstrate understanding of how computation can be used to solve real-world problems. They can plan and execute systematic interactions with a system so that they can interpret the output or behavior of the system. When developing algorithms, they use repeat statements effectively.

Students working in the middle region of the scale can for example:

- Adapt information shown in a network diagram to create a complete set of instructions comprising at least five steps;

- Configure a simulation tool;

- Store and compare data collected using a simulation tool;

- Debug, with some redundancy in the solution, an algorithm for a high-complexity problem (e.g., a problem with multiple task objectives best solved using repeat and conditional statements);

- Create an efficient algorithm that meets all of the objectives for a medium-complexity problem (e.g., a problem with multiple objectives best solved using a repeat statement); and

- Create an inefficient algorithm that meets all of the objectives for a high-complexity problem (e.g., a problem with multiple task objectives best solved using repeat and conditional statements). 


\section{Upper region (above 589 scale points)}

Students showing achievement corresponding to the upper region of the scale demonstrate an understanding of computation as a generalizable problem-solving framework. They can explain how they have executed a systematic approach when using computation to solve real-world problems. Furthermore, students operating within the upper region can develop algorithms that use repeat statements together with conditional statements effectively.

Students working in the middle region of the scale can, for example:

- Explain the value of a digital system for real-world problem solving;

- Complete a simple decision tree with the correct use of both logic and syntax;

- Debug, with the most efficient solution, an algorithm for a high-complexity problem (e.g., a problem with multiple task objectives best solved using repeat and conditional statements); and

- Create an efficient algorithm that meets all of the objectives for a high-complexity problem (e.g., multiple task objectives best solved using repeat and conditional statements).

\section{Example CT tasks}

To provide a clearer understanding of the nature of the $\mathrm{CT}$ scale, we include in this section of the chapter a set of example tasks. These indicate the types and range of tasks that students were required to complete during the ICILS test of CT. The items also provide examples of responses corresponding to the different regions on the CT scale. The data for each example task included in the analysis (including calculation of the ICILS 2018 average) are drawn only from those countries that met the sample participation, test administration, and coding requirements for that task in ICILS 2018. The example tasks are drawn from each of the two CT test modules.

\section{Farm drone tasks (Example Tasks 1 and 2)}

In the farm drone module, students worked within a simple visual coding environment (students had access to drag and drop code blocks each of which performed a specified function) to create, test, and debug code that controls the actions of a drone used in a farming context. The difficulties of the tasks relate to the code functions that were available and the complexity of the sequence of actions required by the drone to complete the task. Students' responses were captured by the assessment system and later scored on the basis of following two characteristics:

The "correctness" with which the drone performs the actions specified in the task. This includes both the degree to which the drone performs required actions and the presence or absence of any unrequired actions.

The "efficiency" of the code. This was measured by comparing the number of code blocks used in the solution with the minimum number required to implement a fully correct solution (with longer code sequences corresponding to lower scores). Each farm drone task included an instruction for students to use as few code blocks as possible.

Ultimately, each coding task received a single score derived by combining the correctness and efficiency scores. For most tasks, the efficiency score was used to moderate the score attributed to completely correct responses. Full details of the scoring for each farm drone coding task are provided in the ICILS 2018 technical report (Fraillon et al. 2020).

The interface design for the Example CT Task 1 module was divided into two functional spaces (Figure 4.1). The test interface space (using the right and bottom of the screen) was the same as that used for the CIL test modules. Unlike in the other CIL and CT test modules, in the farm drone module students could return to previously completed tasks by clicking on the green task box corresponding to the ordinal position of the task. Students could also use a flag toggle to mark tasks that they wanted to go back to if they had sufficient time to review and improve 
their solutions. The stimulus area comprised three separate parts: the code blocks space (at the bottom left of the screen), the farm drone display space (the $9 \times 9$ grid at the top left), and the work space (the central space where code blocks could be arranged to form an algorithm).

All tasks in the farm drone module presented students with the same interface design, with variations in the configuration of the farm, the task objectives, the available code block functions, and the state of the work space. The work space was presented as empty (with only the fixed "when run" command present) for tasks that required students to create code sequences. The work space was presented with pre-populated algorithms for tasks that required students to debug code.

Students could drag code blocks into the work space. Code blocks connected to the "when run" code block would send instructions to the drone when the green "run program" button was clicked. Students could reset the state of the drone and the farm by clicking the blue reset button. They could also reset the state of the work space by clicking the orange reset button.

The complexity of the tasks increased progressively through the farm drone module. The complexity of each task is influenced by the following set of key characteristics:

- The task type (code creation or debugging);

- The variety of available code functions (movement, action, repeat, conditional);

- The number of targets (a target is a tile requiring a specific action to be completed over it such as dropping water, seed, or fertilizer);

- The number of different target types (dirt, low, or high crops);

- Whether or not any given target required more than one action to be completed over it;

- The layout configuration of the targets (single or multiple rows); and

- The number of different materials to be dropped on targets (water, seed, fertilizer).

Figure 4.1: Example CT Task 1 with framework references and overall percent correct

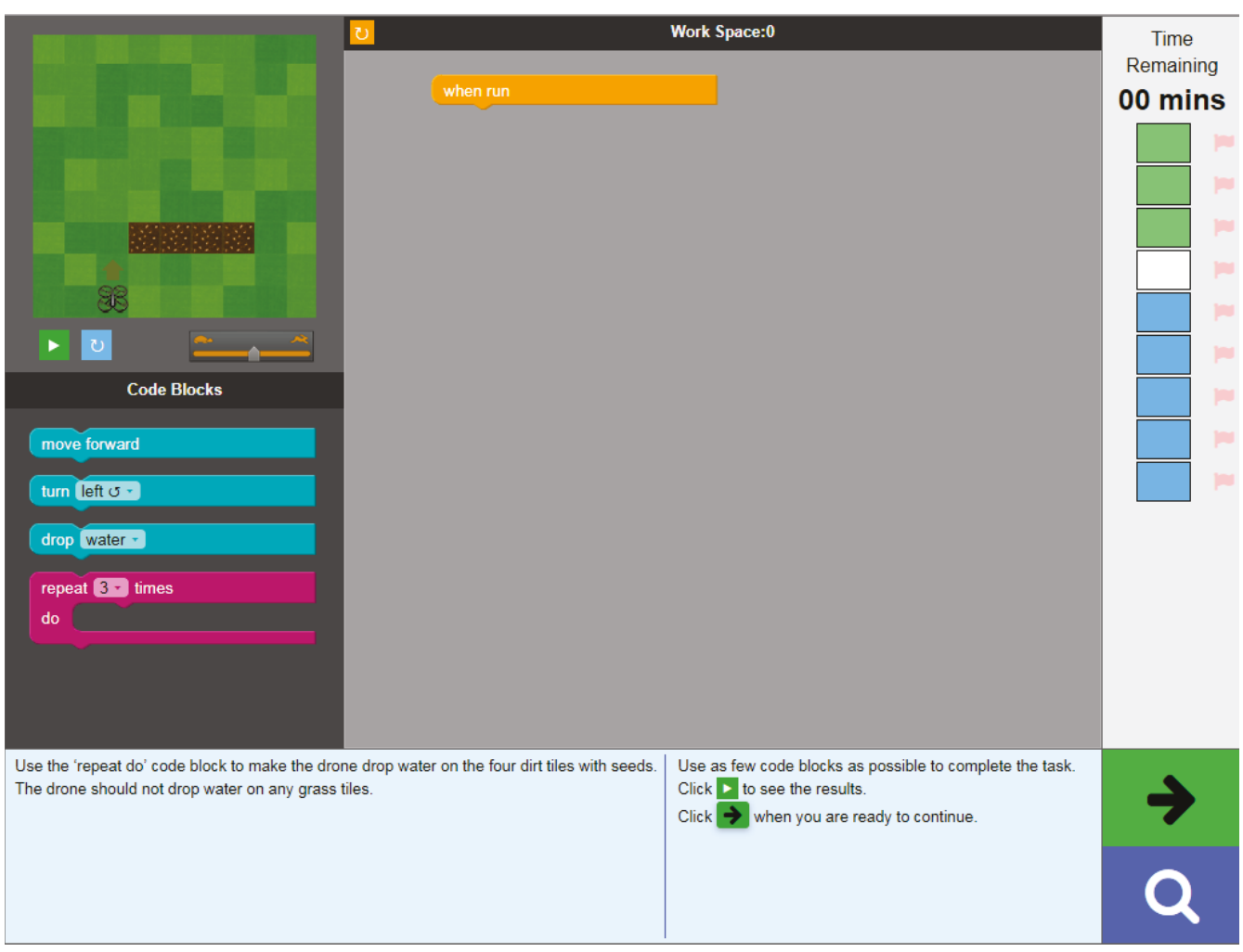


Figure 4.1: Example CT Task 1 with framework references and overall percent correct (contd.)

\begin{tabular}{l|c|c|c}
\hline Score & $\begin{array}{c}\text { CT scale } \\
\text { region }\end{array}$ & $\begin{array}{c}\text { CT scale } \\
\text { difficulty }\end{array}$ & $\begin{array}{c}\text { ICILS 2018 average } \\
\text { percentage correct responses }\end{array}$ \\
\hline At least one of three points & Lower & 353 & $86(0.3)$ \\
\hline At least two of three points & Lower & 396 & $27(0.4)$ \\
\hline Three points & Upper & 613 & \\
\hline \multirow{2}{*}{ ICILS assessment framework reference } \\
\hline \multirow{2}{*}{2.2} & Operationalizing solutions \\
\cline { 2 - 4 } & Developing algorithms, programs, and interfaces \\
\hline
\end{tabular}

\begin{tabular}{|c|c|c|c|c|}
\hline Country & $\begin{array}{l}\text { Percentage scoring } \\
\text { one out of } \\
\text { three points }\end{array}$ & $\begin{array}{r}\text { Percent } \\
\text { two } \\
\text { thre }\end{array}$ & $\begin{array}{l}\text { ge scoring } \\
\text { out of } \\
\text { points }\end{array}$ & $\begin{array}{l}\text { Percentage scoring } \\
\text { three points }\end{array}$ \\
\hline Denmark $^{\dagger 1}$ & $92 \quad(0.5)$ & 83 & $(0.9)$ & $26(1.2)$ \\
\hline Finland & $87(1.0)$ & 80 & $(1.2)$ & $29(1.0)$ \\
\hline France & $87 \quad(0.8)$ & 77 & $(1.0)$ & $40 \quad(1.3)$ \\
\hline Germany & $83(1.2)$ & 73 & $(1.2)$ & $18 \quad(1.2)$ \\
\hline Korea, Republic of & $90 \quad(0.8)$ & 86 & $(1.0)$ & $39(1.9)$ \\
\hline Luxembourg & $76 \quad(0.5)$ & 66 & $(0.5)$ & $16 \quad(0.3)$ \\
\hline Portugal ${ }^{+\dagger}+1$ & $88(0.8)$ & 78 & $(1.1)$ & $20(1.1)$ \\
\hline \multicolumn{5}{|c|}{ Not meeting sample participation requirements } \\
\hline United States & $86 \quad(0.6)$ & 77 & $(0.7)$ & $34(1.1)$ \\
\hline \multicolumn{5}{|c|}{ Benchmarking participant meeting sample participation requirements } \\
\hline North Rhine-Westphalia (Germany) & $84(0.9)$ & 73 & $(1.3)$ & $17(1.1)$ \\
\hline
\end{tabular}

Notes: Standard errors appear in parentheses. Because results are rounded to the nearest whole number, some totals may appear inconsistent.

† Met guidelines for sampling participation rates only after replacement schools were included.

t† Nearly met guidelines for sampling participation rates after replacement schools were included.

National defined population covers $90 \%$ to $95 \%$ of the national target population.

Example CT Task 1 (Figure 4.1) is a medium-complexity code creation task that represents the operationalizing solutions strand of the CT construct. The task objectives required students to make the drone drop water on the four dirt tiles with seeds (the targets) without dropping water on any of the grass tiles using the repeat statement.

Students could receive a score of zero, one, two, or three points on this task. Students who completed only some of the task objectives using significantly more code blocks than the minimum necessary were awarded one score point; on average across all countries, 86 percent of students achieved at least this. The percentages across countries and the benchmarking participant varied from 76 percent to 92 percent. Achievement of a score of one on this task was at the lower end of the lower region on the CT scale.

Students who completed all of the objectives and used the repeat statement but included a few code blocks more than the minimum necessary were awarded two score points; on average across all countries, 77 percent of students achieved at least this. The percentages across countries and benchmarking participants varied from 73 percent to 86 percent. Achievement of a score of two on this task was in the upper end of the lower region of the CT scale. 
Students who could complete all of the task objectives using the repeat statement and with the fewest number of code blocks necessary were awarded the maximum of three score points; on average across all countries, 27 percent of students received the maximum score in this task. The percentages across countries and the benchmarking participant varied from 16 percent to 40 percent. Achievement of a score of three on this task was in the upper region of the CT scale.

Example CT Task 2 (Figure 4.2) is a high-complexity debugging task. The work space was prepopulated with a five-statement algorithm that students had to modify to complete the task objectives.

Figure 4.2: Example CT Task 2 with framework references and overall percent correct

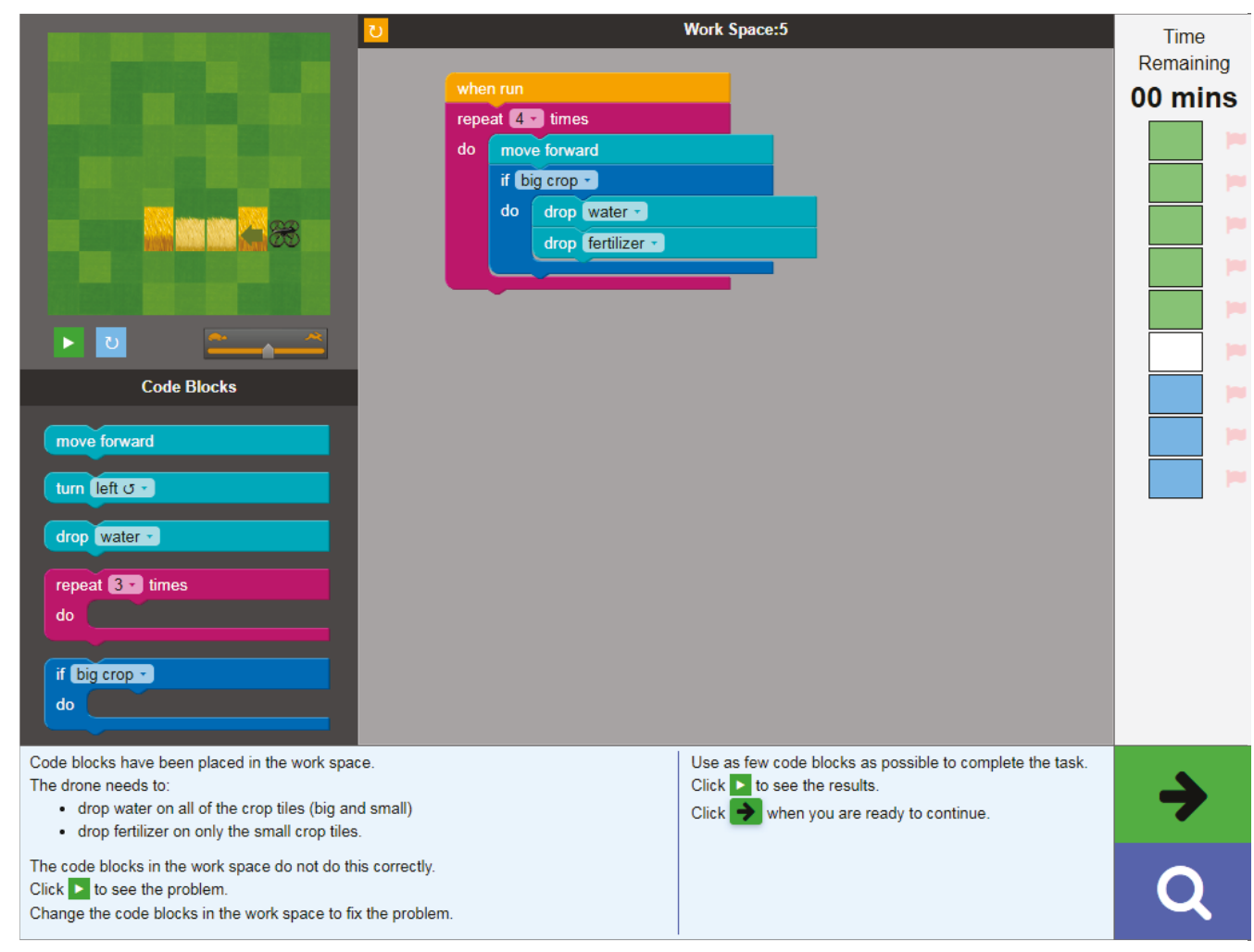

\begin{tabular}{l|c|c|c}
\hline Score & $\begin{array}{c}\text { CT scale } \\
\text { region }\end{array}$ & $\begin{array}{c}\text { CT scale } \\
\text { difficulty }\end{array}$ & $\begin{array}{c}\text { ICILS 2018 average } \\
\text { percentage correct responses }\end{array}$ \\
\hline At least one of three points & Lower & 456 & $63(0.5)$ \\
\hline At least two of three points & Middle & 552 & $37(0.5)$ \\
\hline Three points & Upper & 733 & $8(0.2)$ \\
\hline \multirow{2}{*}{ ICILS assessment framework reference } \\
\hline \multirow{2}{*}{2.1} & Operationalizing solutions \\
\cline { 2 - 4 } & Planning and evaluating solutions \\
\hline
\end{tabular}


Figure 4.2: Example CT Task 2 with framework references and overall percent correct (contd.)

\begin{tabular}{|c|c|c|c|c|c|}
\hline \multirow{2}{*}{$\begin{array}{l}\text { Country } \\
\text { Denmark }^{\dagger 1}\end{array}$} & $\begin{array}{l}\text { Percentage scoring } \\
\text { one out of } \\
\text { three points }\end{array}$ & \multicolumn{2}{|c|}{$\begin{array}{l}\text { Percentage scoring } \\
\text { two out of } \\
\text { three points }\end{array}$} & \multicolumn{2}{|c|}{$\begin{array}{l}\text { Percentage scoring } \\
\text { three points }\end{array}$} \\
\hline & 70 (1.3) & 39 & $(1.2)$ & 8 & $(0.7)$ \\
\hline Finland & 66 (1.3) & 44 & (1.3) & 9 & $(0.7)$ \\
\hline France & $65(1.2)$ & 41 & (1.1) & 12 & $(0.7)$ \\
\hline Germany & $60(1.4)$ & 32 & $(1.2)$ & 7 & $(0.6)$ \\
\hline Korea, Republic of & $74(1.4)$ & 48 & (1.6) & 12 & (0.8) \\
\hline Luxembourg & $48 \quad(0.6)$ & 25 & $(0.4)$ & 5 & $(0.3)$ \\
\hline Portugal $\left.\right|^{\dagger+1}$ & $61(1.6)$ & 31 & (1.3) & 3 & $(0.4)$ \\
\hline \multicolumn{6}{|c|}{ Not meeting sample participation requirements } \\
\hline United States & $60(1.1)$ & 37 & $(0.9)$ & 8 & $(0.4)$ \\
\hline \multicolumn{6}{|c|}{ Benchmarking participant meeting sample participation requirements } \\
\hline North Rhine-Westphalia (Germany) & 61 (1.3) & 32 & (1.3) & 6 & $(0.6)$ \\
\hline
\end{tabular}

Notes: Standard errors appear in parentheses. Because results are rounded to the nearest whole number, some totals may appear inconsistent.

† Met guidelines for sampling participation rates only after replacement schools were included.

t† Nearly met guidelines for sampling participation rates after replacement schools were included.

1 National defined population covers $90 \%$ to $95 \%$ of the national target population.

Example CT Task 2 represents the operationalizing solutions strand of the CT construct and required students to make the drone drop water on the big and small crop tiles and in addition to drop fertilizer on the small crop tiles. The algorithm presented to students in the work space used an if statement nested inside a repeat statement which included non-linear conditional logic. In the logic of the existing algorithm, the decision to drop fertilizer and water was conditional on the size of the crop. In the simplest correction to the algorithm, students could place the "drop water" command outside the conditional statement after the "move forward" command and reconfigure the conditional command to "if small crop."

Students could receive a score of zero, one, two, or three points on this task. Students who could complete all of the objectives but with many more code blocks than the minimum necessary were awarded one score point. This was typically achieved by removing the repeat and if statements and using the move and drop statements using only linear logic. On average across all countries, 63 percent of students achieved at least this. The percentages across countries and the benchmarking participant varied from 48 to 74 percent. Achievement of a score of one on this task was in the lower region on the CT scale.

Students who could complete all of the task objectives with only a few code blocks more than the minimum necessary, by using the repeat and if statements together, were awarded a score of two. On average across all countries, 37 percent of students achieved at least this. The percentages across countries and the benchmarking participant varied from 25 percent to 48 percent. Achievement of a score of two on this task was in the middle region of the CT scale.

Students who were able to correct the algorithm using the minimum number of code blocks were awarded a score of three. These students demonstrated clear control over the non-linear conditional logic of the algorithm. On average across all countries, eight percent of students received the maximum score on this task. The percentages of students who were successful across countries and the benchmarking participant varied from three percent to 12 percent. Achievement of a score of three on this task was in the upper region of the CT scale. 


\section{Automated bus tasks (Example Tasks 3 and 4)}

Example CT Task 3 (Figure 4.3) represents the conceptualizing problems strand of the CT construct. The task presented students with a stopping distance simulator and the objective of finding the minimum viable braking distance under given conditions. Students were required to configure the flowchart according to the instructions to apply a set of conditions for the simulation. They then had to configure the braking distance and run the simulation to identify whether the bus stopped before, or crashed into, the rocks.

Figure 4.3: Example CT Task 3 with framework references and overall percent correct

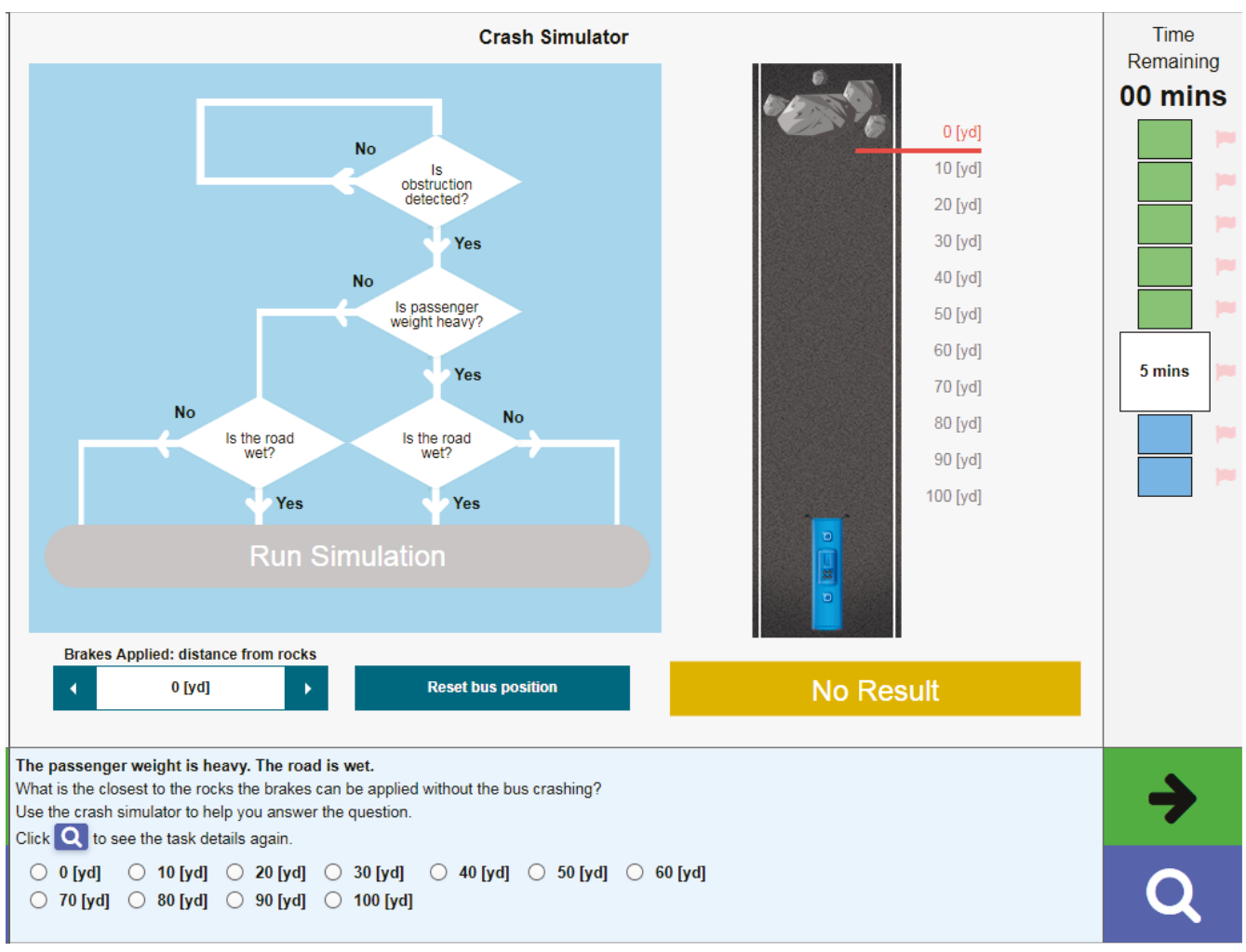

\begin{tabular}{l|c|c|c}
\hline Score & $\begin{array}{c}\text { CT scale } \\
\text { region }\end{array}$ & $\begin{array}{c}\text { CT scale } \\
\text { difficulty }\end{array}$ & $\begin{array}{c}\text { ICILS 2018 average } \\
\text { percentage correct responses }\end{array}$ \\
\hline At least one of two points & Middle & 477 & $58(0.4)$ \\
\hline Two points & Middle & 557 & $36(0.4)$ \\
\hline \multirow{2}{*}{ ICILS assessment framework reference } \\
\hline \multirow{2}{*}{1.3} & Conceptualizing problems \\
\cline { 2 - 4 } & Collecting and representing relevant data \\
\hline
\end{tabular}


Figure 4.3: Example CT Task 3 with framework references and overall percent correct (contd.)

\begin{tabular}{|c|c|c|}
\hline Country & $\begin{array}{l}\text { Percentage scoring } \\
\text { one out of two points }\end{array}$ & $\begin{array}{l}\text { Percentage scoring } \\
\text { two points }\end{array}$ \\
\hline Denmark ${ }^{1}$ & $64 \quad(1.3)$ & $40 \quad(1.3)$ \\
\hline Finland & $62 \quad(1.3)$ & $37(1.3)$ \\
\hline France & $48 \quad(1.1)$ & $27(1.1)$ \\
\hline Germany & $56 \quad(1.2)$ & $32(1.1)$ \\
\hline Korea, Republic of & $72 \quad(1.2)$ & $58 \quad(1.2)$ \\
\hline Luxembourg & $50 \quad(0.6)$ & $28(0.5)$ \\
\hline Portugal ${ }^{\dagger 1}$ & $56 \quad(1.4)$ & $28(1.4)$ \\
\hline \multicolumn{3}{|c|}{ Not meeting sample participation requirements } \\
\hline United States & $57 \quad(1.0)$ & $34(0.9)$ \\
\hline \multicolumn{3}{|c|}{ Benchmarking participant meeting sample participation requirements } \\
\hline North Rhine-Westphalia (Germany) & $55 \quad(1.2)$ & $29(1.3)$ \\
\hline
\end{tabular}

Notes: Standard errors appear in parentheses. Because results are rounded to the nearest whole number, some totals may appear inconsistent.

Met guidelines for sampling participation rates only after replacement schools were included.

it Nearly met guidelines for sampling participation rates after replacement schools were included.

1 National defined population covers $90 \%$ to $95 \%$ of the national target population.

Students could receive a score of zero, one, or two points on this task. One point was awarded to students who configured the simulator using conditions that were not specified but identified a braking distance that was consistent with the configuration they used. Students who configured the simulator correctly to the conditions and identified the correct braking distance were awarded two score points. Scores of one and two on this task were both indicative of achievement in the middle region of the CT scale, with a score of one near the lower end of the region and a score of two at the upper end of the region. On average across all countries, 58 percent of students achieved a score of at least one on this task and 36 percent of students achieved a score of two. These percentages varied across countries and the benchmarking participant between 50 percent and 72 percent for a score of at least one and between 27 percent and 58 percent for a score of two.

In the CT test, Example CT Task 4 (Figure 4.4) was presented to students as the task preceding Example CT Task 3 above. Example CT Task 4 was a planning task in preparation for configuring the simulator and required students have some understanding of flowcharting conventions to complete the decision tree with the labels provided. Students were required to drag and drop the labels from the left of the screen into the decision tree in a way that was consistent with both the logical sequence of the decision-making and the syntax of the decision tree. 
Figure 4.4: Example CT Task 4 with framework references and overall percent correct

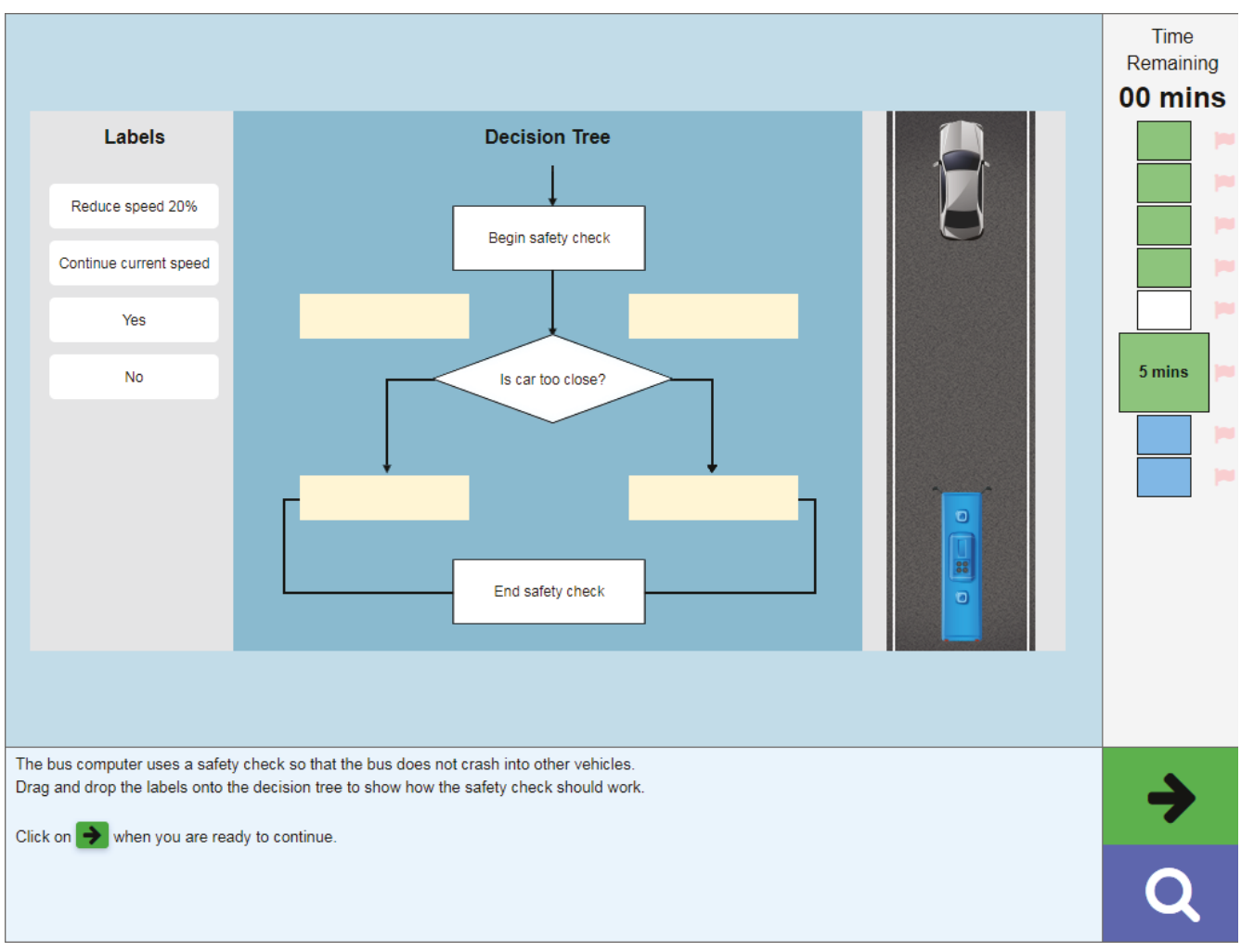

\begin{tabular}{l|c|c|c}
\hline Score & $\begin{array}{c}\text { CT scale } \\
\text { region }\end{array}$ & $\begin{array}{c}\text { CT scale } \\
\text { difficulty }\end{array}$ & $\begin{array}{c}\text { ICILS 2018 average } \\
\text { percentage correct responses }\end{array}$ \\
\hline At least one of two points & Middle & 488 & $56(0.4)$ \\
\hline Two points & Upper & 591 & $28(0.4)$ \\
\hline ICILS assessment framework reference \\
\hline \multirow{2}{*}{1.2} & Conceptualizing problems \\
\cline { 2 - 4 } & Formulating and analyzing problems \\
\hline
\end{tabular}


Figure 4.4: Example CT Task 4 with framework references and overall percent correct (contd.)

\begin{tabular}{|c|c|c|c|}
\hline Country & $\begin{array}{l}\text { Per } \\
\text { one c }\end{array}$ & $\begin{array}{l}\text { entage scoring } \\
\text { ut of two points }\end{array}$ & $\begin{array}{l}\text { Percentage scoring } \\
\text { two points }\end{array}$ \\
\hline Denmark $^{\dagger 1}$ & 55 & (1.3) & $29(1.0)$ \\
\hline Finland & 56 & $(1.2)$ & $27(1.0)$ \\
\hline France & 55 & $(1.4)$ & $30(1.4)$ \\
\hline Germany & 57 & $(1.1)$ & $30(1.0)$ \\
\hline Korea, Republic of & 65 & $(1.2)$ & $37 \quad(1.3)$ \\
\hline Luxembourg & 51 & $(0.6)$ & $24(0.6)$ \\
\hline Portugal ${ }^{\dagger+1}$ & 50 & $(1.2)$ & $20(1.0)$ \\
\hline \multicolumn{4}{|c|}{ Not meeting sample participation requirements } \\
\hline United States & 52 & $(0.7)$ & $24(0.6)$ \\
\hline \multicolumn{4}{|c|}{ Benchmarking participant meeting sample participation requirements } \\
\hline North Rhine-Westphalia (Germany) & 55 & $(1.1)$ & $29(1.0)$ \\
\hline
\end{tabular}

Notes: Standard errors appear in parentheses. Because results are rounded to the nearest whole number, some totals may appear inconsistent.

Met guidelines for sampling participation rates only after replacement schools were included.

+ Nearly met guidelines for sampling participation rates after replacement schools were included.

National defined population covers $90 \%$ to $95 \%$ of the national target population.

Students could receive a score of zero, one, or two points on this task. Students who could use the syntax correctly by dragging the "Yes" and "No" labels to the spaces above the decision point but placed the "Reduce speed 20\%" and "Continue current speed" labels under the wrong decision received one score point. Similarly, students who used the syntax incorrectly by placing the "Yes" and "No" labels in the spaces below the decision point but placed the "Reduce speed 20\%" and "Continue current speed" labels under the correct decision also received one score point. In summary, students who could complete the decision tree with either the correct syntax or the correct logic received one score point. This was indicative of achievement in the middle region of the CT scale. Students who could complete the decision tree with the correct syntax and the correct logic received two score points. This was indicative of achievement in the upper region of the CT scale. On average across all countries, 56 percent of students achieved a score of at least one on this task and 28 percent of students achieved a score of two. These percentages varied across countries and the benchmarking participant between 50 percent and 65 percent for a score of at least one and between 20 percent and 37 percent for a score of two.

\section{Comparison of CT across countries}

\section{Distribution of student achievement scores}

When considering the distribution of student achievement on the CT test for all participating countries and benchmarking participants, it is important to bear in mind that only a small number of countries participated in the ICILS CT international option (Table 4.1; note that the length of the bars in these tables reflect the spread of student scores within each country, highlighting differences in the within-country student score distributions).

The average country scores on the CIL scale ranged between 460 and 536 scale points; the range was equivalent to approximately 0.7 international standard deviations (Table 4.1). Unlike the distribution of CIL, for CT the spread of scores within countries does not appear to be clearly associated with achievement across countries (Table 4.1). However, as was observed for student $\mathrm{CIL}$, the variation in student CT scores within countries was greater than that across countries. Across countries, the distance between the lowest five percent and the highest five percent of 


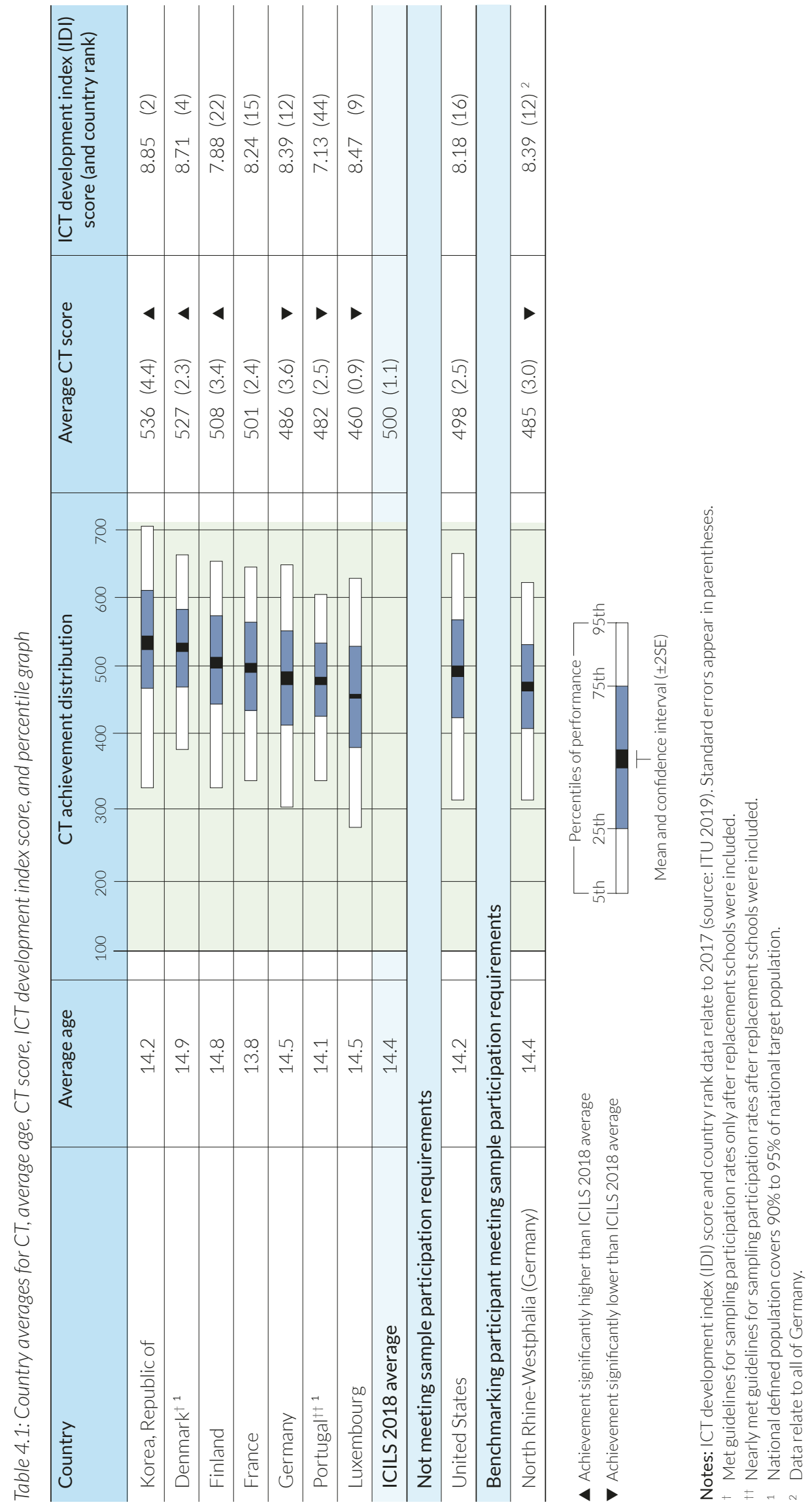




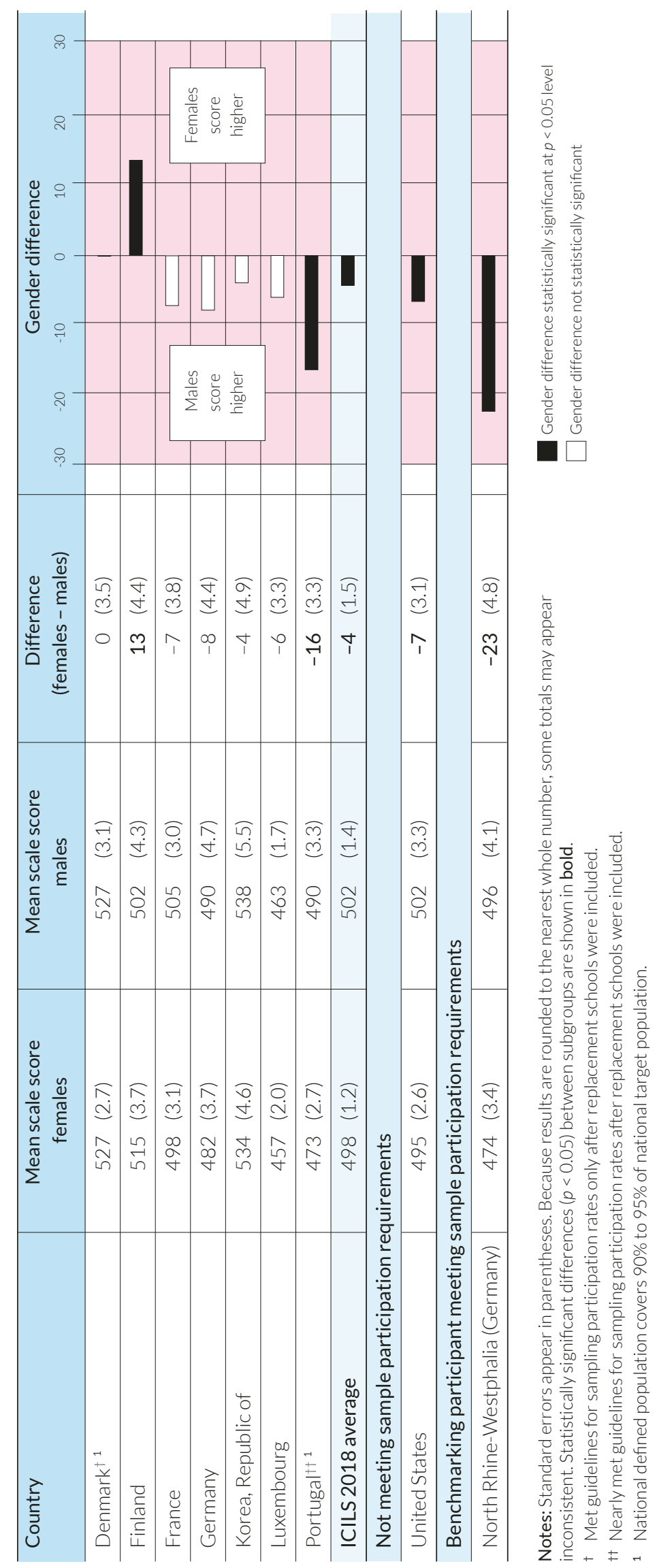


CT scores ranges between 266 and 371 scale points (with a median of 320 scale points or 3.2 standard deviations), in comparison to a range of average scores across all countries of 76 scale points (equivalent to three quarters of an international standard deviation).

\section{CT relative to the ICT development index}

In Chapter 3 we reported that, on average, students had higher levels of CIL in countries with higher ICT development index (IDI) scores. The association between CT achievement and the IDI scores across countries was moderate, with a Pearson's correlation coefficient of 0.43. However, the association between student $\mathrm{CIL}$ and country IDI in the same countries (i.e., only those countries in which students completed the tests of both $\mathrm{CIL}$ and $\mathrm{CT}$ ) was weak, with a Pearson's correlation coefficient of 0.23. A comparison of these correlation coefficients suggest that, across the countries taking part in the ICILS CT assessment, the association between the IDI and a broader notion of digital competence (CIL) was lower than one might have predicted. This is potentially due to this smaller set of countries being relatively more homogeneous with respect to IDI and achievement than the broader set of ICILS 2018 participating countries.

\section{Variation in CT across countries with respect to student background characteristics}

In this section we address Research Question CT 4: What aspects of students' personal and social backgrounds (such as gender and socioeconomic background) are related to students' CT?

Our focus is therefore on the associations between students' CT and student gender, variables associated with students' socioeconomic status, whether or not students had an immigrant background, and the language students spoke at home. Chapter 7 documents further investigation, based on regression modeling, of the relationships between student CT and student-level and school-level factors.

\section{Gender and CT}

In Chapter 3 we reported that the CIL scale scores of female students were statistically significantly higher than those of male students on average across all countries and within all countries and benchmarking participants except Chile, Uruguay, and North Rhine-Westphalia (Germany). A different pattern was evident for the relationship between gender and $\mathrm{CT}$ achievement to that of gender and $\mathrm{CIL}$ achievement. Across all countries the average CT scale score of male students was statistically significantly higher than that of female students (Table 4.2). However, this difference was not consistent at the country level. In Portugal and North Rhine-Westphalia (Germany) the average achievement of male students was statistically significantly higher than that of female students and in Finland the CT achievement of female students was statistically significantly higher than that of male students. In France, Germany, Korea, and Luxembourg the average scores of male students appeared to be higher than those of female students but the differences were not statistically significant. In Chapter 8 we discuss the implications of the differences in achievement by gender found in both CIL and CT in further detail.

\section{Socioeconomic background}

In Chapter 3, details of how background data variables were collected and derived were presented. We reported statistically significant associations between each of the three socioeconomic background variables (parental occupation, parental education, and number of books in the home) and CIL across all countries.

We found a similar pattern of association between socioeconomic background and CT achievement across all countries (Table 4.3) to that reported for CIL in Chapter 3. 


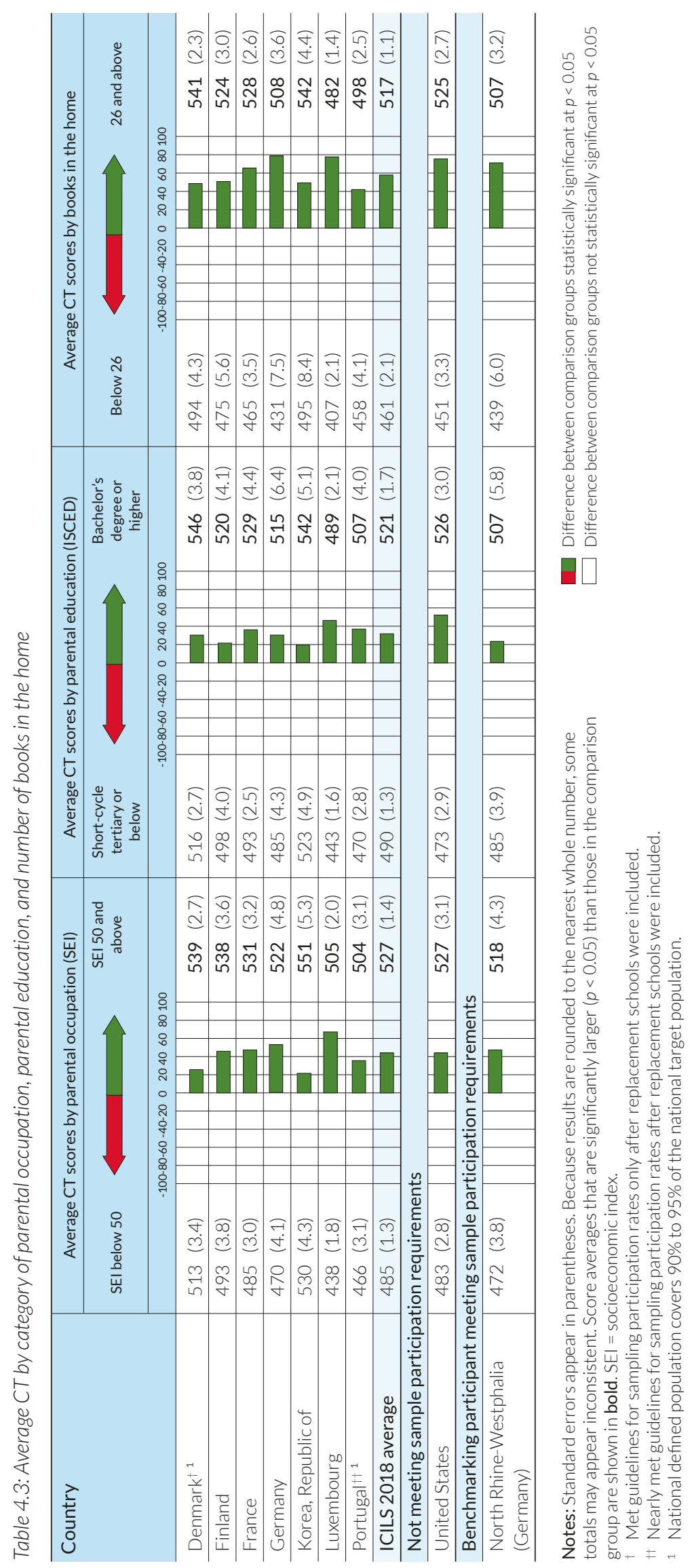


For each of the three socioeconomic background variables in each country, and overall across countries and the benchmarking participant, the average CT scores of students in the "higher" groups were statistically significantly higher than those of students in the "lower" groups. However, the magnitude of the differences between groups for all three variables varied across countries.

On average across all countries, the difference between students in the higher and lower parental occupation categories was $42 \mathrm{CT}$ scale points, with the minimum difference being 21 scale points in Korea and the maximum difference being 67 scale points in Luxembourg.

On average across all countries, the difference between the CT scores of students in the low (short-cycle tertiary or below) and in the high (Bachelor's degree or higher) parental education groups was 31 scale points, with the minimum difference being 19 scale points in Korea and the maximum difference being 46 scale points in Luxembourg.

Cross-nationally, the difference between the average CT scale scores of students who reported having 26 or more books at home and those students who reported fewer than 26 books at home was 57 scale points, with the minimum difference being 40 scale points in Portugal and the maximum difference being 77 scale points in Germany.

All three indicators of students' socioeconomic status contributed to a composite index of socioeconomic status. This index is used in the multilevel regression analyses presented in Chapter 7.

\section{Immigrant status and language use}

In Chapter 3 we reported that the CIL scores of students without immigrant background tended to be higher than those with an immigrant background. We found similar results with $\mathrm{CT}$ where, for six of the seven countries that met the ICILS technical requirements, the students from non-immigrant family backgrounds had statistically significantly higher average CT scores than students from immigrant backgrounds (Table 4.4). On average across countries, the difference between students with immigrant backgrounds and those without was 46 CT scale points, with the minimum difference being 14 scale points in Portugal and the maximum difference being 56 in Finland.

In most participating countries, the majority of students indicated speaking the test language at home. Across countries, CT scores tended to be higher among students speaking the test language at home; the average difference was 47 scale points. For five of the seven participating countries meeting the technical requirements, we recorded statistically significant differences between students speaking the test language and those speaking other languages at home. The statistically significant positive differences varied from 38 scale points in Finland to 64 in France.

\section{Computers at home and experience using computers}

In Chapter 3 we noted that students with more computers at home tended to have higher CIL scores. A similar pattern of association can be seen when considering students' $\mathrm{CT}$ achievement (Table 4.5). On average across countries, the CT scores of students reporting having two or more computers at home were 29 scale points higher than those who reported having fewer than two computers at home. This difference varied from 18 points in Portugal to 43 points in Germany and was statistically significant in all countries. 


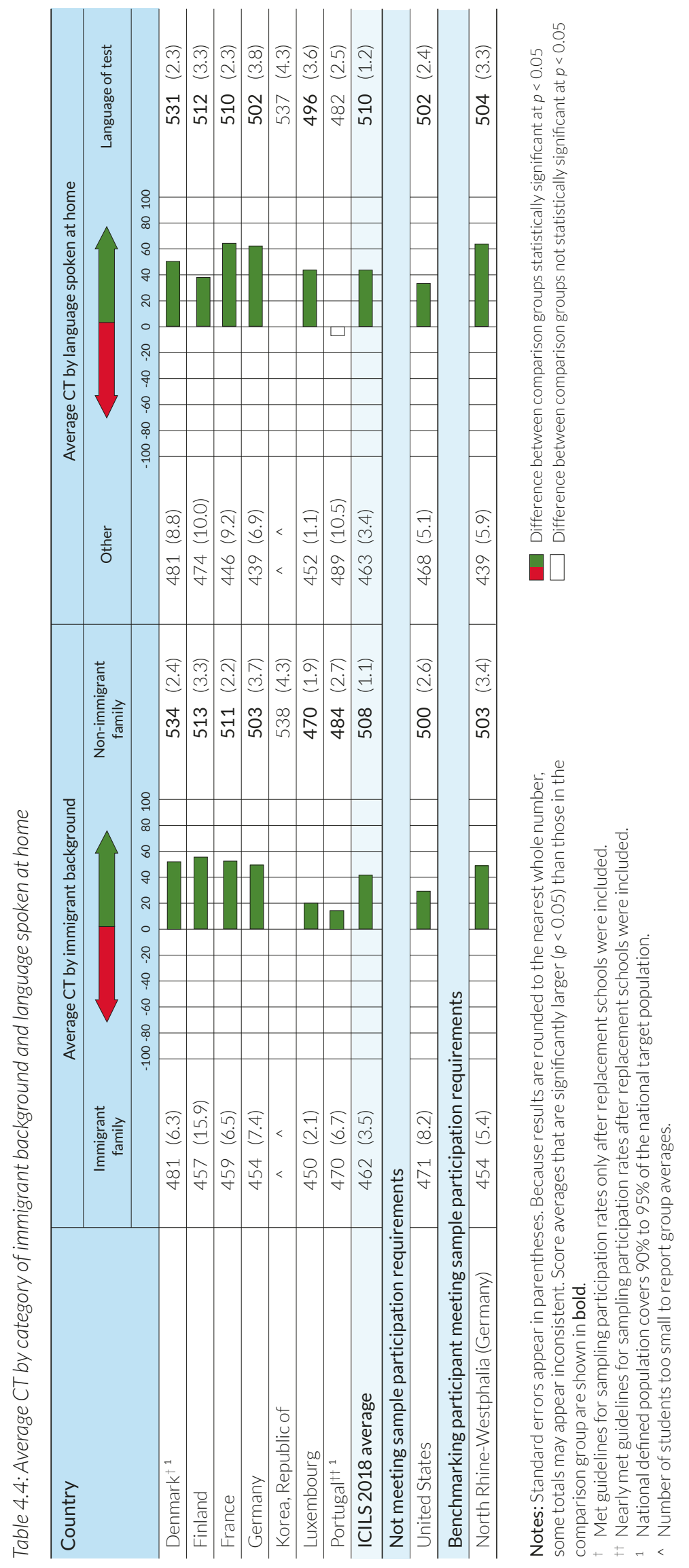




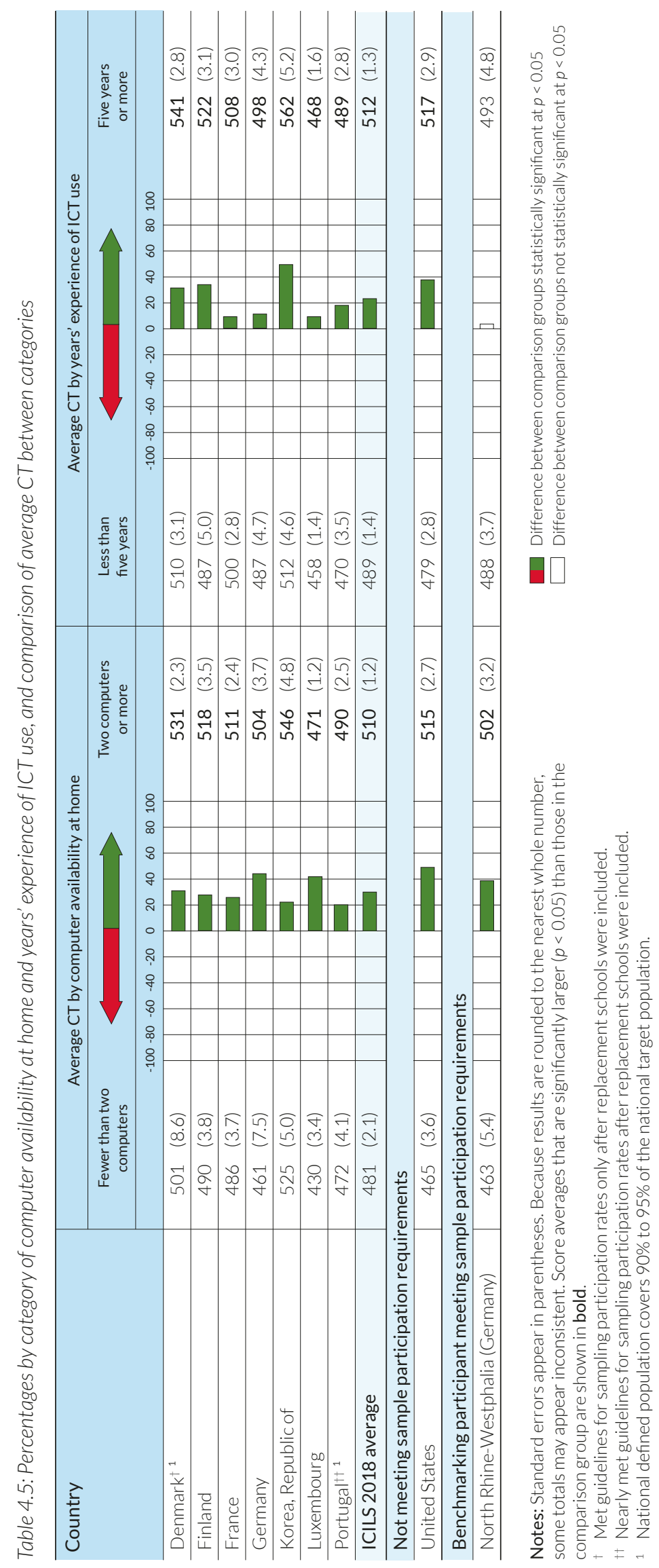


Similarly, students' years of experience using computers was positively associated with CT. On average across all countries, the CT scores of students with five or more years of experience using computers were 23 scale points higher than those with less than five years' experience. This difference varied from eight scale points in France to 50 scale points in Korea and was statistically significant in all countries but not statistically significant in the benchmarking participant North Rhine-Westphalia (Germany).

\section{The association between $\mathrm{CT}$ and $\mathrm{CIL}$}

In this section we address Research Question CT 5: What is the association between students' CIL and CT?

CIL has an operational emphasis on students' abilities to use computer technologies to collect and manage information and to produce and exchange information. In the ICILS test of CIL, this is assessed through students' responses to a broad range of tasks that focus on (receptive and productive) information literacy in a digital environment. CT is a new assessment construct to ICILS. Its focus is on the planning, formulation, implementation, and evaluation of "algorithmic solutions to [real-world] problems so that the solutions could be operationalized with a computer" (Fraillon et al. 2019, p. 27). The ICILS CT assessment combines tasks involving planning for a computeroperationalized solution to a real-world problem and a suite of visual coding tasks.

$\mathrm{CIL}$ and $\mathrm{CT}$ are quite different achievement constructs. This is evident through examination of their definitions and descriptions as well as the tasks used to assess each domain. However, they do share some common features. They both are, and can only be, completed on computer. Each one therefore draws on understandings of how computers can be used to solve problems as described by CIL Aspect 1.1 (knowing about and understanding computer use) and CT Aspect 1.1 (knowing about and understanding digital systems). Furthermore, achievement in each of CIL and CT draws on students' literacy skills (in reading and responding to tasks) and critical thinking (through the evaluation of information, data, and solutions to problems). In ICILS 2018 it was expected that, while the differences between the two domains would result in differences in achievement within students, the commonalities in the foundations of achievement of the domains would lead to a positive association between CIL and CT achievement.

On average across all countries, the correlation between students' CIL and CT scale scores was 0.82 (Table 4.6). This strong correlation between CIL and CT scores was consistent across countries and varied from 0.74 in Korea to 0.89 in Finland. We report the correlations between CIL and CT scores across all countries as well as the average CT scale scores for students performing within each CIL proficiency level across countries (Table 4.3). Across all countries the average CT scores of students increase as the CIL levels of students increase. On average across all countries, the difference in student CT scale scores between students in adjacent CIL levels of achievement varied from $90 \mathrm{CT}$ scale points (between students with CIL of Level 1 and Below Level 1) and 60 CT scale points (between students with CIL of Level 3 and Level 4 or above). Across countries there was a general tendency for the difference in average CT scale scores of students in adjacent CIL levels of achievement to be larger between the lower levels of achievement than between the higher levels. We further investigated the correlation between students' CIL and CT by gender and found that they varied little from the overall correlations reported across countries. The consequences of the strong correlation between CIL and CT and their relationships to student gender are further discussed in Chapter 8. 


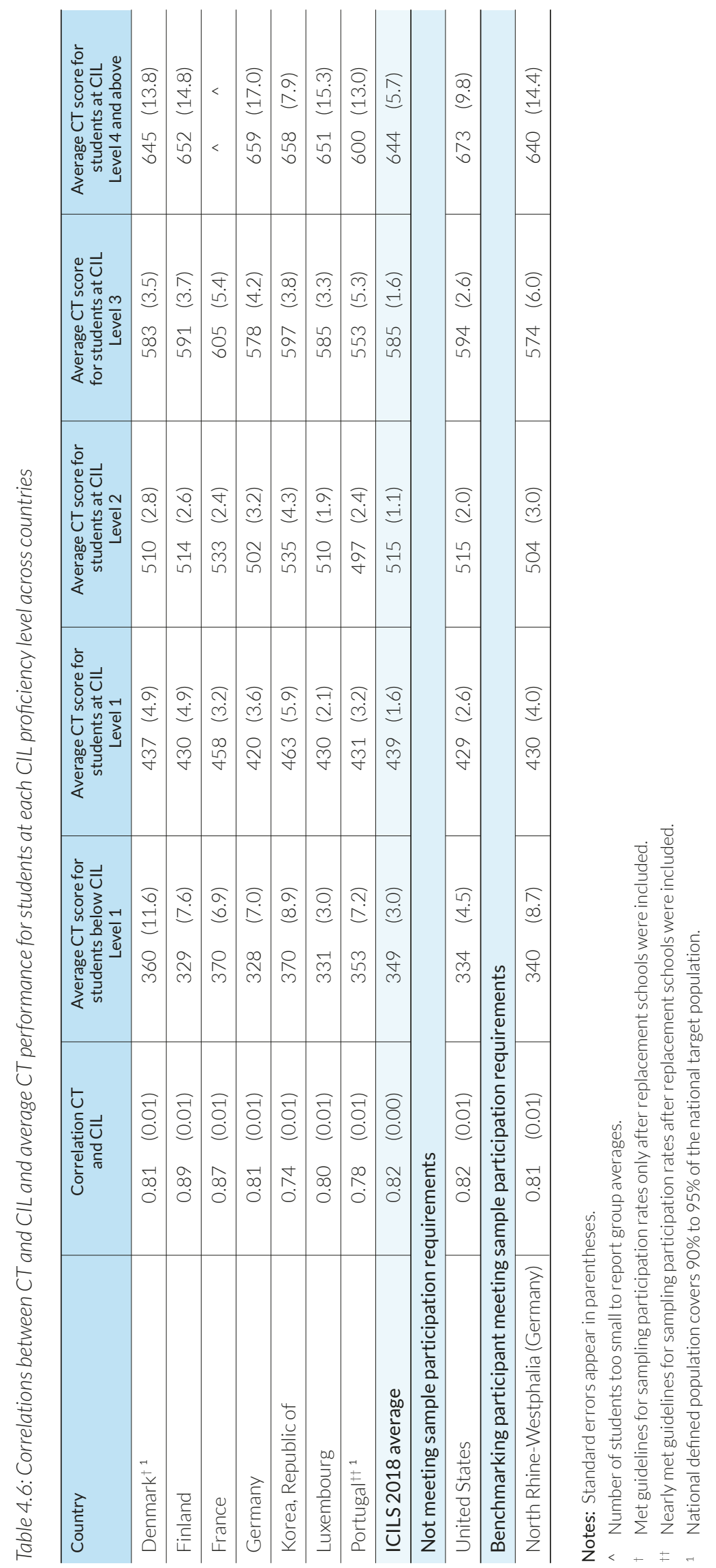




\section{References}

Fraillon, J., Ainley, J., Schulz, W., Duckworth, D., \& Friedman, T. (2019). IEA International Computer and Information Literacy Study 2018 assessment framework. Cham, Switzerland: Springer. Retrieved from https:// www.springer.com/gp/book/9783030193881.

Fraillon, J., Schulz, W., Friedman, T., \& Meyer, S. (Eds.). (2020). IEA International Computer and Information Literacy Study 2018 technical report. Amsterdam, The Netherlands: International Association for the Evaluation of Educational Achievement (IEA). Manuscript in preparation.

ITU. (2019). IDI 2017 rank [webpage]. Geneva, Switzerland: International Telecommunications Union. Retrieved from https://www.itu.int/net4/ITU-D/idi/2017/index.html.

Rasch, G. (1960). Probabilistic models for some intelligence and attainment tests. Copenhagen, Denmark: Nielsen \& Lydiche.

Von Davier, M., Gonzalez, E., \& Mislevy, R. (2009). What are plausible values and why are they useful? In M. von Davier, \& D. Hastedt (Eds.), IERI Monograph Series: Issues and Methodologies in Large-Scale Assessments, Volume 2 (pp. 9-36). Hamburg, Germany/Princeton, NJ: International Association for the Evaluation of Educational Achievement (IEA)/Educational Testing Service (ETS). Retrieved from http://www. ierinstitute.org/fileadmin/Documents/IERI_Monograph/IERI_Monograph_Volume_02_Chapter_01.pdf.

Open Access This chapter is licensed under the terms of the Creative Commons Attribution-NonCommercial 4.0 International License (http://creativecommons.org/licenses/by-nc/4.0/), which permits any noncommercial use, sharing, adaptation, distribution and reproduction in any medium or format, as long as you give appropriate credit to the original author(s) and the source, provide a link to the Creative Commons license and indicate if changes were made.

The images or other third party material in this chapter are included in the chapter's Creative Commons license, unless indicated otherwise in a credit line to the material. If material is not included in the chapter's Creative Commons license and your intended use is not permitted by statutory regulation or exceeds the permitted use, you will need to obtain permission directly from the copyright holder. 


\section{CHAPTER 5:}

\section{Students' engagement with information and communications technologies}

\section{Chapter highlights}

Students were experienced users of information and communications technology (ICT).

- Slightly fewer than half of the students in grade 8 had been using computers for five or more years.

- Computer experience was associated with students' computer and information literacy. (Table 5.1)

Students frequently used ICT for general purposes.

- Seven out of 10 grade 8 students used ICT on a daily basis outside school for general purposes but only one in five students reported ICT use on a daily basis for school-related purposes. (Table 5.2)

- Student use of general applications in ICT was more frequent among those with five or more years of computer experience, those currently studying a computer subject, and those with higher levels of computer literacy. (Table 5.5)

- Most students used ICT at least once each week for leisure activities such as listening to downloaded music or watching videos. (Table 5.10)

- Approximately two thirds of students used ICT to access information about things of personal interest from the internet at least once each week. (Table 5.10)

School-related use of ICT most often involved internet searching and document production.

- The most frequent school-related use of ICT was using the internet to do research. Approximately three students in five did this at least once per week. (Table 5.13)

- About one quarter of the students used ICT on a weekly basis to collaborate with other students or organize their time and work. (Table 5.13)

- One quarter of the students used ICT on a weekly basis to prepare reports and essays. (Table 5.13)

- The ICT tools that students most commonly used in a majority of lessons were computerbased information resources, word processing software, and presentation software. (Table 5.17)

Most students were confident users of ICT and saw benefits of ICT for society.

- Four out of five students were confident about their ability to use ICT to search for information, insert an image into a document, and write or edit text for a school assignment. (Table 5.24)

- There was little difference between male and female students in their confidence in using general ICT applications (Table 5.28) but male students expressed greater confidence regarding their use of specialist ICT applications. (Table 5.29)

- Confidence in using general ICT applications was associated with measured CIL and CT, but confidence in the use of specialist ICT applications was not. (Table 5.36) 
- Most students tended to acknowledge positive outcomes of ICT for society, but around half of the students also agreed that ICT had some negative consequences for society. (Table 5.31)

- Male students had greater expectations than female students of using ICT for work or study in the future. (Table 5.35) 


\section{Introduction}

The International Computer and Information Literacy Study (ICILS) 2018 investigated students' experience of using information and communication technology (ICT), their frequency of using ICT for a range of different purposes at and outside of school, and their dispositions toward the use of ICT. This builds on the knowledge about variations in the extent and type of ICT use by students established in ICILS 2013. With large representative samples it is possible to report not only on levels and patterns of ICT engagement but on the relationships of ICT engagement with student attributes.

Our examination of students' engagement with ICT was informed by opportunity to learn, a construct that has featured in IEA large-scale international assessment studies over a long period of time (Elliott and Bartlett 2016; Scheerens 2017; Schmidt et al. 2013). Opportunity to learn initially referred to the time allocated for students to be taught the concepts being assessed and the curriculum content that was the focus of that time. The construct evolved to take account of the enacted curriculum rather than the intended curriculum (Rowan and Correnti 2009) and whether students were actively engaged during that time (Fisher et al. 1981).

We based our investigation on the in-school and out-of-school time that students engaged with ICT because students learned about and developed skills in using ICT in both environments. Our focus was on the frequency with which students engaged in different types of activities rather than where that engagement took place. We distinguished between ICT engagement for general purposes and ICT engagement for school-related purposes. We also asked students about the content of the ICT learning they had experienced at school and aspects of their attitudes to ICT.

Our concern was to examine the associations between students engagement with ICT and their computer and information literacy (CIL) and computational thinking (CT). This chapter informs Research Question 3: What are the relationships between students' levels of access to, familiarity with, and self-reported proficiency in using computers and their CIL/CT? However, we are not solely interested in the relationships of these aspects with achievement in CIL/CT. Another purpose of ICILS 2018 is to investigate the use of computers and other digital devices by students, as well as their attitudes toward the use of computer technologies. These frame the broader context in which computer technologies are used within and outside school.

\section{Forms of engagement with ICT}

Following the taxonomy proposed by Fredericks et al. (2004), we use the term "engagement" to encompass behavioral engagement (i.e., how students use ICT and how often they use it) and emotional engagement (i.e., students' attitudes toward and feelings about ICT).

In order to assess behavioral engagement with ICT we investigated students' general use of ICT and engagement with ICT for school-related purposes. Students' general use of ICT encompassed overall frequency of use as well as use for three particular purposes: creating or editing information products, social communication and information exchange, and leisure activities. Student engagement with ICT for school-related purposes encompassed overall use of ICT for school-related purposes and patterns of ICT use for school-related purposes. Patterns of use for school-related purposes included the ICT tools that were used and the variations in ICT use across subject areas.

Knowing about students' experience of learning about ICT in school is an important aspect of discerning the enacted curriculum within educational systems. Some literature has argued that students are "digital natives" who learned to use ICT outside school (Prensky 2001). However, others have contended that there are important aspects of ICT use that are not familiar to students and need to be taught (Selwyn 2009). We asked students about the extent to which they had learned about particular aspects of CIL and CT at school. 
In order to assess emotional engagement, we investigated two main aspects of students' perceptions of ICT. The first aspect was students' perceptions of themselves in relation to ICT: ICT self-efficacy. We asked students to indicate how well they felt that they could accomplish various ICT tasks. Based on the results from ICILS 2013 (Fraillon et al. 2014) we formed two constructs from these tasks. The first referred to ICT self-efficacy in relation to general applications (typically embodied in office applications) and the second referred to ICT self-efficacy in relation to specialist or advanced tasks (such as coding, database management, and webpage construction).

Another aspect of students' emotional engagement with ICT was their perceptions of ICT with regard to society in general and their own future engagement with it. We asked about the extent to which they saw ICT as beneficial for society, the extent to which they saw ICT as harmful for society (noting that these are not simply polar opposites), and the extent to which they aspired to engage with ICT in the future.

\section{Data and measures}

In ICILS 2018, grade 8 students completed a computer-based questionnaire concerning their use of and attitudes to ICT after they had completed the ICILS assessment of CIL. Students were advised that ICT could refer to a desktop computer, a notebook, or laptop computer, a netbook computer, a tablet device, or a smartphone (except when being used for talk or text). Student responses to questionnaire items indicated either how frequently they engaged with ICT or particular tasks using ICT, or how strongly they agreed with statements about the use of ICT and their attitudes to ICT. We have reported these data in relation to individual items and to sets of items that were used to derive scales.

When reporting frequency data for individual items we have typically combined frequency response categories to create dichotomous categories such as "daily" or "at least weekly." When we report the percentages of students undertaking a particular activity on a daily (or weekly) basis we use the term prevalence. For responses concerned with attitudes, we grouped response categories such as "strongly agree" and "agree" into agreement and refer to "percentage agreement."

We also used scale scores based on sets of items to provide a more parsimonious picture of differences across countries, differences between subgroups (such as female and male students), and measures of association between two constructs. We used the Rasch partial credit model (Masters and Wright 1987) to construct the scales, and standardized the item response theory (IRT) scores to have an ICILS 2018 average score of 50 points and a standard deviation of 10 points. This means that a difference of two scale points represents one fifth of a standard deviation (and is interpreted as a small difference), and a difference of five scale points represents one half of a standard deviation (and is interpreted as a moderate difference). All student scales included in this report are described in item maps (see Appendix F of this report). The maps relate scale scores to expected item responses under the ICILS scaling model (as illustrated by Figure F.1 in Appendix F). Greater detail of the scaling and equating procedures for questionnaire items is provided in the ICILS 2018 technical report (Fraillon et al. 2020).

We evaluated the cross-country validity of item dimensionality and constructs during the field trial and following the main survey of ICILS 2018. We assessed the extent to which measurement models were congruent across participating countries. In the field trial we made extensive use of both confirmatory factor analysis and item response modeling to examine cross-national measurement equivalence before the final selection of main survey questionnaire items was conducted. When the main survey was completed we checked the measurement equivalence and in a few instances modified the measurement models that were used. These analyses are reported in the ICILS 2018 technical report (Fraillon et al. 2020). 
The scales that we used in analysis and reporting, based on the student questionnaire, were:

- Students' general engagement with ICT

- Frequency of use of general ICT applications

- Frequency of use of specialist ICT applications

- Frequency of use of ICT for social communication

- Frequency of use of ICT for exchanging information

- Frequency of use of ICT for accessing content from the internet

- Student engagement with ICT for school-related purposes

- Frequency of use of ICT for study purposes

- Frequency of use of general applications in class

- Frequency of use of specialist applications in class

- Extent of student learning about ICT at school

- Extent to which students learned about CIL tasks at school

- Extent to which students learned about CT tasks at school

- ICT self-efficacy

- ICT self-efficacy regarding the use of general applications

- ICT self-efficacy regarding the use of specialist applications

- Attitudes to ICT futures

- Perceptions of ICT

- Perceptions of positive effects of ICT on society

- Perceptions of negative effects of ICT on society

- Perceptions of personal futures with ICT

\section{Student general engagement with ICT}

The past four decades have seen substantial growth in the availability and use of ICT by young people in and outside school (Bulfin et al. 2016). Growth in student use of ICT has been accompanied by a growing interest in how these technologies are being used (Bulfin et al. 2016). The European Commission reported that 80 percent of students in lower-secondary school (ISCED 2) engaged in ICT-based activities more frequently at home than at school (European Commission 2013). The report identified three groups of ICT-based activities at home: "fun" (e.g., streaming or downloading multimedia, music, movies, or videos), "learning" (e.g., online news, information searching, and learning programs), and "games." Students were more confident in their "digital competences when they had high access to/use of ICT at home and at school" (European Commission 2013, p. 15). Scherer et al. (2017) identified two profiles of students' ICT use in Norway: students who had low participation in leisure-related internet activities and students who frequently used ICT for a wide range of activities. These profiles were associated with differences in gender, migration status, and motivations.

ICILS 2013 has also been an important source for understanding and reporting students' general ICT use. Bundsgaard and Gerick (2017) used latent class analysis of ICILS 2013 data to identify three clusters reflecting different types of students' computer use. The largest cluster ( $72 \%$ of the sample) had average frequencies of school-related and recreational computer use. The next cluster (12\%) had low frequencies of computer use for communication and study purposes. The third cluster (11\%) had high frequencies of use in general and especially for exchanging information. 
Multivariate analyses based on ICILS 2013 data showed that, after controlling for the effect of background variables such as gender or socioeconomic status, students' experience of computer use and their frequency of computer use at home were positively associated with CIL scores in most countries (Fraillon et al. 2014). Student access to a home internet connection and the number of computers at home also had statistically significant associations with CIL scores in about half of the participating education systems. Greater interest in and enjoyment of ICT use was associated with higher CIL scores in nine out of 14 countries. There was also evidence of an association between CIL scores and the extent to which students reported having learned about ICT-related tasks at school.

In this section we take a closer look at aspects of students' general use of ICT. We also look at their use of ICT for particular purposes and applications. Students reported on the use of general applications (such as word processing, presentation, and internet search software) and specialist ICT applications (such as those concerned with producing or editing graphics and images, videos, music, computer programs, and webpages). Furthermore, they reported on their use of ICT for information exchange, social communication, and recreation. We focus on the proportions of students using ICT for each of these aspects at least once a week as well as on the distribution of scale scores overall and by subgroups.

\section{Student background: Experience with using ICT}

We regarded students' experience of using ICT as an important aspect of student background in relation to their general engagement with ICT, as well as to their development of CIL and CT. Students reported how long (the number of years) they had been using computers, tablet devices, or smartphones (other than the text or talk facilities) (Table 5.1). We asked students to respond separately for each type of device. This approach was different from the one chosen in ICILS 2013 where we asked students to provide an indication of overall use for any of these devices. Therefore these data are not comparable to those from ICILS 2013. However, based on three comparison countries that met sampling requirements in both 2018 and 2013 (Chile, Germany, and Korea), it appears that there was a fall of about 15 percentage points in students with five or more years of computer experience. An explanation for this could be that the use of tablet devices is now more widespread.

Students reported their experience via five response categories ("never or less than one year," "at least one year but less than three years," "at least three years but less than five years," "at least five years but less than seven years," and "seven years or more"). We transformed these categories into dichotomous values reflecting five or more years of experience (experienced users) or less than five years of experience (inexperienced users). We then used these in regression analyses so that we could review the association between this variable and CIL.

On average across the ICILS countries, just under half (46\%) of grade 8 students reported having used computers for five or more years, a little less than one third (31\%) had used tablet devices for five or more years, and 44 percent had used smartphones for at least this period (Table 5.1). Grade 8 students' experience with computers varied across the ICILS 2018 participating entities. The highest percentages of experienced computer users among participating countries were in Finland (69\%) and Portugal (63\%) (Table 5.1). There was also a high percentage of experienced computer users in the benchmarking participant of Moscow (Russian Federation) (67\%). The lowest percentages of experienced computer users were in Germany (36\%), North RhineWestphalia (Germany) (36\%), Italy (36\%), and Kazakhstan (32\%). The pattern was similar for tablet devices, with the highest percentages of experienced users being recorded for Denmark (47\%) and the lowest percentages being recorded for Korea (14\%) and Kazakhstan (19\%). Experience with smartphone use was widespread in Finland (73\%), but less frequent in France (26\%). 


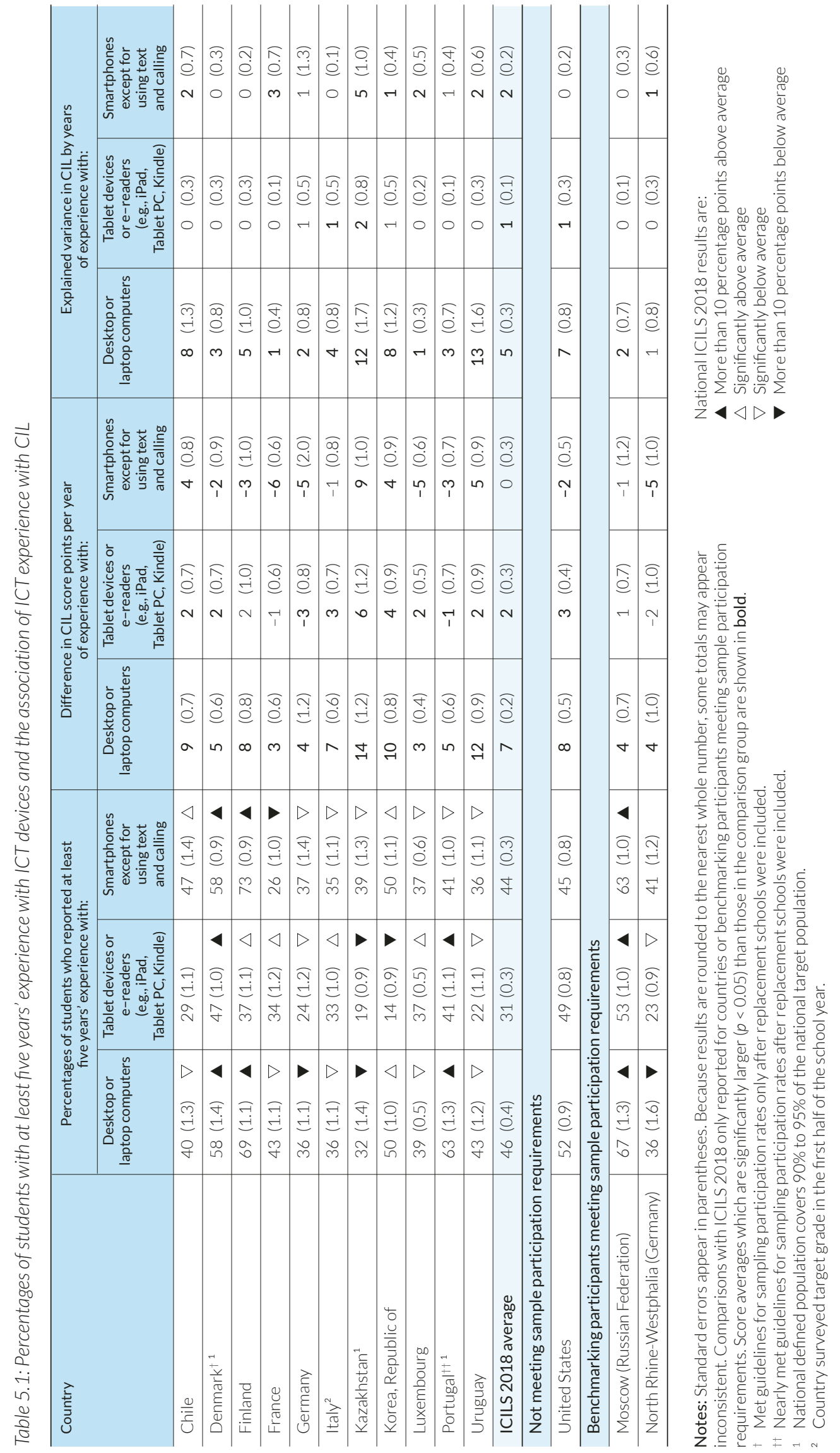


There was a significant association between computer experience and CIL in all participating countries (averaging seven points per year of experience) and a smaller but significant association between experience of using tablet devices and CIL in eight of the participating countries that met sample requirements (averaging two points per year of experience) (Table 5.1). There were significant associations between experience of using smartphones and CIL in 10 participating entities, but some were negative and some were positive so that on average there was no statistically significant effect. On average, student experience of using computers accounted for just five percent of the variance in CIL scores.

\section{Frequency of ICT use}

We computed the percentages of grade 8 students who reported using computers at least once a day in each of four categories: outside of school for school related purposes, outside of school for non-school related purposes, inside school for school related purposes, and inside school for non-school related purposes. ${ }^{19}$ Daily use of ICT for other (i.e., not school-related) purposes outside school was the most frequent use in every country (Table 5.2). On average 70 percent of grade 8 students reported daily use of ICT outside of school for other purposes. Of the participating educational systems the frequency was highest in Germany (83\%) and North Rhine-Westphalia (Germany) (85\%) and lowest in Kazakhstan (48\%). The next most frequent category of daily ICT use was at school for other purposes, which was reported on average by 29 percent of grade 8 students. Among the participating countries, daily use of ICT at school for other purposes was most frequent in Finland (56\%) and Denmark (55\%) and least frequent in Italy (4\%), France (13\%), and Germany (16\%).

Daily use of ICT for school-related purposes was less common than for other purposes. On average across participating countries, 18 percent of grade 8 students used ICT on a daily basis for school-related purposes at school and 21 percent of these students used ICT on a daily basis for school-related purposes outside of school (Table 5.2). Using ICT on a daily basis for schoolrelated purposes at school was most frequently reported in Denmark (81\%) and least frequently (7\% or less) in Germany, Korea, Portugal, and Italy. Daily use of ICT for school-related purposes outside of school was most frequent in Denmark (35\%) and Moscow (Russian Federation) (40\%) and least frequent in North Rhine-Westphalia (Germany) (9\%), Portugal (10\%), Korea (10\%), and Germany (11\%).

It is also evident that in Denmark the frequency of daily use of ICT outside school for other purposes (79\%) is similar to the frequency of daily use at school for school-related purposes (81\%) (Table 5.2). In contrast, there were large differences between the frequency of daily use of ICT outside school for other purposes and the frequency of daily use of ICT at school for school-related purposes in Germany (83\% compared to 4\%), Italy (77\% compared to 7\%), and France (76\% compared to $8 \%$ ). These differences possibly reflect the extent to which ICT is part of teaching and learning in school education and may provide an index of the emphasis on ICT in schooling at lower-secondary level.

19 In ICILS 2013 we reported frequency of use on a weekly rather than a daily basis, and we did not separate usage for general purposes and school-related purposes. Therefore, the data for ICILS 2018 are not comparable with those reported for ICILS 2013, even for the three countries that met sampling requirements in both studies. 
Table 5.2: Percentages of students reporting daily use of ICT in and outside school for school-related and other purposes

\begin{tabular}{|c|c|c|c|c|c|c|c|c|}
\hline \multirow{3}{*}{$\begin{array}{l}\text { Country } \\
\text { Chile }\end{array}$} & \multicolumn{8}{|c|}{ Percentages of students who reported daily use of ICT: } \\
\hline & \multicolumn{2}{|c|}{$\begin{array}{l}\text { At school for } \\
\text { school-related } \\
\text { purposes }\end{array}$} & \multicolumn{2}{|c|}{$\begin{array}{l}\text { At school for } \\
\text { other purposes }\end{array}$} & \multicolumn{2}{|c|}{$\begin{array}{l}\text { Outside of school } \\
\text { for school-related } \\
\text { purposes }\end{array}$} & \multicolumn{2}{|c|}{$\begin{array}{l}\text { Outside of school } \\
\text { for other } \\
\text { purposes }\end{array}$} \\
\hline & $12(0.9)$ & $\nabla$ & $27(1.2)$ & & $14(0.9)$ & $\nabla$ & $62(1.5)$ & $\nabla$ \\
\hline Denmark $^{\dagger^{1}}$ & $81(1.2)$ & $\boldsymbol{\Delta}$ & $55(1.4)$ & $\boldsymbol{\Delta}$ & $35(1.5)$ & $\Delta$ & $79(1.0)$ & $\triangle$ \\
\hline Finland & $12(1.0)$ & $\nabla$ & $56(1.4)$ & $\boldsymbol{\Delta}$ & $15(0.9)$ & $\nabla$ & $79(0.9)$ & $\triangle$ \\
\hline France & $8(0.7)$ & $\nabla$ & $13(1.1)$ & $\nabla$ & $25(0.9)$ & $\triangle$ & $76(0.9)$ & $\triangle$ \\
\hline Germany & $4(0.6)$ & $\nabla$ & $16(1.2)$ & $\nabla$ & $11(0.8)$ & $\nabla$ & $83(0.9)$ & $\boldsymbol{\Delta}$ \\
\hline Italy ${ }^{2}$ & $7 \quad(0.6)$ & $\nabla$ & $4(0.5)$ & $\nabla$ & $22(0.9)$ & & $77(1.0)$ & $\triangle$ \\
\hline Kazakhstan $^{1}$ & $24(1.1)$ & $\triangle$ & $30(1.1)$ & & $31(1.2)$ & $\triangle$ & $48(1.4)$ & $\nabla$ \\
\hline Korea, Republic of & $5(0.5)$ & $\nabla$ & $19(1.0)$ & $\nabla$ & $10(0.7)$ & $\nabla$ & $68(1.0)$ & $\nabla$ \\
\hline Luxembourg & $18(0.6)$ & & $33(0.6)$ & $\triangle$ & $27(0.5)$ & $\triangle$ & $66(0.6)$ & $\nabla$ \\
\hline Portugal $^{+1}+1$ & $7 \quad(0.5)$ & $\nabla$ & $36(1.1)$ & $\triangle$ & $10(0.7)$ & $\nabla$ & 71 (1.3) & \\
\hline Uruguay & $15(0.9)$ & $\nabla$ & $25(1.4)$ & $\nabla$ & $33(1.4)$ & $\boldsymbol{\Delta}$ & $66(1.6)$ & $\nabla$ \\
\hline ICILS 2018 average & $18(0.2)$ & & $29(0.3)$ & & 21 (0.3) & & $70(0.3)$ & \\
\hline \multicolumn{9}{|c|}{ Not meeting sample participation requirements } \\
\hline United States & $43(1.6)$ & & $28(1.0)$ & & $29(0.9)$ & & $66(0.9)$ & \\
\hline \multicolumn{9}{|c|}{ Benchmarking participants meeting sample participation requirements } \\
\hline Moscow (Russian Federation) & $22(0.8)$ & $\triangle$ & $43(1.1)$ & $\boldsymbol{\Delta}$ & $40(1.0)$ & $\boldsymbol{\Delta}$ & $77(1.3)$ & $\triangle$ \\
\hline North Rhine-Westphalia (Germany) & $3(0.5)$ & $\nabla$ & $19(1.5)$ & $\nabla$ & $9(0.8)$ & $\nabla$ & $85(0.9)$ & $\boldsymbol{\Delta}$ \\
\hline
\end{tabular}

Notes: Standard errors appear in parentheses. Because results are rounded to the nearest whole number, some totals may appear inconsistent.

Comparisons with ICILS 2018 only reported for countries or benchmarking participants meeting sample participation requirements.

+ Met guidelines for sampling participation rates only after replacement schools were included.

t† Nearly met guidelines for sampling participation rates after replacement schools were included.

1 National defined population covers $90 \%$ to $95 \%$ of the national target population.

2 Country surveyed target grade in the first half of the school year.
National ICILS 2018 results are:

A More than 10 percentage points above average

$\triangle$ Significantly above average

$\nabla$ Significantly below average

$\boldsymbol{\nabla}$ More than 10 percentage points below average

\section{Use of ICT to create or edit information products}

On average across ICILS 2018 educational systems one third (33\%) of grade 8 students used ICT to write or edit documents at least once each week, one fifth (21\%) used ICT-based spreadsheets for calculations or graphing, and one fifth (19\%) used ICT to develop slideshow presentations (Table 5.3). The prevalence of these uses of ICT on a weekly basis was highest in Denmark (84\%, $51 \%$, and 38\% respectively). These uses of ICT were less prevalent in Korea, Finland, Germany, and North Rhine-Westphalia (Germany).

Based on the three comparable countries ${ }^{20}$ from ICILS 2013 (Fraillon et al. 2014, p. 133), it appears that there may have been a small increase in the weekly use of ICT to write or edit documents (notably in Germany), an increase in the weekly use of spreadsheets (again particularly in Germany), and little change in the weekly use of ICT to develop slideshow presentations.

20 The three countries were Chile, Germany, and Korea. Denmark participated in ICILS 2013, but did not satisfy sampling requirements. 


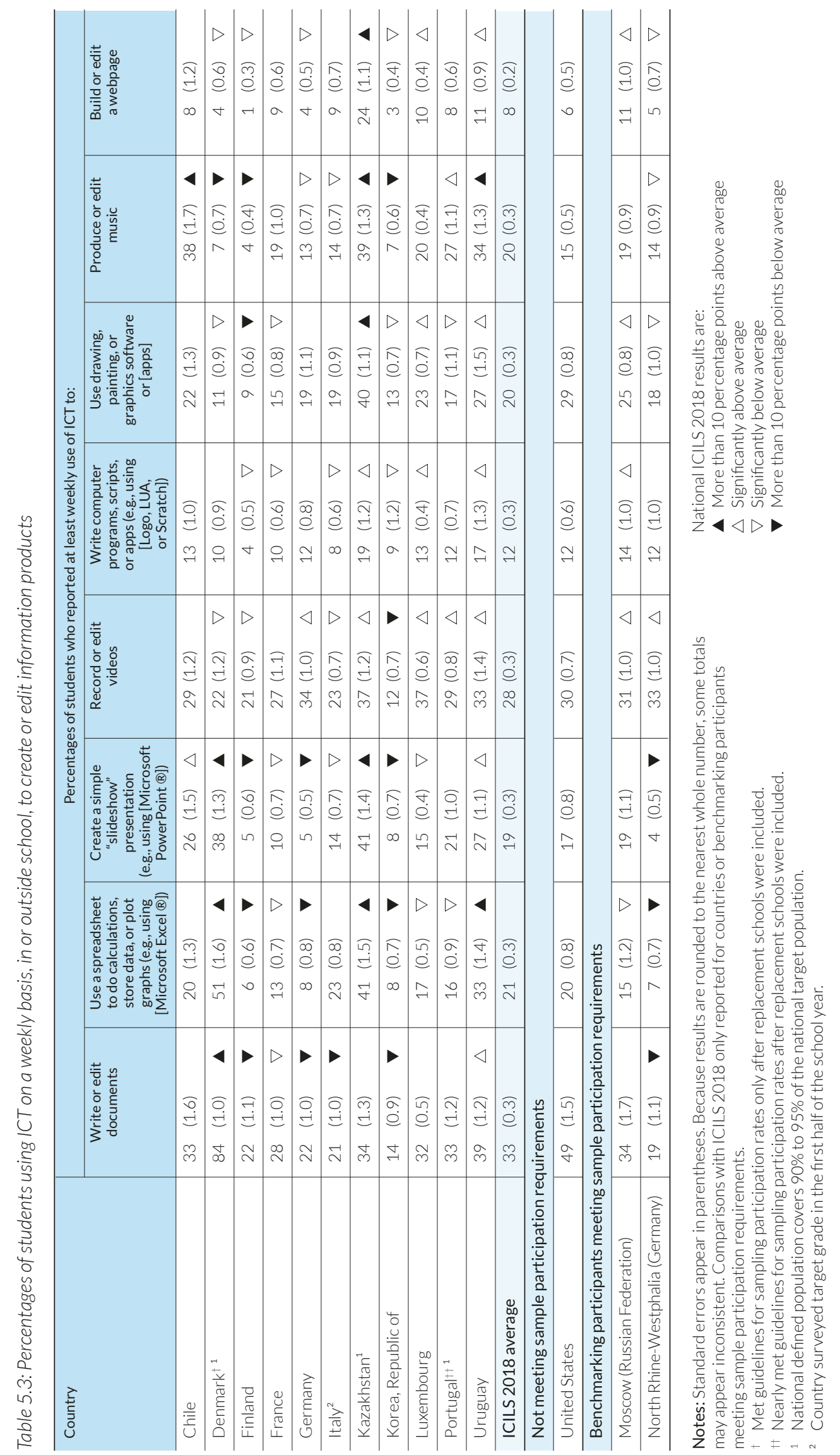


On average across all countries, the specialist applications used at least weekly by the highest percentages of students were: recording or editing videos (28\%), using drawing and painting software (20\%), and producing or editing music (20\%). Activities reported to be conducted on at least a weekly basis by smaller percentages of students were: writing computer programs or scripts (12\%), and building or editing a webpage (8\%). The prevalence of weekly use of music applications varied greatly from nearly two-fifths in Chile (38\%) and Kazakhstan (39\%) to less than one in 14 in Finland (4\%), Denmark (7\%), and Korea (7\%). It is of interest that in Denmark, although there were high proportions of students reporting weekly use of general applications, there was only a low percentage of students indicating weekly use of ICT for music production or editing/building webpages.

Between 2013 and 2018 there appeared to have been increases in the weekly use of drawing, painting, and graphics software in Chile, Germany, and Korea. There were only small increases in the weekly writing of computer programs in these countries.

The items were used to derive two IRT scales reflecting students' use of general applications for activities and students' use of specialist applications for activities, where higher scale scores reflected higher frequency of use. Both scales had satisfactory reliabilities with average Cronbach's alpha coefficients across countries of 0.70 and 0.73 , respectively (the item maps describing these scales are included in Figures F.2 and F.3 in Appendix F).

We used these scale scores (set to metrics with a mean of 50 and a standard deviation of 10 for equally weighted participating countries) to investigate differences among countries in students' use of general applications and specialist applications (Table 5.4). It was evident that the scale scores reflecting reported use of general applications were highest in Denmark and Kazakhstan and lowest in Korea, Finland, and North Rhine-Westphalia (Germany). We recorded the highest scale score of reported use of specialist applications in Kazakhstan and the lowest score in Finland.

We also reviewed the associations between the scale scores representing the use of ICT applications and several aspects of students' experience of, and expertise in, using computers. We compared, for each country, the mean scale scores for the frequency of using general ICT applications (including productivity software) for: ${ }^{21}$

- Students with less than five years of computer experience with those who had five or more years of computer experience;

- Students who studied computer subjects (e.g., computing, computer science, information technology, informatics, or similar) in the current school year with those who did not study computer subjects; and

- Students with CIL scores below Level 2 with students whose CIL scores were at Level 2 or above. 


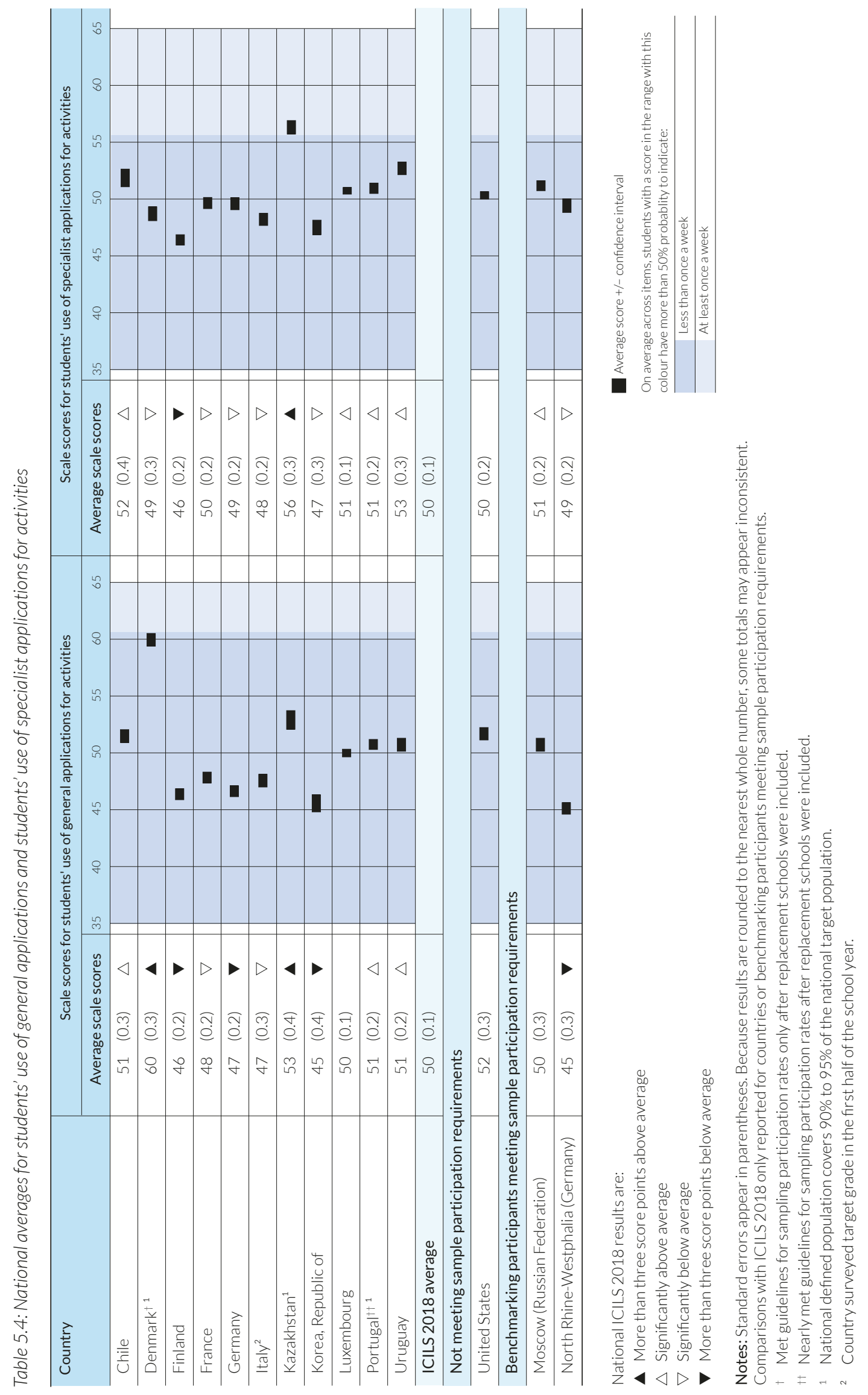




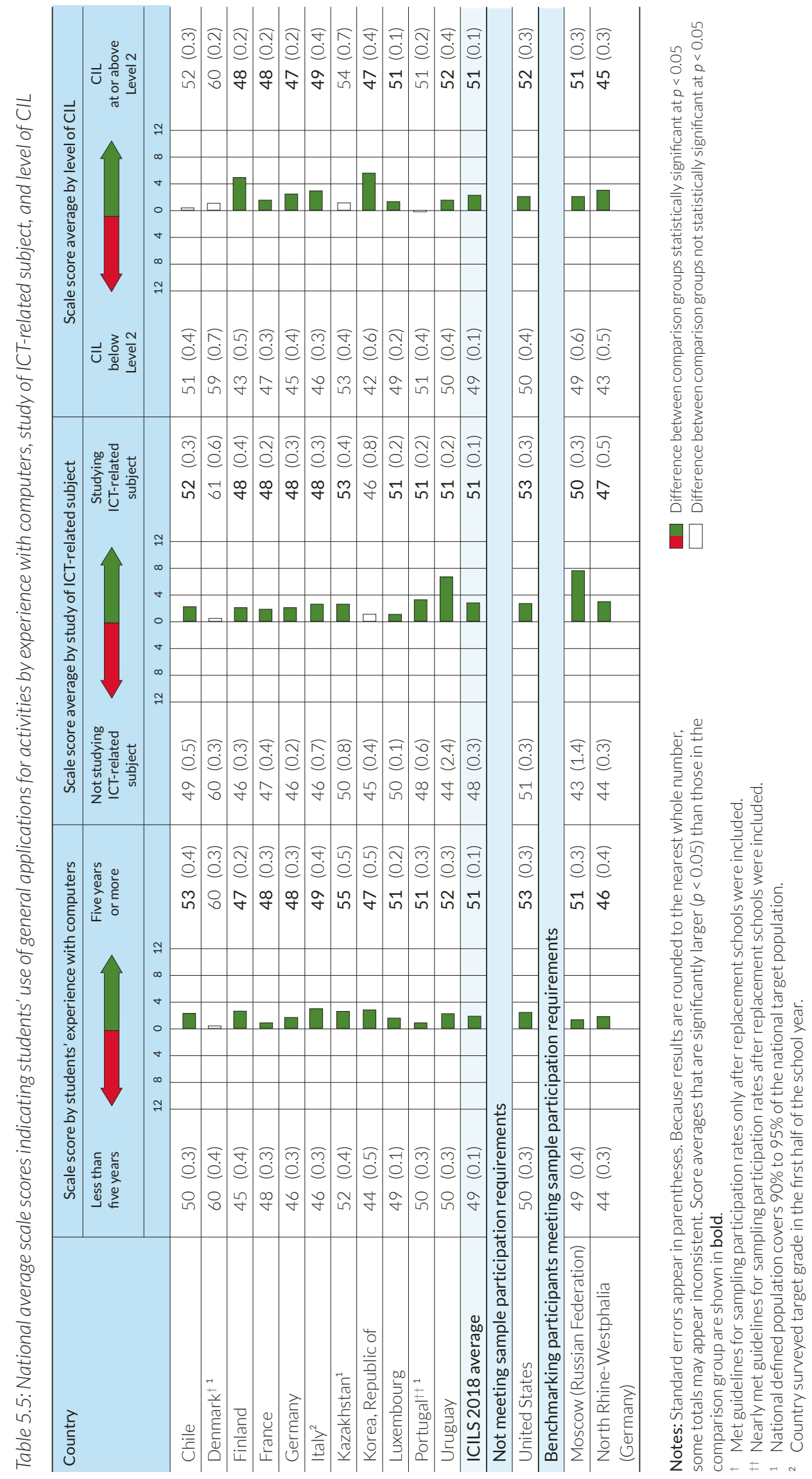


Scale scores for frequency of use of general applications for activities were higher for experienced than inexperienced computer users (Table 5.5). The difference between these groups was significant in all ICILS 2018 countries except Denmark (where scale score was very high). On average across countries, the difference between experienced and inexperienced computer users was two scale points.

We also found that there was more frequent use of general applications for activities among students who studied computing subjects in the current year than by those who did not. This difference in scale scores was significant in all but two countries (Denmark and Korea) and was three scale points on average across participating countries. The difference was particularly large (seven points) in Uruguay and also in the benchmarking participant Moscow (Russian Federation) (also seven points).

There was more frequent use of general applications for activities reported by those with CIL scores at or above Level 2 than by those with CIL scores below Level 2. The difference in scale scores averaged two scale points across countries and was significant in all countries except Chile, Kazakhstan, and Portugal. The difference was largest in Korea (six points) and Finland (four points). Of course we cannot identify the direction of causation but the association may hold important ramifications for the development of skills.

We conducted similar analyses of the association between the frequency of use of specialist ICT applications for activities and student attributes (Table 5.6). The mean scale scores for the frequency of using specialist applications for activities of students with five or more years of computer experience were significantly greater than for other students in 10 of the 13 countries that met sampling requirements, and averaged two scale points.

In eight of 13 countries students who studied computer subjects in the current school year reported more frequent use of specialist applications for activities than those who did not, with an average difference of two scale points. This difference was largest in Moscow (Russian Federation) (six points), Denmark (four points), and Finland (four points). Surprisingly, we found in 10 of the 13 countries that students with CIL scores below Level 2 used specialist ICT applications more frequently than students whose CIL scores at Level 2 or above. On average across countries, the difference was about two scale points. In Finland and Korea, the reverse was true. Students with high CIL scores used these applications more frequently than students with low CIL scores.

\section{Use of ICT for social communication and exchange of information}

ICILS 2013 reported that students made extensive use of ICT for social communication and accessing information (Fraillon et al. 2014). Because a number of the items changed between ICILS 2013 and ICILS 2018 direct comparisons over time are not possible. In ICILS 2018 we asked students to indicate the frequency with which they were using ICT for a variety of communication and information exchange activities. The response categories were "never," "less than once a month," "at least once a month but not every week," "at least once a week but not every day," and "every day." The 10 activities listed in the questionnaire included seven related to communication and three concerned with information exchange. The responses to the questionnaire confirmed that there were two clusters of items that provided the basis for two scales: social communication and information exchange (Table 5.7). 


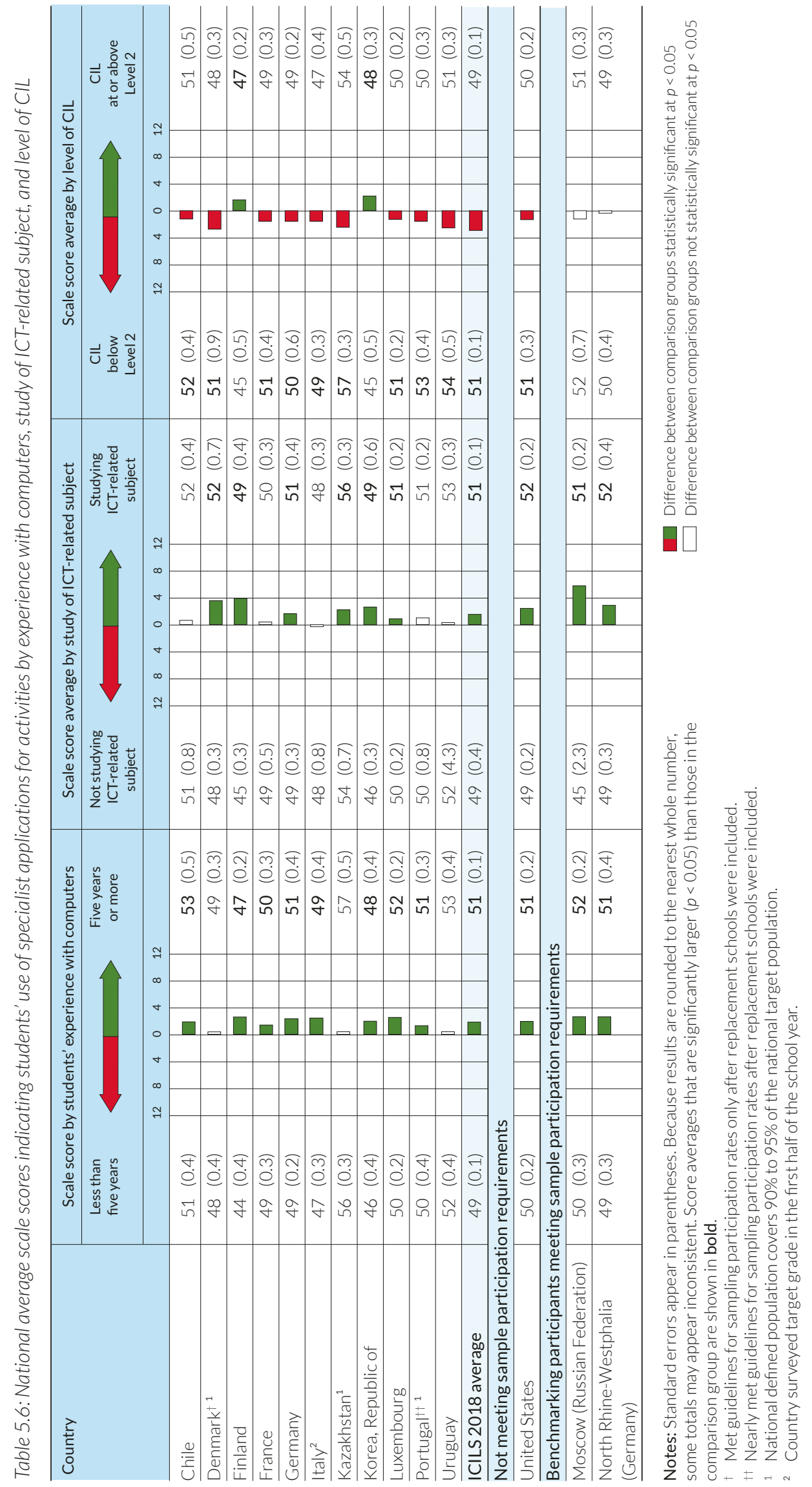



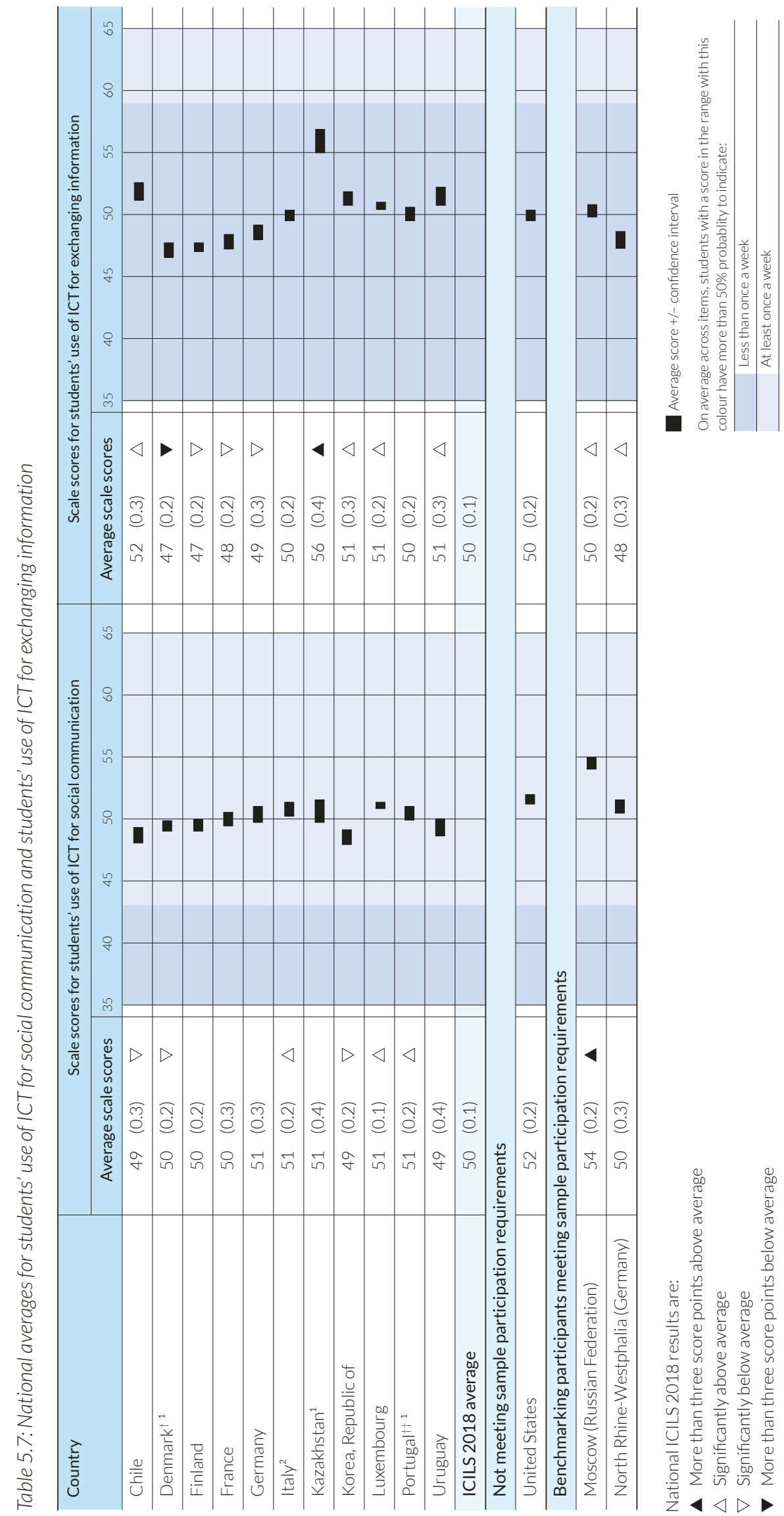
The social communication items were:

- Share news about current events on social media;

- Communicate with friends, family, or other people using instant messaging, voice, or video chat (e.g., Skype, WhatsApp, or Viber);

- Send texts or instant messages to friends, family, or other people;

- Write posts and updates about what happens in your life on social media;

- Post images or video in social networks or online communities (e.g., Facebook, Instagram, or YouTube);

- Watch videos or images that other people have posted online; and

- Send or forward information about events or activities to other people.

The information exchange items were the following:

- Ask questions on forums or Q\&A (question and answer) websites;

- Answer other people's questions on forums or Q\&A websites; and

- Write posts for your own blog (e.g., using WordPress, Tumblr, or Blogger).

The items were used to derive two IRT scales reflecting students' use of ICT for social communication and students' use of ICT for exchanging information, where higher scale scores reflected higher frequency of use. Both scales had satisfactory reliabilities with average Cronbach's alpha coefficients across countries of 0.77 and 0.75 respectively (the item maps describing these scales are included in Figures F.4 and F.5, Appendix F).

An inspection of national mean scale scores for the frequency of social communication and for information exchange indicated small differences among countries on the social communication scale but larger differences among countries on the information exchange scale (Table 5.7). Scale scores reflecting the use of ICT for information exchange were relatively high in Kazakhstan and Chile and relatively low in Denmark and Finland.

The average scale scores for the use of ICT for social communication were significantly higher for students who were experienced computer users than other students in all countries except Denmark, and the average difference between the two comparison groups was three scale points (Table 5.8).

In only two countries (Kazakhstan and Portugal) did students who were currently studying computing subjects have higher scores on the ICT for social communication scale than those who were not studying ICT (Table 5.8). In Finland, students who were currently studying computer subjects had lower scores on the ICT for social communication scale than other students. In most countries there was no significant difference between the two groups of students.

In four ICILS 2018 countries, students whose CIL scores were at Level 2 or above used ICT for social communication more frequently than students with CIL scores below Level 2. On average across educational systems the difference was just one scale point. The opposite was true for North Rhine-Westphalia (Germany).

The scale score reflecting frequency of use of ICT for exchanging information was significantly higher for students who were experienced computer users than for other students in nine of the ICILS countries, but the average difference was only one scale point (Table 5.9). In just four of the countries, students who were currently studying computing subjects had higher scores on the use of ICT for exchanging information scale than those who were not. In 11 of the ICILS countries, students with CIL scores below Level 2 had higher scale scores for ICT use to exchange information than students whose CIL scores were at Level 2 or above. On average across countries the difference was three scale points. The largest differences were evident in Denmark (five points), Germany (four points), and Luxembourg (four points). 


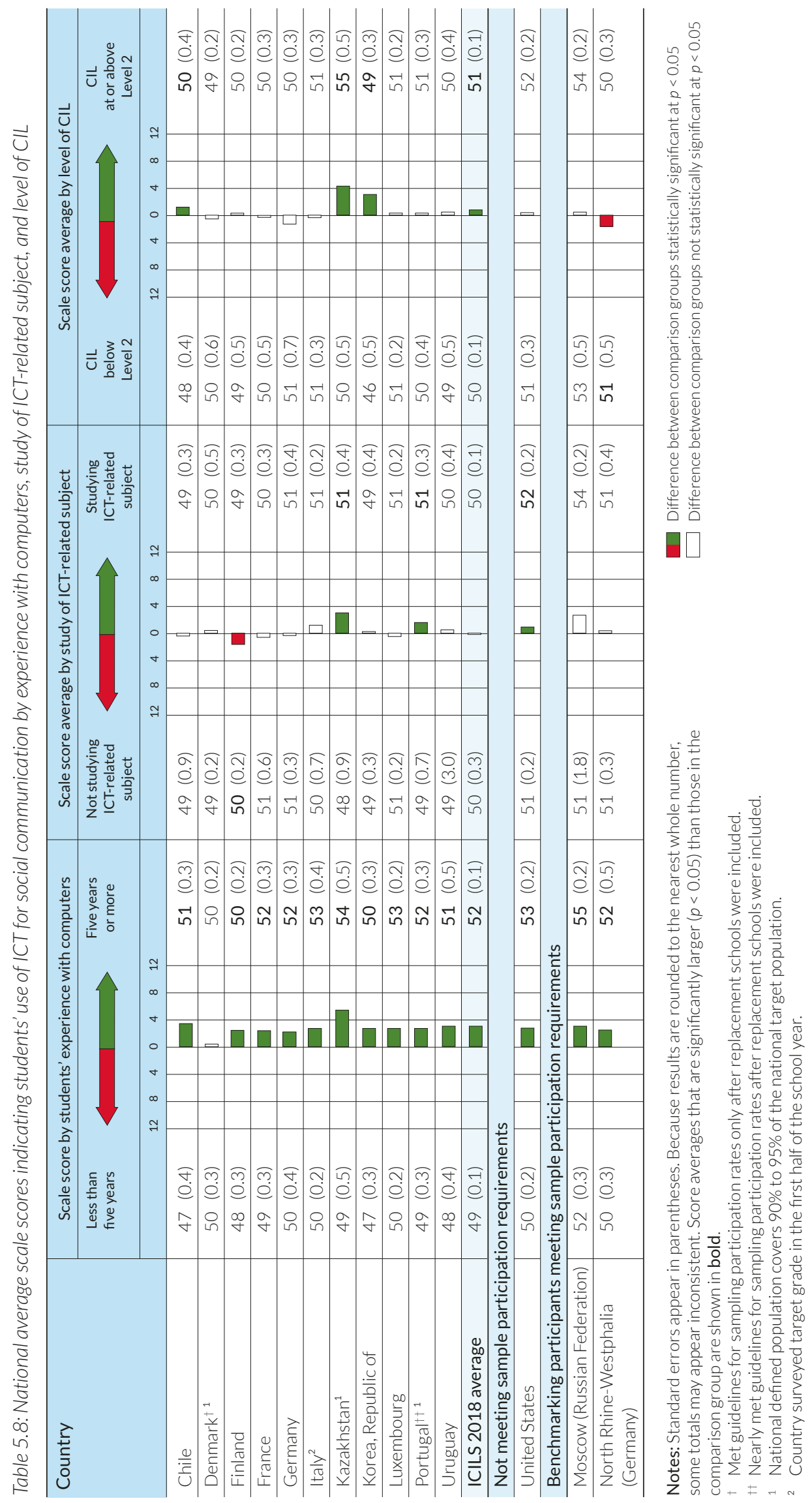




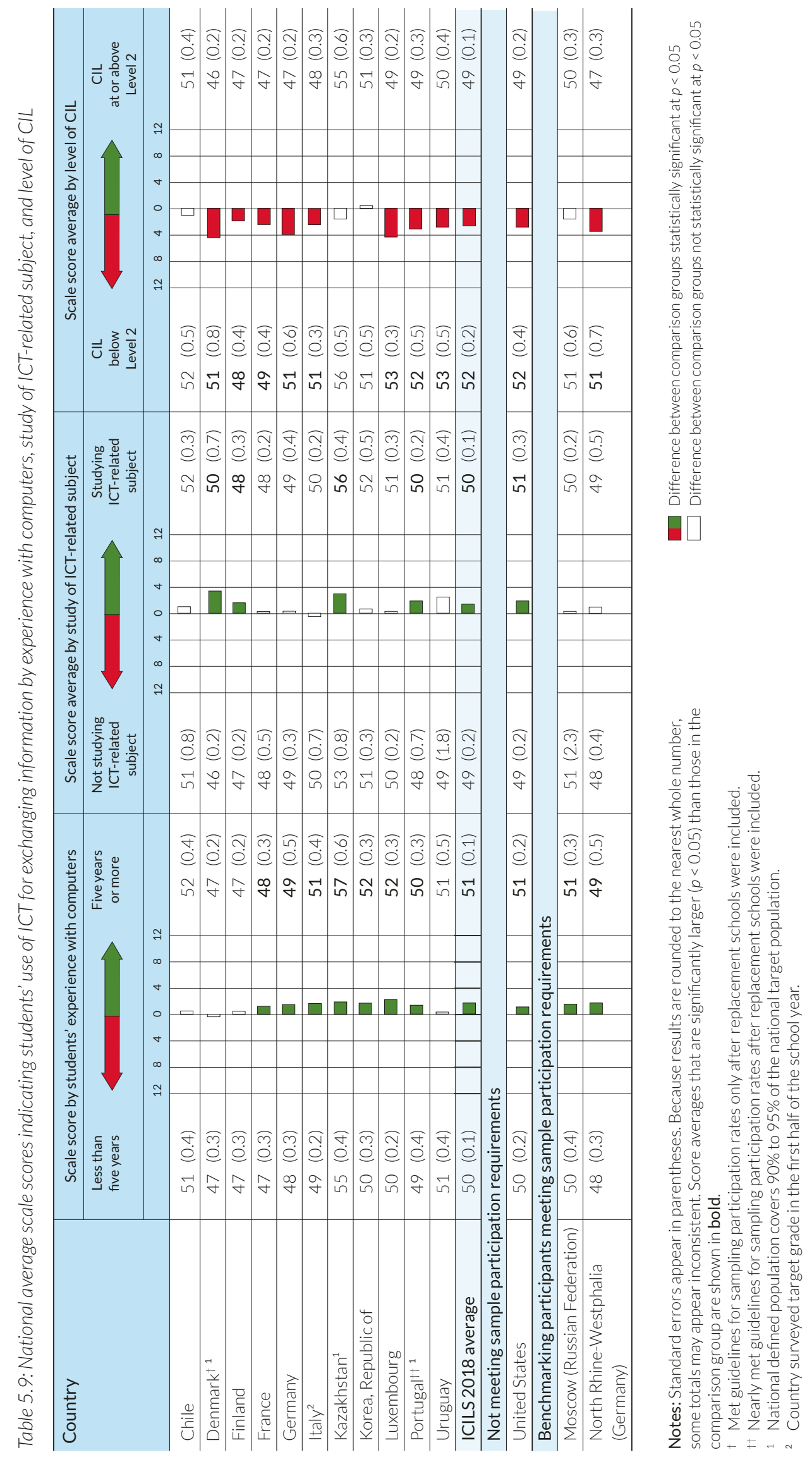




\section{Use of ICT for leisure activities}

Prior research has shown that students tend to use ICT frequently for leisure activities (Tobias et al. 2011) and this was confirmed in ICILS 2013 (Fraillon et al. 2014, p. 143). ICILS 2018 included leisure activities that involved accessing content from the internet (but not necessarily for study or school) as well as recreational activities such as playing games, listening to downloaded music, or watching downloaded or streamed TV or movies. The ICILS 2018 student questionnaire asked students to indicate how often they used computers for leisure activities. For reporting purposes, we categorized these as the percentages who reported doing these activities at least once each week (Table 5.10).

There was a high prevalence of using ICT for recreation on a weekly basis (Table 5.10). On average across ICILS 2018 countries, 83 percent of students used ICT to listen to downloaded or streamed music at least once each week, 71 percent used ICT to play single-player games at least once each week, and 68 percent used ICT to watch downloaded or streamed TV shows or movies on a weekly basis. Using ICT to watch downloaded or streamed TV shows or movies on a weekly basis was most common in Denmark (81\%) and Moscow (Russian Federation) (83\%), and least common in Korea (57\%).

In the three comparable countries from ICILS 2013 (Chile, Germany, and Korea) there appeared to have been an increase in the use of ICT to access "the internet to find out about places to go or activities to do," "read reviews on the internet of things you might want to buy," and "watch downloaded or streamed TV shows or movies" (see Fraillon et al. 2014, p. 142). Other items had been altered from ICILS 2013 so that it is not possible to make other comparisons.

The activities that involved accessing content from the internet were (in decreasing order of average percentages):

- Search for online information about things you are interested in (69\%);

- Use websites, forums, or online videos to find out how to do something (50\%);

- Read news stories on the internet (50\%);

- Read reviews on the internet of things you might want to buy (39\%); and

- Search the internet to find information about places to go or activities to do (36\%).

The activities that involved accessing content from the internet formed a reliable scale (average Cronbach's alpha across countries $=0.75$ ) representing the frequency with which students accessed content from the internet (see the corresponding item map in Figure F.6 in Appendix F). Students from Kazakhstan scored highest on this scale and those from Germany scored lowest (Table 5.11). In Denmark, Finland, Germany, and Portugal male students scored higher than female students (i.e., use the internet more often to access content), but in Korea and Kazakhstan the reverse was the case. On average across countries, there was no significant difference between female and male students.

On the basis of results from this scale we concluded that, on average across countries, weekly ICT use for accessing content from the internet was higher (by two scale points) for experienced computer users than for inexperienced computer users, and higher for those with high levels of home computer resources than for those who had low levels of home computer resources (by two scale points) (Table 5.12). The difference associated with computer experience was significant in all but one of the ICILS 2018 countries (Denmark). The difference associated with home computer resources was significant in all but two of the ICILS 2018 countries (Denmark and Germany). 


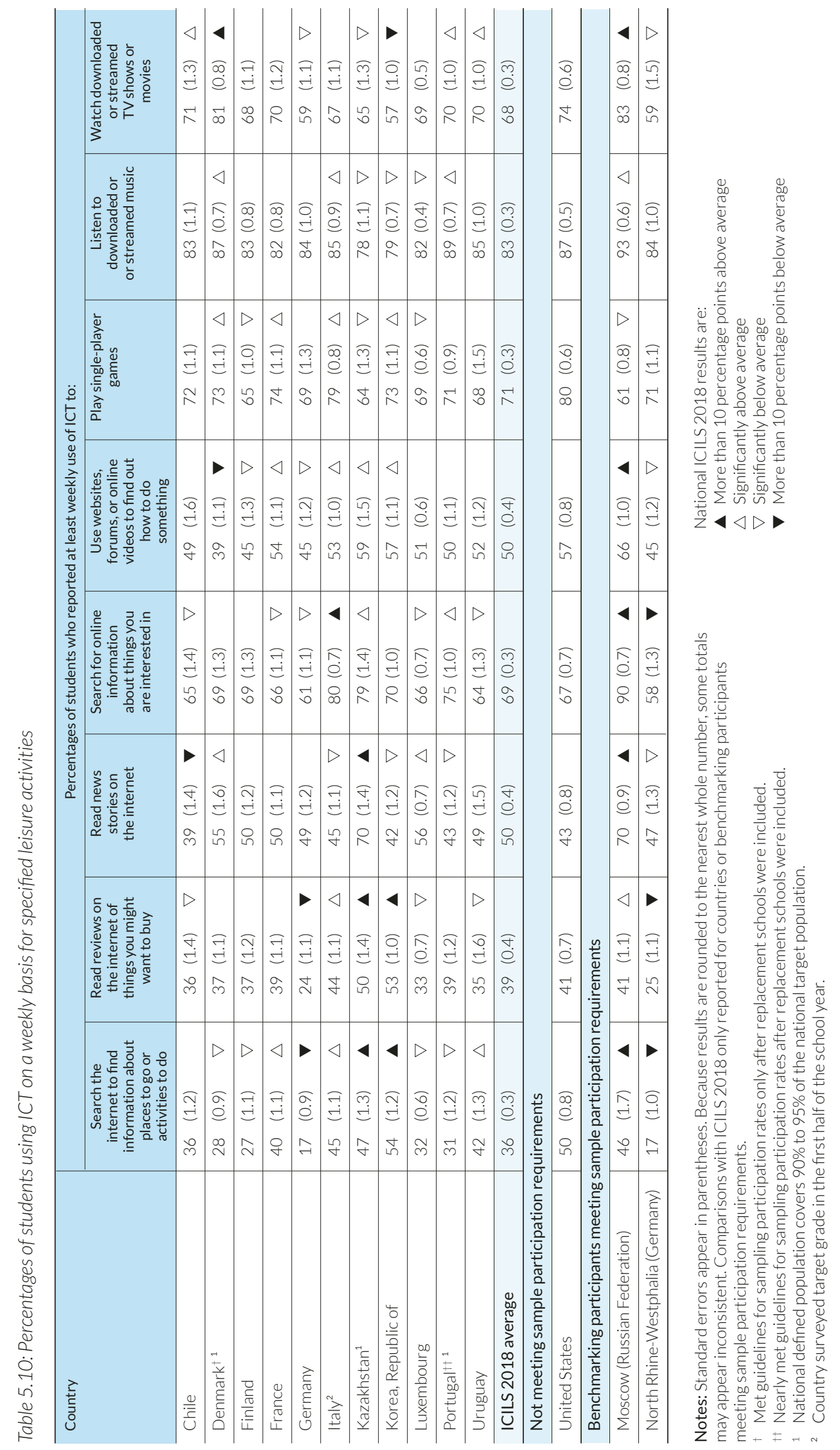



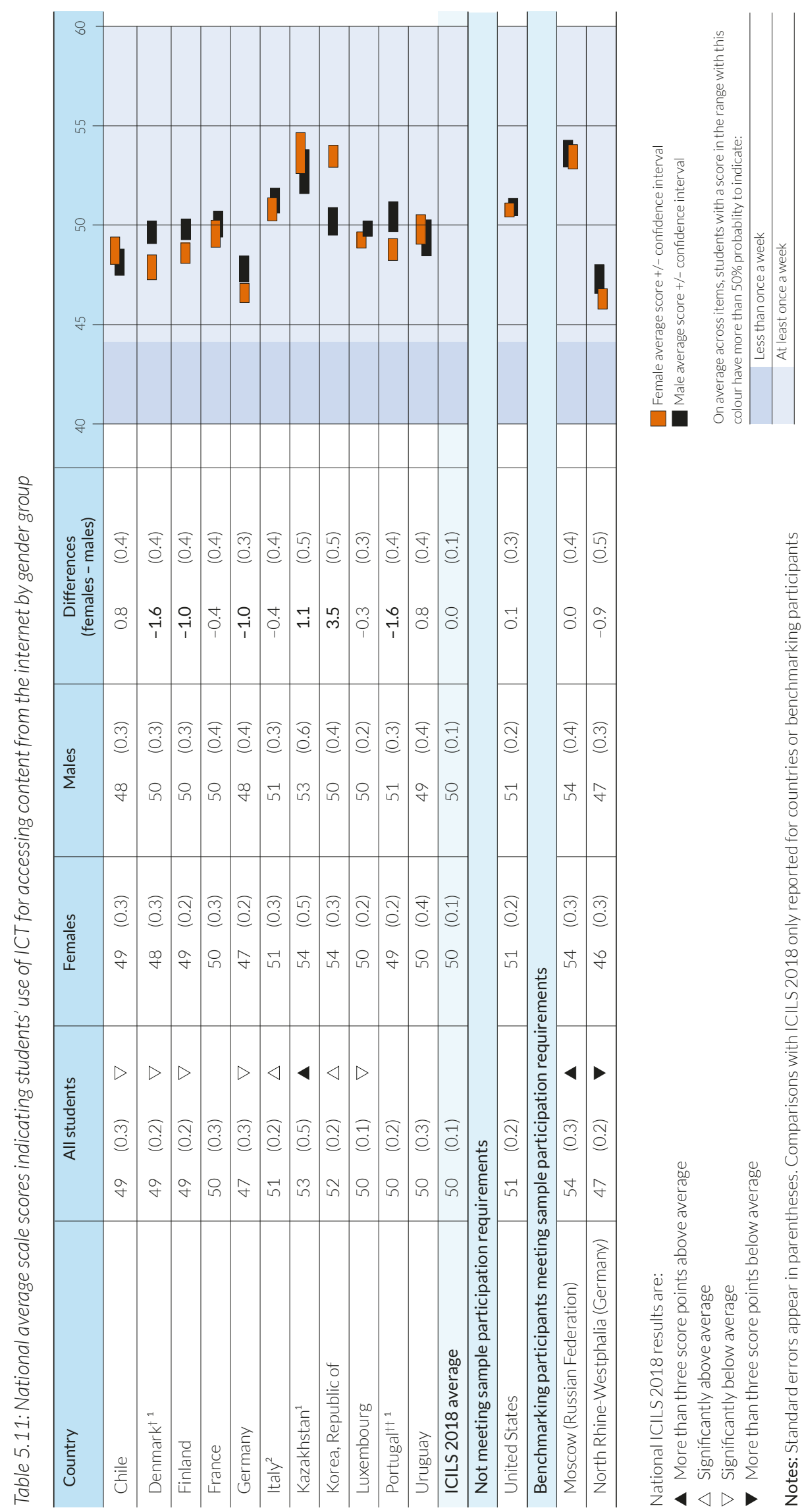

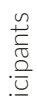

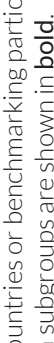

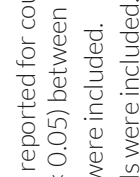

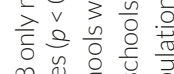

出

ลิ

Ч

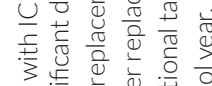

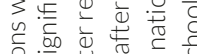

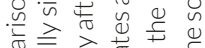

है.

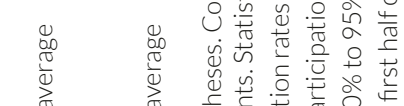

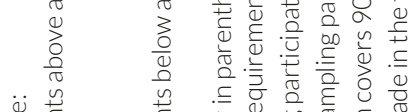

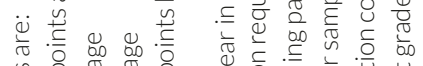

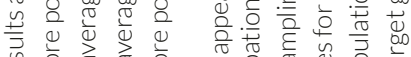

凹్

o

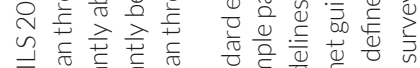

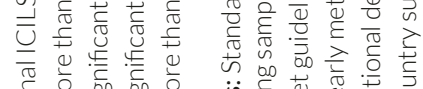

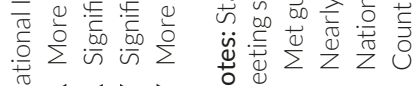




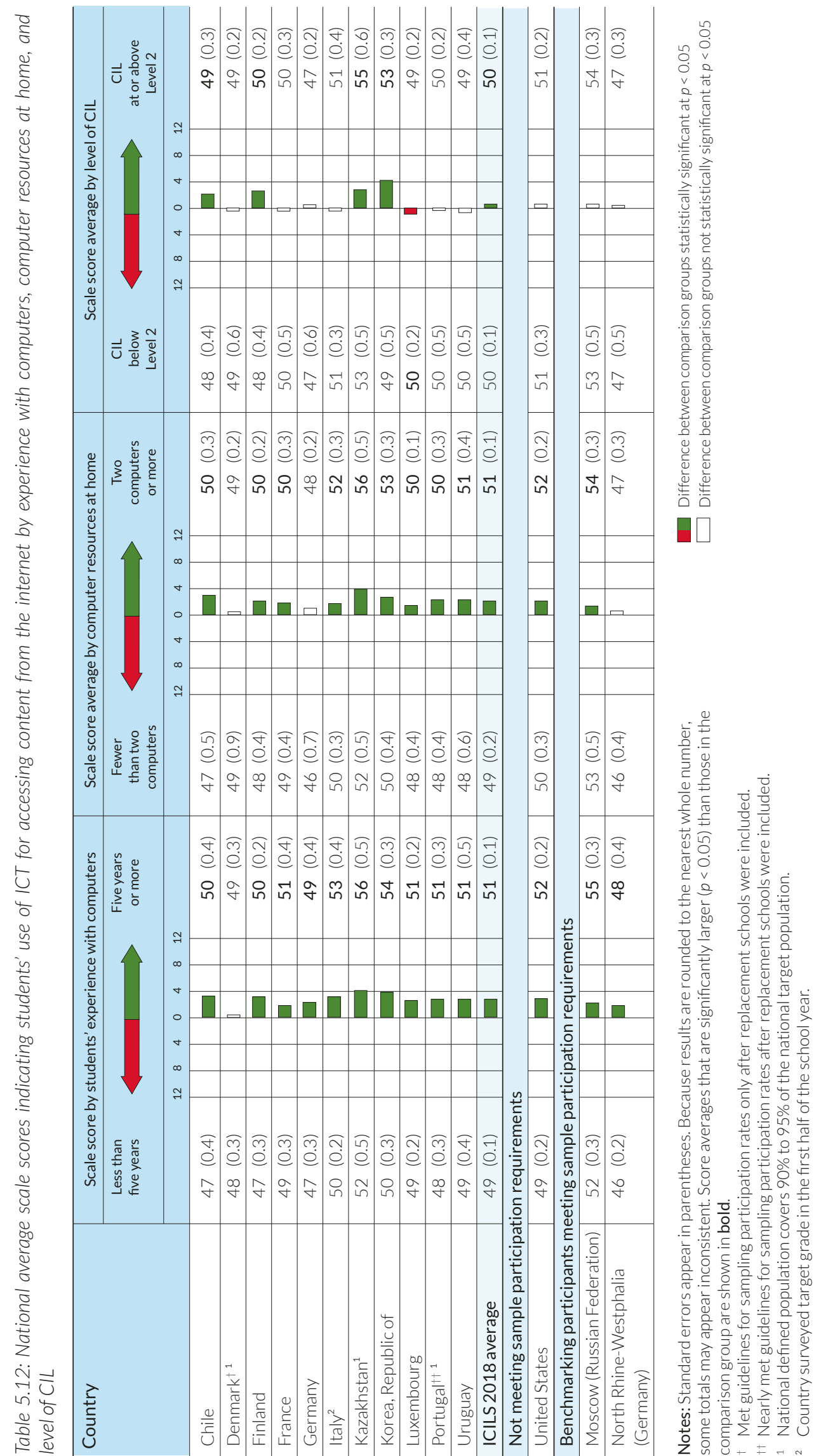


There were small differences on the scale representing the frequency with which students accessed content from the internet between students with CIL scores at or above Level 2 and those with CIL scores below Level 2 (differences in scale scores averaged one scale point). In Korea and Kazakhstan, the differences were a little larger (by four and three scale points).

\section{Inferences}

Grade 8 students were highly engaged with ICT, but much more engaged outside school than at school. Seven out of 10 grade 8 students used ICT on a daily basis outside school for general purposes but only one student in five used ICT on a daily basis outside school for school-related purposes. In contrast, fewer than one student in five used ICT at school for school-related purposes and three students in 10 used ICT at school for general purposes. The mismatch between ICT engagement out-of-school and ICT engagement in school is wider in some countries than others. This difference possibly provides an indication of the extent to which ICT has become incorporated in pedagogy.

Students' general use of ICT most commonly involved writing and editing documents, listening to downloaded music or videos, accessing information from the internet, and playing games. Most students used ICT at least once each week for leisure activities such as listening to downloaded music or watching videos. Approximately two thirds of students used ICT to access information about things of personal interest from the internet at least once each week. Students' general use of ICT may provide opportunities for them to develop and refine their ICT skills but there remains a question of the extent to which this experience is linked to systemic teaching in schools.

\section{Student engagement with ICT for school-related purposes}

The ICILS 2018 student questionnaire asked students about a number of aspects of ICT use for school-related purposes. It asked students about the extent of ICT use for school-related purposes, the use of ICT across subject areas, the ICT tools used in class, and the extent to which they learned about CIL at school.

ICILS 2013 reported that there were greater cross-national differences in student participation in ICT-based activities at school than in ICT-based activities outside of school (Fraillon et al. 2014). Similarly, more than half of the grade 8 students surveyed in TIMSS 2015 used the internet to access information and resources, and more than two thirds used the internet to collaborate with other students (Martin et al. 2016). However, TIMSS 2015 also found that only one fifth of grade 8 students reported working with computers as part of their mathematics lessons at least once a month (Martin et al. 2016; Mullis et al. 2016).

School use of ICT appears to have mainly focused on general applications (productivity and internet access software) (Fraillon et al. 2014). Students in the European Commission (2013) study rarely reported using specialist applications (e.g., data-logging tools and computer simulations) that might be considered particularly well suited to ICT use. In contrast, a third of the students said they used digital textbooks and multimedia resources on at least a weekly basis. There was a positive association between amount of student-centered learning and frequency of ICT use for classroom activities. A review of a number of studies by Fu (2013) also concluded that greater ICT use was associated with the amount of student-centered learning even though the direction of causation was not clear. Even though ICT has been propounded as having the potential to impact on pedagogy (Aparicio et al. 2016) the extent of this impact is less than envisaged and dependent on teacher characteristics (Comi et al. 2016; Vrasidas 2015). It appears that classroom ICT use in secondary schools is influenced by the availability of appropriate software, teacher expertise and self-efficacy, and the extent of collaboration among teachers (Gil-Flores et al. 2017). Technological, pedagogical, and content knowledge appears to influence the implementation of ICT in classrooms (Willermark 2017). Gerick et al. (2017) identified the influence of school 


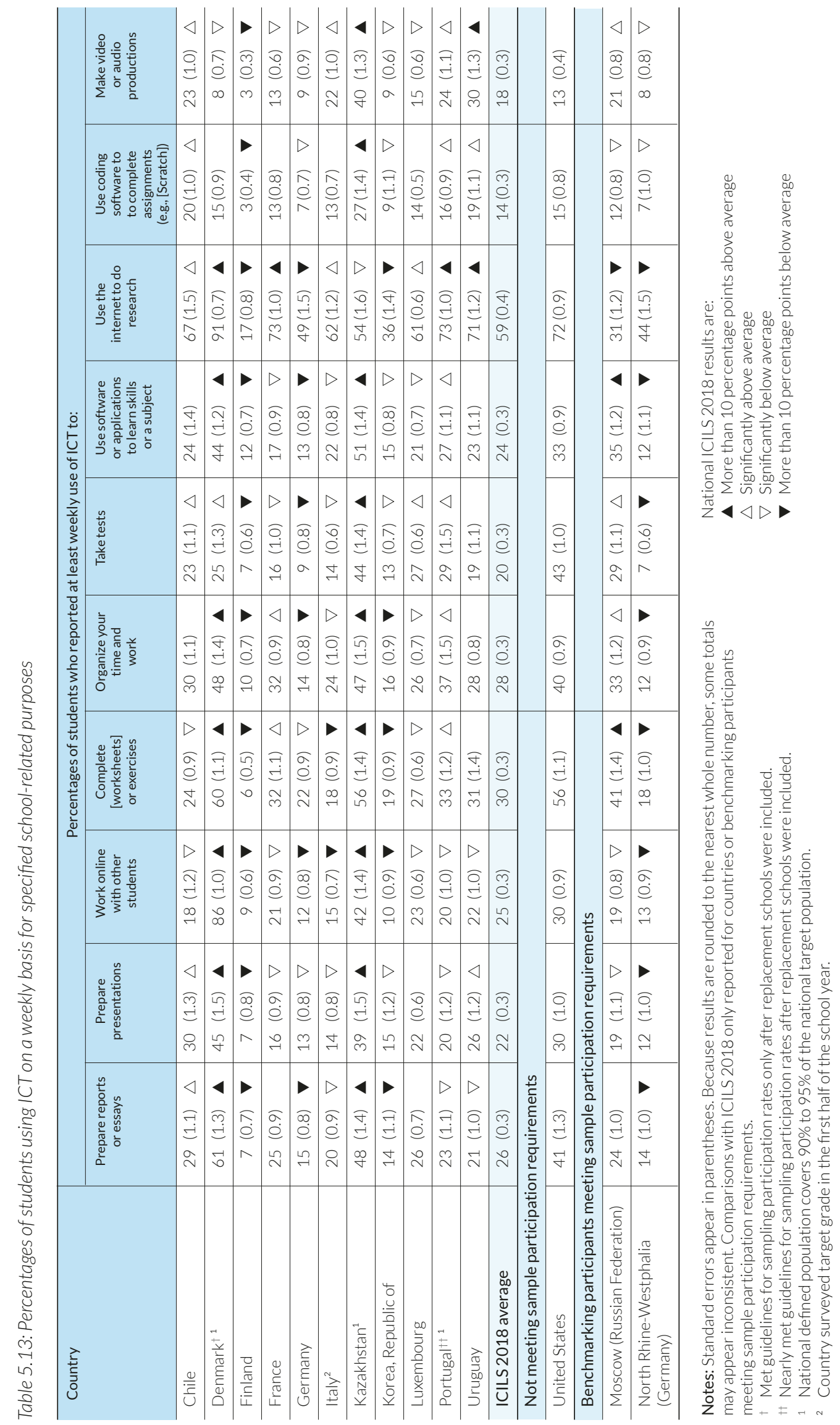


factors (especially the confidence of teachers in using ICT) on the use of ICT by students but noted that the strength of these influences was different in different countries. Data from ICILS 2013 showed that computer and internet access at school vary across and within countries, and are associated with student background and school contexts (Fraillon et al. 2014).

\section{Extent of student engagement with ICT for school-related purposes}

We asked students to report how often they used ICT for particular school-related purposes that ranged from the conventional to less conventional. These included the following:

- Prepare reports or essays;

- Prepare presentations;

- Work online with other students;

- Complete worksheets or exercises;

- Organize your time and work;

- Take tests;

- Use software or applications to learn skills or a subject (e.g., mathematics tutoring software, language learning software);

- Use the internet to do research;

- Use coding software to complete assignments (e.g., Scratch); and

- Make video or audio productions.

Although students could respond to the question using a set of categories (from "never" to "every school day") we reported the percentages who reported using ICT for a specified school-related purpose at least once each week 22 (Table 5.13). Among the school-related purposes, by far the most frequently recorded use of ICT was to "use the internet to do research." On average across countries this was reported as at least a weekly occurrence by three fifths (59\%) of students. In Denmark this was reported as a weekly occurrence by nine tenths (91\%) of students. It was also reported by seven out of 10 students in Portugal (73\%) and Uruguay (71\%). In some countries relatively few students reported using the internet to do research. In Finland only 17 percent of students reported using the internet for research on a weekly basis, and in Korea only 36 percent said that they used the internet to do research on a weekly basis.

Two of the forms of use of ICT for school-related purposes concerned how students did their work. One of these was organizing their own time and work (in the sense of self-regulation) and the other was working online with other students (collaboration). On average across countries one quarter of students (25\% for self-regulation and 28\% for collaboration) reported using ICT for these purposes on a weekly basis. The most common of these uses of ICT on a weekly basis were in Denmark (48\% for self-regulation and 86\% for collaboration) and Kazakhstan (47\% for self-regulation and $42 \%$ for collaboration). The least common weekly use of ICT for self-regulation was in Germany (9\%), followed by Finland (10\%) and Korea (14\%). The least common weekly use of ICT for collaboration was in Finland (9\%), followed by Korea (10\%) and Germany (12\%).

There was a group of purposes listed that could be considered conventional school activities: completing worksheets or exercises (averaging 30\%), preparing reports (averaging 26\%), preparing presentations (averaging 22\%), and taking tests (averaging 20\%). Denmark recorded the highest level of weekly use of ICT for three of these conventional purposes (61\% for preparing reports, $60 \%$ for completing worksheets or exercises, and $45 \%$ for preparing presentations). The lowest

22 In ICILS 2013 we reported use of ICT for each purpose at least once per month. Therefore the two sets of data are not comparable. 
levels of weekly use of ICT for preparing reports were in Finland (7\%) and Korea (14\%). The least widespread weekly use of ICT for completing worksheets were in Finland (6\%), Italy (18\%), and Korea (19\%). The lowest prevalence of ICT use for preparing presentations was in Finland (7\%). Taking tests using ICT on a weekly basis was most common in Kazakhstan (44\%) and least common in Finland (7\%).

Use of ICT-based software or applications to learn skills or subject content on a weekly basis was most common in Denmark (44\%) and Kazakhstan (51\%) and least common in Finland (12\%). On average across countries, 24 percent of students reported using these forms of ICT-based instructional software on a weekly basis.

The weekly use of ICT for the two listed specialist purposes was reported by fewer than one in five students. Using ICT on a weekly basis for making video or audio productions was reported by 18 percent of students on average and the weekly use of coding software such as Scratch to complete assignments was reported by 14 percent of students on average across countries. High levels of use of ICT for these purposes were reported for Kazakhstan (40\% and 27\%), and very low levels of use were reported for Finland (3\% for each form of use).

We constructed a scale that represented the use of ICT applications as a whole for schoolrelated purposes with an average reliability across participating countries of 0.83 (please see the corresponding item map in Figure F.7 in Appendix F), where higher scale scores indicated more frequent use. We observed that the use of ICT for school-related purposes was, on average across countries, slightly greater (by just one scale point) for female than male students (Table 5.14). ICT use for school-related purposes was notably higher than the ICILS 2018 average in Denmark (57 points) and Kazakhstan (56 points), and notably lower in Korea (46 points) and Finland (43 points) (Table 5.14).

We also observed that the use of ICT for school-related purposes was a little higher on average for students who were experienced computer users than for other students (by two scale points) and a little higher on average for students who were currently studying a computer-related subject than for students who were not (by two scale points) (Table 5.15). The differences associated with computer experience were significant in seven of the ICILS 2018 countries, and was greatest in Finland (three scale points). The differences in the use of ICT for school-related purposes between those who currently studied a computer subject and other students were significant in seven ICILS 2018 countries and greatest in Portugal and Kazakhstan. The difference was also large in Moscow (Russian Federation).

On average across countries, there was no significant difference in the use of ICT for schoolrelated purposes between those students who had CIL scores at or above Level 2 and students who had CIL scores below Level 2 (Table 5.15). However, there were significant differences between these two groups of students in Finland and Korea (in each case by four scale points) in favor of those with higher CIL levels. In five ICILS 2018 countries the direction of difference was in favor of those with lower CIL levels, and in four countries there was no significant difference. 

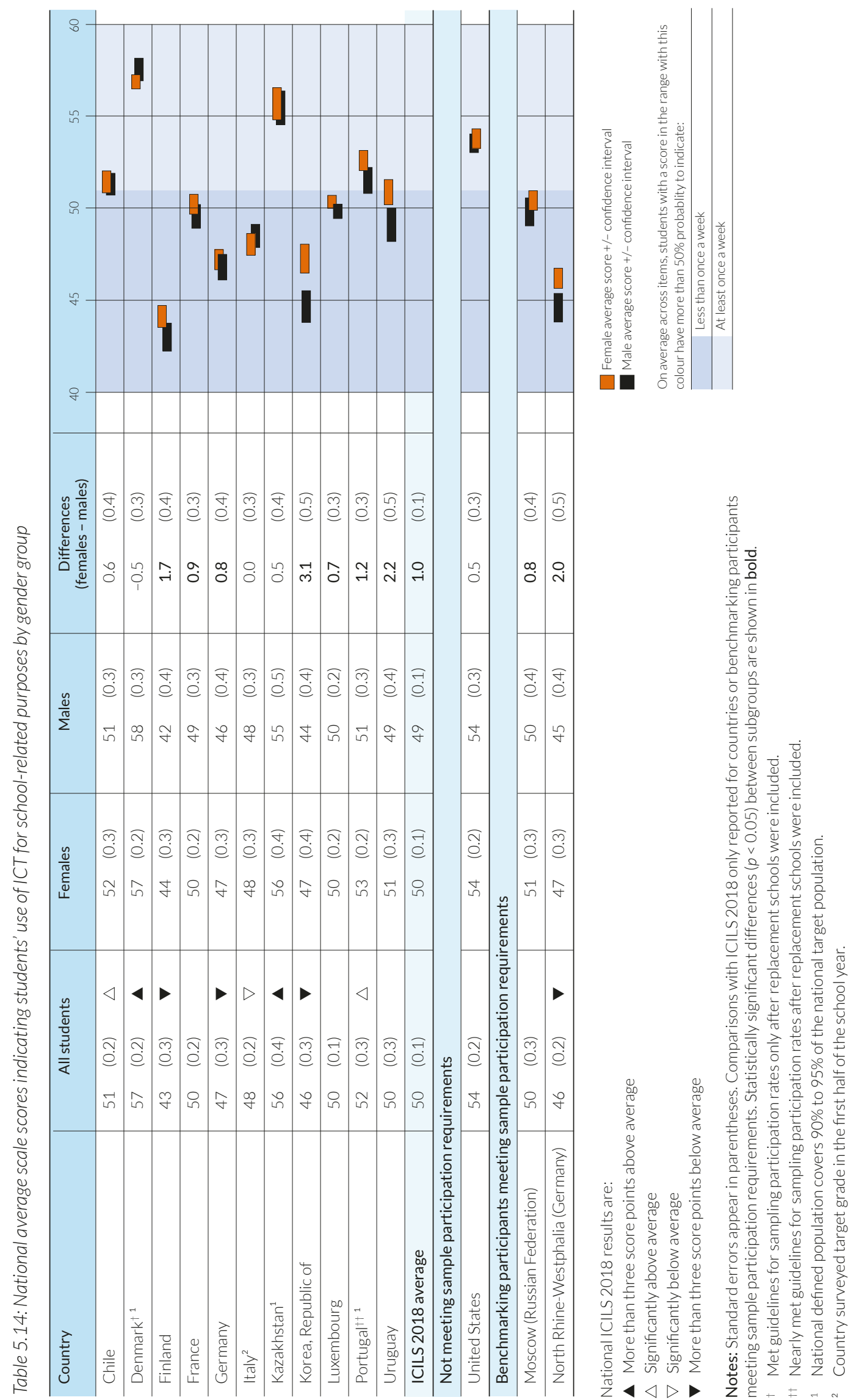


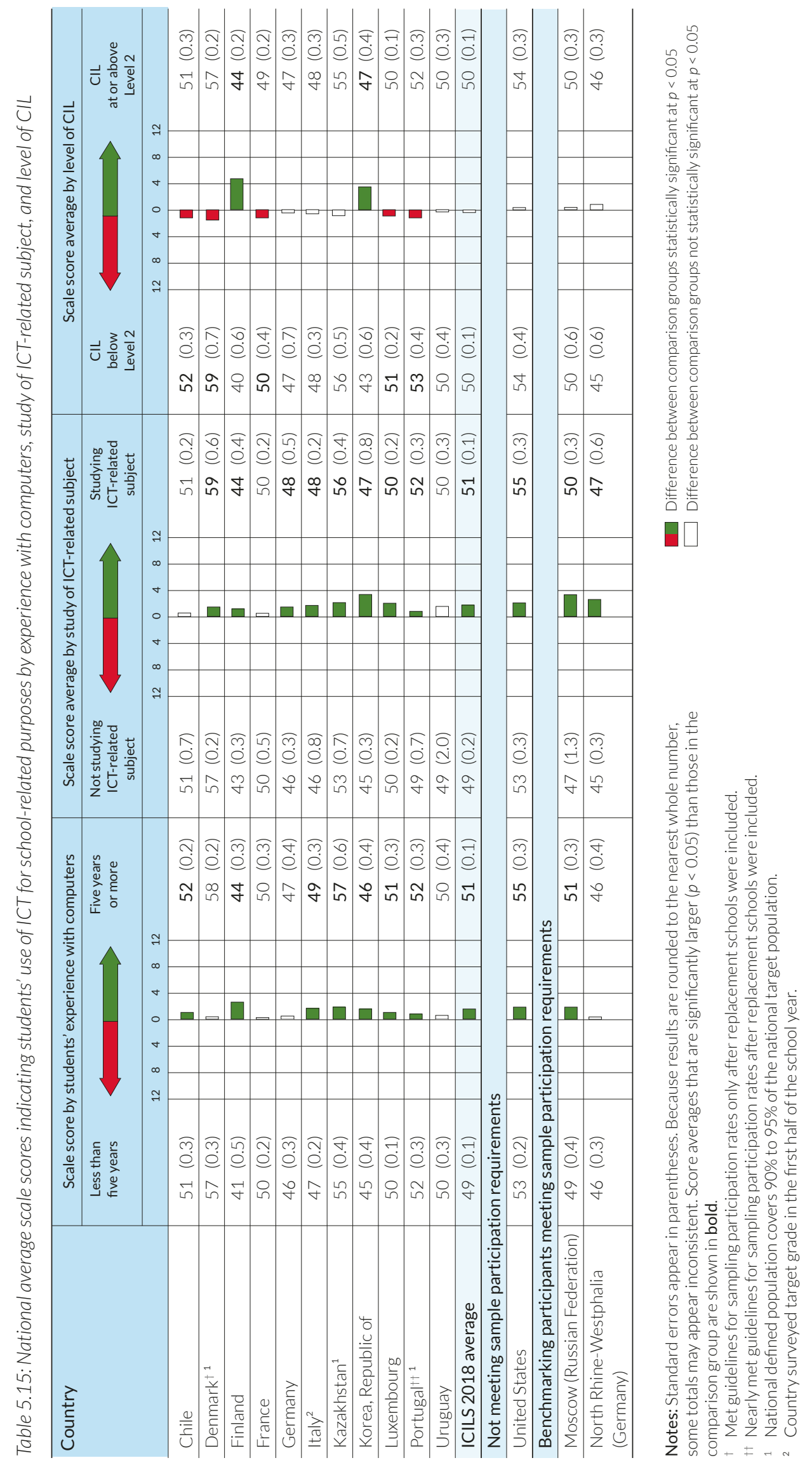




\section{Use of ICT across subject areas}

Research literature over a number of years has suggested that there are differences among subject areas in the extent of use of ICT (Fraillon et al. 2014; Howard et al. 2014). In ICILS 2018 we asked students how often they used computers during lessons in designated subjects or subject areas ("never," "in some lessons," "in most lessons," "in every or almost every lesson," and "I don't study this subject/these subjects"). Student responses in the last category were treated as missing responses. The list of subjects or subject areas that students had to consider was based on a list developed for the OECD Teaching and Learning International Study (TALIS) (OECD 2014):

- Language arts: survey language;

- Language arts: foreign or other national languages;

- Mathematics;

- Sciences (general science and/or physics, chemistry, biology, geology, earth sciences);

- Human sciences or humanities (history, geography, civics, law, economics, etc.);

- Creative arts (visual arts, music, dance, drama, etc.);

- Information technology, computer studies, or similar;

- Practical or vocational studies; and

- Other.

We recorded the extent of use of computers during lessons in specified subject areas as the percentage of students who reported having used computers in most lessons, or in every or almost every lesson, in that subject area. We found that, on average across countries, the subject area with the greatest use of computers was information technology (49\%) (Table 5.16). Across the subject areas of language arts (27\%), sciences (27\%), foreign languages (26\%), and mathematics (25\%) there was little variation. The use of computers was a little less in the creative arts (23\%).

The subject areas with the lowest percentages of students who reported using computers in most lessons were practical or vocational (19\%) and "other" subjects (e.g., moral/ethics, physical education, personal and social development) that could not be classified in the eight listed subject areas (17\%).

In the core subject areas of language arts, mathematics, sciences, and human sciences, as well as in foreign languages, use of computers in most lessons was reported by an overwhelming majority of students in Denmark (69\% to 85\%). High levels of computer use in these subject areas were also reported in Kazakhstan (36\% to 45\%). In Germany the use of computers in most lessons in these subject areas was reported by around one tenth of the students ( $8 \%$ to $11 \%$ ). Similar levels of computer usage were reported in North Rhine-Westphalia (Germany) (6\% to 11\%). Low levels of computer use in these subject areas were also reported in Luxembourg (16\% to 20\%) and Finland (13\% to 18\%).

High levels of computer use in the creative arts were reported in Kazakhstan (29\%) and Denmark (27\%). Low levels of computer use in the creative arts were reported in Germany (13\%) and North Rhine-Westphalia (Germany) (16\%). There were relatively high levels of computer use in practical or vocational studies in Kazakhstan (34\%) but very low levels in Germany (11\%), Finland (11\%), and North Rhine-Westphalia (Germany) (9\%).

On average across countries, approximately half the students (49\%) reported using computers in most lessons for information technology, computer studies, or similar. National percentages for this indicator were high in Denmark (75\%), Portugal (67\%), and Uruguay (69\%), but low in France (18\%) and Italy (26\%). 

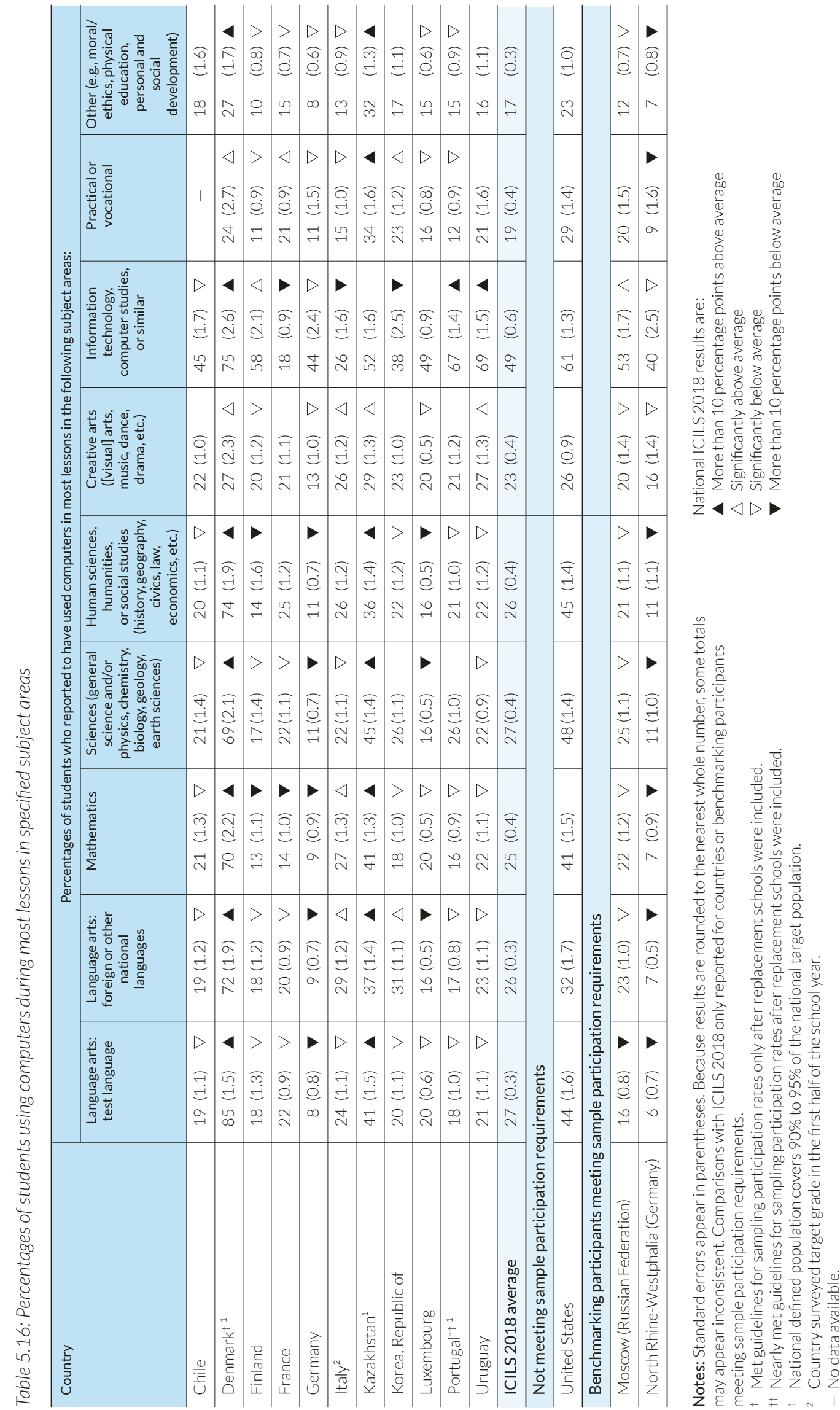


\section{Use of ICT during lessons}

In ICILS 2018 we asked students how often they used each of 11 listed ICT tools during lessons. Students responded using the options: "never," "in some lessons," "in most lessons," or "in every or almost every lesson." We recorded the use of each tool in terms of the percentage of students who used it in "most" or in "every or almost every lesson" (Table 5.17). In the text we refer to this as use in the majority of lessons.

On average across countries, the most used ICT tools were computer-based information resources (e.g., websites, wikis, and encyclopedias) (29\%), word processing software (28\%), and presentation software (26\%). Use of computer-based information resources in the majority of lessons was prevalent in Denmark (59\%) and Finland (41\%) but not in Germany (11\%), North Rhine-Westphalia (Germany) (12\%), and Korea (15\%). Use of word processing and presentation software in the majority of lessons was notably high in Denmark (82\% and 50\% respectively) and Kazakhstan (39\% and 38\%) but low in Italy (14\% and 15\%). Use of word processing software on a weekly basis was also notably low in Korea (11\%). Of productivity tools, spreadsheet use in the majority of lessons was only reported by 16 percent of students on average across ICILS 2018 countries.

Although computer-based information resources were widely used on the majority of lessons, interactive digital learning resources were not. On average across countries, only 15 percent of students used these in a majority of lessons, and there was little variation among countries. Similarly, there was low usage of specialist tools even though there was high use of common productivity software. An average of only 14 percent of students used graphing or drawing software in a majority of lessons and only 11 percent of students used multimedia production tools (e.g., media capture and editing, web production) in a majority of lessons.

There were several tools listed that could be categorized as learning tools. The most frequently used of these were tutorial software or practice programs. On average across ICILS 2018 countries, 13 percent of students used these tools in a majority of lessons. Just nine percent of students reported using concept mapping software, and eight percent reported using simulations and modeling software, in a majority of lessons. Tools for digitally capturing real-world data were used in a majority of lessons by only 10 percent of students on average.

From the responses to these items we developed two scales (Table 5.18). One of these scales represented the extent to which general applications (productivity, word processing, and presentation software and computer-based information resources) were used in class (average Cronbach's al pha across countries was 0.72). The other represented the extent to which specialist applications (multimedia production, concept mapping, real-world data capture, simulations and modeling software, computer-based information resources, interactive digital learning resources, and graphing or drawing software) were used during lessons (average Cronbach's alpha across countries was 0.84). Tutorial software and spreadsheets were not included in either scale. (Figures F.8 and F.9 in Appendix F contain the two item maps for these two scales.)

We found that general applications were used in class to a greater extent in Denmark and Kazakhstan than the international average and to a smaller extent in Germany, North RhineWestphalia (Germany), Italy, and Korea (Table 5.18). The difference between the countries with the highest and lowest scale scores was quite large, being about 15 scale points. 


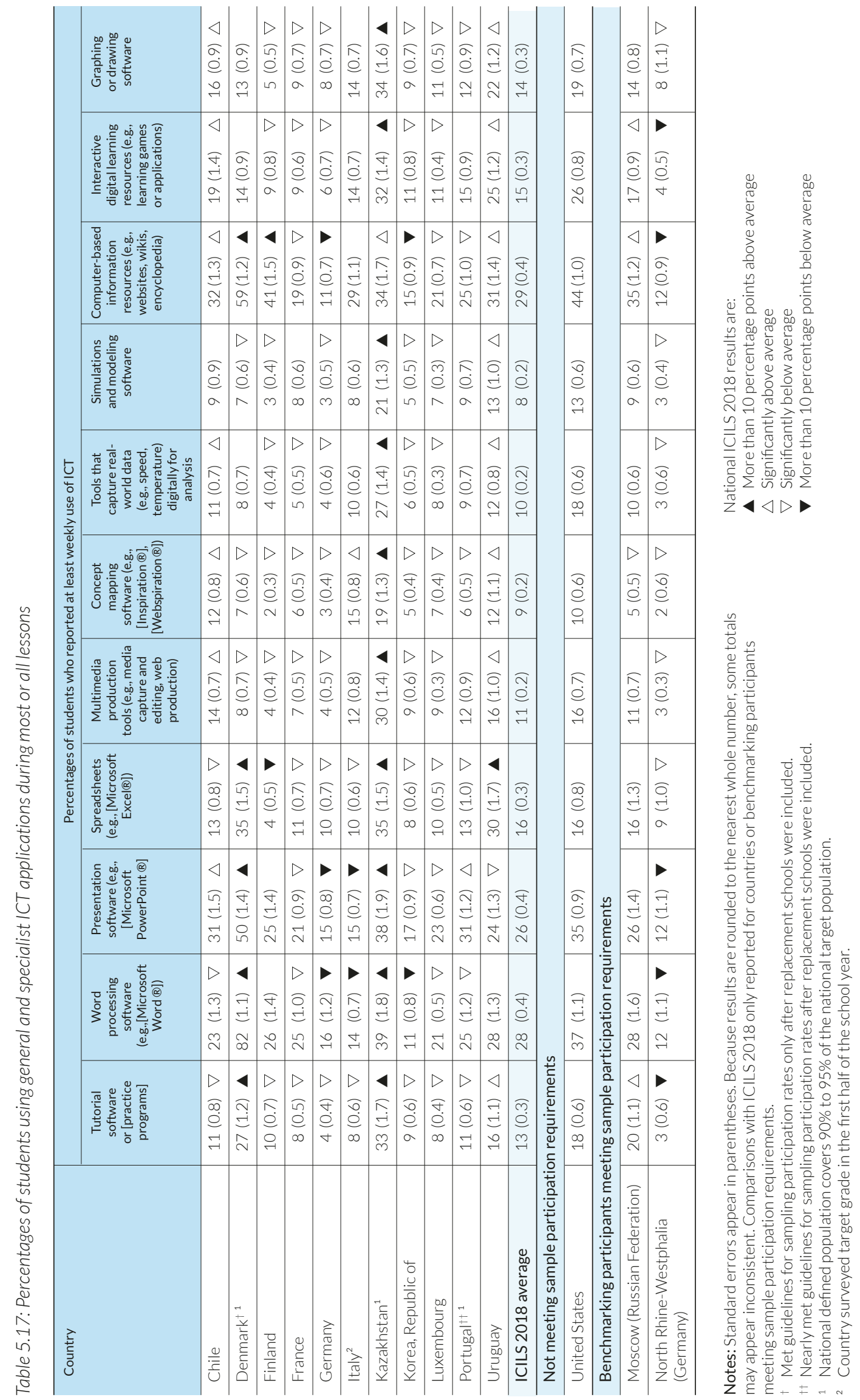



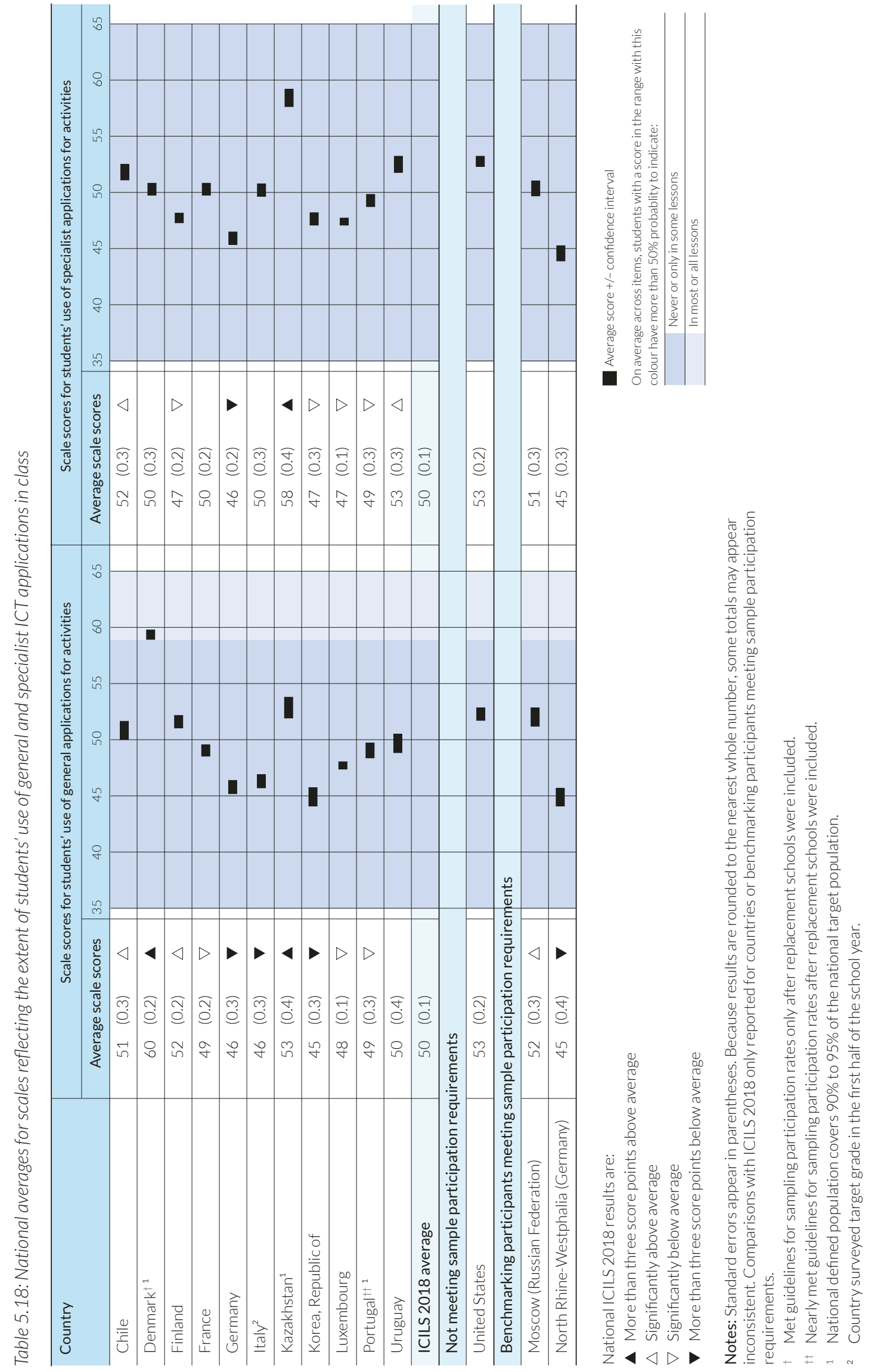
The use of general applications in class was slightly more frequently reported by female than male students, a difference which was statistically significant overall as well as in several individual countries (Table 5.19). In Germany, male students reported greater use of general applications in class than did female students. Using general applications in class was more frequently reported by students who were currently studying ICT than by students who were not. On average the difference was three scale points and the difference was four or more scale points in Chile, Kazakhstan, and Portugal. The difference was also large in the benchmarking participants: Moscow (Russian Federation) and North Rhine-Westphalia (Germany).

Use of specialist applications in class was more frequently reported by male students than by female students overall (by an average of two scale points), and the difference was significant in eight of the 11 ICILS 2018 countries (Table 5.20). In the remaining five ICILS 2018 countries the differences were not significant. However, the use of specialist applications in class was more frequently reported by students who were studying ICT than by those who were not (by an average of three scale points) in all except two ICILS 2018 countries. Surprisingly, the use of specialist applications in class was more frequently reported by students whose CIL score was below Level 2 than by students whose CIL scores were at or above Level 2. This unexpected result deserves further investigation, including the possibility that it might reflect differences in the types of subjects studied by low and high achieving students.

\section{Inferences}

ICT use for school-related purposes varies according to context. It appears to depend on the extent to which ICT is embedded in national curricula and pedagogy. The extent to which students use ICT for school-related purposes was higher than the ICILS 2018 average in Denmark and Kazakhstan and lower in Korea and Finland. ICT use for school-related pruposes also varied across subject areas: the greatest use occurred in foreign languages and the sciences and the lowest use of computers occurred in practical or vocational studies. ICT use for school-related purposes was also associated with student attributes. It was a little higher on average for students who were experienced computer users than those who were less-experienced computer users and was higher for students who were currently studying a computer-related subject than for students who were not.

ICT use for school-related purposes predominantly involved general applications. The most frequent reported school-related use of ICT among grade 8 students was for doing research on the internet. Approximately three students in five reported doing this at least once per week using computer-based information resources. About one quarter of the students used ICT in class on a weekly basis to create and edit documents (i.e., prepare reports and essays) using word processing and presentation software. Lower percentages of students indicating the use of applications using the potential of ICT to transform pedagogy (such as concept mapping software, simulations and modeling software, or digitally capturing real-world data). These findings may suggest that there remains a challenge to make use of the full potential of ICT in schools. 


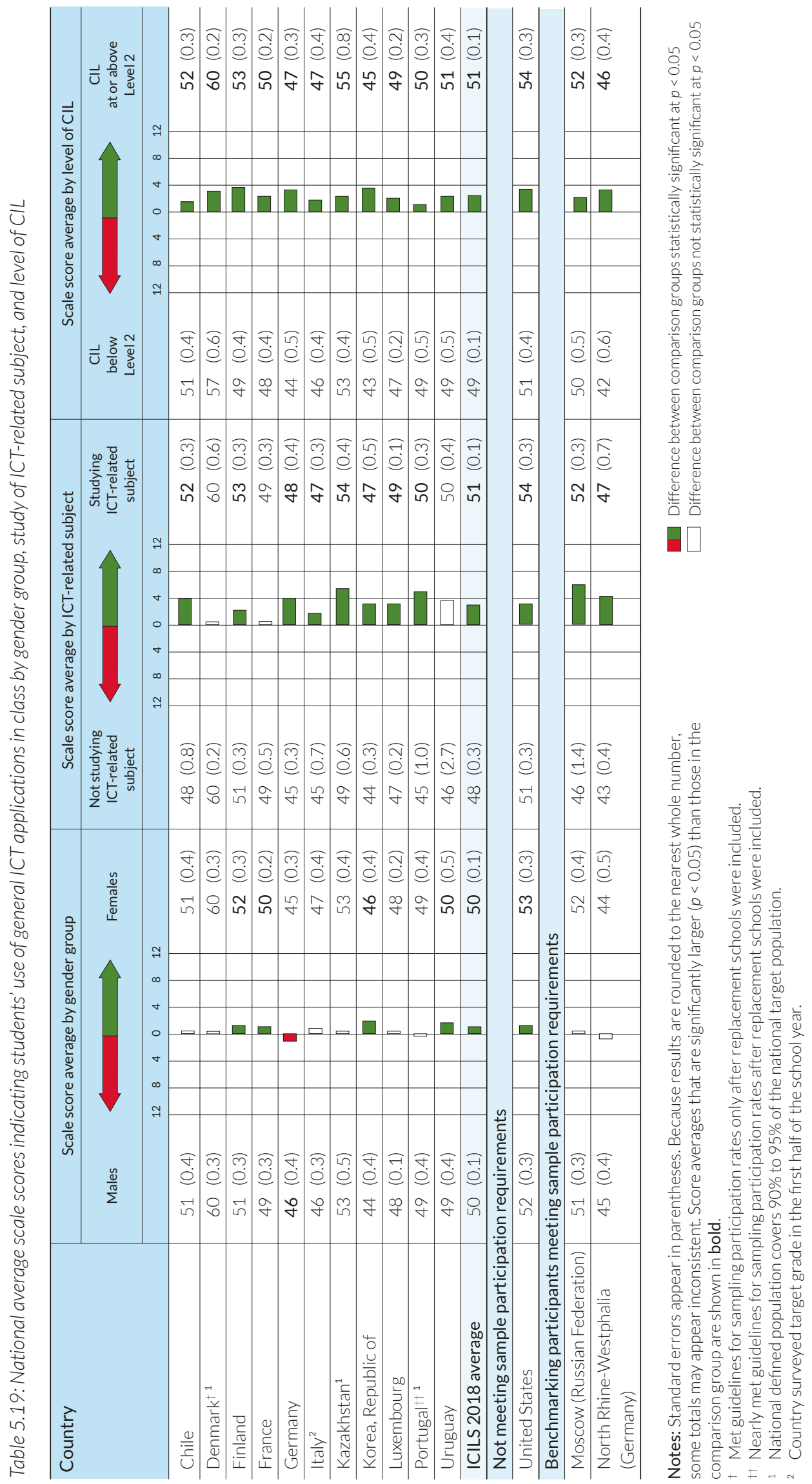




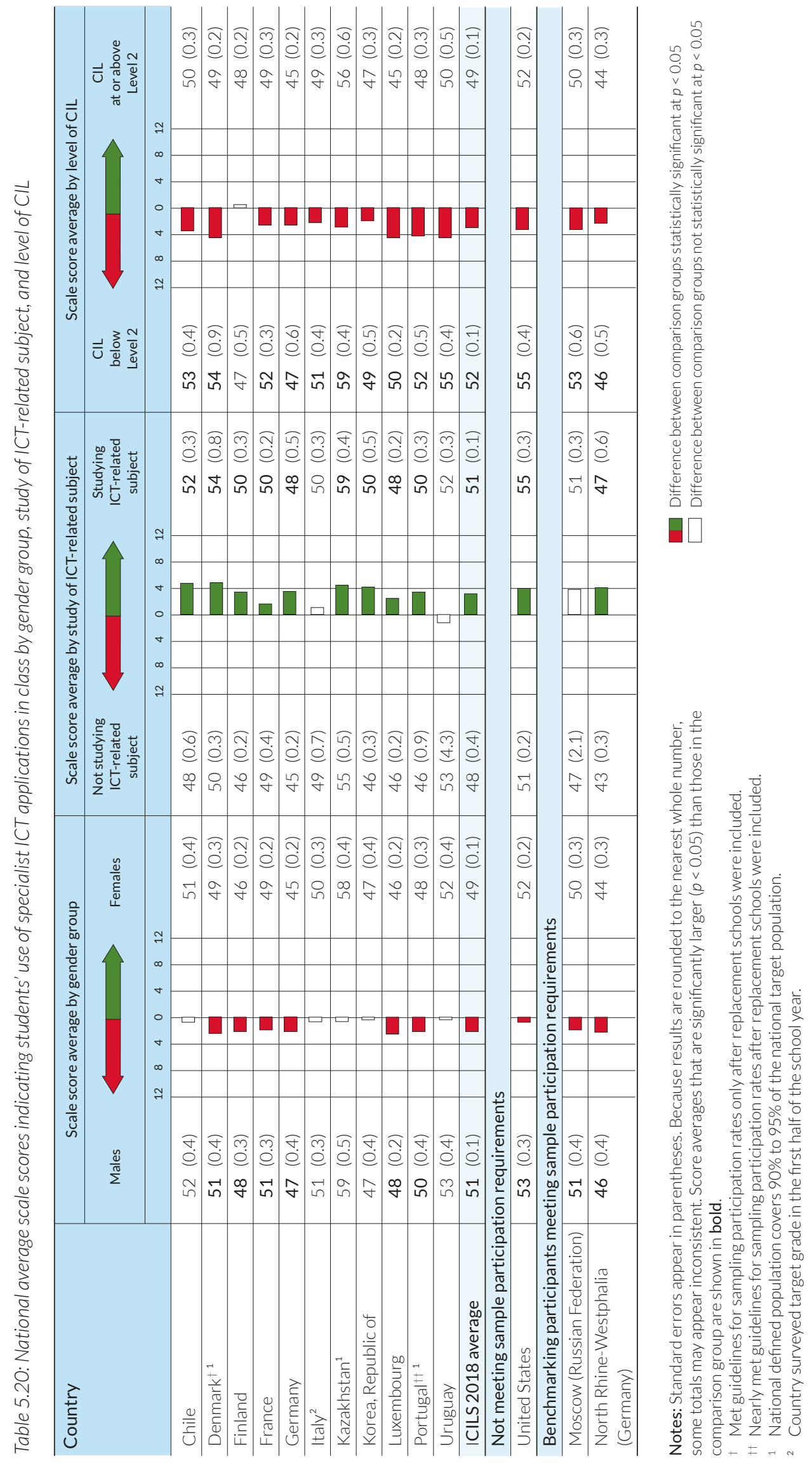




\section{Learning about ICT at school}

At the beginning of this chapter, we noted that opportunity to learn referred to the time allocated for students to be taught the concepts being assessed and the curriculum content that was the focus of that time (Scheerens 2017). In ICILS 2018 the concepts being assessed were CIL and CT. Although it was not possible to measure the time allocated to teaching CIL and CT, because they were sometimes taught in several curriculum areas, it was possible to ask students to indicate the emphasis placed on learning about these two dimensions of ICT. In the student questionnaire we asked students to indicate the extent to which they had learned ("to a large extent," "to a moderate extent," "to a small extent," "not at all") how to do various ICT tasks.

\section{Learning about CIL at school}

The ICT tasks that we took as being concerned with CIL were:

- Provide references to internet sources;

- Search for information using ICT;

- Present information for a given audience or purpose using ICT;

- Work out whether to trust information from the internet;

- Decide what information obtained from the internet is relevant to include in school work;

- Organize information obtained from internet sources;

- Decide where to look for information on the internet about an unfamiliar topic; and

- Use ICT to collaborate with others.

We examined the percentages recording that they learned about CIL tasks to a large or moderate extent (Table 5.21). These data indicated small variations across the various tasks, ranging from 60 percent for "use ICT to collaborate with others" to 74 percent for "search for information using ICT." Overall, the results suggested that students learn about constituent components of CIL at school. The percentage of students was notably high in Denmark (for all tasks except "organize information obtained from internet sources"), Kazakhstan, Portugal, and Moscow (Russian Federation). The percentages were generally low in France, Luxembourg, and Germany.

In order to explore differences among groups of students in countries, in students' reported learning of CIL tasks, we derived a scale based on student responses to the eight aspects of CIL shown above. The scale had a reliability of 0.88 (Cronbach's alpha) on average across ICILS countries (the item map for this scale is shown in Figure F.10 in Appendix F). Higher scores on the scale indicate greater attribution to school-based CIL learning. The scale scores confirmed what we had observed in the frequency distributions for items. Students in Denmark, Kazakhstan, Portugal, and Moscow (Russian Federation), recorded notably high average scores on this scale. France, Germany, Luxembourg, and North Rhine-Westphalia (Germany) recorded notably low scores on this scale (Table 5.22). Differences between female and male students in the extent to which they attributed their CIL learning to school instruction were very small, being only one scale point in favor of female students, on average across countries, and being statistically significant (but less than two scale points) in five of the ICILS 2018 countries. In Chile and Finland, female students scored higher (by just under two scale points) than male students.

The differences in the CIL learning scale scores between students with five or more years of computer experience and those with less than five years of computer experience were significant and positive in six countries but were small (Table 5.23). The largest difference was three scale points for Korea. In Uruguay the direction of the difference was in the reverse direction. On average across countries, there was no difference associated with computer experience. Not surprisingly, the CIL learning scale scores were higher for students currently studying ICT subjects than for those who were not. This difference was significant and positive in eight ICILS 2018 


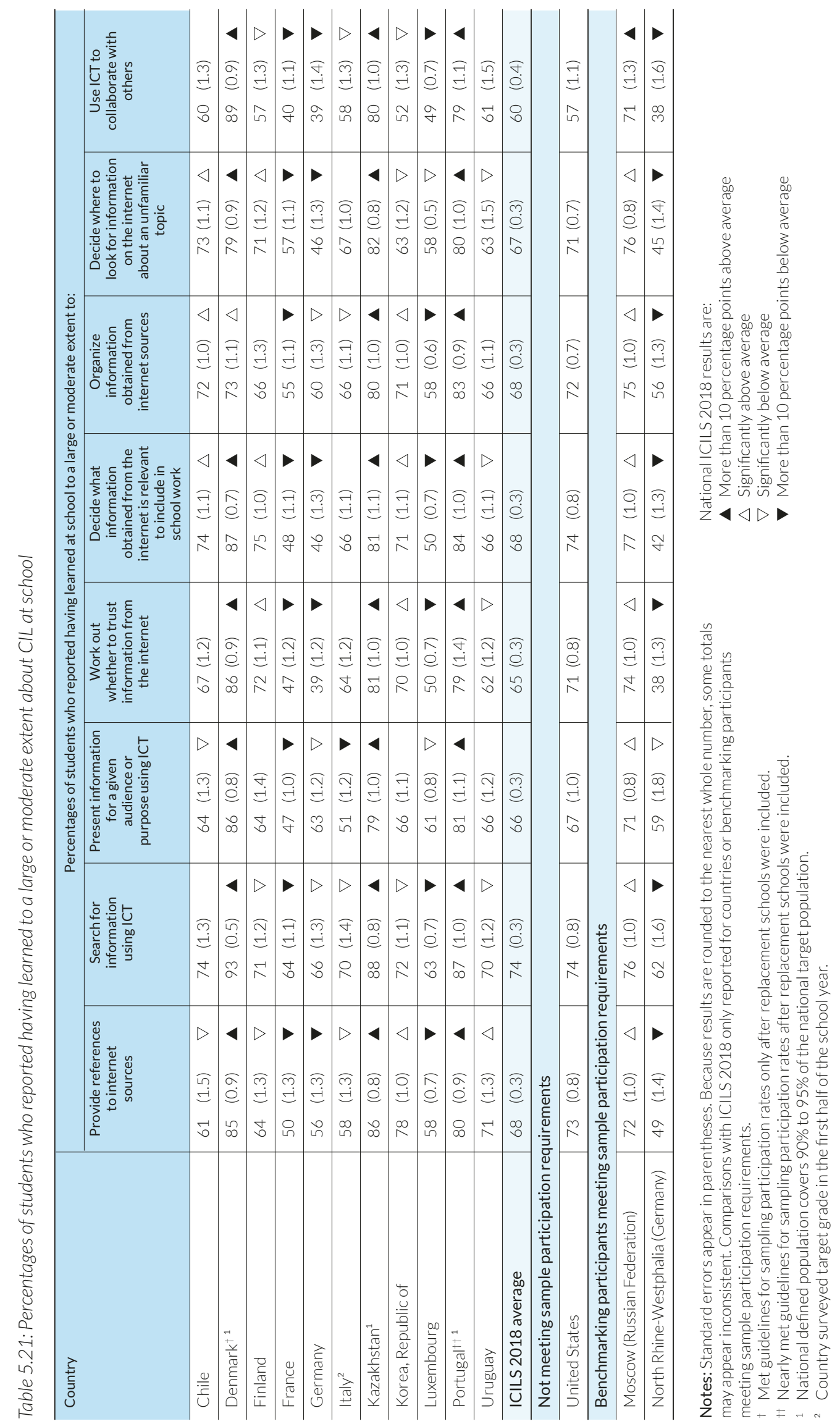



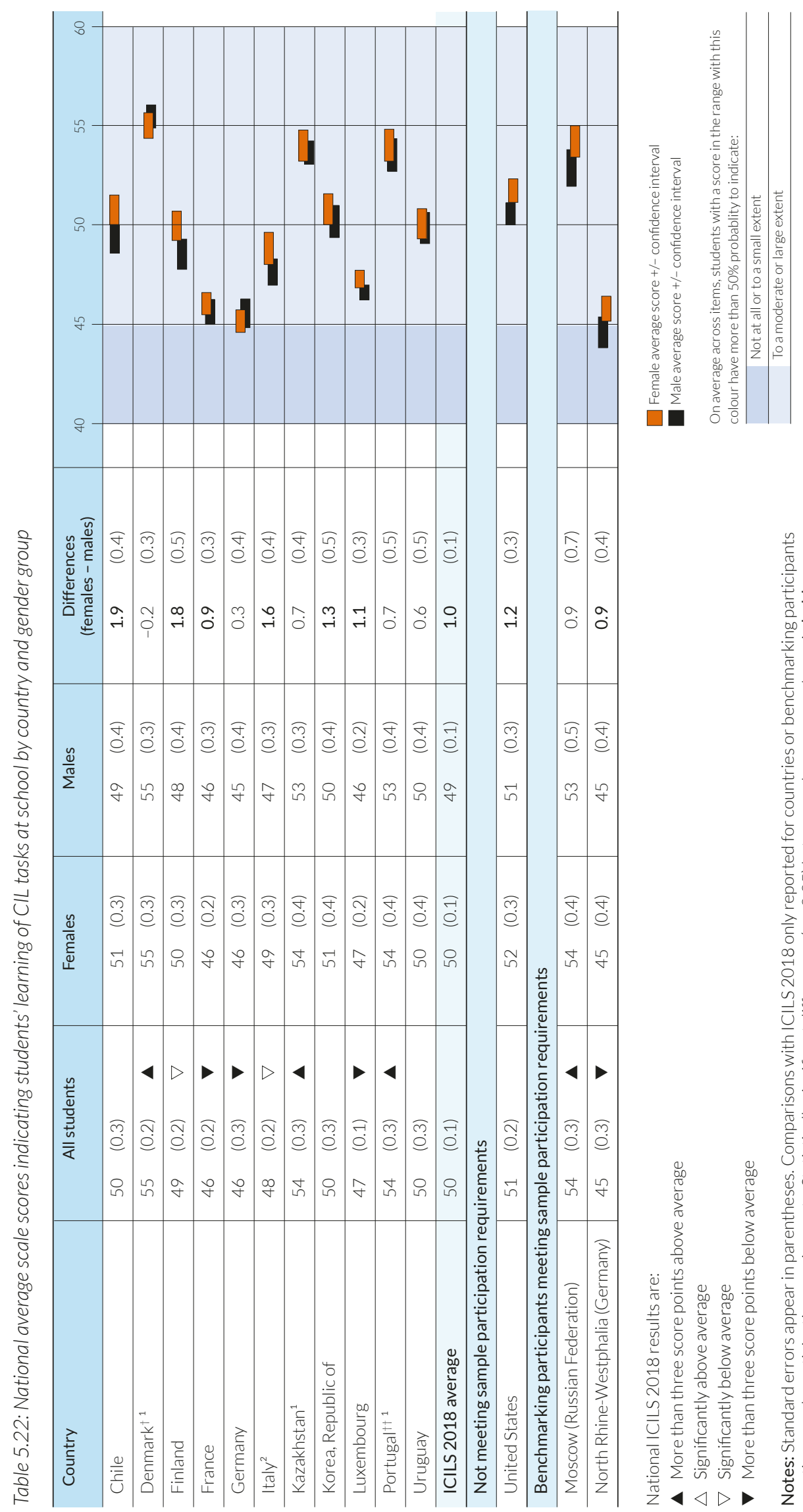

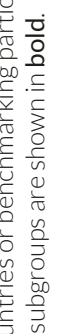

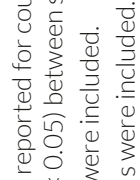

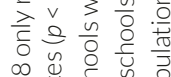

-

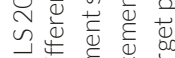

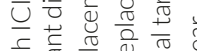

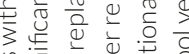

ᄃ

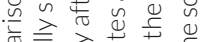

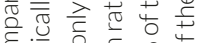

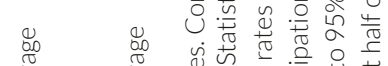

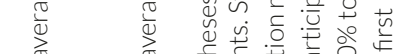

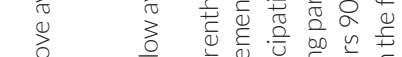

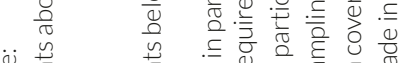

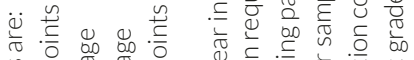

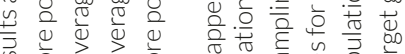

U్

क \&

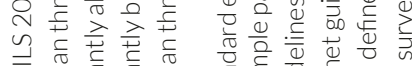

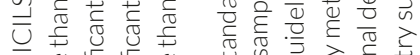

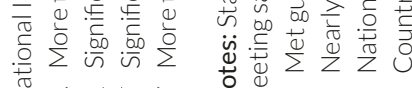


countries and averaged two scale points overall. The difference was large in Portugal (six points) and Uruguay (six points). In Denmark the difference was in the opposite direction.

$\mathrm{CIL}$ learning at school scale scores were significantly higher for students with CIL scores at or above Level 2 than for students with CIL scores below Level 2 overall in eight ICILS 2018 countries as well as Moscow (Russian Federation) (Table 5.23). On average across ICILS 2018 countries the difference was two scale points and in Denmark the difference was four scale points. In Uruguay there was a small difference in the reverse direction.

\section{Learning about CT at school}

In the student questionnaire we asked students to indicate the extent to which they had learned how to do various CT-related tasks at school. The tasks were:

- Display information in different ways;

- Break a complex process into smaller parts;

- Understand diagrams that describe or show real-world problems;

- Plan tasks by setting out the steps needed to complete them;

- Use tools to make diagrams that help to solve problems;

- Use simulations to help understand or solve real-world problems;

- Make flow diagrams to show the different parts of a process;

- Record and evaluate data to understand and solve a problem; and

- Use real-world data to solve and revise solutions to problems.

We examined the percentages of students who reported having learned aspects of $\mathrm{CT}$ to a large or moderate extent (Table 5.24). These data indicated variations across the aspects of CT ranging from 45 percent for "make flow diagrams to show the different parts of a process" to 76 percent for "display information in different ways." Overall, the results suggested that students had learned about aspects of CT at school. However, there appeared to be larger differences among countries for learning about CT than had been the case for learning about CIL. The percentages of students were notably higher on average in Kazakhstan, Chile, and Uruguay as well as in Denmark on some aspects of CT. The percentages of students were also high in Moscow (Russian Federation). The percentages were generally low across these eight tasks in Luxembourg, Germany, North Rhine-Westphalia (Germany), as well as in France and Portugal on some aspects of $\mathrm{CT}$.

In order to explore differences in countries and among groups of students in countries, in students' reported learning of CT-related tasks, we derived a scale based on student reports of learning about aspects of $\mathrm{CT}$ with an average Cronbach's alpha across countries of 0.90 (Figure F.11 in Appendix F shows the corresponding item map for this scale). Higher scores on the scale indicate greater attribution to school for learning about CT. The scale scores confirmed what we had observed in the frequency distributions for items. Students in Kazakhstan, Chile, and Uruguay, as well as Moscow (Russian Federation), recorded high average scores on this scale but Germany and Luxembourg recorded low scores on this scale (Table 5.25). 


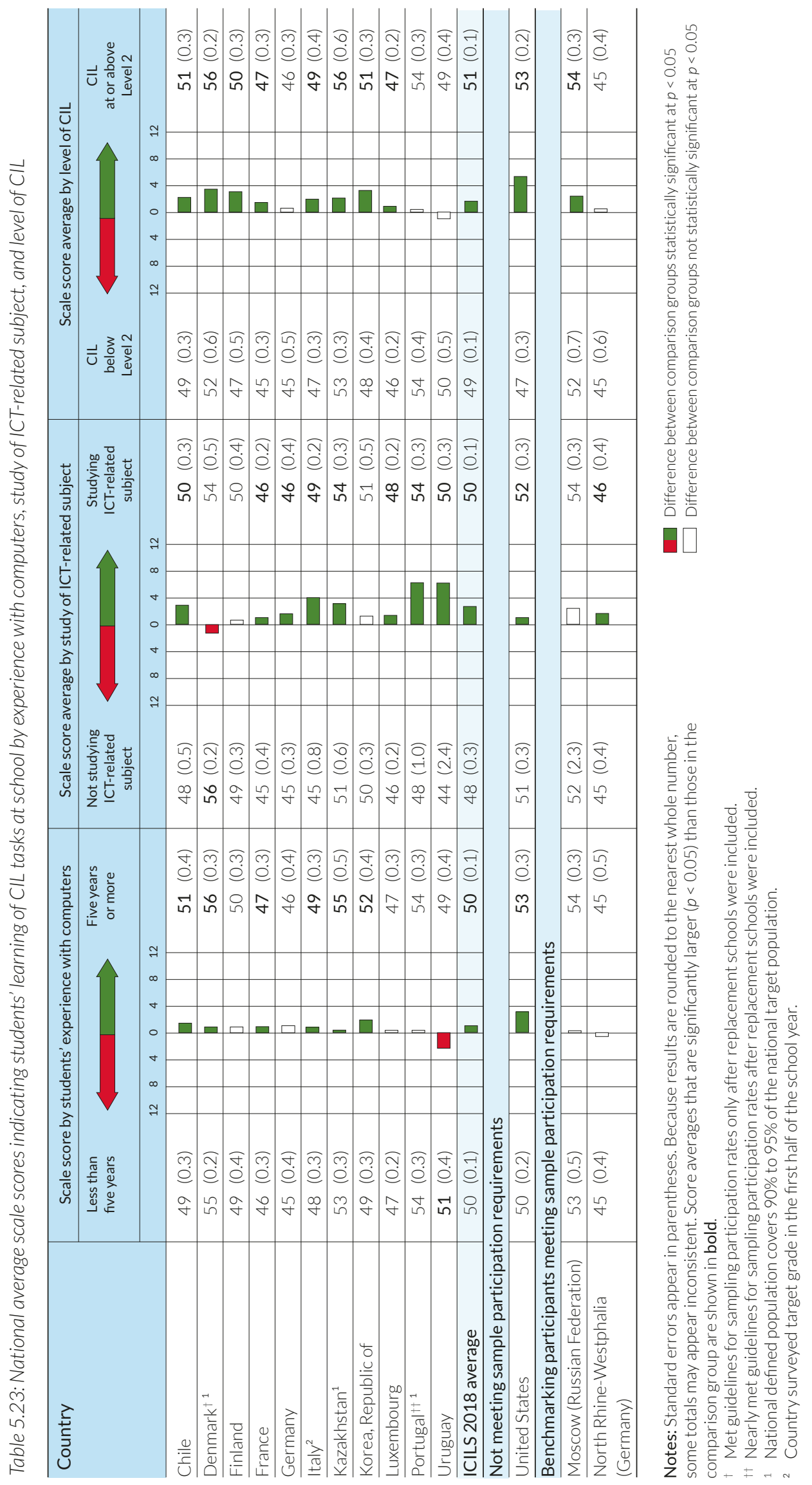




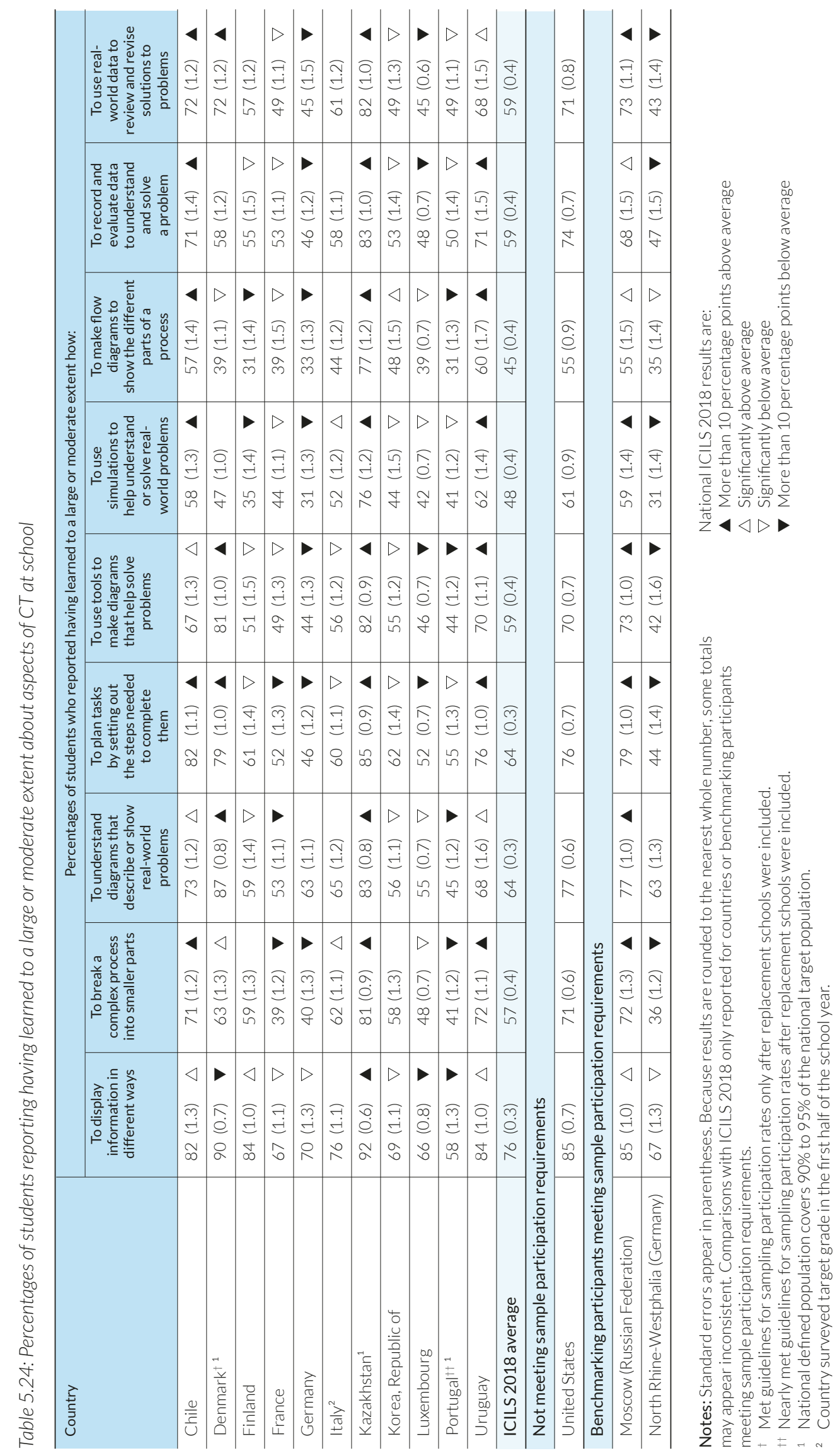




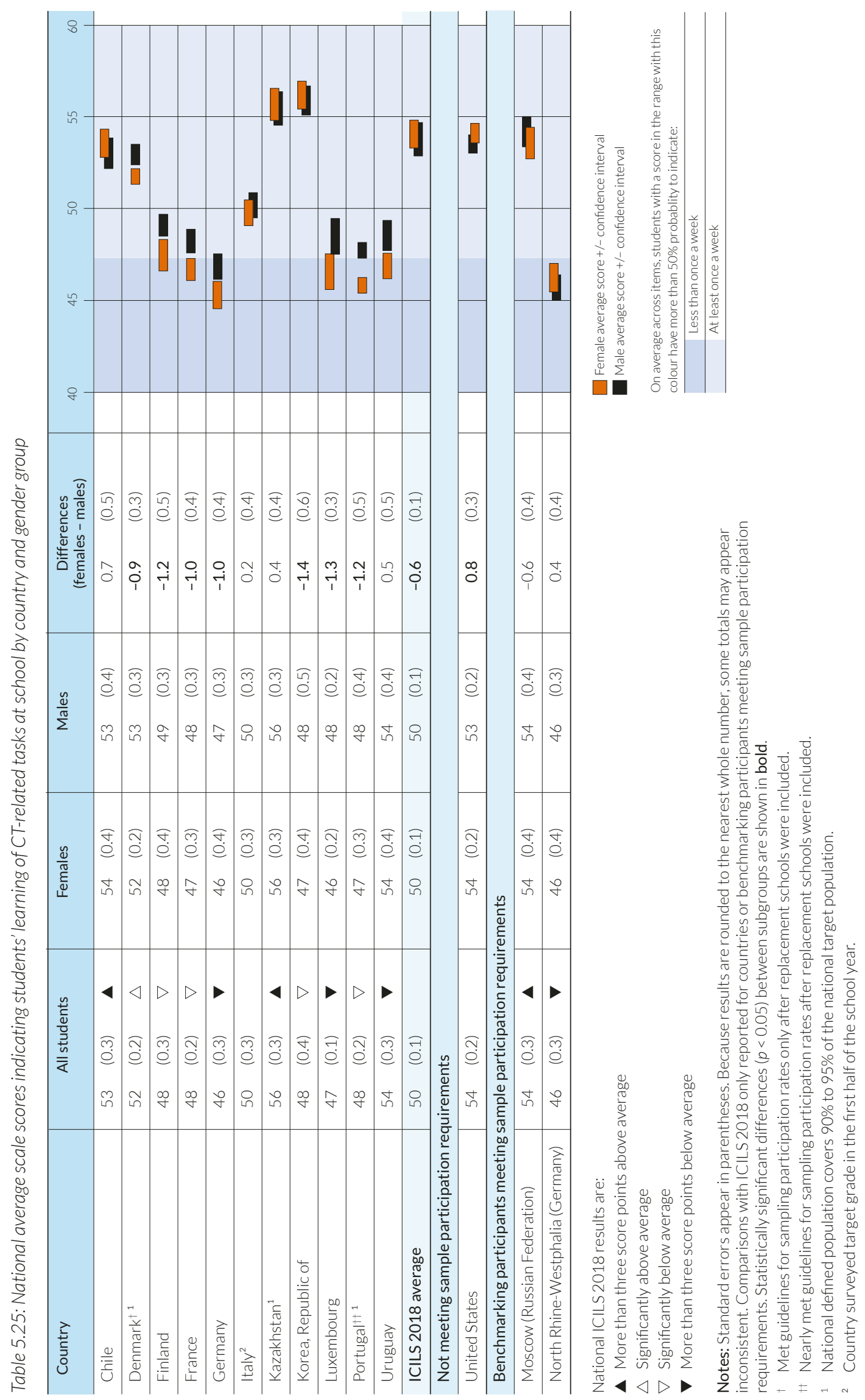


Differences between female and male students in the extent to which they attributed their CTrelated learning to school instruction were very small, being less than one scale point in favor of male students, on average across countries, and being statistically significant in seven ICILS 2018 countries (Table 5.25). Although the differences were small, the overall pattern of differences was the converse to that found for students' reports of learning CIL in which female students tended to report more than male students that they had learned about CIL in school (Table 5.22).

Students with five or more years of computer experience had significantly higher scale scores than those with less than five years of experience in just three ICILS 2018 countries (Italy, Kazakhstan, and Denmark). However, in North Rhine-Westphalia (Germany) there was a small difference in a negative direction (Table 5.26). The CT learning scale scores were higher for students currently studying ICT subjects than for those who were not. This difference was significant in all countries except Uruguay and averaged three scale points overall. Among ICILS 2018 countries the difference was largest in Portugal (four scale points); however, in Moscow (Russian Federation) the difference was six scale points.

\section{Student perceptions of ICT}

We investigated two main aspects of students' perceptions of ICT as part of the broad field of emotional engagement with ICT. The first aspect was students' perceptions of themselves in relation to ICT: ICT self-efficacy. We asked students to indicate how well they felt that they could accomplish various ICT tasks. Based on the results from ICILS 2013 (Fraillon et al. 2014) we formed two constructs from these tasks. The first referred to ICT self-efficacy in relation to common productivity applications (typically embodied in office applications) and the second referred to ICT self-efficacy in relation to specialist tasks (such as coding, database management, and webpage construction).

The second aspect of students' emotional engagement with ICT was their attitudes to ICT in their futures. We asked about the extent to which they saw aspects of ICT as beneficial for society, the extent to which they saw aspects of ICT as detrimental for society. Our conception of ICT societal futures envisaged these as separate dimensions rather than as simple polar opposites. According to this conception it was possible to envisage some aspects of ICT as beneficial for society and other aspects as detrimental to society. We also asked students about the extent to which they saw ICT as important for their personal futures.

\section{ICT self-efficacy}

The concept of self-efficacy refers to an individual's belief in their capacity to organize and execute a course of action to obtain specific outcomes (Bandura 1997). This, in turn, influences their choices with regard to undertaking tasks, the effort they expend on them, and the extent to which they persevere with a task. In ICILS 2013, we invoked two constructs that referenced ICT self-efficacy: ICT self-efficacy regarding the use of general applications and ICT self-efficacy regarding the use of specialist applications. In ICILS 2013 we referred to these constructs as ICT self-efficacy in basic ICT skills and ICT self-efficacy in advanced ICT skills. ICILS 2013 found that ICT self-efficacy in basic ICT skills, which was based on student confidence in undertaking general ICT-based tasks such as creating or editing documents, or searching and finding information on the internet, was positively associated with CIL. However, ICT self-efficacy in advanced ICT skills, which was based on student confidence to carry out tasks such as building or editing a webpage, or creating a computer program or macro, was not associated with CIL (Fraillon et al. 2014; Rohatgi et al. 2016).

As part of the ICILS 2018 student questionnaire we asked students to indicate how well they thought they could do each of 13 ICT-based tasks. The response categories were "I know how to do this," "I have never done this but I could work out how to do this," and "I do not think I could do this." For the purposes of analyses at the item level, we collapsed the second and third 


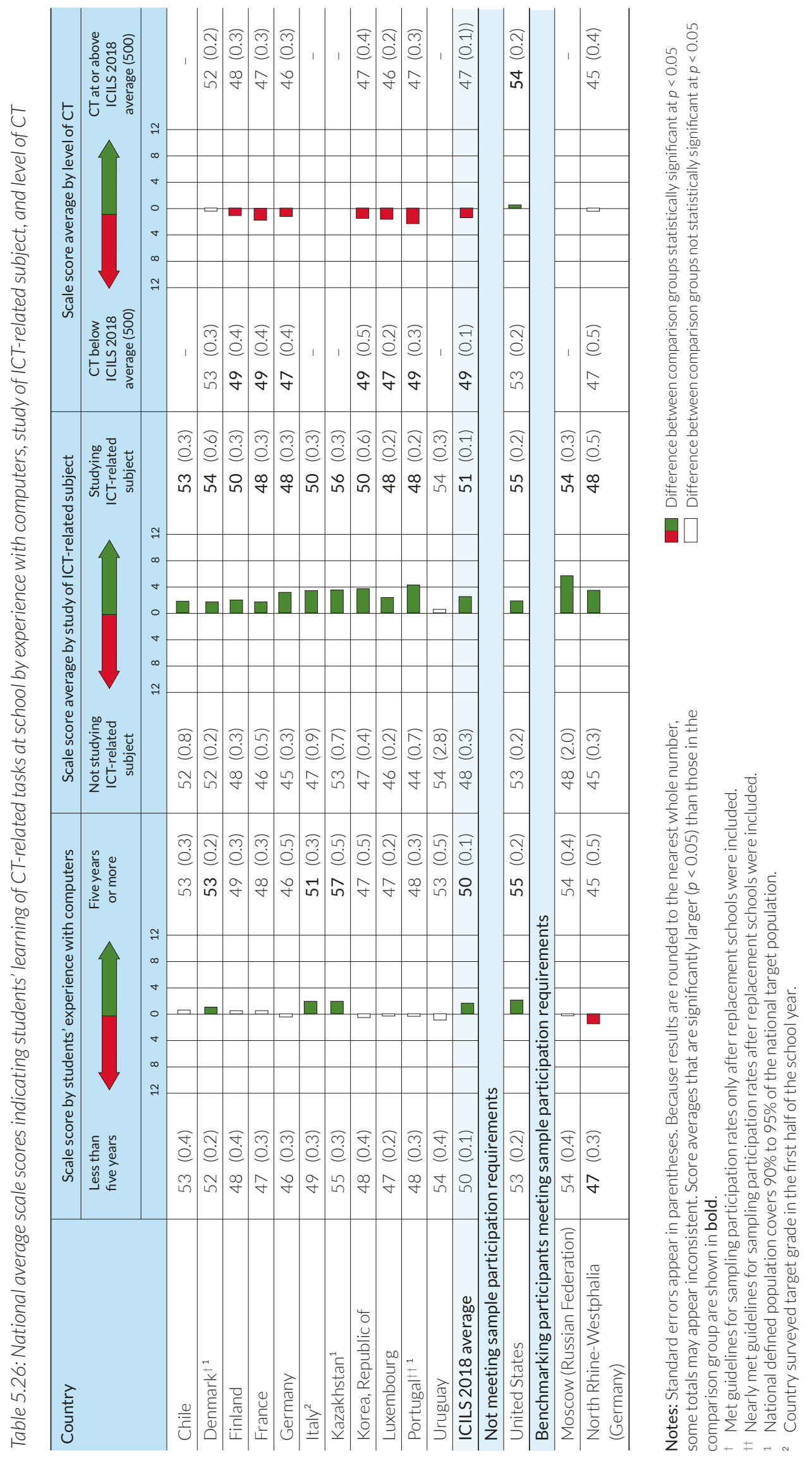


categories and gave the first category a score of one and the second a score of zero.

The tasks listed were (in order of increasing difficulty):

- Search for and find relevant information for a school project on the internet;

- Insert an image into a document or message;

- Install a program or app;

- Write or edit text for a school assignment;

- Upload text, images, or video to an online profile;

- Edit digital photographs or other graphic images;

- Judge whether you can trust information you find on the internet;

- Create a multimedia presentation (with sound, pictures, or video);

- Change the settings on your device to improve the way it operates;

- Set up a local area network of computers or other ICT;

- Build or edit a webpage;

- Create a database (e.g., using Microsoft Access $($ )); and

- Create a computer program, macro, or app (e.g., in Basic, Visual Basic).

The percentages of students who reported that they knew how to do these tasks by themselves, which reflect how difficult students perceived each task to be, ranged from 18 percent ("create a computer program or macro") to 88 percent ("search for and find information you need on the internet") (Table 5.27). There were also differences among countries. More than nine out of 10 students in Denmark indicated that they could search for and find relevant information for a school project on the internet (95\%), write or edit text for a school assignment (94\%), and insert an image into a document or message (94\%).

We formed two scales based on these items in order to explore across-country and other differences in students' ICT self-efficacy. One of those scales (based on eight items) reflected students' ICT self-efficacy regarding the use of general applications (coefficient alpha $=0.83$ ). The other (based on four items) was related to students' ICT self-efficacy regarding the use of specialist applications ${ }^{23}$ (coefficient alpha $=0.73$ ). (The corresponding item maps are shown in Figures 6.11 and F.13 in Appendix F.)

There were only small differences among countries on these scales, although the mean score on the ICT self-efficacy (general applications) scale for Kazakhstan was low (45) and for Portugal was high (53) (Table 5.28). Interestingly, the mean score on the ICT self-efficacy (specialist applications) scale for Kazakhstan was high (53) and the mean score for Denmark was low (47).

Statistically significant gender differences in ICT self-efficacy (general applications), favoring female students, emerged in Korea, Chile, and Kazakhstan. However, on average, there was little difference in the ICT self-efficacy (general applications) scores of female and male students (Table 5.29). The scores for female students were, on average, two scale points higher than those for male students. There were significant differences in ICT self-efficacy (general applications) associated with computer experience in every country and overall by three scale points in favor of those who had been using a computer for five or more years compared with those who had less than five years of experience.

There was a substantial difference in ICT self-efficacy (general applications) between those with CIL scores at or above Level 2 and those with CIL scores below Level 2. On average students with high CIL scores had ICT self-efficacy regarding the use of general applications that was five

23 One of the items (change the settings on your device to improve the way it operates) was not used in calculating scale scores because it did not fit with either of the ICT self-efficacy scales. 


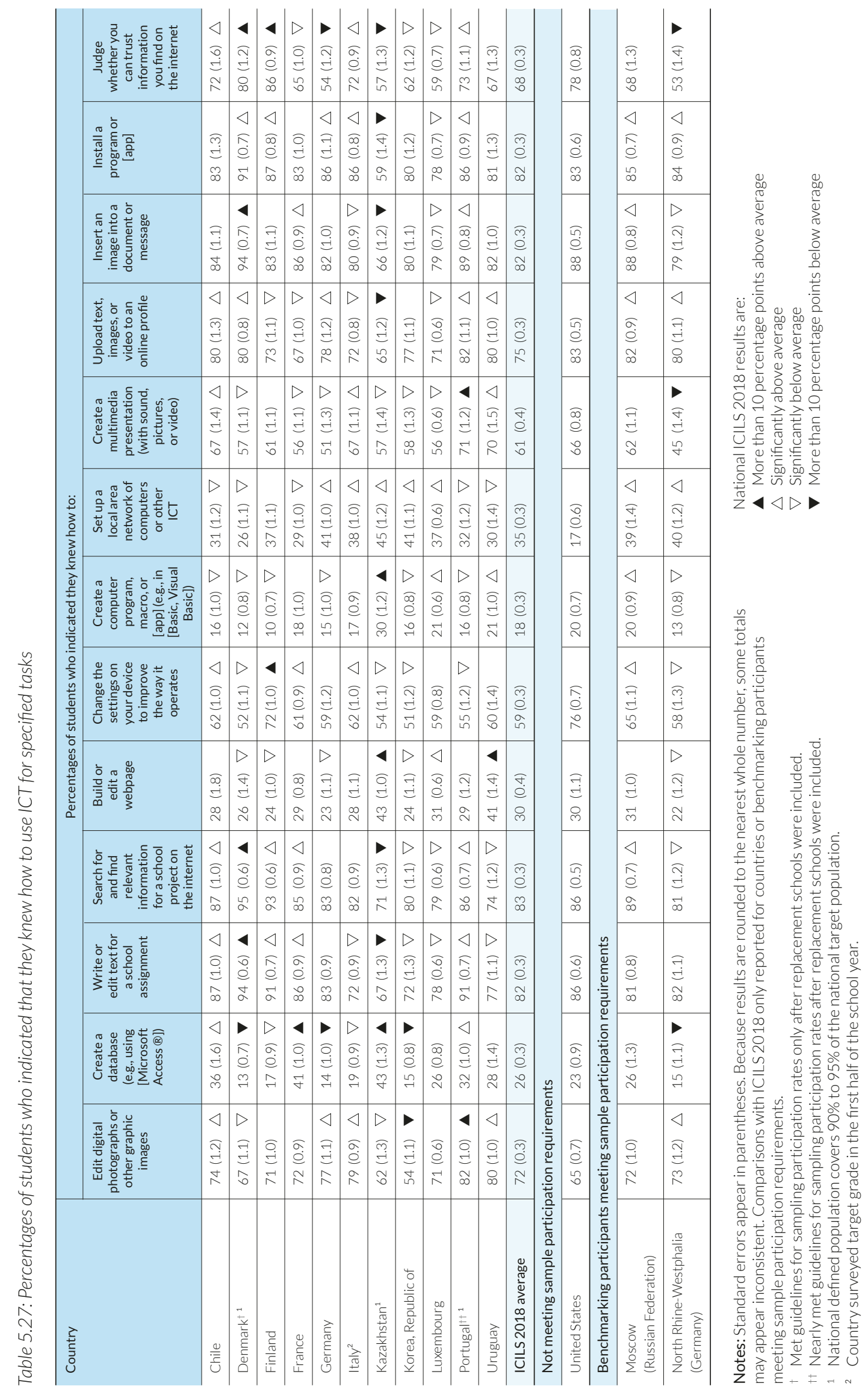




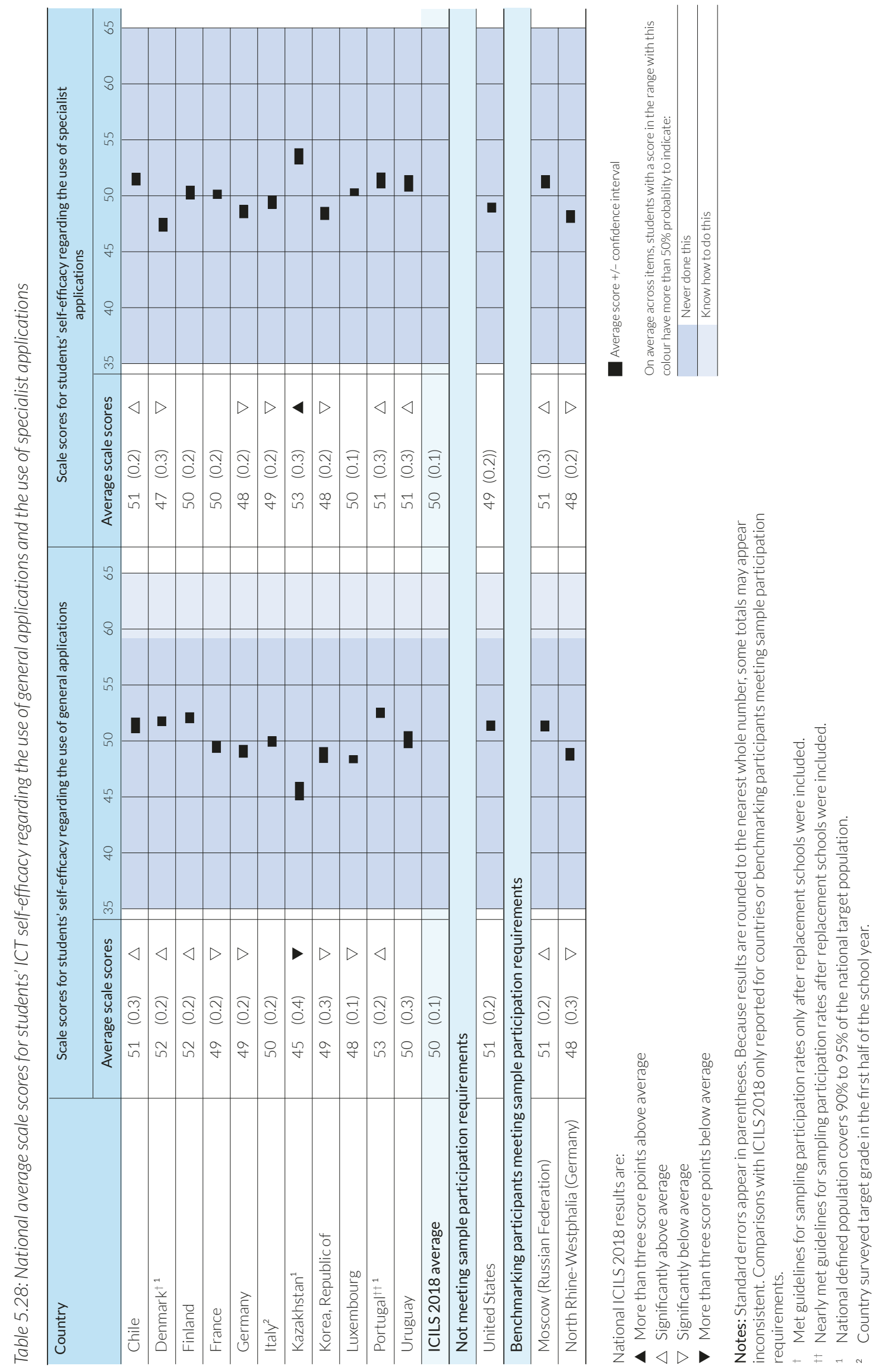




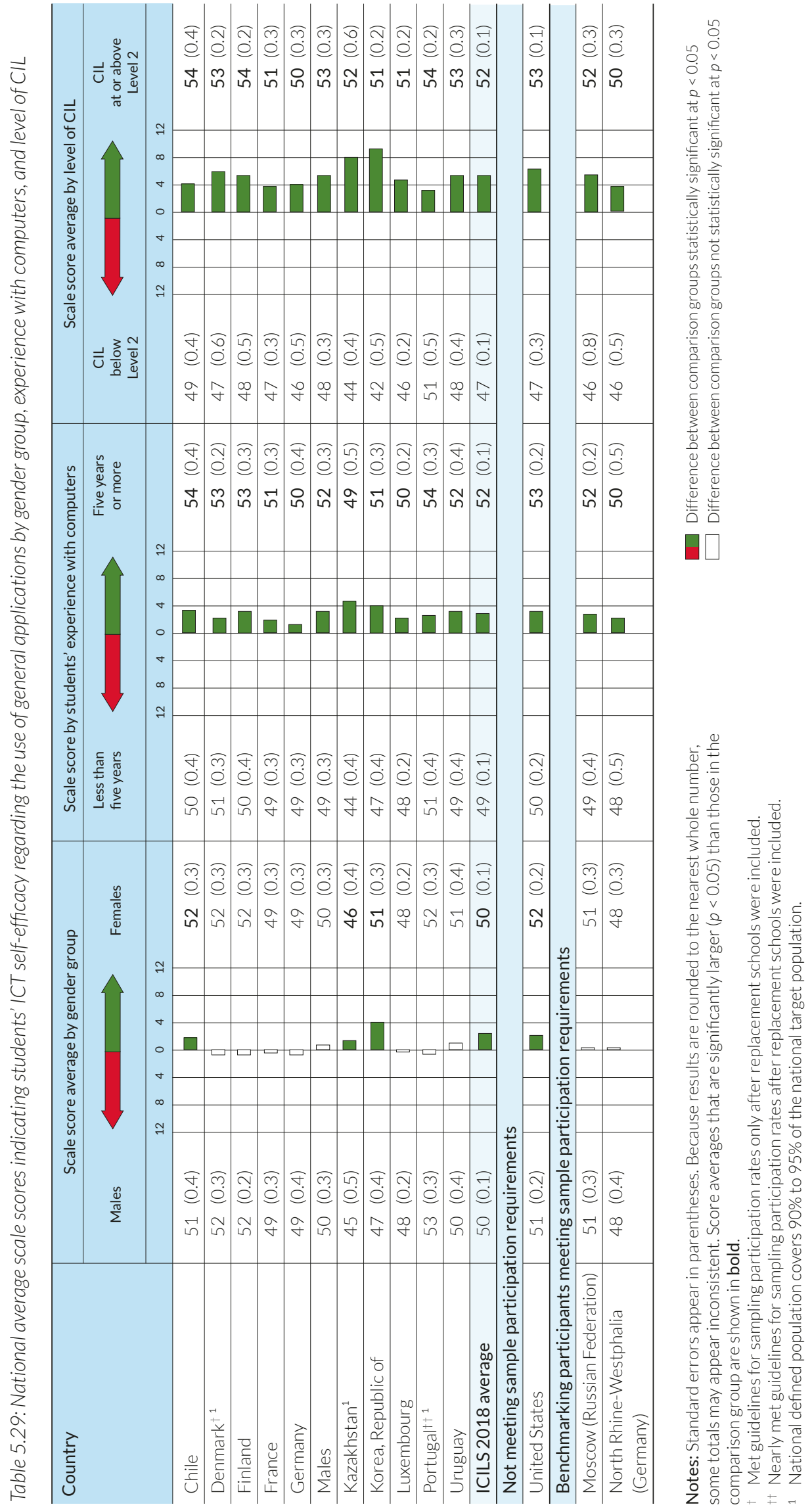


scale score points higher than among students with low CIL scores (Table 5.29). The difference was nine scale points in Korea.

There were significant gender differences in ICT self-efficacy regarding the use of specialist applications favoring male students in all countries. On average the difference was four scale points (Table 5.30). The gap was large in Denmark (eight points), Germany, and North RhineWestphalia (Germany) (both six points).

The differences associated with computer experience were much more closely aligned to what we expected. The ICT self-efficacy (specialist applications) scores of students with five or more years of computer experience were, on average across countries, two points higher than the ICT self-efficacy (specialist applications) scores of students with less than five years of computer experience (Table 5.30). The difference was largest in Germany, North Rhine-Westphalia (Germany), Luxembourg, and Italy (three points).

There was little systematic difference between the ICT self-efficacy (specialist applications) scores of students and their CIL score. Those with CIL scores at or above Level 2 had higher specialist ICT self-efficacy scores than those with CIL scores below Level 2 in two countries, but the reverse was observed in six countries and there was no significant difference in five countries.

\section{Attitudes to ICT in society}

We asked students to indicate their attitudes to the value of ICT in society. We presented them with a set of 11 statements that balanced positive and negative views of ICT (Table 5.31). Students responded to these items using four response categories ("strongly agree" to "strongly disagree"). We reported the percentage agreement for each item by combining the percentages who strongly agreed or agreed with the statement.

There were high percentages who expressed agreement with statements referring to positive outcomes of ICT for society such as "ICT helps us to understand the world better" (86\%), "advances in ICT usually improve people's living conditions" (85\%), "ICT is valuable to society" (84\%), and "advances in ICT bring many social benefits" (83\%). On the other hand there were moderately high percentages who expressed reservations by recording agreements with statements referring to negative outcomes of ICT for society such as "people spend far too much time using ICT" (80\%), "using ICT may be dangerous for people's health" (69\%), "using ICT makes people more isolated in society" (66\%), and "with more ICT there will be fewer jobs" (52\%).

There were also three items that were concerned with expectations of future ICT use for work and study: "learning how to use ICT applications will help me to do the work I am interested in" (68\%), "I hope to find a job that involves specialist ICT" (51\%), and "I would like to study subjects related to ICT after secondary school" (49\%).

We did not observe large differences among countries and constructed three scales representing: perceptions of positive outcomes of ICT for society (average coefficient alpha $=0.75$ ); perceptions of negative outcomes of ICT for society (average coefficient alpha $=0.66$ ); and, to explore differences among countries and subgroups, expectations of future ICT use for work and study (coefficient alpha $=0.80$ ) (see Figures F.14, F.15, and F.17 in Appendix F for corresponding items maps).

We observed stronger support for positive outcomes of ICT for society in Korea, Portugal, and Moscow (Russian Federation) and less strong support for positive outcomes of ICT for society in Luxembourg (Table 5.32). We also observed stronger support for negative outcomes of ICT for society in Chile and Uruguay and less strong support for negative outcomes of ICT for society in Finland, Denmark, and Moscow (Russian Federation).

Stronger support for positive outcomes of ICT for society was expressed by male than by female 


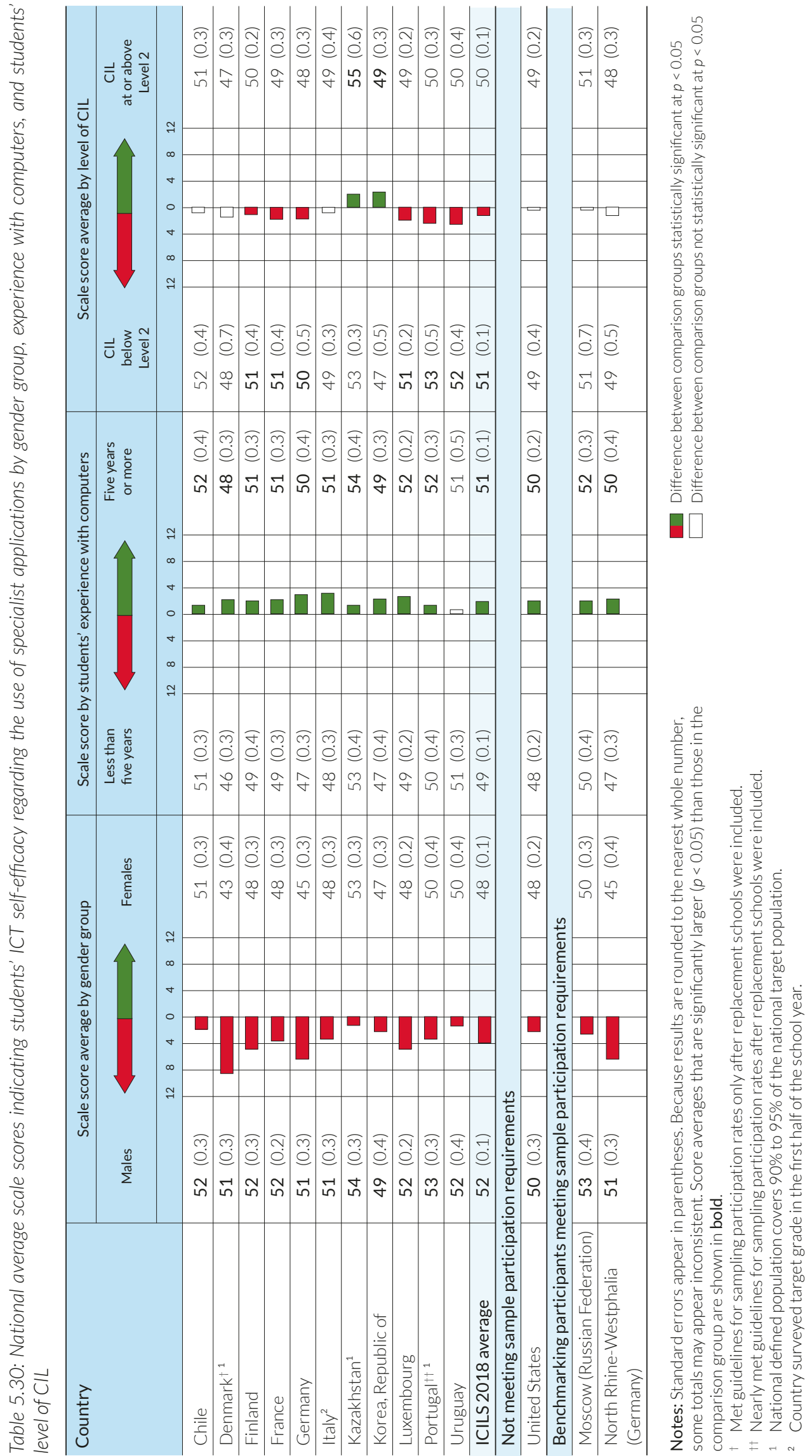




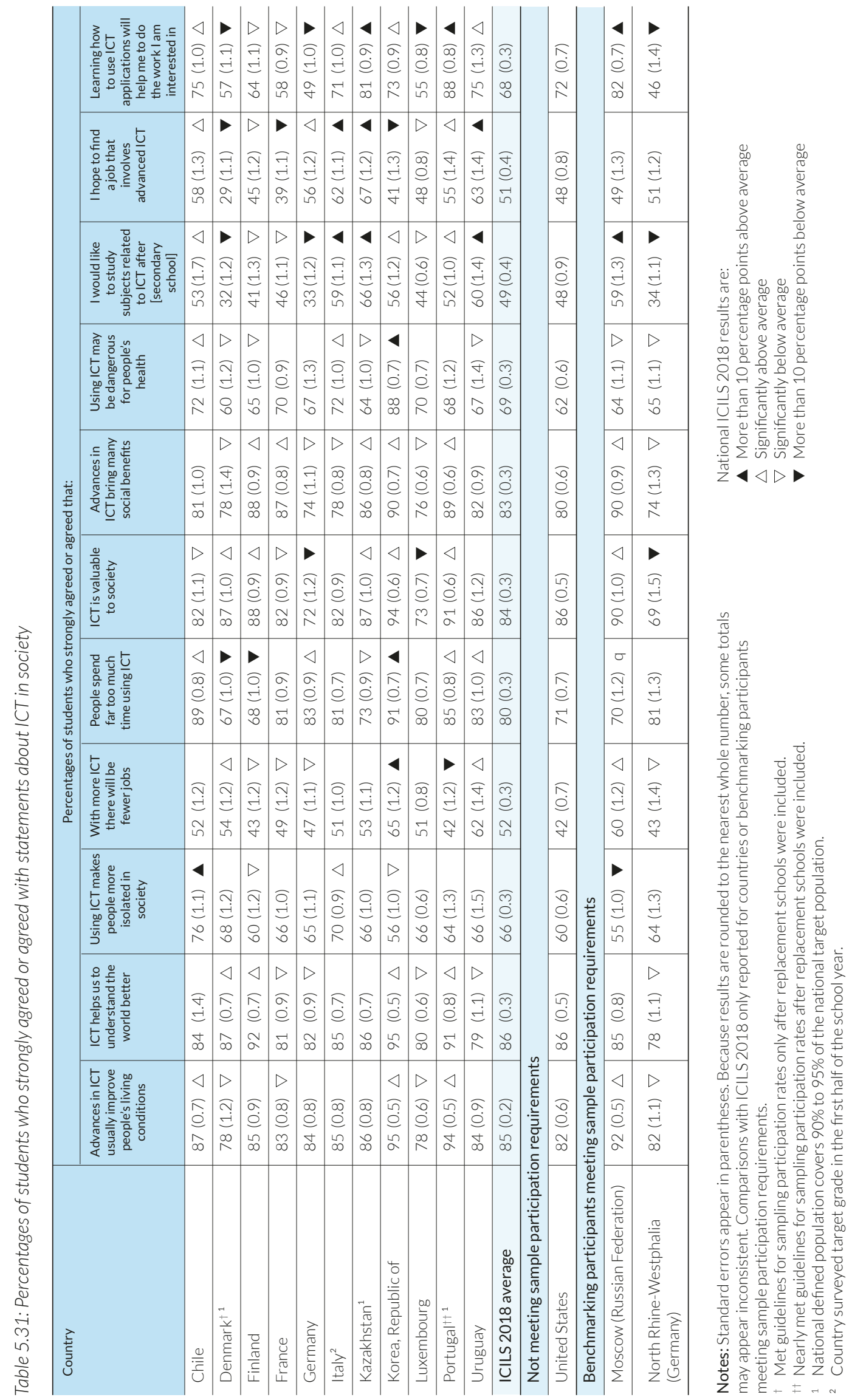




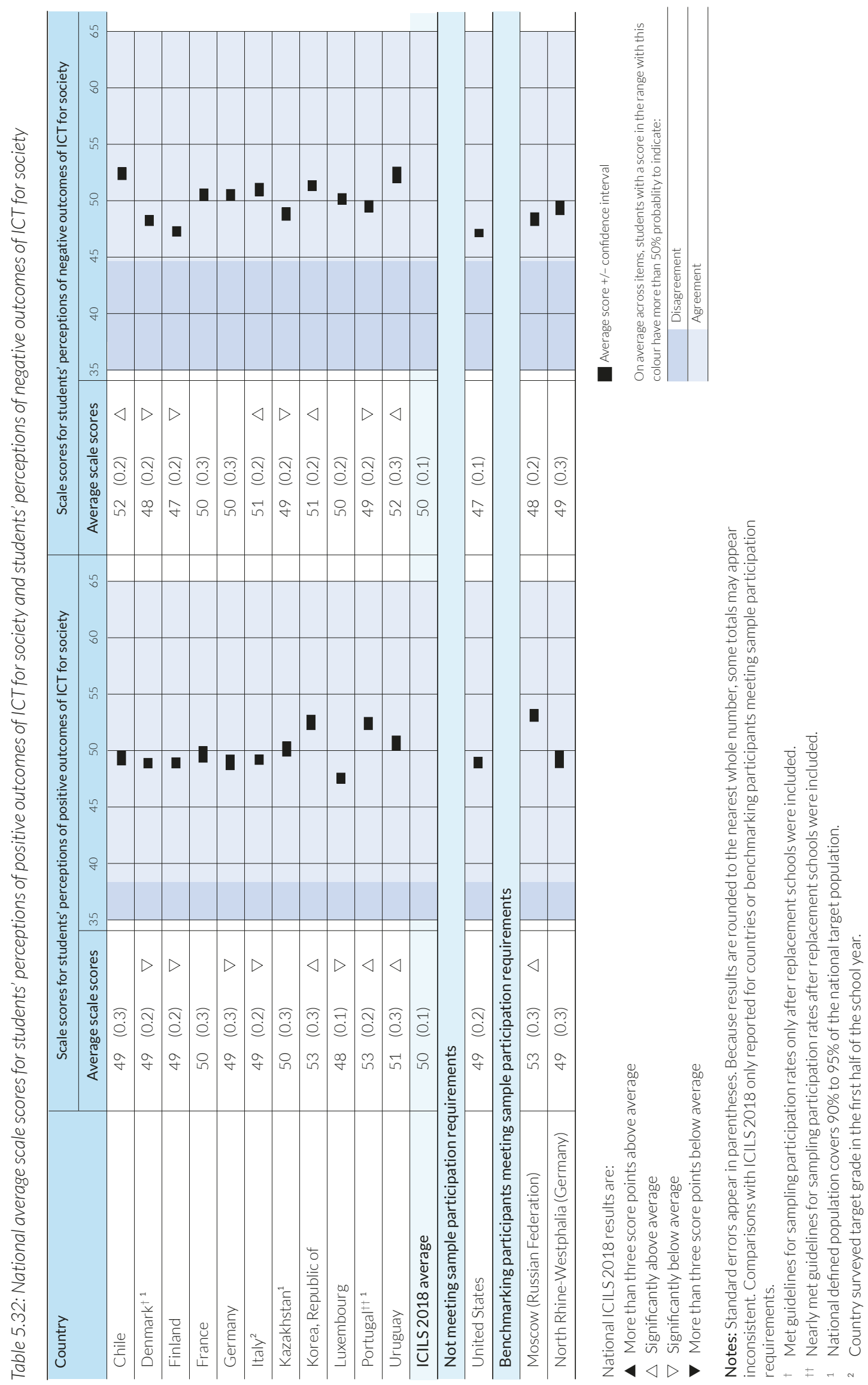


students in all countries (Table 5.33). On average across ICILS 2018 countries, the difference was three scale points, but in Germany, North Rhine-Westphalia (Germany), and Denmark the difference was six scale points.

Students with five or more years of computer experience expressed significantly more strongly positive views of ICT for society than students with less than five years of computer experience, in all countries (Table 5.33). On average across countries, the difference was two scale points. More positive views of ICT for society were expressed by students with CIL scores at Level 2 or above in just five ICILS 2018 countries, and the average difference was two scale points.

More strongly negative views of ICT for society were expressed by female students than by male students in eight ICILS 2018 countries (Table 5.34). On average across countries the difference was two scale points. The difference between male and female students was largest in Germany (the difference was three scale points). There was no significant difference in the strength of negative perceptions of ICT for society between male and female students in Chile, Kazakhstan, and Uruguay.

There were few significant differences, and no difference on average across countries, in the strength of negative perceptions of ICT for society associated with computer experience or CIL (Table 5.34). In Chile more experienced computer users expressed negative views of ICT for society more strongly than other students and in Denmark less experienced computer users expressed negative views of ICT for society more strongly than other students.

There was no overall difference in the strength of negative perceptions of ICT for society between students with CIL scores at Level 2 or above and students with CIL scores below Level 2 (Table 5.34). Among ICILS 2018 countries, only in Portugal was there a significant difference with more strongly negative views expressed by students with lower CIL. In Moscow (Russian Federation) students with lower CIL scores were also more likely to have negative perceptions of ICT for society (a scale difference of two points).

The scale scores for student expectations of future ICT use in work and study differed among countries, with students in Uruguay expressing the most positive scores and students in Denmark expressing the least positive scores (Table 5.35). The difference between these two countries was seven scale points. In all countries male students recorded significantly higher expectations of future ICT use than did female students. On average across countries the difference was five scale points (Table 5.35).

\section{Associations of students' ICT self-efficacy with CIL and CT}

Students' ICT self-efficacy (general applications) scores were significantly and moderately correlated with CIL in all countries (Table 5.36). On average across countries, the correlation coefficient was 0.32 and it ranged from 0.24 (Portugal) to 0.38 (Italy). In contrast there was little correlation between ICT self-efficacy (specialist applications) scores and CIL. In seven ICILS 2018 countries the correlation coefficient was negative but small, in two countries it was positive but small, and in two countries it was not significant. On average the correlation coefficient was -0.04.

Students' CT was also significantly but moderately correlated with ICT self-efficacy (general applications) scores in all seven participating ICILS 2018 countries. On average across countries the correlation coefficient was 0.26 (Table 5.36). Again there were weak correlations of CT and ICT with ICT self-efficacy (specialist applications) scores. On average across countries, the correlation coefficient was -0.04 . The correlation coefficient was always small and was significant and negative in three countries, significant and positive in one country, and not significant in the remaining three countries. 


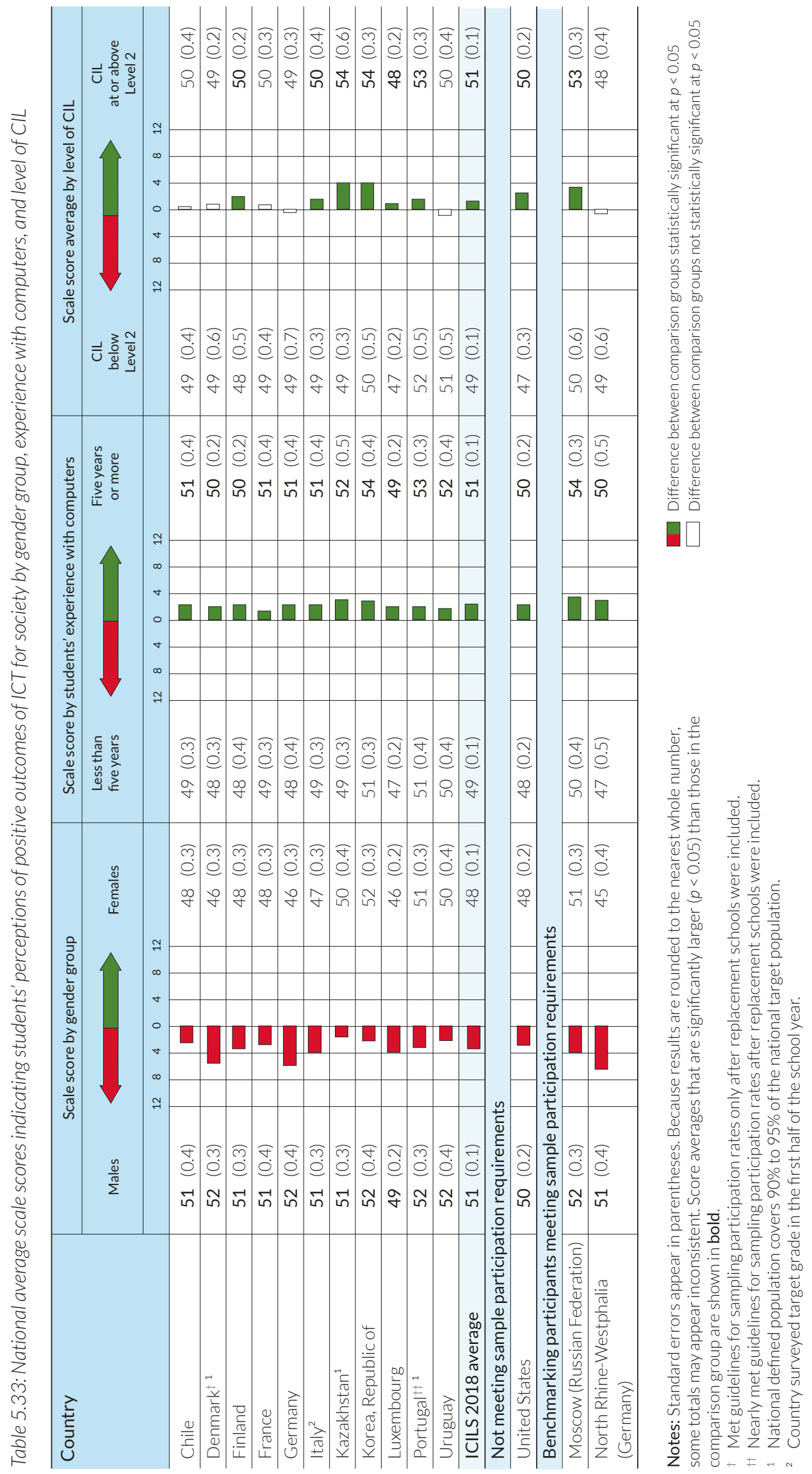




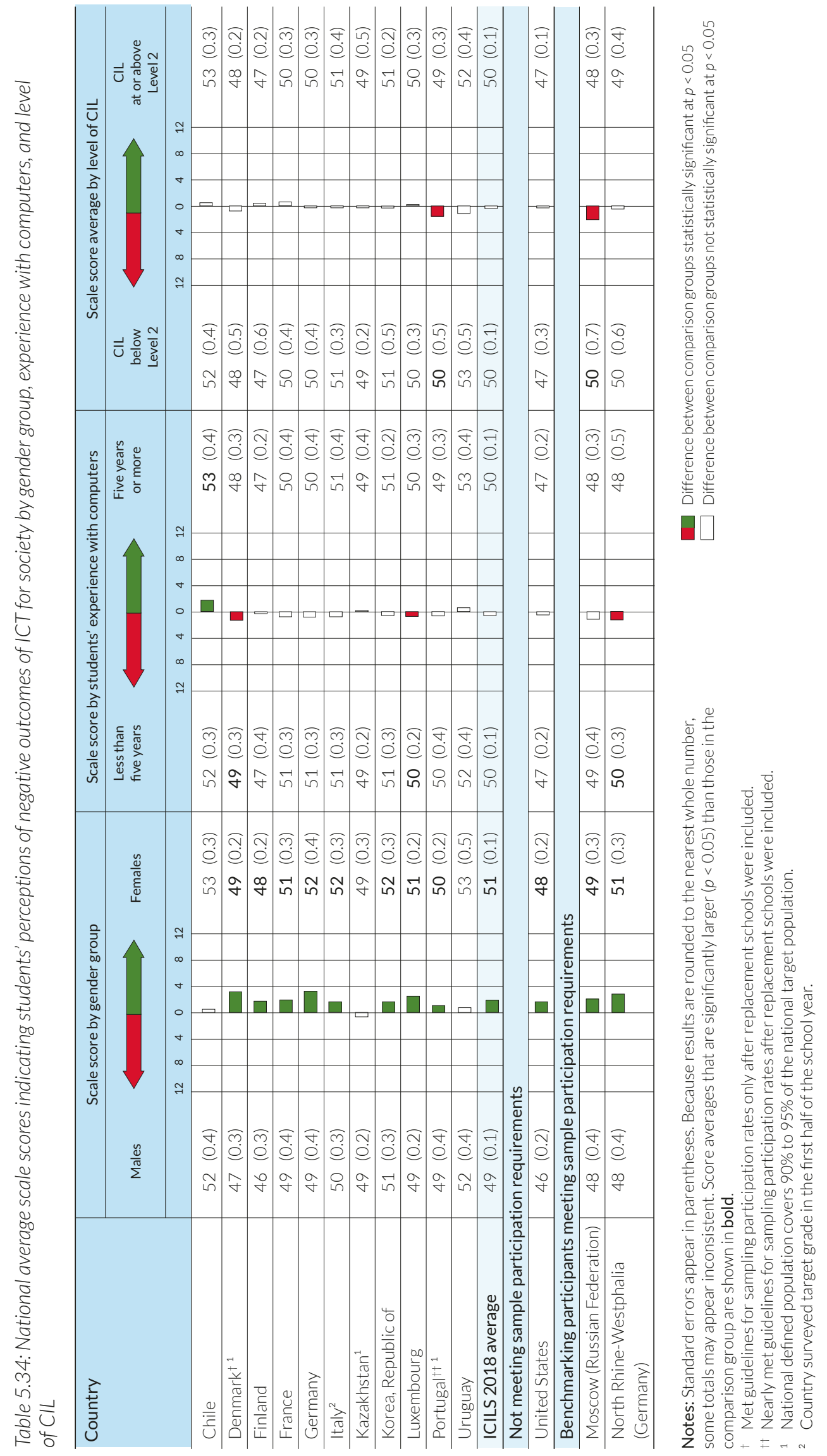



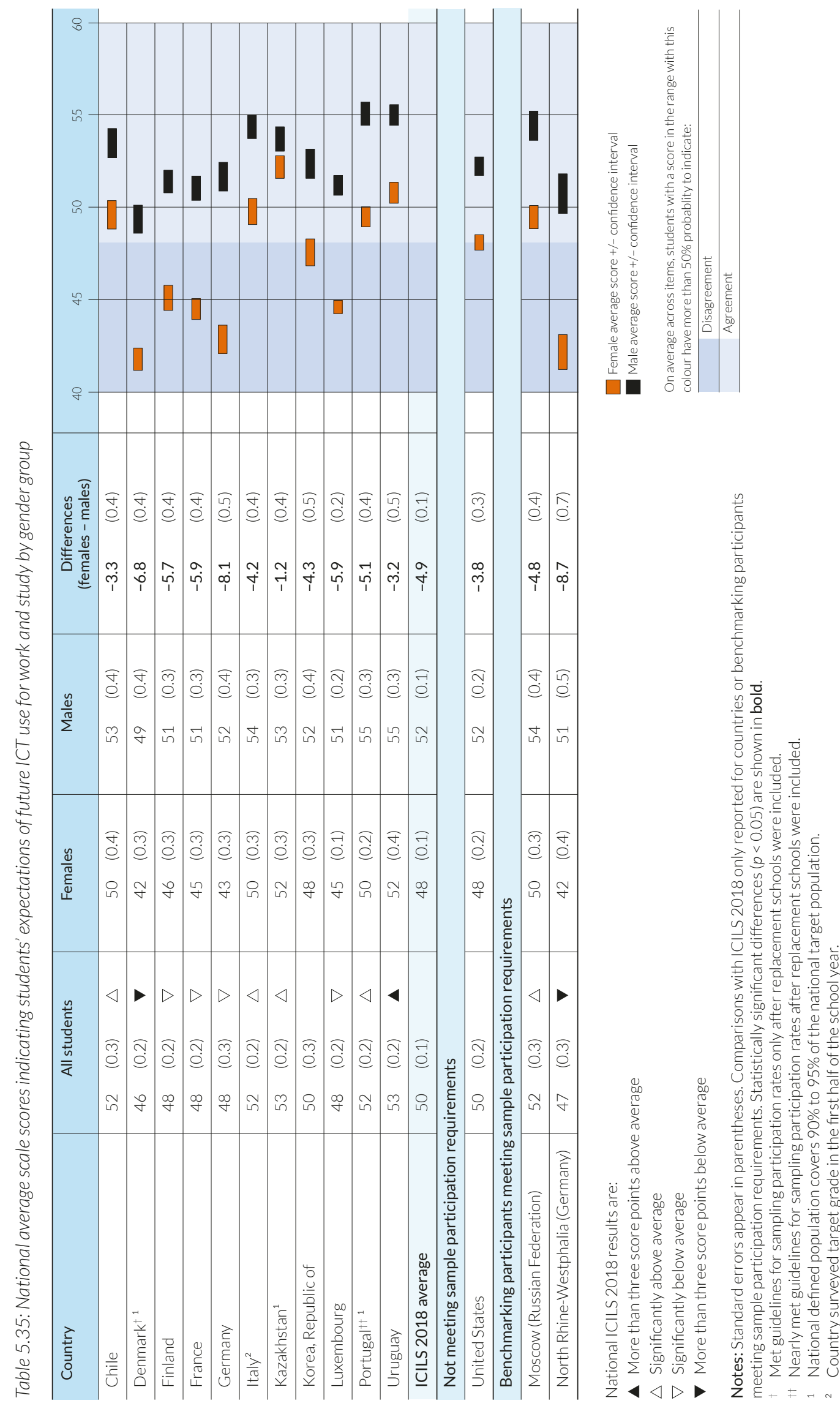
Table 5.36: Correlation coefficients of students' ICT self-efficacy for both general applications and specialist applications with CIL and CT

\begin{tabular}{|c|c|c|c|c|c|c|c|}
\hline \multirow[t]{2}{*}{ Country } & \multicolumn{4}{|c|}{ Correlation of CIL with: } & \multicolumn{3}{|c|}{ Correlation of CT with: } \\
\hline & \multicolumn{2}{|c|}{$\begin{array}{c}\text { Students' ICT } \\
\text { self-efficacy } \\
\text { regarding the use of } \\
\text { general applications }\end{array}$} & \multicolumn{2}{|c|}{$\begin{array}{l}\text { Students' ICT } \\
\text { self-efficacy } \\
\text { regarding the use of } \\
\text { specialist applications }\end{array}$} & \multicolumn{2}{|c|}{$\begin{array}{c}\text { Students' ICT } \\
\text { self-efficacy } \\
\text { regarding the use of } \\
\text { general applications }\end{array}$} & $\begin{array}{c}\text { Students' ICT } \\
\text { self-efficacy } \\
\text { regarding the use of } \\
\text { specialist applications }\end{array}$ \\
\hline Chile & 0.33 & (0.03) & -0.06 & $(0.03)$ & & & \\
\hline Denmark $^{\dagger 1}$ & 0.33 & (0.03) & -0.03 & $(0.03)$ & 0.3010 & $(0.02)$ & $0.02 \quad(0.03)$ \\
\hline Finland & 0.33 & $(0.02)$ & -0.06 & $(0.02)$ & 0.3010 & (0.02) & $-0.03 \quad(0.02)$ \\
\hline France & 0.25 & $(0.02)$ & -0.09 & $(0.02)$ & 0.19 & (0.02) & $-0.11(0.03)$ \\
\hline Germany & 0.26 & (0.03) & -0.07 & $(0.03)$ & $0.18 \quad(C$ & (0.03) & $-0.03(0.03)$ \\
\hline Italy ${ }^{2}$ & 0.38 & $(0.02)$ & 0.00 & $(0.02)$ & & & \\
\hline Kazakhstan ${ }^{1}$ & 0.34 & (0.03) & 0.12 & $(0.03)$ & & & \\
\hline Korea, Republic of & 0.48 & (0.02) & 0.15 & $(0.02)$ & 0.3910 & (0.02) & $0.10 \quad(0.02)$ \\
\hline Luxembourg & 0.28 & (0.01) & -0.10 & $(0.01)$ & 0.24 & (0.01) & $-0.08 \quad(0.01)$ \\
\hline Portugal ${ }^{+1}+1$ & 0.24 & (0.03) & -0.15 & $(0.03)$ & 0.21 & (0.03) & $-0.16(0.03)$ \\
\hline Uruguay & 0.34 & $(0.02)$ & -0.11 & $(0.03)$ & & & \\
\hline ICILS 2018 average & 0.32( & (0.01) & -0.04 & $(0.01)$ & 0.26 & (0.01) & $-0.04 \quad(0.01)$ \\
\hline \multicolumn{8}{|c|}{ Not meeting sample participation requirements } \\
\hline United States & $0.39(($ & $(0.01)$ & 0.01 & $(0.01)$ & $0.31(C$ & $(0.01)$ & $-0.01 \quad(0.02)$ \\
\hline \multicolumn{8}{|c|}{ Benchmarking participants meeting sample participation requirements } \\
\hline Moscow (Russian Federation) & $0.27(($ & (0.03) & -0.03 & $(0.03)$ & & & \\
\hline North Rhine-Westphalia (Germany) & $0.26(($ & (0.03) & -0.03 & $(0.03)$ & $0.17 \quad(C$ & $(0.03)$ & $-0.01(0.03)$ \\
\hline
\end{tabular}

Notes: Standard errors appear in parentheses. Statistically significant coefficients $(p<0.05)$ are shown in bold.

† Met guidelines for sampling participation rates only after replacement schools were included.

t† Nearly met guidelines for sampling participation rates after replacement schools were included.

National defined population covers $90 \%$ to $95 \%$ of the national target population.

Country surveyed target grade in the first half of the school year. 


\section{References}

Aparicio, M., Bacao, F., \& Oliveira, T. (2016). An e-learning theoretical framework. Journal of Educational Technology Systems, 19(1), 292-307.

Bandura, A. (1997). Self-efficacy: the exercise of control. New York, NY: W.H. Freeman.

Bulfin, S., Johnson, N., Nemorin, S., \& Selwyn, N. (2016). Nagging, noobs and new tricks-students' perceptions of school as a context for digital technology use. Educational Studies, 42(3), 239-251. Retrieved from https://doi.org/10.1080/03055698.2016.1160824.

Bundsgaard, J., \& Gerick, J. (2017). Patterns of students' computer use and relations to their computer and information literacy: Results of a latent class analysis and implications for teaching and learning. Largescale Assessments in Education, 5(17), 1-15. Retrieved from https://largescaleassessmentsineducation. springeropen.com/articles/10.1186/s40536-017-0052-8.

Comi, S.L., Argentin, G., Gui, M., Origo, F., \& Pagani, L. (2016). Is it the way they use it? Teachers, ICT and student achievement. Economics of Education Review, 56, 24-39. Retrieved from https://doi.org/10.1016/j. econedurev.2016.11.007.

Elliott, S.N., \& Bartlett, B.J. (2016). Opportunity to learn. Oxford Handbooks Online: Scholarly Research Reviews. Oxford, UK/New York, NY: Oxford University Press. Retrieved from https://www.oxfordhandbooks. com/view/10.1093/oxfordhb/9780199935291.001.0001/oxfordhb-9780199935291-e-70.

European Commission. (2013). Survey of schools: ICT in education. Benchmarking access, use and attitudes to technology in Europe's schools (final report). Brussels, Belgium: Author. Retrieved from https://ec.europa. eu/digital-agenda/sites/digital-agenda/files/KK-31-13-401-EN-N.pdf.

Fisher, C., Berliner, D., Filby, N., Marliave, R., Cahen, L., \& Dishaw, M. (1981). Teaching behaviors, academic learning time, and student achievement: An overview. The Journal of Classroom Interaction, 17(1), 2-15. Retrieved from http://www.jstor.org/stable/43997772.

Fraillon, J., Ainley, J., Schulz, W., Friedman, T., \& Gebhardt, E. (2014). Preparing for life in a digital age: The IEA International Computer and Information Literacy Study international report. Cham, Switzerland: Springer. Retrieved from https://www.springer.com/gp/book/9783319142210.

Fraillon, J., Schulz, W., Friedman, T., \& Meyer, S. (Eds.). (2020). IEA International Computer and Information Literacy Study 2018 technical report. Amsterdam, The Netherlands: International Association for the Evaluation of Educational Achievement (IEA). Manuscript in preparation.

Fredericks, J., Blumenfeld, P., \& Paris, A. (2004). School engagement: Potential of the concept, state of the evidence. Review of Educational Research, 74(1), 59-96. Retrieved from https://doi.org/10.3102\% 2F00346543074001059.

Fu, J.S. (2013). ICT in education: a critical literature review and its implications. International Journal of Education and Development using Information and Communication Technology, 9(1), 112-125.

Gerick, J., Eickelmann, B., \& Bos, W. (2017). School-level predictors for the use of ICT in schools and students' CIL in international comparison. Large-scale Assessments in Education, 5(1), 1-13. Retrieved from https://doi.org/10.1186/s40536-017-0037-7.

Gil-Flores, J., Rodríguez-Santero, J., \& Torres-Gordillo, J. (2017). Factors that explain the use of ICT in secondary-education classrooms: The role of teacher characteristics and school infrastructure. Computers in Human Behavior, 68, 441-449. Retrieved from https://doi.org/10.1016/j.chb.2016.11.057.

Howard, S., Chan, A., \& Caputi, P. (2014). More than beliefs: Subject areas and teachers' integration of laptops in secondary teaching. British Journal of Educational Technology, 46(2), 360-369. Retrieved from https://doi.org/10.1111/bjet.12139.

Martin, M.O., Mullis, I.V.S., Foy, P., \& Hooper, M. (2016). TIMSS 2015 international results in science. Chestnut Hill, MA: TIMSS \& PIRLS International Study Center, Boston College. Retrieved from http:// timssandpirls.bc.edu/timss2015/international-results/.

Masters, G.N., \& Wright, B.D. (1997). The partial credit model. In W.J. van der Linden, \& R.K. Hambleton (Eds.), Handbook of modern item response theory (pp. 101-122). New York, NY: Springer.

Mullis, I.V.S., Martin, M.O., Foy, P., \& Hooper, M. (2016). TIMSS 2015 international results in mathematics. Chestnut Hill, MA: TIMSS \& PIRLS International Study Center, Boston College. Retrieved from http:// timssandpirls.bc.edu/timss2015/international-results/.

OECD. (2014). TALIS 2013 results: An international perspective on teaching and learning. Paris, France: Author. Retrieved from https://dx.doi.org/10.1787/9789264196261-en.

Prensky, M. (2001). Digital natives, digital immigrants: Part 1. On the Horizon, 9(5), 1-6. 
Rohatgi, A., Scherer, R., \& Hatlevik, O. (2016). The role of ICT self-efficacy for students' ICT use and their achievement in a computer and information literacy test. Computers \& Education, 102, 103-116. Retrieved from https://doi.org/10.1016/j.compedu.2016.08.001.

Rowan, B., \& Correnti, R. (2009). Studying reading instruction with teacher logs: Lessons from the Study of Instructional Improvement. Educational Researcher, 38(2), 120-131. Retrieved from https://psycnet. apa.org/doi/10.3102/0013189X09332375.

Scheerens, J. (Ed.). (2017). Opportunity to learn, curriculum alignment and test preparation: A research review. Heidelberg, Germany: Springer.

Schmidt, W.H., Zoido, P., \& Cogan, L. (2013). Schooling matters: Opportunity to learn in PISA 2012. OECD Education Working Papers No. 95. Paris, France: OECD.

Scherer, R., Rohatgi, A., \& Hatlevik, O. (2017). Students' profiles of ICT use: Identification, determinants, and relations to achievement in a computer and information literacy test. Computers in Human Behavior, 70, 486-499. Retrieved from https://doi.org/10.1016/j.chb.2017.01.034.

Selwyn, N. (2009). The digital native - myth and reality. Aslib Proceedings, 61(4), 364-379. Retrieved from https://doi.org/10.1108/00012530910973776.

Vrasidas, C. (2015). The rhetoric of reform and teachers' use of ICT. British Journal of Educational Technology, 46(20), 370-380. Retrieved from https://doi.org/10.1111/bjet.12149.

Willermark, S. (2017). Technological pedagogical and content knowledge: A review of empirical studies published from 2011 to 2016. Journal of Educational Computing Research, 56(3), 315-343.

Open Access This chapter is licensed under the terms of the Creative Commons Attribution-NonCommercial 4.0 International License (http://creativecommons.org/licenses/by-nc/4.0/), which permits any noncommercial use, sharing, adaptation, distribution and reproduction in any medium or format, as long as you give appropriate credit to the original author(s) and the source, provide a link to the Creative Commons license and indicate if changes were made.

The images or other third party material in this chapter are included in the chapter's Creative Commons license, unless indicated otherwise in a credit line to the material. If material is not included in the chapter's Creative Commons license and your intended use is not permitted by statutory regulation or exceeds the permitted use, you will need to obtain permission directly from the copyright holder. 


\section{Teaching with and about information and communications technologies}

\section{Chapter highlights}

On average across countries, most teachers tended to have experience and familiarity with information and communications technology (ICT).

- More than two thirds of teachers on average had at least five years of experience with the use of ICT during lessons or with their preparation. (Table 6.1)

- While ICT use was quite widespread among teachers in general, more frequent use when teaching was only reported by less than half of the teachers, with considerable variation across participating countries. (Table 6.1)

Most teachers tended to recognize the value of ICT use for teaching and were confident about using this technology.

- While majorities among teachers across countries expressed confidence when undertaking a large number of different ICT-related tasks, they lacked confidence regarding the use of online discussions, online collaboration, and the use of learning management systems. (Table 6.2)

- Older teachers felt less confident in using ICT (Table 6.3) and teachers who used ICT more frequently for teaching were more confident about using ICT. (Table 6.7)

- Large majorities among teachers endorsed the advantages of ICT use for student learning (Table 6.4), but there were also considerable proportions of teachers mindful of negative effects. (Table 6.5)

- In most countries, teachers with higher levels of endorsement of positive outcomes when using ICT for teaching and those who reported daily ICT use for teaching were less concerned about its potential negative effects. (Table 6.6)

There were considerable differences across countries in the availability of ICT at schools, the extent of teacher collaboration, and conditions for professional learning.

- ICILS 2018 school and teacher data show large differences in the availability and appropriateness of ICT resources across countries. (Table 6.8, Table 6.9, and Table 6.10)

- Majorities among teachers perceived collaboration between teachers (Table 6.11) and those who reported a greater extent of collaboration also perceived higher levels of ICT availability at their schools. (Table 6.12)

- Teachers who used ICT more frequently in class were also more positive about teacher collaboration and ICT resources at school. (Table 6.13)

- Teacher and school-level reports suggest large differences between countries in the expectations and requirements with regard to teacher qualifications for ICT use as well as the participation in professional learning activities. (Table 6.14 and Table 6.15) 
Teachers' placed some or strong emphasis on developing skills related to computer and information literacy and computational thinking.

- There was considerable variation in teacher emphasis across different subject areas. (Table 6.16 and Table 6.18)

- Teachers' confidence in using ICT, positive perceptions of pedagogical ICT use, and positive perceptions of teacher collaboration were positively associated with teacher emphasis on student learning of computer and information literacy and coding-related tasks. (Table 6.17 and Table 6.19)

Teachers' use of ICT in classrooms was still limited and depended on complexity of tasks and applications.

- Teachers tended to report higher levels of use for general utility tools than for digital learning tools. (Table 6.20 and Table 6.21)

- Teachers' use of ICT for student activities and teaching practices varies both across the different types of activities/practices as well as considerably across countries. (Table 6.22 and Table 6.23) 


\section{Introduction}

The International Computer and Information Literacy Study (ICILS) 2018 contextual framework (Fraillon et al. 2019) assumes that computer and information literacy (CIL) and computational thinking (CT) are influenced by context factors that are either antecedents (e.g., school resources) or process-related (e.g., teaching practices) and can be located at different levels including in the wider community, schools and classrooms, home and peer contexts, and the individual student level. Further details of this conceptual model are provided in Chapter 1. In this chapter we will focus on antecedent and process-related contextual variables that are located at the level of schools and classrooms.

Analyses of students' acquisition of CIL and CT need to acknowledge the key role that schools and classrooms play, and in this context it is interesting to note that results from a meta-analysis highlighted the positive impact of the use of information and communications technology (ICT) on classroom achievement (Tamin et al. 2011). In recent decades there has been a considerable increase in an educational policy focus on providing schools and teachers with ICT for use in education. However, results from cross-national studies have repeatedly illustrated that there are considerable differences across countries, across different subject areas, and across schools within countries, as well as between different subgroups of teachers, in particular related to age (Fraillon et al. 2014; Kozma 2003; Law et al. 2008). Research has also emphasized the importance of system and school factors in supporting teachers' pedagogical use of ICT (Eickelmann 2011; Gerick et al. 2017).

In this chapter we report the results of analyses related to teaching with and about ICT at schools across participating countries. It is based on data derived from the teacher, school principal, and ICT coordinator questionnaires, and addresses Research Question 2 related to CIL and CT: What aspects of schools and countries are related to students' CIL/CT? To this end, the chapter reviews variation in approaches to and variation in the use and availability of ICT across different national contexts. It also focuses on teachers' familiarity with ICT, their views regarding its use for teaching and learning, and the extent to which it is used in classrooms. Furthermore, it reviews the emphasis teachers place on developing CIL and CT across different subject areas and their relationship with the actual use of ICT in lessons.

The ICILS teacher survey gathered data from all teachers at sampled schools who taught at the target grade in each country (typically grade 8). Samples of 15 teachers were selected at random in each participating school and invited to participate in the survey. In schools with 20 or fewer teachers, all of them were invited to complete the questionnaire.

To capture teachers' ICT-related perceptions in their in-class teaching, ICILS 2018 asked teachers some questions with regard to a specific reference class taught at the target grade. Teachers were asked to identify the reference class as the first class they taught on the Tuesday (or on the next day in the week they were teaching if they did not have classes on Tuesday) following the last weekend. A large number of questions were then asked about that particular reference class.

ICILS 2018 also collected data at the school level using two instruments. School principals completed a 10-minute questionnaire providing information about school characteristics, school approaches to CIL and CT learning, and incorporating ICT into teaching and learning. Schools were also asked to name an ICT coordinator, this could be either a formal or informal position or be another specifically nominated staff member with knowledge about ICT-related issues at school. These staff members completed a 10-minute questionnaire providing information about ICT resources, and technical and pedagogical support for ICT use for teaching and learning at school. 
Data from both of these instruments were reported at the level of students by matching school data to individual learners. In line with common practice in other IEA studies, this was done to provide a better picture of school contexts for the "average student" in each country as schools with few students would otherwise have the same weight as larger schools with much higher numbers of students.

The ICILS 2018 teacher questionnaire was used to measure a number of constructs that underpin scales and items presented in this chapter. We used item response theory (IRT) scaling (Masters and Wright 1997; Rasch 1960) to derive the scales presented in this chapter, which were set to a metric with a mean of 50 and a standard deviation of 10, with equally weighted national data from those countries that had met the IEA sampling requirements for the teacher survey. All scales are described in item maps contained in Appendix F of this report. The maps relate scale scores to expected item responses under the ICILS scaling model (also illustrated in Figure F.1, Appendix F). Greater detail regarding the scaling procedures for questionnaire items will be provided in the ICILS 2018 technical report (Fraillon et al. 2020).

In five countries the teacher participation rates did not meet the IEA requirements for sampling participation. Therefore, in adherence to IEA standards for reporting, teacher questionnaire results from this relatively large group of countries are reported in an extra section of the respective reporting tables and not included in comparisons with those from other countries. Readers are advised to interpret teacher data from countries not meeting the sample participation requirements with due caution.

\section{Teachers' familiarity with and views of ICT}

\section{Teachers' experience and use}

Prior research has indicated relationships between experiences of teaching staff with ICT, the extent of its use, and their attitudes toward digital technologies as tools for teaching and learning (see Drossel et al. 2017; Fraillon et al. 2014; Nikolopolou and Gialamas 2016). The ICILS 2018 teacher questionnaire asked teachers about their (approximate) years of experience ("never," "less than two years," "between two and five years," or "more than five years") with using ICT for teaching purposes during lessons as well as when preparing lessons. Given that majorities of teachers across all countries were found in the highest categories of years of experience, we present the results in percentages of teachers reporting to have five or more years of experience.

Furthermore, teachers were asked to rate their frequency ("never," "less than once a month," "at least once a month but not weekly," "at least once a week but not every day," or "every day") of using ICT at school when teaching, at school for other work-related purposes, outside school for work-related purposes, and outside school for non-work-related purposes. Results are presented as percentages of teachers who reported using ICT every day.

On average across participating countries, about two thirds of teachers reported having five or more years of experience with the use of ICT during lessons, while an even higher percentage (72\%) reported having a similar length of experience with the use of ICT for preparing lessons (Table 6.1). The highest percentages of teachers indicating long experience for both activities were recorded in Denmark, Portugal, and the benchmarking participant Moscow (Russian Federation), while the lowest percentages were reported in Italy, Kazakhstan, and the benchmarking participant North Rhine-Westphalia (Germany). 


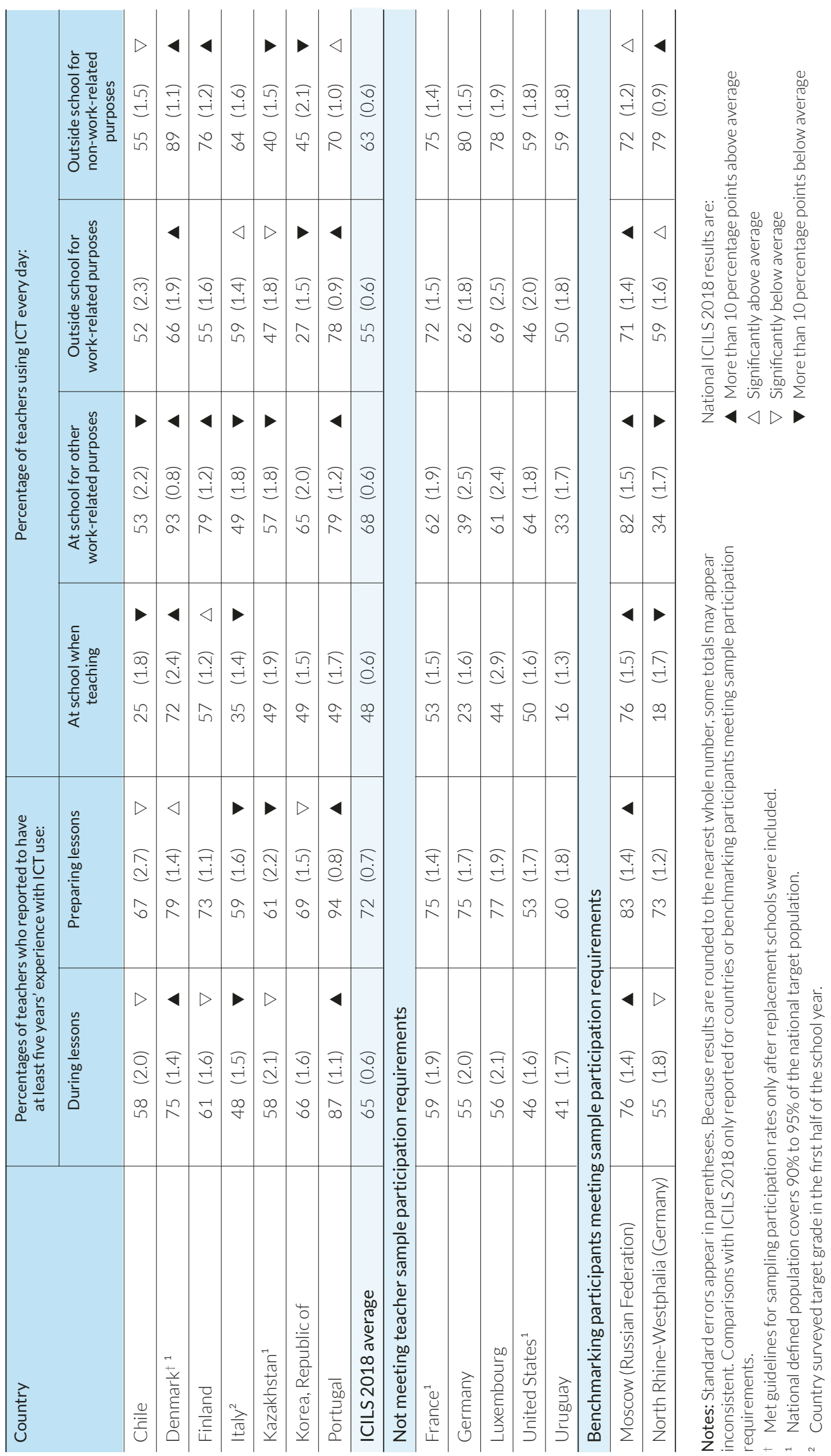




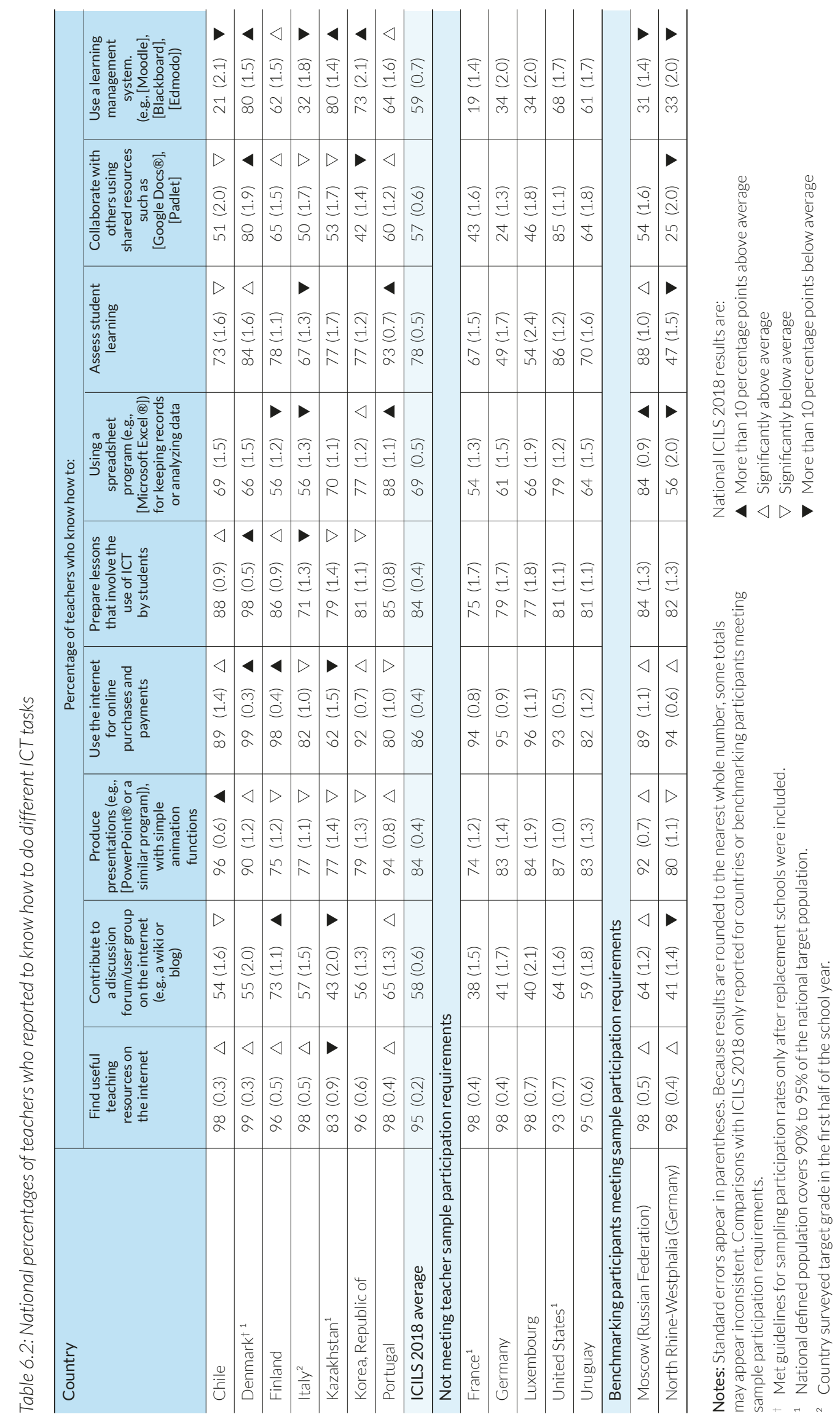


On average across countries, two thirds of teachers used ICT daily for other work-related purposes at school while less than half of the teachers reported daily use of ICT when teaching. The highest percentages of ICT for teaching were found among teachers in Denmark, Finland, and Moscow (Russian Federation), while the lowest percentages of this type of ICT use were recorded in Chile, Italy, and North Rhine-Westphalia (Germany). In most countries, more than half of the teachers reported daily use of ICT for work-related purposes at school; however, in the benchmarking participant North Rhine-Westphalia (Germany) we found very low percentages, with only every fifth teacher reporting use of ICT for these purposes.

Percentages of at least weekly ICT use for work-related purposes tended to be above 50 percent in most countries; however, among teachers in Korea only about a quarter fell into this category. Using ICT at least weekly for non-work-related purposes was reported by most teachers across countries; however, somewhat lower percentages were recorded in Kazakhstan and Korea.

\section{Teachers' ICT-related self-efficacy}

Bandura's (1997) concept of self-efficacy refers to individuals' belief in their capacities to organize and execute a course of action to obtain specific outcomes, which in turn influence their choices with regard to undertaking tasks, the efforts with which they conduct them, and their extent of perseveration. There is evidence that teachers' sense of self-efficacy regarding the use of ICT influences its use by teachers in the classroom (Fraillon et al. 2014; Hatlevik 2017; Hatlevik and Hatlevik 2018; Law et al. 2008; Nikolopolou and Gialamas 2016). ICILS 2018 asked teachers to rate how well they can do a range of different ICT tasks ("I know how to do this," "I haven't done this but I could find out how," "I do not think I could do this"). Results are presented as the percentages of teachers who reported to know how to do each of these tasks (Table 6.2).

On average across participating countries, we found that more than three quarters of teachers believed they knew how to "find useful teaching resources on the internet" (95\%), "produce presentations (e.g., [PowerPoint $\AA$ or a similar program]), with simple animation functions" (84\%), "use the internet for online purchases and payments" (86\%), "prepare lessons that involve the use of ICT by students" (86\%), and "assess student learning" (78\%). Somewhat more than two thirds expressed confidence in "using a spreadsheet program for keeping records or analyzing data" (69\%). We observed the lowest levels of confidence (somewhat more than half of the teachers) for "contributing to a discussion forum/user group on the internet (e.g., a wiki or blog)" (58\%), "collaborating with others using shared resources such as Google Docs $®$ or Padlet" (57\%), and "using a learning management system" (59\%). Notably lower levels of confidence were recorded in some individual countries, such as for the use of a learning management system in Chile (21\%) or collaboration with others using shared resources in North Rhine-Westphalia (Germany) (25\%).

All nine items were used to derive an IRT scale reflecting teachers ICT self-efficacy, where higher scales reflect higher levels of self-efficacy. The scale had satisfactory reliability (an average Cronbach's alpha of 0.80) across participating countries (Figure F.17 in Appendix F contains the corresponding item map showing how scale scores relate to item responses). The highest levels of teachers' ICT self-efficacy were observed in Denmark and Portugal, while teachers in Italy, Kazakhstan, and North Rhine-Westphalia (Germany) had the lowest levels of teacher selfefficacy (Table 6.3). 

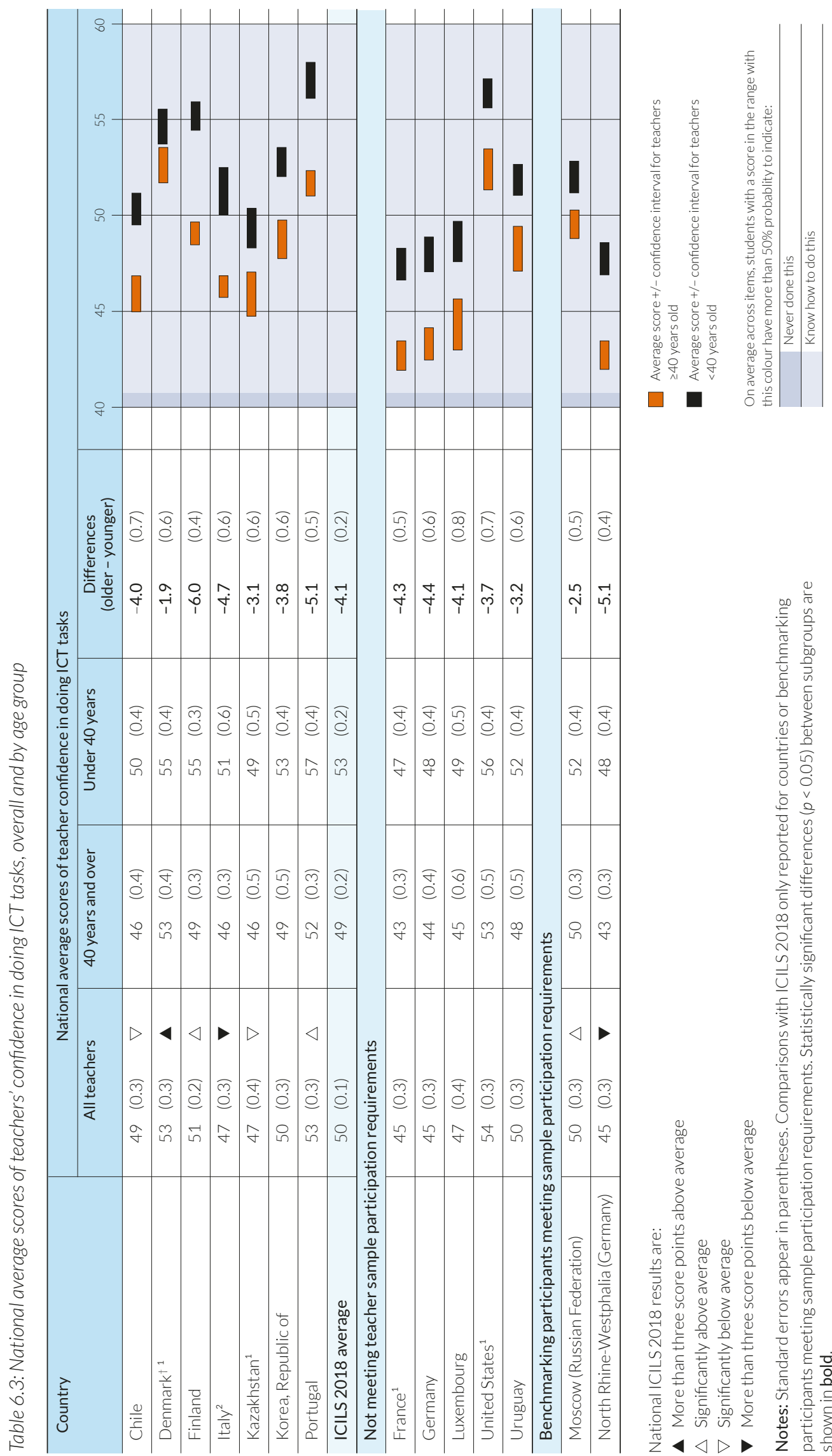
To review differences in ICT-related self-efficacy between younger and older teachers, we distinguished between teachers who were 40 years of age and older and those who were younger than 40 years at the time of the survey. In all participating ICILS 2018 countries we observed significantly higher scale scores for teachers who were younger than 40 years compared with those who were 40 years of age and older, with an average scale score difference of about four points (more than an international standard deviation), ranging from a two-point difference in Denmark to a six-point difference in Finland. These results confirm earlier findings (see, for example, Fraillon et al. 2014) about the association between age and teacher ICT-related selfefficacy, as well as illustrating notable differences in this association across countries.

\section{Teachers' views of ICT for teaching and learning}

Positive teacher attitudes toward the use of ICT for teaching and learning are regarded as important key factors for the implementation of digital technologies for teaching and learning at schools (Lawrence and Tar 2018; Tondeur et al. 2017). European survey data from 2011 illustrated that across the region teachers tended to express positive attitudes toward the use of ICT in the classroom (Wastiau et al. 2013) and ICILS 2013 data also revealed that across participating countries there was a widespread recognition of positive benefits from using ICT in teaching (Fraillon et al. 2014).

ICILS 2018 continued to gather teachers' views on using ICT for teaching and learning by asking them about their level of agreement or disagreement ("strongly agree," "agree," "disagree," or "strongly disagree") with a number of statements. Seven of these statements related to positive outcomes of using ICT in education that were helping with student learning, while another six statements referred to outcomes that reflected potential impediments of learning. Results are presented in the following two tables as percentages of teachers who agreed or strongly agreed with each of these statements.

Across participating countries, large majorities among teachers agreed with statements about positive outcomes of using ICT in teaching and learning (Table 6.4). The highest proportions of agreement (above 85\%) were recorded for the statements "helps students develop greater interest in learning," "enables students to access better sources of information," and "helps students to work at a level appropriate to their learning needs." The lowest proportions on average (below 75\%) were observed for the statements "improves academic performance of students" and "helps students develop skills in planning and self-regulation of their work." The remaining two statements ("helps students develop problem-solving skills" and "enables students to collaborate more effectively") were endorsed by almost 80 percent across countries.

When comparing results across countries, there was relatively little variation for the three items that on average had the highest levels of endorsement. However, the statement relating to the improvement of academic performance received varying levels of agreement by teachers across countries. While two thirds or more of teachers expressed agreement with this statement in Chile, Denmark, Kazakhstan, and Portugal, less than half of the teachers endorsed this notion in Finland and North Rhine-Westphalia (Germany).

On average across participating countries, only two of the statements about negative outcomes of using ICT in teaching and learning, expressing that ICT use results in "students copying material from internet sources" (71\%) and in "poorer written expression among students" (52\%), were endorsed by more than half of the teachers (Table 6.5). In most countries, less than a quarter of surveyed teachers endorsed the notion that using ICT "impedes concept formation by students;" however, this was seen as a problem by more than two thirds of teachers in Kazakhstan. Less than half of the teachers across ICILS 2018 countries agreed that ICT use "distracts students from learning" (37\%), "results in poorer calculation and estimation skills among students" (41\%), or "limits the amount of personal communication among students" (46\%). 


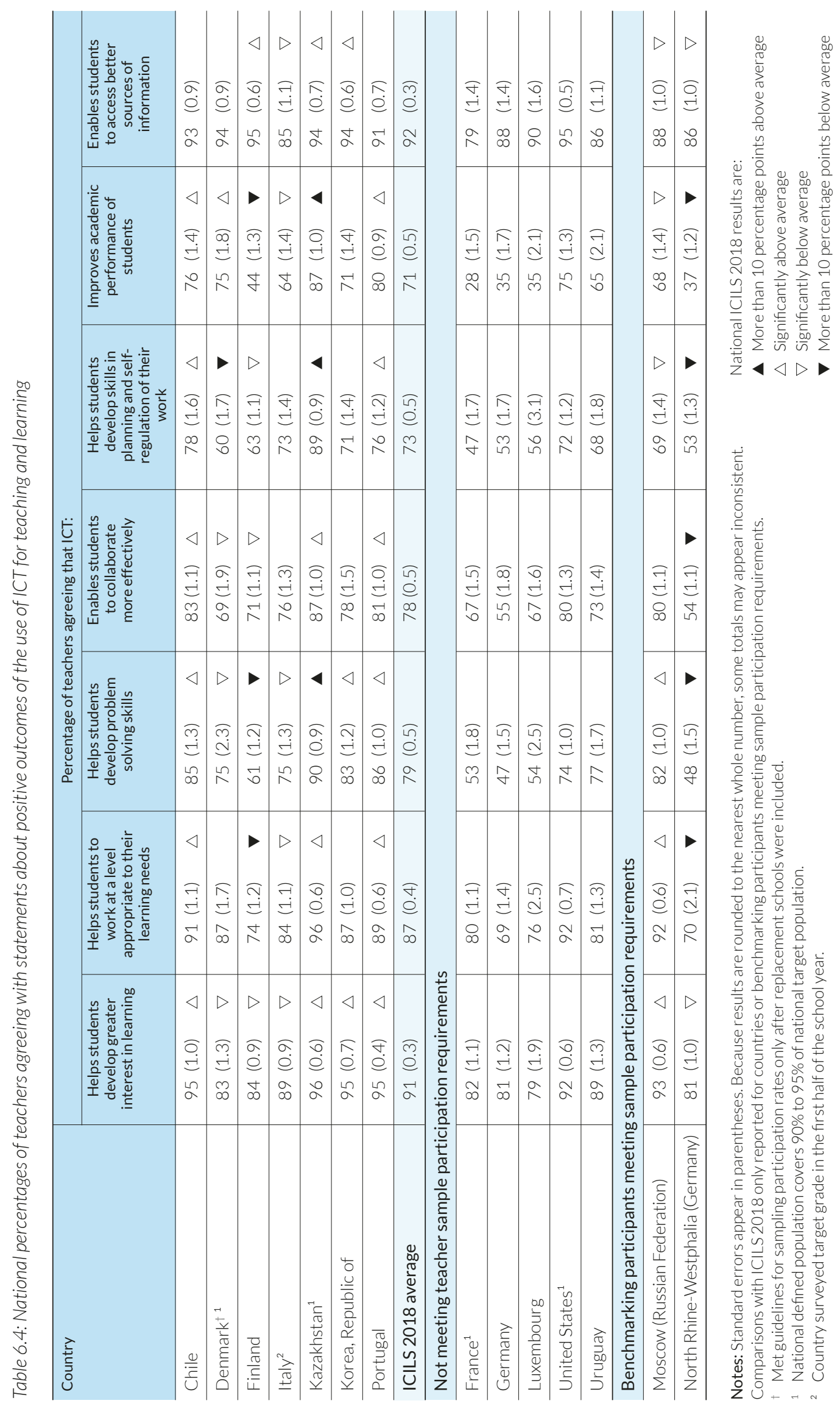




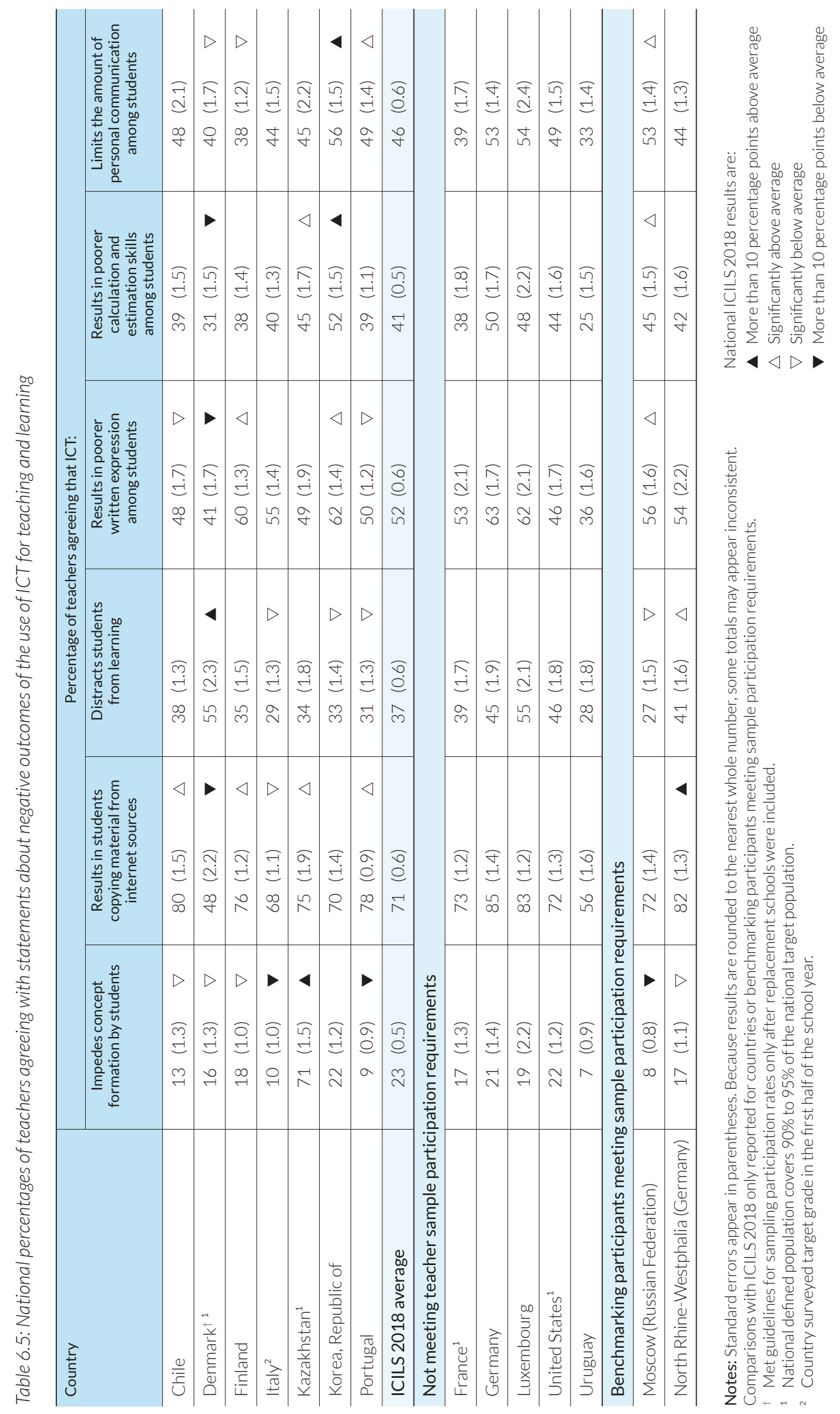


Across participating countries there was some notable variation in teachers' agreement with these statements about negative effects of using ICT. In Kazakhstan and Korea, relatively high levels of endorsement were recorded, while Danish teachers were least likely to agree with notions of negative outcomes. However, these patterns were also not entirely consistent; for example, more than half of the teachers in Denmark agreed that ICT use may distract students, while in most other countries lower proportions among teachers were of this view.

The items related to effects of ICT use for teaching and learning were used to derive two IRT scales, one indicating perceptions of positive outcomes when using ICT in teaching and learning (based on the seven items shown in Table 6.4) and the other reflecting perceptions of negative outcomes when using ICT in teaching and learning (based on the six items shown in Table 6.5). Both scales had satisfactory reliabilities (Cronbach alpha coefficients on average across ICILS 2018 countries were 0.84 and 0.80 respectively). Higher scale scores (set to a metric where 50 is the average ICILS 2018 scale score and 10 the standard deviation for the combined pooled data set) reflect higher levels of agreement with the respective statements used for measurement (see Figures F.18 and F.19 in Appendix F for item maps linking scales scores to expected item responses).

When comparing average scale scores for both scales across participating ICILS 2018 countries (Table 6.6), the results show that there is relatively more variation across countries for teachers' perceptions of positive outcomes than for teachers' perceptions of negative outcomes when using ICT for teaching and learning. The highest endorsements of positive outcomes when using ICT in teaching and learning were observed in Chile and Kazakhstan, while notably lower scores on this scale were recorded in Finland and North Rhine-Westphalia (Germany). For the scale measuring teachers' perceptions of negative outcomes when using ICT, the highest scores were found in Kazakhstan and the lowest scores in Denmark.

The correlation at the country level between average scale scores for these two scales was -0.29 , which demonstrates that there was no strong consistent pattern where countries with on average higher levels of recognition of positive outcomes also had teachers who tended to be less concerned about negative outcomes. However, the correlations within countries (see Table 6.6) show that teachers who agreed more with statements about positive consequences of ICT use were also more likely to disagree with those reflecting negative ones. On average, a moderate negative correlation (Pearson's r) of -0.36 was recorded, which was consistently negative in all participating countries except Kazakhstan, where we observed a weak (albeit statistically significant) positive correlation.

\section{Associations of teachers' use of digital technologies with their views of ICT}

ICILS 2013 results showed that teachers' views of ICT are associated with the extent to which they use it for teaching purposes (Fraillon et al. 2014, p. 210). To review the relationship between the two factors we compared average scale scores across two groups of teachers, those who used ICT for teaching on a daily basis and those who used ICT less frequently (Table 6.7).

The results show that teachers who reported a daily use of ICT for teaching had significantly higher scale scores for ICT self-efficacy and perceptions of positive outcomes when using ICT for teaching and learning. Correspondingly, daily users of ICT for teaching and learning were less likely to recognize negative consequences of using ICT. On average across participating countries, teachers who used ICT for teaching on a daily basis had scale scores of ICT self-efficacy that were four points higher than those in the comparison group (with differences ranging from two to more than five points). Differences between the two comparison groups for perceptions of positive outcomes of ICT use for teaching and learning were slightly smaller (about three points), with hardly any variation across countries. Daily users of ICT for teaching had, on average, about two points less on the scale measuring perceptions of negative outcomes when using ICT compared to other teachers (with differences varying across countries to a limited degree between one and three points). 


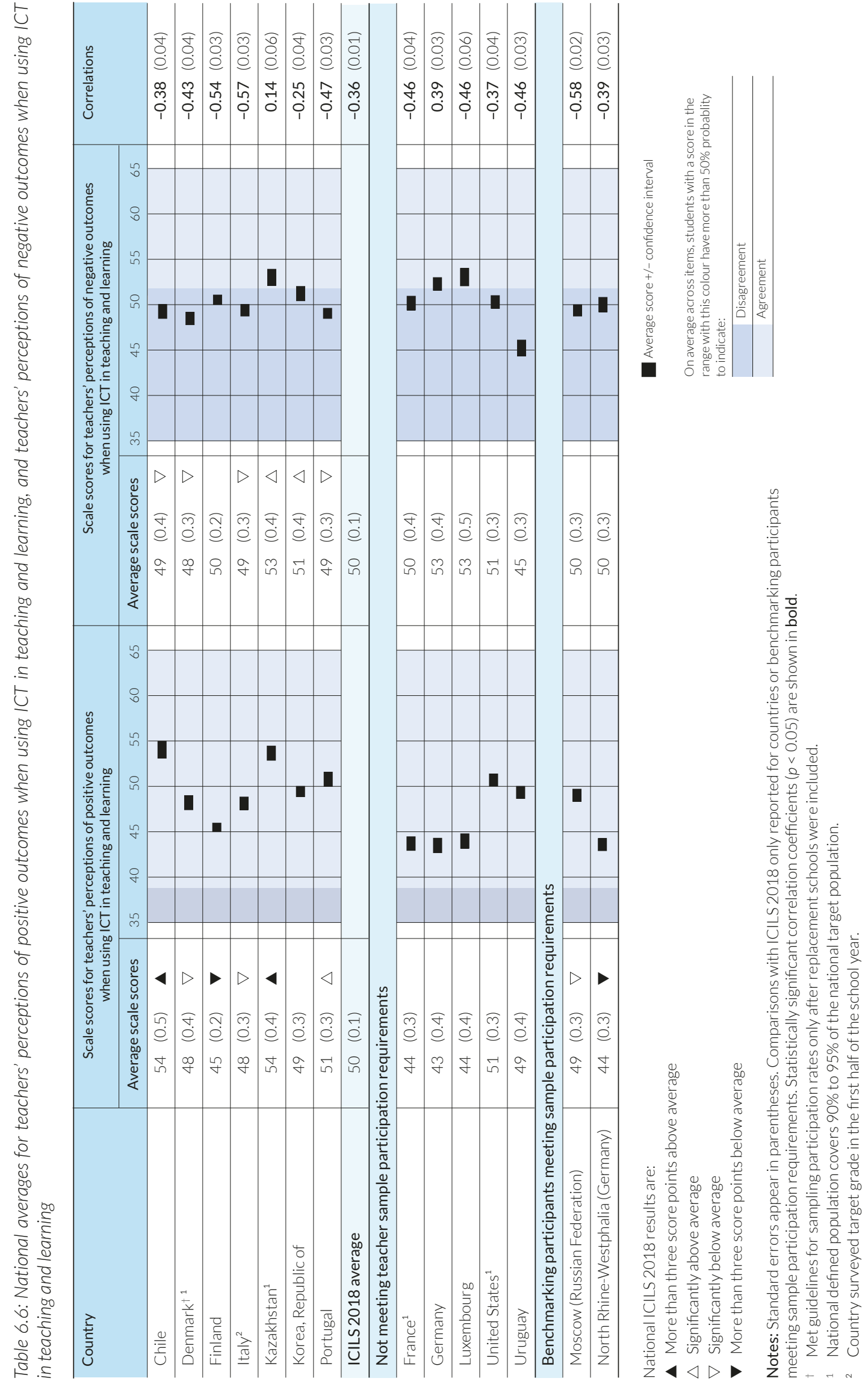




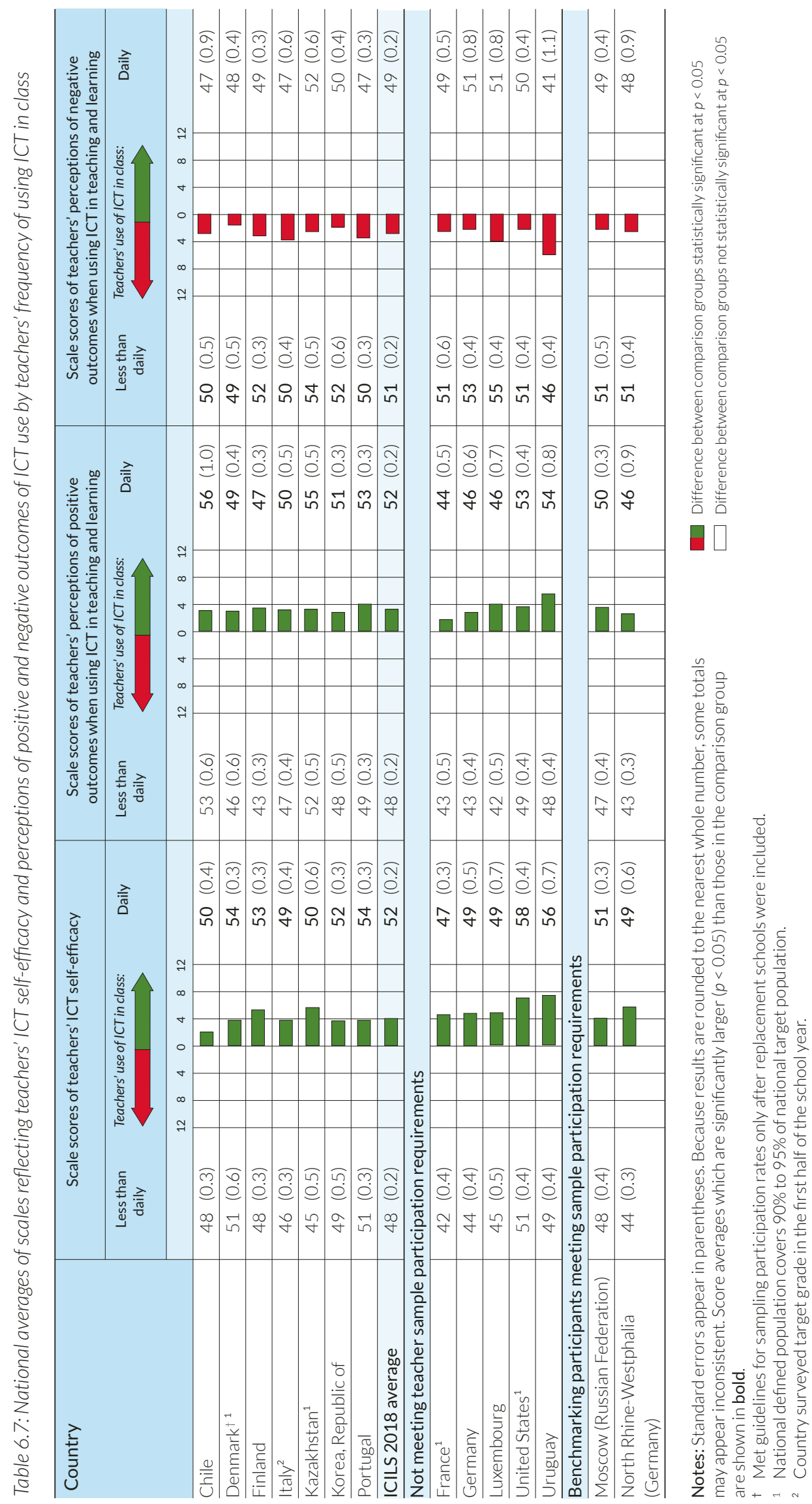




\section{Perceptions of schools' ICT learning environments}

\section{Perceptions of school resources for ICT use}

Research has suggested that school-level factors related to ICT resourcing and priorities influence both the way in which teachers use ICT for teaching and learning, and students' ICT-related learning (Fraillon et al. 2014; Gerick et al. 2017; Lawrence and Tar 2018). In this section, we will use data collected from teachers, school principals, and ICT coordinators to review perceptions of ICT learning environments at schools in participating ICILS 2018 countries.

School ICT coordinators were asked about the extent to which they perceived that the use of ICT for teaching was hindered by different factors ("a lot," "to some extent," "very little," or "not at all"). One group of factors related to the lack of computer resources at school, while the other group of factors related to pedagogical resources. The results were reported at the level of students: that is, in percentages of students who were enrolled at schools where each of the factors was reported as a hindrance to ICT use for teaching a lot or to some extent.

Across countries, almost half of students studied at schools where insufficient bandwidth or speed (48\%), not enough computers for instruction (48\%), and lack of sufficiently powerful computers (47\%) were reported as hindrances (Table 6.8). Slightly lower proportions of students were enrolled at schools with problems maintaining ICT equipment (44\%) and not having enough computer software (38\%), while on average less than a third of students studied at schools where having too few computers with internet connections was reported as a problem.

There was considerable variation across countries in the percentages of students at schools where insufficient computer resources were viewed as a problem. While in Denmark, Korea, and Luxembourg only few students were enrolled at schools where computer resources were reported as hindrances for using ICT for teaching, this was the case for substantially higher proportions of students in Germany, Italy, Portugal, and Uruguay.

Compared to the results for computer resource hindrances, we observed generally higher proportions of students at schools where the lack of pedagogical resources was seen as a hindrance to using ICT for teaching across participating countries (Table 6.9). Almost two thirds of students studied at schools where insufficient ICT skills among teachers (65\%) and insufficient time for teachers to prepare lessons (64\%) were viewed as hindrances for using ICT for teaching. On average, half or more of surveyed students were enrolled at schools where the lack of effective professional learning resources for teachers (59\%), lack of incentives for teachers to integrate ICT in their teaching (57\%), and insufficient pedagogic support for the use of ICT (50\%) were reported as problems. Across countries, lack of an effective online learning support platform at their schools affected the relatively lowest proportion of students (44\%).

Again, we observed substantial differences across participating countries. While in Denmark, Kazakhstan, Korea, and Moscow (Russian Federation) the proportions of students at schools with a reported lack of pedagogical resources tended to be smaller across the different factors, these percentages were higher in Finland, Germany, Portugal, and Uruguay. However, it should be noted that these patterns were not always consistent across the different factors. For example, in most countries there were high proportions of students studying at schools where insufficient ICT skills and insufficient time for preparing lessons were regarded as hindering ICT use for teaching and learning.

The teacher questionnaire collected data on teacher perceptions of ICT resources at their schools by asking them about their agreement or disagreement with a number of statements ("strongly agree," "agree," "disagree," or "strongly disagree"). Seven of these items (excepting the item "ICT is considered a priority for use in teaching") were used to derive an IRT scale reflecting teachers' perceptions of the availability of ICT resources at school. The scale had satisfactory reliability across 

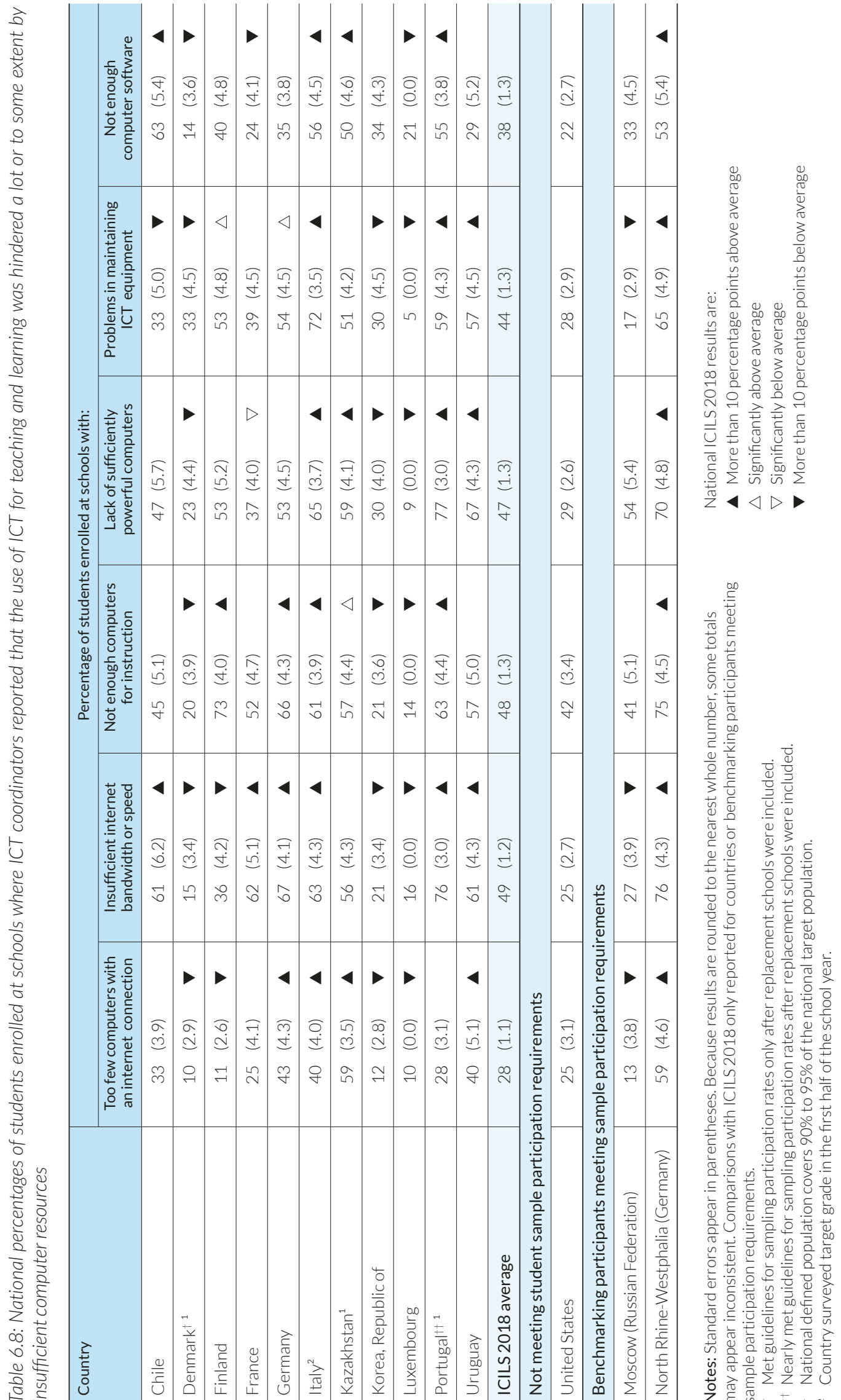


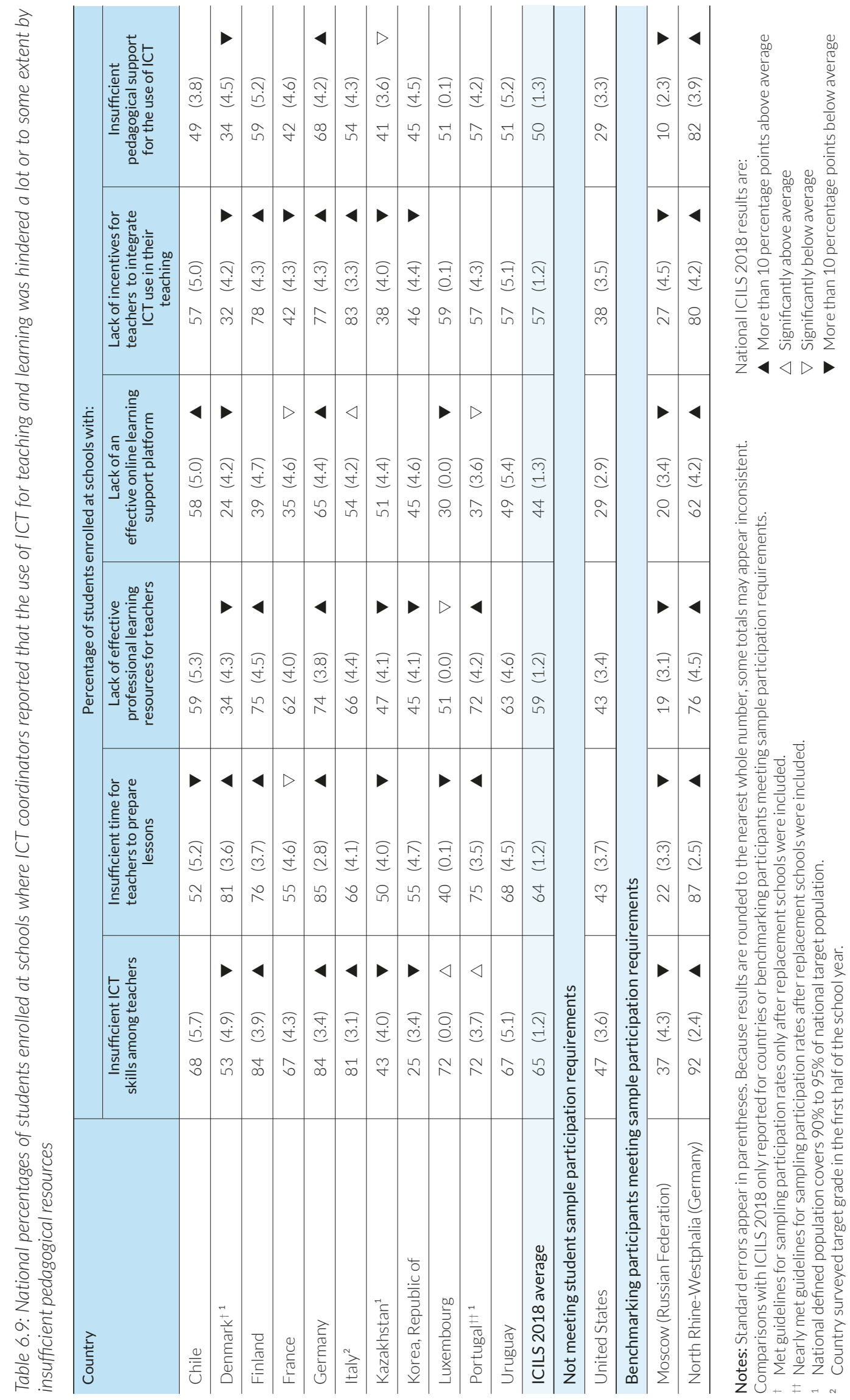


participating countries (Cronbach's alpha $=0.87$ ), and higher scores indicate perceptions of greater availability of ICT resources (see the corresponding item map in Figure F.2O in Appendix F linking scale scores to expected item responses).

The results at the item level show that typically more than 80 percent of teachers expressed agreement (incorporating "strongly agree" and "agree" responses) that ICT was considered a priority for use in teaching across participating countries, with somewhat lower proportions recorded in Italy (74\%) and considerably lower percentages found in North Rhine-Westphalia (Germany) (33\%) (Table 6.10). On average across participating countries, over half of the teachers also endorsed the statements that their school had sufficient ICT equipment (62\%), that their school's computer equipment was up-to-date (61\%), that their school had access to sufficient digital learning resources (59\%), that there was sufficient time to develop expertise in ICT (51\%), and that there was sufficient support to maintain ICT resources (55\%). Less than half of the teachers, on average across countries, agreed that there was enough time to prepare lessons incorporating ICT (41\%); however, there was some variation regarding this aspect, as two thirds or more of teachers in Kazakhstan and Moscow (Russian Federation) regarded time for this as sufficient.

Research has suggested that there are benefits of teacher collaboration with colleagues for the development of ICT self-efficacy and promoting the use of ICT for teaching purposes (see, for example, Caspersen and Raaen 2014; Drossel et al. 2017; Fraillon et al. 2014). ICILS 2018 asked teachers about their perceptions of whether and how ICT is used as part of collaborative teaching and learning at their school. ICILS 2018 asked teachers about their agreement or disagreement with five statements regarding collaboration among colleagues regarding the use of ICT ("strongly agree," "agree," "disagree," or "strongly disagree"). All five items were the basis for an IRT scale reflecting teachers' perceptions of the collaboration between teachers when using ICT. The scale had satisfactory reliability across participating countries (Cronbach's alpha $=0.86$ ) and higher scores indicate perceptions of greater collaboration between teachers (see the corresponding item map in Figure F.21 in Appendix F linking scale scores to expected item responses).

On average across participating countries, teachers tended to express agreement (incorporating "strongly agree" and "agree" responses) with statements regarding the collaborative use of ICT in teaching and learning at their schools (Table 6.11). About three-quarters agreed with the statements that they discussed with other teachers how to use ICT for teaching topics (75\%) and that they shared ICT-based resources with other school teachers (74\%). Furthermore, about two thirds of teachers agreed that they worked together with other teachers on improving the use of ICT in classrooms (65\%) and that they observed how other teachers used ICT in teaching (71\%). The lowest percentages of agreement were recorded for the statement regarding collaboration with colleagues to develop ICT-based lessons; however, in most countries more than half the teachers expressed agreement (61\% on average).

There were some notable differences across countries regarding agreement with the statements related to teacher collaboration. While in Kazakhstan and Moscow (Russian Federation) very large majorities (above $80 \%$ ) agreed with all of the statements, there were particularly low proportions of agreement in North Rhine-Westphalia (Germany) with the statements regarding working together with colleagues on improvements in the use of ICT in lessons (36\%) and collaboration to develop ICT-based sessions (30\%).

When comparing national average scale scores for teachers' perceptions of the availability of ICT resources at school and teachers' perceptions of collaboration between teachers when using ICT, we observed considerable variation across countries for both scales (Table 6.12). When looking at the distribution of national averages across countries, it becomes evident that in countries where teachers perceived greater levels of availability of ICT resources, there were also 


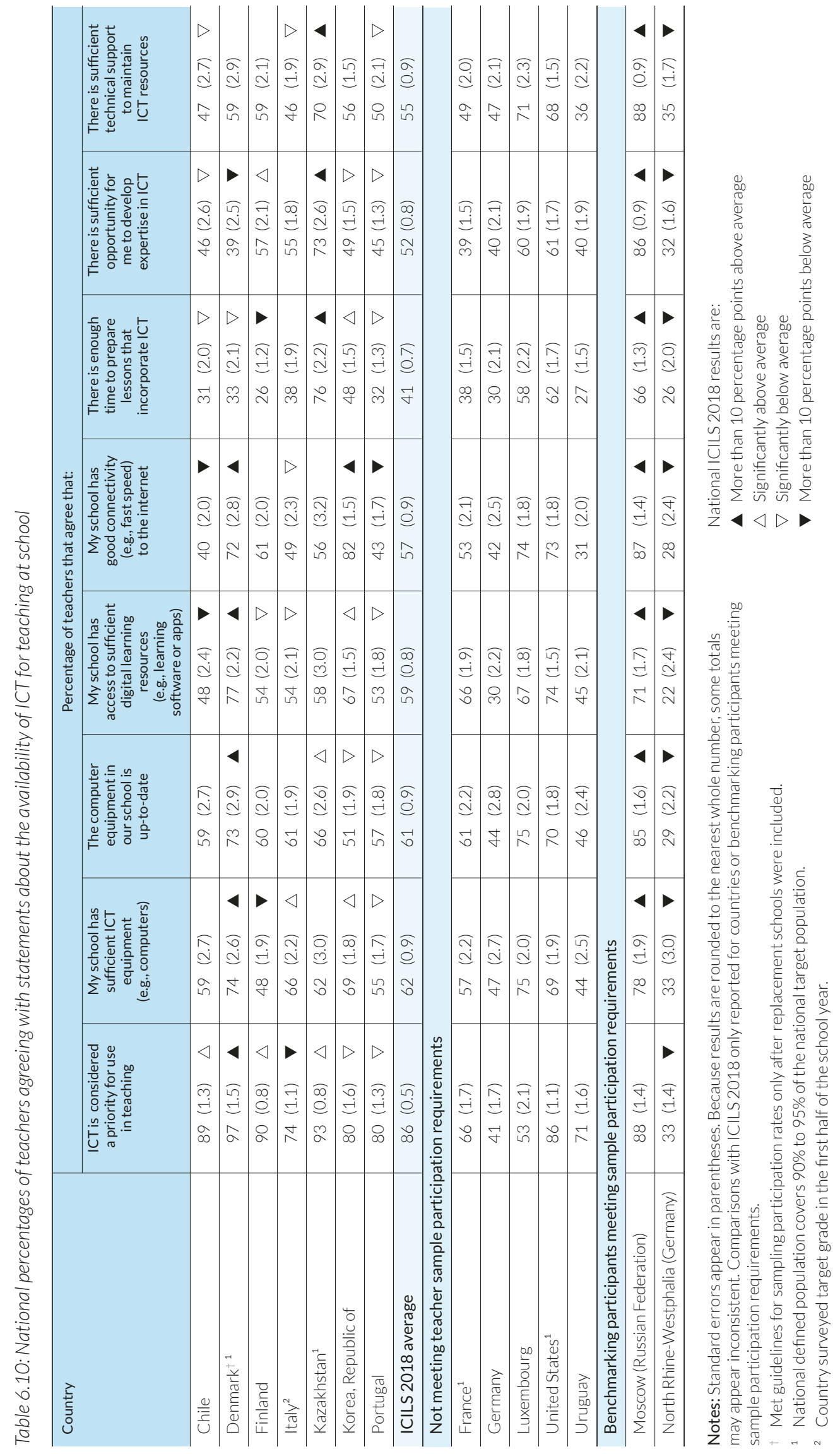


Table 6.11: National percentages of teachers agreeing with statements about the collaborative use of ICT in teaching and learning

\begin{tabular}{|c|c|c|c|c|c|c|c|c|c|c|c|}
\hline \multirow{3}{*}{$\begin{array}{l}\text { Country } \\
\text { Chile }\end{array}$} & \multicolumn{11}{|c|}{ Percentage of teachers that agree that: } \\
\hline & \multicolumn{2}{|c|}{$\begin{array}{l}\text { I work together with } \\
\text { other teachers on } \\
\text { improving the use of } \\
\text { ICT in classroom } \\
\text { teaching }\end{array}$} & \multicolumn{2}{|c|}{$\begin{array}{l}\text { I collaborate with } \\
\text { colleagues to } \\
\text { develop ICT-based } \\
\text { lessons }\end{array}$} & \multicolumn{3}{|c|}{$\begin{array}{l}\text { I observe how } \\
\text { other teachers } \\
\text { use ICT in teaching }\end{array}$} & \multicolumn{2}{|c|}{$\begin{array}{l}\text { I discuss with } \\
\text { other teachers } \\
\text { how to use ICT } \\
\text { in teaching topics }\end{array}$} & \multicolumn{2}{|c|}{$\begin{array}{l}\text { I share ICT-based } \\
\text { resources with } \\
\text { other teachers in } \\
\text { in my school }\end{array}$} \\
\hline & $57(1.9)$ & $\nabla$ & $59(1.8)$ & & & $(1.2)$ & $\nabla$ & $62(1.5)$ & $\nabla$ & $69(1.4)$ & $\nabla$ \\
\hline Denmark $^{\dagger 1}$ & $63(2.2)$ & & $57(2.0)$ & $\nabla$ & 57 & (1.9) & $\nabla$ & $75(1.5)$ & & $79(1.4)$ & $\triangle$ \\
\hline Finland & $68(1.1)$ & $\triangle$ & $56(1.4)$ & $\nabla$ & 75 & $(1.2)$ & $\triangle$ & $78(1.0)$ & $\triangle$ & $56(1.0)$ & $\boldsymbol{\nabla}$ \\
\hline Italy ${ }^{2}$ & $68 \quad(1.4)$ & & 59 (1.8) & & 74 & $(1.3)$ & $\triangle$ & $80(1.5)$ & $\triangle$ & $73(1.5)$ & \\
\hline Kazakhstan $^{1}$ & $94(0.9)$ & $\Delta$ & $93(0.7)$ & $\Delta$ & 90 & (1.2) & $\Delta$ & $93(0.8)$ & $\Delta$ & $93(0.9)$ & $\boldsymbol{\Delta}$ \\
\hline Korea, Republic of & $50 \quad(1.6)$ & $\nabla$ & 51 (1.9) & $\nabla$ & 69 & $(1.3)$ & $\nabla$ & $65(1.4)$ & $\nabla$ & $66(1.5)$ & $\nabla$ \\
\hline Portugal & $55 \quad(1.3)$ & $\nabla$ & $55(1.3)$ & $\nabla$ & 67 & (1.3) & $\nabla$ & $74(1.2)$ & & $82(1.0)$ & $\triangle$ \\
\hline ICILS 2018 average & $65(0.6)$ & & $61(0.6)$ & & 71 & $(0.5)$ & & $75(0.5)$ & & $74(0.5)$ & \\
\hline \multicolumn{12}{|c|}{ Not meeting teacher sample participation requirements } \\
\hline France $^{1}$ & $55(1.7)$ & & $44(1.6)$ & & 58 & $(1.4)$ & & $82(1.1)$ & & $64(1.6)$ & \\
\hline Germany & $38(1.8)$ & & $33(1.8)$ & & 54 & $(2.3)$ & & $58(2.0)$ & & $54(2.1)$ & \\
\hline Luxembourg & $47(2.1)$ & & $39(2.1)$ & & 67 & $(2.1)$ & & $81(2.0)$ & & $70(1.9)$ & \\
\hline United States ${ }^{1}$ & $66(1.5)$ & & $59(1.8)$ & & 63 & $(1.5)$ & & $75(1.2)$ & & $74(1.3)$ & \\
\hline Uruguay & $70(1.2)$ & & $67(1.4)$ & & 79 & $(1.4)$ & & $86(1.0)$ & & $78(1.2)$ & \\
\hline \multicolumn{12}{|c|}{ Benchmarking participants meeting sample participation requirements } \\
\hline Moscow (Russian Federation) & $82(1.3)$ & $\Delta$ & $80(1.4)$ & $\Delta$ & 91 & $(0.8)$ & $\Delta$ & $95(0.5)$ & $\Delta$ & $87(0.8)$ & $\boldsymbol{\Delta}$ \\
\hline North Rhine-Westphalia (Germany) & $36(2.4)$ & $\boldsymbol{\nabla}$ & $30(2.0)$ & $\nabla$ & 57 & $(2.0)$ & $\nabla$ & $67(1.7)$ & $\nabla$ & $61(1.9)$ & $\boldsymbol{\nabla}$ \\
\hline
\end{tabular}

Notes: Standard errors appear in parentheses. Because results are rounded to the nearest whole number, some totals may appear inconsistent. Comparisons with ICILS 2018 only reported for countries or benchmarking participants meeting sample participation requirements.

+ Met guidelines for sampling participation rates only after replacement schools were included.

1 National defined population covers $90 \%$ to $95 \%$ of the national target population.

2 Country surveyed target grade in the first half of the school year.
National ICILS 2018 results are:

- More than 10 percentage points above average

$\triangle$ Significantly above average

$\nabla$ Significantly below average

$\boldsymbol{\nabla}$ More than 10 percentage points below average

teacher perceptions of greater collaboration between colleagues on the use of ICT at schools. The country-level correlation between national average scores on these two scales was 0.65. The correlation coefficients within countries (accompanied by their respective standard errors) indicate that teachers who perceived greater availability of ICT at their schools also tended to perceive higher levels of teacher collaboration. The average correlation coefficient across countries was 0.36, ranging from 0.24 (in Finland) to 0.53 (in Moscow, Russian Federation), and the associations were statistically significant in all countries.

The highest teacher perceptions scale scores regarding the availability of ICT resources at school were recorded in Denmark, Kazakhstan, and Moscow (Russian Federation), while the lowest average was observed in North Rhine-Westphalia (Germany). For perceptions of teacher collaboration, we found the highest averages in Kazakhstan and Moscow (Russian Federation) and the lowest average again in the German benchmarking participant North Rhine-Westphalia.

Earlier, and in line with findings from the previous ICILS cycle in 2013 (Fraillon et al. 2014), we found evidence for an association between teachers' daily use of ICT for teaching and their views regarding this technology. In order to review the extent to which perceptions of ICT availability and collaboration were related to the frequency of teachers' use of ICT, we compared scale score averages between teachers who reported daily use of ICT for teaching with those teachers who reported less frequent use (Table 6.13). 


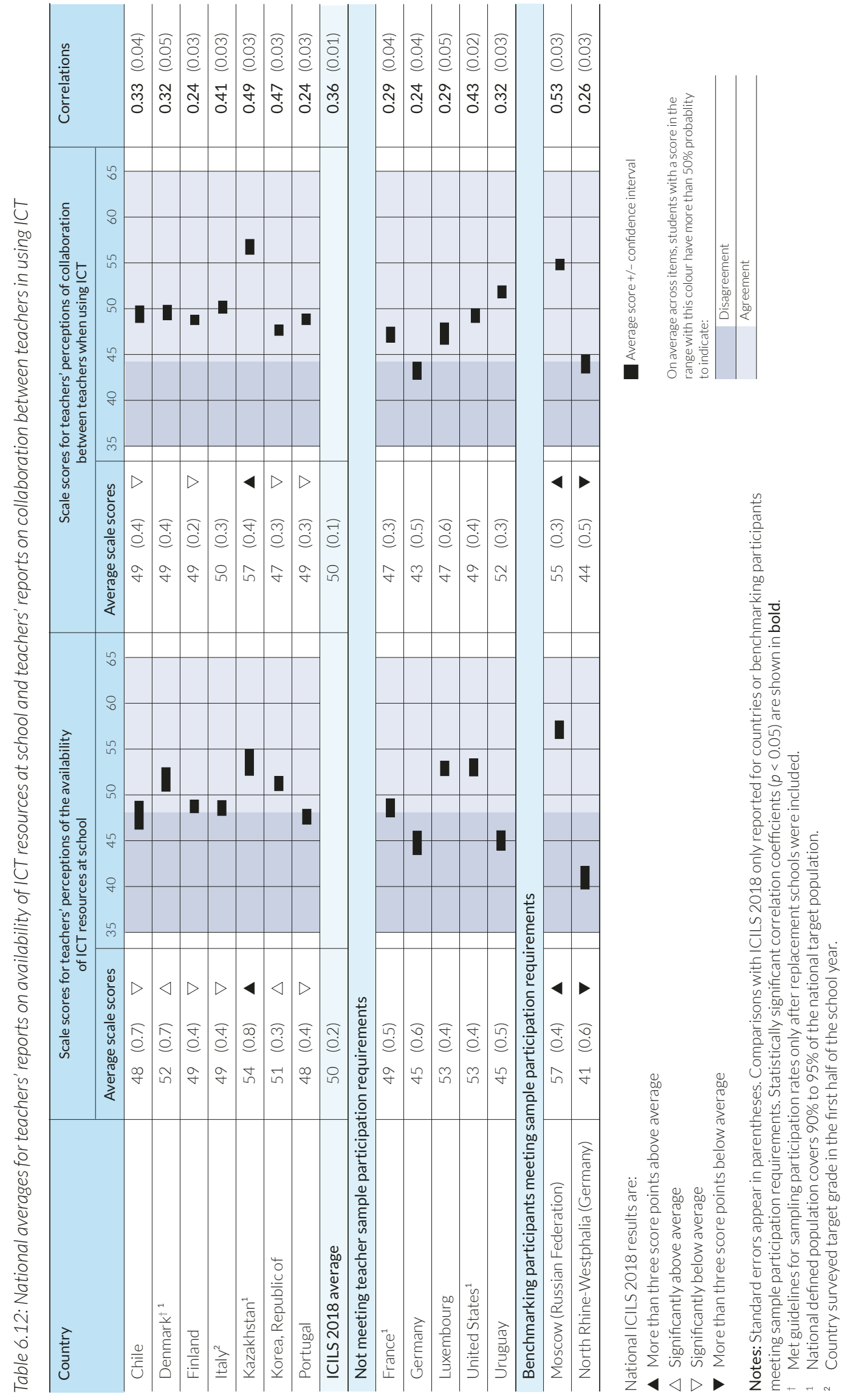




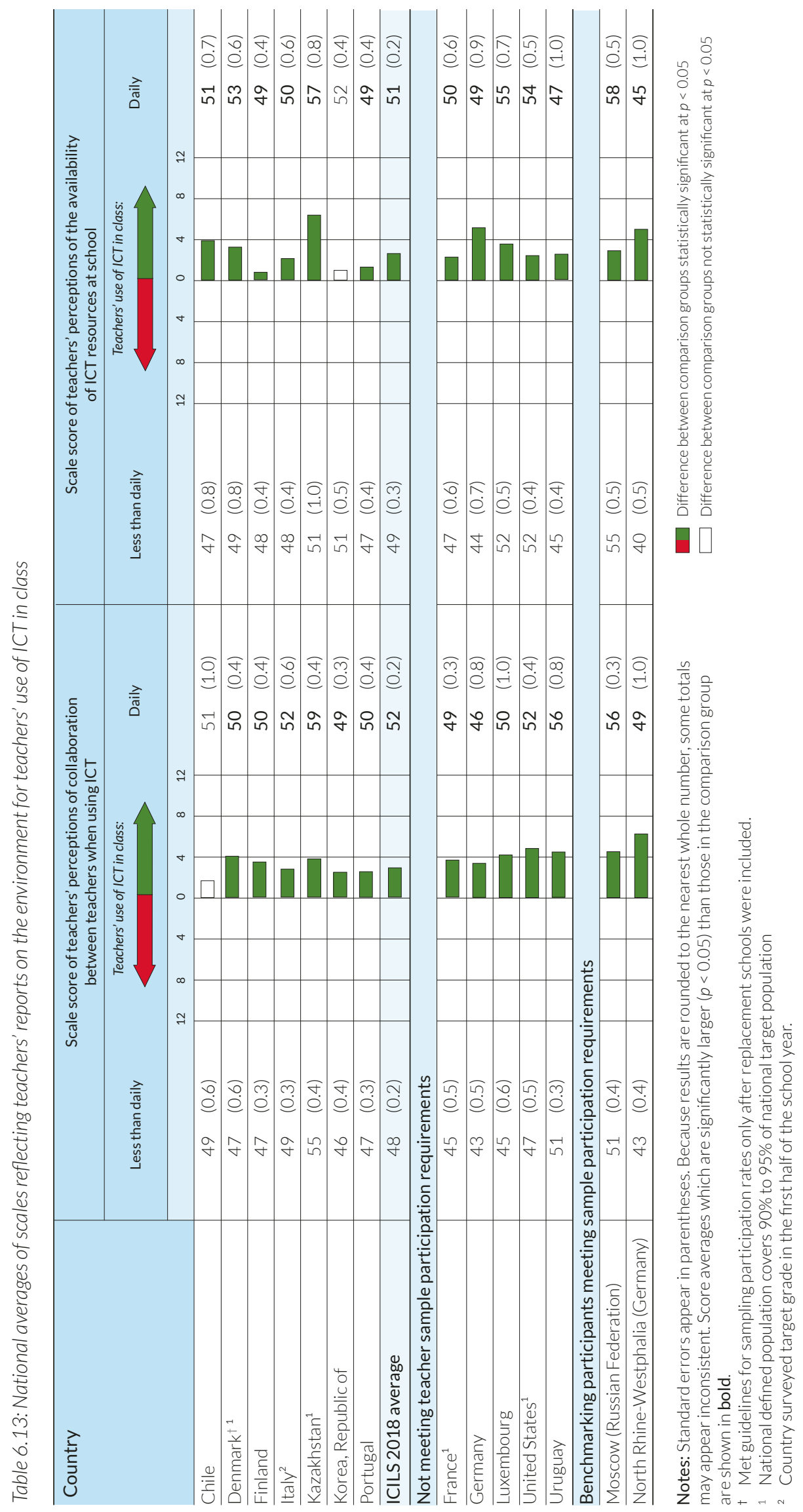


The results demonstrate that across participating countries teachers who used ICT on a daily basis for teaching tended to have more positive views of the availability of ICT resources as well as of the extent of collaboration between teachers. In most countries the scale score differences were statistically significant, except for in Chile regarding the availability of ICT resources at school and in Korea regarding teacher collaboration when using ICT. Differences between the comparison groups were on average more than three score points for teachers' perceptions of ICT availability, with the largest difference recorded for North Rhine-Westphalia (Germany). Teachers who used ICT on a daily basis were also more likely to perceive higher levels of teacher collaboration regarding ICT: the average score point difference was almost three points, with the largest differences (above five points) recorded in Kazakhstan and North Rhine-Westphalia (Germany).

These data suggest that there were differences in the perceptions of ICT resources and teacher collaboration depending on how often teachers use ICT in class. Readers should note that these bivariate associations do not indicate any clear causality. While it is possible that teachers less concerned with (and perhaps less knowledgeable of) ICT use tend to perceive ICT environments as less favorable, it is also possible that the association is rather explained by the enablement of teachers' use of ICT through higher levels of resources and collaboration with colleagues.

\section{Perceptions of professional development for pedagogical ICT use}

The development of teacher expertise in ICT-related teaching and learning has been identified as an important variable in enabling teachers' use of ICT and the teaching and learning of ICT-related skills (Charalambos and Glass 2007; Law et al. 2008; Lawrence and Tar 2018; Scherer and Siddiq 2015). The ICILS 2018 school principal questionnaire asked about schools' expectations and requirements of teachers' acquisition of knowledge with regard to a wider range of ICT-based activities. Principals rated the expectation of teachers' acquisition of knowledge to undertake a range of ICT-based activities as "expected and required," "expected but not required," or "not expected." The results are presented as the percentages of students who study at schools where principals reported each of the professional development activities as both expected and required.

The results show very large differences across participating countries (Table 6.14). While in Kazakhstan and Moscow (Russian Federation) for all activities, and in Denmark for most activities, there were majorities of students who studied at schools where these were required, in most countries only relatively few students were enrolled at institutions where teachers were expected and required to have the corresponding knowledge for these ICT-related activities. For the requirement of integrating ICT into teaching and learning we found the highest proportions of students at schools where this was the case (52\% on average). Few students across countries were enrolled at schools where teachers were expected and required to acquire knowledge about the use of e-portfolios for assessment (17\%) or about the use of ICT for developing authentic assignments for students (18\%).

The ICILS 2018 teacher questionnaire included a question regarding the respondents' participation in a range of different professional learning activities related to ICT over the past two years, where respondents were asked to state whether they had done each of these "not at all," "once only," or "more than once." The results are presented as percentages of teachers who reported having participated at least once in these activities (i.e., combining percentages in the last two response categories).

On average across countries, more than half of the surveyed teachers reported having participated at least once over the past two years in a course on ICT applications (51\%), observed other teachers using ICT in teaching (59\%), and shared digital teaching and learning resources in a digital workspace with others (57\%) (Table 6.15). While half of the teachers reported having received training in subject-specific digital teaching and learning resources, less than half of 


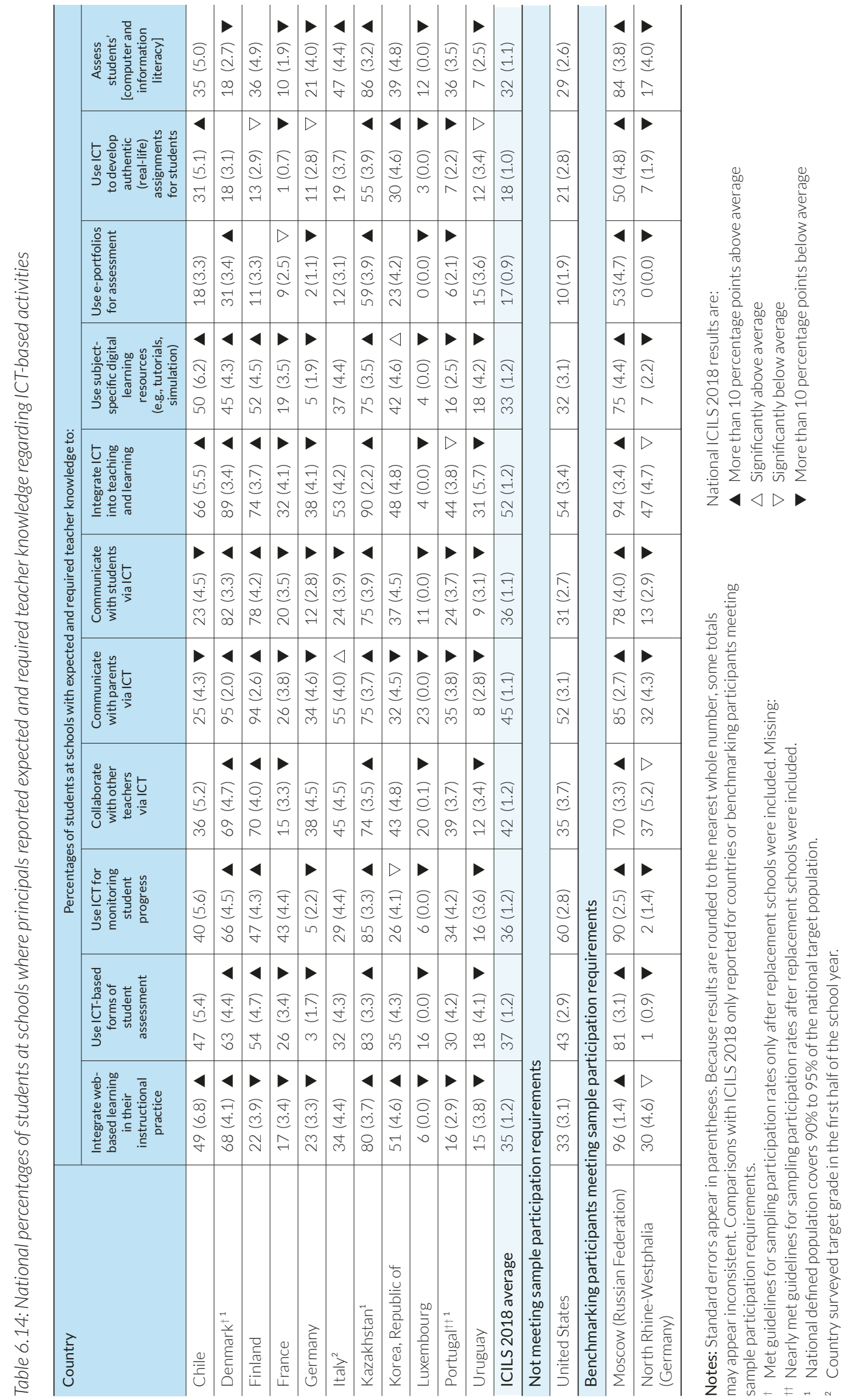




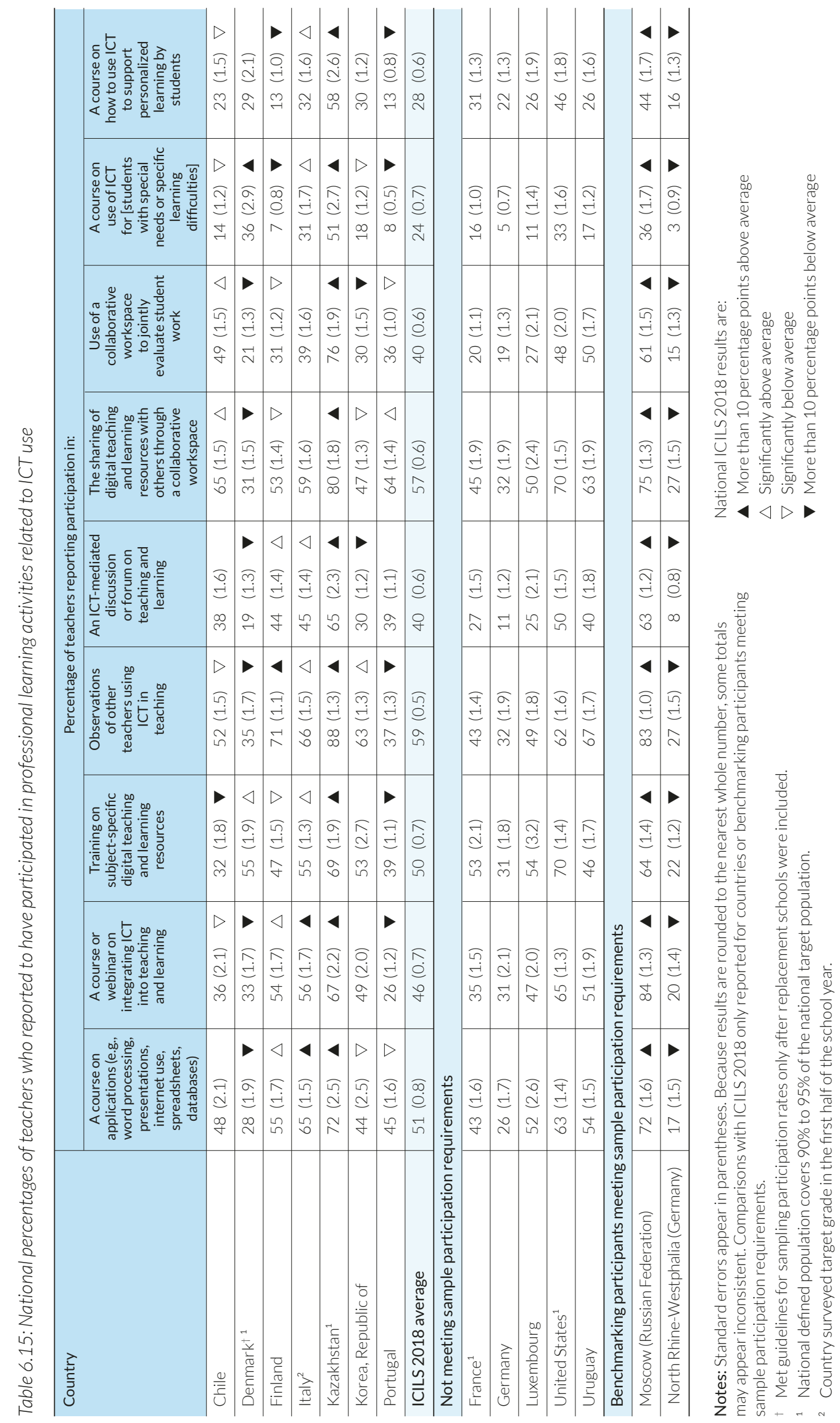


them reported participation in courses or webinars on integrating ICT into teaching and learning (46\%), in ICT-mediated discussions or fora on teaching and learning (40\%), or in collaborative workspaces to jointly evaluate student work. Less than a third of teachers on average across countries reported participation in courses on the use of ICT for students with special needs or specific learning difficulties (24\%) and in courses on how to use ICT to support personalized learning of students (28\%).

There were notable variations across participating countries and benchmarking entities. While relatively high percentages among teachers in Italy, Kazakhstan, and Moscow (Russian Federation) tended to report participation in these activities, these proportions were notably smaller in Denmark, Portugal, and, in particular, in North Rhine-Westphalia (Germany). It is noteworthy that some of the countries where teachers reported low participation in professional learning activities, there were also reports of high levels of ICT use and self-efficacy, while some of those with high levels of participation were characterized by relatively lower levels of ICT use and self-efficacy. However, this finding is consistent with an interpretation that suggests that in countries with low levels of ICT use more professional learning is offered so as to support and encourage further ICT use. In countries where there are already high levels of ICT use there may be less perceived need to provide professional learning to support its use.

\section{Teacher emphasis on learning CIL and CT}

\section{Teachers' emphasis on developing CIL-related skills}

While teachers' self-efficacy, their perceptions of, and their attitudes toward the use of ICT have been highlighted as important factors influencing the implementation of digital learning at school (Lawrence and Tar 2018; Tondeur et al. 2017), it is also important to consider the extent to which teachers place emphasis on the teaching of digital skills during class (Siddiq et al. 2016). Results from ICILS 2013 showed that across participating countries there were relatively high levels of teachers who reported to emphasize CIL-related skills in their teaching, and that the extent of this emphasis was related to their sense of ICT self-efficacy, views of the use of ICT in class, and perceptions of teacher collaboration regarding ICT use at school (Fraillon et al. 2014).

To capture the emphasis on developing CIL/CT, ICILS 2018 asked teachers to answer a question with regard to the specific reference class at the target grade, which they had identified prior to the question (see introduction to this chapter).

Teachers were asked about the emphasis they gave in their reference class to developing nine different ICT-based capabilities in their students ("strong emphasis," "some emphasis," "little emphasis," or "no emphasis"):

(a) to access information efficiently (85\% on average across countries reported some or strong emphasis)

(b) to display information for a given audience/purpose (78\%)

(c) to evaluate the credibility of digital information (74\%)

(d) to share digital information with others (71\%)

(e) to use computer software to construct digital work products (e.g., presentations, documents, images, and diagrams) (76\%)

(f) to provide digital feedback on the work of others (such as classmates) (49\%)

(g) to explore a range of digital resources when searching for information (75\%)

(h) to provide references for digital information sources (67\%)

(i) to understand the consequences of making information publicly available online (67\%). 
Across countries most teachers reported some or strong emphasis in their teaching on these capabilities. All nine items were used to derive an IRT scale reflecting teachers' emphasis on developing ICT-based capabilities in class. The scale has satisfactory reliabilities across countries (Cronbach's alpha $=0.90$ ) and items were scored so that higher scale scores indicated stronger emphasis on the development of ICT-related capabilities (see the corresponding item map in Figure F.22 in Appendix F).

The highest levels of teacher emphasis were recorded in Italy and Kazakhstan, while teachers in Finland and, in particular, in North Rhine-Westphalia (Germany) reported lower levels of emphasis (Table 6.16). When comparing teacher emphasis across different subject areas, ${ }^{24}$ not surprisingly the highest average scores (across countries) were reported by teachers referring to ICT-related classes (i.e., subjects that focus on teaching ICT-related skills). We also observed relatively high scores with regard to test language and human sciences classes. The lowest scores of teacher emphasis were observed for mathematics and classes related to other subjects such as vocational, moral/ethics, and physical education. These findings are broadly consistent with those from ICILS 2013 (Fraillon et al. 2014).

To assess the associations of teacher emphasis with other ICT-related perceptions, we estimated linear multiple regression models to explain variance in teacher emphasis on teaching ICT-based skills. We used the following scales as predictors in this model: teachers' self-efficacy, teachers' positive views of using ICT for teaching and learning, teachers' reports on collaboration between teachers when using ICT, and teachers' reports on the availability of ICT resources at school. Furthermore, we included teachers' reported experience with the use of ICT during lessons as an additional predictor variable.

All predictor variables were nationally standardized to having national average scores of zero and standard deviations of one. Therefore, the unstandardized regression coefficients (Table 6.17) indicate changes in teacher emphasis scores corresponding to an increase in one national standard deviation in each of the predictor variables after controlling for the effects of all other variables in the model. For teachers' experience with pedagogical use of ICT, we coded the responses so that regression coefficients indicate the change in scale scores with (approximately) one year of further experience. ${ }^{25}$

Both teachers' ICT self-efficacy and teachers' reports on ICT-related collaboration between teachers were statistically significant and consistent predictors of teacher emphasis in developing CIL in all countries. With one national standard deviation on the ICT self-efficacy scale, there was (on average across participating countries) an associated increase of over two score points in teacher emphasis in developing CIL (equivalent to approximately one fifth of a standard deviation). An increase of one national standard deviation in the teacher collaboration scale was (on average) associated with more than two score points increase.

Teachers' positive views of the use of ICT for teaching and learning were also positively and significantly associated with their emphasis on students' learning of ICT in all countries; on average, one national standard deviation was associated with an increase of almost two score points. The scale scores reflecting teachers' reports of the availability of ICT resources at school were not consistently associated with teacher emphasis on developing CIL; we found statistically significant coefficients only in Chile and Kazakhstan. Teachers' experience with the use of ICT during lessons was consistently positively associated with their emphasis on learning CIL-related skills. On average across countries, one more year of experience was approximately associated with an increase of about one score point.

24 In some countries, the number of teachers in subject-area subgroups were too small (below 30) to report estimates.

25 The response categories were coded as follows: "never" = 0, "less than two years" = 1, "between two and five years" $=3$, and "more than five years" $=5$. 


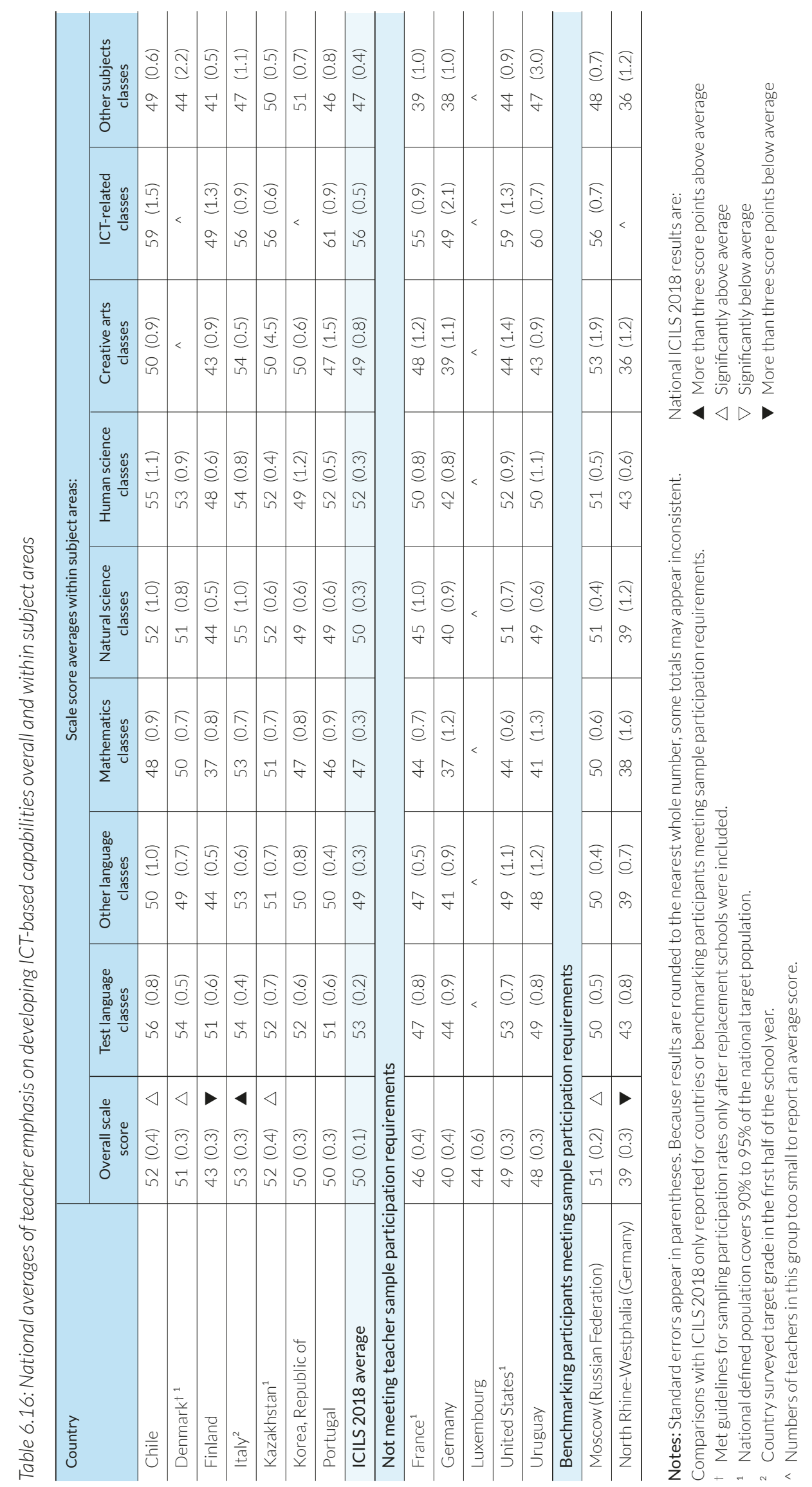




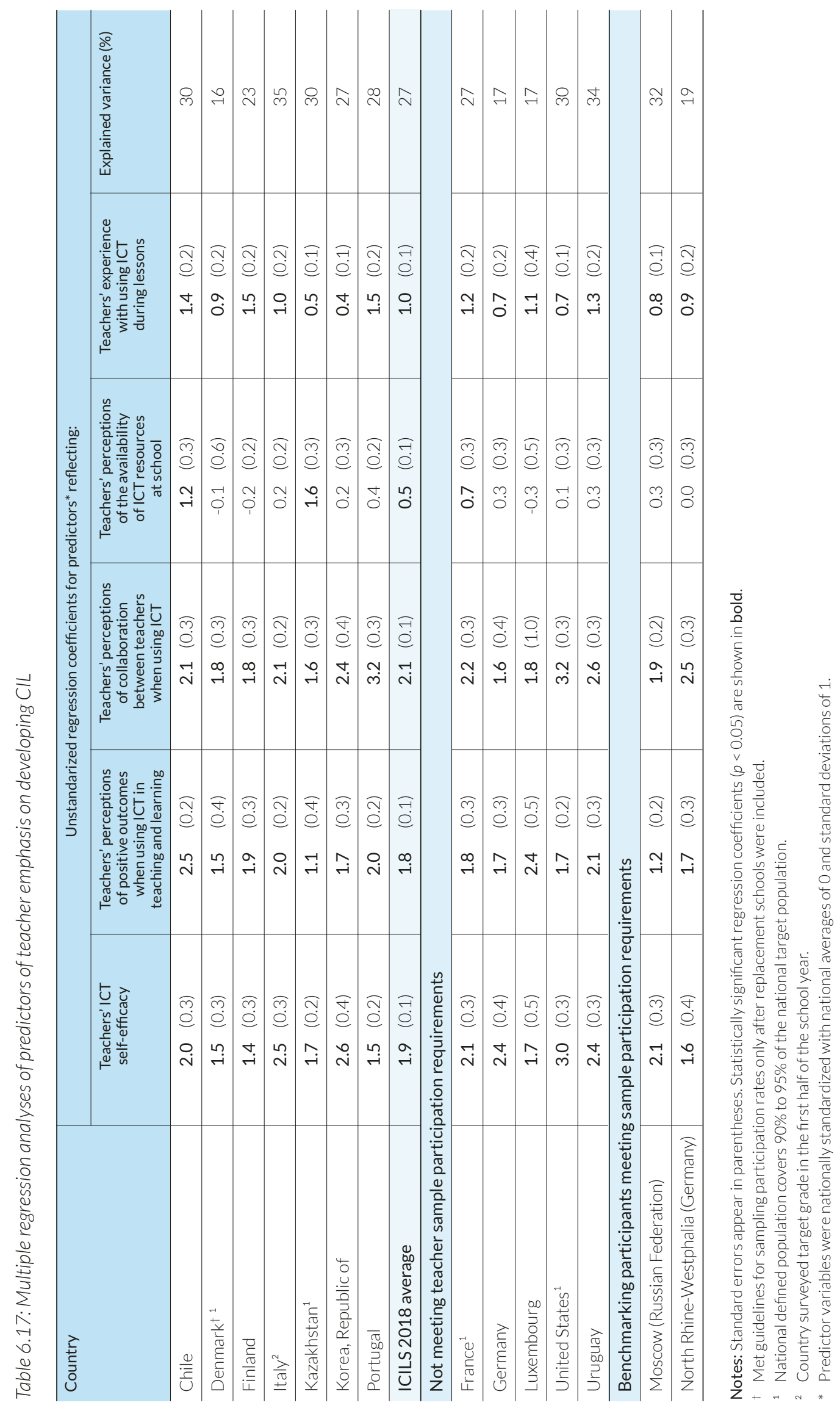


On average across participating countries, the regression model explained 27 percent of the variance in teachers' emphasis scores, ranging from 16 percent in Denmark to 35 percent in Italy. However, readers should be cautious about drawing any conclusions about causality from these analyses, as the cross-sectional design does not allow any causal interpretation. For example, it is possible that perceptions of teacher collaborations are also influenced by the teachers' own emphasis on teaching ICT-related skills, which leads to the need for more communication on how to achieve this.

\section{Teachers' emphasis on developing CT-related skills}

In recognition of the optional assessment of CT as part of ICILS 2018, the teacher questionnaire also included a question about how much emphasis teachers placed on teaching the following CT-related skills ("strong emphasis," "some emphasis," "little emphasis," or "no emphasis"):

(a) to display information in different ways (on average across countries $84 \%$ placed some or strong emphasis on this skill)

(b) to break a complex process into smaller parts (77\%)

(c) to understand diagrams that describe or show real-world problems (65\%)

(d) to plan tasks by setting out the steps needed to complete them (76\%)

(e) to use tools making diagrams that help solve problems (48\%)

(f) to use simulations to help understand or solve real-world problems (48\%)

(g) to make flow diagrams to show the different parts of a process (36\%)

(h) to record and evaluate data to understand and solve a problem (62\%)

(i) to use real-world data to review and revise solutions to problems (64\%).

All nine items were used to derive an IRT scale reflecting teachers' emphasis on teaching CTrelated skills in class. The scale has satisfactory reliabilities across countries (Cronbach's alpha $=0.90$ ) and items were scored so that higher scale scores indicated stronger emphasis on the teaching of CT-related tasks (see Figure F.23 in Appendix F, for the corresponding item map, which illustrates how scale scores are related to expected item responses).

The highest average scores for teacher emphasis on teaching CT-related skills were observed in Italy, Kazakhstan, and Moscow (Russian Federation), while we observed notably lower scale scores in Finland and North Rhine-Westphalia (Germany) (Table 6.18). When comparing teacher emphasis on the teaching of CT-related skills across subject areas, the highest scale scores were recorded for ICT-related classes, followed by mathematics and natural sciences, while the lowest scale scores were found for other language classes and other subjects' classes.

We also regressed scale scores reflecting teacher emphasis on teaching CT-related tasks on (nationally standardized) scale scores reflecting teachers' ICT self-efficacy, positive views on using ICT in teaching, perceptions of collaboration with other teachers for using ICT in teaching, views of the availability of ICT resources at school, and teachers' experience with using ICT during lessons (Table 6.19). The results show broadly similar results to those we observed for teacher emphasis on CIL-related skills.

Teachers' perceptions of collaboration with colleagues regarding the use of ICT for teaching were consistently positive and significantly related to teacher emphasis on CT-related skills. On average, an increase in one national standard deviation in the scale reflecting perceptions of teacher collaboration when using ICT was associated with an increase of over two scale score points in teacher emphasis on the teaching of CT-related tasks. Teachers' ICT self-efficacy was also consistently and significantly related to teacher emphasis on teaching CT-related skills (an increase of one national standard deviation corresponded to an increase of more than one score point in teacher emphasis) and teachers' positive views of ICT use in teaching were also a consistent and significant predictor (with an average effect of 1.1 scale score points). 


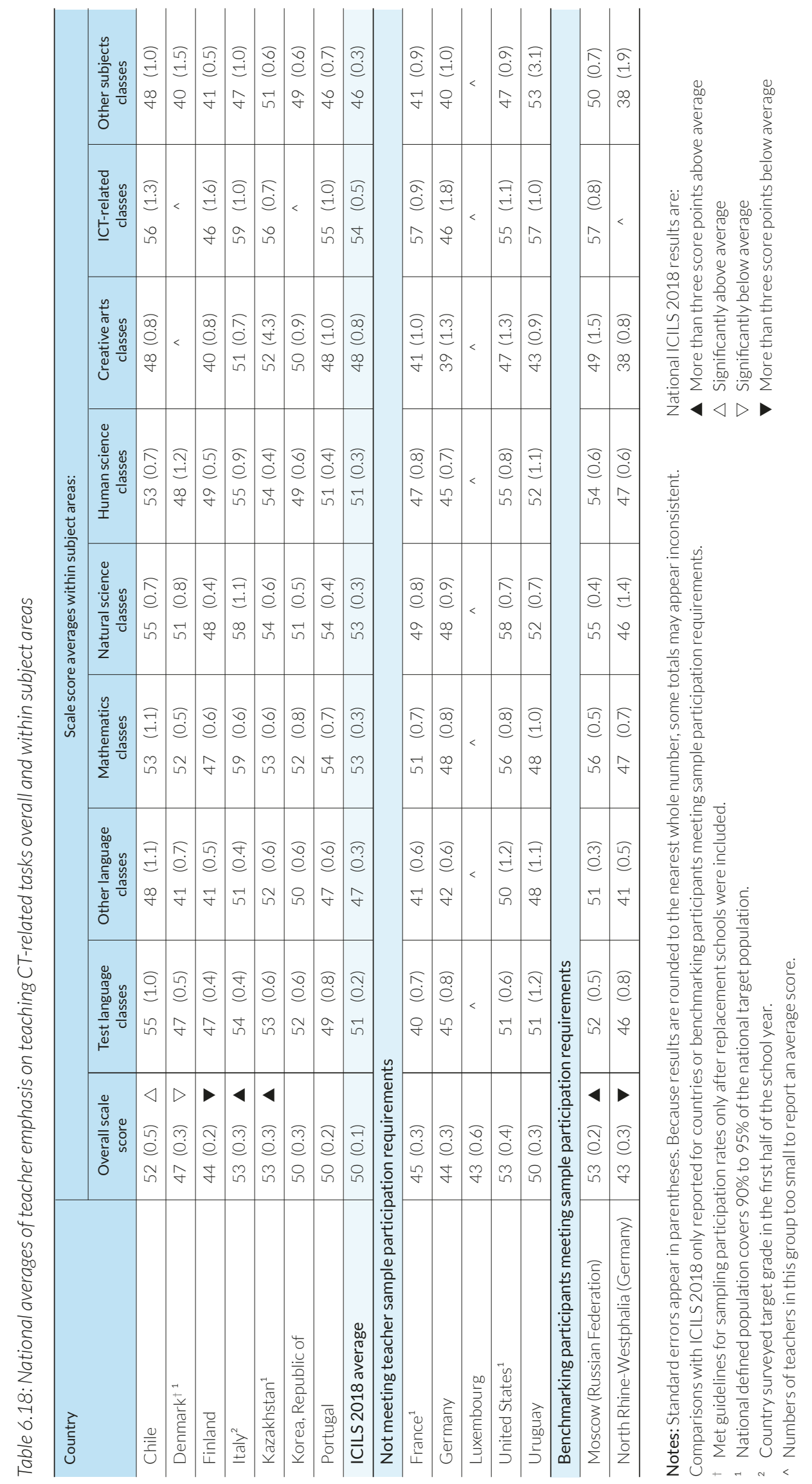




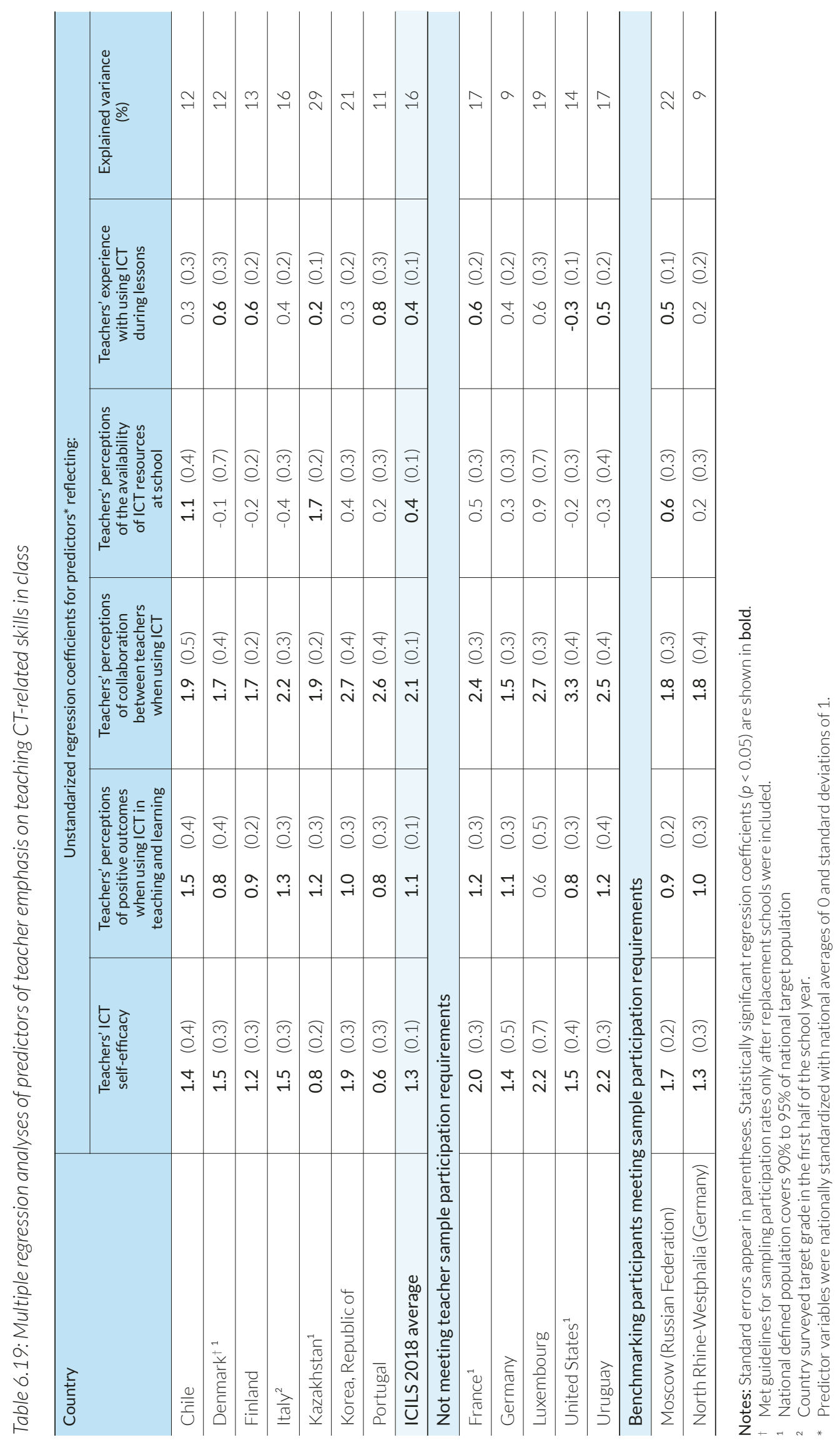


Teacher reports on the availability of ICT resources at school were positive predictors only in Chile and Kazakhstan, a result that is similar to the multiple regression results for teacher emphasis on CIL-related skills. Teachers' experience with the pedagogical use of ICT was a less consistent predictor in this model. We found significant effects only in about half the participating countries and, on average, approximately one year of further experience was associated with about half a score point of emphasis on the learning of CT-related skills.

The regression model explained 16 percent of the variance in scale scores reflecting teacher emphasis on CT-related skills, ranging from nine percent in North Rhine-Westphalia (Germany) and 11 percent in Portugal to 29 percent in Kazakhstan. When interpreting these results, it is important to remember the caveats with regard to drawing causal conclusions based on crosssectional data made earlier in this chapter.

\section{Teachers' use of ICT for teaching and learning}

Results from previous cross-national studies such as SITES 2006 (Law et al. 2008) and ICILS 2013 (Fraillon et al. 2014) have shown that schools and classrooms vary in the extent to which educators use ICT in teaching. Even though e-learning technologies are widely perceived as bringing transformative effects to classrooms (see Aparicio et al. 2016; Burbules 2007), their implementation has been relatively limited (see Cuban 2001; Stošic 2015; Vrasidas 2015) and the effectiveness of ICT for promoting learning appears to depend on teachers' actual practices and their ability of integrate digital technologies into teaching practice (Comi et al. 2017). The ICILS 2013 results showed that, while majorities of teachers reported using ICT for teaching, they used it more frequently for relatively simple tasks than more complex tasks (see Fraillon et al. 2014).

\section{Teachers' use of ICT tools in class}

ICILS 2018 asked teachers to rate the frequency ("never," "in some lessons," "in most lessons," or "in every, or almost every lesson") with which they used 16 different tools when teaching the nominated reference class during the current school year. The tools can be subdivided into general utility ICT tools and (more specific) digital learning tools.

There were differences in the percentages of teachers who reported using various general utility ICT tools "in most lessons" or "in every, or almost every lesson" (i.e., combining the two highest frequency categories) (Table 6.20). On average across countries, the most frequently used general utility tools were those for word processing (43\%) and presentations (43\%), followed by using computer-based information for capture and editing (36\%), and digital contents linked with textbooks (32\%). Meanwhile, spreadsheets (17\%), video and photo software for capture and editing (15\%), and communication software (22\%) were less frequently used by teachers. There were also some notable differences across countries: while teachers in Kazakhstan, Korea, and Moscow (Russian Federation) tended to report higher levels of use across the different tools, the lowest levels of use were recorded in Italy and North Rhine-Westphalia (Germany).

When reviewing the percentages of teachers who reported using digital learning tools in most lessons, or in almost every or every lesson (Table 6.21), we found generally lower proportions of teachers with frequent use than for general utility software. The most frequently used learning tools were learning management systems, which, on average across countries, 28 percent of teachers reported as used in most lessons or more frequently. In this context it is worth noting that across participating countries, teachers expressed less confidence in using these tools compared to other forms of ICT use (see Table 6.2). The proportions of teachers that were using this type of tool varied considerably, from only five percent or less in Chile, Italy, Portugal, and North Rhine-Westphalia (Germany), to more than half of the teachers in Finland (53\%) and Kazakhstan (73\%). 


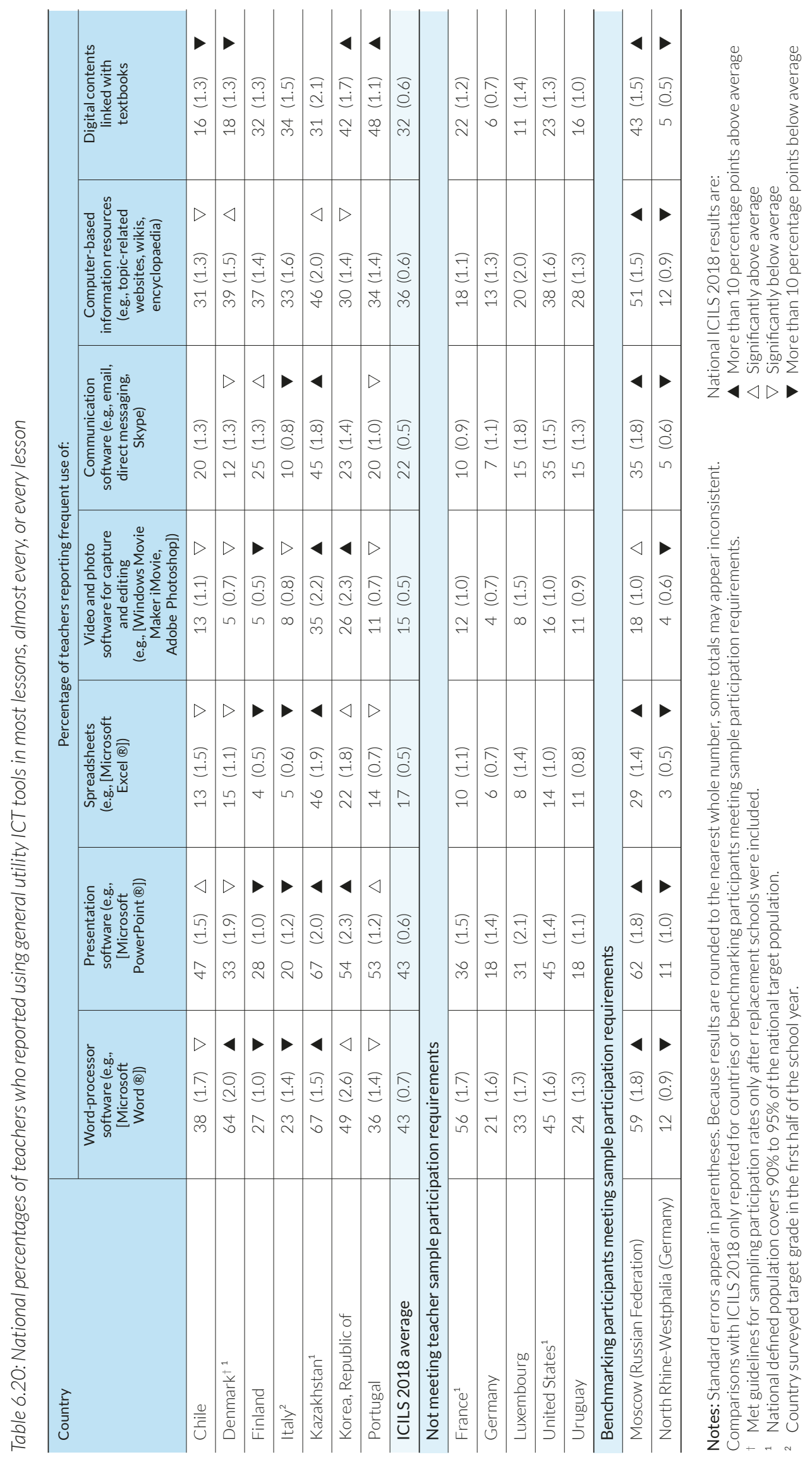




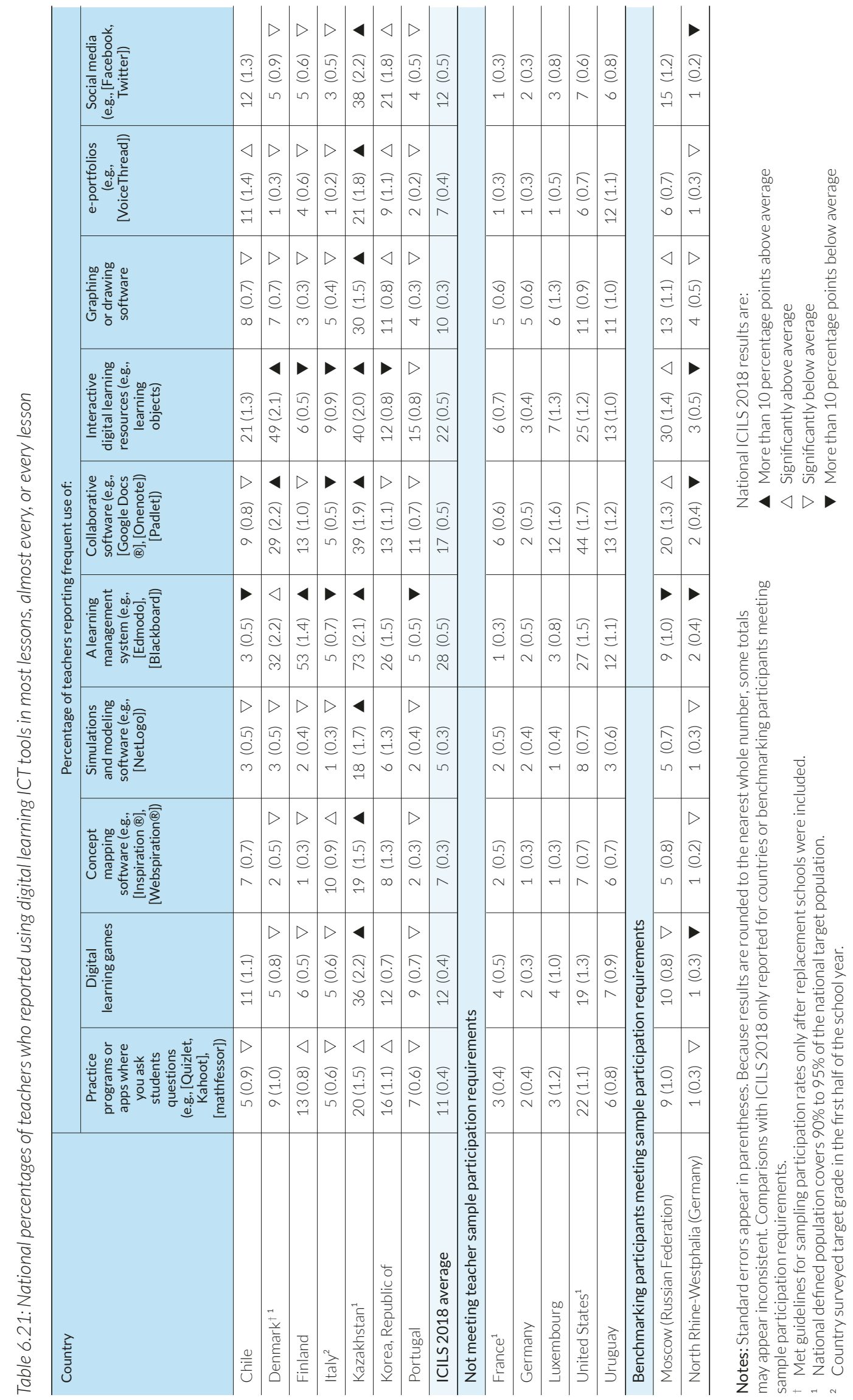


Interactive learning resources were more frequently used (22\%) than most other digital learning tools. In addition, there were notable between-country variations in the proportions of teachers who reported more frequent use of interactive learning resources, ranging from less than 10 percent in Chile, Italy, and North Rhine-Westphalia (Germany), to almost half of the teachers in Denmark. Frequent use of collaborative software was reported by 17 percent of the teachers on average, again with considerable variation in the proportions across countries.

More frequent use of practice programs or apps to ask students questions, digital learning games, graphing or drawing software, and social media were, on average, reported by about 10 percent of the surveyed teachers, again with some variations across countries. The least commonly used digital learning tools (reported by on average $<10 \%$ of teachers) were concept mapping software, simulation and modeling software, and e-portfolios.

\section{Teachers' use of ICT for class activities and teaching practices}

ICILS 2018 was also interested in finding out about the extent to which ICT was used for different types of learning activities in class. Teachers were asked to provide information about whether their students engaged in a set range of activities, and how often they used ICT as part of these activities ("they do not engage in this activity," "they never use ICT in this activity," "they sometimes use ICT in this activity," "they often use ICT in this activity," or "they always use ICT in this activity"). We present the results as percentages of teachers who reported that their students often or always used ICT; data from teachers who indicated that their students had not engaged in each of these activities were not included in these percentages (Table 6.22).

On average across participating countries, half or almost half of the teachers reported that students frequently used ICT when collecting data for a project (50\%), creating visual products or videos (47\%), working on extended projects of more than a week (46\%), and working on short assignments of less than a week's duration (46\%). More than a third of teachers (on average) also reported that students often or always used ICT when submitting completed work assessments (41\%), sharing products with other students (40\%), working individually on learning materials at their own pace (37\%), undertaking open-ended investigations or field work (35\%), and evaluating information resulting from a search (34\%). Less than a third of teachers reported frequent use of ICT by students when analyzing data (32\%), communicating on projects with other students in other schools (28\%), explaining and discussing ideas with other students (26\%), engaging in reflections on their learning experiences (22\%), and planning a sequence of learning activities for themselves (22\%).

We also observed notable differences across countries. While relatively low proportions of teachers in Finland, Portugal, and North Rhine-Westphalia (Germany) reported frequent use of ICT for these different learning activities, they tended to be much higher in Denmark, Kazakhstan, and Moscow (Russian Federation). When reviewing these results, readers should consider that these percentages are based on only those teachers who reported that their students engaged in each of the learning activities, and that there were substantial proportions of teachers who reported that these were not undertaken in their reference class (ranging from 10\% for work on extended projects, to $31 \%$ for reflections on learning experiences).

The ICILS 2018 teacher questionnaire also included a question regarding their use of teaching practices and the frequency of use of ICT when applying them ("I do not use this practice with the reference class," "I never use ICT with this practice," "I sometimes use ICT with this practice," "I often use ICT with this practice," or "I always use ICT with this practice"). Again, the results are presented as percentages of teachers who often or always used ICT based on all teachers who reported using each of these practices (teachers who did not use this practice with the reference class were excluded from the calculations). 


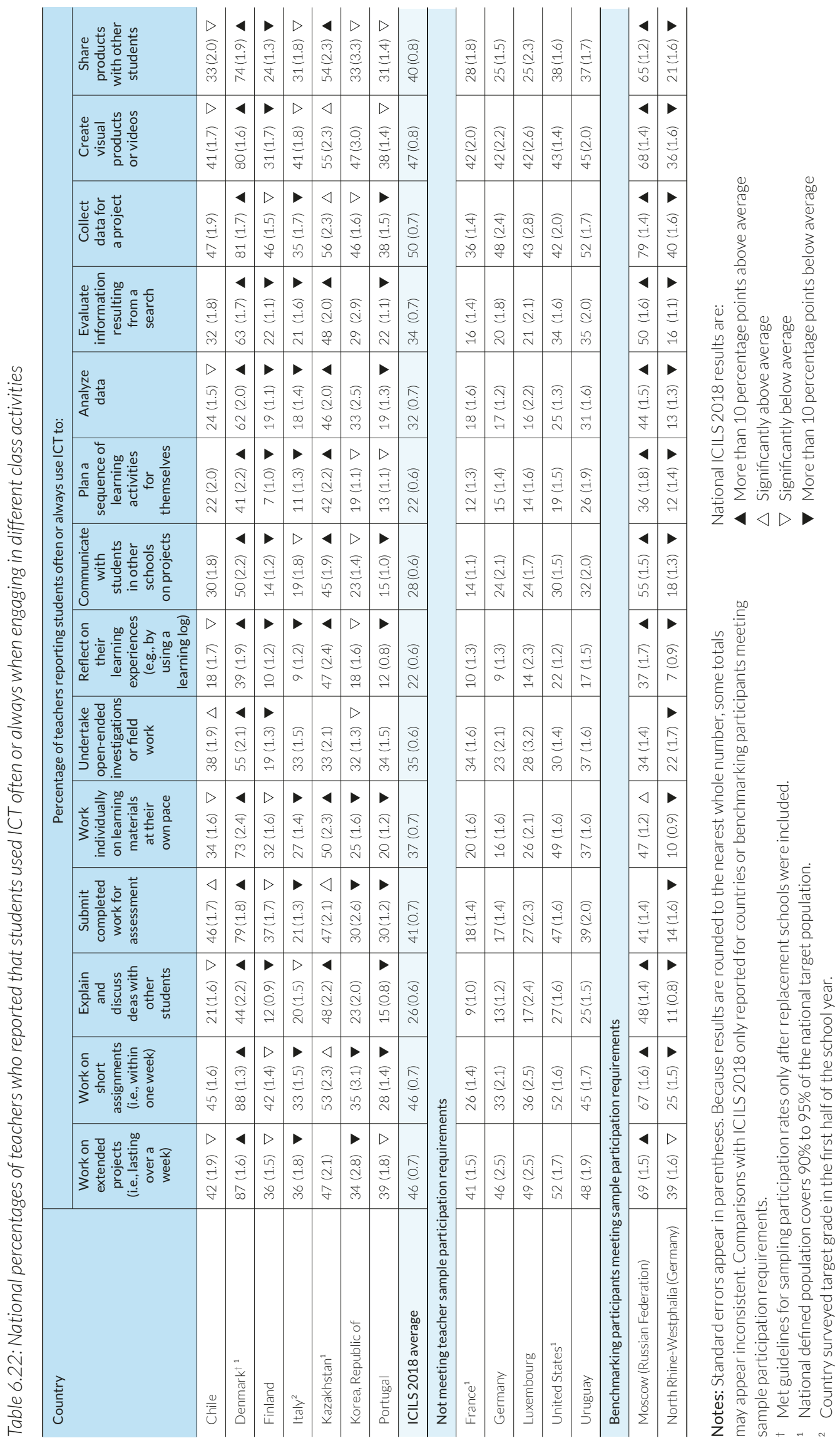




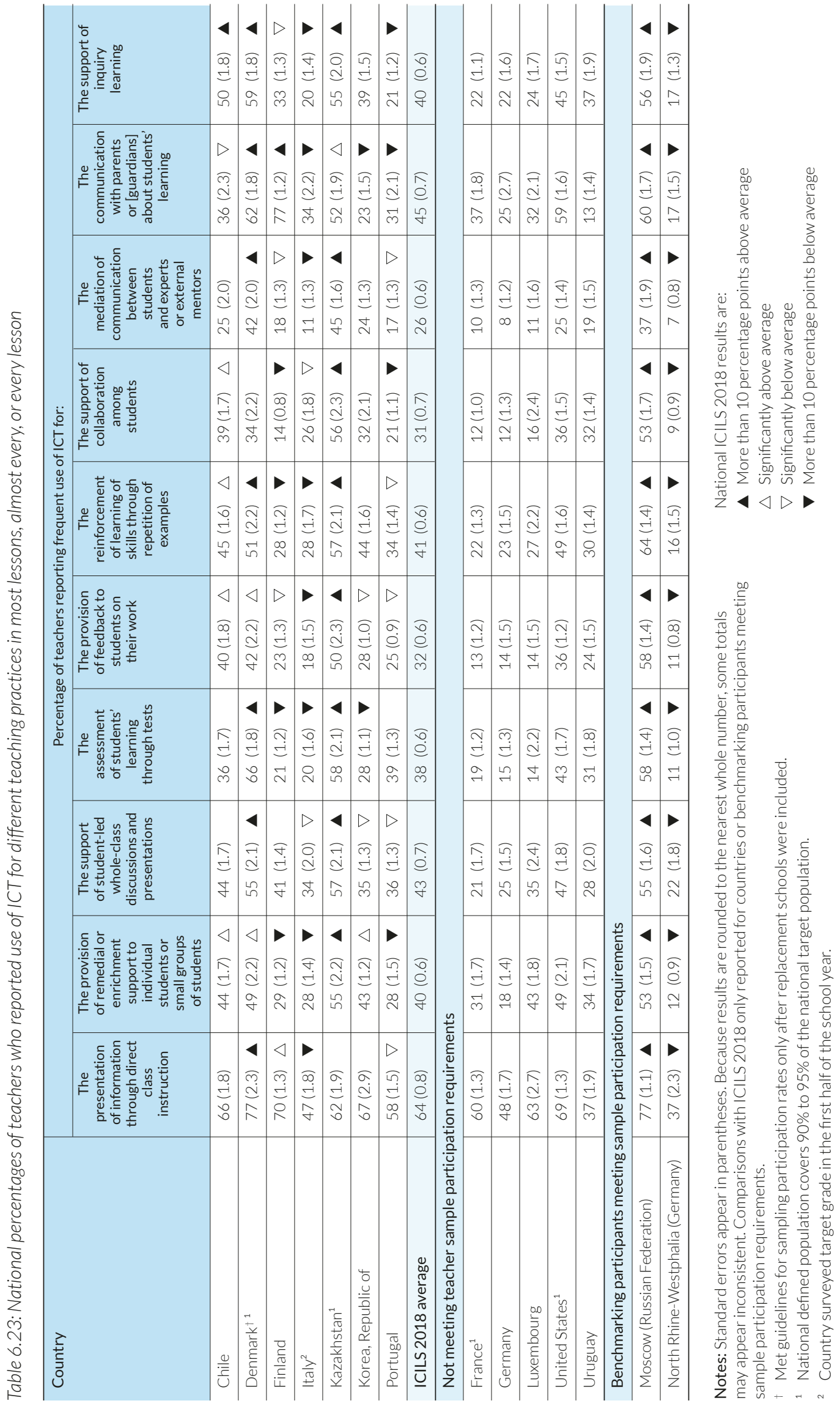


On average across ICILS 2018 countries, almost two-thirds of teachers who presented information through direct class instruction reported often or always using ICT (64\%) (Table 6.23). Between a third and a half of those teachers often or always made use of ICT when communicating with parents or guardians about students' learning (45\%), when supporting student-led whole-class group discussions and presentations (43\%), when providing remedial or enrichment support to individuals or groups of students (40\%), when supporting inquiry learning (40\%), and when assessing students' learning through tests (38\%). Less than a third of teachers reported more frequent use of ICT when providing feedback to students on their work (32\%), when supporting collaboration among students (31\%), and when mediating communication between students and experts or external mentors (26\%).

Again we observed considerable variation across countries. While teachers in Denmark, Kazakhstan, and Moscow (Russian Federation) reported relatively high frequencies of ICT use across the different teaching practices, frequent ICT use tended to be much lower in Italy and North Rhine-Westphalia (Germany). When interpreting these data it is important to note that the percentages were based only on teachers who reported applying these teaching practices; the proportions of teachers who did not use these practices in their reference class ranged (on average across countries) from six percent (for presenting information through direct instruction) to 33 percent (for mediating communication between students and experts or external mentors).

\section{References}

Aparicio, M., Bacao, F., \& Oliveira, T. (2016). An e-learning theoretical framework. Educational Technology \& Society, 19(1), 292-307.

Bandura, A. (1997). Self-efficacy: The exercise of control. New York, NY: W.H. Freeman.

Burbules, N. (2007). E-lessons learned. National Society for the Study of Education 2007 Yearbook, 106(2), 207-216.

Caspersen, J., \& Raaen, F.D. (2014). Novice teachers and how they cope. Teachers and Teaching: Theory and Practice, 20, 189-211.

Charalambos, V., \& Glass, G. (2007). Teacher professional development and ICT: Strategies and models. National Society for the Study of Education 2007 Yearbook, 106(2), 87-102.

Comi, S.L., Argentin, G., Gui, M., Origo, F., \& Pagani, L. (2017). Is it the way they use it? Teachers, ICT and student achievement. Economics of Education Review, 56, 24-39.

Cuban, L. (2001). Oversold and underused: Computers in the classroom. Cambridge, MA: Harvard University Press.

Drossel, K., Eickelmann, B., \& Gerick, J. (2017). Predictors of teachers' use of ICT in school -the relevance of school characteristics, teachers' attitudes and teacher collaboration. Education and Information Technologies, 22(2), 551-573. Retrieved from https://link.springer.com/article/10.1007\%2Fs10639-016-9476-y.

Eickelmann, B. (2011). Supportive and hindering factors to a sustainable implementation of ICT in schools. Journal for Educational Research Online, 3(1), 75-103.

Fraillon, J., Ainley, J., Schulz, W., Duckworth, D., \& Friedman, T. (2019). IEA International Computer and Information Literacy Study 2018 assessment framework. Cham, Switzerland: Springer. Retrieved from https:// www.springer.com/gp/book/9783030193881.

Fraillon, J., Ainley, J., Schulz, W., Friedman, T., \& Gebhardt, E. (2014). Preparing for life in a digital age: The IEA International Computer and Information Literacy Study international report. Cham, Switzerland: Springer. Retrieved from https://www.springer.com/gp/book/9783319142210.

Fraillon, J., Schulz, W., \& Ainley, J. (2013). International Computer and Information Literacy Study assessment framework. Amsterdam, The Netherlands: International Association for the Evaluation of Educational Achievement (IEA). Retrieved from https://www.iea.nl/publications/assessment-framework/internationalcomputer-and-information-literacy-study-2013.

Fraillon, J., Schulz, W., Friedman, T., \& Meyer, S. (Eds.). (2020). IEA International Computer and Information Literacy Study 2018 technical report. Amsterdam, The Netherlands: International Association for the Evaluation of Educational Achievement (IEA). Manuscript in preparation. 
Gerick, J., Eickelmann, B., \& Bos, W. (2017). School-level predictors for the use of ICT in schools and students' CIL in international comparison. Large-scale Assessments in Education, 5, 5. Retrieved from https:// doi.org/10.1186/s40536-017-0037-7.

Hatlevik, O.E. (2017). Examining the relationship between teacher's self-efficacy, their digital competence, strategies to evaluate information, and use of ICT at school. Scandinavian Journal of Educational Research, 61(5), 555-567.

Hatlevik, I., \& Hatlevik, O.E. (2018). Examining the relationship between teachers' ICT self-efficacy for educational purposes, collegial collaboration, lack of facilitation and the use of ICT in teaching practice. Frontiers in Psychology, 9, 935. Retrieved from https://doi.org/10.3389/fpsyg.2018.00935.

Kozma, R. (Ed.). (2003). Technology, innovation, and educatinal change: A global perspective. Eugene, OR: International Society for Technology in Education (ISTE).

Law, N., Pelgrum, W., \& Plomp, T. (2008). Pedagogy and ICT use in schools around the world: Findings from the IEA SITES 2006 study. (CERC studies in comparative education; No. 23.) Hong Kong SAR/The Netherlands: Comparative Education Research Centre, University of Hong Kong/Springer. Retrieved from https://www.springer.com/gp/book/9781402089275.

Lawrence, J.E., \& Tar, U.A. (2018). Factors that influence teachers' adoption and integration of ICT in teaching/learning process. Educational Media International, 55(1), 79-105.

Masters, G.N., \& Wright, B.D. (1997). The partial credit model. In W. J. van der Linden, \& R.K. Hambleton (Eds.), Handbook of modern item response theory (pp. 101-122). New York, NY: Springer. Retrieved from https://link.springer.com/chapter/10.1007/978-1-4757-2691-6_6.

Nikolopoulou, K., \& Gialamas, V. (2016). Barriers to ICT use in high schools: Greek teachers' perceptions. Journal of Computers in Education, 3(1), 59-75.

Rasch, G. (1960). Probabilistic models for some intelligence and attainment tests. Copenhagen, Denmark: Nielsen \& Lydiche.

Scherer, R., \& Siddiq, F. (2015). Revisiting teachers' computer self-efficacy: A differentiated view on gender differences. Computers in Human Behavior, 53, 48-57. Retrieved from https://doi.org/10.1016/j. chb.2015.06.038.

Siddiq, F., Scherer, R., \& Tondeur, J. (2016). Teachers' emphasis on developing students' digital information and communication skills (TEDDICS): A new construct in 21st century education. Computers \& Education, 92-93, 1-14. Retrieved from https://doi.org/10.1016/j.compedu.2015.10.006.

Stošić, L. (2015). The importance of educational technology in teaching. International Journal of Cognitive Research in Science, Engineering and Education (IJCRSEE), 3(1), 111-114. Retrieved from http://www.ijcrsee. com/index.php/ijcrsee/article/view/122.

Tamin, R., Bernard, R., Borokhovski, E., Abrami, P., \& Schmid, R. (2011). What forty years of research says about the impact of technology on learning: A second-order meta-analysis and validation study. Review of Educational Research, 81(1), 4-28. Retrieved from https://doi.org/10.3102\%2F0034654310393361.

Tondeur, J., van Braak, J., Ertmer, P.A., \& Ottenbreit-Leftwich, A. (2017). Understanding the relationship between teachers' pedagogical beliefs and technology use in education: a systematic review of qualitative evidence. Educational Technology Research and Development, 65(3), 555-575.

Vrasidas, C. (2015). The rhetoric of reform and teachers' use of ICT. British Journal of Educational Technology, 46, 370-380. Retrieved from https://onlinelibrary.wiley.com/doi/abs/10.1111/bjet.12149.

Wastiau, P., Blamire, R., Kearney, C., Quittre, V., Van de Gaer, E., \& Monseur, C. (2013). The use of ICT in education: a survey of schools in Europe. European Journal of Education, 48, 11-27. Retrieved from https://onlinelibrary.wiley.com/doi/abs/10.1111/ejed.12020.

Open Access This chapter is licensed under the terms of the Creative Commons Attribution-NonCommercial 4.0 International License (http://creativecommons.org/licenses/by-nc/4.0/), which permits any noncommercial use, sharing, adaptation, distribution and reproduction in any medium or format, as long as you give appropriate credit to the original author(s) and the source, provide a link to the Creative Commons license and indicate if changes were made.

The images or other third party material in this chapter are included in the chapter's Creative Commons license, unless indicated otherwise in a credit line to the material. If material is not included in the chapter's Creative Commons license and your intended use is not permitted by statutory regulation or exceeds the permitted use, you will need to obtain permission directly from the copyright holder. 
CHAPTER 7:

\section{Investigating variations in computer and information literacy and computational thinking}

\section{Chapter highlights}

There are differences in the proportion of variance between schools in computer and information literacy (CIL) and computational thinking (CT) scores.

- There were considerable differences in the variance for both CIL and CT as well as the proportion of variance found between schools across participating countries. (Table 7.1 and Table 7.6)

- Multilevel models explained most of the variance in CIL and CT scores at the school level while less variance was accounted for within schools. (Table 7.1 and Table 7.2)

There are consistent net effects on CIL and CT by personal and social background factors.

- Female gender tended to be positively related to CIL but negatively related to CT scores. (Table 7.2 and Table 7.7)

- Use of test language was a positive predictor of CIL and CT in some countries, in particular those with larger proportions of students speaking another language at home. (Table 7.2 and Table 7.7)

- Both expected university education and socioeconomic background are consistent positive predictors of both CIL and CT across countries, however, the effect sizes vary across countries. (Table 7.2 and Table 7.7)

There are consistent net effects on CIL and CT by a number of student-level predictor variables related to experience and use of information and communication technology (ICT) across countries.

- Students' daily use of ICT and experience with computers were consistent positive predictors of both CIL and CT. (Table 7.3 and Table 7.8)

- Availability of computers at home was a positive predictor in most countries but had weaker effects after controlling for personal and social background. (Table 7.3 and Table 7.8)

- Student reports on having learned about CIL-related tasks at school and on the use of general ICT applications in class tended to be a positive predictor of student CIL in a number of countries. (Table 7.3)

- Student reports on having been taught CT-related tasks had negative effects on CT scores across countries. (Table 7.8)

There are mostly inconsistent net effects on CIL and CT by school-level predictor variables related to ICT across countries.

- Schools' socioeconomic context (as measured by aggregated student scores reflecting family background) was a consistent positive predictor of CIL and CT in almost all countries. (Table 7.2 and Table 7.6)

- In the few countries where ICT-related school-level predictor variables had significant associations, these were often no longer significant after controlling for social context variables. (Table 7.5 and Table 7.10) 


\section{Background}

In previous chapters we have described some of the associations of computer and information literacy $(\mathrm{CIL})$ and computational thinking $(\mathrm{CT})$ with a number of variables, for example gender or those related to home background. This chapter investigates the combined influence of a number of variables on variations in CIL and CT including individual (student level) as well as context (school level) variables. This chapter addresses, for both CIL and CT, the following research questions:

RQ 2 What aspects of schools and education systems are related to student achievement?

RQ 3 What characteristics of students' levels of access to, familiarity with, and self-reported proficiency in using computers are related to student achievement?

RQ 4 What aspects of students' personal and social backgrounds (such as gender, socioeconomic background, and language background) are related to student achievement?

In this chapter, we use multilevel models to review the extent to which different factors at the student and school level are associated with variations in CIL and CT scores. Factors of interest will be those related to access to, use of, and familiarity with information and communications technology (ICT), school context factors, as well as variables reflecting the personal and social background of students.

Prior to the International Computer and Information Literacy Study (ICILS) 2013, research into learning outcomes related to ICT and factors influencing student knowledge in this area had generally been limited to national studies. In a number of countries these national evaluations provided evidence about factors explaining variation in ICT-related capabilities among students.

Sample surveys carried out as part of the Australian National Assessment Program for ICT literacy showed that students' gender (female), socioeconomic background, and experience and current use of computers were positive predictors of variation in ICT literacy (ACARA [Australian Curriculum, Assessment and Reporting Authority] 2012, 2015; MCEECDYA [Ministerial Council for Education, Early Childhood Development and Youth Affairs] 2010; MCEETYA [Ministerial Council on Education, Employment, Training and Youth Affairs] 2007). In the United States, results from the National Assessment of Educational Progress Technology and Engineering Literacy assessment indicated substantial differences with regard to the ICT skills scale between gender groups, parental education, ethnic background, and school location (US Department of Education, National Center for Education Statistics 2016).

ICT literacy was also assessed as part of the Chilean national assessment of students' ICT competencies, known as SIMCE TIC. Multilevel analyses of these data illustrated considerable variation among schools as well as effects of cultural background, socioeconomic status, and school characteristics (private/public, subsidies) on digital competencies (Román and Murrillo 2013). Further analyses also provided evidence of strong effects of prior achievement in reading and mathematics on digital competencies (San Martin et al. 2013).

Analyses of Norwegian grade 9 data collected in 2009 emphasized the importance of home factors (such as family background) but also of having a supportive school climate (Hatlevik 2009). In their analyses of survey data from Norwegian upper-secondary schools, Hatlevik and Christopherson (2013) revealed substantial variation within and between schools, with home conditions and academic aspirations as important predictors of digital competence. Multilevel analyses of data collected among grade 7 students also highlighted the importance of mastery orientation and self-efficacy as predictors of digital competence (Hatlevik et al. 2015).

At the international level, the Programme for International Student Assessment (PISA) assessed the performance of 15 -year-old students in digital reading across 16 countries (OECD [Organisation for Economic Cooperation and Development] 2011). Even though this international 
study assessed reading competencies in a digital environment, it also partly reflects skills related to CIL. Results from this study showed that socioeconomic background and computer use were positively associated with digital reading skills. However, no clear association was found with the use of computers at school.

Multilevel analyses carried out using data from ICILS 2013 showed that students' experience with computers as well as regular use at home had significant positive effects on CIL in many countries even after controlling for the influence of personal and social context. ICT resources, in particular the number of computers at home, did not have any effects once socioeconomic background was taken into account (Fraillon et al. 2014).

\section{Data and methods}

To develop a model to explain variation in each of $\mathrm{CI}$ and $\mathrm{CT}$ we used prior research literature and the contextual framework for ICILS 2018 in order to determine possible predictors of variation in CIL and CT for inclusion in the multivariate analyses presented in this chapter. The final indicators of home and school context in the model were chosen following exhaustive exploratory analyses of their conceptual importance as well as preliminary empirical evidence of their association with the two criterion variables CIL and CT.

Statistical modeling of the kind presented in this chapter assumes a logical structure where sets of predictor variables are used to explain variation in dependent variables. However, given the limitations of international studies such as ICILS and their cross-sectional design (Rutkowski and Delandshere 2016) it is not possible to draw firm conclusions about causal relationships from these data. Rather, these first analyses are conducted to review associations between contextual variables and $\mathrm{CI}$ or $\mathrm{CT}$, which may suggest possible causal relationships but are not necessarily robust evidence of causality.

The ICILS 2018 contextual framework (Fraillon et al. 2019) assumes that students' CIL and CT are influenced by context variables located at different levels (wider community, schools/ classrooms, individual learner, and home) which consist of antecedents as well as process-related factors. In the analysis of CIL and CT presented in this chapter, we included variables pertaining to the school/classroom context, the context of the individual learner, and the home context. Another distinction introduced for the analysis in this report is made between (1) personal and social background factors, and (2) context variables related to ICT and the learning context for CIL and CT.

The model chosen for analysis of both CIL and CT includes predictors which can be classified using the following broad categories:

- Personal and social background: Previous research and results from other analyses of this study (see Chapter 3) illustrated how much gender, students' expectations of educational attainment, and parental socioeconomic status are associated with students' CIL. These variables were included at the student level in Model 1 and Model 3 (see later for more detailed discussion of the models used).

- Social context of schools: The average socioeconomic status of the student body was used as a factor that has been shown to be associated with a variety of learning outcomes. This variable was included at the school level in Model 1 and Model 3.

- ICT resources and use at home: These predictors include ICT resources at home, personal experience with ICT, students' use of ICT at home and school, and students' experiences with learning about ICT at school. These variables were included at the student level in Model 2 and Model 3.

- ICT resources and use at school: Information on the schools' ICT resources and ICT use were collected through the ICT coordinator, principal, and teacher questionnaires. The school CIL learning context includes the expectations of school principals regarding teacher use of ICT 
for collaboration/communication at school and teacher reports of their average experience of the use of ICT for teaching at school. These variables were included at the school level in Model 2 and Model 3.

The personal and social student background characteristics included in the analysis were:

- Students' gender: This variable was coded as 1 for females and 0 for males.

- Students' use of the test language: This variable was coded as 1 for speaking the test language at home most of the time and 0 for other students.

- Students' expected university attainment: This variable reflects students' expectations to attain a university education (coded as 1 = expected, 0 = not expected).

- Students' socioeconomic background: This variable is composite index standardized to have a mean of $O$ and a standard deviation of 1 within each country and centered on school averages so that it indicates the effect of socioeconomic background within schools. The index consisted of factor scores from a principal component analysis of:

- Highest parental occupation (as indicated by the international socioeconomic index of occupational status scores of both parents);

- Highest parental education (categorical variable with $0=$ lower-secondary or lower education, 1 = upper-secondary education, 2 = post-secondary non-university education, 3 = university education); and

- Number of books at home (categorical variable with $0=0$-10 books, 1 = 11-25 books, 2 = 26-100 books, 3 = more than 100 books).

The schools' social intake was measured with the following variable:

- School socioeconomic context: This variable reflects the average of student scores on the composite index of socioeconomic background. It indicates the average socio economic background of enrolled students and the resulting social context in which students learn.

The following variables indicated ICT resources and use at home:

- Number of computers at home: Students reported the number of desktop and portable computers, the resulting indicator variable was coded 1 (two or more computers) and 0 (no or only one computer).

- Experience with computers: This variable reflects how long the individual student has used computers and was coded as 1 (five or more years of experience) and 0 (less than five years of experience).

- Use of ICT: This variable reflects the frequency with which each individual student uses ICT at school or outside of school for both school-related purposes or other purposes, and it was coded as 1 (daily use) and 0 (less than daily use).

- Students' reports on using general ICT applications in class: The three-item scale is based on a question that required students to indicate with what frequency they have used wordprocessing software, presentation software, and computer-based information sources at school. Values are item response theory (IRT) scores, which were standardized for this analysis within each country to having a mean of $\mathrm{O}$ and a standard deviation of 1.

- Students' reports on learning of CIL or CT: This consisted of

- Students' reports on learning of CIL-related tasks at school: The index is based on a set of eight items that required students to indicate whether they had learned about different $\mathrm{CIL}$ tasks ${ }^{26}$ at school. Values are IRT scores, which were standardized for this analysis within

26 The CIL-related tasks were: provide references to internet sources; search for information using ICT; present information for a given audience or purpose using ICT; work out whether to trust information from the internet; decide what information obtained from the internet is relevant to include in school work; organize information obtained from internet sources; decide where to look for information on the internet about an unfamiliar topic; and use ICT to collaborate with others. 
each country to having a mean of 0 and a standard deviation of 1 . This variable was only included in the model explaining variation of CIL.

- Students' reports on learning of CT-related tasks at school: The index is based on a set of nine items that required students to indicate whether they had learned about different CIL tasks ${ }^{27}$ during the current school year. Values are IRT scores, which were standardized for this analysis within each country to having a mean of $O$ and a standard deviation of 1. This variable was only included in the model explaining variation of CT.

The following school-level predictors reflect ICT resources and use at school:

- Availability of ICT resources for teaching and learning: This measure, based on the ICT coordinator questionnaire, was computed using reports on the availability of 13 different computer and ICT resources. ${ }^{28}$ The items were coded as available to teachers and students (2), available to either students or teachers (1), and not available (0), so that higher IRT scale scores indicate more ICT resources at school. Values are IRT scores, which were standardized for this analysis at the student level within each country to having a mean of $O$ and a standard deviation of 1.

- School principals' reports on expectations for teacher communication using ICT: Principals reported whether teachers at the school were expected and required, expected but not required, or not expected to collaborate or communicate via ICT with teachers, parents, and students. The three items were used to derive an index where higher scale scores represent higher expectations/requirements in this respect. Values are IRT scores, which were standardized for this analysis at the student level within each country to having a mean of 0 and a standard deviation of 1.

- Average time of teachers' experience with using ICT for teaching: This index reflects the average time teachers at the school reported to have used ICT for teaching purposes. Response categories for the item were scored as 0 (never), 1 (less than two years), 3 (two to five years), and 5 (more than five years).

- Teacher reports on ICT use for class activities: This IRT scale is based on a question asking teachers about the extent to which students used ICT for activities in class, and higher scores reflect greater use of ICT. Values are IRT scores, which were standardized for this analysis at the student level within each country to having a mean of 0 and a standard deviation of 1 .

During multivariate analyses, any issues relating to missing data tend to become more prevalent than in other forms of analysis because of the simultaneous inclusion of numerous variables. To address the missing data issue, we first excluded from the analyses the small proportion of students for whom there were no student questionnaire data (this was viable because only small proportions of students had missing data for the student-level variables). For the variables derived from the ICT coordinator questionnaire (ICT resources at school), school principal questionnaire (expectations for teacher collaboration/communication via ICT), and the teacher survey (teacher experience with ICT use during lessons, ICT use for class activities) there were higher proportions of missing data. These were treated by setting missing values to national averages or modes

27 The CT-related tasks were: to display information in different ways; to break a complex process into smaller parts; to understand diagrams that describe or show real-world problems; to plan tasks by setting out the steps needed to complete them; to use tools to make diagrams that help solve problems; to use simulations to help understand or solve real-world problems; to make flow diagrams to show the different parts of a process; to record and evaluate data to understand and solve a problem; and to use real-world data to review and revise solutions to problems.

28 The following ICT resources were used for scaling: digital learning resources that can only be used online; access to the internet through the school network; access to an education site or network maintained by education authorities; email accounts for school-related use; practice programs or [apps] where teachers decide which questions are asked of students (e.g., [Quizlet, Kahoot], [mathfessor]); single user digital learning games (e.g., [languages online]); multiuser digital learning games with graphics and inquiry tasks (e.g., [Quest Atlantis]); video and photo software for capture and editing (e.g., [Windows Movie Maker, iMovie, Adobe Photoshop]); concept mapping software (e.g., [Inspiration $(B]$, [Webspiration $(\mathbb{1})$ ); data logging and monitoring tools (e.g., [Logger Pro]) that capture real-world data digitally for analysis (e.g., speed, temperature); a learning management system (e.g., [Edmodo], [Blackboard]); graphing or drawing software; e-portfolios (e.g., [VoiceThread]); digital contents linked with textbooks. 
respectively, and then by adding a missing indicator variable for missing school data (for each of the two indicators) and another one for entirely missing teacher data. This particular approach (see Cohen and Cohen 1975) was chosen given its simplicity and the relatively limited amount of missing values in a majority of countries.

On average across participating countries, data from about 92 percent of tested students were included in the analysis. In two countries (Germany and Uruguay) and one benchmarking participant (North Rhine-Westphalia, Germany) this proportion was below 85 percent and the results are annotated accordingly. For these countries, as well as those that did not meet the IEA sampling participation requirements, readers should interpret results with due caution. More detailed information on the multilevel modeling and treatment of missing data will be presented in the ICILS 2018 technical report (Fraillon et al. 2020).

In Luxembourg, student sample participation requirements were met and 38 of a total of 41 schools participated in the ICILS 2018 survey. Given this relatively low number of units available for analyses at the school level, which would have led to reduced statistical power and precision at the school level, data from this country are not included in the analyses presented in this chapter.

Due to the hierarchical nature of the survey data, we conducted multivariate multilevel regression analysis (see Raudenbush and Bryk 2002). We estimated, for each national sample, two-level hierarchical models with students nested within schools. The analyses were carried out using the software package Mplus (version 7; see Muthén and Muthén 1998-2012) and estimates were obtained after applying appropriate sampling weights at the student and school level. The school-level weights reflect the probabilities of schools to be selected as well as potential non-response adjustments, while student-level weights reflect the probabilities of individual students to be sampled within schools as well as possible adjustments for non-response. The weights were scaled so that the sum of weights is equal to the number of units at each level.

When interpreting results from a multilevel analysis, it is also important to be aware that student level variables in a two-level model have a different meaning from those in a single-level regression analysis. This is because student-level coefficients reflect the effect a variable has within schools. Because of this, effects at this level may differ from the findings that emerged from the bivariate analyses reported in previous chapters. ${ }^{29}$

In addition to estimates of overall and explained variance at the two levels in each of the countries, we will present unstandardized regression coefficients with indications of their statistical significance $(p<0.05)$. These predictor variables were coded in ways that allow a substantial interpretation of these coefficients. Positive coefficients indicate that the estimated net increase in CIL or CT score points equivalent with a corresponding increase of one in the predictor variable, while negative coefficients estimate a decrease. With regard to the interpretation of what a value of one means for each factor, we can distinguish three types of predictor variables:

- For dichotomous indicators, the regression coefficient reflects the estimated net effect in CIL or CT score points between the group with code of one when compared to all other students (female versus male students, speaking test language at home versus others, expecting a university qualification versus others, having two or more computers at home versus others, having at least five years of experience with computers versus others, daily ICT use versus others). ${ }^{30}$

29 Multilevel analysis allows the estimation of random effects models, where within-school effects vary across schools as well as interaction effects between school-level predictors and the slopes of student-level predictors within schools. However, in this first analysis of ICILS data regarding factors influencing CIL, all student-level effects were estimated as fixed effects that did not vary across schools.

30 For example, a coefficient of 5 for the gender indicator denotes that (within schools) females are predicted to have five score points more than males after controlling for all other variables, while a coefficient of - 5 would indicate that males are expected to have five score points more than females. 
- For categorical indicator variables (this only applies to the estimated years of teacher experience with ICT for teaching) the regression coefficient reflects the estimated effect of having one more year of experience across teachers in a school.

- For scale indicator variables regression coefficient indicates the change in CIL or CT score with an increase of one national standard deviation in the predictor variable (students' socioeconomic background, students' reports on learning about CIL-or CT-related tasks at school, students' reports on the use of general ICT applications in class, ICT coordinators', reports on ICT resources at school, principals' reports on expectations of teacher communication via ICT, teachers' reports on students' use of ICT for class activities).

When conducting the multilevel analysis of CIL and CT, four different models were estimated:

- Model $\mathrm{O}$ (the "null model") which included no predictor variables other than school intercepts;

- Model 1 which included only predictor variables related to the personal and socioeconomic background of students and schools' social intake;

- Model 2 which included only predictor variables related to ICT as student- and school-level predictors; and

- Model 3 which included all predictor variables from Models 1 and 2.

Using only the first group of predictors in Model 1, the second group in Model 2, and the combined set of predictors in Model 3, allows a review of the effects of background and ICTrelated predictors by themselves, as well as after controlling for the other types of predictors at student and school levels.

Because Model 0 provides estimates of the variance at each level (within and between schools) before the inclusion of predictors, it provides the point from which to determine how much the subsequent models explained the variance. Model 1 includes only those predictors that are either personal or social background factors, while Model 2 includes only those factors that are directly related to ICT (resources, familiarity, learning context). The final Model 3 provides information about how much variance is explained when both types of predictor variables are included in the model. Comparing effects of ICT-related Model 2 predictors with those from Model 3 illustrates the extent to which these effects are related to the effect of personal and social background predictor variables (either at the student or school level).

\section{Explaining variation in CIL}

Before considering the estimated effects at the student and school level, we compared the variance estimates for CIL at each level (students and schools) and overall, as well as the percentages of variance between schools (Table 7.1). For Chile, for example, we found that a variance in CIL scores of 6750, of which 4790 was observed within school (i.e., at the student level) and 1959 between schools (i.e., at the school level). This indicates that 29 percent of the variance is due to differences between schools. The following columns indicate the percentages of the variance that was explained by each model within and between schools. For example, in Chile Model 3 explains 16 percent of the variance within schools and 80 percent of the variance between schools.

Generally, we found considerable differences across participating countries. The overall variance (i.e., the combined variance at school and student level) ranged from about 4000 in Denmark to over 10,000 in Kazakhstan. The percentages of variance that was found between schools also varied substantially. While in Finland, Korea, and Moscow (Russian Federation) only around a tenth of the variance was found between schools, the corresponding estimates for Germany and Kazakhstan were around 50 percent and in Uruguay above 40 percent. 


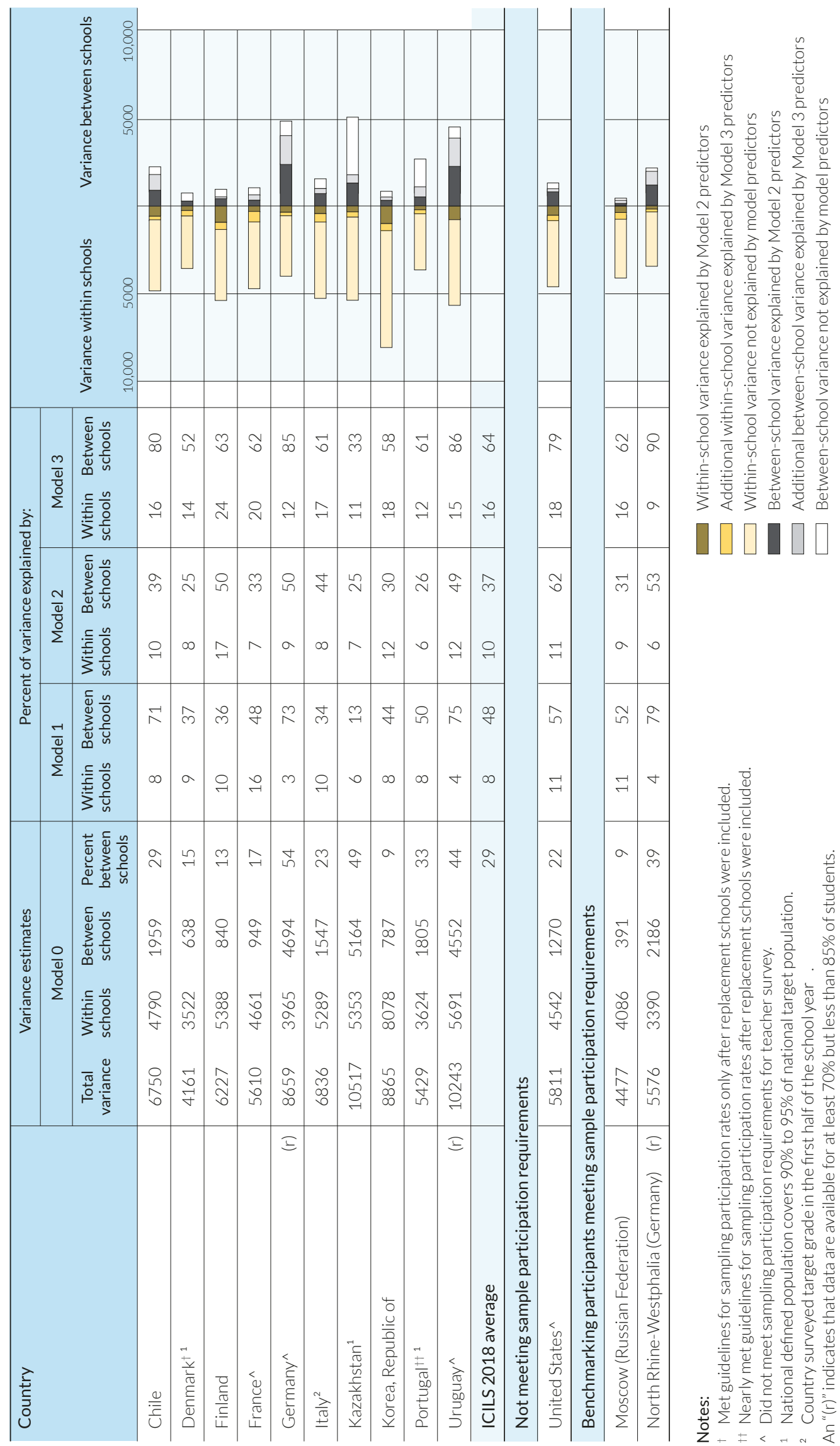


Model 1 (including the personal and social context factors) explained, on average, eight percent at the student level (ranging from 3\% in Germany to 16\% in France) and 48 percent at the school level (ranging from 13\% in Kazakhstan to 79\% in North Rhine-Westphalia, Germany). Model 2 (including ICT-related factors) explained on average 10 percent at the student level (ranging from $6 \%$ in Portugal and North Rhine-Westphalia, Germany, to 17\% in Finland) and 37 percent at the school level (ranging from 25\% in Denmark and Kazakhstan to 50\% in Finland and Germany). The final Model 3 (including all predictors) had an average variance explanation of 16 percent at the student level (lowest with 11\% in Kazakhstan and highest with 24\% in Finland) and 64 percent at the school level (lowest with 33\% in Kazakhstan and highest with $86 \%$ in Uruguay).

Note that this type of table (Table 7.1) aims to illustrate the amount of variance found at each level. In most countries substantial proportions of additional variance are explained once the latter type of variables is included in the final model.

When reviewing the unstandardized regression coefficients in the following tables, it is important to keep in mind that these are effects within schools that are possibly different from overall (single-level) effects of each of these factors. Furthermore, it is important to acknowledge that these are net effects (i.e., associations after controlling for all other variables in a particular model). Therefore, it is plausible to find effects that are somewhat different from bivariate associations reported in previous chapters.

Amongst the personal and social context factors (Table 7.2) included in Model 1 explaining variation in CIL, (female) gender tended to have positive effects in most countries (with the exception of Chile, Kazakhstan, Portugal, and Uruguay as well as the two benchmarking participants) and was on average associated with a net difference of $11 \mathrm{CIL}$ score points. The effects of using the test language at home were statistically significant in five countries (as well as in the two benchmarking participants) and on average there was a net effect of about 21 CIL score points. It should be kept in mind that in some countries there were relatively small subgroups of students speaking another language at home, which is reflected in the relatively large standard errors for the estimates in these countries. For both gender and test language, Model 3 coefficients (after controlling for effects of ICT-related variables) were very similar to those in Model 1.

In all participating countries (with the exception of Germany), expected university education was strongly associated with CIL, on average the effect was 27 score points in Model 1 and 23 in Model 3 , with considerable differences across countries. Larger differences across countries were observed for the effect of socioeconomic background, both at the student level (on average 11 points in Model 1, ranging from less than seven points in Korea and Portugal to almost 17 points in France) and at the school level (about 37 points in Model 1, ranging from about 16 points in Korea to 77 points in Germany).

Amongst the ICT-related variables at student level (Table 7.3), daily ICT use by students was consistently and strongly related to CIL. On average, it was associated with about 27 score points in Model 2 and 24 points in Model 3 (ranging from 15 in Italy and Kazakhstan to 38 in Germany). Also having five or more years of experience with computers was a statistically significant predictor in all countries, with an average effect of almost nine score points in Model 2 and eight points in Model 3 (with significant coefficients ranging from about three in France to 13 in Korea). Having two or more computers at home was a positive Model 2 predictor in six out of 10 countries (on average associated with almost $11 \mathrm{CIL}$ score points, and significant effects ranging from seven in Portugal to about 16 in Denmark, France, and the benchmarking participant Moscow, Russian Federation). In Model 3, the effect of this variable was statistically significant in only five countries and the average effect was less than six score points after controlling for personal and social context variables. 


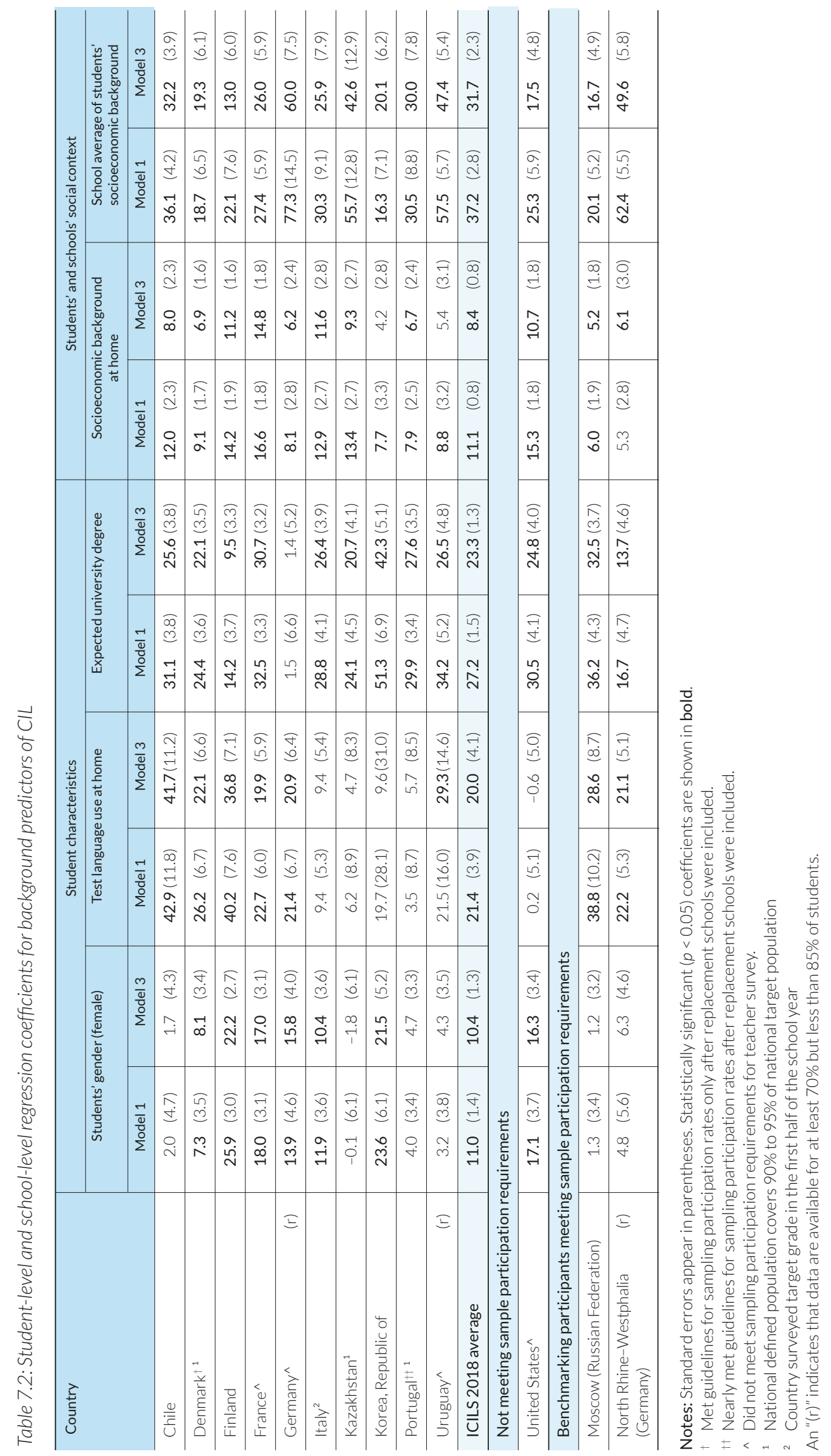




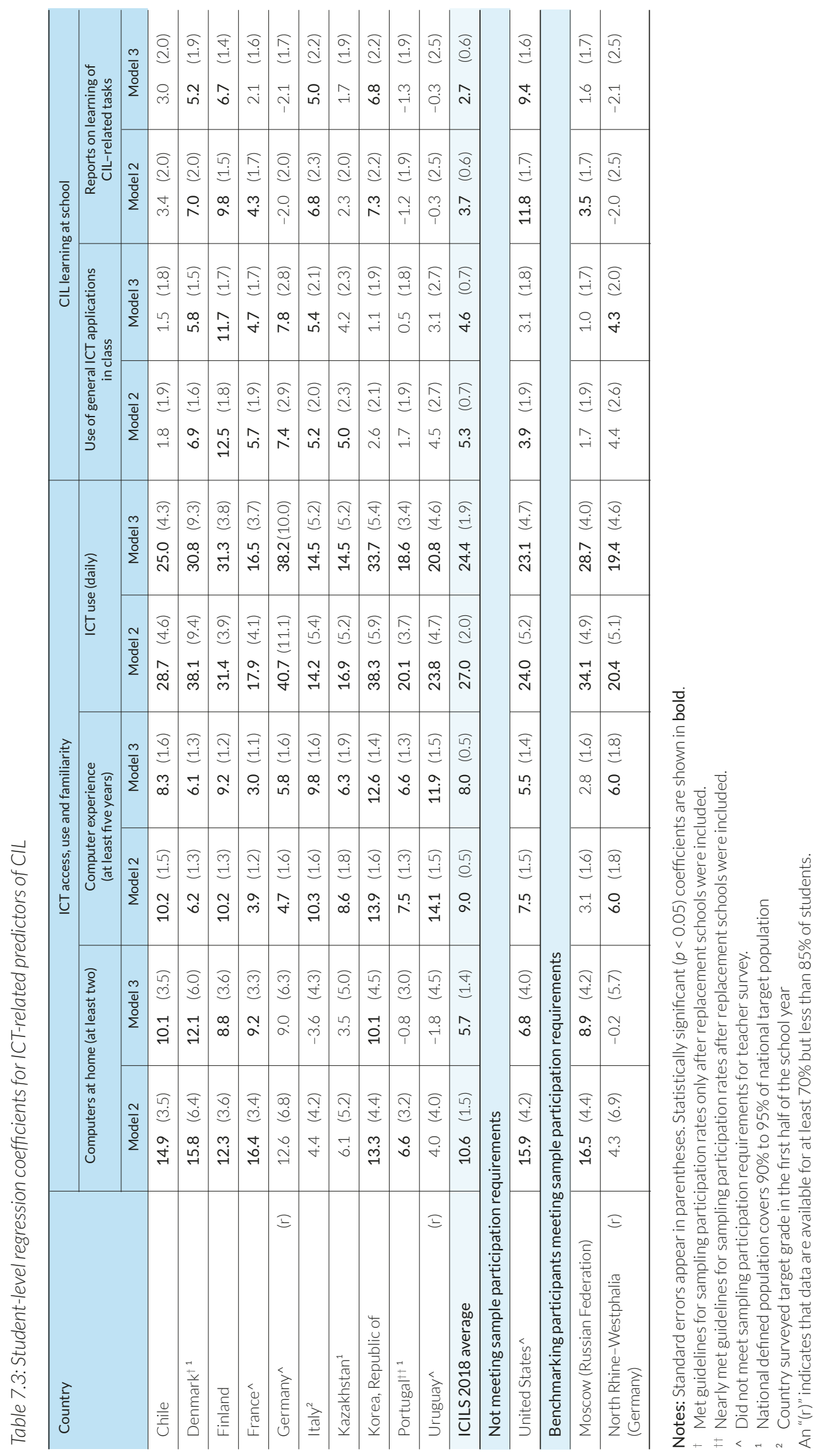


Students' reports on the use of general ICT applications during class had positive associations with CIL in five out of 10 countries, and on average one national standard deviation was associated with over five points in Model 2 and less than five points in Model 3. Students' perceptions of having learned about CIL-related tasks was a significant predictor in five countries and the benchmarking participant Moscow (Russian Federation) in Model 2 (with an average effect of almost four points), and in four countries in Model 3 (on average associated with less than three points).

When reviewing the effects of school-level predictors, we observe less consistency in the associations of these variables with CIL (Table 7.4). School expectations of teacher collaboration or communication via ICT was a significant positive Model 2 predictor in Germany (with 23 points) and Portugal (with 12 points), as well as in the benchmarking participant North RhineWestphalia (Germany). In Model 3 this factor was only significant in Germany (with a regression coefficient of 10 points).

ICT coordinator reports on the availability of school resources had significant positive effects on CIL in Germany (24 points) for Model 2. This variable was a positive predictor in Germany and Portugal for Model 3 after controlling for social context variables.

The average years of experience of teachers using ICT for teaching was a significant positive Model 2 predictor of CIL in Chile, Kazakhstan, Uruguay, and the benchmarking participant of North Rhine-Westphalia (Germany). However, after controlling for personal and social background variables in Model 3 this was only a significant positive predictor in Chile and North RhineWestphalia (Germany). Teacher reports on students' ICT use for class activities had significant positive associations with CIL for Model 2 in Finland and France. However, no significant effects in any of the countries meeting IEA sample participation requirements were recorded after controlling for social context variables as part of Model 3.

We summarized the results by displaying the numbers of significant positive and negative effects per country (by accounting only for countries meeting IEA sample participation requirements) in each of the models (Table 7.5). For example, for (female) gender, we recorded six instances where this Model 1 predictor had statistically significant positive effects across countries, while there were no countries where this variable had a negative effect. The same numbers were found when including all predictors in Model 3. Generally, we can observe that while student-level ICT-related variables remain significant after controlling for personal and social context variables (i.e., comparing Model 2 and 3), the few significant associations of school-level variables in Model 2 are further reduced after controlling for social context factors in Model 3.

\section{Explaining variation in $\mathrm{CT}$}

To explain variation in students' CT scores, we applied almost the same models as for CIL. The only difference was the use of the scale reflecting students' report on learning about CT-related tasks, instead of including the scale reflecting students' perceptions of having learned about CILrelated tasks at school. The analyses included data from six countries that met the IEA sampling participation requirements, data from the United States (which were reported separately as they had insufficient participation rates), and data from the benchmarking participant North RhineWestphalia (Germany) (data which are also included in the German national sample).

The results regarding the variance estimates for CT (overall, within, and between schools) and variance explanation by different models at each level are somewhat similar to those for CIL. (Table 7.6). There was considerable variation with regard to the overall variance of CT scores across countries, ranging from slightly below 7000 in Denmark and Portugal to more than 12,000 in Germany and Korea. The proportion of variance between schools also differed considerably, ranging from seven percent in Denmark to 46 percent in Germany. On average across countries, the proportion of variance between schools was 20 percent. Model 1 predictors (related to 


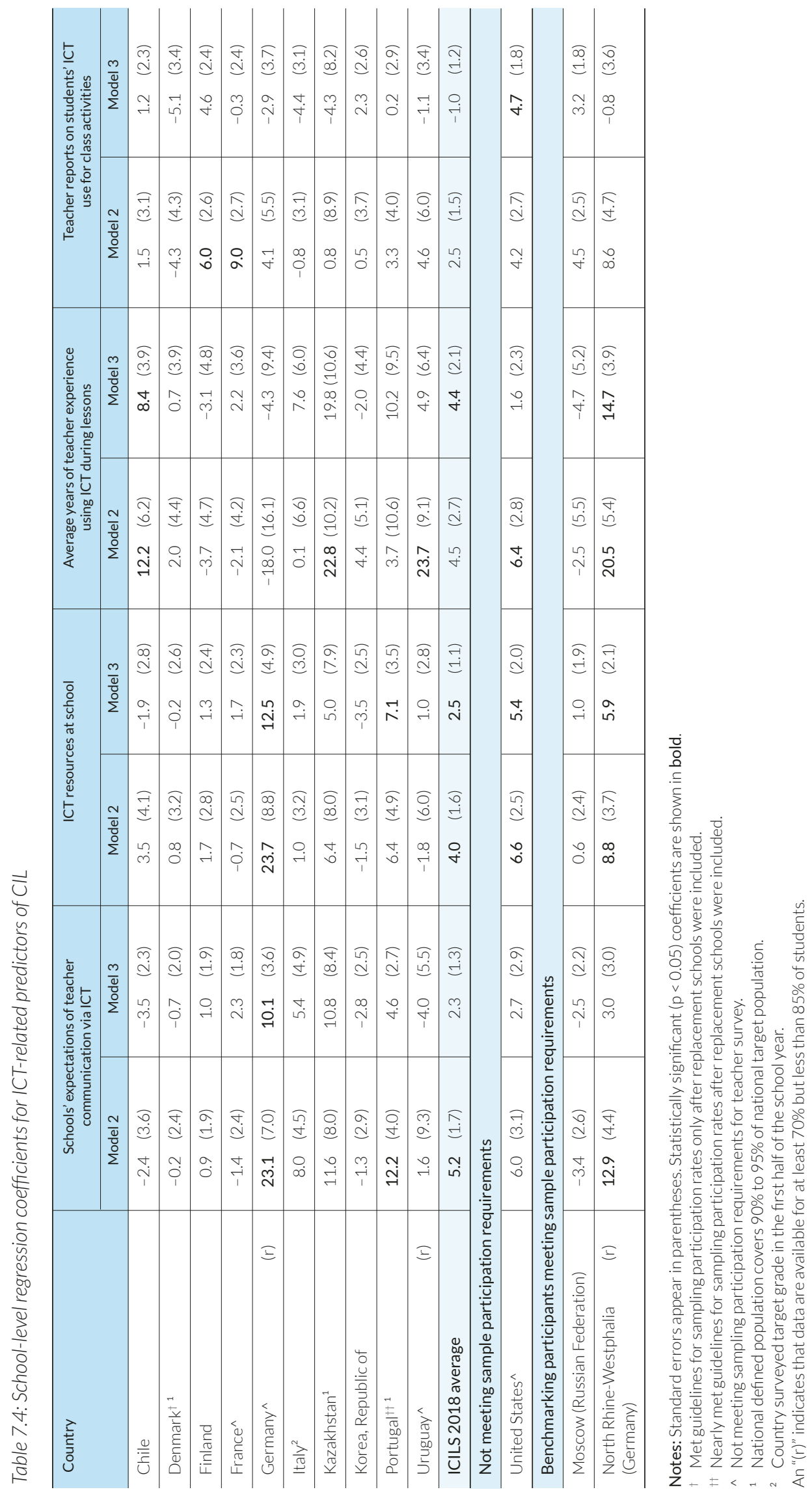




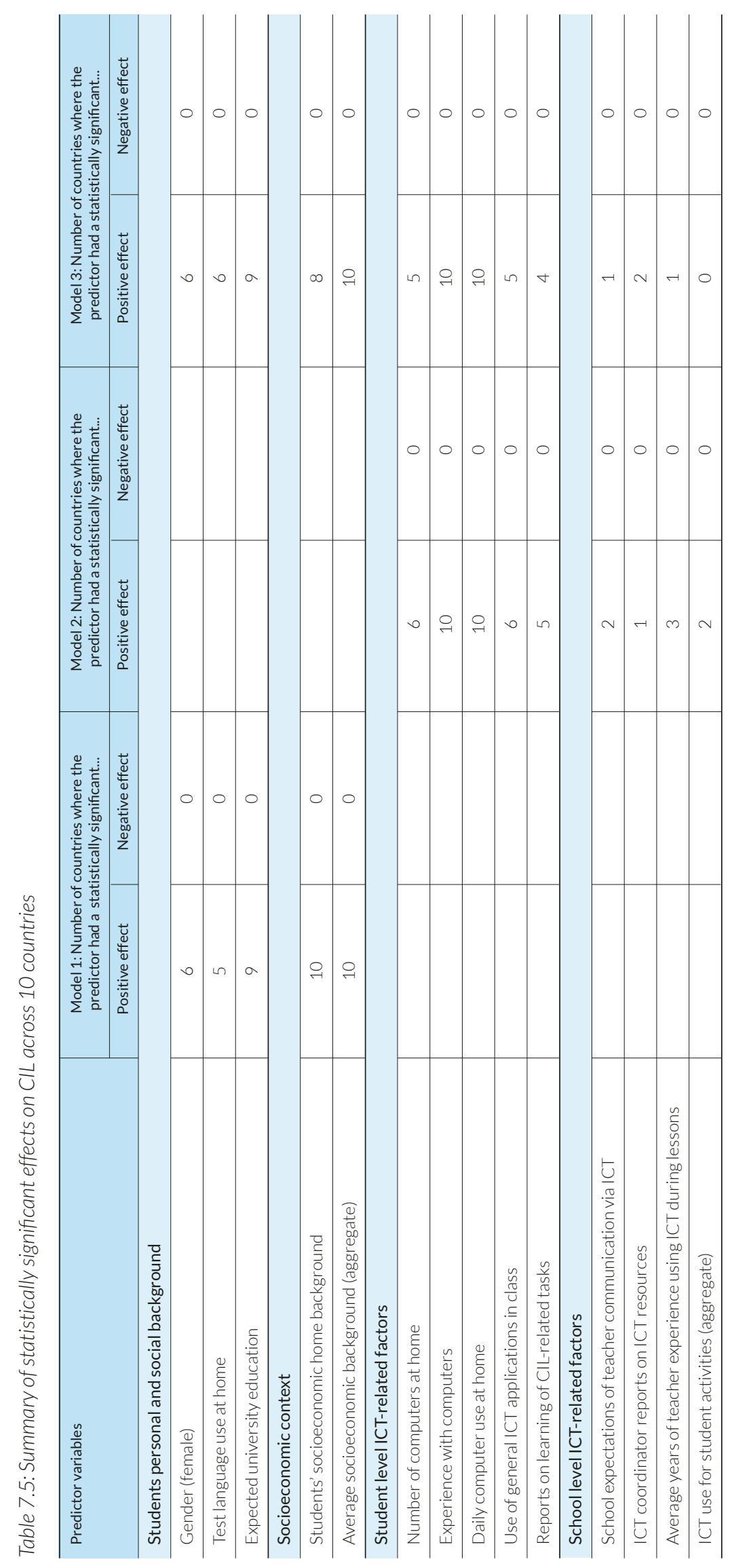




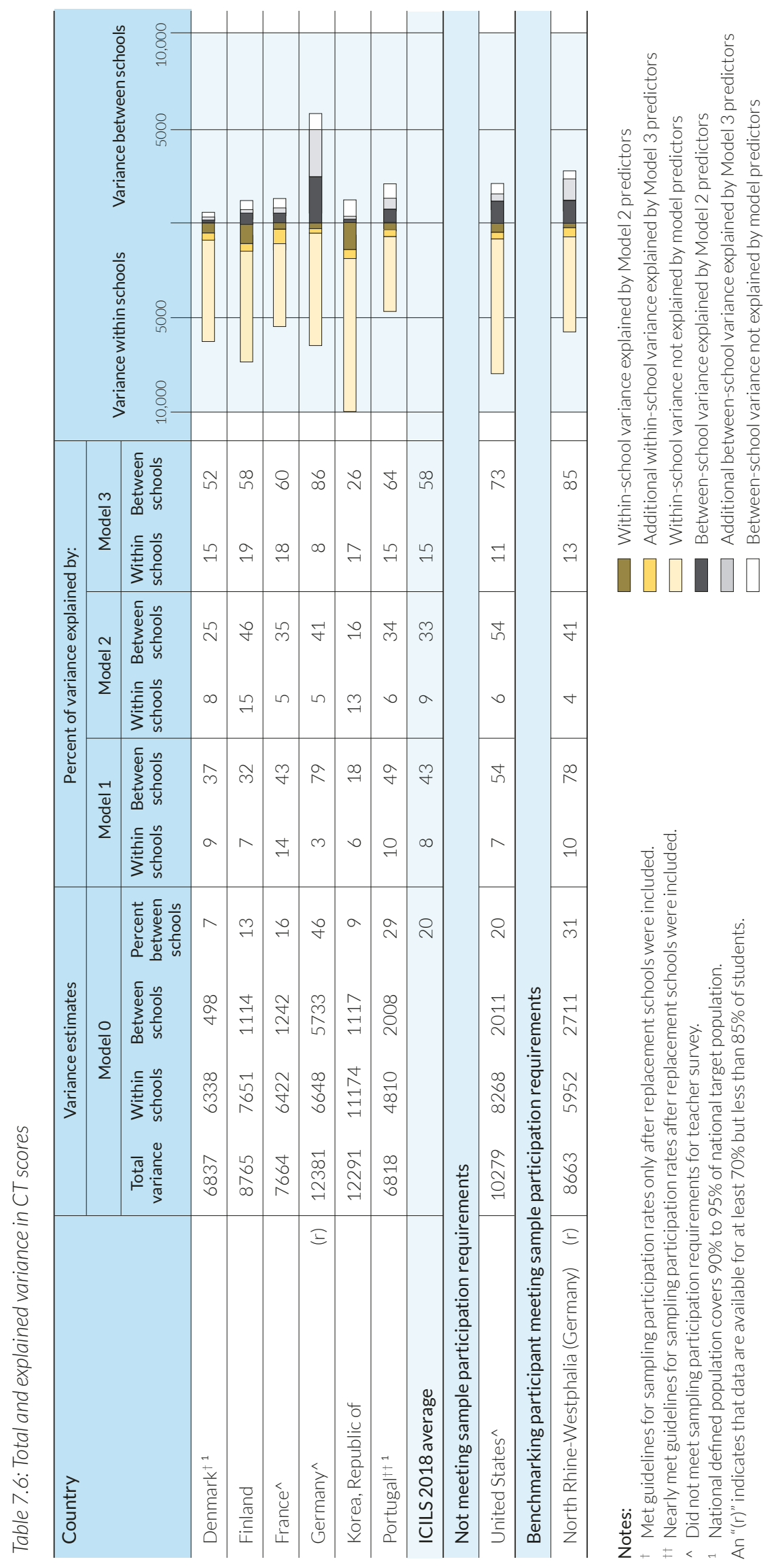


personal and social background) explained on average eight percent within schools (ranging from 3\% in Germany to 14\% in France) and 43 percent between schools (ranging from 18\% in Korea to $79 \%$ in Germany). The corresponding estimates of explained variance for Model 2 were nine percent within schools (ranging from 5\% or less in France, Germany, and the benchmarking participant North Rhine-Westphalia, Germany, to 15\% in Finland) and 33 percent between schools (ranging from 16\% in Korea to 46\% in Finland). For Model 3 these were 15 percent on average within schools (lowest was $8 \%$ in Germany and highest was 19\% in Finland) and 58 percent at the school level (lowest was 26\% in Korea and 86\% in Germany).

When reviewing the unstandardized regression coefficients for variables related to personal and social background (Table 7.7), we observed relatively strong and mostly significant negative associations with female gender in all countries except Finland, where a positive relationship was observed (Model 1). On average we recorded a net effect of about -12 score points. When comparing these results with the (mostly smaller) gender differences reported in Chapter 4 , readers should be mindful that the coefficients presented here are those estimated within schools and after controlling for other variables in the model. Typically, gender effects remained unchanged after taking other ICT-related factors into account (Model 3). However, in some countries the negative coefficients were somewhat stronger than in Model 1.

Use of test language at home had statistically significant positive effects on CT score in four countries (Chile, Finland, France, and Germany) and the benchmarking participant North Rhine-Westphalia (Germany) in both Model 1 and Model 3. Expected university education was consistently a significant positive predictor of CT (similar to the results for $\mathrm{CIL}$ ), with the exception of Germany. On average we observed a net effect of almost 21 score points, which was only slightly lower for Model 3 where ICT-related factors were considered as well.

The within-school effects of socioeconomic background were significant and positive in all countries, on average across participating countries one national standard deviation was associated with a change of almost 15 score points in Model 1 and with over 12 points in Model 3. However, they ranged from less than 10 points in Germany to more than 20 score points in France. The effects at the school level were significant and positive in all countries except Denmark and Korea, in both models. For Model 1, we recorded effects of about 30 score points on average, with significant effects ranging from about 21 points in Finland to almost 88 points in Germany.

When reviewing the effects of ICT-related variables on CT at the student level (Table 7.8), we noted similar results to those found for CIL. The most consistent positive predictor was students' daily use of ICT, associated with more than 33 points on average, ranging from about 20 (in France) to almost 48 score points (in Korea). These coefficients were only slightly smaller for Model 3 after controlling for personal and social background factors, with an average effect of 31 points. Having five or more years of experience with computers was also a positive and significant predictor in all countries except Germany, with an average effect of almost nine score points in Model 2 (and about eight points for Model 3). Larger effects for this predictor of 10 or more score points were observed in Denmark, Finland, and Korea.

Having two or more computers at home had significant positive effects for Model 2 in all countries except Germany and Portugal. On average across participating countries, we observed an effect of about 12 score points. However, after controlling for factors related to personal and social background, for Model 3 this predictor was only significant in Finland with a considerably smaller effect coefficient. In Portugal, for Model 3 we recorded a significant negative effect after controlling for personal and social background factors.

Student report on the use of general ICT applications in class had significant positive associations within schools with CT in Denmark, Finland, and France. For Model 2 in these countries one 


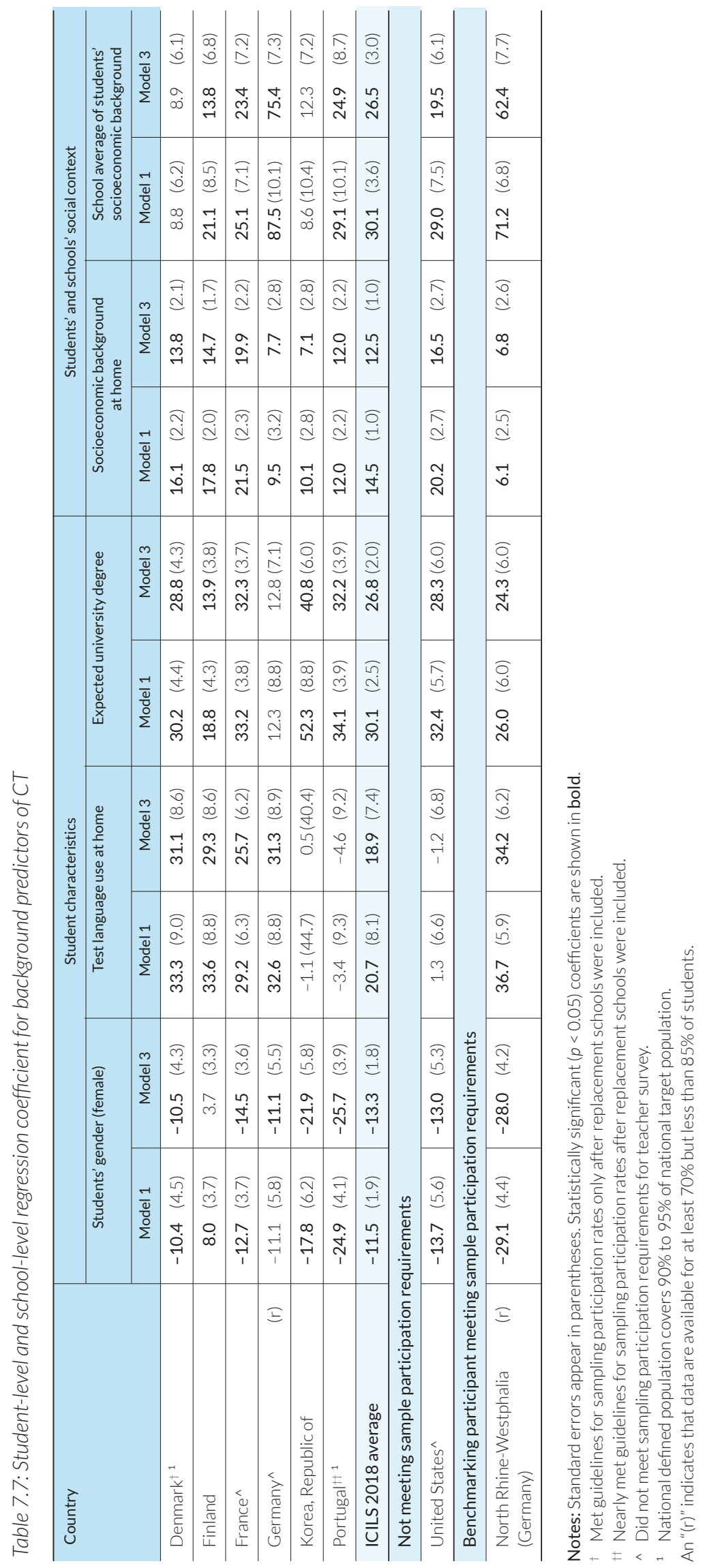




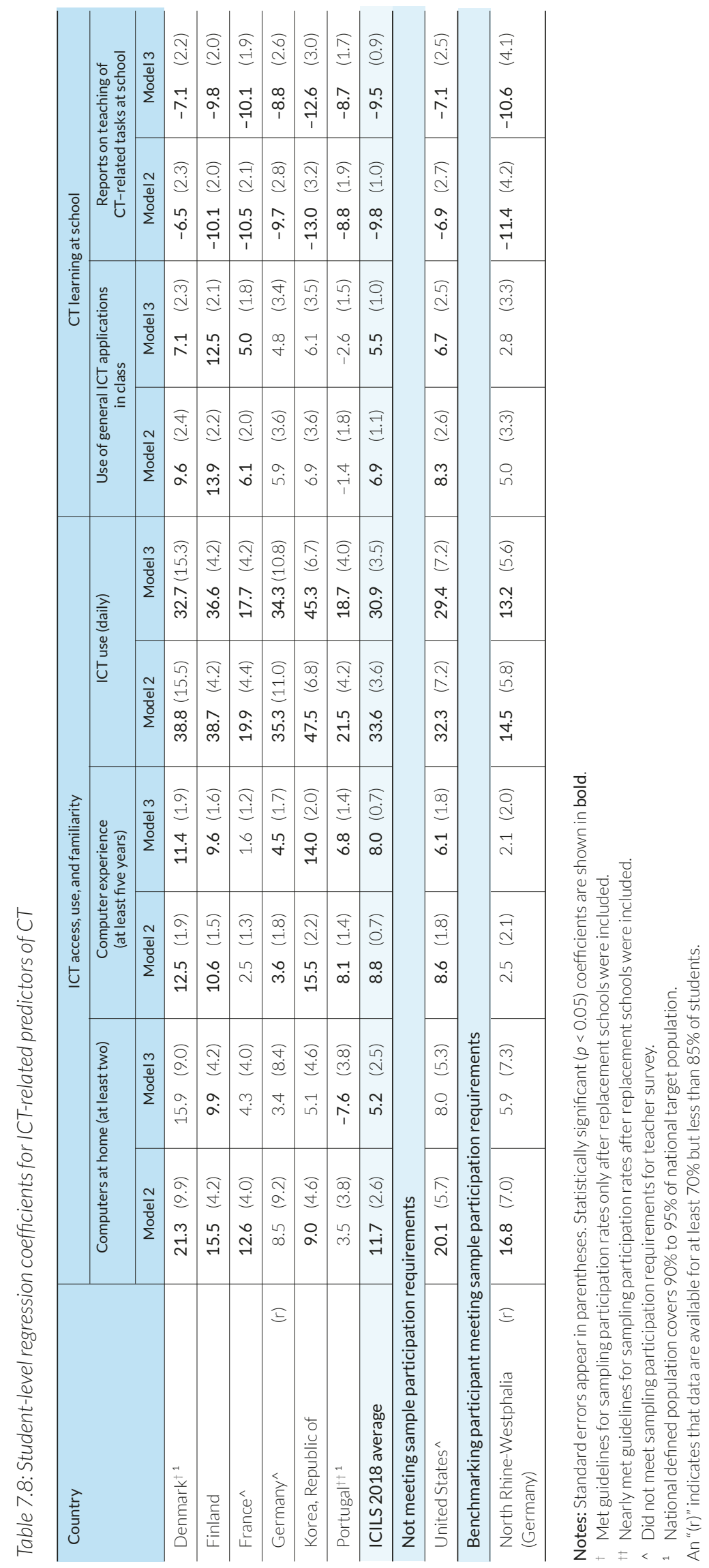


national standard deviation was associated with increases of about 10, 14, and six points respectively. Similar effects were recorded in these three countries for Model 3 where personal and social background factors were included.

Students' reports on learning of CT-related tasks during the current school year was a significant negative predictor in all countries for Models 2 and 3. One national standard deviation was on average associated with almost 10 score points in both models. It is possible that this finding is due to the fact that positive responses are related experiences with remedial instruction aimed at students who are less proficient with ICT. Alternatively, it is also possible that more knowledgeable students were better able to understand the content of the items and less inclined to give affirmative responses given the absence of more in-depth instruction related to these tasks at school.

For both models, schools' expectations of teachers' use of ICT for communication via ICT has significant positive effects on CT at the school level in Germany and Portugal. However, in both countries these effects decreased after controlling for social context variables in Model 3 (Table 7.9). The scale reflecting ICT resources at school was a significant positive predictor in Germany for Model 2 (24 score points) and Model 3 (11 score points), and also had significant positive associations with CT in Portugal after controlling for social context factors (Model 3: almost eight score points).

The average experience of teachers with using ICT for teaching did not show any significant associations with CT across countries except in the benchmarking participant North RhineWestphalia (Germany) (in both Models 2 and 3). Aggregated teacher reports on the use of ICT for student class activities was a significant positive Model 2 predictor in Finland and France, however, this association was no longer statistically significant in France in Model 3 after controlling for the schools' socioeconomic context.

When summarizing the significant effects across the six countries that participated in the CT option and met IEA sample participation requirements, we can see that (female) gender had significant negative net associations in four countries and a positive association in one country as part of Model 1. In the final Model 3 we found significant negative effects in five countries (Table 7.10). Furthermore, we observed that school-level factors related to ICT were not consistent predictors across countries. However, student-level factors related to ICT experience and learning tended to remain significant predictors when included in Model 3. Generally, the findings are roughly similar to those from the analyses of CIL. However, the observed negative effects of students' reports on learning of CT-related skills in class are noteworthy and warrant further investigation in future secondary analyses. 


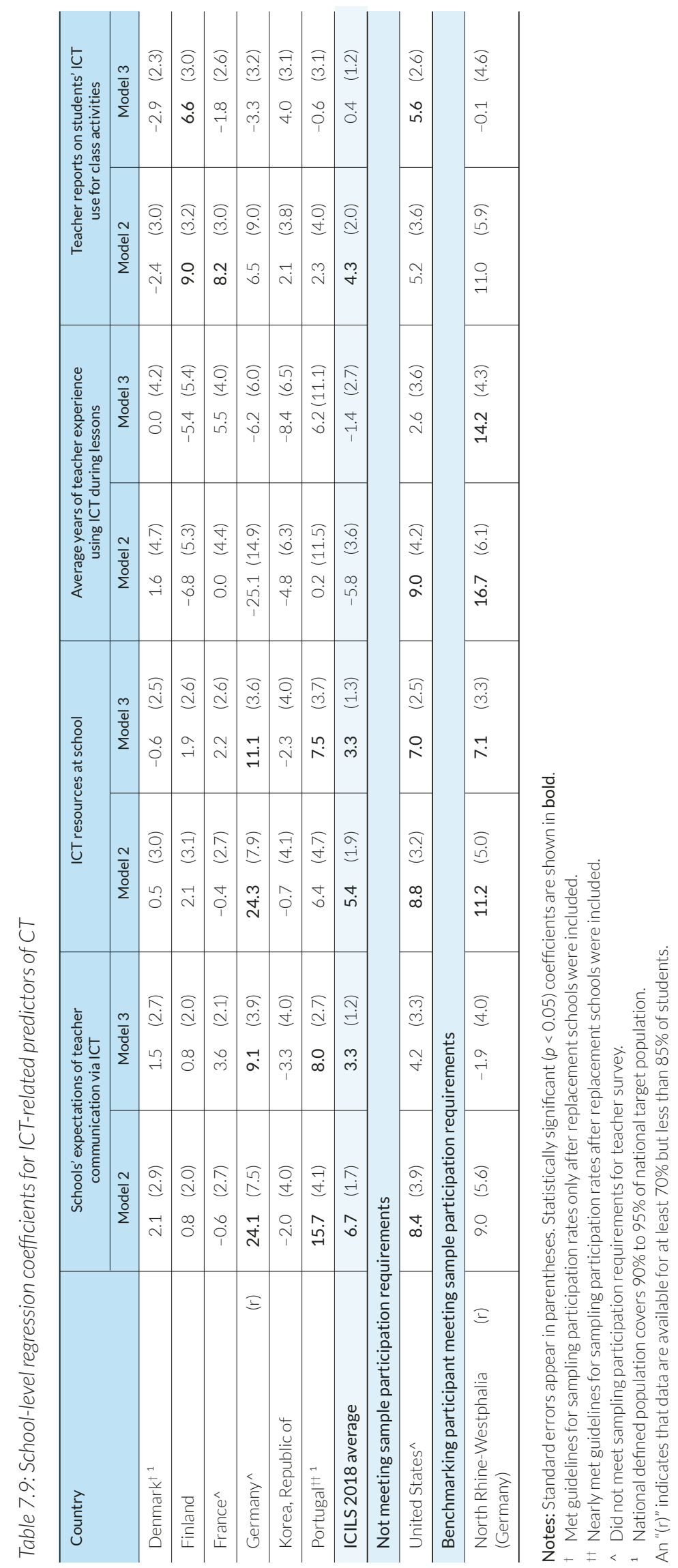




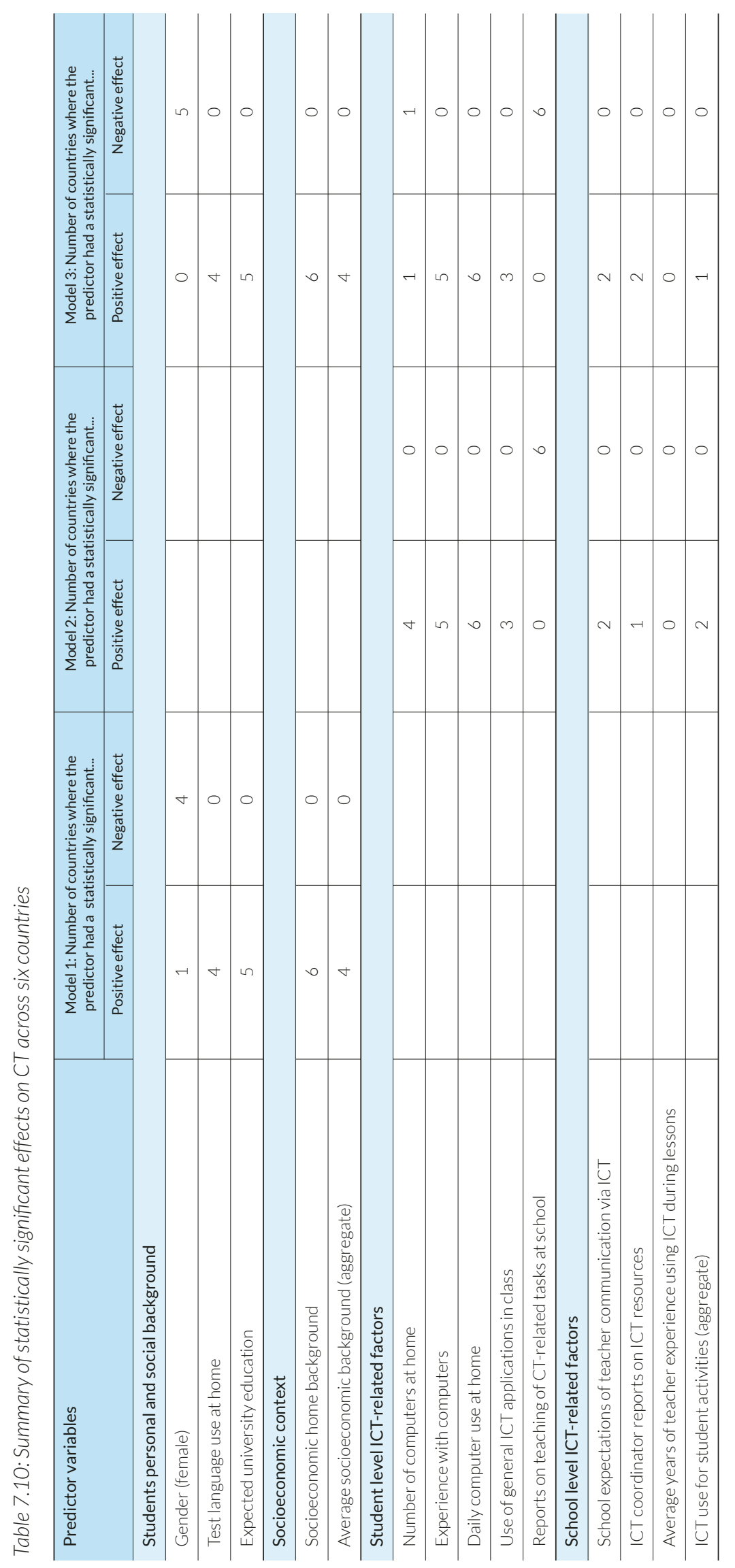




\section{References}

ACARA. (2012). National Assessment Program-ICT literacy. Years 6 \& 10 report. 2011. Sydney, Australia: Australian Curriculum, Assessment and Reporting Authority. Retrieved from https://www.nap.edu. au/_resources/NAP_ICTL_2011_Public_Report_Final.pdf.

ACARA. (2015). National Assessment Program -ICT literacy. Years 6 \& 10 report. 2014. Sydney, Australia: Australian Curriculum, Assessment and Reporting Authority. Retrieved from: http://www.nap.edu. au/_resources/D15_8761_NAP-ICT_2014_Public_Report_Final.pdf.

Cohen, J., \& Cohen, P. (1975). Applied multiple regression/correlation analysis for the behavioral sciences. Hillsdale, NJ: Lawrence Erlbaum Associates.

Fraillon, J., Ainley, J., Schulz, W., Duckworth, D., \& Friedman, T. (2019). IEA International Computer and Information Literacy Study 2018 assessment framework. Cham, Switzerland: Springer. Retrieved from https:// www.springer.com/gp/book/9783030193881.

Fraillon, J., Ainley, J., Schulz, W., Friedman, T., \& Gebhardt, E. (2014). Preparing for life in a digital age: The IEA International Computer and Information Literacy Study international report. Cham, Switzerland: Springer. Retrieved from https://www.springer.com/gp/book/9783319142210.

Fraillon, J., Schulz, W., Friedman, T., \& Meyer, S. (Eds.). (2020). IEA International Computer and Information Literacy Study 2018 technical report. Amsterdam, The Netherlands: International Association for the Evaluation of Educational Achievement (IEA). Manuscript in preparation.

Hatlevik, O.E. (2009). How to identify and understand digital literacy among 9th grade Norwegian students: Examining the influences from school and home on students' digital literacy. Nordic Journal of Digital Literacy, 4(3-4), 159-174.

Hatlevik, O.E., \& Christophersen, K.A. (2013). Digital competence at the beginning of upper secondary school: Identifying factors explaining digital inclusion. Computers \& Education, 63(1), 240-247. Retrieved from https://doi.org/10.1016/j.compedu.2012.11.015.

Hatlevik, O.E., Ottestad, G., \& Throndsen, I. (2014). Predictors of digital competence in 7th grade: a multilevel analysis. Journal of Computer Assisted Learning, 31, 220-231.

MCEECDYA [Ministerial Council for Education, Early Childhood Development and Youth Affairs]. (2010). National assessment program-ICT literacy. Years 6 \& 10 report. 2008. Carlton South, Australia: Curriculum Corporation. Retrieved from https://files.eric.ed.gov/fulltext/ED534805.pdf.

MCEETYA [Ministerial Council for Education, Early Childhood Development and Youth Affairs]. (2007). National assessment program-ICT literacy. Years 6 and 10 report. 2005. Carlton South, Australia: Curriculum Corporation. Retrieved from https://www.nap.edu.au/_resources/2005_ICTL_Public_Report_file_main.pdf.

Muthén, L.K., \& Muthén, B.O. (1998-2012). Mplus user's guide (seventh ed.). Los Angeles, CA: Muthén \& Muthén. Retrieved from https://www.statmodel.com/download/usersguide/Mplus\%20user\%20guide\%20 Ver_7_r3_web.pdf.

OECD. (2011). PISA 2009 results: Students on line. Digital technologies and performance (Volume VI). Paris, France: Author. Retrieved from http://dx.doi.org/10.1787/9789264112995-en.

Raudenbush, S. W., \& Bryk, A. S. (2002). Hierarchical linear models: Applications and data analysis methods. Newbury Park, CA: SAGE.

Román, M., \& Murrillo, J. (2013). Estimación del efecto escolar para la competencia digital. Aporte del liceo en el desarrollo de las habilidades TIC en estudiantes de secundaria en Chile [Investigation into the effect of school on digital competency. The contribution of the lyceum to the development of ICT in Chilean high school students]. In CEPPE, Desarrollo de habilidades digitales para el siglo XXI en Chile: ¿Qué dice el SIMCE TIC? [Developing digital skills for the twenty-first century in Chile: What does ICT SIMCE say?] (pp. 141-176). Santiago, Chile: LOM Ediciones.

Rutkowski, D., \& Delandshere, G. (2016). Causal inferences with large scale assessment data: Using a validity framework. Large-scale Assessments in Education, 4(6). Retrieved from https:// largescaleassessmentsineducation.springeropen.com/articles/10.1186/s40536-016-0019-1.

San Martín, E., Claro, M., Cabello, T., \& Preiss, D. (2013). Habilidades TICs para el aprendizaje y su relación con el conocimiento escolar en lenguaje y matemáticas [ICT skills for learning and their relationship to school knowledge in language and mathematics]. In CEPPE. Desarrollo de habilidades digitales para el siglo XXI en Chile: ¿Qué dice el SIMCE TIC? [Developing digital skills for the twenty-first century in Chile: What does ICT SIMCE say?] (pp. 229-248). Santiago, Chile: LOM Ediciones.

US Department of Education, National Center for Education Statistics. (2016). The nation's report card: 2014 Technology \& Engineering Literacy (TEL) report card at grade 8 (NCES2016119). Retrieved from https:// www.nationsreportcard.gov/tel_2014/. 
Open Access This chapter is licensed under the terms of the Creative Commons Attribution-NonCommercial 4.0 International License (http://creativecommons.org/licenses/by-nc/4.0/), which permits any noncommercial use, sharing, adaptation, distribution and reproduction in any medium or format, as long as you give appropriate credit to the original author(s) and the source, provide a link to the Creative Commons license and indicate if changes were made.

The images or other third party material in this chapter are included in the chapter's Creative Commons license, unless indicated otherwise in a credit line to the material. If material is not included in the chapter's Creative Commons license and your intended use is not permitted by statutory regulation or exceeds the permitted use, you will need to obtain permission directly from the copyright holder. 
CHAPTER 8:

\section{Reflections on the IEA International Computer and Information Literacy Study 2018}

In this chapter we reflect on the contribution of the International Computer and Information Literacy Study (ICILS) to understanding the extent to which young people are able to use information and communication technology (ICT) productively for a range of purposes. Those purposes relate to what happens in school and in other environments such as home, society, and future workplaces. In addition, we provide perspectives on factors that are associated with development of the digital capacities of young people. We provide an overview of the main themes emerging from the analyses presented in this report. Within each theme, we reflect on the implications of these results for developments in policy and practice that support the teaching and learning of ICT-related competencies in schools.

\section{ICILS as a pioneering study}

ICILS 2013 was the first cycle of the study. It established an agreed definition and explication of computer and information literacy $(\mathrm{CI})$ as a student learning outcome. Furthermore, it operationalized a standardized approach to the measurement of CIL in an international largescale assessment (ILSA), and established measures of CIL that could be used to monitor and investigate a critical aspect of students' digital competence.

ICILS 2018 has extended the work of ICILS 2013 in investigating grade 8 students' capacities to use ICT productively for a range of purposes, including those that go beyond a basic use of computers. ICILS 2018 updated the digital contexts for the measurement of students' CIL and investigated in greater detail the nature of classroom teaching activities associated with the development of CIL. In addition, it developed and implemented an objective assessment of computational thinking (CT). While concepts associated with CT have been recognized since the advent of computing as a field of study in the 1940s (Denning 2017), the role of CT in curricula has waxed and waned since the introduction of personal computers in schools in the final quarter of the twentieth century. In recent years, there has been a resurgence of interest in the teaching and learning of CT as both a foundation for the effective use of digital technologies and as a transferable set of problem solving skills. ICILS 2018 included an option for countries to collect objective data measuring students' capacities to plan and operationalize computer-based solutions to real-world problems. ICILS 2018 established both a framework for measuring and reporting achievement in $\mathrm{CT}$ and baseline measures against which $\mathrm{CT}$ can be monitored over time. ICILS remains at the forefront of innovation in the measurement and research of digital literacy related competences in ILSA.

\section{The nature of CIL and CT \\ Describing CIL}

CIL refers to an "individual's ability to use computers to investigate, create, and communicate in order to participate effectively at home, at school, in the workplace, and in society" (Fraillon et al. 2013, p. 17). In ICILS, there is an emphasis on students' abilities to use computer technologies to collect and manage information and to produce and exchange information.

The CIL achievement scale was established with a midpoint (average) of 500 and with 100 scale points as one standard deviation of achievement across ICILS 2013 countries. Theoretically, the scale is "unbounded" at the top and bottom allowing for the measurement and description of extremely high and low CIL achievement. The scale has been described using four levels of achievement. Each level spans 85 scale points and the described levels of the scale range from Level 1 (from 407 to 491 scale points) to Level 4 (above 661 scale points). The levels were 
established such that when a student's achievement is reported to be within a given level, we can be confident that the level describes the CIL that can be demonstrated by the student, even if the student's CIL scale score is near the bottom of the level. Students within any given level can be assumed to have mastered content at lower levels.

Students working at Level 1 (from 407 to 491 scale points) demonstrate familiarity with the basic range of software commands that enable them to access files and complete routine text and layout editing under instruction. They recognize not only some basic conventions used by electronic communications software, including knowing which communication tool to use in a given context, but also the potential for misuse of computers by unauthorized users.

Students working at Level 2 (from 492 to 576 scale points) demonstrate basic use of computers as information resources. They are able to locate explicit information in simple digital resources, select and add content to information products, and exercise some control over laying out and formatting text and images in information products. They can explain the advantage of using a given communication tool in a given context and demonstrate awareness of the need to protect access to some electronic information and of possible consequences of unwanted access to information.

Students working at Level 3 (from 577 to 661 scale points) possess sufficient knowledge, skills, and understanding to independently search for and locate information. They also have the ability to edit and create information products. They can select relevant information from within electronic resources, and the information products they create exhibit their capacity to control layout and design. Furthermore, students working at Level 3 demonstrate awareness that the information they access may be biased, inaccurate, or unreliable. They also can evaluate the weaknesses of the use of a given communication tool in a given context.

Students working at Level 4 (above 661 scale points) execute control and evaluative judgment when searching for information and creating information products. They also demonstrate awareness of audience and purpose when searching for information, selecting information to include in information products, and formatting and laying out the information products they create. Students working at Level 4 additionally demonstrate awareness of the potential for information to be a commercial and malleable commodity and apply the conventions of a given communication tool in a given context to support inclusivity.

\section{Describing CT}

In ICILS 2018, CT is defined as "an individual's ability to recognize aspects of real-world problems which are appropriate for computational formulation and to evaluate and develop algorithmic solutions to those problems so that the solutions could be operationalized with a computer" (Fraillon et al. 2019, p. 27). In ICILS there is an emphasis in CT on students' abilities to conceptualize problems, plan and evaluate solutions, and to operationalize solutions using algorithms and simple computer code.

The ICILS 2018 assessment of CT is the first time that an objective assessment of CT has been created and used in data collection in an ILSA. Data collected in 2018 were used to establish the CT achievement scale. The scale was centered around a midpoint of 500 (determined using the average achievement of the ICILS 2018 countries participating in the CT assessment) and with 100 scale points representing one standard deviation of achievement across the ICILS 2018 countries that participated in the CT assessment.

The CT scale has been described according to three regions of achievement. The primary purpose of these regions is to describe the increase in complexity of CT knowledge, skills, and understandings from low to high achievement in order to understand learning progress in this newly defined area. 
Students showing achievement corresponding to the lower region of the scale demonstrate familiarity with the basic conventions of digital systems to configure inputs, observe events, and record observations when planning computational solutions to given problems. When developing solutions in the form of algorithms, they can use a linear (step by step) sequence of instructions to meet task objectives.

Students showing achievement corresponding to the middle region of the scale demonstrate understanding of how computation can be used to solve real-world problems. They can plan and execute systematic interactions with a system so that they can interpret the output or behavior of the system. When developing algorithms, they use repeat statements effectively.

Students showing achievement corresponding to the upper region of the scale demonstrate an understanding of computation as a generalizable problem-solving framework. They can explain how they have executed a systematic approach when using computation to solve real-world problems. Furthermore, students operating within the upper region can develop algorithms that use repeat statements together with conditional statements effectively.

\section{$\mathrm{CIL}$ and $\mathrm{CT}$ achievements vary greatly within countries}

There were large variations that existed in student CIL and CT proficiency within countries. We will address variations in CIL and CT in turn.

\section{Variations in CIL}

In ICILS 2018, the average CIL achievement of students across countries varied from 395 scale points to 553 scale points, which spans from Below Level 1 to within Level 3 (Table 3.4). Of particular interest in ICILS were the variations in CIL achievement within countries. Even within the countries with higher average CIL achievement there were many students who were able to demonstrate only the basic functional skills described in CIL Level 1. Students working at this level can for example:

- Identify who receives an email by carbon copy (CC);

- Identify problems that can result from mass messaging;

- Record key points from a video into a text-based note taking application;

- Use software to crop an image;

- Place a title in a prominent position on a webpage;

- Create a suitable title for a slide show;

- Insert an image into a document; and

- Suggest one or more risks of failing to log out from a user account when using a publicly accessible computer.

In ICILS 2018 more than one quarter of students in all but one country and one benchmarking participant were performing at Level 1 or Below Level 1. In five countries, the proportion was more than one half (Table 3.5). So regardless of variations in CIL achievement across countries, there remained large numbers of students who were able to complete only the most basic functional tasks on a computer.

With this in mind, across all countries there were students who were achieving at the higher levels on the CIL scale. In three countries and one benchmarking participant more than one quarter of students were performing at Level 3 or above (Table 3.5). As a minimum these students are able to, for example:

- Identify when content published on the internet may be biased as a result of a publisher's content guidelines or advertising revenue directing content; 
- Select relevant information according to given criteria to include in a website;

- Know what information is useful to include when recording a source of information from the internet;

- Use generic online mapping software to represent text information as a map route;

- Select an appropriate website navigation structure for given content;

- Select and adapt some relevant information from given sources when creating a poster;

- Demonstrate control of color and contrast to support readability of a poster; and

- Demonstrate control of text layout when creating a presentation.

While variations in CIL existed across countries, the variation within countries was large. Within each ICILS 2018 country or benchmarking participant the difference in achievement between the top five percent of students and the bottom five percent of students was more than 200 scale points (Table 3.4). This within country difference is larger than the difference in mean CIL achievement between the highest and lowest achieving countries. The existence of these large variations in achievement within countries and the proportions of students demonstrating only the most basic CIL skills suggest that acquisition of these skills cannot be left to incidental learning.

In ICILS 2013, we questioned the relevance of the description of the current generation of young people as digital natives. The ICILS 2018 data again support the contention that, regardless of our own impressions of the facility with which young people embrace new technologies, there remain large proportions of young people who can complete only the most basic technical operations when using a computer. One danger of assuming that young people are imbued with a capacity to manage complex functions on computers is that we may infer that there is little need to formally address knowledge, skills, and understandings as part of schooling. The ICILS 2018 data support the findings of ICILS 2013 in demonstrating that many grade 8 students have developed little more than rudimentary CIL capacities. Formal schooling needs to play a more significant role in developing these capacities within young people given that it is clear that, for many students, they are not currently being developed through other means.

\section{Variations in CT}

In ICILS 2018, the average CT of students across countries varied by 76 scale points, from 460 to 536 scale points, all of which are in the middle region of the scale. However, within countries there was considerable variation in student CT. In all countries the difference in CT between the top and the bottom five percent of students was greater than 250 scale points, more than three times the difference between the highest and lowest average CT across countries (Table 4.1).

In all but two countries more than one quarter of students' ${ }^{C T}$ scores were less than 459 scale points. This is described as CT achievement in the lower region of the CT scale. These students were, at most, able to:

- Create a complete but suboptimal route from one location to another on a network diagram;

- Partially debug an algorithm that uses a repeat statement by correcting the logic of connected statements;

- Create an efficient algorithm that meets all of the given task objectives for a low-complexity problem (i.e., a problem with a limited set of available commands and objectives); and

- Create an inefficient algorithm that meets all of the given task objectives for a mediumcomplexity problem (e.g., a problem with multiple objectives best solved using a repeat statement). 
As was reported for CIL achievement, regardless of variations in achievement across countries, there were large proportions of students who are able to complete only the most basic CTrelated tasks. Where tasks were more complex, such as those with simple iterative logic or with multiple solutions, these students would typically provide incomplete or inefficient solutions.

Across countries, between two and 16 percent of students had CT achievement scores of more than 639 scale points, or in the upper region of the scale. These students were likely to be able to:

- Explain the value of a digital system for real-world problem solving;

- Complete a simple decision tree with the correct use of both logic and syntax;

- Debug, with the most efficient solution, an algorithm for a high-complexity problem (e.g., a problem with multiple task objectives best solved using repeat and conditional statements); and

- Create an efficient algorithm that meets all of the objectives for a high-complexity problem (e.g., multiple task objectives best solved using repeat and conditional statements).

It is encouraging to note that some students, albeit in relatively small proportions, demonstrated understandings of the use of digital systems in real-world problem solving and were able to create efficient algorithms expressed as visual code commands. The broad range of student CT achievement within countries shows that these skills can be developed by grade 8 students but suggests that these skills may not be developed through exposure to and use of digital devices alone. In Chapter 2, we reported considerable variation across countries regarding their national curriculum emphases on CT although most countries do provide a separate CIL-related subject that includes at least some coding. There is opportunity across countries to increase the emphasis on the core aspects of CT in curriculum and learning programs.

\section{CIL, CT, digital literacy, and student gender}

In ICILS 2018 CIL and CT are conceptualized, operationalized, measured, and reported as separate areas of learning. The two domains are clearly discrete in their focus. CIL emphasizes information literacy in receptive and productive communicative contexts, whereas CT emphasizes problem specification and the creation of solutions that can be implemented by computers. Despite the obvious conceptual and operational differences, it is clear that the two domains are practically linked because both involve interaction with digital devices. At a conceptual level, the domains are both rooted in an understanding of how computers process the information we provide them, how they are used as tools, and the conventions associated with computer use and software environments.

These two ICILS domains can be regarded as complementary aspects of a broader notion of digital competence. However, the complementarity of the two domains and their contribution to a larger notion of digital competence remains a question for further investigation. For example, the CIL content in ICILS can be seen to relate to each of the five competence areas (information and data literacy; communication and collaboration; digital content creation; safety; and problem solving) described in the European Commission's DigComp 2.0 Framework (Vuorikari et al. 2016). The ICILS CT content domain can be regarded as particularly relevant to the DigComp problem-solving competence area. While it is possible to see how the two ICILS achievement domains can be considered under an example of a broader notion of digital competence, the Computational Thinking Study under the EU Science Hub, lists the relationship between CT and digital literacy/digital competence as one of the areas in which more evidence-based research is needed (European Commission 2019). ICILS 2018 data and data to be obtained from future cycles of ICILS may contribute to better understanding of this connection. Under an alternative approach, the US National Assessment of Educational Progress Technology and Engineering 
Literacy assessment includes content that overlaps with each of CIL and CT although without the same emphasis on CT as a form of problem solving processes (see, NAGB [National Assessment Government Board] 2014).

ICILS 2018 has provided empirical data that contributes to our understanding of the relationship between CIL and CT. Achievement in the two domains were highly correlated. Across ICILS countries that participated in CIL and CT the correlation in achievement ranged from 0.74 to 0.89. The high correlation between CIL and CT may be explained, in part, by the relationship of achievement in each domain to general academic ability. However, despite the strong association between CIL and CT achievement, data from ICILS 2018 show different patterns of achievement in each of CIL and CT by student gender. Female students showed consistently higher CIL achievement than male students, and male students tended to demonstrate higher CT achievement than female students.

If one accepts the proposition that CIL achievement relates to information literacy in a general ICT context and CT achievement relates more to specialized ICT use, then the difference in the association between each of CIL and CT and student gender is consistent with the patterns of gender difference in students' uses of and attitudes towards the use of ICT. Female students tended to report using ICT for school-related purposes and using general ICT applications slightly more than male students. Where differences occur, female students tended to report learning more about CIL-related content at school than did male students and overall there was little reported difference in students' general ICT self-efficacy. However, male students reported more than female students that they were learning about CT-related content at school. Male students also reported consistently higher ICT self-efficacy regarding specialist ICT tasks, generally more positive perceptions about the role of ICT in society, and generally less negative perceptions about the role of ICT in society.

The ICILS 2018 data regarding CIL, CT, and student gender are consistent with current beliefs about the differences in female and male students' attitudes towards and uses of ICT. Female students are stronger users of ICT for general school-related tasks (such as locating information from within digital sources and creating digital artefacts to communicate information to others). Male students are more confident to approach, and slightly stronger at dealing with, specialist ICT tasks (such as changing computer settings or creating programs). These findings provide a challenge to curricular and educational policy. If CIL and CT are valued by policymakers as components of a broader digital literacy necessary for effective participation in an increasingly digital world, then ICILS 2018 raises questions about how these gender differences in attitudes and achievement may be addressed.

\section{Evidence of the digital divide}

The notion of a digital divide is, at its simplest, a reference to the varying opportunities and access that people have to ICT. Hohlfeld et al. (2008) postulated a model for researching the digital divide in schools, which can be considered to have three levels: access to technological infrastructure; the use of technology in the classroom; and the use of technology to empower individuals. While ICILS 2018 was not designed with a particular model of the digital divide in mind, for the purpose of this discussion we accept the proposition that consideration of the digital divide can extend beyond access to technology to include how technology is used in schools and how students are empowered through technology to participate in their digital world.

Twelve of the 14 ICILS 2018 countries and benchmarking participants indicated that reducing the digital divide between groups of students was emphasized in their plans, policies, and priorities regarding the use of ICT (see Chapter 2). In ICILS 2018, the relationships between student socioeconomic status (SES) and CIL and CT were consistent and clear. Across ICILS countries student SES (both for individual students and averaged within their schools) was a strong 
predictor of student CIL and CT. Other consistent predictors were students' experience of using computers and their frequency of using ICT at home (Tables 3.8, 3.10, 4.3, 4.5, 7.5, and 7.10).

While the relationship between student SES and educational achievement is a consistent and pervasive finding in ILSA studies across all learning areas, in ICILS the relationship of SES to CIL and CT appears to involve a combination of factors. The generally observed outcome of SESrelated educational advantage or disadvantage combines with the specific SES-related influences relating to the digital divide. Students from low SES backgrounds may have limited access to ICT infrastructure and the educational benefits associated with its use in learning about CIL and CT.

It is beyond the scope of this report to investigate in detail the nature and effect of the digital divide within and across individual ICILS countries. However, evidence of a digital divide is clearly apparent in the student achievement results in both CIL and CT. This finding alone warrants consideration about how countries may work to reduce the divide. The ICILS data offer the potential to examine evidence of a digital divide within countries, not just in terms of infrastructure provision and access to ICT but to probe differences in approaches to the teaching and learning of CIL and CT in schools. The ICILS teacher and school-level data offer a resource to be investigated from this perspective.

\section{Digital devices as digital textbooks}

ICILS 2013 called into question "the idealized images commonly associated with visions of ICT in teaching and learning" (Fraillon et al. 2014, p. 257). One of these images related to the degree to which digital technologies were being used to transform classrooms from traditional teacher-centered environments into more constructivist learning environments. In ICILS 2013, we found that the most commonly reported uses of computers in classes by students related to tasks associated with document preparation and presentations. The activities reported most frequently by teachers related to presenting information to students and skills development through repetition. The conclusion in 2013 was that "computers were most commonly being used to access digital textbooks and workbooks rather than to provide dynamic, interactive pedagogical tools" (Fraillon et al. 2014, p. 257).

In ICILS 2018 we again sought to investigate the ways in which students and teachers perceived the use of ICT in teaching and learning. As the countries that participated in ICILS 2018 are largely different to those that participated in ICILS 2013, we will not discuss changes within countries, rather we will discuss the findings of ICILS 2018 (reported in detail in Chapters 5 and 6) as a snapshot of ICT use in classes across a broad range of countries in 2018 . The context for this can be compared to that of ICILS 2013 in which a similar snapshot was made, albeit across a somewhat different but similarly broad set of countries.

In ICILS 2018 the activities using ICT applications reported most frequently by students in their lessons were using computer-based information resources, word-processing software, and presentation software. The least frequently reported activities were using simulations and modeling software, concept mapping software, and tools that capture real-world data (Table 5.17).

The general ICT utility tools reported most frequently used by teachers in most lessons were word-processor software, presentation software, computer-based information resources, and digital contents linked with textbooks. Each of these was reported, on average across countries, to be used in most lessons by more than 30 percent of teachers. In comparison, teachers reported less use of digital learning tools in class (Table 6.20). Learning management systems and interactive digital learning resources were the digital learning ICT tools reported on average across all countries by more than 20 percent of teachers to be used in most lessons. The least frequently reported digital learning tools were practice programs or apps, e-portfolios, concept mapping software, and simulations and modeling software, all of which were reported to be used in most lessons by fewer than 10 percent of teachers (Table 6.21). 
High proportions of students did, however, report having learned to a large or moderate extent a range of content and processes associated with each of CIL and CT. On average across countries, CIL-related activities were reported to have been learned about at school, to a large or moderate extent, by more than 60 percent of students (Table 5.21). Only two aspects of CT (to make flow diagrams to show the different parts of a process and to use simulations to help understand or solve real-world problems) were reported to have been learned at school, to a moderate or large extent, by fewer than 50 percent of students on average across countries (Table 5.24).

Students' reported experience of learning about CIL and CT in class was consistent with teacher reports of their emphasis on CIL- and CT-related capabilities in their classes. On average, across countries more than 60 percent of teachers reported placing some or a strong emphasis on CIL-related capabilities with the exception of to provide digital feedback on the work of others, which was emphasized by 49 percent of teachers (see Chapter 6). While CT-related capabilities were less frequently reported to be emphasized by teachers than CIL-related capabilities, more than 60 percent of teachers reported placing some or strong emphasis on six of nine CT-related capabilities with the remaining three being emphasized by fewer than 50 percent of teachers (see Chapter 6).

So, while it is positive news that teachers and students agree that CIL and CT learning are being included in classes, the picture of classroom use of ICT in ICILS 2018 is similar to that reported in ICILS 2013 (albeit in a largely different set of countries). Despite the passage of time between 2013 and 2018 and the concomitant increase in the availability of digital technology resources for teaching and learning, the observation from ICILS 2013 that computers in school education were most commonly being used as digital textbooks remains valid. For policymakers this raises a number of questions about the contrast between the messages that are frequently provided around the use of ICT in teaching and learning and the reality of classroom practice. The questions should not only relate to the reasons for, or even the detailed nature of, the mismatch between pedagogical rhetoric and classroom realities. Rather, the questions should extend to what it is reasonable to expect from classroom teachers in their use of ICT in teaching and what best practice use of ICT looks like within countries, schools, and across learning areas. Schools and teachers should not be offered unrealistic and unachievable idealized images of ICT use in classrooms. However, further work needs to be done to determine what should be presented to schools and teachers as desirable, productive, and even "best practice" in the use of ICT in teaching.

\section{Supporting teachers to use ICT in their teaching}

We can see from the data reported in Chapter 2 that the development of CIL- and CT-related competencies are valued across ICILS countries. They are emphasized within educational plans and policies and manifest in countries' commitments to providing infrastructure, professional learning support for teachers, and learning materials relating to these areas. While CIL has a greater emphasis in curriculum across countries than $\mathrm{CT}$, both are represented in the curricula of most ICILS countries. This commitment across countries to developing digital literacy related competencies brings with it the question of what the ICILS 2018 data on teaching with and about ICT (see Chapter 6) can further tell us about how teachers can best be supported to use ICT in their teaching and to facilitate student learning in CIL and CT.

\section{Provision of ICT}

Across the ICILS 2018 countries, teachers were generally well experienced with the use of ICT in their preparation and delivery of lessons and overall indicated that they were confident to use ICT in their teaching for a broad range of actions. However, despite these positive indicators, on average across all ICILS countries, fewer than half the teachers reported using ICT in their teaching every day, and in only one country was ICT use reported to be used in teaching daily 
by more than 70 percent of teachers (Table 6.1). This raises the additional question of what can be done to increase the use of ICT in teaching.

Unsurprisingly, we found that teachers were more likely to use ICT in teaching if they believed they were in a school where there were sufficient ICT resources available to them. In this case, ICT resources referred to infrastructure, technical support, time to plan lessons, and having the opportunity to develop expertise in ICT (Table 6.10 and 6.13). It is interesting to note that teachers perceived the practical support associated with the provision of time and opportunity to develop skills as congruent with the provision of ICT infrastructure. This suggests that, while the provision of ICT infrastructure in schools can impact on the likelihood of teachers using ICT, they should be accompanied with the provision of time for teachers to plan for ICT use and develop ICT skills. When developing ICT plans and policies, it may be valuable to consider teacher time and opportunities to learn as aspects of infrastructure rather than as separate aspects of policy and planning.

\section{Collaborative school environment}

In ICILS 2013 teachers' perceptions of the degree to which they were in a collaborative school environment regarding the implementation of ICT emerged as a factor relating to teachers' likelihood to emphasize CIL in their teaching. In ICILS 2018, across a largely different set of countries, teachers' perceptions of collaboration regarding the use of ICT was again an important factor in explaining teacher practice.

In ICILS 2018, while the student assessment of CT was optional for countries, the teacher questionnaire completed by all countries included a question relating to teachers' emphasis on CT-related tasks in their teaching. In all ICILS 2018 countries, teacher perceptions of collaboration regarding the use of ICT was associated with their emphasis on developing both CIL- and CTrelated outcomes in their students (Tables 6.17 and 6.19).

This finding was consistent with that of ICILS 2013. Across the two cycles of ICILS we can see that teacher responses to their perception of working in a collaborative school environment have been expressed across a broad range of countries and with reference to their teaching of CIL and CT. To this effect we can see that the findings of ICILS 2018 have confirmed and strengthened those of ICILS 2013 and should be given due attention by policymakers when planning how to support the work of teachers in schools. Teachers are providing the clear message that their implementation of CIL- and CT-related content in their teaching is advantaged by the sense that they are working in a school with a collaborative approach to the use of ICT.

\section{Nurturing confident and enthusiastic teachers}

In ICILS 2018 we found that teachers' beliefs in their own capacities to use ICT and also their beliefs about ICT are positively associated with each other and to the degree of emphasis they place on CIL and CT in their teaching. Teachers with higher ICT self-efficacy were more likely to hold more positive views about the use of ICT in teaching and less negative views about the limitations of ICT use (Table 6.7). From this we can develop an image of teachers who are confident and vigorous proponents of ICT in education in comparison to those who lack confidence and belief in the pedagogical value of ICT. Ideally, education systems would work to support the development of the former profile in their teachers.

While teacher confidence to complete tasks using ICT was generally high, this confidence did vary across countries but more importantly with age within countries. In all countries, teachers under the age of 40 expressed higher levels of ICT self-efficacy than teachers aged 40 years or older (Table 6.3). The ICILS 2018 data raise the question of whether targeted programs to support the development of ICT use by older teachers may help to redress this imbalance. 


\section{Future directions for research}

In this report, we have offered a first look at the findings from ICILS 2018, suggested themes that have emerged in 2018, and reflected on those that have persisted since ICILS 2013. The ICILS 2018 results both answer questions relating to student learning of CIL and CT and give rise to new questions. The ICILS international database is a rich resource of data collected in ICILS 2018 that can be used to support scholars to research CIL, CT, and the contexts in which they are being developed in young people. ${ }^{31}$

Opportunities exist to investigate further the measurement properties of CIL and CT and how they may be used, for example, to identify specific areas of strength or need for students or subgroups of students within and across countries. In this report we can see strong evidence of the digital divide within countries. Further research using data from ICILS 2018 could investigate the details of the digital divide, not only in terms of the ICT resources that are available to young people but also in terms of their experience of education with ICT. ICILS has also uncovered clear evidence of gender differences in student outcomes in CIL and CT and in the pattern of differences across the two. Questions remain about what this means for our collective ambitions to support all people to develop broad digital competences.

Why, for example, do female students consistently show higher CIL performance than male students and yet male students demonstrate higher levels of engagement with and generally higher achievement in the specialized ICT use associated with CT? Is this pattern consistent within all countries, are there subgroups of students within countries for whom the gender differences do not follow the pattern? What can policymakers and schools do to redress these differences? This leads to a broader set of questions associated with the nature of teaching of $\mathrm{CIL}$ and CT in schools. Further exploration of the variety of approaches to CIL and CT education across and within ICILS countries may help to answer such questions.

In ICILS we collected detailed information from teachers and students about classroom experiences with ICT and in the teaching and learning of CIL and CT. One clear theme in this report, and of ICILS 2013, was that the most frequent uses of ICT in teaching are as digital aids in the execution of somewhat "traditional" classroom practices. The ICILS 2018 data offer the opportunity for further detailed investigation of the nature, patterns, and even profiles of school and classroom practices with ICT. This extends to the influences on teachers' propensity, willingness, and confidence to use ICT in their teaching and to incorporate the teaching of aspects of CIL and CT in their classes.

There is widespread international agreement about the importance of developing digital competences such as CIL and CT in young people. ICILS 2018 has provided clear evidence that that the knowledge, skills, and understandings that comprise these competences are not developed simply through exposure to technology. They require the support of formal education. However, more work needs to be done on how these competences are learned and how they can best be taught.

A third cycle of ICILS is planned for 2023. In ICILS 2023 we plan to build on and to extend the work of ICILS 2013 and 2018. The measures of CIL and CT will continue and be extended to include a large suite of content, including content that reflects developments in digital applications and the use of digital applications between 2018 and 2023. We will investigate the contribution of process data (data collected about the way in which students complete tasks) to our understanding of CIL and CT, and update and extend the measures dealing with the contexts in which students develop CIL and CT. ICILS will continue to be at the forefront of research into students' preparedness for life in a rapidly evolving digital world.

31 The ICILS 2018 international database is to be released to the public in March 2020. 


\section{References}

Denning, P. J. (2017). Remaining trouble spots with computational thinking. Communications of the ACM, 60(6), 33-39. Retrieved from https://cacm.acm.org/magazines/2017/6/217742remainingtrouble- spots-with-computational-thinking/abstract.

European Commission. (2019). The computational thinking study [webpage]. Brussels, Belgium: European Commission, Joint Research Centre. Retrieved from https://ec.europa.eu/jrc/en/ computational-thinking.

Fraillon, J., Ainley, J., Schulz, W., Duckworth, D., \& Friedman, T. (2019). IEA International Computer and Information Literacy Study 2018 assessment framework. Cham, Switzerland: Springer. Retrieved from https://www.springer.com/gp/book/9783030193881.

Fraillon, J., Ainley, J., Schulz, W., Friedman, T., \& Gebhardt, E. (2014). Preparing for life in a digital age: The IEA International Computer and Information Literacy Study international report. Cham, Switzerland: Springer. Retrieved from https://www.springer.com/gp/book/9783319142210.

Fraillon, J., Schulz, W., \& Ainley, J. (2013). International Computer and Information Literacy Study assessment framework. Amsterdam, The Netherlands: International Association for the Evaluation of Educational Achievement (IEA). Retrieved from https://www.iea.nl/publications/assessmentframework/international-computer-and-information-literacy-study-2013.

Hohlfeld, T.N., Ritzhaupt, A.D., Barron, A.E., \& Kemker, K. (2008). Examining the digital divide in K-12 public schools: Four-year trends for supporting ICT literacy in Florida. Computers \& Education, 51(4), 1648-1663. Retrieved from https://doi.org/10.1016/j.compedu.2008.04.002.

NAGB. (2014). 2014 Abridged Technology and Engineering Literacy framework for the 2014 National Assessment of Educational Progress. Washington, DC: National Assessment Governing Board. Retrieved from https://files.eric.ed.gov/fulltext/ED563941.pdf.

Vuorikari, R., Punie, Y., Carretero Gomez, S., \& van den Brande, G. (2016). DigComp 2.0: The digital competence framework for citizens. Update phase 1: The conceptual reference model. Joint Research Centre Report EUR 27948 EN. Luxembourg: Publication Office of the European Union. Retrieved from https://doi.org/10.2791/11517.

Open Access This chapter is licensed under the terms of the Creative Commons Attribution-NonCommercial 4.0 International License (http://creativecommons.org/licenses/by-nc/4.0/), which permits any noncommercial use, sharing, adaptation, distribution and reproduction in any medium or format, as long as you give appropriate credit to the original author(s) and the source, provide a link to the Creative Commons license and indicate if changes were made.

The images or other third party material in this chapter are included in the chapter's Creative Commons license, unless indicated otherwise in a credit line to the material. If material is not included in the chapter's Creative Commons license and your intended use is not permitted by statutory regulation or exceeds the permitted use, you will need to obtain permission directly from the copyright holder. 


\section{APPENDIXA:}

\section{Sampling information and participation rates}

Table A.1: Coverage of ICILS 2018 target population

\begin{tabular}{|c|c|c|c|c|}
\hline \multirow[t]{2}{*}{ Country } & \multirow{2}{*}{$\begin{array}{l}\text { International target } \\
\text { population coverage (\%) }\end{array}$} & \multicolumn{3}{|c|}{ Exclusions from target population (\%) } \\
\hline & & At school level & Within sample & Overall \\
\hline Chile & 100 & 0.5 & 0.8 & 1.3 \\
\hline Denmark & 100 & 3.1 & 4.4 & 7.5 \\
\hline Finland & 100 & 1.6 & 2.4 & 4.0 \\
\hline France & 100 & 3.4 & 1.3 & 4.7 \\
\hline Germany & 100 & 1.5 & 2.9 & 4.3 \\
\hline Italy & 100 & 0.1 & 2.9 & 3.0 \\
\hline Kazakhstan & 100 & 3.4 & 2.1 & 5.6 \\
\hline Korea & 100 & 0.9 & 0.6 & 1.5 \\
\hline Luxembourg & 100 & 0.0 & 3.9 & 3.9 \\
\hline Portugal & 100 & 0.8 & 8.0 & 8.9 \\
\hline United States & 100 & 0.0 & 5.0 & 5.0 \\
\hline Uruguay & 100 & 1.1 & 0.0 & 1.1 \\
\hline \multicolumn{5}{|l|}{ Benchmarking participants } \\
\hline Moscow (Russian Federation) & 100 & 0.7 & 2.3 & 3.0 \\
\hline North Rhine-Westphalia (Germany) & 100 & 1.4 & 3.1 & 4.6 \\
\hline
\end{tabular}

Note: Results are rounded to one decimal place. 


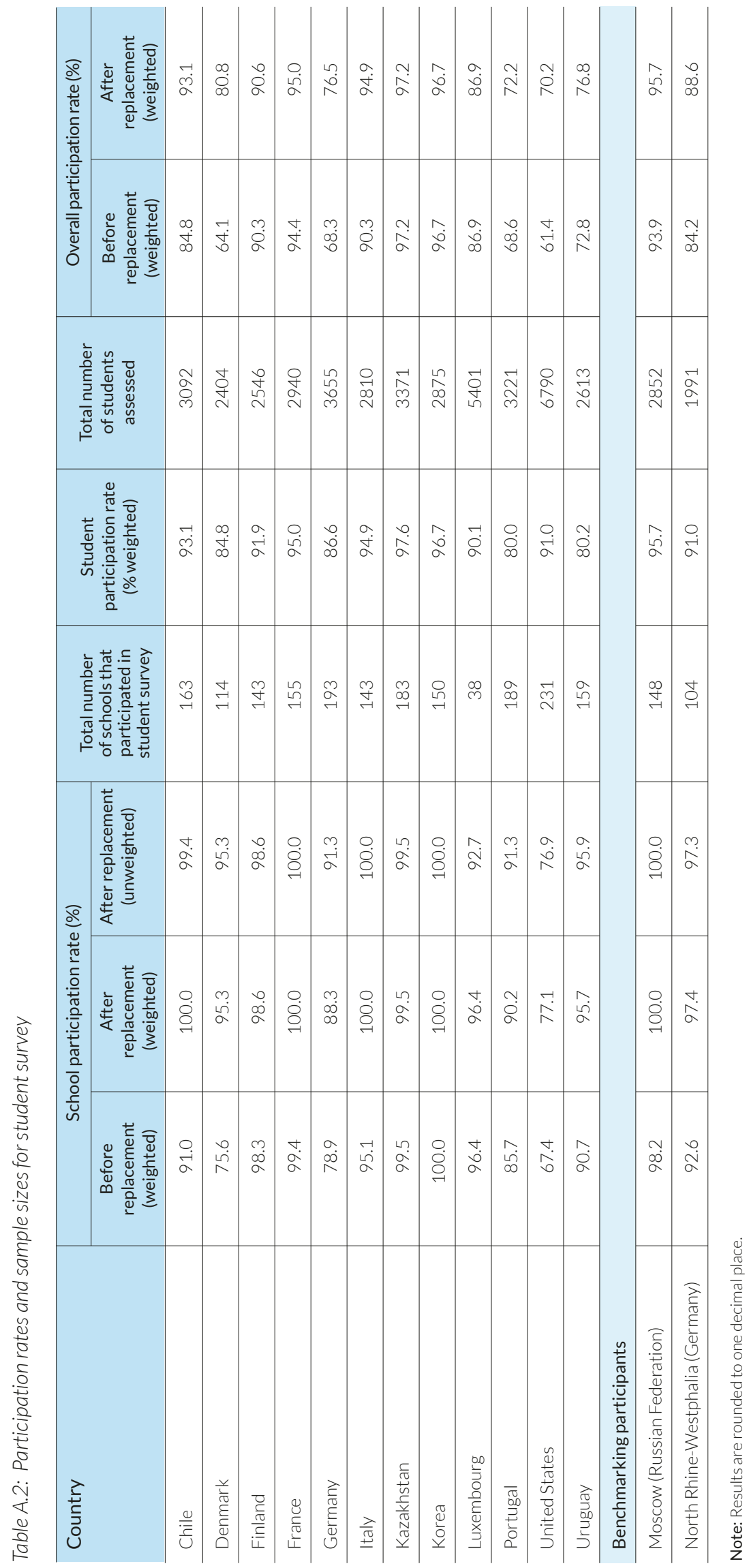




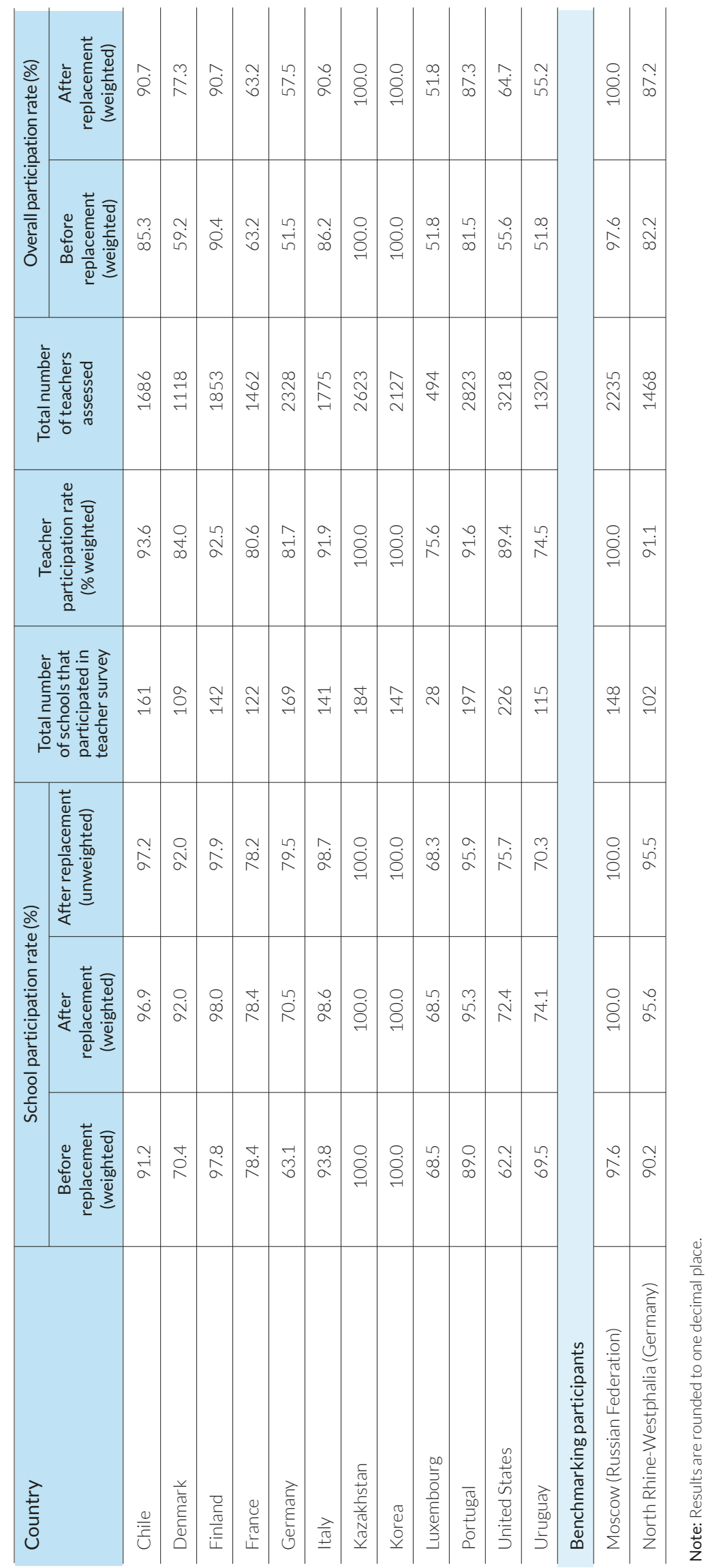


APPENDIX B:

Percentage correct by country for example large task scoring criteria
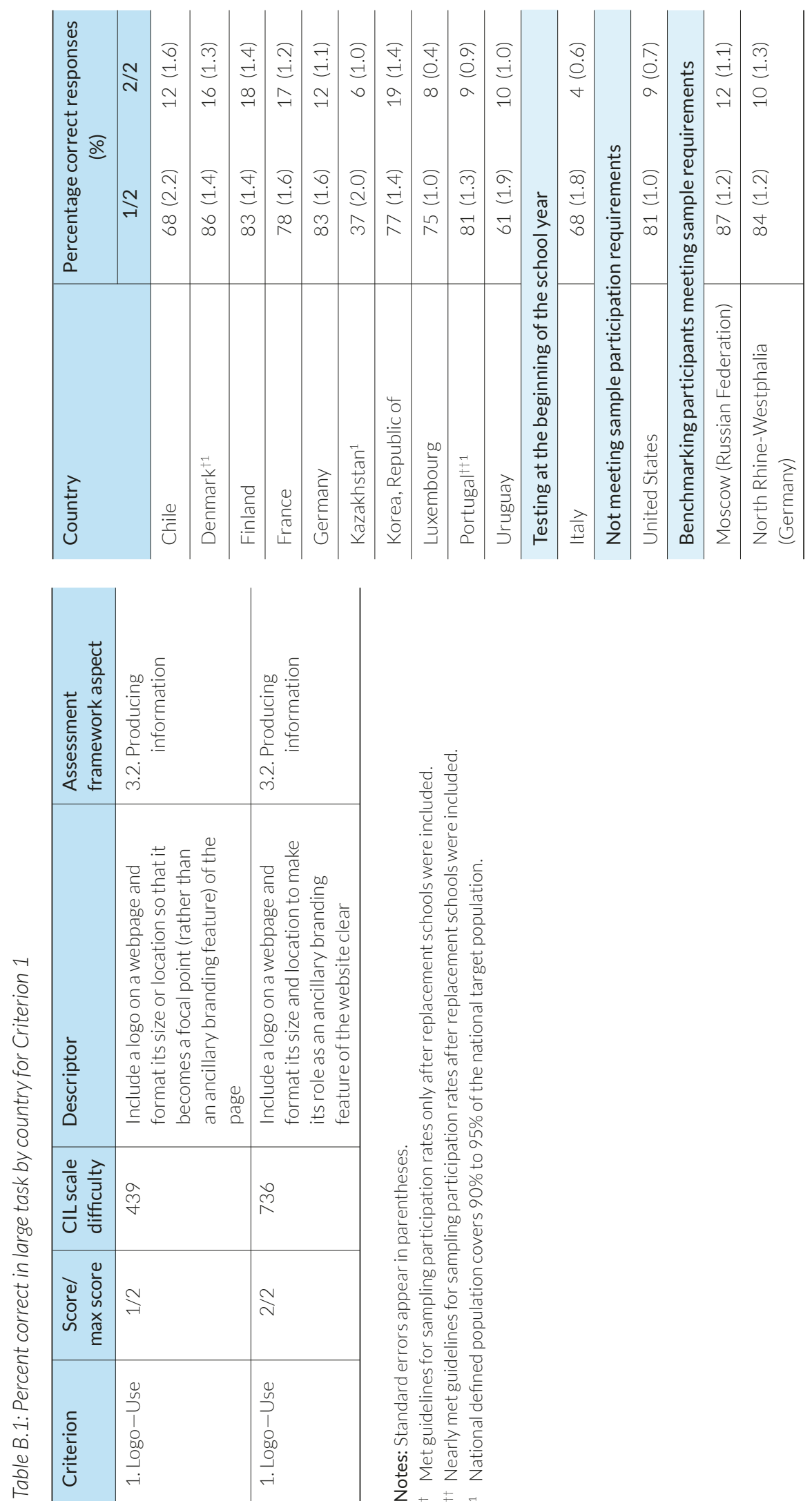

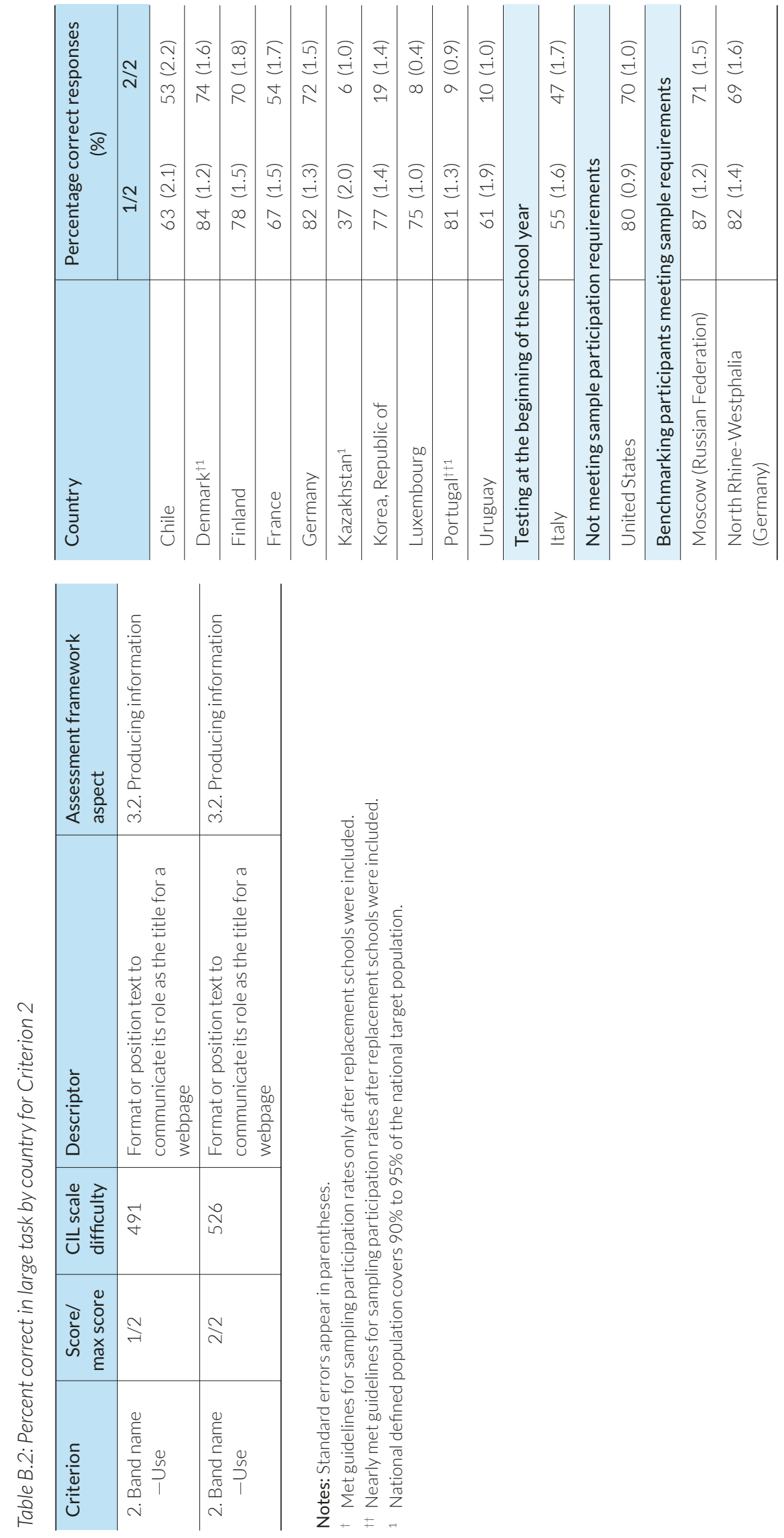

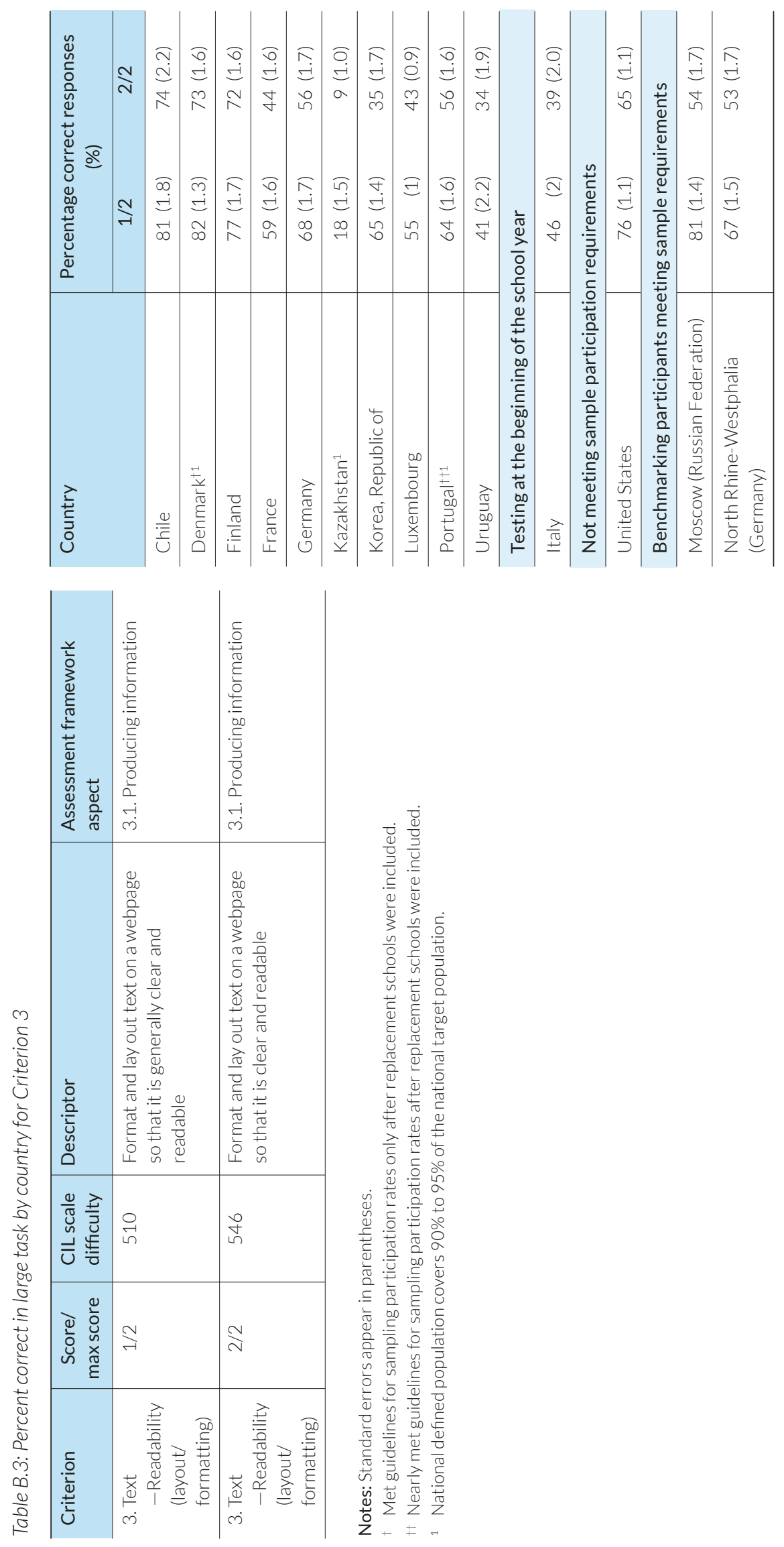

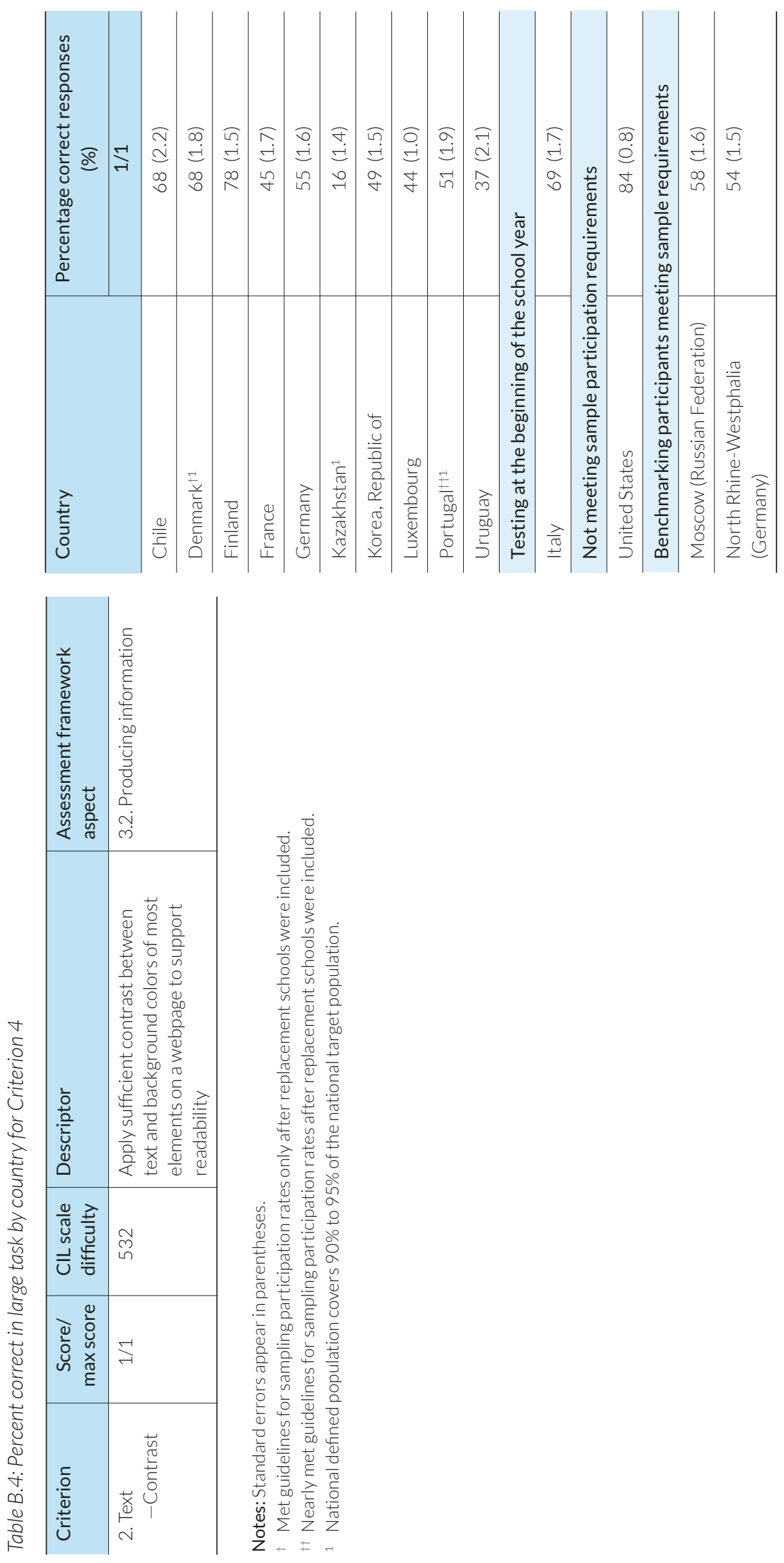

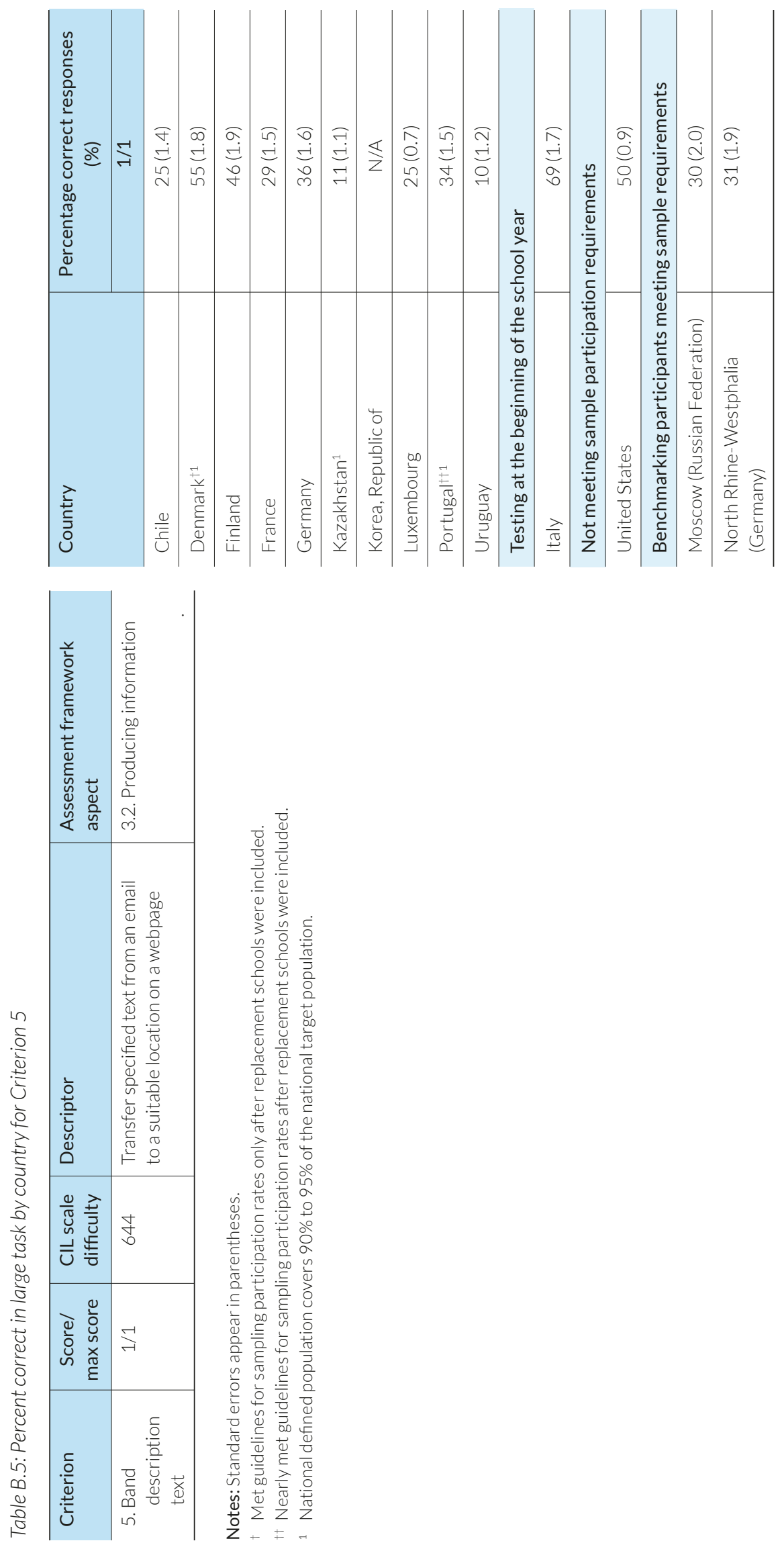

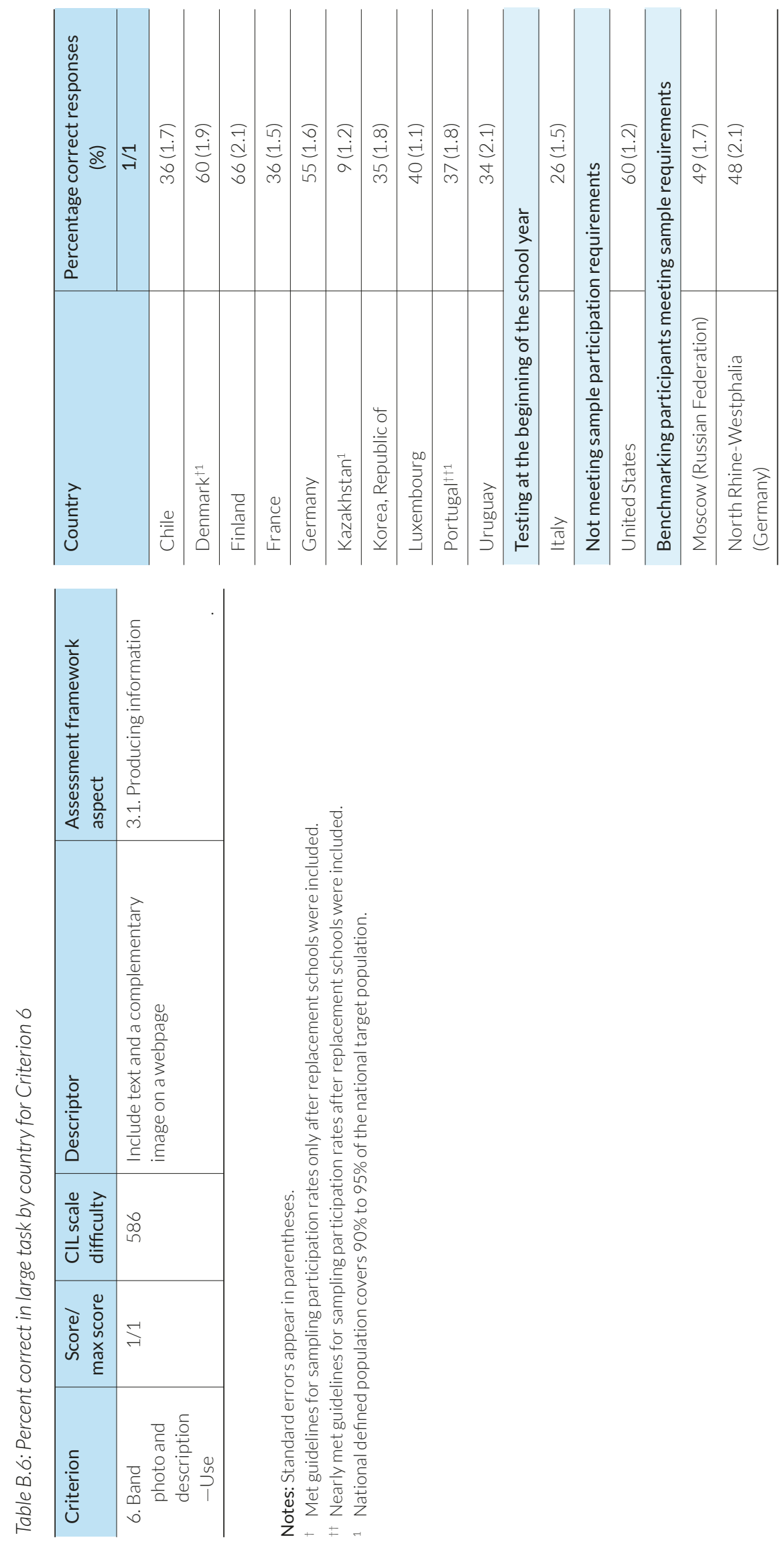

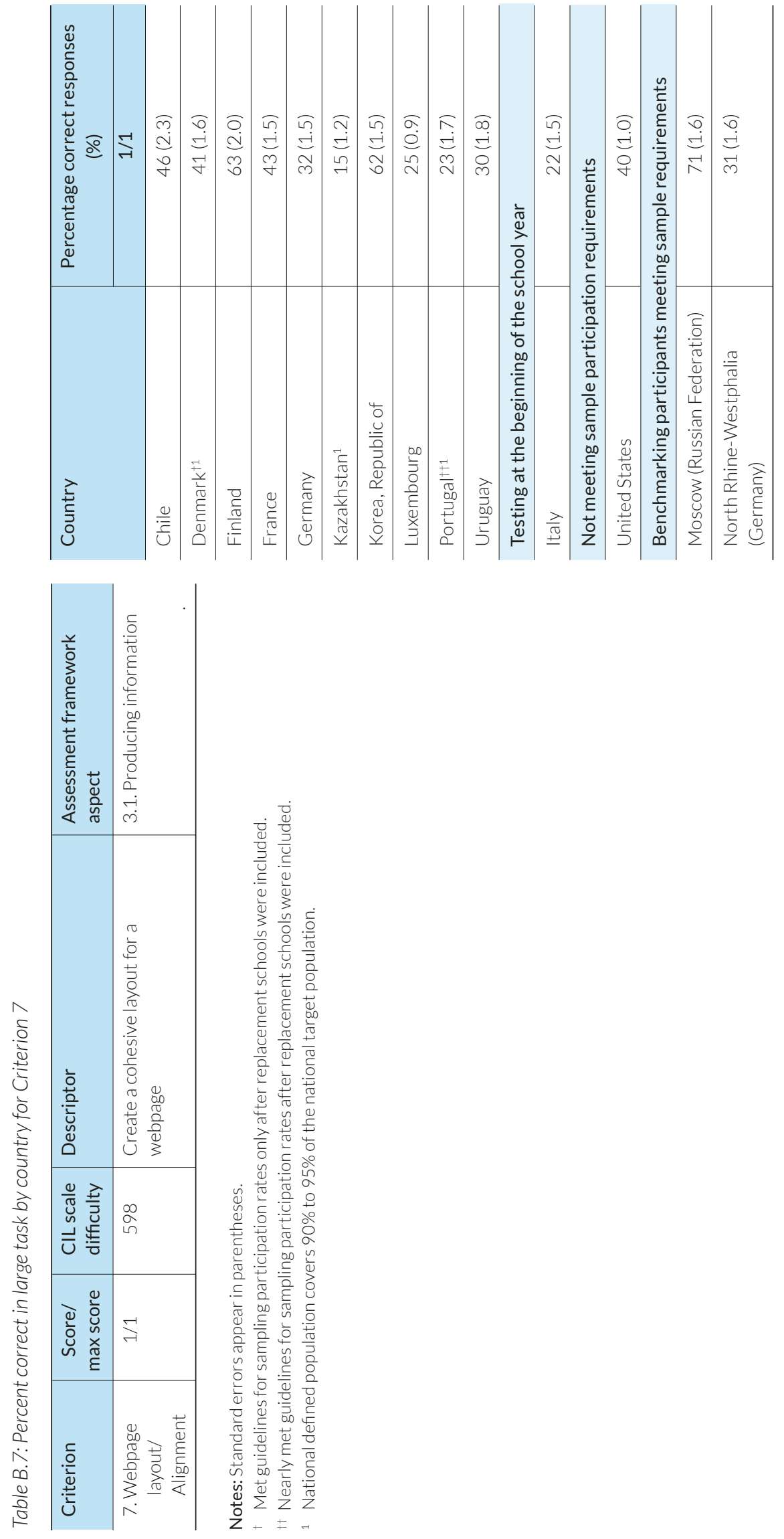
APPENDIXC:

Percentiles, means, and standard deviations of computer and information literacy and computational thinking

Table C.1: Percentiles of computer and information literacy

\begin{tabular}{|c|c|c|c|c|c|c|c|}
\hline \multirow{2}{*}{$\begin{array}{l}\text { Country } \\
\text { Chile }\end{array}$} & 5th percentile & \multicolumn{2}{|c|}{ 25th percentile } & \multicolumn{2}{|c|}{ 75th percentile } & \multicolumn{2}{|c|}{ 95th percentile } \\
\hline & 325 (11.3) & 425 & (6.2) & 534 & (3.5) & 600 & (5.7) \\
\hline Denmark $^{{ }^{1}}$ & $435 \quad(6.0)$ & 515 & (3.0) & 598 & (2.4) & 650 & (3.9) \\
\hline Finland & $381 \quad(7.6)$ & 486 & $(4.2)$ & 587 & (3.6) & 645 & $(4.0)$ \\
\hline France & $357 \quad(9.6)$ & 448 & (4.0) & 555 & (2.8) & 618 & (3.8) \\
\hline Germany & $372 \quad(9.0)$ & 470 & $(4.7)$ & 574 & (2.5) & 634 & $(4.3)$ \\
\hline Kazakhstan $^{1}$ & $217 \quad(9.8)$ & 322 & (7.7) & 471 & (6.8) & 564 & (8.9) \\
\hline Korea, Republic of & $370 \quad(7.1)$ & 481 & $(4.9)$ & 610 & (2.8) & 682 & $(4.8)$ \\
\hline Luxembourg & $329 \quad$ (3.9) & 428 & (1.9) & 542 & (1.2) & 606 & (2.1) \\
\hline Portugal ${ }^{+\dagger}{ }^{1}$ & (8.3) & 472 & (4.0) & 565 & (3.7) & 623 & (3.3) \\
\hline Uruguay & 280 & 380 & (5.5) & 527 & (5.3) & 605 & $(7.0)$ \\
\hline \multicolumn{8}{|c|}{ Testing at the beginning of the school year } \\
\hline Italy & 315 & 410 & (5.6) & 518 & $(2.7)$ & 587 & (3.8) \\
\hline \multicolumn{8}{|c|}{ Not meeting sample participation requirements } \\
\hline United States & $373(4.9)$ & 469 & (3.1) & 576 & $(2.2)$ & 638 & (3.1) \\
\hline \multicolumn{8}{|c|}{ Benchmarking participants meeting sample participation requirements } \\
\hline Moscow (Russian Federation) & 425 & 509 & (2.8) & 595 & (2.5) & 651 & (3.7) \\
\hline North Rhine-Westphalia (Germany) & $385 \quad(7.5)$ & 467 & (3.9) & 565 & (3.2) & 629 & (3.8) \\
\hline
\end{tabular}

Notes: Standard errors appear in parentheses.

+ Met guidelines for sampling participation rates only after replacement schools were included.

t† Nearly met guidelines for sampling participation rates after replacement schools were included.

National defined population covers $90 \%$ to $95 \%$ of the national target population. 


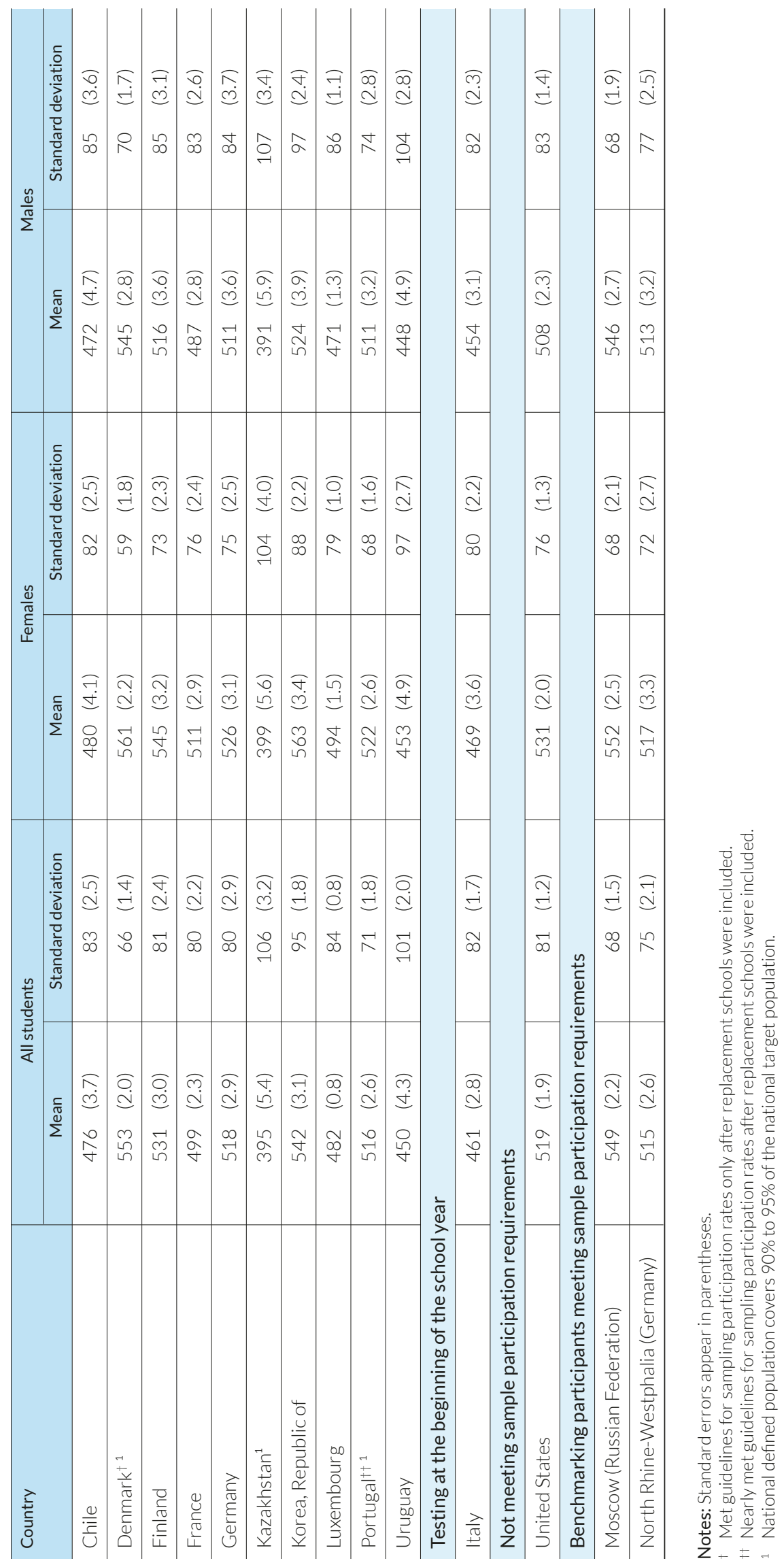


Table C.3: Percentiles of computational thinking

\begin{tabular}{|c|c|c|c|c|}
\hline Country & 5th percentile & 25th percentile & 75th percentile & 95th percentile \\
\hline Denmark ${ }^{1}$ & $385 \quad(7.3)$ & $475 \quad(4.1)$ & $585 \quad(2.8)$ & $661(4.2)$ \\
\hline Finland & $331(10.0)$ & $449 \quad(4.7)$ & $575 \quad(5.0)$ & $652 \quad(5.3)$ \\
\hline France & $342 \quad(8.3)$ & 441 (3.2) & $566 \quad(2.4)$ & $646 \quad(4.8)$ \\
\hline Germany & $305(10.1)$ & $421 \quad(6.3)$ & $553 \quad(4.7)$ & $649 \quad(7.5)$ \\
\hline Korea, Republic of & 332 (13.3) & $471 \quad(5.8)$ & $612 \quad(4.2)$ & $702 \quad(6.7)$ \\
\hline Luxembourg & $273 \quad(3.5)$ & 391 (2.3) & $533 \quad(1.5)$ & $628 \quad(3.6)$ \\
\hline Portugal ${ }^{\dagger+1}$ & 341 (8.3) & $431 \quad(3.1)$ & $535 \quad(3.5)$ & $607 \quad(4.9)$ \\
\hline \multicolumn{5}{|c|}{ Not meeting sample participation requirements } \\
\hline United States & $313 \quad(5.1)$ & $429 \quad(3.6)$ & $573 \quad(2.9)$ & $668 \quad(5.2)$ \\
\hline \multicolumn{5}{|c|}{ Benchmarking participant meeting sample participation requirements } \\
\hline North Rhine-Westphalia (Germany) & $325 \quad(6.7)$ & $425 \quad(4.4)$ & $547 \quad(3.9)$ & 638 (7.2) \\
\hline
\end{tabular}

Notes: Standard errors appear in parentheses.

- Met guidelines for sampling participation rates only after replacement schools were included.

t+ Nearly met guidelines for sampling participation rates after replacement schools were included.

1 National defined population covers $90 \%$ to $95 \%$ of the national target population. 


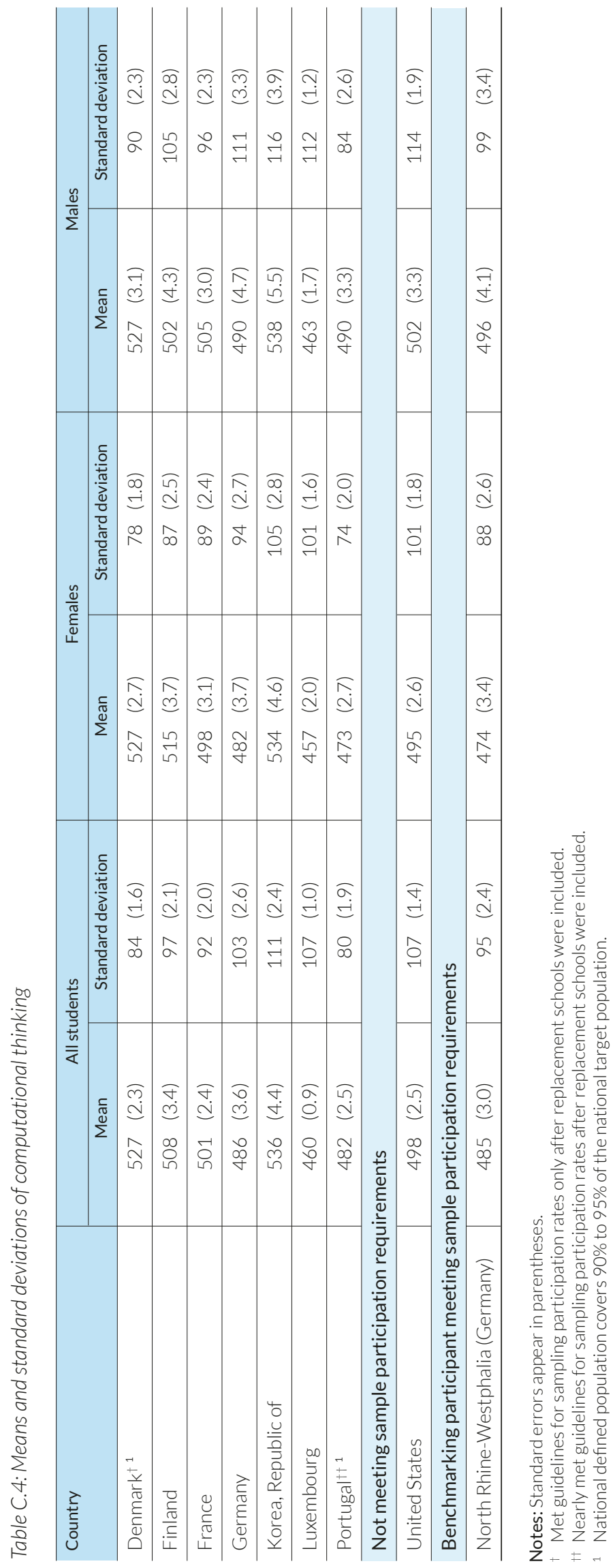


APPENDIX D:

Pair-wise comparisons of average achievement data

Table D.1: Pair-wise comparisons of average computer and information literacy scores

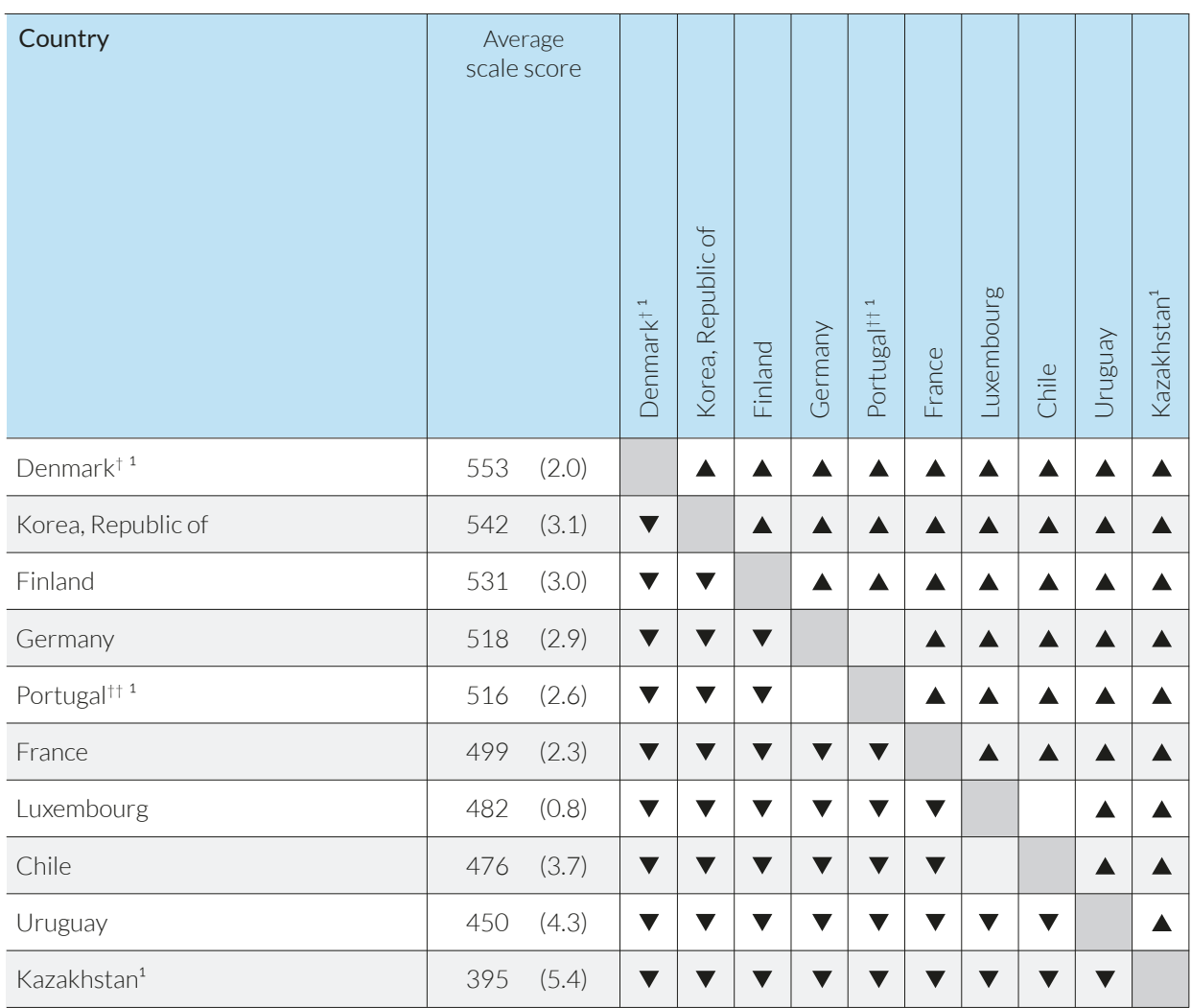

- Achievement significantly higher than in comparison country

$\boldsymbol{\nabla}$ Achievement significantly lower than in comparison country

Notes: Standard errors appear in parentheses. Because results are rounded to the nearest whole number, some totals may appear inconsistent.

+ Met guidelines for sampling participation rates only after replacement schools were included.

+ Nearly met guidelines for sampling participation rates after replacement schools were included.

1 National defined population covers $90 \%$ to $95 \%$ of national target population. 
Table D.2: Pair-wise comparisons of average computational thinking scores

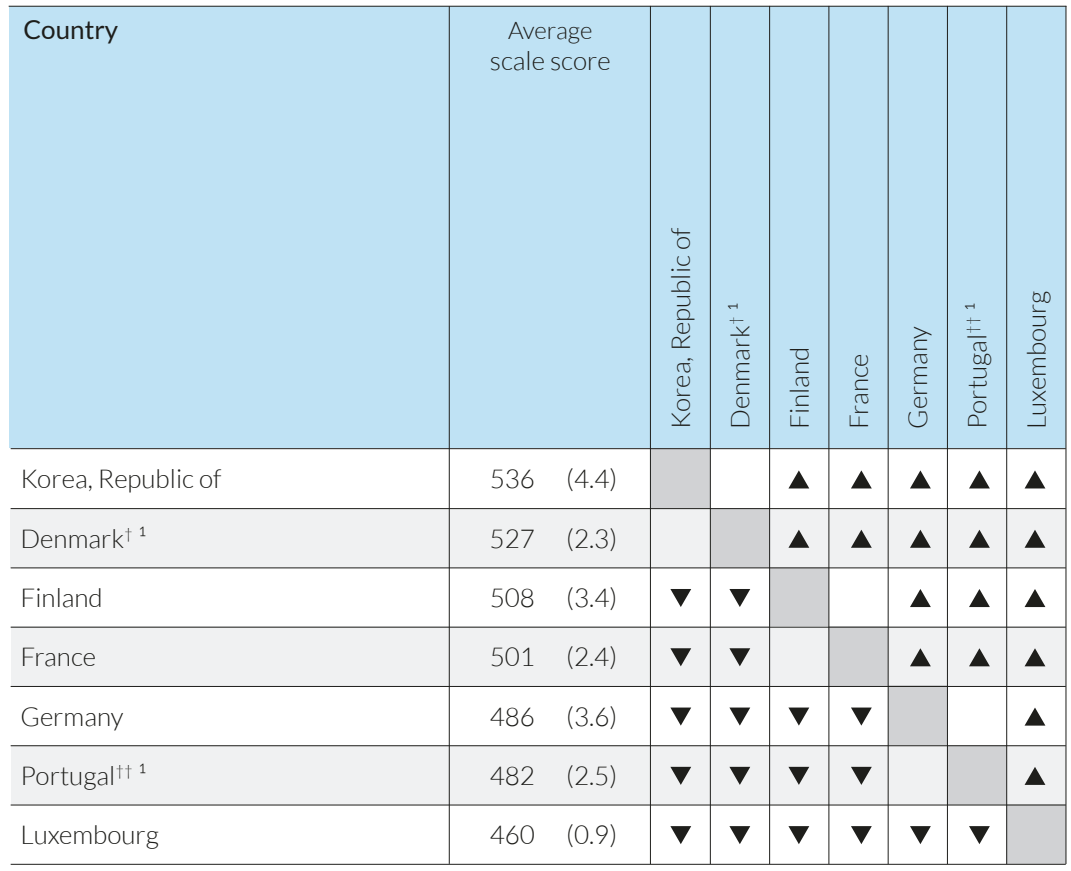

A Achievement significantly higher than in comparison country

$\boldsymbol{\nabla}$ Achievement significantly lower than in comparison country

Notes: Standard errors appear in parentheses. Because results are rounded to the nearest whole number, some totals may appear inconsistent.

Met guidelines for sampling participation rates only after replacement schools were included.

t† Nearly met guidelines for sampling participation rates after replacement schools were included.

1 National defined population covers $90 \%$ to $95 \%$ of national target population. 


\section{APPENDIXE:}

\section{Student percentages for dichotomous variables}

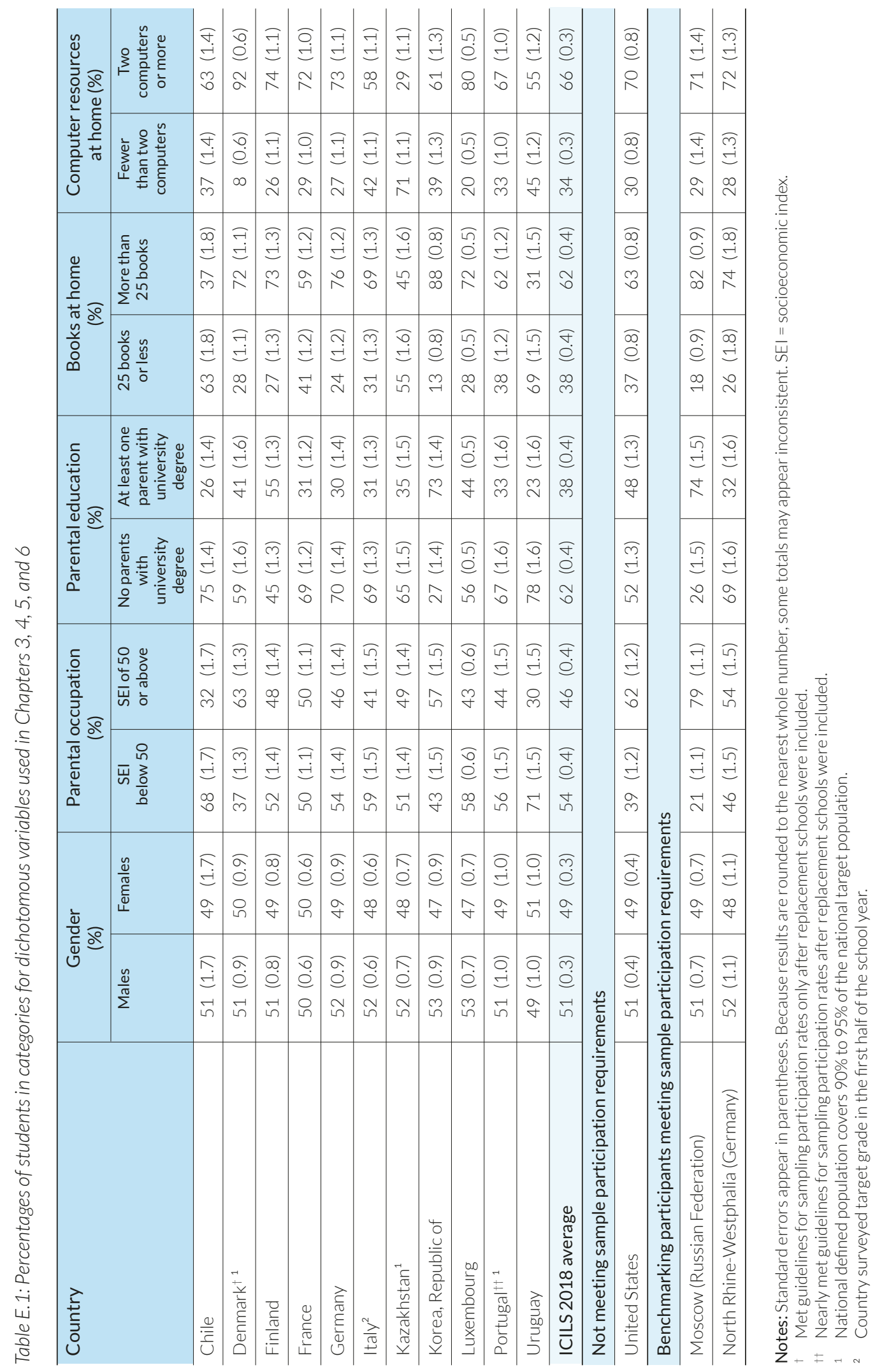




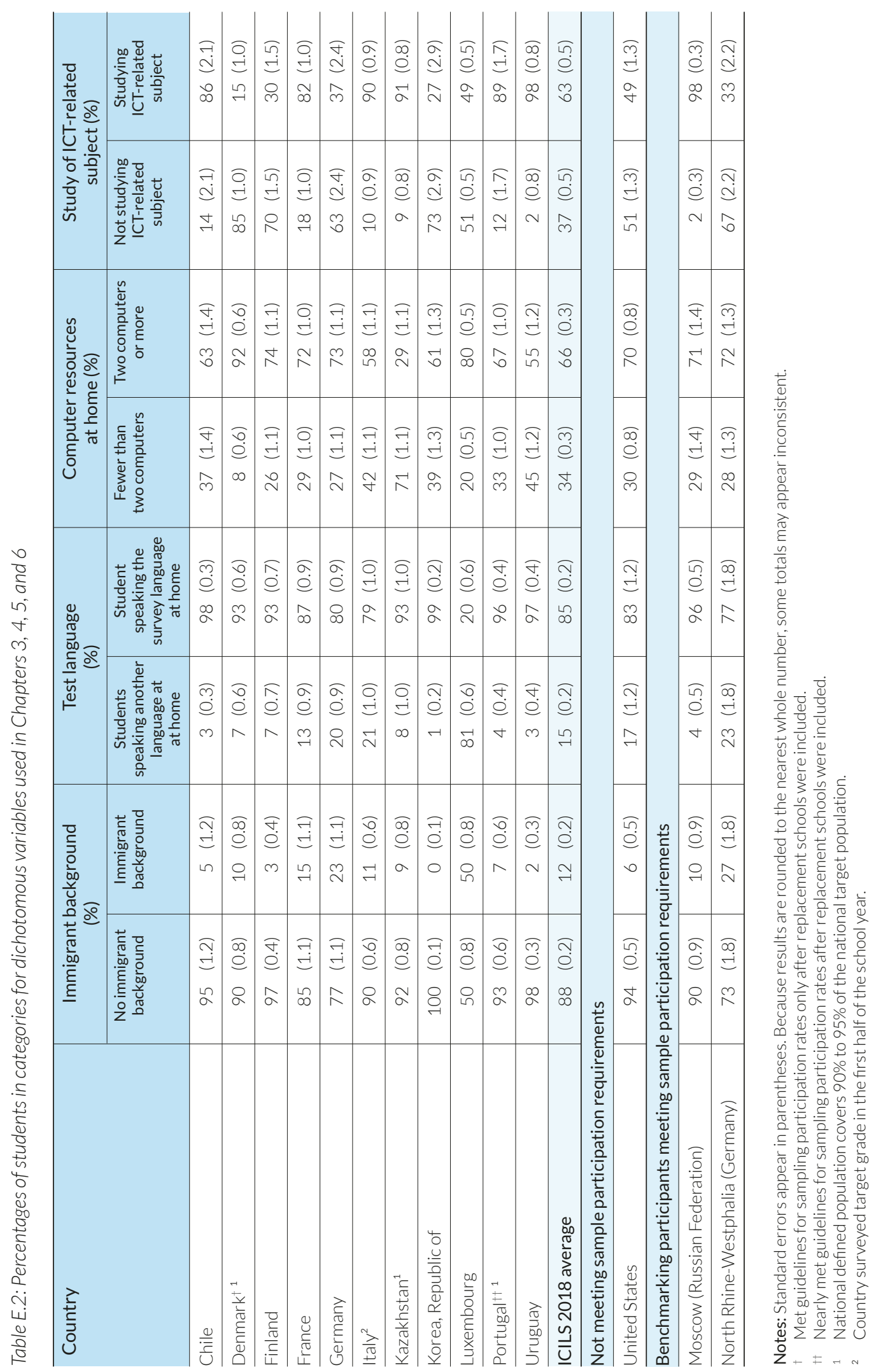




\section{APPENDIX F: Item maps}

ICILS 2018 used sets of student and teacher questionnaire items to measure constructs relevant to the learning context for students' acquisition of CIL and CT, and use of ICT for teaching and learning. Typically, this information was obtained using sets of Likert-type items with more than four categories (for example, "strongly agree," "agree," "disagree," and "strongly disagree") or other types of rating scales (for example, "never," "less than once a month," "at least once a month but not every week," "at least once a week but not every school day," and "every school day"). The responses to the items were then recoded so that the scale scores reflected the strength or frequency of the attitudes or perceptions that were measured.

We used the Rasch partial credit model (Masters and Wright 1997) for scaling and the resulting weighted likelihood estimates (Warm 1989) were transformed into a metric with a mean of 50 and a standard deviation of 10 for equally weighted ICILS 2018 national samples that satisfied guidelines for sample participation. Further details about the scaling and equating procedures will be provided in the ICILS 2018 technical report (Fraillon et al. 2020).

The resulting ICILS 2018 scale scores can be interpreted with regard to the average across countries participating in this study, but they do not reveal the extent to which students endorsed the items used for measurement. However, our application of the Rasch partial credit model allows us to map scale scores to item responses. Thus, it is possible for each scale score to predict the most likely item response for a respondent. (For an application of these properties in the previous survey, see Schulz and Friedman 2015.)

This appendix provides item maps for each questionnaire scale presented in the report. The maps provide a prediction of the minimum coded score (e.g., 0 = "strongly disagree", 1 = "disagree", 2 = "agree," and 3 = "strongly agree") a respondent would obtain on a Likert-type item based on their questionnaire scale score. For example, it can be predicated that students with a certain scale score have a 50 percent probability of at least agreeing (or strongly agreeing) with a particular item (see example item in Figure F.1). For each item, it is possible to determine Thurstonian thresholds; these are the points at which a minimum item score becomes more likely than any lower score, and they determine the boundaries between item categories on the item map.

This information can also be summarized at the scale level by calculating the average thresholds across all of the corresponding scaled items. For example, when using four-point Likert-type scales, this was typically done for the second threshold, making it possible to predict how likely it would be for a respondent with a certain scale score to have (on average across items) responses in the two lower or two upper categories. Using this approach for items measuring agreement made it possible to distinguish between scale scores for the respondents who were most likely to agree or disagree with the average item used for deriving the scale.

In some of the reporting tables with national average scale scores, means are depicted as boxes that indicate their mean values, plus or minus sampling error, as two color graphical displays (see, for example, Table 5.32). If national average scores are represented by the darker shaded area, on average across items students would have had responses in the respective lower item categories (for example, "strongly disagree" or "disagree"). If these scores are represented by the lighter shaded areas, then students' average item responses would have been in the upper item response categories (for example, "strongly agree," or "agree"). 
Figure F.1: Example of questionnaire item map

Scale scores $($ mean $=50$, standard deviation $=10)$

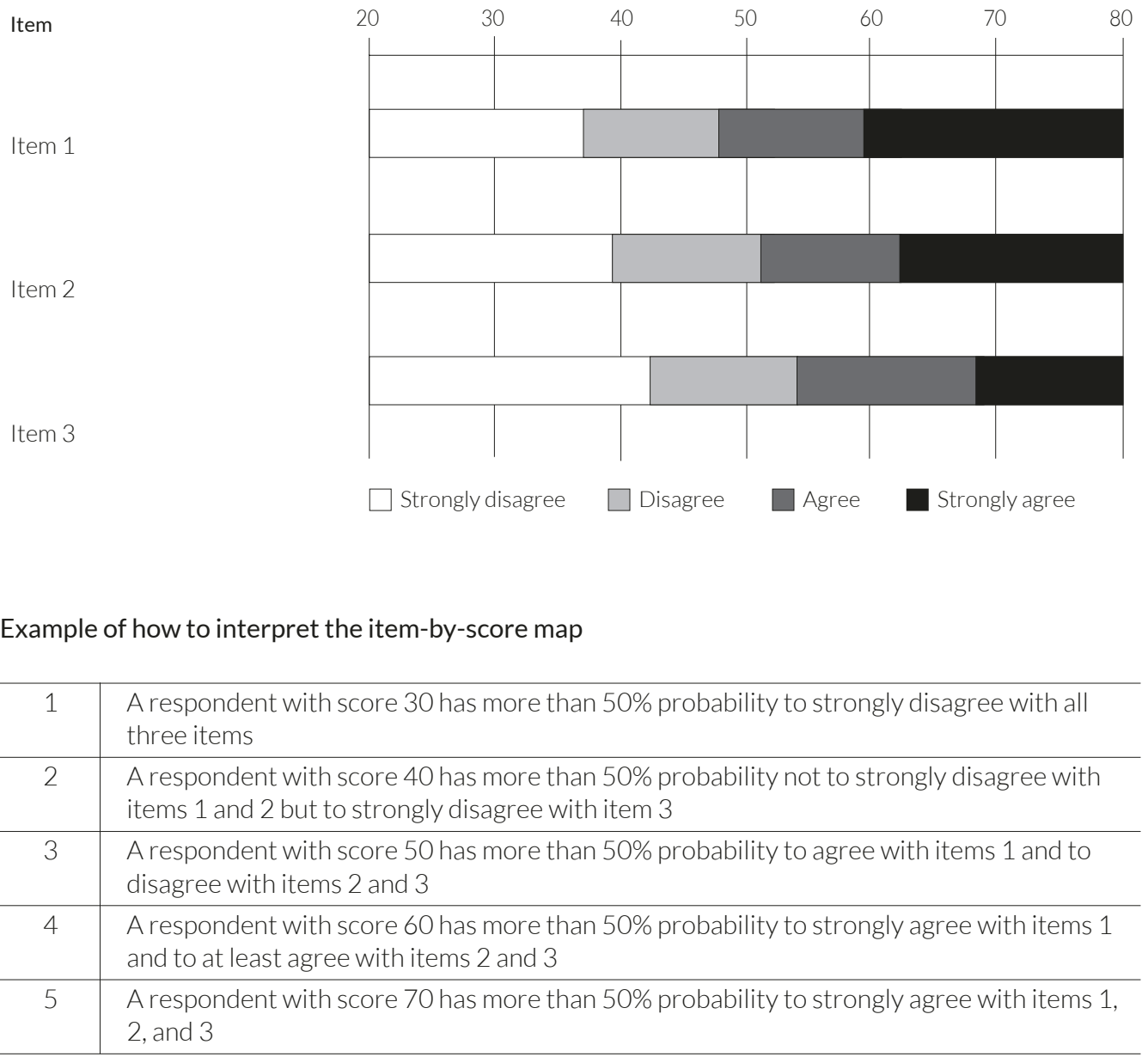


Figure F.2: Item map for the scale reflecting students' use of general applications for activities

How often do you use ICT for each of the following activities?

Write or edit documents

Use a spreadsheet to do calculations, store data, or plot graphs (e.g., using [Microsoft Excel $\left.{ }^{\circledR}\right]$ )

Create a simple "slideshow" presentation (e.g., using [Microsoft PowerPoint $(\mathbb{]}])$

\section{Scores}

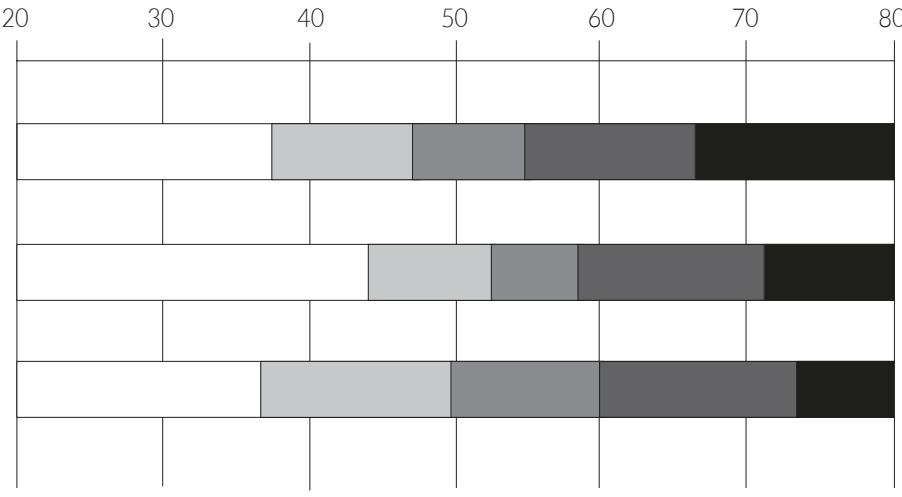

Never

$\square$ Less than once a month

At least once a month but not every week

At least once a week but not every day

Every day
Write or edit documents

Use a spreadsheet to do calculations, store data, or plot graphs (e.g., using [Microsoft Excel $®$ ])

Create a simple "slideshow" presentation (e.g., using [Microsoft PowerPoint $\left.{ }^{\circledR}\right]$ )
Sum

100

100 100 
Figure F.3: Item map for the scale reflecting students' use of specialist applications for activities

How often do you use ICT for each of the following activities?

Record or edit videos

Write computer programs, scripts, or apps (e.g., using [Logo, LUA, or Scratch])

Use drawing, painting, or graphics software or [apps]

Produce or edit music

Build or edit a webpage

Record or edit videos

Write computer programs, scripts, or apps

(e.g., using [Logo, LUA, or Scratch])

Use drawing, painting, or graphics software or [apps]

Produce or edit music

Build or edit a webpage

\section{Scores}

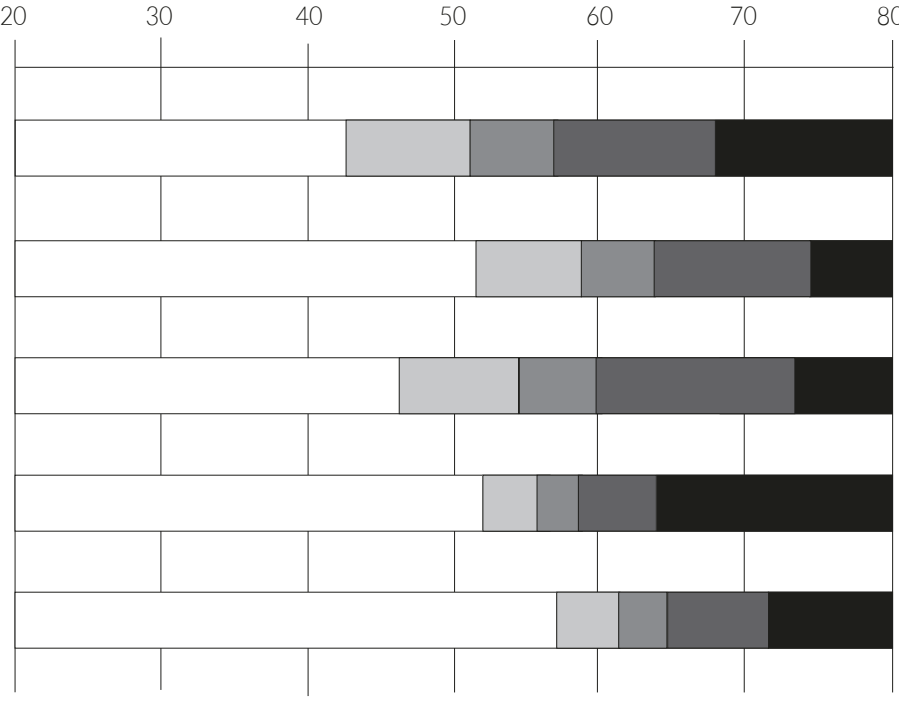

$\square$ Never

$\square$ Less than once a month

$\square$ At least once a month but not every week

At least once a week but not every day

Every day
Sum

\begin{tabular}{|l|l|l|l|l|}
\hline 28 & 26 & 19 & 19 & 9 \\
\hline
\end{tabular}

100

\begin{tabular}{|l|l|l|l|}
\hline 54 & 23 & 12 & 8 \\
\hline
\end{tabular}

100

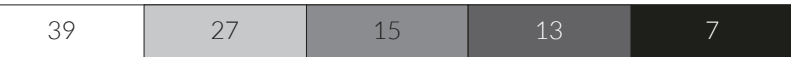
100

\begin{tabular}{|l|l|l|l|}
\hline 55 & 15 & 10 & 10 \\
\hline
\end{tabular}

100

\begin{tabular}{|l|l|l|l|}
\hline 70 & 15 & 7 & 5 \\
\hline
\end{tabular}

(1) 
Figure F.4: Item map for the scale reflecting students' use of ICT for social communication

How often do you use ICT to do each of the following communication activities?

Share news about current events on social media

Communicate with friends, family, or other people using instant messaging, voice, or video chat (e.g., [Skype, WhatsApp, Viber])

Send texts or instant messages to friends, family, or other people

Write posts and updates about what happens in your life on social media

Post images or video in social networks or online communities (e.g., [Facebook, Instagram, or YouTube])

Watch videos or images that other people have posted online

Send or forward information about events or activities to other people

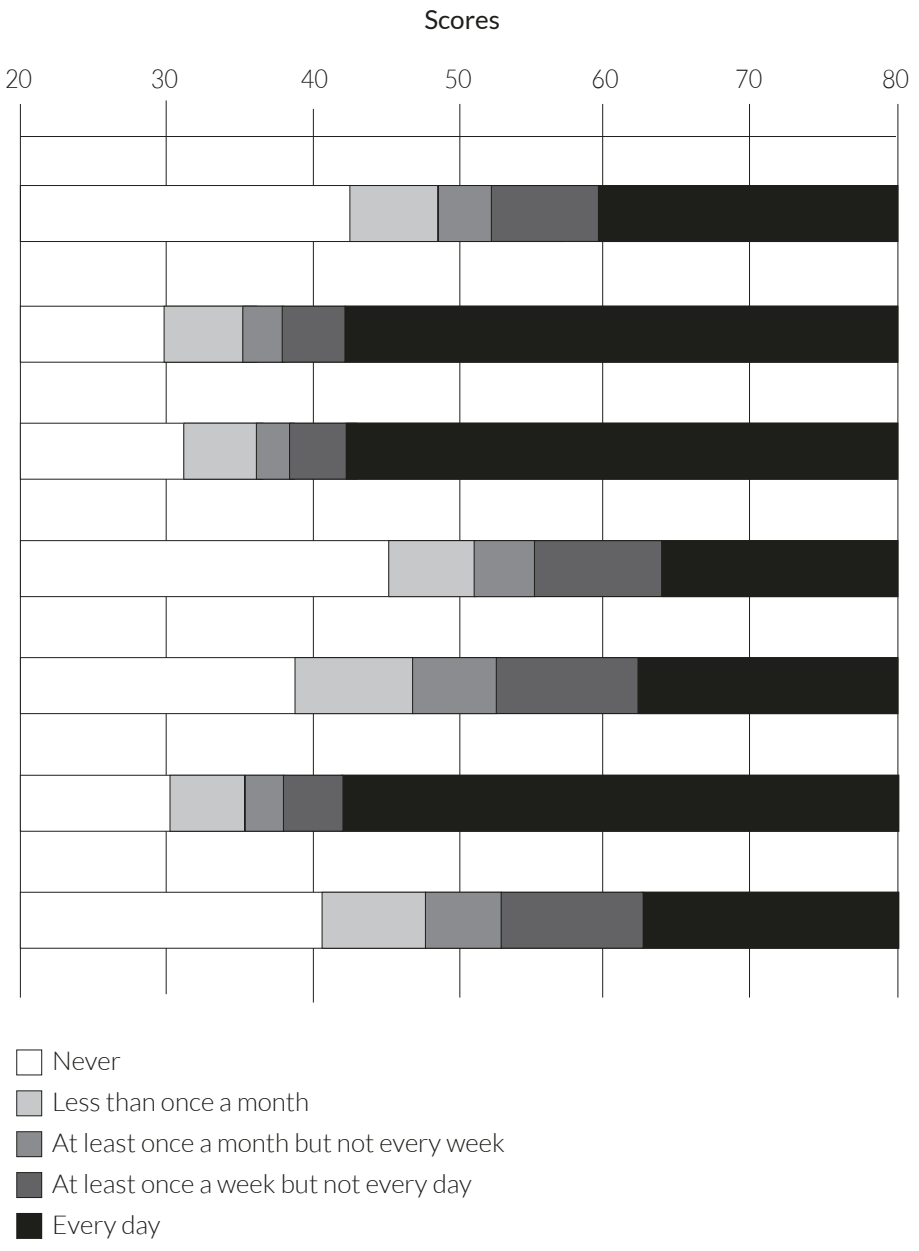

\begin{tabular}{|l|l|l|l|}
\hline 27 & 19 & 14 & 20 \\
\hline
\end{tabular}

Communicate with friends, family, or other people using instant messaging, voice, or video chat (e.g., [Skype, WhatsApp, Viber])

\begin{tabular}{|l|l|l|l|}
\hline 4 & 5 & 6 & 16 \\
\hline
\end{tabular}

Send texts or instant messages to friends, family, or other people

\begin{tabular}{|l|l|l|l|}
\hline 5 & 5 & 6 & 15 \\
\hline
\end{tabular}

Write posts and updates about what happens in your life on social media

\begin{tabular}{|l|l|l|l|}
\hline 34 & 19 & 15 & 18 \\
\hline
\end{tabular}

Post images or video in social networks or online communities (e.g., [Facebook, Instagram, or YouTube])

\begin{tabular}{|l|l|l|l|}
\hline 19 & 20 & 21 & 23 \\
\hline
\end{tabular}

Watch videos or images that other people have posted online

\begin{tabular}{|l|l|l|ll|}
\hline 4 & 4 & 6 & 15 & 71 \\
\hline 22 & 19 & 19 & 22 & 17 \\
\hline
\end{tabular}


Figure F.5: Item map for the scale reflecting students' use of ICT for exchanging information

How often do you use ICT to do each of the following communication activities?

Ask questions on forums or [Q\&A] websites

Answer other peoples' questions on forums or [Q\&A] websites

Write posts for your own blog (e.g., [WordPress, Tumblr, Blogger])

Ask questions on forums or [Q\&A] websites

Answer other peoples' questions on forums or [Q\&A] websites

Write posts for your own blog (e.g., [WordPress, Tumblr, Blogger])
Scores

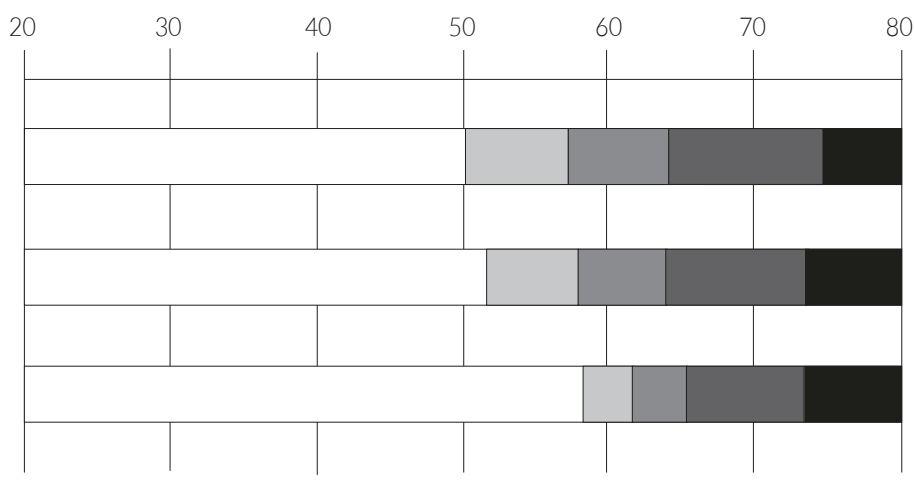

Never

Less than once a month

At least once a month but not every week

At least once a week but not every day

Every day

\begin{tabular}{|l|l|l|l|l|}
\hline 60 & 17 & 11 & 8 & 4 \\
\hline
\end{tabular}

\begin{tabular}{l|l|l|l|l}
63 & 16 & 10 & 7 & 5
\end{tabular}

4
80 
Figure F.6: Item map for the scale reflecting students' use of ICT for accessing content from the internet

How often do you use ICT to do each of the following leisure activities?

Search the internet to find information about places to go or activities to do

Read reviews on the internet of things you might want to buy

Read news stories on the internet

Search for online information about things you are interested in

Use websites, forums, or online videos to find out how to do something

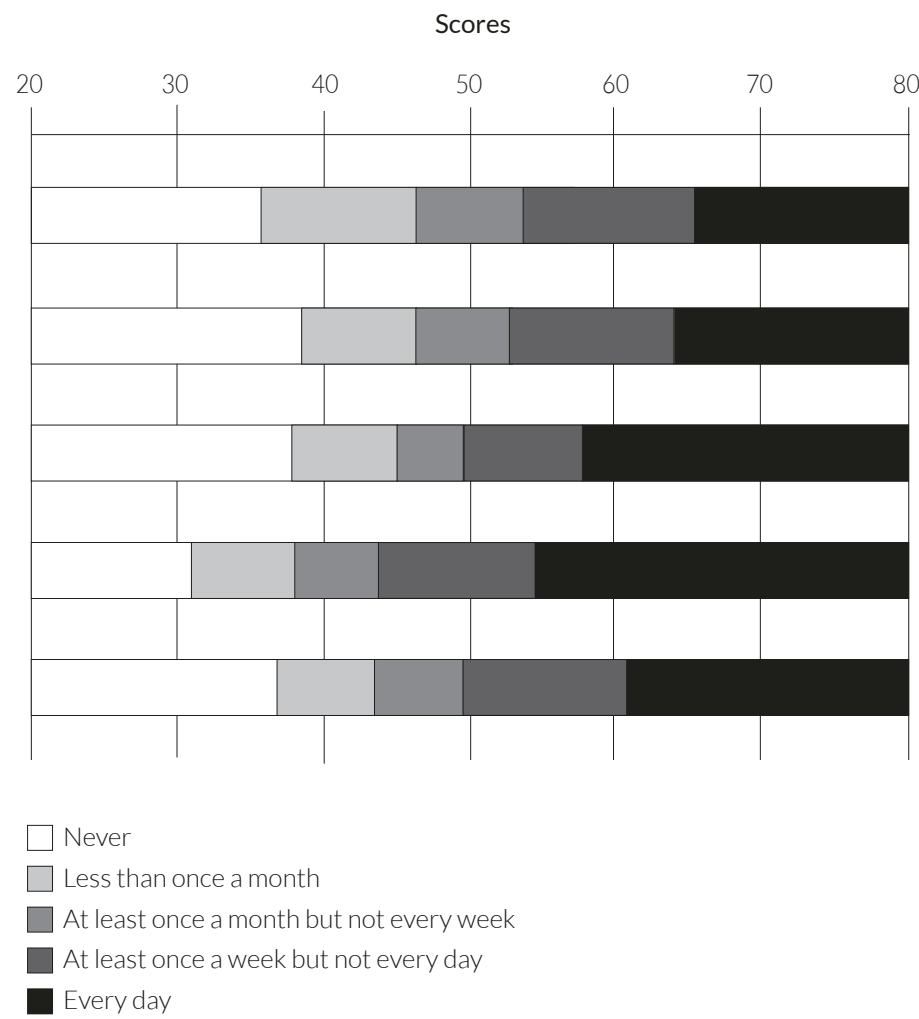

Search the internet to find information about places to go or activities to do

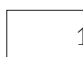

14 25

25

Read reviews on the internet of things you might want to buy

Read news stories on the internet

Search for online information about things you are interested in

\begin{tabular}{l}
\begin{tabular}{|l|l|l|l|l|}
\hline 17 & 20 & 24 & 25 & 14 \\
\hline 15 & 17 & 18 & 25 & 25 \\
\hline 5 & 9 & 16 & 34 & 36 \\
\hline
\end{tabular} \\
\hline
\end{tabular}

Use websites, forums, or online videos to find out how to do something

13 15 
Figure F.7: Item map for the scale reflecting students' use of ICT for study purposes

How often do you use ICT for the following schoolrelated purposes?

Prepare reports or essays

Prepare presentations

Work online with other students

Complete [worksheets] or exercises

Organize your time and work

Take tests

Use software or applications to learn skills or a subject (e.g., mathematics tutoring software, language learning software)

Use the internet to do research

Use coding software to complete assignments (e.g., [Scratch])

Make video or audio productions

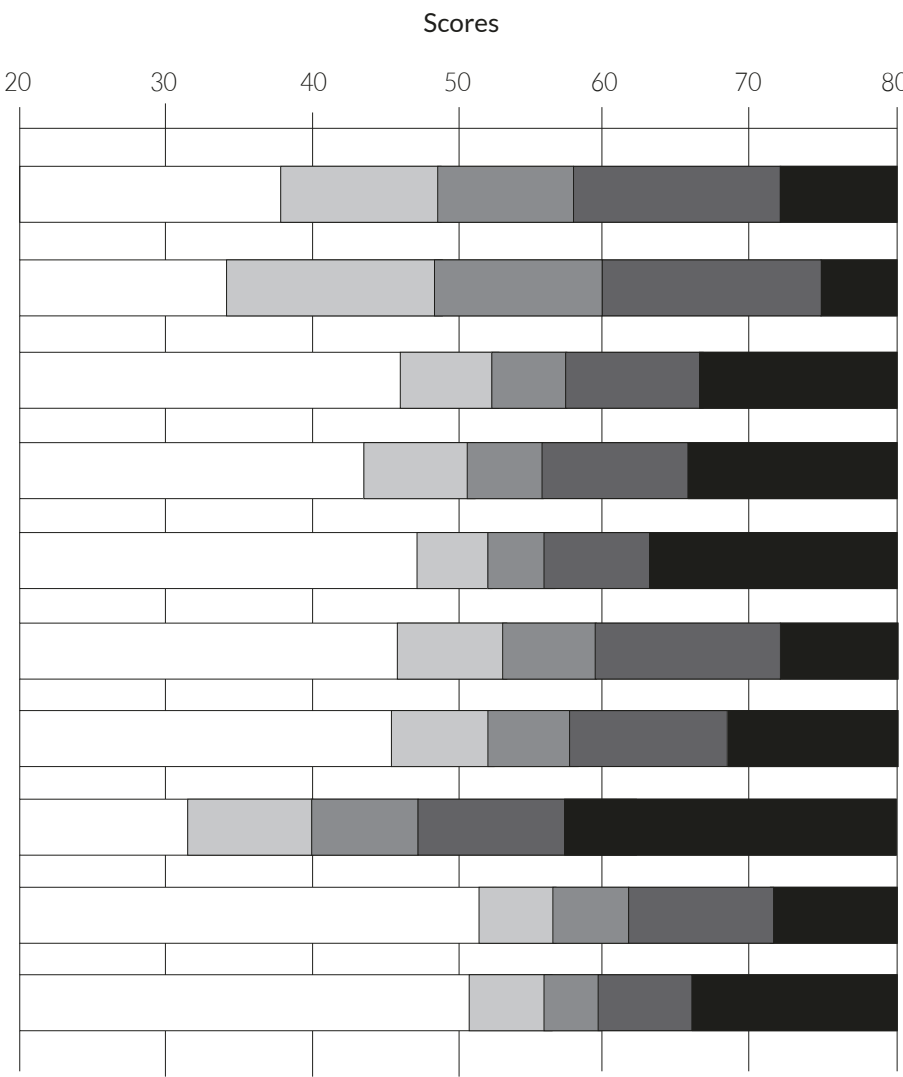

$\square$ Never

$\square$ Less than once a month

$\square$ At least once a month but not every week

$\square$ At least once a week but not every day

Every day
80

Prepare reports or essays

Prepare presentations

Work online with other students

Complete [worksheets] or exercises

Organize your time and work

\section{Take tests}

Use software or applications to learn skills or a subject (e.g., mathematics tutoring software, language learning software)

Use the internet to do research

Use coding software to complete assignments (e.g., $[$ Scratch])

Make video or audio productions

\begin{tabular}{|l|l|l|l|}
\hline 18 & 28 & 28 & 21 \\
\hline
\end{tabular}

\begin{tabular}{|l|l|l|l|l|}
\hline 13 & 32 & 33 & 19 & 4 \\
\hline
\end{tabular}

100

\begin{tabular}{|l|l|l|l|l|}
\hline 35 & 22 & 17 & 16 & 9 \\
\hline
\end{tabular}

\begin{tabular}{|l|l|l|l|}
\hline 29 & 23 & 19 & 20 \\
\hline
\end{tabular}

\begin{tabular}{|c|c|c|c|c|}
\hline 38 & 18 & 15 & 16 & 13 \\
\hline 36 & 24 & 20 & 16 & 5 \\
\hline
\end{tabular}

\begin{tabular}{|l|l|l|l|l|}
\hline 34 & 22 & 19 & 17 & 7 \\
\hline
\end{tabular}

\begin{tabular}{|c|c|c|c|c|}
\hline 7 & 13 & 21 & 31 & 28 \\
\hline
\end{tabular}

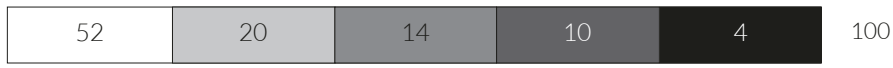

\begin{tabular}{|l|l|l|l|l|}
\hline 50 & 21 & 12 & 10 & 8 \\
\hline
\end{tabular}


Figure F.8: Item map for the scale reflecting students' use of general applications in class

When studying throughout this school year, how often did you use the following tools during class?

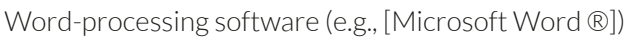

Presentation software (e.g., [Microsoft PowerPoint $\left.{ }^{\circledR}\right]$ )

Computer-based information resources (e.g., websites, wikis, encyclopaedia)

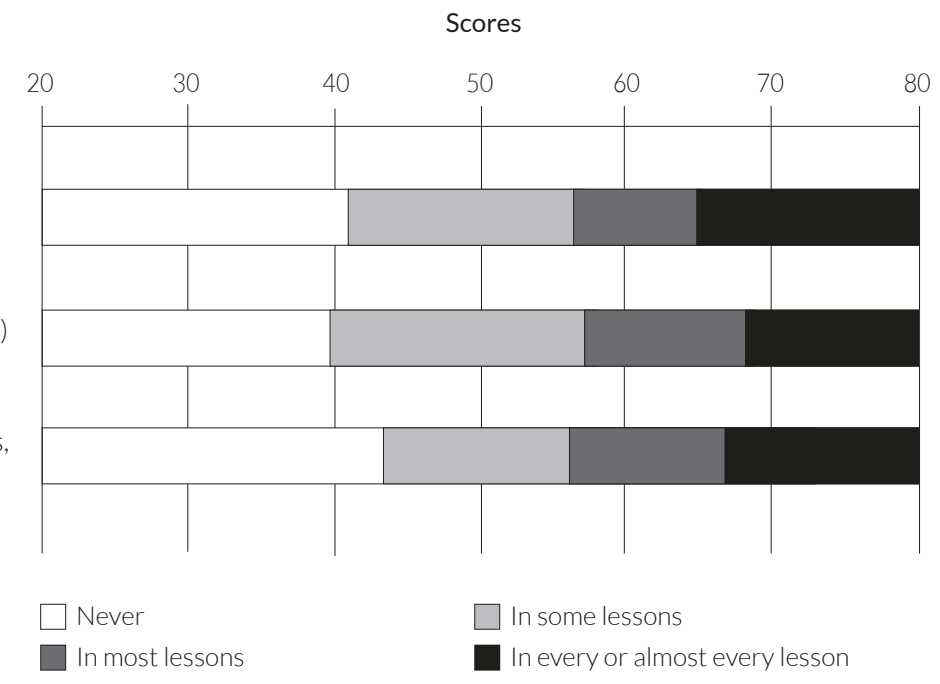

Sum

Word-processing software (e.g., [Microsoft Word $(R]$ )

\begin{tabular}{|c|c|c|c|}
\hline 23 & 48 & 20 & 9 \\
\hline 20 & 53 & 21 & 5 \\
\hline 29 & 42 & 22 & 7 \\
\hline
\end{tabular}

100

Presentation software (e.g., [Microsoft PowerPoint (B])

Computer-based information resources (e.g., websites, wikis, encyclopaedia)

100 100 
Figure F.9: Item map for the scale reflecting students' use of specialist applications in class

When studying throughout this school year, how often did you use the following tools during class?

Multimedia production tools (e.g., media capture and editing, web production)

Concept mapping software (e.g., [Inspiration ${ }^{\circledR}$ ], [Webspiration $($ ])

Tools that capture real-world data (e.g., speed, temperature) digitally for analysis

Simulations and modeling software

Interactive digital learning resources (e.g., learning games or applications)

Graphing or drawing software

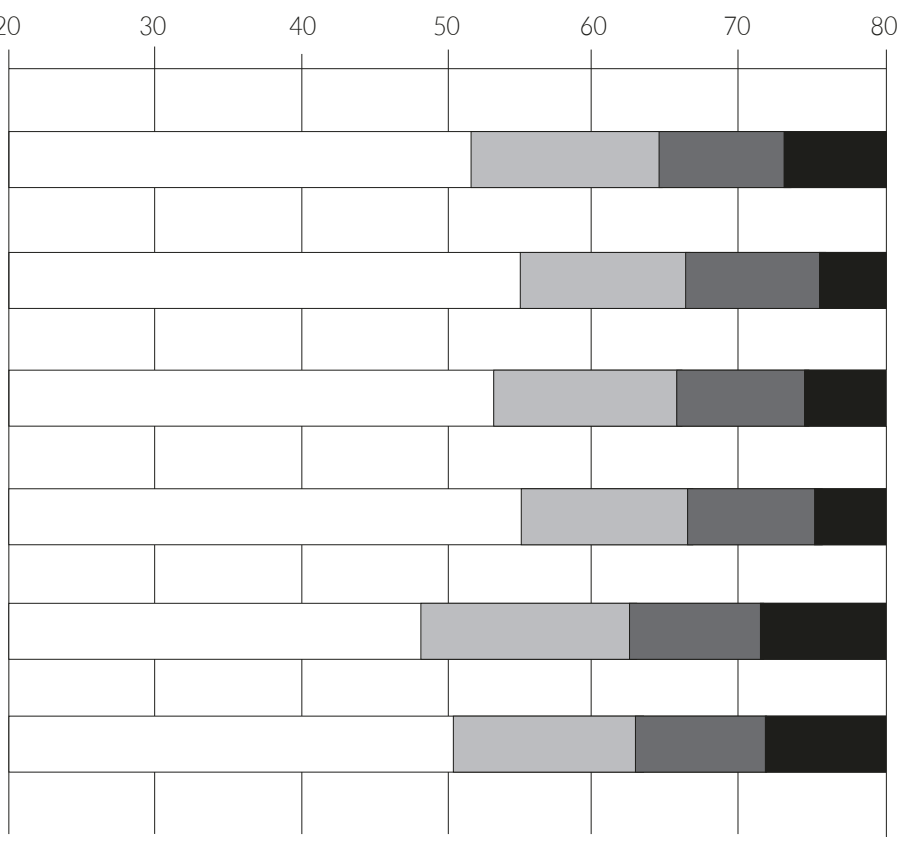

$\square$ Never

$\square$ In most lessons

$\square$ In some lessons

- In every or almost every lesson

Multimedia production tools (e.g, media capture and editing, web production)

Concept mapping software (e.g., [Inspiration $®$ ], [Webspiration $\mathbb{R}]$ )

Tools that capture real-world data (e.g., speed, temperature) digitally for analysis

Simulations and modeling software

Interactive digital learning resources (e.g., learning games or applications)

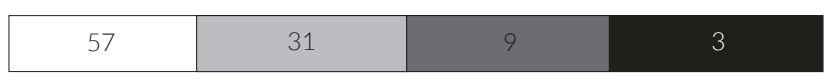

Graphing or drawing software

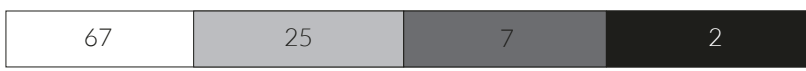

100

\begin{tabular}{|l|l|ll|}
\hline 62 & 29 & 7 & 2 \\
\hline
\end{tabular}

100

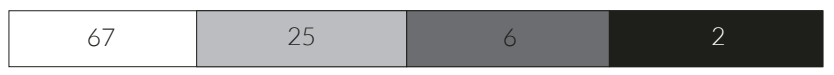

100

\begin{tabular}{|l|l|l|l|}
\hline 48 & 37 & 11 & 4 \\
\hline
\end{tabular}

100

\begin{tabular}{|l|l|l|l|}
\hline 54 & 32 & 10 & 4 \\
\hline
\end{tabular}


Figure F.10: Item map for the scale reflecting students' learning of ICT tasks at school

At school, to what extent have you learned how to do the following tasks?

Provide references to internet sources

Search for information using ICT

Present information for a given audience or purpose using ICT

Work out whether to trust information from the internet

Decide what information obtained from the internet is relevant to include in school work

Organize information obtained from internet sources

Decide where to look for information on the internet about an unfamiliar topic

Use ICT to collaborate with others

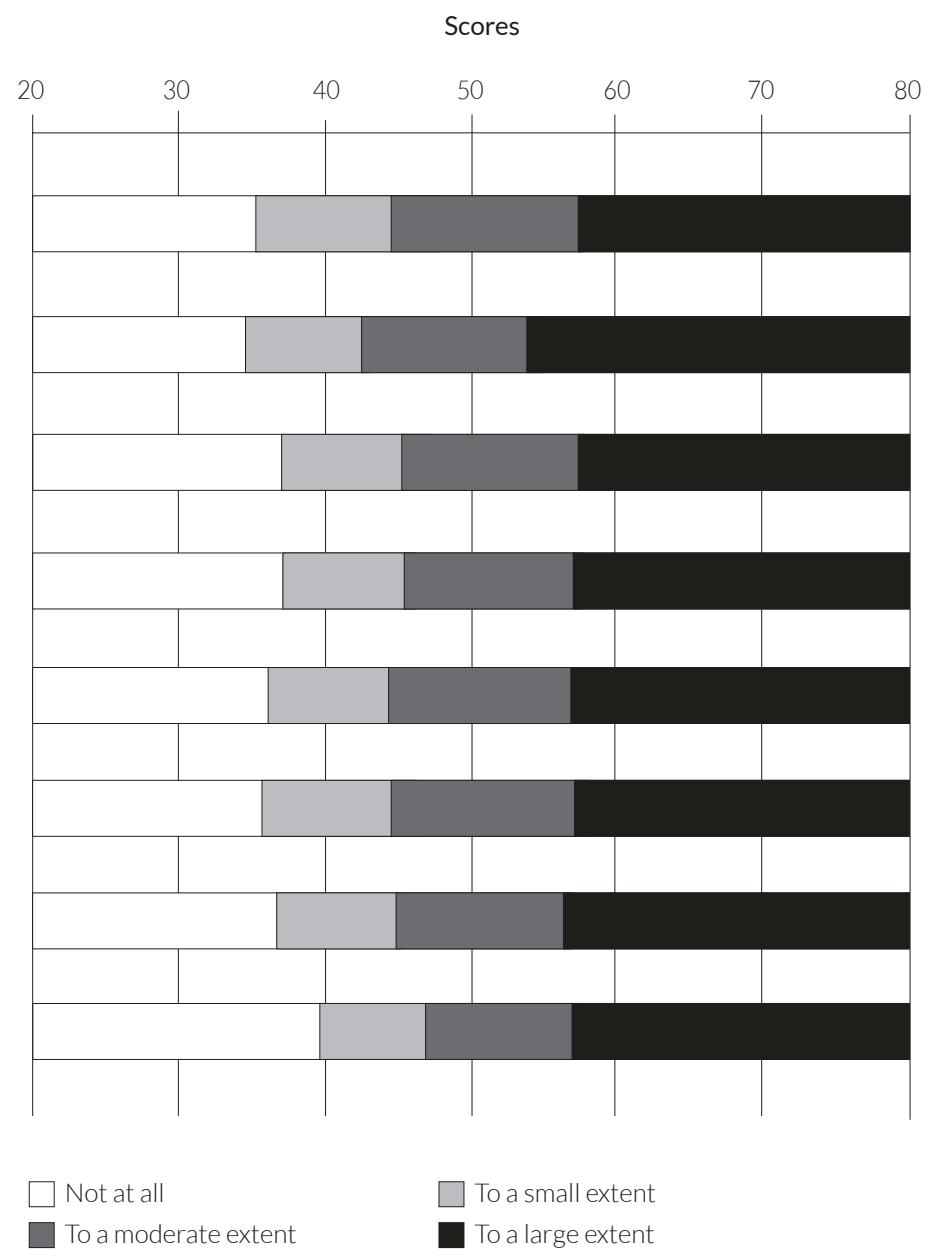

Provide references to internet sources

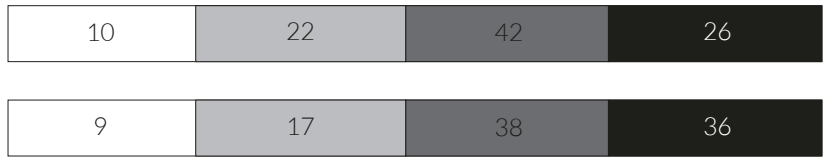

100

Search for information using ICT

\begin{tabular}{|l|l|l|}
\hline 12 & 21 & 40 \\
\hline
\end{tabular}

100

Present information for a given audience or purpose using ICT

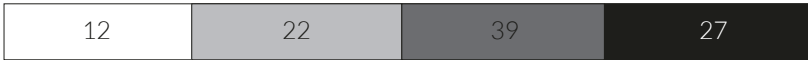
internet

Decide what information obtained from the internet is relevant to include in school work

\begin{tabular}{|l|l|l|l|}
\hline 12 & 21 & 39 & 29 \\
\hline \multicolumn{3}{|l|}{} \\
\hline 17 & 23 & 34 & 27 \\
\hline
\end{tabular}

Organize information obtained from internet sources

Decide where to look for information on the internet about an unfamiliar topic

\begin{tabular}{|l|l|l|l|}
\hline 12 & 21 & 39 & 29 \\
\hline
\end{tabular}

Use ICT to collaborate with others 
Figure F.11: Item map for the scale reflecting students' learning of ICT coding tasks at school

When studying during the current school year, to what extent have you been taught how to do the following tasks?

To display information in different ways

To break a complex process into smaller parts

To understand diagrams that describe or show realworld problems

To plan tasks by setting out the steps needed to complete them

To use tools to make diagrams that help solve problems

To use simulations to help understand or solve realworld problems

To make flow diagrams to show the different parts of a process

To record and evaluate data to understand and solve a problem

To use real-world data to review and revise solutions to problems

\section{To display information in different ways}

To break a complex process into smaller parts

To understand diagrams that describe or show realworld problems

To plan tasks by setting out the steps needed to complete them

To use tools to make diagrams that help solve problems

To use simulations to help understand or solve realworld problems

To make flow diagrams to show the different parts of a process

To record and evaluate data to understand and solve a problem

To use real-world data to review and revise solutions to problems

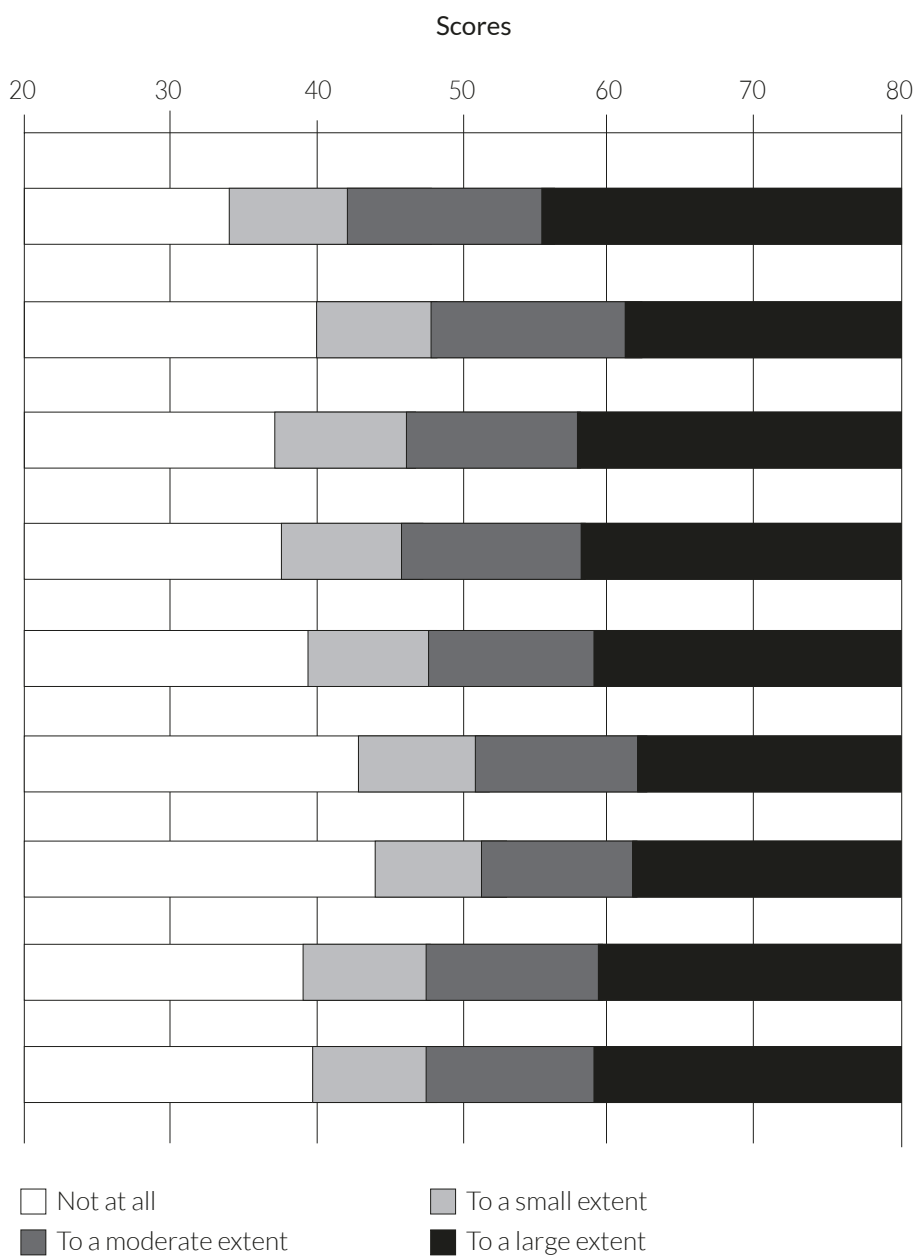

Sum

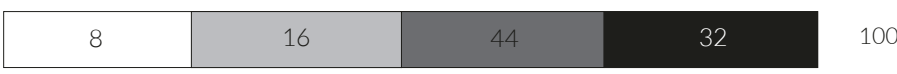

\begin{tabular}{|l|l|l|l|}
\hline 18 & 25 & 41 & 17 \\
\hline
\end{tabular}

\begin{tabular}{|l|l|l|l|}
\hline 12 & 23 & 40 & 24 \\
\hline
\end{tabular}

\begin{tabular}{|l|l|l|l|}
\hline 13 & 23 & 41 & 24 \\
\hline
\end{tabular}

\begin{tabular}{|l|l|ll|}
\hline 28 & 28 & 30 & 15 \\
\hline
\end{tabular}

\begin{tabular}{|l|l|ll|}
\hline 17 & 24 & 38 & 22 \\
\hline
\end{tabular}

\begin{tabular}{|l|l|ll|}
\hline 28 & 28 & 30 & 15 \\
\hline
\end{tabular}

\begin{tabular}{|l|l|ll|}
\hline 16 & 26 & 39 & 20 \\
\hline
\end{tabular}

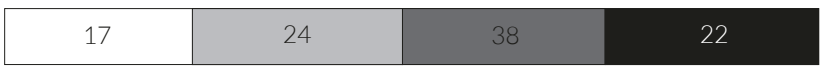


Figure F.12: Item map for the scale reflecting students' self-efficacy regarding the use of general applications

How well can you do each of these tasks when using ICT?

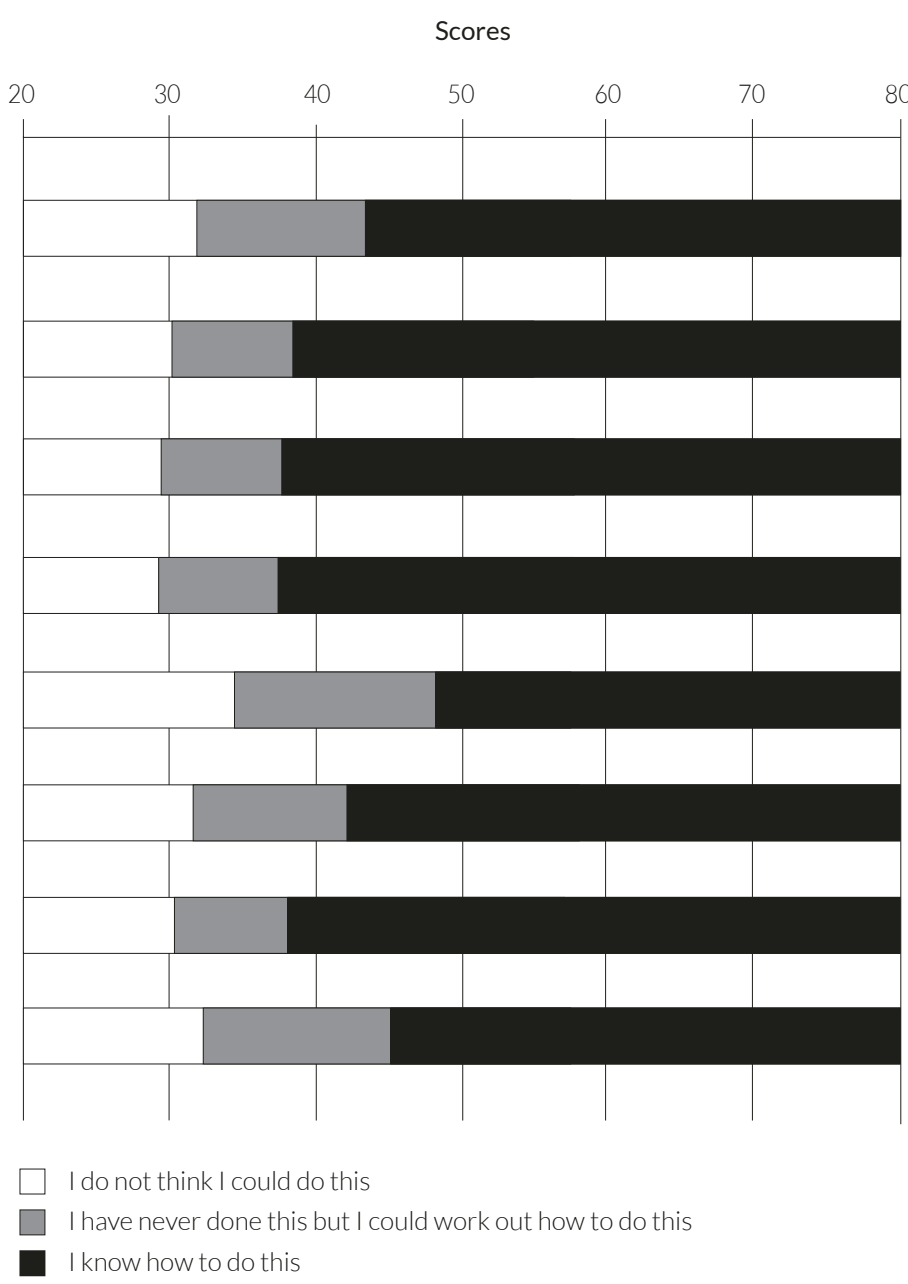

Judge whether you can trust information you find on the internet

Search for and find relevant information for a school project on the internet

Create a multimedia presentation (with sound, pictures, or video)

Upload text, images, or video to an online profile

Insert an image into a document or message

Install a program or [app]

Edit digital photographs or other graphic images

Write or edit text for a school assignment

Search for and find relevant information for a school project on the internet

Create a multimedia presentation (with sound, pictures, or video)

Upload text, images, or video to an online profile

Insert an image into a document or message

Install a program or [app]

Judge whether you can trust information you find on the internet

\begin{tabular}{|c|c|c|}
\hline 8 & 21 & 72 \\
\hline \multicolumn{3}{|l|}{} \\
\hline 6 & 12 & 82 \\
\hline
\end{tabular}

\begin{tabular}{|l|l|l|}
\hline 5 & 12 & 83 \\
\hline
\end{tabular}

\begin{tabular}{|l|l|l|}
\hline 11 & 28 & 61 \\
\hline
\end{tabular}

\begin{tabular}{|l|l|l|}
\hline 6 & 12 & 82 \\
\hline
\end{tabular}

\begin{tabular}{|l|l|l|}
\hline 8 & 24 & 68 \\
\hline
\end{tabular}

\begin{tabular}{|l|l|l|}
\hline 6 & 12 & 82 \\
\hline
\end{tabular}

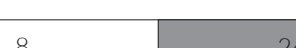

$24 \quad 68$

68 
Figure F.13: Item map for the scale reflecting students' ICT self-efficacy regarding the use of specialist applications

How well can you do each of these tasks when using ICT?

Create a database (e.g., using [Microsoft Access $(\mathbb{B}])$

Build or edit a webpage

Create a computer program, macro, or [app] (e.g., in [Basic, Visual Basic])

Set up a local area network of computers or other ICT

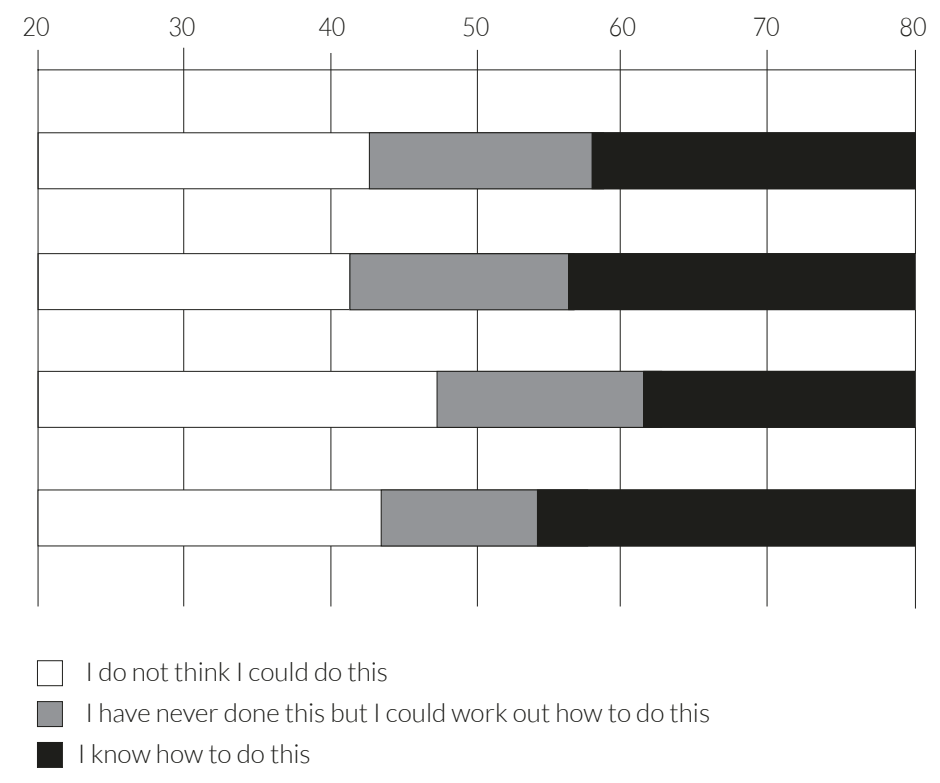

Create a database (e.g., using [Microsoft Access $®]$ )

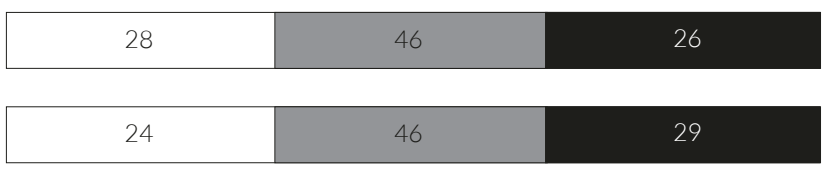

Sum

Build or edit a webpage

42

41

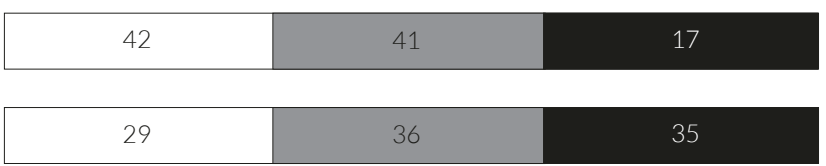

100

Create a computer program, macro, or [app]

(e.g., in [Basic, Visual Basic])

100

Set up a local area network of computers or other ICT

100 
Figure F.14: Item map for the scale reflecting students' perceptions of positive outcomes of ICT for society

How much do you agree or disagree with the following statements about ICT?

Advances in ICT usually improve people's living conditions

ICT helps us to understand the world better

ICT is valuable to society

Advances in ICT bring many social benefits

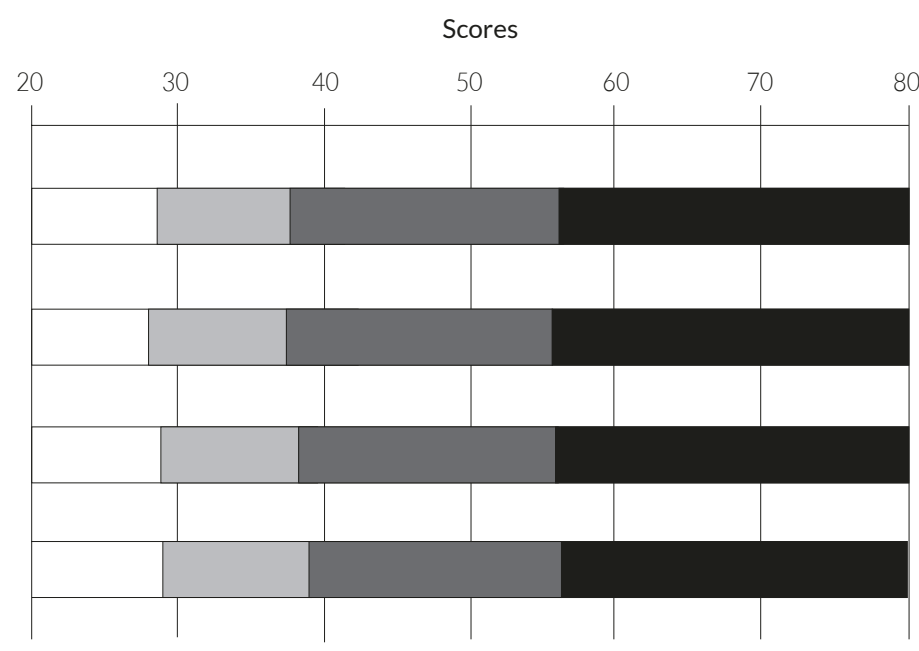
$\square$ Strongly disagree
$\square$ Disagree
$\square$ Agree
Strongly agree

Sum

Advances in ICT usually improve people's living conditions

\begin{tabular}{|l|l|l|l|}
\hline 3 & 12 & 55 & 31 \\
\hline \multicolumn{3}{|l|}{} \\
\hline 2 & 12 & 53 & 33 \\
\hline
\end{tabular}

100

ICT helps us to understand the world better

\begin{tabular}{|l|l|l|l|}
\hline 3 & 13 & 52 & 32 \\
\hline
\end{tabular}

100

ICT is valuable to society

3 14 
Figure F.15: Item map for the scale reflecting students' perceptions of negative outcomes of ICT for society

How much do you agree or disagree with the following statements about ICT?

Using ICT makes people more isolated in society

With more ICT there will be fewer jobs

People spend far too much time using ICT

Using ICT may be dangerous for people's health

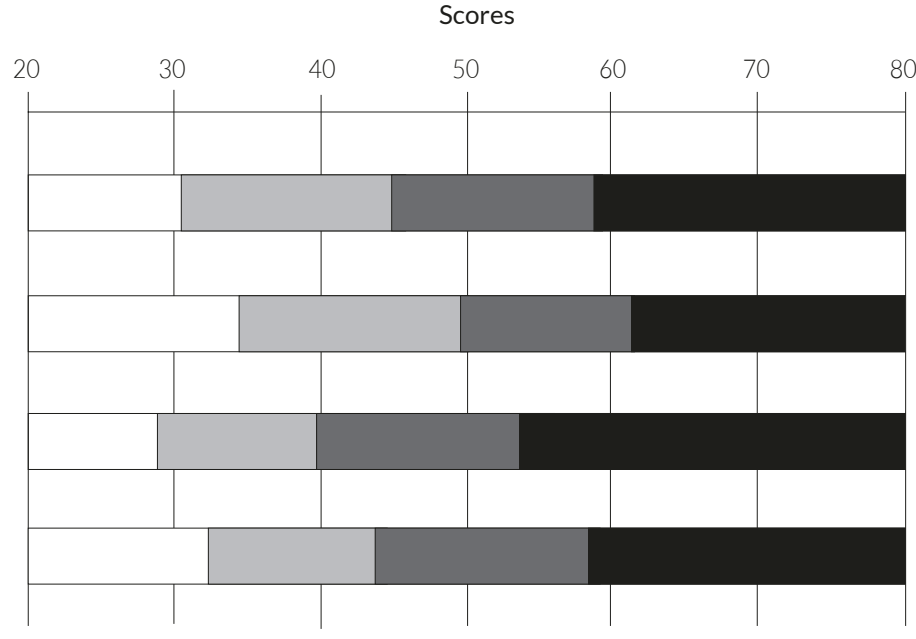
$\square$ Strongly disagree
Disagree
Agree
Strongly agree

Sum

Using ICT makes people more isolated in society

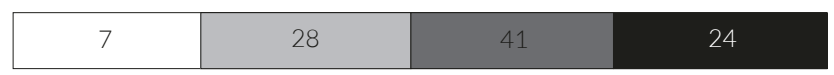

100

With more ICT there will be fewer jobs

\begin{tabular}{|c|c|c|c|}
\hline 12 & 37 & 34 & 18 \\
\hline
\end{tabular}

100

People spend far too much time using ICT

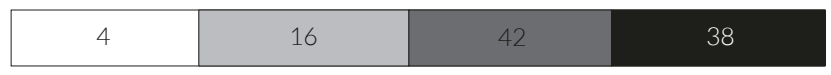

100

Using ICT may be dangerous for people's health 
Figure F.16: Item map for the scale reflecting students' expectations of future ICT use for work and study

How much do you agree or disagree with the following statements about ICT?

I would like to study subjects related to ICT after [secondary school]

I hope to find a job that involves advanced ICT

Learning how to use ICT applications will help me to do the work I am interested in

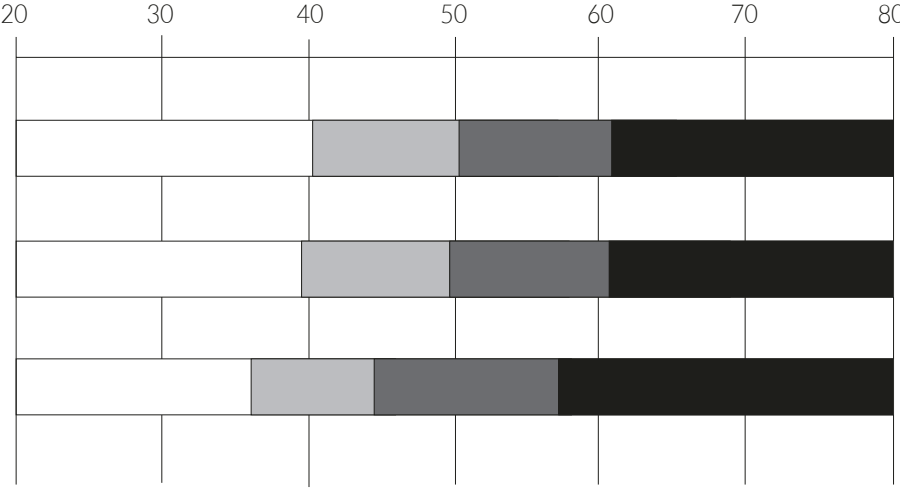

Strongly disagree

Agree

Disagree

Strongly agree
Sum

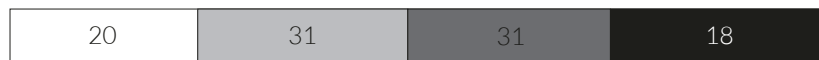

100

I would like to study subjects related to ICT after [secondary school]

I hope to find a job that involves advanced ICT

Learning how to use ICT applications will help me to do the work I am interested in

$$
18
$$

32

41

18 100 
Figure F.17: Item map for the scale reflecting teachers' ICT self-efficacy

How well can you do these tasks using ICT?

Find useful teaching resources on the internet

Contribute to a discussion forum/user group on the internet (e.g., a wiki or blog)

Produce presentations (e.g., [PowerPoint $®$ or a similar program]), with simple animation functions

Use the internet for online purchases and payments

Prepare lessons that involve the use of ICT by students

Using a spreadsheet program (e.g., [Microsoft Excel (B]) for keeping records or analyzing data

Assess student learning

Collaborate with others using shared resources such as [Google Docs $®$ ], [Padlet]

Use a learning management system (e.g., [Moodle], [Blackboard], [Edmodo])

Find useful teaching resources on the internet

Contribute to a discussion forum/user group on the internet (e.g,. a wiki or blog)

Produce presentations (e.g., [PowerPoint $®$ or a similar program]), with simple animation functions

Use the internet for online purchases and payments

Prepare lessons that involve the use of ICT by students

Using a spreadsheet program (e.g., [Microsoft Excel

(B]) for keeping records or analyzing data

Assess student learning

Collaborate with others using shared resources such

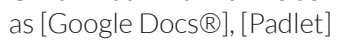

Use a learning management system (e.g., [Moodle], [Blackboard], [Edmodo])

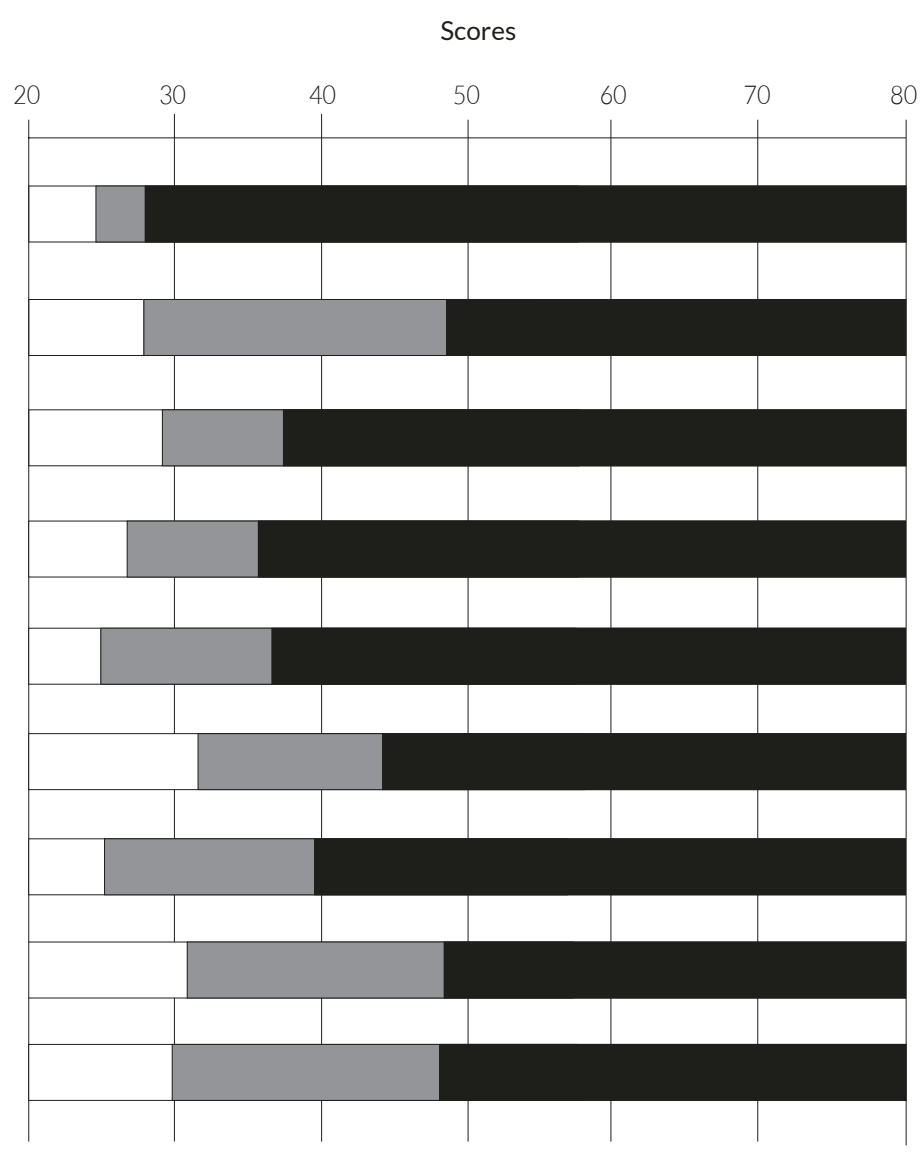

I do not think I could do this

$\square$ I have never done this but I could work out how to do this

I know how to do this

Sum
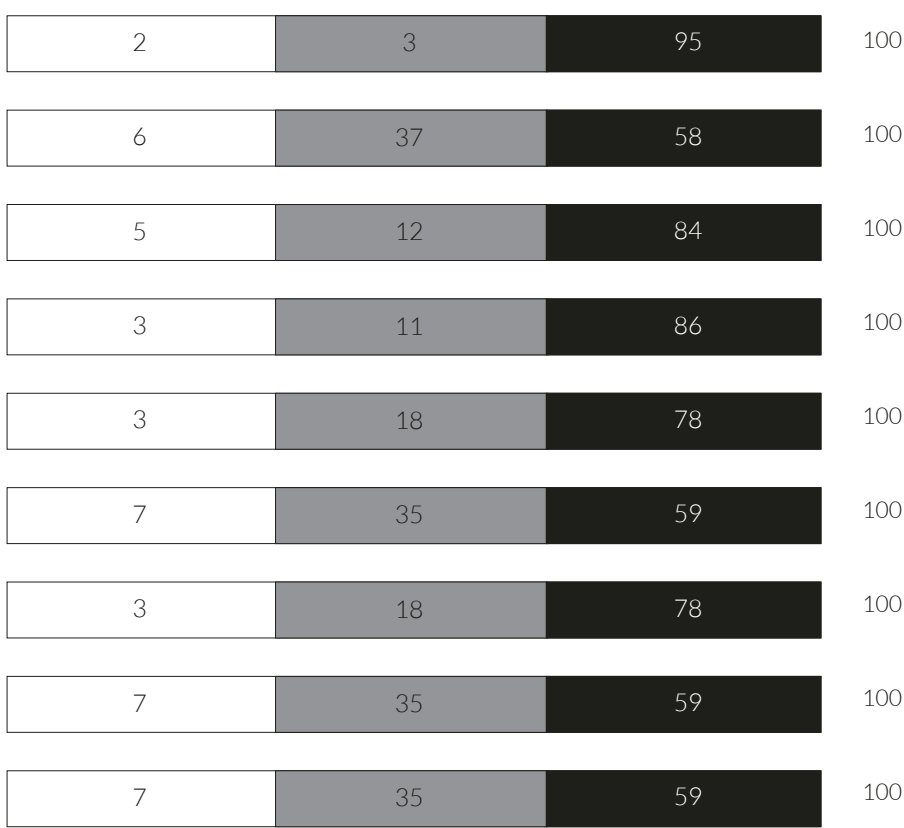
Figure F.18: Item map for the scale reflecting teachers' perceptions of positive outcomes when using ICT in teaching and learning

To what extent do you agree or disagree with the following practices and principles in relation to the use of ICT in teaching and learning?

Helps students develop greater interest in learning

Helps students to work at a level appropriate to their learning needs

Helps students develop problem-solving skills

Enables students to collaborate more effectively

Helps students develop skills in planning and selfregulation of their work

Improves academic performance of students.

Enables students to access better sources of information

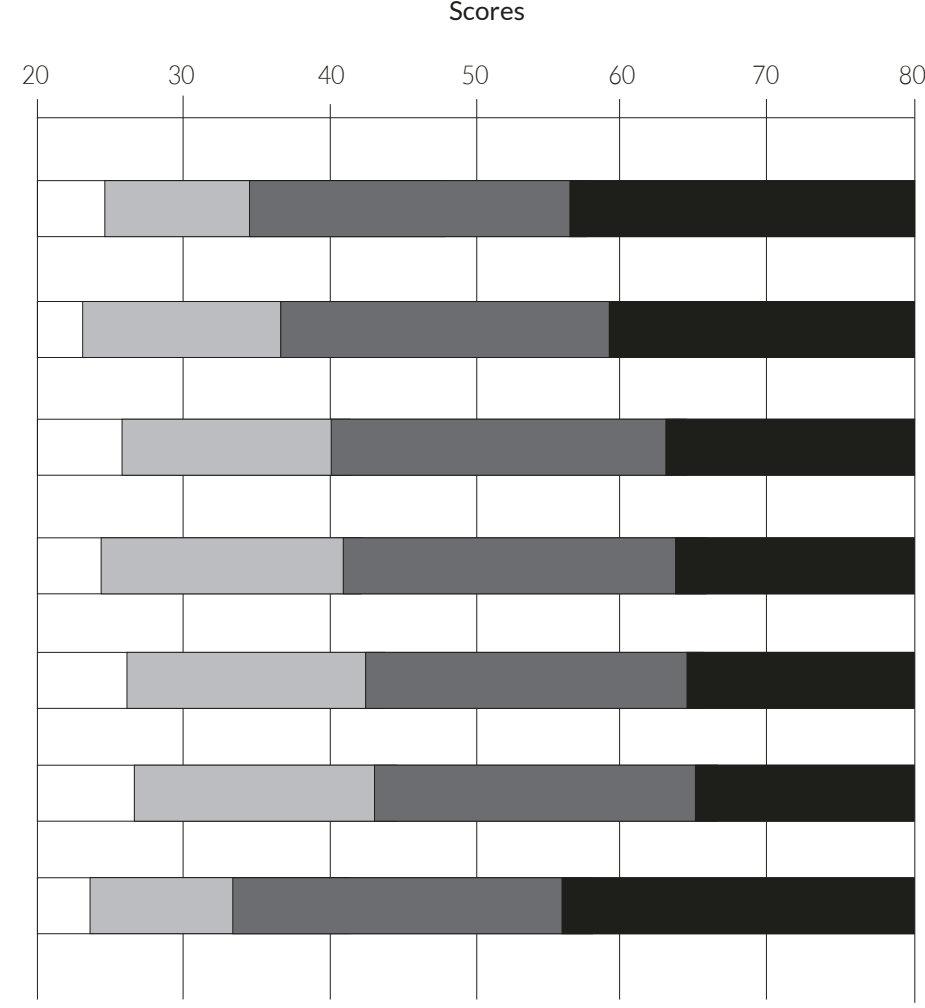

$\square$ Strongly disagree

Agree $\square$ Disagree

Strongly agree

Helps students develop greater interest in learning

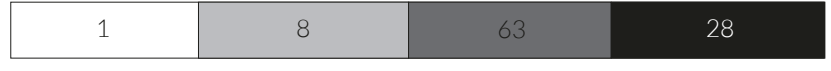

Helps students to work at a level appropriate to their learning needs

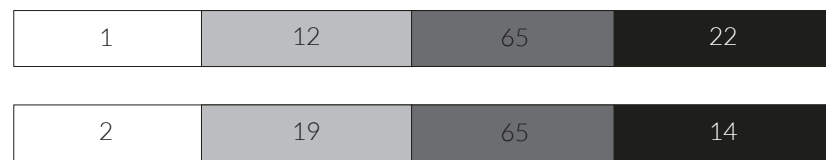

Helps students develop problem-solving skills

Enables students to collaborate more effectively

Helps students develop skills in planning and selfregulation of their work

\begin{tabular}{|c|c|c|c|}
\hline 1 & 21 & 65 & 13 \\
\hline 2 & 25 & 61 & 12 \\
\hline
\end{tabular}

Improves academic performance of students

2 27

Enables students to access better sources of information 
Figure F.19: Item map for the scale reflecting teachers' perceptions of negative outcomes when using ICT in teaching and learning

To what extent do you agree or disagree with the following practices and principles in relation to the use of ICT in teaching and learning?

Impedes concept formation by students

Results in students copying material from internet sources

Distracts students from learning

Results in poorer written expression among students

Results in poorer calculation and estimation skills among students

Limits the amount of personal communication among students

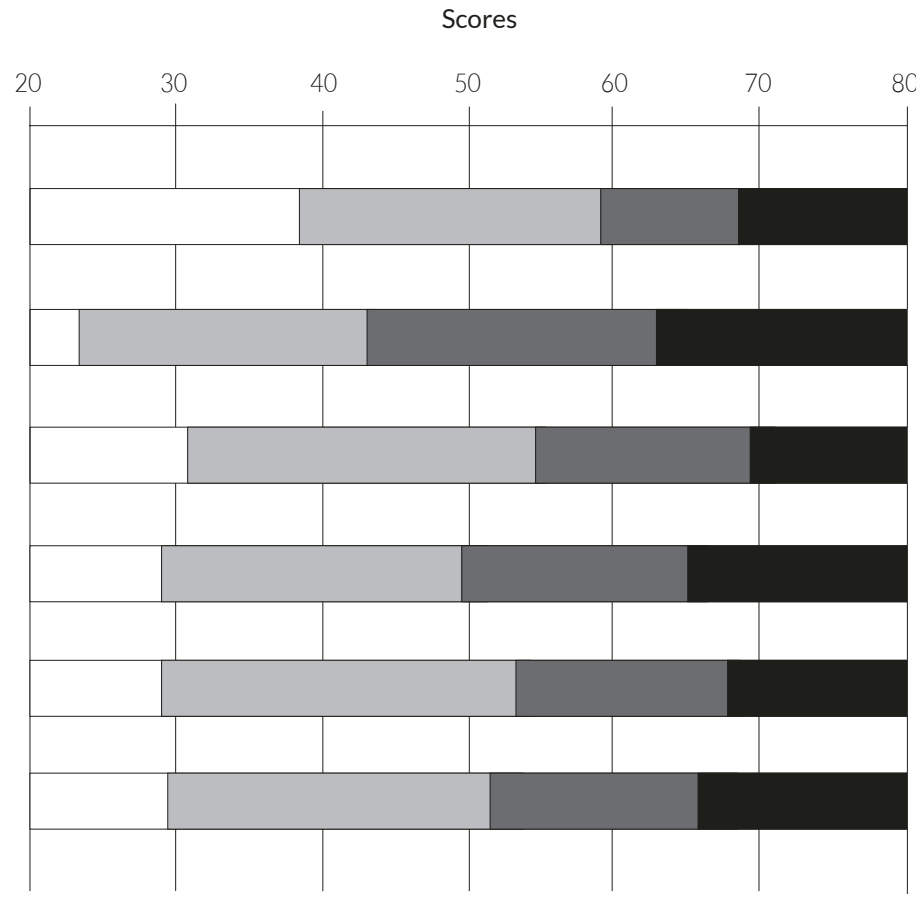
$\square$ Strongly disagree
$\square$ Disagree
$\square$ Agree
Strongly agree

Impedes concept formation by students

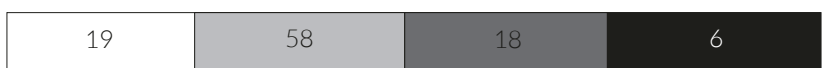

100

Results in students copying material from internet sources

\begin{tabular}{|l|l|l|l|}
\hline 2 & 27 & 55 & 16 \\
\hline
\end{tabular}

Distracts students from learning

Results in poorer written expression among students

\begin{tabular}{|l|l|l|l|}
\hline 8 & 56 & 31 & 6 \\
\hline
\end{tabular}

\begin{tabular}{|l|l|l|l|}
\hline 6 & 42 & 41 & 11 \\
\hline
\end{tabular}

100

Results in poorer calculation and estimation skills among students

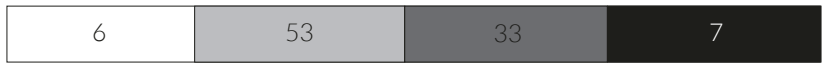

100

Limits the amount of personal communication among students

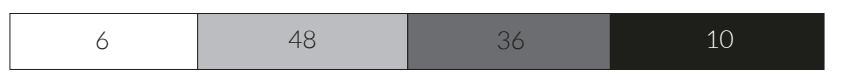

100 
Figure F.20: Item map for the scale reflecting teachers' perceptions of the availability of ICT resources at school

To what extent do you agree or disagree with the following statements about using ICT in teaching at your school?

My school has sufficient ICT equipment (e.g., computers)

The computer equipment in our school is up-to-date

My school has access to sufficient digital learning resources (e.g., learning software or [apps])

My school has good connectivity (e.g., fast speed) to the internet

There is enough time to prepare lessons that incorporate ICT

There is sufficient opportunity for me to develop expertise in ICT

There is sufficient technical support to maintain ICT resources

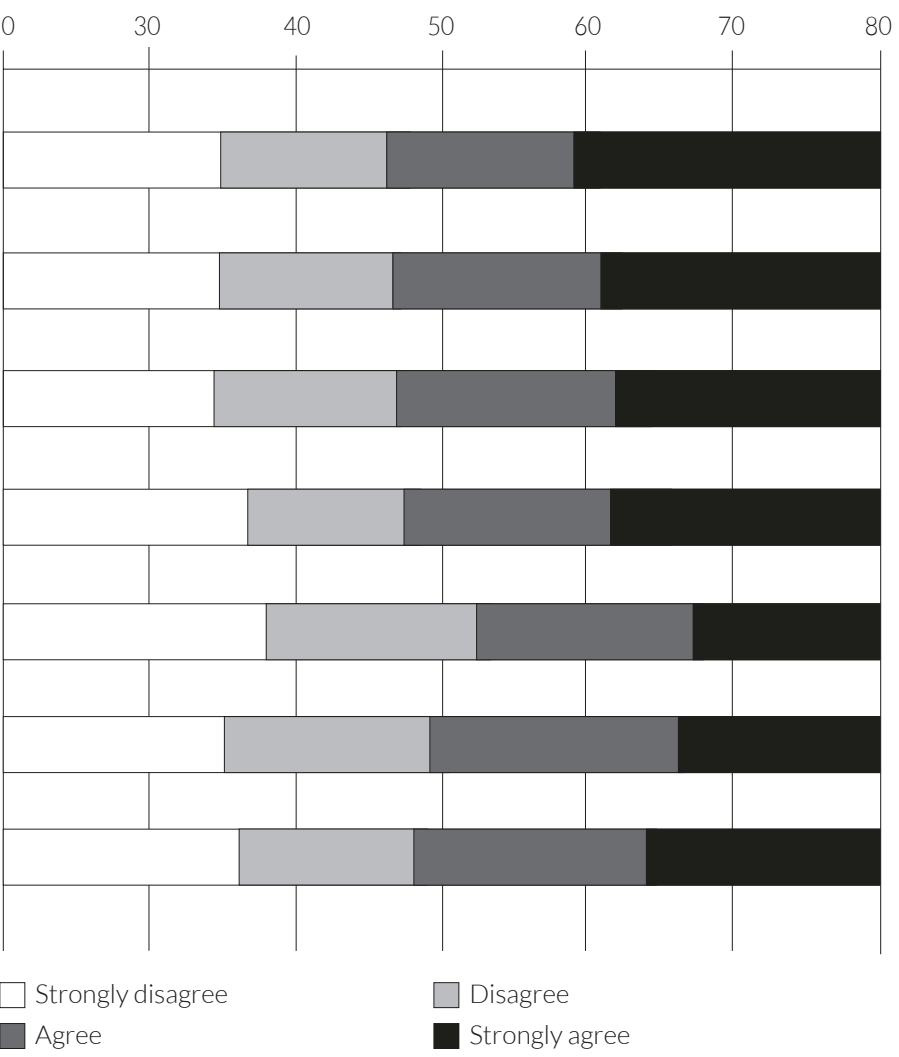

Sum

My school has sufficient ICT equipment (e.g., computers)

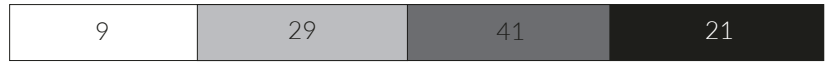

100

The computer equipment in our school is up-to-date

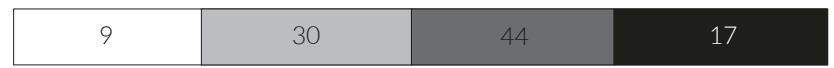

100

My school has access to sufficient digital learning resources (e.g., learning software or [apps])

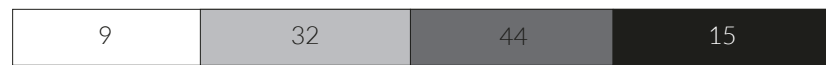

My school has good connectivity (e.g., fast speed) to the internet

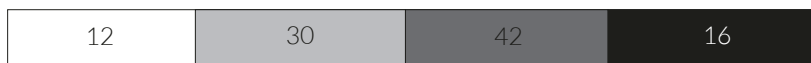

There is enough time to prepare lessons that incorporate ICT

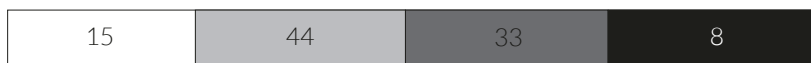

There is sufficient opportunity for me to develop expertise in ICT

\begin{tabular}{|l|l|ll|}
\hline 10 & 38 & 43 & 9 \\
\hline
\end{tabular}

There is sufficient technical support to maintain ICT resources 
Figure F.21: Item map for the scale reflecting teachers' perceptions of collaboration between teachers when using ICT

To what extent do you agree or disagree with the following statements about your use of ICT in teaching and learning at your school?

I work together with other teachers on improving the use of ICT in classroom teaching

I collaborate with colleagues to develop ICT-based lessons

I observe how other teachers use ICT in teaching

I discuss with other teachers how to use ICT in teaching topics

I share ICT-based resources with other teachers in my school

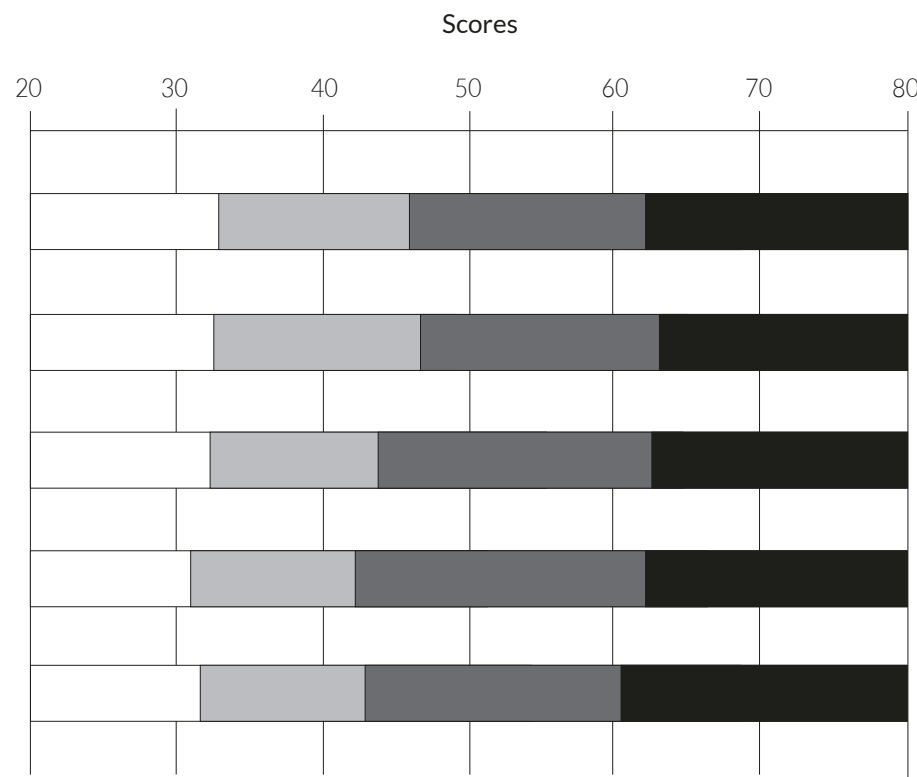
$\square$ Strongly disagree
$\square$ Disagree
Agree
Strongly agree

I work together with other teachers on improving the use of ICT in classroom teaching

\begin{tabular}{|c|c|c|c|}
\hline 6 & 29 & 50 & 15 \\
\hline 6 & 33 & 49 & 13 \\
\hline 5 & 24 & 57 & 14 \\
\hline
\end{tabular}

I discuss with other teachers how to use ICT in teaching topics

\begin{tabular}{|l|l|ll|}
\hline 4 & 21 & 61 & 14 \\
\hline
\end{tabular}

I share ICT-based resources with other teachers in my school

\begin{tabular}{|l|l|l|l|}
\hline 5 & 22 & 56 & 18 \\
\hline
\end{tabular}


Figure F.22: Item map for the scale reflecting teachers' emphasis on developing ICT capabilities in class

In your teaching the reference class in this school year how much emphasis have you given to developing the following ICT-based capabilities in your students?

To access information efficiently

To display information for a given audience/purpose

To evaluate the credibility of digital information

To share digital information with others

To use computer software to construct digital work products (e.g., presentations, documents, images, and diagrams)

To provide digital feedback on the work of others (such as classmates)

To explore a range of digital resources when searching for information

To provide references for digital information sources

To understand the consequences of making information publicly available online

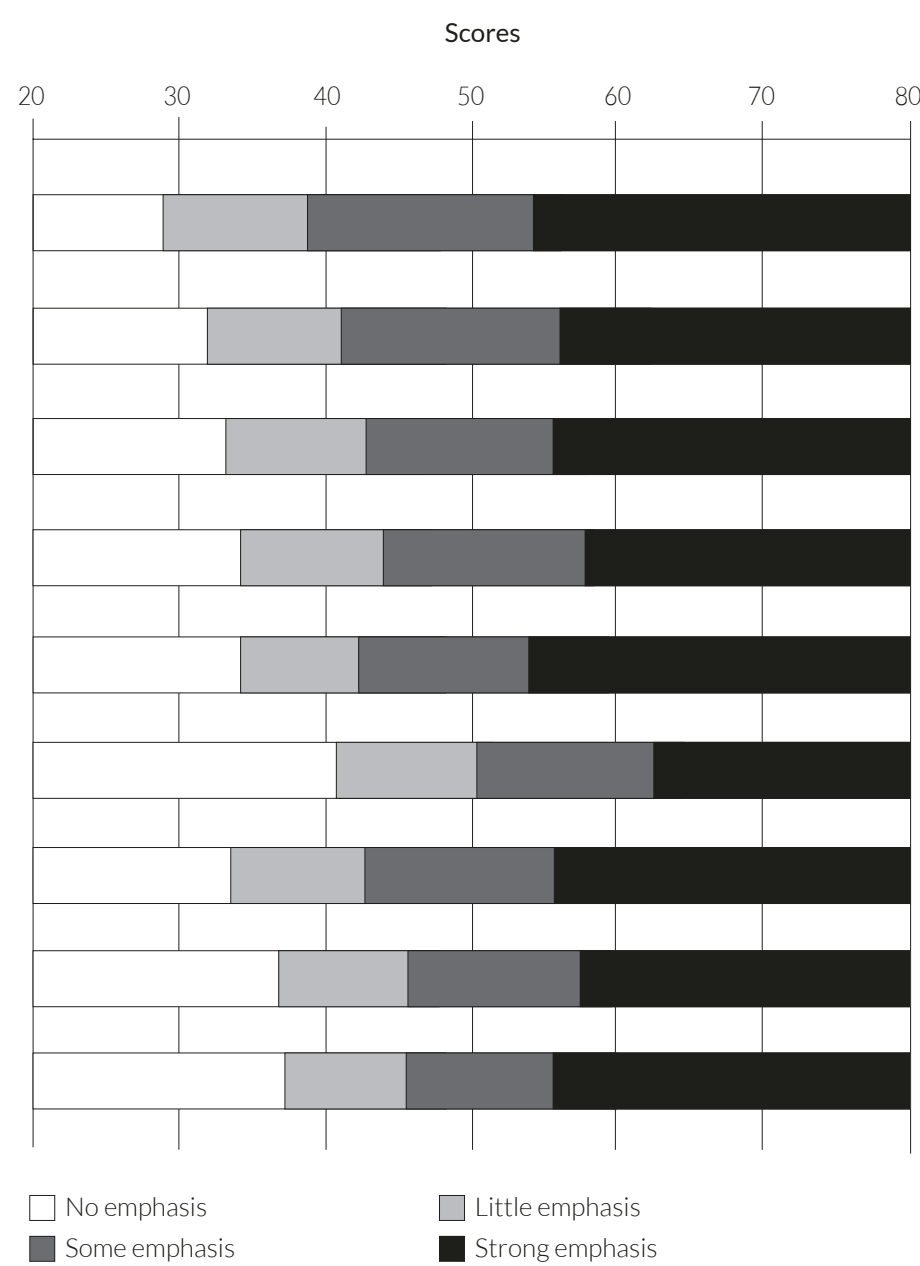

To access information efficiently

To display information for a given audience/purpose

To evaluate the credibility of digital information

To share digital information with others

To use computer software to construct digital work products (e.g., presentations, documents, images, and diagrams)

To provide digital feedback on the work of others (such as classmates)

To explore a range of digital resources when searching for information

To provide references for digital information sources

To understand the consequences of making information publicly available online

\begin{tabular}{|l|l|l|l|}
\hline 4 & 12 & 47 & 37 \\
\hline
\end{tabular}

\begin{tabular}{|l|l|l|l|}
\hline 6 & 16 & 47 & 31 \\
\hline
\end{tabular}

\begin{tabular}{|l|l|ll|}
\hline 7 & 19 & 42 & 32 \\
\hline
\end{tabular}

\begin{tabular}{|l|l|l|l|}
\hline 8 & 21 & 45 & 26 \\
\hline
\end{tabular}

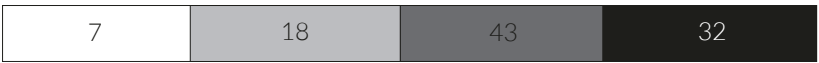

\begin{tabular}{|l|l|ll|}
\hline 12 & 22 & 36 & 30 \\
\hline
\end{tabular}

\begin{tabular}{|l|l|l|l|}
\hline 7 & 18 & 43 & 32 \\
\hline
\end{tabular}

\begin{tabular}{|l|l|l|l|}
\hline 11 & 22 & 41 & 26 \\
\hline
\end{tabular}


Figure F.23: Item map for the scale reflecting teachers' emphasis of teaching CT-related tasks in class

In your teaching of the reference class this school year, how much emphasis have you given to teaching the following skills?

To display information in different ways

To break a complex process into smaller parts

To understand diagrams that describe or show realworld problems

To plan tasks by setting out the steps needed to complete them

To use tools making diagrams that help solve problems

To use simulations to help understand or solve realworld problems

To make flow diagrams to show the different parts of a process

To record and evaluate data to understand and solve a problem

To use real-world data to review and revise solutions to problems

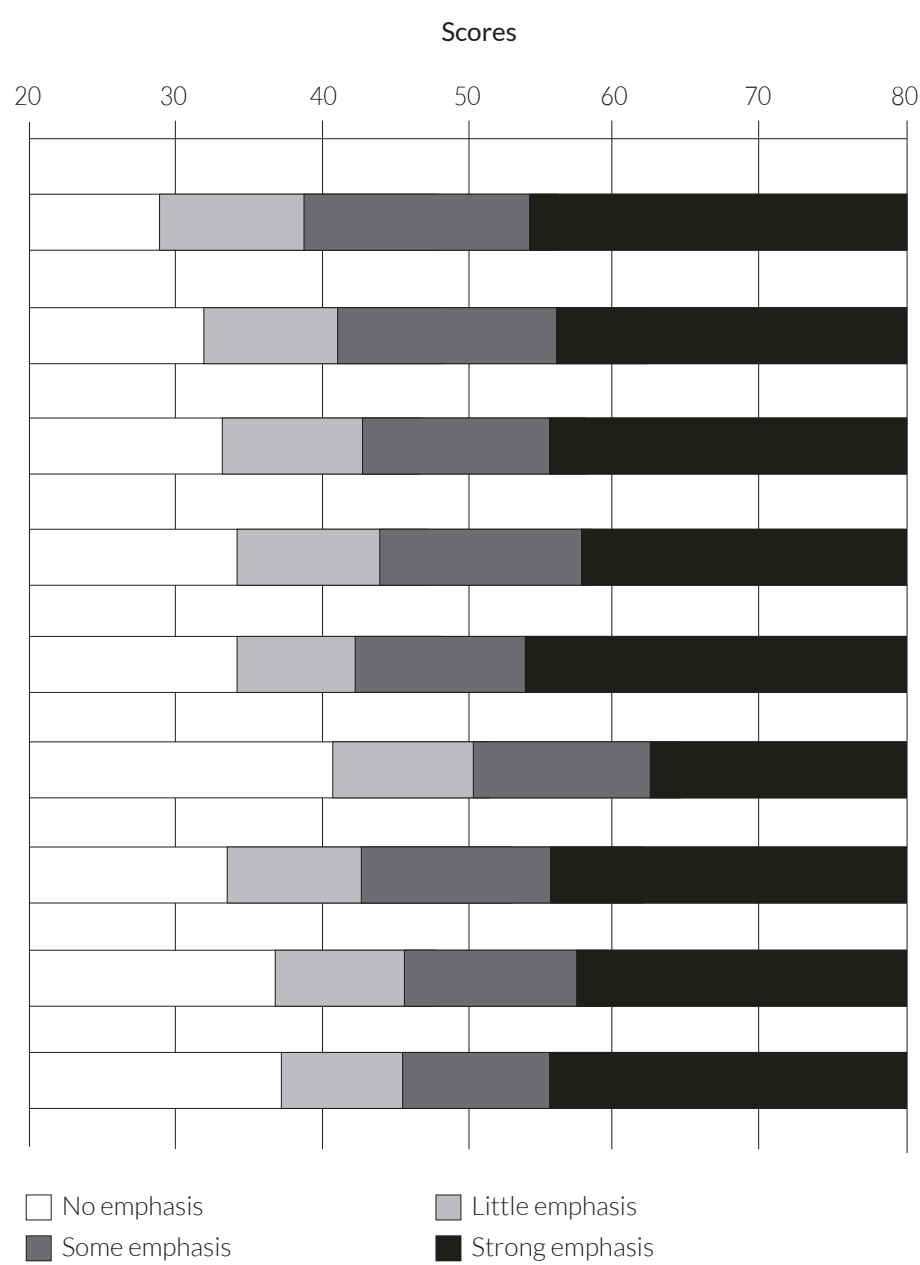

Some emphasis

Sum

To display information in different ways

To break a complex process into smaller parts

To understand diagrams that describe or show realworld problems

To plan tasks by setting out the steps needed to complete them

To use tools making diagrams that help solve problems

To use simulations to help understand or solve realworld problems

To make flow diagrams to show the different parts of a process

To record and evaluate data to understand and solve a problem

To use real-world data to review and revise solutions to problems

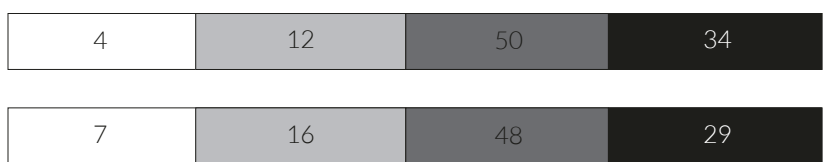

100

\begin{tabular}{|l|l|l|l|}
\hline 7 & 16 & 48 & 29 \\
\hline
\end{tabular}

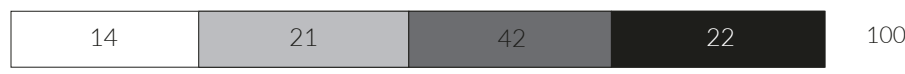

\begin{tabular}{|l|l|l|l|}
\hline 7 & 17 & 46 & 30 \\
\hline
\end{tabular}

\begin{tabular}{|l|l|l|l|}
\hline 35 & 29 & 27 & 9 \\
\hline
\end{tabular}

\begin{tabular}{|l|l|l|l|}
\hline 15 & 21 & 42 & 22 \\
\hline
\end{tabular}
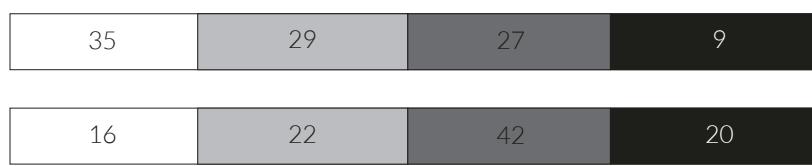

16 22 


\section{References}

Fraillon, J., Schulz, W., Friedman, T., \& Meyer, S. (Eds.). (2020). IEA International Computer and Information Literacy Study 2018 technical report. Amsterdam, The Netherlands: International Association for the Evaluation of Educational Achievement (IEA). Manuscript in preparation.

Masters, G. N., \& Wright, B. D. (1997). The partial credit model. In W. J. van der Linden, \& R. K. Hambleton (Eds.), Handbook of modern item response theory (pp. 100-222). New York, NY: Springer.

Schulz, W., \& Friedman, T. (2015). Scaling procedures for ICILS questionnaire items. In J. Fraillon, W. Schulz, T. Friedman, J. Ainley, \& E. Gebhardt (Eds.), ICILS 2013 technical report (pp. 177-220). Amsterdam, The Netherlands: International Association for the Evaluation of Educational Achievement (IEA). Retrieved from https://www.iea.nl/publications/technical-reports/icils-2013-technical-report.

Warm, T.A. (1989). Weighted likelihood estimation of ability in item response theory. Psychometrika, 54(3), 427-520. 


\title{
APPENDIX G: \\ Organizations and individuals involved in ICILS 2018
}

\section{International study center}

The international study center is located at the Australian Council for Educational Research (ACER). ACER is responsible for designing and implementing the study in close cooperation with the IEA offices in Amsterdam, the Netherlands and Hamburg, Germany.

\author{
Staff at ACER \\ Julian Fraillon, research director \\ John Ainley, project coordinator \\ Wolfram Schulz, assessment coordinator \\ Tim Friedman, project researcher \\ Daniel Duckworth, test developer \\ Melissa Hughes, test developer \\ Laila Helou, quality assurer \\ Alex Daraganov, data analyst \\ Renee Kwong, data analyst \\ Leigh Patterson, data analyst \\ Louise Ockwell, data analyst \\ Katja Bischof, project researcher
}

International Association for the Evaluation of Educational Achievement (IEA)

IEA provided overall support in coordinating and implementing ICILS 2018. IEA Amsterdam, the Netherlands, was responsible for membership, translation verification, quality control, and the publication and wider dissemination of the report. IEA Hamburg, Germany, was mainly responsible for managing field operations, sampling procedures, and data processing.

\author{
Staff at IEA Amsterdam \\ Dirk Hastedt, executive director \\ Andrea Netten, director IEA Amsterdam \\ Roel Burgers, financial director \\ Michelle Djekić, research and liaison officer (project team) \\ Sandra Dohr, junior research officer (project team) \\ David Ebbs, senior research officer (project team) \\ Sive Finlay, head of communications \\ Isabelle Gémin, senior financial officer \\ Mirjam Govaerts, public relations and events officer \\ Gina Lamprell, junior publications officer \\ Jennifer Ross, media and outreach officer \\ Jasmin Schiffer, graphic designer \\ Jan-Philipp Wagner, junior research officer (project team) \\ Gillian Wilson, senior publications officer
}




\section{Staff at IEA Hamburg}

Juliane Hencke, director IEA Hamburg

Heiko Sibberns, director IEA Hamburg (former)

Ralph Carstens, co-head of international studies unit

Sebastian Meyer, ICILS international data manager

Michael Jung, ICILS international data manager (former)

Ekaterina Mikheeva, ICILS deputy international data manager

Lars Borchert, ICILS deputy international data manager (former)

Sabine Meinck, head of research and analysis, and sampling units

Sabine Tieck, research analyst (sampling)

Sabine Weber, research analyst (sampling)

Karsten Penon, research analyst (sampling)

Duygu Savascl, research analyst (sampling)

Oriana Mora, research analyst

Adeoye Oyekan, research analyst

Hannah Köhler, research analyst

Lorelia Lerps, research analyst

Rea Car, research analyst

Clara Beyer, research analyst

Yasin Afana, research analyst

Guido Martin, head of coding unit

Katharina Sedelmayr, research analyst (coding)

Deepti Kalamadi, programmer

Maike Junod, programmer

Limiao Duan, programmer

Devi Prasath, programmer (former)

Bettina Wietzorek, meeting and seminar coordinator

\section{SoNET Systems}

SoNET Systems was responsible for developing the software systems underpinning the computerbased student assessment instruments for the main survey. This work included development of the test and questionnaire items, the assessment delivery system, and the web-based translation, scoring, and data-management modules.

\section{Staff at SoNET systems}

Mike Janic, managing director Stephen Birchall, deputy CEO

Erhan Halil, product development manager

Rakshit Shingala, team leader

James Liu, analyst programmer

Nilupuli Lunuwila, analyst programmer

Richard Feng, analyst programmer

Stephen Ainley, quality assurance

Ranil Weerasinghe, quality assurance

Grigory Loskutov, IT coordinator 


\section{ICILS sampling referee}

Marc Joncas was the sampling referee for the study. He provided invaluable advice on all sampling-related aspects of the study.

\section{National research coordinators}

The national research coordinators played a crucial role in the development of the project. They provided policy- and content-oriented advice on the development of the instruments and were responsible for the implementation of ICILS in the participating countries.

\section{Chile}

Carolina Leyton

María Victoria Martinez

Tabita Nilo

National Agency for Educational Quality

\section{Denmark}

Jeppe Bundsgaard

Danish School of Education, Aarhus University

\section{Finland}

Kaisa Leino

Finnish Institute for Educational Research, University of Jyväskylä

\section{France}

Marion Le Cam

Ministry of National Education

\section{Germany and North Rhine-Westphalia (Germany)}

Birgit Eickelmann

Institute for Educational Science, University of Paderborn

\section{Italy}

Elisa Caponera

Riccardo Pietracci

INVALSI (Istituto Nazionale per la Valutazione del Sistema Educativo di Istruzione e di Formazione)

Gemma De Sanctis (until May 2018)

MIUR (Ministero dell'Istruzione, dell'Università e della Ricerca)

\section{Kazakhstan}

Aigerim Zuyeva

Ruslan Abrayev

Department for International Comparative Studies, Ministry of Education and Science

\section{Luxembourg}

Catalina Lomos

Luxembourg Institute of Socio-Economic Research (LISER)

\section{Moscow (Russian Federation)}

Elena Zozulia

Moscow Center for Quality of Education

\section{Portugal}

Vanda Lourenco

IAVE, IP-Institute of Educational Evaluation

Republic of Korea

Sangwook Park

Kyongah Sang

Korea Institute for Curriculum and Evaluation 


\author{
United States \\ Lydia Malley \\ Linda Hamilton \\ National Center for Education Statistics, US Department of Education \\ Uruguay \\ Cristobal Cobo \\ Center for Research-Ceibal Foundation \\ Cecilia Hughes \\ Evaluation and Monitoring Department at Plan Ceibal
}

